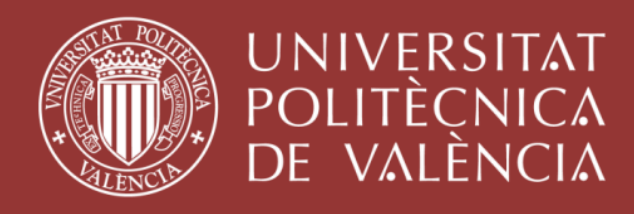

\title{
ESTUDIO DE LA ACTIVIDAD INDUSTRIAL Y SU IMPACTO EN EL MEDIO URBANO EN LA CIUDAD DE VALENCIA DESDE 1.985
}

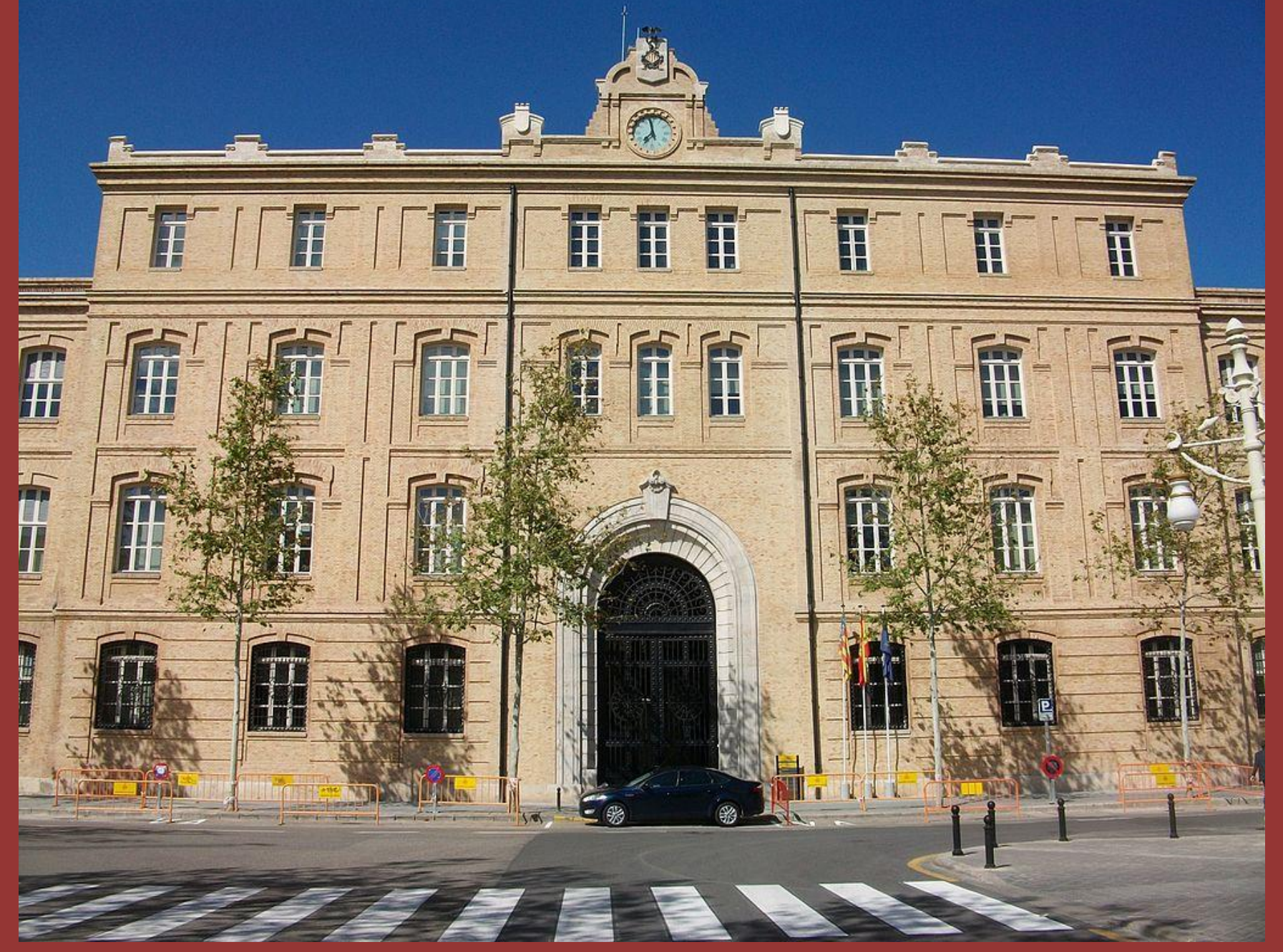

Doctorando: Amadeo Pascual Galán

Directores de Tesis:

Francisco Taberner Pastor Jorge Luis Garcia Valldecabres 


\section{INDICE}

I. Introducción

II. Antecedentes.

1 Necesidad de crear un nuevo orden urbano

2 Evolución social y económica 12

3 Planeamientos recientes 14

- Plan General del $46 \quad 15$

- Ley del Suelo del $56 \quad 16$

- Plan General del $66 \quad 17$

- $\quad$ Plan General del $88 \quad 19$

- Ley del Suelo del $90 \quad 21$

III. Objetivos de la investigación.

Localizar las industrias durante el periodo de vigencia del PG $88 \quad 22$

Evolución 23

Las ordenanzas del Plan general que afectan directamente

a la evolución de las industrias

IV. Metodología.

1. Justificación

2. Diseño y contenido de la ficha 31

2.1 Localización 31

2.2 Actividades 34

2.3 Superficies ocupadas por la industria

2.4 Energía Infraestructuras y Medio Ambiente 36

2.5 Personal y Transporte $\quad 40$

2.6 Planeamiento y Tipología Edificatoria 41

3. Criterios de selección 44 
V. Análisis pormenorizado por distritos

Relación de distritos

\begin{tabular}{lr} 
D1 Ciutat Vella & 50 \\
D2 L'Eixample & 70 \\
\hline D3 Extramurs & 91 \\
\hline D4 Campanar & 113 \\
\hline D5 Zaidía & 133 \\
\hline D6 Pla del Real & 159 \\
\hline D7 Olivereta & 181 \\
\hline D8 Patraix & 205 \\
\hline D9 Jesús & 242 \\
\hline D10 Cuatre Carreres & 270 \\
\hline D11 Poblats Maritims & 300 \\
\hline D12 Camins al Grao & 337
\end{tabular}

Límites geográficos

Evolución del 85 al 2014

- Plano ubicación

- Listado industrias

- Características

- Impacto.

- Edificios de interés

- Gráficos

- Fichas

VI. Conclusiones

1. Conclusiones generales

2. Conclusiones particulares de Valencia Aporte de cuadros y gráficos generales de la Ciudad 371

3. Síntesis final. Evolución industrial 393

VII. Bibliografía 397

VIII. Colaboradores 399 


\section{INTRODUCCIÓN}

El presente Estudio de Localización Industrial se basa, en la extraordinaria importancia que tiene la industria en el desarrollo urbano de la ciudad, ya que requiere de un alto consumo de suelo, destinado a la fabricación de productos y almacenamiento de materias primas con sus consecuencias derivadas de la propia actividad, por lo que es necesario actuar sobre ellas, limitando las actividades industriales y planificando su desarrollo.

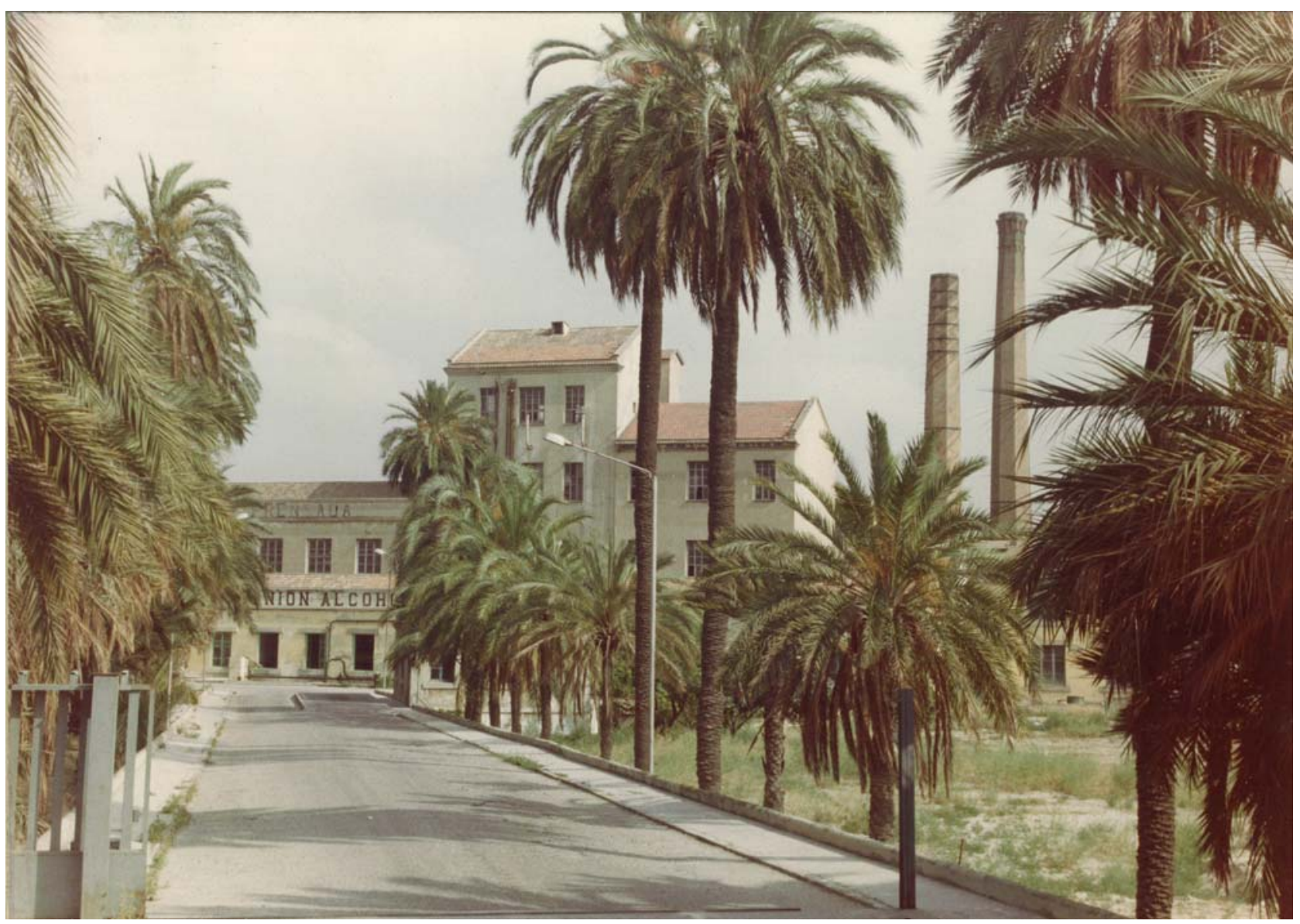

Foto 1: Original Unión Alcoholera en Paseo de la Alameda de Valencia en 1985. Fuente: Elaboración propia.

En el último siglo, con el desarrollo industrial, se han visto obligadas a emigrar a la periferia en busca de suelo de bajo coste, en ocasiones agrícola y alejado de las áreas residenciales, pero con el crecimiento de las ciudades, vuelven a quedar dentro de ellas con los consiguientes problemas medio ambientales que ocasionan, humos, ruidos, contaminación del suelo y de las aguas incluso algunas de ellas, las menos al día de hoy sin alcantarillado. 


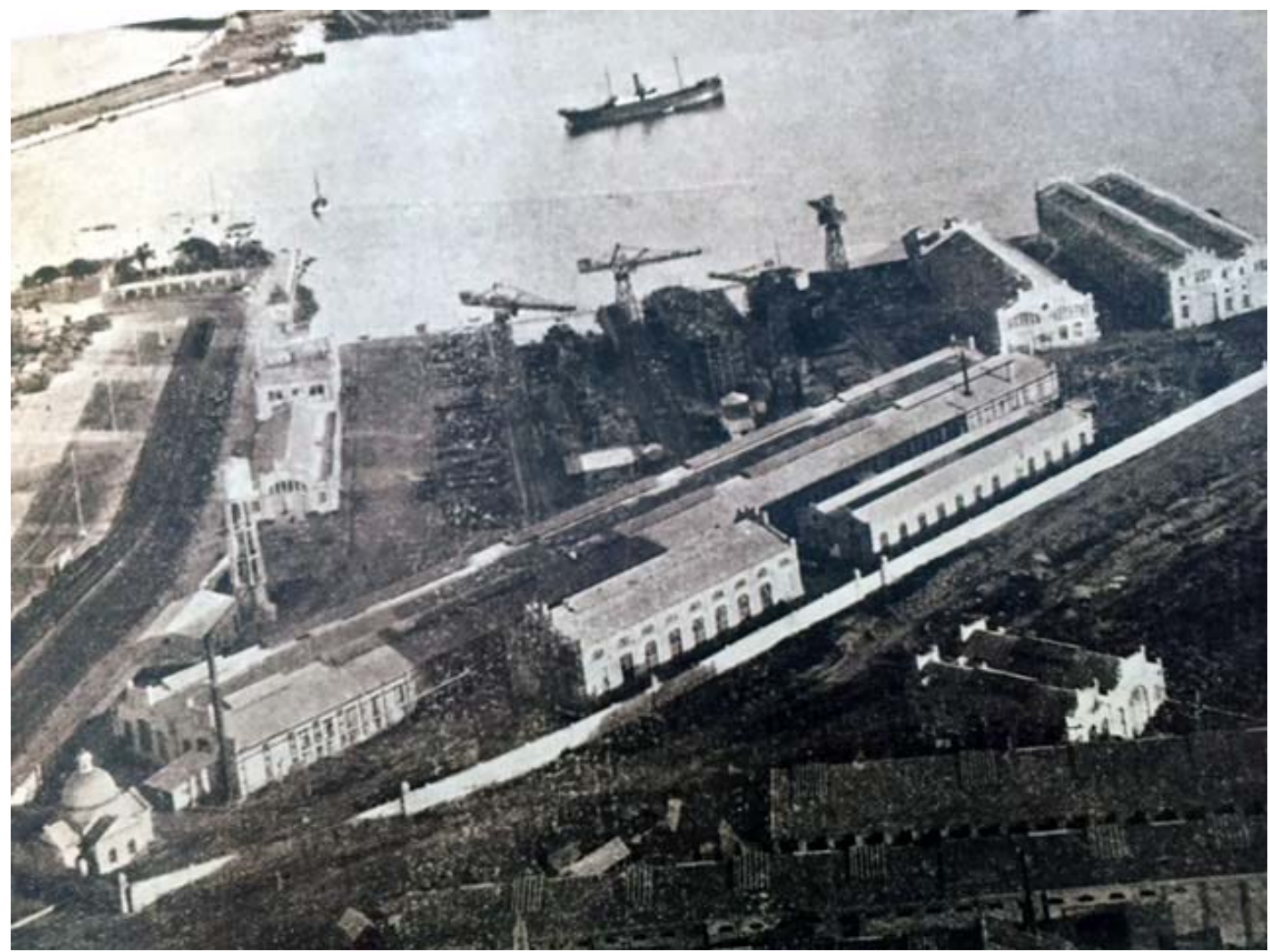

Foto 2: Fotografía aérea de los Astilleros de Valencia el 11 de Diciembre de 1934.

Impreso. Archivo José Huguet.

Fuente: Álvarez, A. y Ballester, B. Ayuntamiento de Valencia. VALENCIA INDUSTRIAL: LaS fundiciones. Valencia. 2001 (p. 175).

Justo es decir que, emplea abundante mano de obra dependiendo mucho de la actividad que desarrolla, generalmente la mano de obra no tiene una relación directa con la superficie ocupada por la industria, nos encontraremos con actividades industriales que ocupan una gran superficie, por ejemplo; la madera, almacenes de contenedores... y sin embargo tienen bajo índice de ocupación.

Un número importante de ellas ha requerido mano de obra poco especializada, lo que supuso un flujo importante de operarios que venían de actividades agrícolas poco rentables, que se han integrado en la ciudad quedándose en ella, haciendo crecer rápidamente el área de Valencia y su entorno más inmediato. 


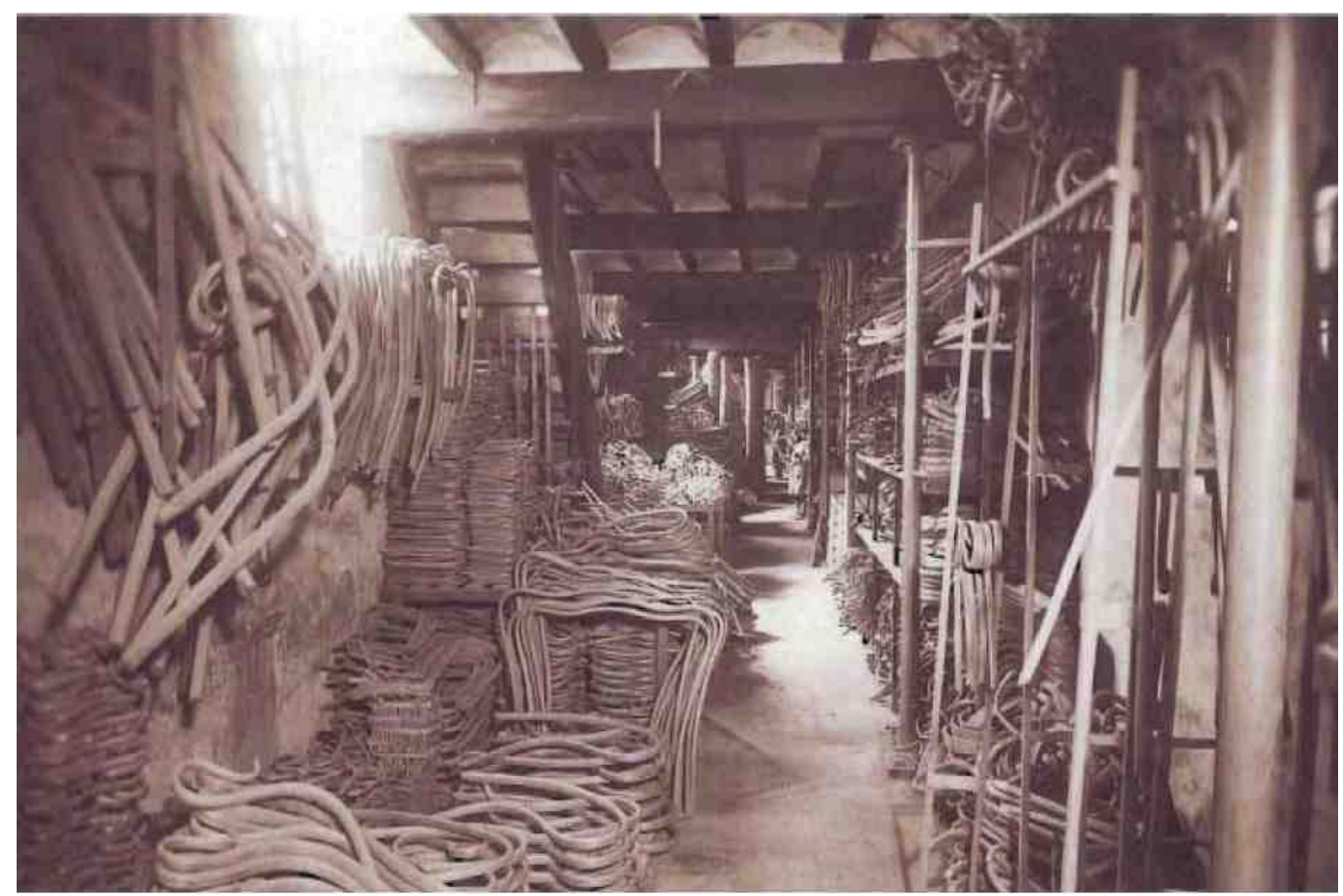

Foto 3: Industria de la madera. Almacén de mueble curvado Ventura Feliu en Valencia.

Fuente: Álvarez, A. y Ballester, B. Ayuntamiento de Valencia. VALENCIA INDUSTRIAL: Las fundiciones. Valencia. 2001 (p. 26).

Como consecuencia de todo ello, la Industria tiene una extraordinaria importancia en el mundo económico y urbano, tanto por el proceso de fabricación y comercialización como por el suelo que consume y que con posterioridad devuelve a la ciudad, para planificar de nuevo sobre él, en forma de viales, zonas verdes, equipamientos, viviendas...

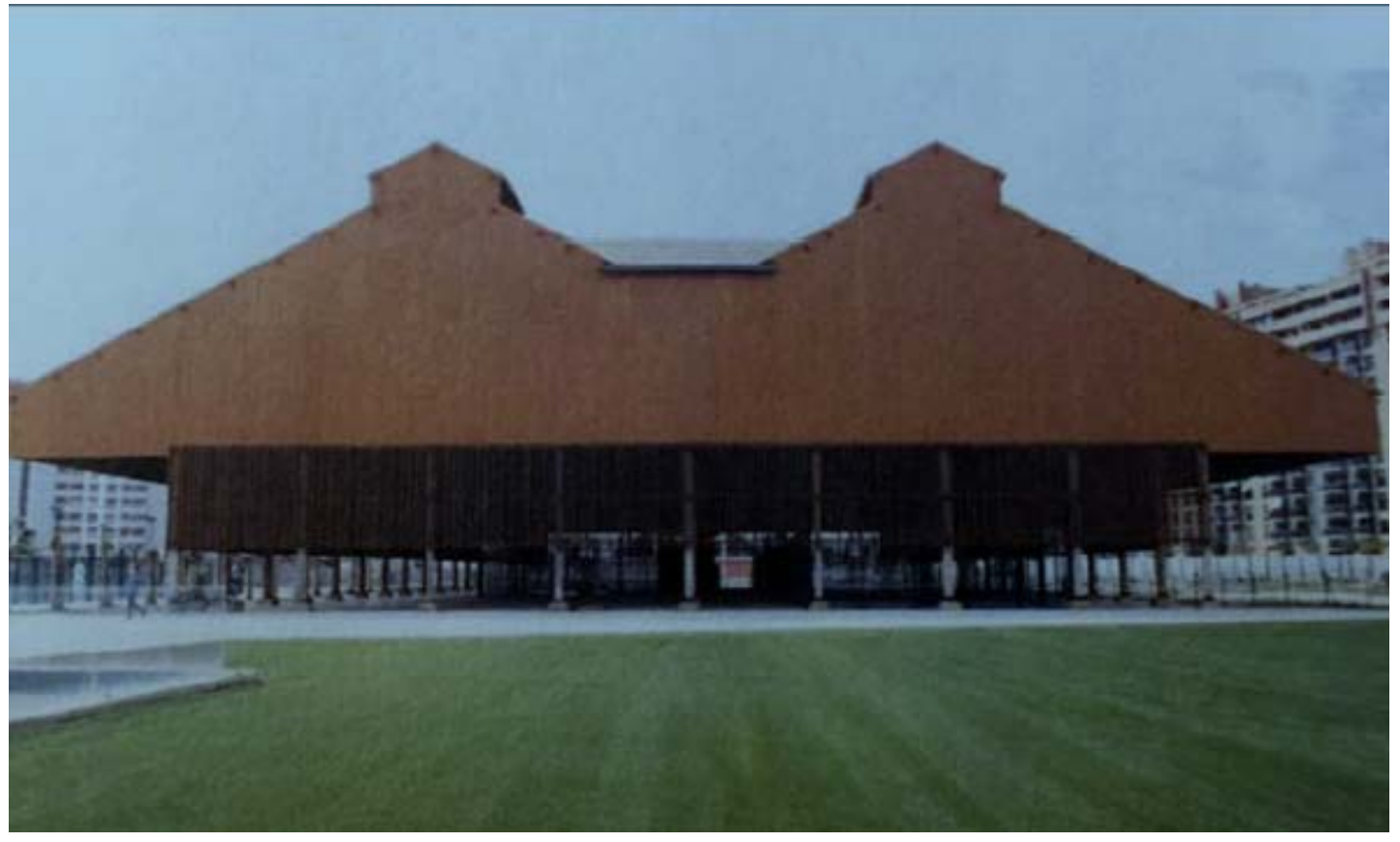

Foto 4: Naves de Cros en Valencia

Fuente: Mosalve, R. Las naves de Cros en Valencia. Universidad Politécnica de Valencia. Escuela Técnica Superior Ingeniería de la Edificación.(s.f.)(p.17) 
Genera riqueza, pero consume también abundantes recursos naturales como son el agua, gas, electricidad y materias primas diversas sin que hasta la actualidad se planteen soluciones eficientes energéticas y medio ambientales que son fácilmente amortizables en el tiempo. Mayoritariamente tiene planteamientos derivados de sus beneficios y comercialización de sus productos Esto hace que tenga una notable incidencia en el medio ambiente y en el urbano más próximo cuyo control se hace necesario, para evitar posibles efectos negativos derivados de la propia actividad.

Es por esto que este estudio trata, de localizar las actividades industriales en la ciudad de Valencia indicando, la actividad que desarrolla, superficie que ocupan, tipología edificatoria, mano de obra que emplean y el impacto medio ambiental que tiene en su entorno más próximo.
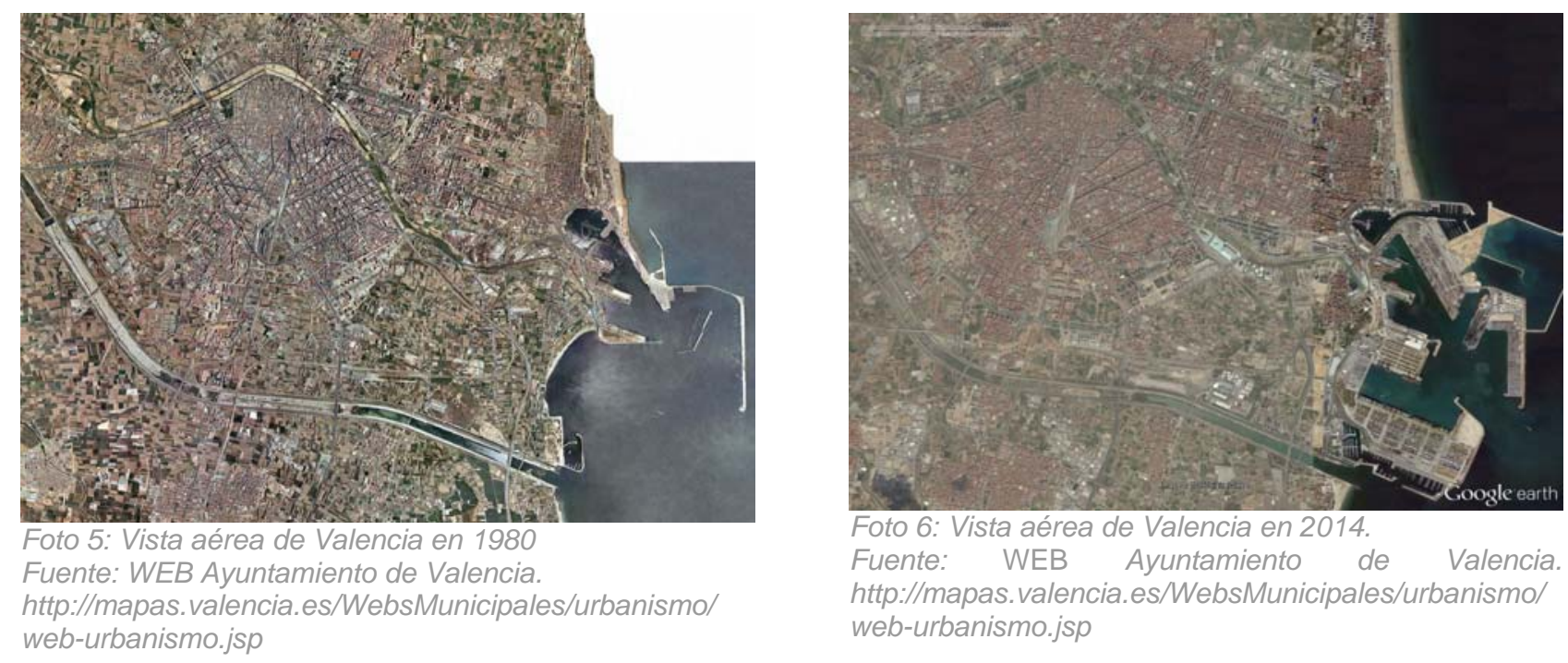

En la actualidad tendríamos que poder garantizar espacios adecuados para asentamientos industriales, evitando que se generen plusvalías en el suelo ocupado por las industrias, como consecuencia de calificaciones que aumentan notablemente el aprovechamiento del suelo y producen en unos casos, el éxodo de las industrias de la ciudad a zonas periféricas con la consiguiente transformación del suelo industrial en residencial o terciario y otros, lo que ocasiona en un período de tiempo breve el deterioro de los edificios y la degradación del medio urbano.

Es esta una situación que se repite y se viene produciendo a lo largo de la historia en cualquier ciudad industrializada. 


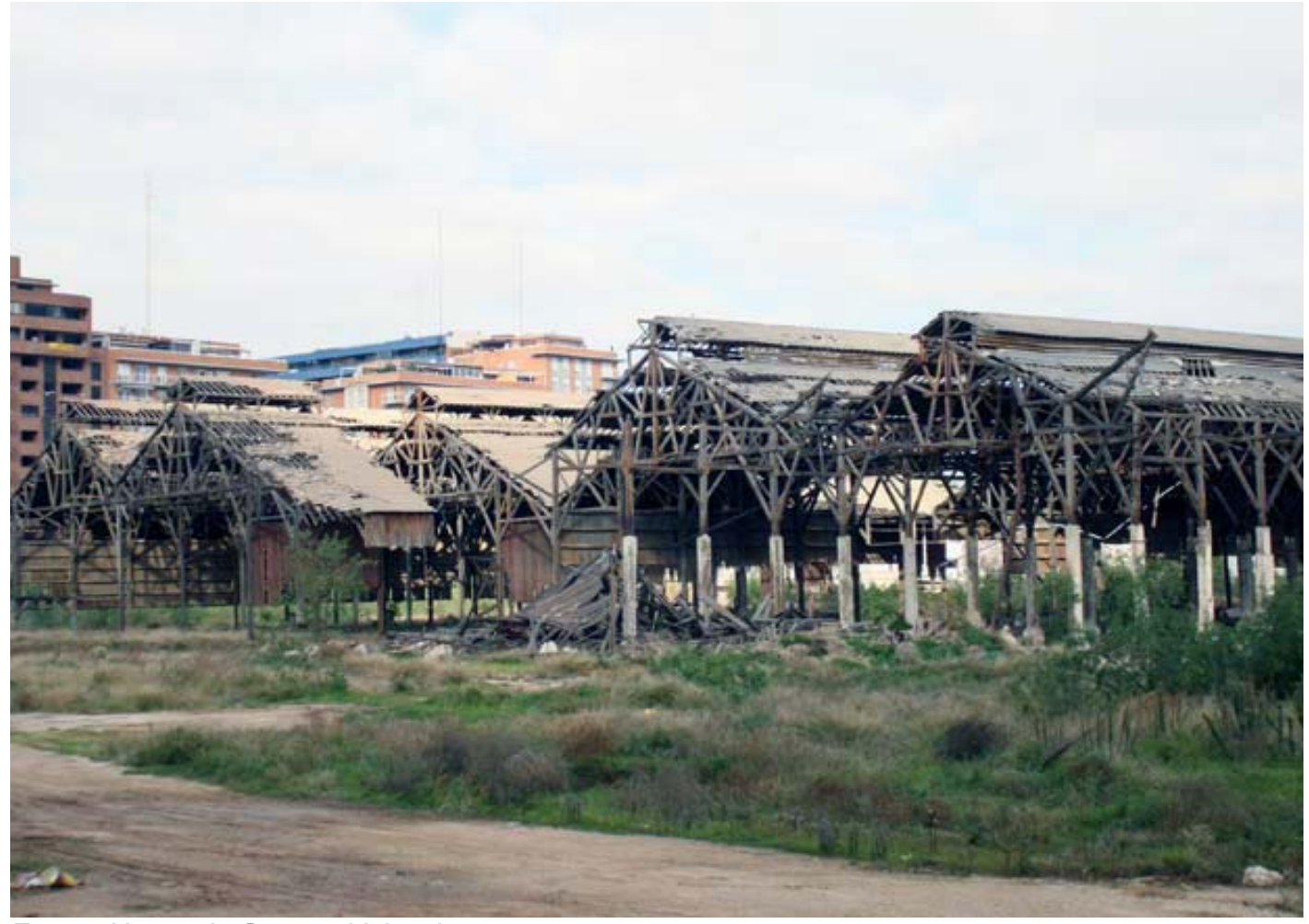

Foto 7: Naves de Cros en Valencia.

Fuente: Mosalve, R. Las naves de Cros en Valencia. Universidad Politécnica de Valencia. Escuela Técnica Superior Ingeniería de la Edificación.(s.f.)(p.4)

\section{ANTECEDENTES}

\section{NECESIDAD DE CREAR UN NUEVO ORDEN URBANO}

Ya en el siglo XIX siendo Alcalde Presidente del Ayuntamiento de Valencia D. Juan Miguel de San Vicente se pública el Bando de Buen Gobierno de 1848 en el cual en el artículo 194 se hace mención a los establecimientos insalubres diciendo así:

"Se prohíbe establecer en parajes públicos tenerías, fábricas de velas de sebo y otras que puedan incomodar al vecindario; todas las cuales deberán precisamente situarse en los muros ó en los puntos menos habitados de la ciudad." 


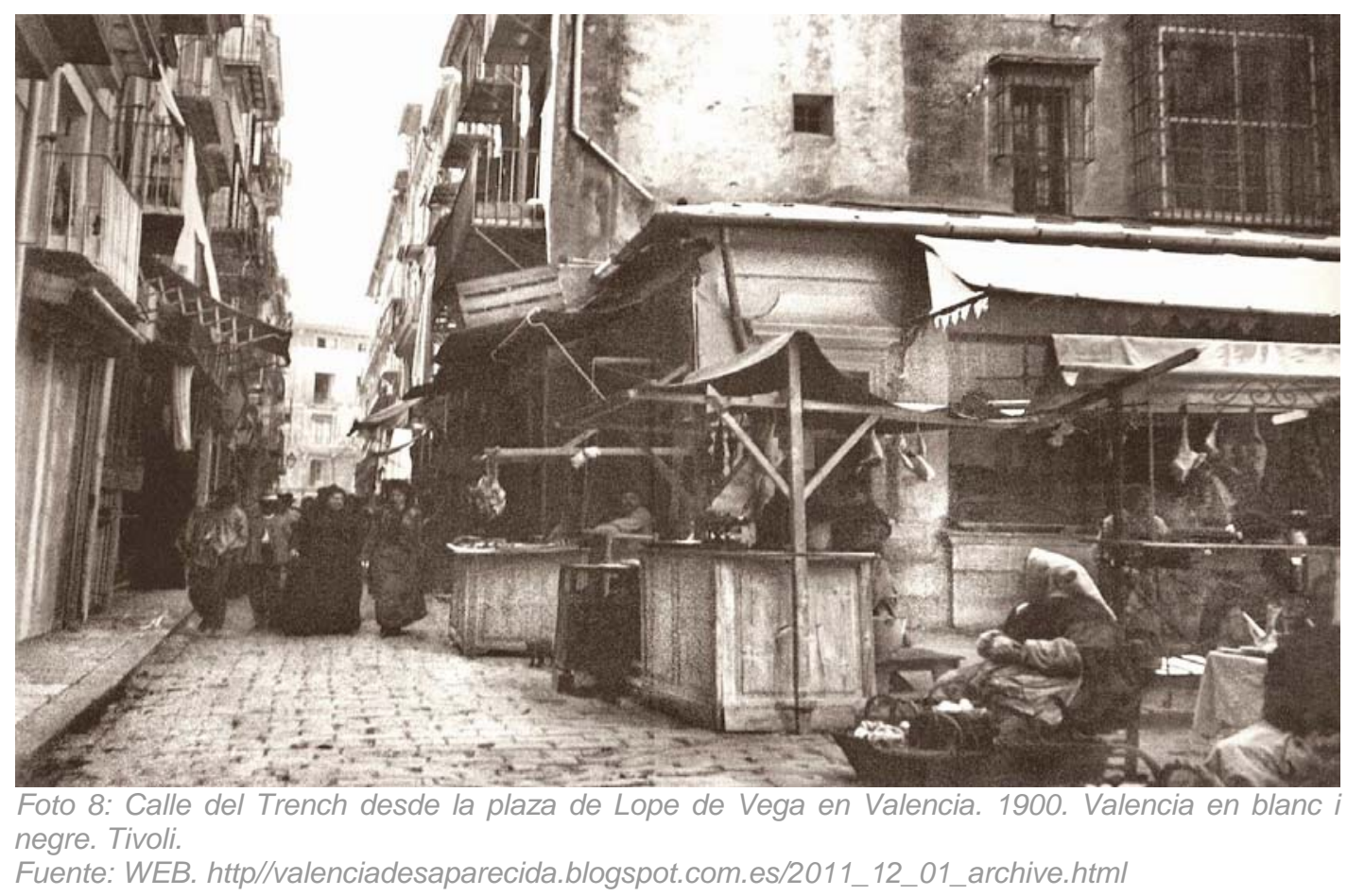

Se puede ver como se empieza a tomar conciencia ya en esa época en cuanto a las actividades molestas e insalubres, regulando su ubicación en la ciudad para minimizar los posibles efectos adversos sobre la población.

De igual modo en el artículo 237 se regula la publicidad de las actividades industriales o de comercio:

"A la colocación de toda muestra, rótulo o inscripción, la venta de géneros o artículos, ó el ejercicio de cualquier arte, profesión ó industria, deberá preceder la aprobación de la Autoridad local, a la que se presentará al efecto el proyecto o boceto, que someterá cuando lo considere necesario a la censura de corporaciones o personas inteligentes." 


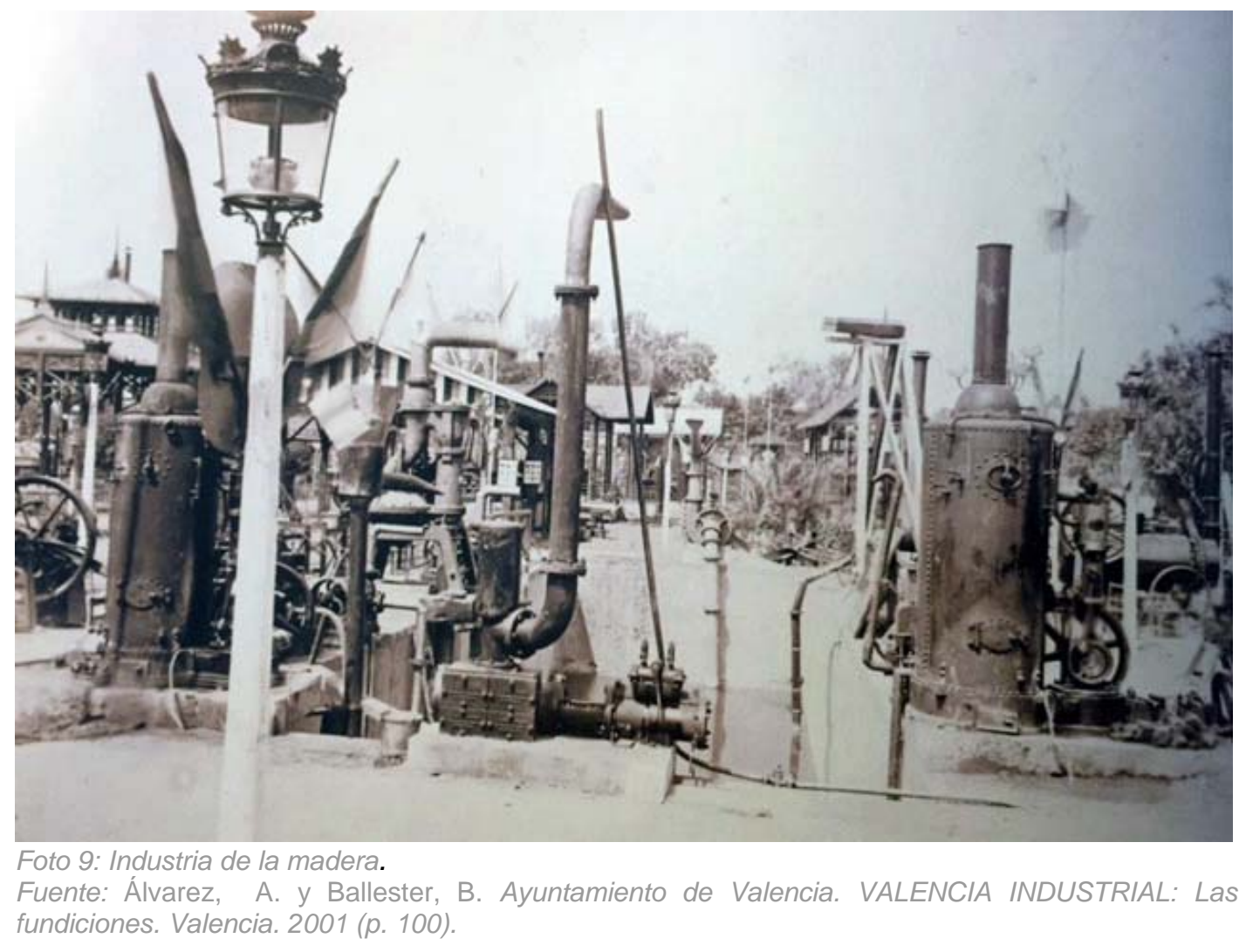

Posteriormente en el Bando General de Buen Gobierno de 1859 siendo Alcalde de Valencia D. Francisco de Llano son ampliadas estas regulaciones, añadiéndose en el artículo 277 un apartado referente a los establecimientos incómodos diciendo así:

"Las herrerías, cuchillerías, forjadores de plata, calderos, latoneros, molinos de chocolate y otros oficios que producen gran ruido e incomodidad, se situarán en adelante en los arrabales, y los que hoy se hallan en los puntos céntricos de la población no podrán volverse a abrir en caso de cerrarse: de todos modos procurarán en las horas y modos del trabajo conciliarse con la comodidad y reposo del vecindario."

Será a partir de la década de 1850 a 1860 cuando se irán abandonando las agrupaciones de actividades en sólo determinados sectores urbanos para imponerse su diseminación por todo el conjunto ciudadano. A partir de la desaparición de las murallas en 1865, y a pesar del todavía arraigado carácter artesanal de las instalaciones industriales, la posibilidad de espacio libre más allá de los muros se convierte en factor determinante de un cambio de dirección en las futuras localizaciones de las mismas. Este proceso culmina en el siglo XX con la búsqueda de áreas periféricas, teniendo presente el tamaño como condicionante de localización, si bien la pequeña dimensión de 
la empresa hace que sean escasas las zonas de Valencia en las que estos establecimientos están ausentes

Los sectores de la ciudad periféricos industriales, en la mayoría de los casos, son herencia de las antiguas concentraciones gremiales.

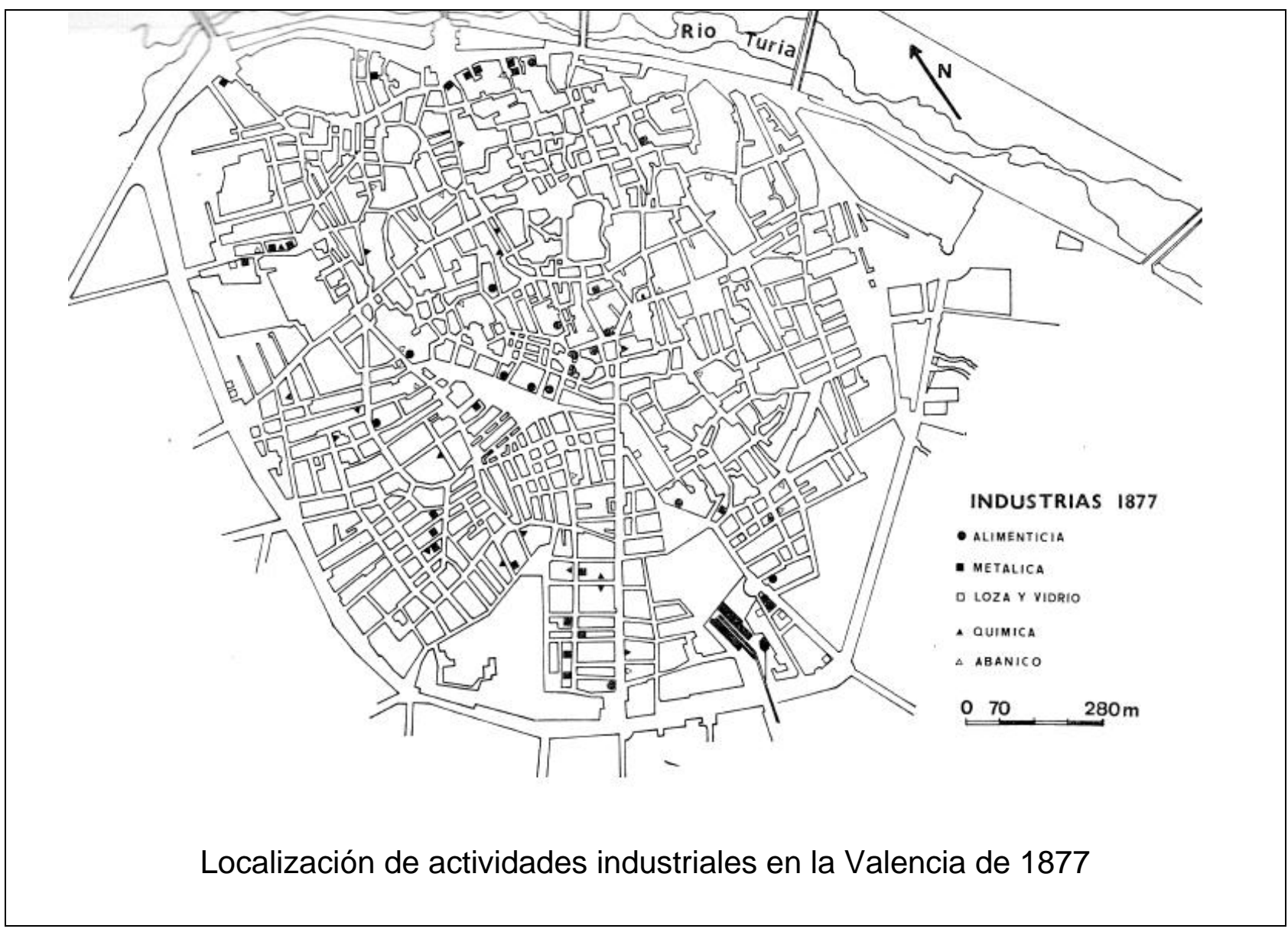

Foto 10: Industrias en el interior del casco histórico de Valencia en 1877. María Teixidor de Otto.

Fuente: Cano, J.J., Blasco M. del C. Universidad Politécnica de Valencia. El espacio industrial en la Comunidad Valenciana. 2002 (p. 47).

En las últimas décadas, el crecimiento de las ciudades con la consiguiente plusvalía del suelo urbano, las mejoras de las comunicaciones junto a criterios de mejora de control del medio ambiente han producido el éxodo de un gran número de grandes y medianas empresas hacia las afueras de las ciudades, aunque, eso si, manteniéndose dentro de las áreas metropolitanas. Ello ha supuesto un cambio radical en la relación ciudad-industria, cuya tendencia evolutiva parece responder a estos dos modelos:

- La ciudad "nursery" considerada como guardería de la pequeña industria, que se genera y desarrolla en la misma y, que una vez alcanza determinado tamaño, emigra de la ciudad buscando mayores superficies de suelo a precios acordes con 
la actividad industrial, y con unas condiciones de accesibilidad, infraestructura y servicios que mejoren las del asentamiento primitivo.

- La ciudad " terciaria " en la que se incrementa el asentamiento de actividades administrativas y de servicios, tendiéndose sin embargo al traslado de asentamientos industriales y residenciales fuera de la ciudad.

Comparando estos dos modelos y aunque los dos se dan en la actualidad, podía ser el primero de ellos el que más se aproxime a las previsiones para el futuro de la ciudad de Valencia y que suponen la recuperación de edificios industriales como grandes contenedores, con el objeto de recolocar en ellos pequeñas industrias compatibles con los usos residenciales conformando mini espacios industriales.

Por tanto es importante conocer, no sólo donde se localiza la actividad industrial actualmente y cuales son sus características en cuanto a incidencia medioambiental, accesibilidad, servicios urbanísticos, relación con otras industrias complementarias, etc., sino también donde se encuentran los edificios industriales en desuso cuya recuperación para ese u otro fin puede ser válida, y donde se localizan las bolsas de áreas industriales cuyo abandono o traslado ha producido la degradación del medio urbano e incluso el éxodo de la mano de obra vinculada a las mismas. 


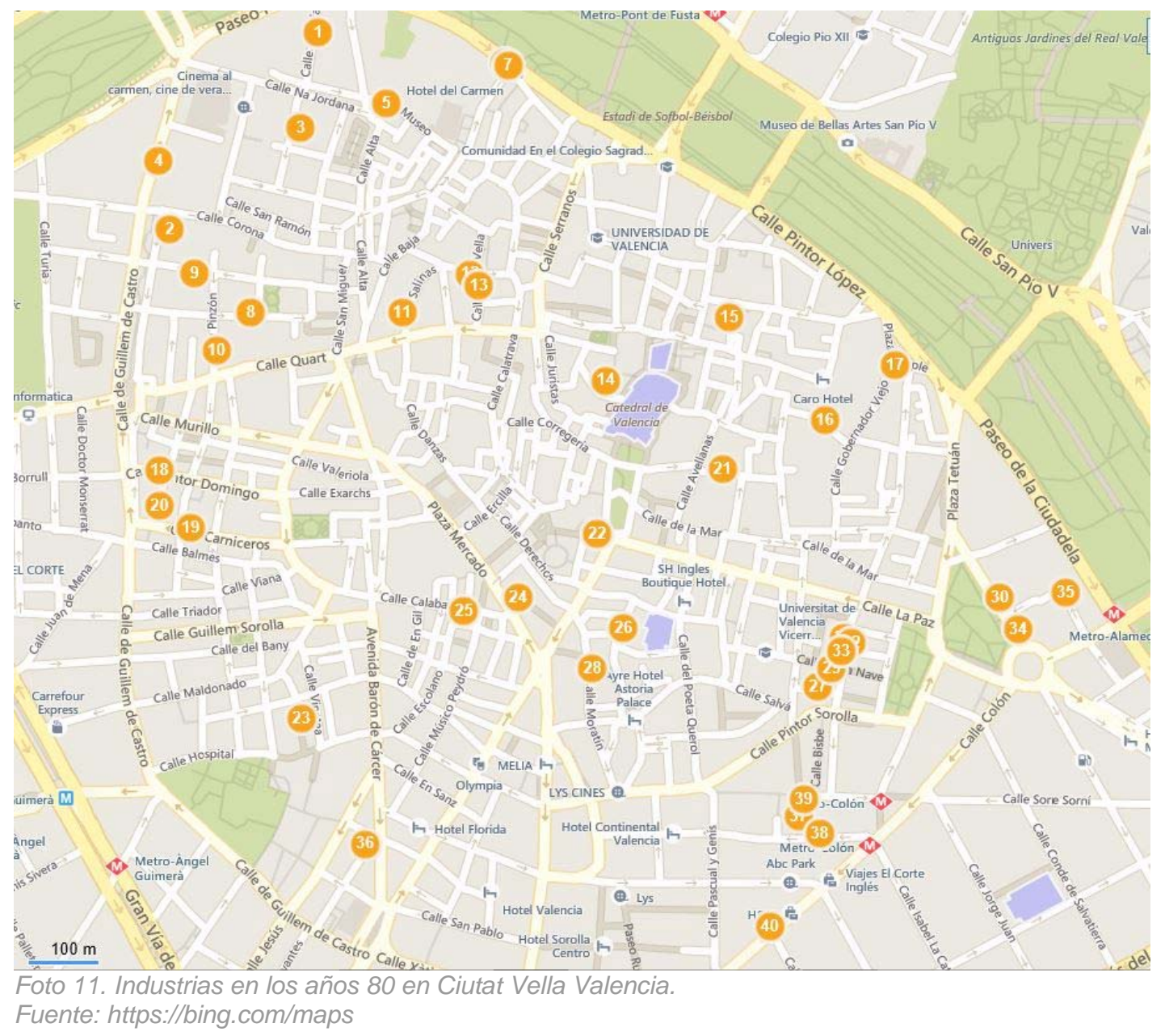

\section{EVOLUCIÓN SOCIAL Y ECONÓMICA}

Podemos indicar que a través del factor suelo, el planeamiento puede intervenir en los procesos sociales y económicos de tal forma que, aunque no sea determinante de los mismos si que puede contribuir al sostenimiento de determinadas actividades, e incluso a la creación de otras mediante su intervención en el mercado del suelo.

En los años 40, España es un país sin una estructura económica sólida, pero lentamente comienza un crecimiento demográfico y económico que nos lleva a la década de los años 50 y 60, que es cuando se empieza a recuperar. 


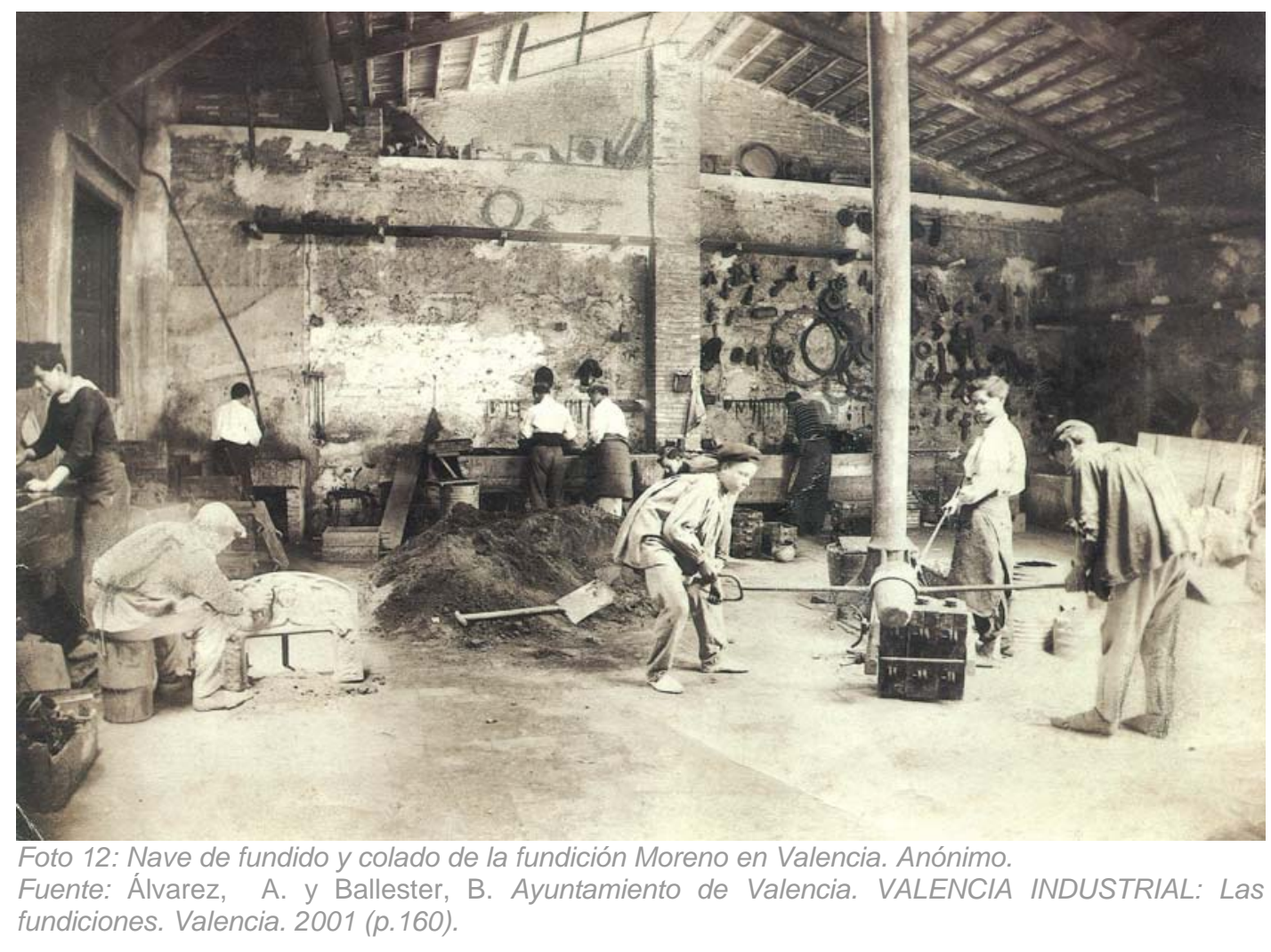

La agricultura y la industria son la principal fuente de riqueza y en los años 60 la productividad y la población dedicada al sector industrial se sitúan incluso por encima de algunos países desarrollados. La industria se desarrolla de forma tradicional, es decir, lo hace donde anteriormente se localizaban las zonas industriales.

En los años posteriores a la guerra, se mantienen los mismos parámetros que en la República, no se modificaron y la transformación se hace de forma tradicional.

Con la organización social y económica de la ciudad en el siglo XX, se tiende a crear una nueva idea de planificación urbanística, lo que lleva a crear un conjunto diferenciado de funciones específicas, donde cada una tiene un lugar asignado y con ello se trata de que no se ubique en otro lugar diferente al especificado.

Es así como surge la idea de zonificación donde se determinan áreas específicas totalmente diferenciadas, para usos determinados y ordenados en función de la actividad que se desarrolla en ellos. 


\section{PLANEAMIENTOS RECIENTES}

A principio del siglo XX, la zonificación metropolitana de la ciudad, distingue entre, residencial, comercial e industrial. La confianza depositada en la industria le proporciona un papel relevante y trae consigo la ampliación del espacio urbano y el crecimiento demográfico con la consiguiente agregación de municipios colindantes.

En este período de tiempo la ubicación de las nuevas industrias se planifica con un margen de futuro bastante amplio pero siempre resulta insuficiente porque nunca se consigue predecir un futuro lejano. Conocidas las previsiones y tendencias que ya funcionaban en otros países europeos, las manzanas o edificios industriales se estiman acorde a las grandes industrias del momento, que se corresponderían con tamaño mediano a grande de la actualidad y estaría entre 20.000 y 30.000 m2, con distintos niveles de ocupación.

Así pues se genera la idea de planificación urbanística, organizándose como un conjunto diferenciado de actividades, donde cada una tiene un lugar determinado no pudiéndose ubicar en otro lugar diferente al especificado.

La zonificación es pues, el mejor instrumento para organizar la ciudad de una forma ordenada teniendo en cuenta las posibilidades que ofrece para su desarrollo. A pesar de ello, las industrias no aceptan tal control, porque creen que les coarta sus posibilidades de crecimiento y optan por alejarse de las ciudades.

La zonificación de suelo en áreas urbanas para uso industrial proporciona un menor índice de especulación del mismo, menor que el uso vivienda, creando un suelo mas estable económicamente. Para ello es necesario crear servicios, infraestructuras y prestaciones en áreas industriales dentro de la zona urbana.

Generalmente las áreas industriales se localizan próximas a las líneas de ferrocarril, junto a puertos y cauces de ríos creándose nuevos muelles, estaciones ferroviarias, ramales fluviales, así como explanadas y planicies para el almacenamiento y la producción junto a las infraestructuras de transporte sobre el suelo agrícola y forestal. Como consecuencia se crea suelo edificable definitivo en áreas metropolitanas.

La forma de distribución de las actividades se basa en los principios de reducción de costes y aumento de producción, es decir, mayor rendimiento, precio del suelo, 
proximidad de espacios libres y existencia de infraestructuras. Las industrias se reagrupan por sectores, se trasladan a la periferia.

La zonificación regula además de los usos, la densidad, la forma de edificar y el crecimiento.

Se establecen varios tipos de asentamientos, que incluso perduran hasta la actualidad

- $\quad$ Residenciales.

- Industriales.

- $\quad$ Mixtos (residenciales y comerciales).

Aun hoy en día podemos ver ejemplos recientes, como puede ser el Polígono Vara de Quart, donde conviven vivienda e industria.

\section{PLAN GENERAL DEL 46}

En 1944 se comienza a redactar en Valencia el Plan General de Ordenación Urbana y en 1946 se aprueba el documento por medio de la Ley de Bases para la Ordenación Urbana de Valencia y su Comarca, esta Ley daba origen a la Corporación Administrativa de Gran Valencia y su Comarca.

En los años 50 Valencia comienza a recuperar el desarrollo industrial que había adquirido antes de la guerra civil. La industria se sitúa en el área metropolitana, tal y como señalaba el Plan disponiendo de la infraestructura de los ejes de transporte y de las instalaciones portuarias.

Se localiza en las vías y nudos de comunicación, como son el Ferrocarril y la Avenida del Puerto donde se establecen sectores tan importantes como son la madera, metal, química y alimentación, se aprovechan de la llegada de materias y la posterior exportación del producto elaborado.

El Plan del 46 aprovecha las infraestructuras y servicios como ferrocarril, puertos, red viaria, Se estudia una zona industrial de grandes dimensiones destinada a zona franca del puerto, en la parte norte del área metropolitana de Valencia, unas áreas industriales junto al puerto y otras en los núcleos vecinos. 


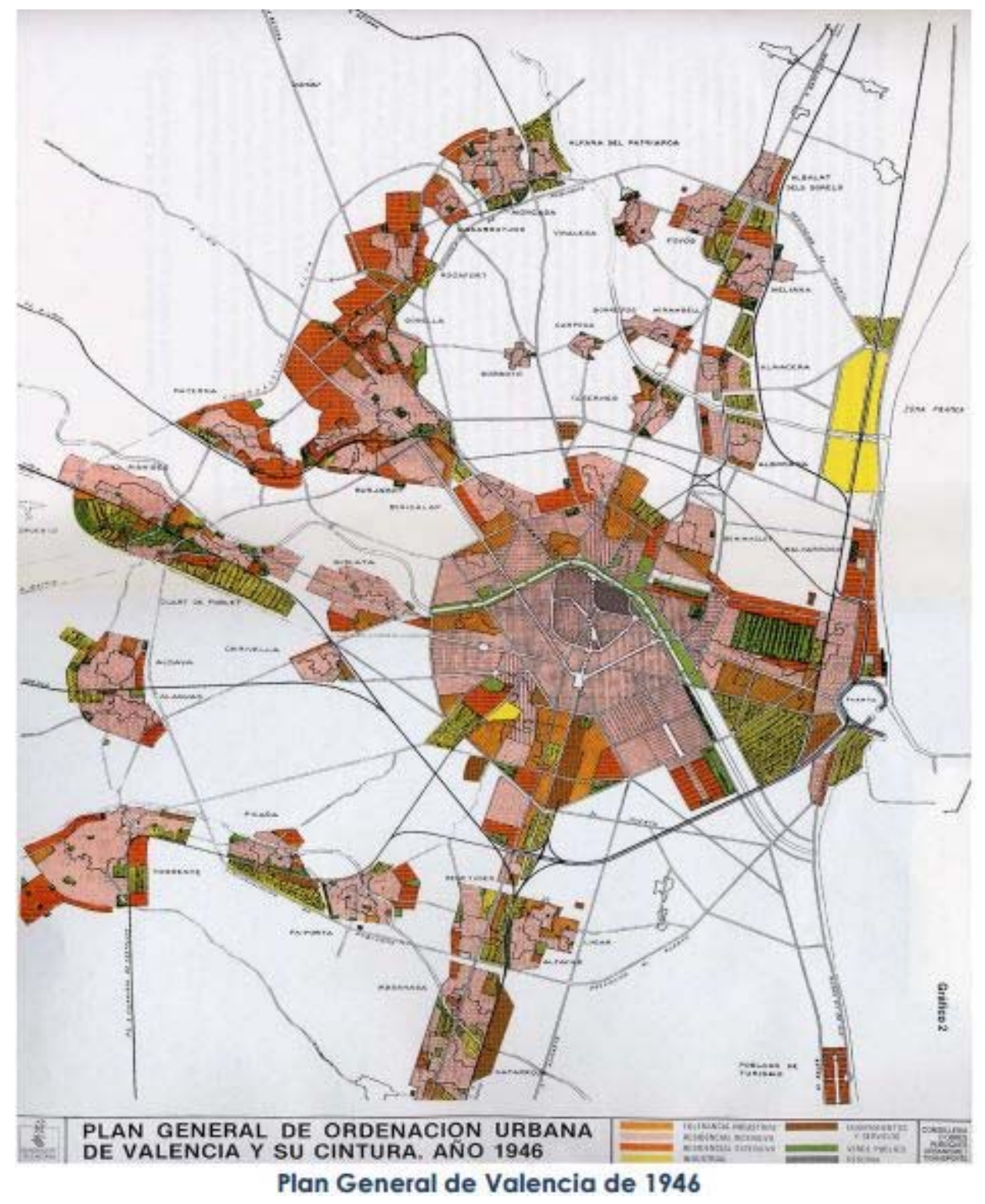

Foto 13: Plan General de Valencia de 1946.Fuente: WEB.http://www.plancabanyal.es/upload/planos/4b252562.jpg

\section{LEY DEL SUELO DEL 56}

La ley sobre régimen del suelo y ordenación urbana del 56 establece entre sus prioridades la industrialización lo que supone un cambio en el planeamiento de la zona de los ensanches.

Se basa en los modelos europeos con una organización territorial del centro y una periférica. Se fijan las directrices de los Planes Generales y los Planes Parciales.

El Plan General marca las directrices generales de la ordenación global del municipio.

El Plan Parcial urbanizaba y edificaba por sectores el municipio. 
Se trata de un código urbanístico aventajado a los países europeos.

La Ley no se consiguió aplicara corto plazo y fue debido a que, aunque se produjo la creación del Ministerio de la Vivienda en el año 1957 para asumir todos los aspectos urbanísticos los municipios siguen dependiendo del Ministerio de Gobernación y, ello sumado a la carencia de medios y capacidad de gestión de los técnicos encargados de aplicar la Ley. A ello se suma el rápido desarrollo de las ciudades que justifica la concesión de licencias sin tener en cuenta el sistema de gestión de la planificación ,creando un crecimiento sin coherencia de organización, del cual quedan multitud de ejemplos en nuestras ciudades que resulta difícil de entender.

\section{PLAN GENERAL DEL 66}

Tras la riada del año 1957, se aprueba en 1966 el Plan General de Valencia donde se estudian tres propuestas para desviar el río Turia y evitar este tipo de desastres:

- Solución Norte (desvío por el barranco del Carraixet).

- Solución Centro (mantener su situación alejándola del puerto en el tramo final).

- Solución Sur (desvío a partir de Manises).

La solución Sur fue la finalmente aprobada (Plan Sur) diferencia tres zonas industriales:

- Zona del Puerto.

- Zona Sudoeste.

- Área entre Manises y Paterna.

La industria, junto con las infraestructuras del transporte, forma la columna vertebral del desarrollo del Plan, siendo superiores al desarrollo residencial. La industria se beneficia de los dos cinturones circulares y de las radiales que comunican la zona central de la ciudad aunque es el Puerto el punto principal del desarrollo industrial. Se crea un número de industrias tan elevado que supera la demanda de aquellos tiempos. Se entiende este hecho como un signo de progreso. Se antepone este desarrollo industrial a cualquier otro uso, poniendo a su disposición todo lo necesario en cuanto a localización.

La ubicación localizada al norte y oeste de la ciudad es defendida frente al aumento de zona industrial al este de la ciudad que ocasionaría la entrada de humos y 
materias contaminantes gracias al viento marítimo que domina en Valencia. El último tramo del antiguo cauce hasta el mar queda imposibilitado para ubicar industria. Se distingue entre:

- Industria normal.

Zonas industriales donde se prohíbe industrias que por su actividad tengan que estar aisladas.

- Industria especial.

- Zonas industriales ubicadas junto a accesos importantes y donde queda prohibida las actividades molestas, nocivas o peligrosas.

- Industria dispersa.

Zona industrial donde sólo está regulado el volumen máximo pero no su acceso y urbanización que será a cargo de cada industria.

De los tres tipos sólo la primera ha resultado tener criterios de regulación, la segunda depende de las vías junto a las que se ubican y la tercera, al regular sólo el volumen, no tiene ninguna lógica de planeamiento ni ocupación.

Esta tolerancia industrial justifica las $1.100 \mathrm{Ha}$ de zonificación industrial dentro del área metropolitana de Valencia de las que aproximadamente $50 \mathrm{Ha}$. corresponden al Polígono Vara de Quart y $235 \mathrm{Ha}$. al Polígono Fuente del Jarro de Paterna, redactados en el primer y segundo programas de polígonos industriales entre los años 1960 y 1964.

En la década de los 60 se redactaron varios Programas de Polígonos Industriales:

- $\quad$ Primer Programa de Polígonos Industriales.

Año: 1960

Redactado por la Gerencia de Urbanización del Ministerio de la Vivienda.

Segundo Programa de Polígonos Industriales.

Año: 1960-1964

- $\quad$ Tercer Programa de Polígonos Industriales.

Año: 1965-1969

Redactado por INUR

La crisis económica de los años 70 provocará cambios urbanísticos que tratan de subsanar los errores cometidos en años anteriores. Se tiene una perspectiva del caos 
urbanístico en el que se agrupan las industrias, con una falta de criterio en su organización.

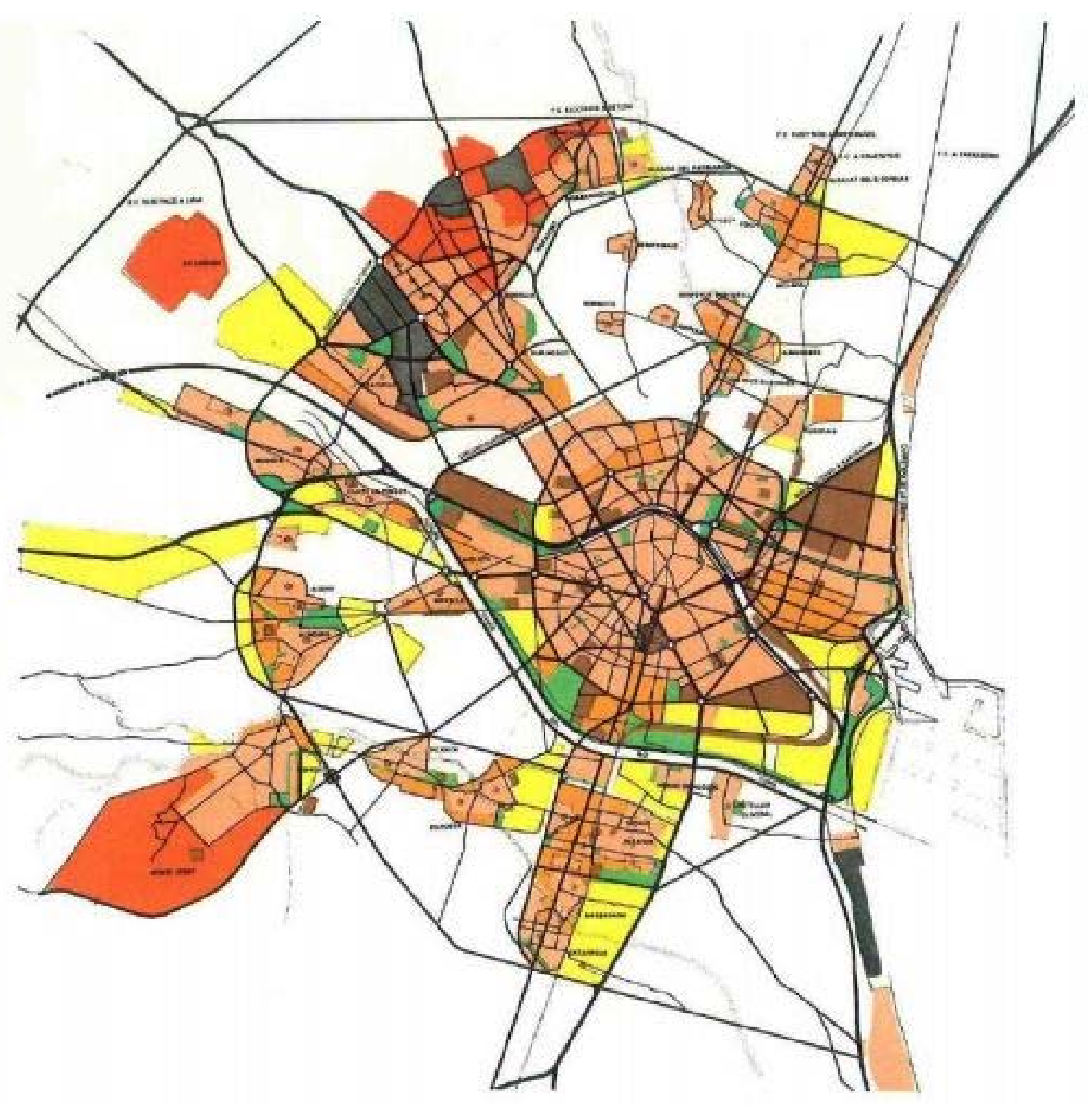

Plan General de Valencia de 1966

Foto 14: Plan General de Valencia de 1966. Fuente: WEB.http://www.plancabanyal.es/upload/planos/ad31df3c.jpg

\section{PLAN GENERAL DEL 88}

El Plan General actual se basa en criterios mas reales, "Es el marco básico regulador del planeamiento urbanístico que incide sobre Valencia y delimita primariamente, las facultades que integran el contenido del derecho de propiedad relativas a la utilización y transformación de terrenos y construcciones según su clasificación y calificación urbanística". 
Fija el Desarrollo del Plan en base a unos Principios Generales, unos Instrumentos de Ordenación, unas condiciones de desarrollo limitativas de la Ejecución del Suelo Urbano y unas condiciones de desarrollo en Suelo Urbanizable Programado.

Establece la Ejecución del Planeamiento en Suelo Urbano, en Suelo Urbanizable Programado y en Suelo Urbanizable No Programado.

Es en las Ordenanzas Particulares de las Zonas de Calificación Urbanística, en los capítulos del uno al sexto donde nos indican los tipos de industria que puede convivir con las distintas áreas residenciales y terciarias y en el capítulo séptimo Zona de Industrias y Almacenes, donde fija las condiciones que tienen que reunir las industrias en las Áreas Industriales.

Ello nos servirá de base para analizar la evolución industrial en el área metropolitana de Valencia, analizando distrito a distrito urbanístico según el Plan General, localizando las diversas industrias y clasificándolas por actividades que desarrollan, superficie, topología, numero de empleados e impacto medio ambiental.

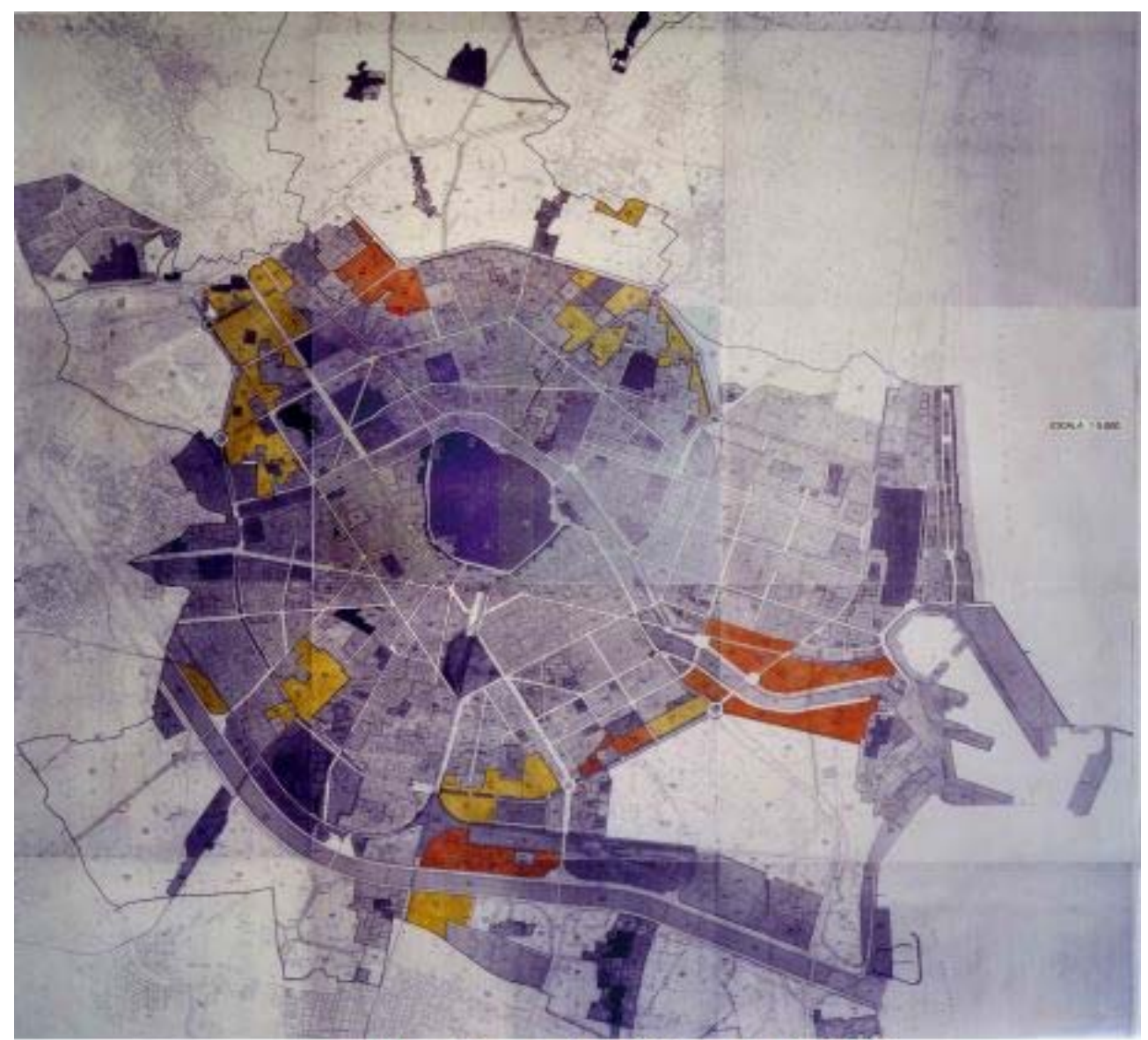

Plan General de Valencia de 1988 


\section{LEY DEL SUELO DEL 90.}

La Ley Sobre el Régimen del Suelo y Ordenación Urbana del 90, en su preámbulo dice:

"El fuerte incremento del precio del suelo, que excede de cualquier limite razonable en muchos lugares, y su repercusión en los precios finales de las viviendas y, en general, en los costes de implantación de actividades económicas....hay que promover las condiciones necesarias para conseguir una utilización del suelo de acuerdo con el interés general e impedir la especulación".

Es el alto coste de implantación en las nuevas áreas industriales lo que le impide a las industrias el emigrar a Polígonos Industriales y por otro lado, las normas que fija el Plan General para ellas les impide subsistir en el lugar que tienen en la actualidad. Como consecuencia de ello entre otras causas se produce una baja considerable de Industrias en el casco urbano de Valencia. 


\section{OBJETIVOS DE LA INVESTIGACIÓN}

\section{LOCALIZAR LAS INDUSTRIAS DURANTE EL PERIODO DE VIGENCIA DEL PG 88}

El presente trabajo tiene como objetivo, conocer a partir de 1985 y en la vigencia del actual Plan General:

- La localización exacta de las diferentes instalaciones industriales emplazadas en el término municipal.

- Su magnitud.

- Tipología.

- Características de accesibilidad.

- Grado de ocupación y empleo.

- Tolerancia medioambiental del asentamiento.

- Actividad en relación con la estructura urbana residencial.

- La evolución de las actividades, durante la vigencia del actual Plan General.

Se plantea como un estudio sectorial de información urbanística, cuyo objetivo más inmediato respecto a las actividades productivas es el mantenimiento de las mismas como medio de evitar la pérdida de empleo, con especial consideración hacia aquellas actividades industriales compatibles con la ciudad consolidada, cuya erradicación viene determinada generalmente, no por sus características intrínsecas sino por el planeamiento vigente que da edificabilidades muy superiores a las existentes, resultando rentable la venta del suelo y el consiguiente traslado de la industria.

Con ese objetivo se pretende evitar fenómenos de tercerización o especialización funcional excesivos, tales como los iniciados en el Centro Histórico, atajados tras la aprobación de los Planes Especiales de Protección.

Gracias a este estudio se puede conocer, de forma satisfactoria, las necesidades y localizaciones industriales de la ciudad y así poder analizar nuevos emplazamientos de áreas industriales.

La presencia y desarrollo de la actividad industrial en las áreas urbanas responde a razones económicas: 
- Por un lado las economías de aglomeración ,es decir, las ventajas económicas derivadas de la concentración de actividades complementarias que junto a la existencia de mercados de trabajos amplios y especializados, mayores niveles de desarrollo de las comunicaciones y servicios y la proximidad a los puntos de consumo favorecen la creación y el mantenimiento de industrias en el seno de las áreas urbanas.

- Por otro lado las economías externas, es decir, el hecho de que parte de los costos de las empresas sean factores no inherentes a ellas, como es el caso de las infraestructuras y servicios urbanísticos básicos, accesos rodados, abastecimiento de agua, energía eléctrica, alcantarillado, teléfonos, etc. hacen que sea más rentable para una empresa producir en las áreas urbanas que en las áreas rurales.

Son éstas razones de localización que afectan especialmente a las grandes y medianas empresas puesto que en las empresas pequeñas suelen tener mayor importancia al arraigo a determinadas zonas, la proximidad a la residencia del propietario, así como otros factores de tipo personal.

El planeamiento industrial en nuestra Comunidad, es relativamente reciente, pero se ha planificado durante la segunda mitad del siglo $X X$, y procede fundamentalmente de la transformación y ocupación del suelo rústico y en menor medida del urbano. Se rige por unas previsiones a futuro y unas ordenanzas que controlan la implantación de la industria.

El desconocimiento de la propia actividad industrial plantea problemas a futuro de entorno y convivencia con el suelo urbano residencial.

\section{EVOLUCIÓN}

El objetivo es, investigando el pasado más próximo que es el que determina el Plan General de 1988 hasta el día de hoy y conocida la evolución histórica anterior al 88 de la actividad industrial, analizar los problemas propios de las empresas para fijar unos criterios más racionales de implantación:

1. Estudiar la actividad industrial en la ciudad de Valencia distrito a distrito, inventariando los diferentes sectores industriales y enumerando el número de 
industrias, superficie de ocupación de las actividades industriales, número de empleados y densidad de empleo de las diferentes actividades.

2. Conocidos los parámetros anteriores, determinar cuales son los sectores dominantes y su demanda de suelo.

3. Que actividades industriales producen máximo empleo y cuales ocupan una gran superficie de suelo con un nivel de empleo bajo.

4. Estudiar las diversas actividades industriales que conviven con la población y determinar cuales son inocuas y pueden convivir con la ciudad y cuales son ruidosas y contaminantes y han de emigrar a lugares más apropiados, y que incidencia han tenido las ordenanzas del PG y el Reglamento de Actividades.

5. Introducir nuevos criterios de ubicación industrial, basados en un orden de empleo, convivencia con el suelo residencial, transporte y economía. Se trata de aprovechar al máximo los recursos disponibles ya que nosotros no contabilizamos estas circunstancias a la hora de diseñar y ubicar las empresas. Simplemente dotamos de suelo, sin un conocimiento exacto de su impacto social o medio ambiental. En general lo intuimos pero no lo planificamos.

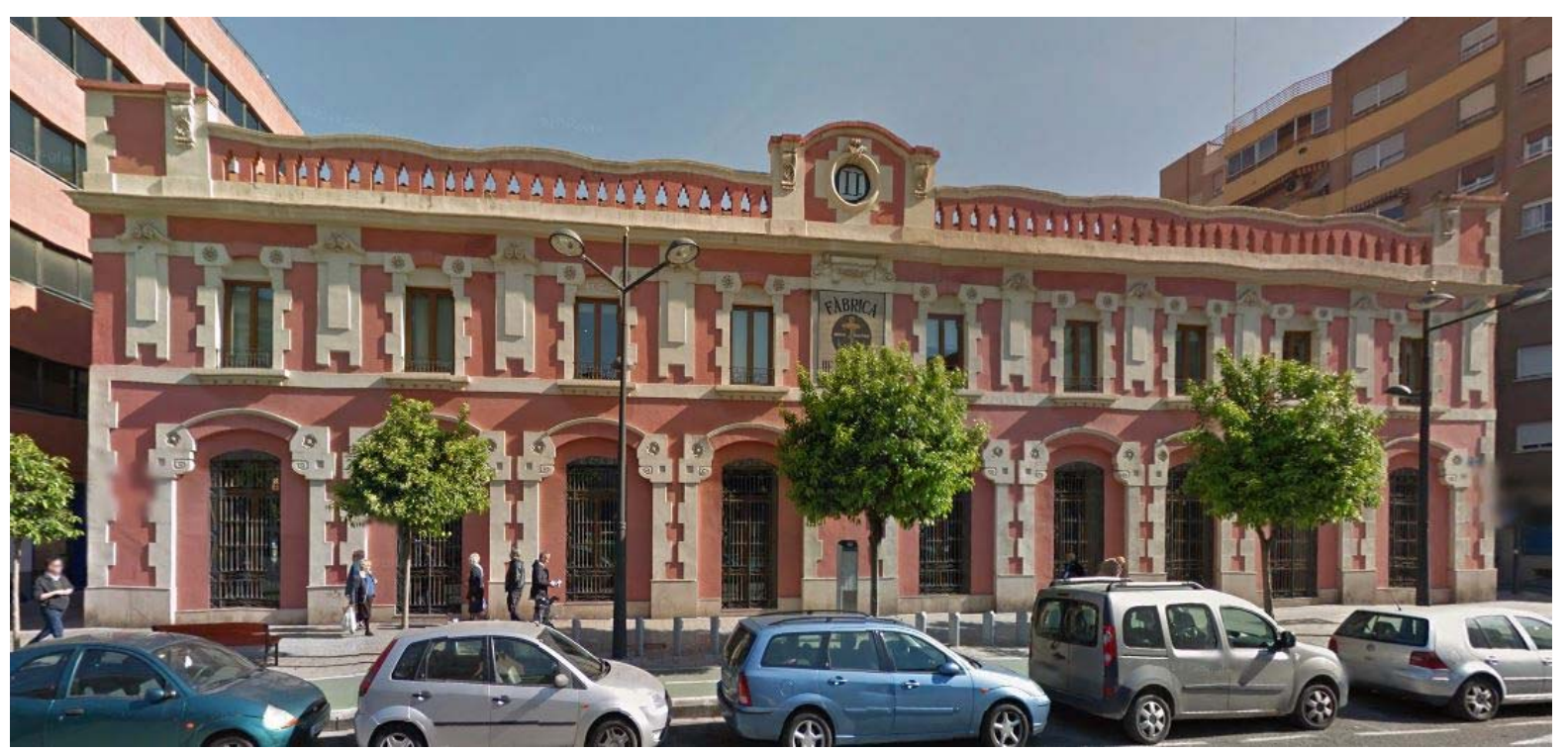

Foto 16: Industrias aceiteras Casanova. Avda. Puerto, 193. Valencia. 2014

Fuente: WEB.http://www.google.es/maps/place/Av.+del+Puerto,+193,+46022+Valencia (Street View) 
Generalmente las industrias comienzan ocupando los bajos de las viviendas, los espacios colindantes a ellas y lugares residenciales a las afueras de la población, deteriorando la imagen de la ciudad y la vida cotidiana de sus habitantes con el ruido, contaminación y molestias que generan algunas de ellas.

Se comienza por poco en la actividad industrial y se termina con mucho, permanece atrapada en el tiempo, sin infraestructuras adecuadas, con una implantación deficiente y sin posibilidad económica de reubicarse en otro lugar. Habitualmente no se dispone de recursos suficientes para implantarse en otro lugar que les pueda ofrecer más posibilidades de desarrollo y crecimiento.

Como consecuencia de ello perdura su implantación en el tiempo y se quedan ocupando lugares estratégicos de la ciudad impidiendo su desarrollo.

El Plan General dicta una serie de ordenanzas industriales por zonas que afectan directamente a las actividades y que provocaran como veremos mas adelante la deslocalización de las mismas, siendo casi siempre beneficioso para la ciudad.

\section{LAS ORDENANZAS DEL PG QUE AFECTAN DIRECTAMENTE A LA EVOLUCIÓN DE LAS INDUSTRIAS}

\section{USOS INDUSTRIALES.}

Ind. 1. Locales industriales compatibles con la vivienda.

Comprende aquellas actividades industriales no calificadas por el Reglamento de actividades molestas, insalubres, nocivas y peligrosas y aquellas calificadas que por no considerarse incompatibles con las viviendas se recojan expresamente en la Ordenanza Municipal específicas.

Ind. 2. Uso industrial enclavado en Zonas no Residenciales.

Comprende aquellas actividades industriales calificadas por el Reglamento de Actividades molestas, insalubres, nocivas y peligrosas que por no considerarse incompatibles con las zonas no residenciales en las que se ubican, se recogen expresamente en la Ordenanzas Municipales específicas. 
Ind. 3. Uso industrial limitado a Zonas de uso dominante Industrial y de Almacén.

Comprende aquellas actividades industriales calificadas con el Reglamento de actividades molestas, insalubres, nocivas y peligrosas que por no considerarse incompatibles con el medio urbano se recojan expresamente en las Ordenanzas municipales específicas.

Alm. 1. Uso Almacén compatible con la vivienda.

Comprende actividades de guarda o almacenaje no calificadas por el Reglamento de actividades molestas, insalubres, nocivas y peligrosas y aquellas calificadas que por no considerarse incompatibles con las viviendas se recojan expresamente en las Ordenanzas municipales específicas.

Cabe distinguir:

- $\quad$ Superficie $\leq 120 \mathrm{~m}^{2}$

- Superficie $>120 \mathrm{~m}^{2}<600 \mathrm{~m}^{2} \quad$ Ancho de vía $8 \mathrm{~m}$.

- Superficie $>600 \mathrm{~m}^{2}<1.600 \mathrm{~m}^{2} \quad$ Ancho de vía $12 \mathrm{~m}$.

Alm. 2. Uso Almacén enclavado en Zonas no residenciales.

Comprende actividades de guarda o almacenaje calificadas por el Reglamento de actividades molestas, insalubres, nocivas y peligrosas que por no considerarse incompatibles con las Zonas de uso no residencial en las que se ubican se recojan expresamente en las Ordenanzas municipales específicas.

Alm. 3. Uso Almacén limitado a zonas de uso Dominante Industrial y Almacén.

Comprende las actividades de guarda o almacenaje calificadas por el Reglamento de actividades molestas, insalubres, nocivas y peligrosas que por no considerarse compatibles con el medio urbano se recojan expresamente en las Ordenanzas municipales específicas.

\section{SUBZONAS}

- Zonas Conjuntos Históricos Protegidos.
CHP. $1 \quad$ Ciutat Vella
CHP. 2 Grao - Cabanyal
CHP. 3 Poblats y Pobles del Nort, del Sud y de l'Oest 
Se prohíben expresamente:

Ind. 2, Ind. 3

Alm. 2, Alm. 3

- Zona Ensanche.

ENS. 1 Ensanche.

ENS. 2 Ensanche Protegido

Se prohíben expresamente:

Ind. 2, Ind. 3

Alm. 2, Alm. 3

- Zona de Edificación Abierta.

Rpf. Residencial Plurifamiliar

Se prohíben expresamente:

Ind. 2, Ind. 3

Alm. 2, Alm. 3

- Zona Vivienda Unifamiliar.

UFA-1 Vivienda Unifamiliar agrupada del tipo "Casas de Poble".

UFA-2 Vivienda Unifamiliar en hilera.

UFA- 3 Vivienda Unifamiliar aislada.

Se prohíben expresamente:

Ind. 2, Ind. 3

Alm. 1a, Alm. 1b hasta $250 \mathrm{~m}^{2}$.

- Zona Terciario.

TER. 1 Feria Muestrario Internacional.

TER. 2 Terciario de media densidad.

TER. 3 Enclave terciario.

TER. 4 Terciario de baja densidad.

TER. 5 Enclave Terciario Polivalente 
Se prohíben expresamente:

Ind. 2, Ind. 3

Alm. 3

- Zona Industrial y Almacenes.

IND. 1 Área de enclaves Industriales.

IND. 2 Polígonos Industriales

Uso global dominante es Industrial y Almacén. 


\section{METODOLOGÍA}

\section{JUSTIFICACION}

Dentro del planteamiento se deberían de integrar los Criterios y Objetivos que atañen a la actividad Industrial:

1.- "Establecer el suelo industrial con un criterio realista y ajustado a la demanda previsible, analizando su emplazamiento en base a las variables de accesibilidad, impacto medioambiental, entorno urbano y población residencial próxima.

Calcular como dato previo si existe demanda futura de este tipo de suelo que justifique calificaciones a añadir al suelo industrial ya ejecutado".

2.- "Definir un sistema de zonificaciones que tenga en cuenta de forma primordial las tipologías existentes y que permita una adecuada integración de usos dentro de la ciudad, evitando la especialización y la segregación salvo para aquellas actividades manifiestamente incompatibles".

Estos criterios y objetivos deberían reflejar el contenido de la política urbanística respecto de la actividad productiva, debiendo adoptar medidas cautelares que impidan efectos sociales y medioambientales negativos por parte de la actividad y promoviendo unas mejores condiciones para el desarrollo de la misma (infraestructura y servicio, proximidad a la residencia de la mano de obra, etc.).

Para ello deberán establecerse Las relaciones más adecuadas entre las actividades productoras y la capacidad del espacio necesario para contenerlas, es decir, deberá precederse a la calificación de usos que tendrá una doble finalidad:

a) Control de actividades con efectos no deseables.

b) Fomento y potenciación de nuevas implantaciones.

Es evidente pues la necesidad de identificar las actividades productivas, en nuestro caso concretamente las industriales, conocer sus necesidades de espacio, infraestructuras, servicios, impacto medioambiental nivel de empleo, etc., con el objeto de que el Planeamiento regule las condiciones y el modo en que las actividades pueden consumir el espacio urbano. 
El suelo como factor de localización industrial de primer orden, en el que el planeamiento puede incidir muy directamente, no ha sido tratado hasta épocas recientes como tal, al contrario que otros factores: materias primas, mano de obra, transporte, mercado. Sin embargo, cuando el suelo está urbanizado, dotado de equipamientos e integrado en la ordenación territorial y económica, es un bien escaso y por tanto social y económico, que se convierte en un instrumento de política urbanística social y económica, que para demostrar su eficacia requiere un tratamiento especifico que puede sintetizarse en los tres puntos siguientes:

- Que la política de localización este plenamente integrada en la planificación urbana y territorial.

- Que se estudien en profundidad los servicios, incentivos y equipamientos que deben adoptarse.

- Que se establezcan con claridad sus objetivos socioeconómicos.

El método se basa principalmente en la recopilación de datos fiables que se obtienen de organismos públicos y privados como el Ayuntamiento de Valencia, la Cámara de Comercio, Industria, Aguas Potables o Iberdrola y de bibliografía para contrastarlos con los inventarios actuales. De esa manera, partiendo de los conocimientos históricos del desarrollo industrial en la ciudad de Valencia y de los datos actuales obrantes en el Plan General de Valencia, se puede hacer un inventario bastante exacto de la actividad industrial. Esto proporciona datos que como se verá más adelante chocan creencias históricas. Como ejemplos significativos, mencionar brevemente que la densidad de población industrial en el centro histórico de Valencia es diez veces superior a la existente en el distrito marítimo, fuertemente industrializado y que la actividad que más espacio ocupa, como es la del almacenamiento de contenedores marítimos, es la de menor empleo y la que más deteriora el entorno rústico y urbano. Todo ello solamente puede ser obtenido del inventario de las industrias con un estudio pormenorizado de las mismas. 


\section{DISEÑO Y CONTENIDO DE LA FICHA}

El criterio en el diseño de de la ficha se centra en agrupar contenidos que sean fácilmente diferenciables en la lectura e interpretación de la misma tratando, por otra parte, de que la toma de datos se refleje en respuestas concretas, a modo de cuestionarlo, de forma que la información así obtenida pueda ser mecanizada mediante ordenador.

Así pues el contenido de la ficha se estructura en los siguientes grupos de datos:

1.- Identificación

2.- Superficie

3.- Infraestructura

4.- Servicios urbanísticos

5.- incidencias en el medio ambiente

6.- Transporte generado

7.- Personal empleado

8.- Adecuación al Planeamiento

9.- Tipología

Dentro de estos apartados generales se encuentran los siguientes datos pormenorizados identificados por el número que le corresponde en la ficha.

\subsection{Localización}

\section{IDENTIFICACION}

1. Empresa:

Propietario o razón social de la misma.

2. Emplazamiento:

Domicilio de la actividad con indicación del distrito municipal y barrio. 
3. Domicilio social:

Se incluye solo cuando es diferente del de la actividad.

4. Nivel de funcionamiento:

Se trata de una apreciación porcentual, en el momento de cumplimentar la ficha, referida al trabajo que desarrolla la empresa en la actualidad respecto al nivel óptimo de producción.

5. Clave:

Código por el que se identifica la empresa en el presente estudio. Está directamente relacionado con la cartografía empleada razón por la cual existen tres códigos distintos a saber:

a) Parcelarios del Ministerio de Hacienda E: 1/1000 son los que se han utilizado mayoritariamente por las siguientes razones:

1. Fácil identificación y localización, por tener grafiados los nombres de las calles y números de policía.

2. Disponibilidad y operatividad: Se disponía de los parcelarios correspondientes a la práctica totalidad del suelo urbano, lo que no sucedía con la cartografía municipal más reciente.

Por otra parte, esta cartografía no es válida en las áreas periféricas, donde se han producido cambios notorios, ni en las áreas no urbanas pues los parcelarios corresponden al catastro de Urbana.

Para una mejor interpretación del código empleado pondremos un ejemplo:

Claves AB-5

AB: Identificación del plano parcelario en el que se encuentra emplazada la actividad. 
5: Número de orden que identifica a la industria dentro del plano parcelarlo citado y del distrito a que corresponde.

b) Cartografía municipal 1.983-84 (E:1/1000). Corresponde a la fotogrametría realizada en 1.983 .

Se ha utilizado subsidiariamente a la anterior, puesto que pese al alto grado de precisión y actualidad de sus datos, no se disponía, al iniciar el trabajo más que de un bajo porcentaje de la misma y por otra parte, carecía de la rotulación de calles y números de policía.

No obstante se ha utilizado en áreas donde el trazado urbano o la parcelación han variado sensiblemente. Un ejemplo del código empleado es el siguiente:

Clave: $6 \mathrm{E} / 5-7$

6E/5: Identificación del plano fotogramétrico correspondiente al vuelo del año 1.983

7: Número de orden que identifica a la industria dentro del plano citado y del distrito a que corresponde.

c) Cartografía municipal 1.983-84 (E:1/5000)

Corresponde, como la anterior, a la fotogrametría realizada en 1.983 , aunque difieren en la escala.

Se ha utilizado para localizar las industrias situadas en áreas no urbanas o las que por su gran dimensión, no quedarían definidas totalmente en un plano a escala 1:1000

La clave empleada en estos casos es como la del siguiente ejemplo

Clave: $4 \mathrm{~F} / 5000-2$

4F/5000: Identificación del plano. 
2: Número de orden asignado a la industria dentro del plano citado y del distrito a que corresponda.

\subsection{Actividades}

6. C.N.A.E.:

En este apartado se Identifica la actividad mediante el código correspondiente a la Clasificación Nacional de Actividades Económicas, que constituye un sistema jerarquizado por rama productora. El sistema de codificación empleado es el decimal con siete dígitos, aunque este Estudio solo ha empleado los tres primeros y a lo sumo cuatro, que corresponden a los diferentes subgrupos de la C.N.A.E.

Ejemplos:

Código CNAE

3.111

3.112

3.211

3.212
Actividad

Fundición de piezas de hierro y acero.

Fundición de piezas de metales no férreos y sus aleaciones.

Construcción de maquinaria agrícolas.

Construcción de tractores agrícolas.

7. NIRI / AÑO:

Corresponde al número de inscripción de la empresa en el Registro Industrial de Consellería de Industria y el año de inscripción en el mismo.

8. Régimen de Tenencia:

Indica si el local ocupado por la empresa es propiedad de la misma o no. 
9. Teléfono:

Este dato permite una fácil y rápida comunicación con la empresa.

Plano de emplazamiento e identificación fotográfica:

Aunque están situados al dorso de la ficha, corresponden al apartado de identificación ya habiendo sido explicada la cartografía utilizada.

En cuanto a la identificación fotográfica suele venir definida por una fotografía de tamaño $9 \times 13 \mathrm{~cm}$. aunque cuando el tamaño o las características de la empresa lo requieren, se ha aumentado el número de fotografías incorporándolas a una ficha complementaria. La dirección en que se toma la fotografía se indica mediante una flecha.

\subsection{Superficies ocupadas por la industria}

\section{SUPERFICIE:}

Son datos aproximados procedentes de la empresa contrastados sobre el plano de situación. Cuando no ha habido respuesta se ha intentado dar una valoración aproximada.

10. Parcela:

Indica la superficie de la parcela, esté ocupada o no.

11. Ocupada:

Indica la superficie de parcela ocupada por la edificación.

12. Construida:

Indica la superficie total edificada de la actividad industrial.

13. Aparcamiento:

Superficie de parcela de dominio privado dedicada a aparcamiento. 
14. Taller:

Indica el \% sobre el total, destinado a zona productiva.

15. Almacén:

$\%$ de superficie dedicada a almacenamiento de material.

16. Oficina:

\% de superficie dedicada a administración.

17. Otros:

\% de áreas no detallados previamente.

\subsection{Energía Infraestructuras y Medio Ambiente}

\section{INFRAESTRUCTURA:}

Energía:

Se refiere a energía eléctrica. Otros tipos de productos energéticos vienen recogidos en el apartado de Medio Ambiente.

18. Energía Eléctrica:

Si dispone de ella o no.

19. Línea de tendido particular:

Si es propia o no.

20. Aérea o subterránea. 
21. Subestación de la que procede el tendido eléctrico:

Es este un dato que no se ha podido determinar por la dificultad que supone su obtención de Hidroeléctrica.

Potencia:

Los datos referidos a este punto han sido de difícil obtención, habiéndose debido tomar los datos frecuentemente de recibos de Hidroeléctrica.

22. Potencia contratada:

Referida a alumbrado y fuerza motriz medida en Kilovatios (KW) o caballos de vapor (C.V).

23. Potencia en motores, en su caso.

24. Potencia en transformadores, en su caso medida en kilovoltioamperios (KVA).

Abastecimiento de agua:

25. Existencia o no de agua potable en la empresa.

26. Tipo de captación.

27. Caudal / consumo de agua en $\mathrm{m} 3 / \mathrm{sg}$. 
Alcantarillado:

28. Existencia o no del alcantarillado.

29. Lugar de vertido, diferenciándose así si es a red de alcantarillado, a acequia, barranco, etc.

30. Tipo de vertido efectuado, para detectarla posibilidad de contaminación. Generalmente se reduce a aguas sanitarias, en la ficha "aguas negras".

\section{SERVICIOS URBANISTICOS:}

Se recoge en este apartado los datos referentes a alumbrado y pavimentación públicos, no los propios de la edificación o parcela.

Alumbrado:

31. Existencia o no de alumbrado público.

32. Nivel de iluminación del acceso en su caso.

33. Grado de conservación de la instalación, en su caso.

Pavimentación:

34. Existencia o no de pavimentación.

35. Estado de conservación de la misma. 
36. Existencia o no de aceras.

37. Estado de conservación de las mismas.

\section{MEDIO AMBIENTE:}

Se recogen en este apartado datos relativos a las posibles molestias o contaminación que la industria puede provocar en el medio ambiente.

38. Existencia o no de ruidos en el exterior de la industria, con origen en la propia industria.

39. Existencia de viviendas próximas, termino muy relativo que depende de la apreciación en la toma de datos.

40. Tipo de vertido, especialmente referido a las características potencialmente contaminantes del mismo.

41. Existencia o no de chimeneas que producen o pueden producir humos y altura de las mismas en metros.

42. Tipo de combustible empleado, en su caso. 


\subsection{Personal y Transporte}

\section{TRANSPORTE:}

43. Disponibilidad o no de transporte de operarios por parte de la empresa.

Este dato se ha mostrado ineficaz por dos motivos:

1.- La casi inexistencia de empresas con transporte propio.

2.- La ausencia de casilla referida al transporte mediante vehículo propio, de cada trabajador.

3.- La inexactitud y variabilidad de dichos datos.

44. Número de vehículos de mercancía que reciben por semana y carga media por vehículo. Este es un dato generalmente muy variable por lo que su contestación producía ciertas reticencias.

45 y 46 . Origen y destino de las mercancías.

\section{PERSONAL}

47. Numero de trabajadores de la empresa, fijos o no.

48. Procedencia de los mismos en \%, indicándose si son del mismo Distrito en que está ubicada la empresa, o de cualquier otro dentro del término de Valencia o de otro municipio. 


\subsection{Planeamiento y Tipología Edificatoria}

\section{PLANEAMIENTO}

49. Indica si se ajusta a la ordenación vigente o no.

Dada la ambigüedad y complejidad de este concepto, así como el elevado número de modificaciones a que se ha visto sujeto el Planeamiento General, este epígrafe no ha sido cumplimentado, dejando a criterio de la Oficina Municipal del Plan su definición final.

\section{TIPOLOGIA DE LA EDIFICACION.}

50. Indica la fecha aproximada del edificio que alberga la actividad Industrial. Para ello se han clasificado tres grandes periodos con el siguiente criterio:

Antes de 1.900.

Puesto que fue en los últimos años del siglo XIX, cuando se comienza a usar el acero laminado en la edificación (hasta entonces solo se habían utilizado columnas de hierro fundido) siendo el Salón de Racionistas (1.885) el primer ejemplo de aplicación del acero, no llegándose a usar en vigas hasta los primeros años del siglo XX.

Coincidió con esta aplicación del acero, la finalización del movimiento historicista (Los "Neos") iniciado a mediados del siglo XIX y el comienzo de un nuevo lenguaje arquitectónico, el modernismo, que si bien no tuvo gran duración la última obra modernista puedo considerarse el Mercado de Colón (1.914) si que ha tenido una gran significación en la arquitectura Valenciana del siglo $X X$.

En cuanto a la actividad industrial, tras la crisis de la Industria sedera a mediados del XIX, resurge el proceso industrializador a finales de siglo, como consecuencia de las transformaciones en el sistema productivo industrial y de la concentración de población y recursos en la ciudad. 


\section{$\underline{1.900-1.960}$}

Se determina este periodo con el objeto de diferenciar, el importante desarrollo industrial comprendido entre 1.900 y 1.930 la población activa industrial en Valencia se multiplica por tres entre 1900 y 1930 lo que supone un incremento en cifras absolutas de 33.100 personas, con el paréntesis de la primera guerra mundial, paralelamente al cual tienen lugar grandes cambios en la morfología urbana: Planes de Ensanche y Reforma interior, ampliador del puerto, etc.

Con la guerra civil española se interrumpe este proceso, dando lugar a un cierto trasvase de población activa hacia la agricultura, y a un estancamiento de la actividad económica durante la etapa autárquica y de aislamiento, que no finalizara hasta la segunda mitad de los años cincuenta, con el Plan de Estabilización Económica de 1.959.

Desde el punto de vista constructivo, pese a corresponder a este período el primer edificio de hormigón armado, Docks Comerciales del Puerto (1.909), de Demetrio Ribes y Víctor Gosálvez, continúa utilizándose mayoritariamente la estructura mixta base de muros de ladrillo y vigas cerchas de acero, que han sustituido a las de madera, utilizadas hasta final del XIX, permitiendo luces de viga de mayor dimensión y por tanto espacios más diáfanos.

\section{Posterior a 1.960}

Es este un período que viene determinado por la fuerte reactivación económica y especialmente industrial, en la década de los años 60 y primera mitad de los 70, y cuyo escenario más que la ciudad de Valencia, lo constituye su cinturón metropolitano, con la transformación de zonas tradicionalmente agrarias en industriales.

Corresponde también a esta época el desarrollo pleno de las estructuras de hormigón arriado aunque en edificios especialmente industriales, son más utilizadas las estructuras metálicas. Las construcciones industriales en este periodo no responden, en general, a ningún tipo de planteamiento estilístico, siendo los condicionantes económicos los únicos considerados, cuyo resultado es la nave industrial "tipo": estructura metálica en soportes y 
cerchas, cubierta de fibrocemento y cerramiento de ladrillo o bloques de hormigón premoldeado, enfoscado y pintado.

Un signo externo de "calidad" en la edificación industrial viene determinado por el uso como revestimiento o cerramiento, de chapa ondulada de hierro, pintada.

51. Estado de conservación del edificio:

Se refiere al conjunto del edificio en el que esté ubicada la industria, simplificándose su apreciación mediante la adscripción a tres niveles: bueno, regular y malo

52. Tipo de emplazamiento:

Se establecen distintos tipos de industria en función de su emplazamiento:

- Edificación aislada en la parcela

- Edificación entre medianeras

- Edificación en patio de manzana

- Ubicación en edificio de otro uso, generalmente plantas bajas, situadas en edificios de vivienda.

\section{3 a 57. TIPOLOGIA ESTRUCTURAL}

Intenta definir este apartado la tipología estructural del edificio mediante el sistema constructivo y los materiales empleados, diferenciando la estructura propiamente dicha (vigas, cerchas) e introduciendo otros elementos de interés para la definición del "tipo", como es la luz libre entre apoyos en vigas o cerchas.

Así, por ejemplo, una estructura de fábrica de ladrillos y vigas de madera no tendrá normalmente una luz libre superior a 6 metros, aunque si podría tenerla si en vez de vigas se utilizasen cerchas de madera, no dándose en cualquier caso luces superiores a 10 metros. 
Otro caso es el de una estructura realizada con soportes y cerchas metálicas, sistema que permite alcanzar luces libres superiores a 10 metros No se ha contemplado el caso de estructuras espaciales por su escasa o nula implantación. De hecho no ha sido inventariada ninguna con estas características.

Son muchos los casos en que se dan en la misma industria más de un tipo constructivo como consecuencia de ampliaciones, reformas o de la diversidad de usos (oficinas, almacenamiento, taller el más dominante significativo de ellos., etc.)

\section{CRITERIOS DE SELECCION.}

Tras el análisis y valoración de la información obtenida a través de los listados facilitados por los Organismos correspondientes, en las que se determinaron las siguientes bases de selección, en función de la finalidad del presente Estudio de Localización Industrial:

1.- Inventariar las actividades clasificadas en los epígrafes 1 al 5 de la C.N.A.E. en los que se incluye algunas actividades del sector primario: minería, producción y distribución de energía, etc. y todas las del sector secundario, es decir, productos Industriales.

2.- Incluir en el Inventario aquellas actividades especiales referidas por lo general a servicios públicos no incluidos en los anteriores, otros grandes centros de almacenamiento, etc.

Dada la dificultad que ha supuesto la obtención de la información de estas actividades y por otro lado, dada su heterogeneidad que las hacia difícilmente inscribibles en el modelo de ficha establecido, aportaremos su relación y localización sobre un plano a escala 1:10.000, pero no sus fichas respectivas.

3.- Suprimir, por su escaso impacto medioambiental y pequeño consumo de superficie las actividades industriales con menos de 5 trabajadores y de 15 caballos de vapor, de potencia. 
Es esta una condición no excluyente, ya que en el caso de que una industria de estas características ocupase un espacio considerable o tuviera un impacto negativo en su entorno, sería condición suficiente para formar parte del presente inventario, puesto que como ya se explicó con anterioridad en la presente Memoria, consideramos estos dos factores como los fundamentales de cara a la Revisión del Plan General.

4.- No incluir como actividad industrial las Delegaciones u Oficinas Centrales de empresas, cuando no tenga lugar en ellas actividad productiva alguna y se limiten tan sólo a una labor administrativa, incluida por tanto en el sector de servicios.

Es este el caso de un gran número de empresas con domicilio social en Valencia y actividad en otro Municipio, v.g. "Valenciana de Cementos".

5.- Incluir, según lo expuesto en el apartado 3, en cuanto a consumo de superficie e impacto medioambiental, los locales de almacenamiento y distribución de mercancías, pues pese a no realizarse en ellos una actividad productiva en sentido estricto, si que tienen unas características tipológicas y funcionales muy semejantes a las industriales. Ocupación de suelo e impacto en la escena urbana.

6.- Incluir en el presente Estudio edificios industriales en desuso que por sus dimensiones y cualidades arquitectónicas puedan ser objeto de reutilización, bien manteniendo un uso industrial compatible con su entorno o bien habilitándolos para ubicar en ellos actividades públicas de carácter educativo, recreativo, cultural, comercial, etc.

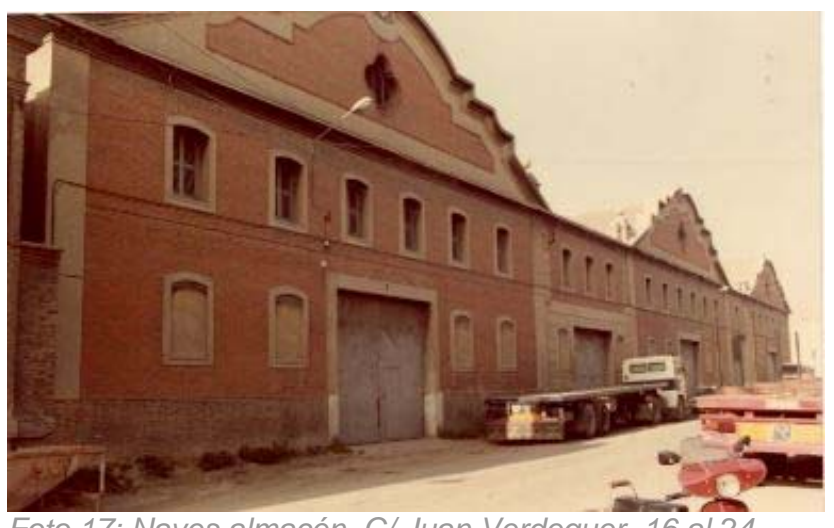

Foto 17: Naves almacén. C/ Juan Verdeguer, 16 al 24 Valencia.1985 Fuente: Elaboración propia

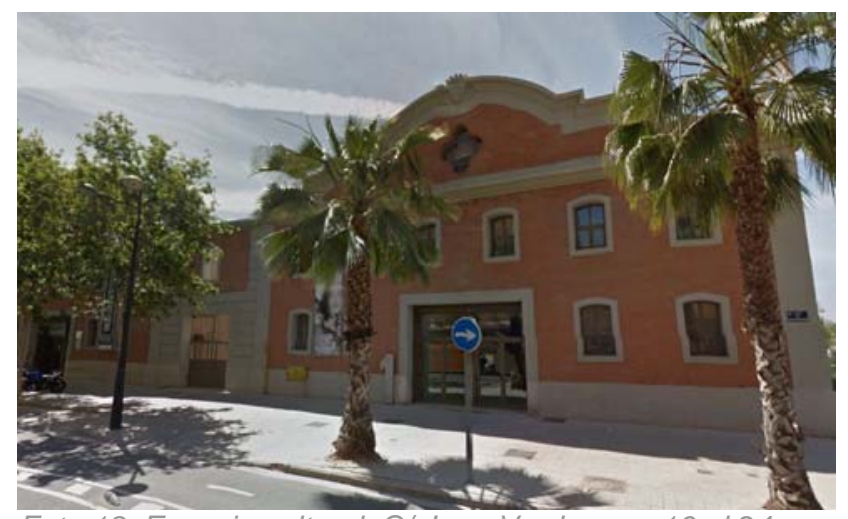

Foto 18: Espacio cultural. C/ Juan Verdeguer, 16 al 24. Valencia 2015 Fuente: WEB. http://www.google.es/maps (Street View) 
En base a los criterios expuestos no se contemplan un gran número de industriales de la construcción, autónomos cuya actividad la desarrollan por tanto en diversos lugares y cuyo material de trabajo requiere en muchos casos estar dado de alta en el Registro Industrial; es el caso, por ejemplo, de electricistas, fontaneros, etc.

Otras empresas de la construcción, como las inmobiliarias, no han sido tenidas en cuenta según lo expuesto en el apartado 4 de los criterios de selección, ya que se limitan a una labor administrativa realizándose la actividad industrial en otro lugar. Por tanto se han contemplado tan sólo los locales que ocupar una superficie considerable, generalmente de almacenamiento de material.

El suelo, factor de localización industrial de primer orden en el que el planeamiento puede incidir muy directamente, no ha sido tratado hasta épocas recientes como tal, al contrario que otros factores: materias primas, mano de obra, transporte, mercado. Sin embargo, cuando el suelo está urbanizado, dotado de equipamientos e integrado en la ordenación territorial y económica, es un bien escaso y por tanto económico, que se convierte en un instrumento de política urbanística y económica, que para demostrar su eficacia requiere un tratamiento especifico que puede sintetizarse en los tres puntos siguientes:

- Que la política de localización este plenamente integrada en la planificación urbana y territorial.

- Que se estudien en profundidad los servicios, incentivos y equipamientos que deben adoptarse.

- Que se establezcan con claridad sus objetivos socioeconómicos.

El método se basa principalmente en la recopilación de datos fiables que se obtienen de organismos públicos y privados como el Ayuntamiento de Valencia, la Cámara de Comercio, Industria, Aguas Potables o Iberdrola y de bibliografía para contrastarlos con los inventarios actuales. De esa manera, partiendo de los conocimientos históricos del desarrollo industrial en la ciudad de Valencia y de los datos actuales obrantes en el Plan General de Valencia, se puede hacer un inventario bastante exacto de la actividad industrial. Esto proporciona datos que como se verá mas adelante chocan creencias históricas. Como ejemplos significativos, mencionar brevemente que la 
densidad de población industrial en el centro histórico de Valencia es diez veces superior a la existente en el distrito marítimo, fuertemente industrializado y que la actividad que más espacio ocupa, como es la del almacenamiento de contenedores marítimos, es la de menor empleo y la que más deteriora el entorno rústico y urbano. Todo ello solamente puede ser obtenido del inventario de las industrias con un estudio pormenorizado de las mismas.

Para ello se elaboran:

- Fichas resumen de las diferentes actividades industriales con datos de: número de empresas, número de empleados, superficie que ocupa, tipología, infraestructuras, medio ambiente, combustible.

- Cuadros resumen del conjunto de las actividades industriales en el distrito.

- Cuadros resumen de la densidad de empleados $/ \mathrm{m}^{2}$ actividad.

- Cuadros de impacto en el medio urbano.

Puesto que la base de este trabajo era obtener una información fidedigna de la localización industrial en Valencia y su incidencia en el medio ambiente, contemplando un gran número de variables urbanísticas y sociológicas se consideró fundamental que la obtención de dicha información fuese lo más homogénea y objetiva posible a lo largo de todo el trabajo, siendo totalmente necesario por otra parte, que dicha información fuese procesable para permitir un tratamiento ágil y variado de la información. 


\section{DISEÑO Y CONTENIDO DE LAS FICHAS}

\begin{tabular}{|c|c|c|}
\hline \multirow{2}{*}{\multicolumn{3}{|c|}{$\begin{array}{l}\text { DEFINICIONES DE LOS TÉRMINOS EMPLEADOS EN LAS FICHAS SOBRE EL "ESTUDIO DE } \\
\text { OCALIZACIÓN DE ACTIVIDADES INDUSTRIALES Y SU INFLUENCIA EN EL MEDIO URBANO EN }\end{array}$}} \\
\hline & & \\
\hline \multicolumn{3}{|c|}{ LA CIUDAD DE VALENCIA DESDE 1985" } \\
\hline EMPLAZAMIENTO & \multicolumn{2}{|c|}{$\begin{array}{l}\text { Distrito Municipal de Valencia en el que ubican las } \\
\text { empresas. }\end{array}$} \\
\hline ACTIVIDAD & \multicolumn{2}{|c|}{ Operaciones o tareas desarrolladas por las empresas. } \\
\hline \multirow[t]{9}{*}{ SUPERFICIE } & № EMPRESAS: & $\begin{array}{l}\text { Número de empresas pertenecientes a una } \\
\text { misma actividad. }\end{array}$ \\
\hline & № EMPLEADOS: & $\begin{array}{l}\text { Número de empleados totales en plantilla de las } \\
\text { empresas. }\end{array}$ \\
\hline & SUP. ACTIVIDAD & Superficie de la actividad industrial en el distrito \\
\hline & IND: & expresada en $\mathrm{m}^{2}$. \\
\hline & SUP. MEDIA: & $\begin{array}{l}\text { (superficie de la actividad industrial en el distrito } \\
\text { / } \mathrm{n} \text { o empresas) expresada en } \mathrm{m}^{2} \text {. }\end{array}$ \\
\hline & SUP. TOTAL SUELO & Superficie total industrial del distrito expresado \\
\hline & IND: & en $\mathrm{m}^{2}$. \\
\hline & $\%$ SUP. & Porcentaje de la superficie industrial ocupada \\
\hline & INDUSTRIAL: & por la actividad en el distrito. \\
\hline \multirow[t]{3}{*}{ TIPOLOGÍA } & AISLADA: & $\begin{array}{l}\text { Porcentaje de empresas sin colindantes próximos } \\
\text { a sus medianeras. }\end{array}$ \\
\hline & ENTRE & Porcentaje de empresas con colindantes en \\
\hline & MEDIANERAS: & contacto con sus medianeras. \\
\hline
\end{tabular}




\begin{tabular}{|c|c|c|}
\hline INFRAESTRUCTURAS & ENERGÍA & Porcentaje de empresas abastecidas de energía \\
\hline & ELÉCTRICA: & proveniente de la red eléctrica. \\
\hline & AGUA POTABLE: & $\begin{array}{l}\text { Porcentaje de empresas abastecidas de agua } \\
\text { proveniente de la red de suministro. }\end{array}$ \\
\hline & ALCANTARILLADO: & $\begin{array}{l}\text { Porcentaje de empresas con conexión a la red de } \\
\text { saneamiento. }\end{array}$ \\
\hline MEDIO AMBIENTE & RUIDOS: & $\begin{array}{l}\text { Porcentaje de empresas generadoras de ruido } \\
\text { durante su funcionamiento. }\end{array}$ \\
\hline & VIVIENDAS & Porcentaje de empresas cercanas a núcleos \\
\hline & PRÓXIMAS: & residenciales. \\
\hline & AGUAS & Porcentaje de empresas generadoras de aguas \\
\hline & RESIDUALES: & residuales provenientes de la actividad industrial. \\
\hline & CHIMENEAS: & $\begin{array}{l}\text { Porcentaje de empresas generadoras de humos } \\
\text { emitidos por chimeneas provenientes de la } \\
\text { actividad industrial. }\end{array}$ \\
\hline COMBUSTIBLE & FUEL: & $\begin{array}{l}\text { Porcentaje de empresas que utilizan fuel como } \\
\text { fuente de energía en su proceso industrial. }\end{array}$ \\
\hline & GASOIL: & $\begin{array}{l}\text { Porcentaje de empresas que utilizan gasoil como } \\
\text { fuente de energía en su proceso industrial. }\end{array}$ \\
\hline & OTROS: & $\begin{array}{l}\text { Porcentaje de empresas que utilizan otro tipo de } \\
\text { combustible distinto al fuel y gasoil como fuente } \\
\text { de energía en su proceso industrial. }\end{array}$ \\
\hline
\end{tabular}




\section{ANÁLISIS PORMENORIZADO POR DISTRITOS.}

\section{DISTRITO 1.- CIUTAT VELLA}

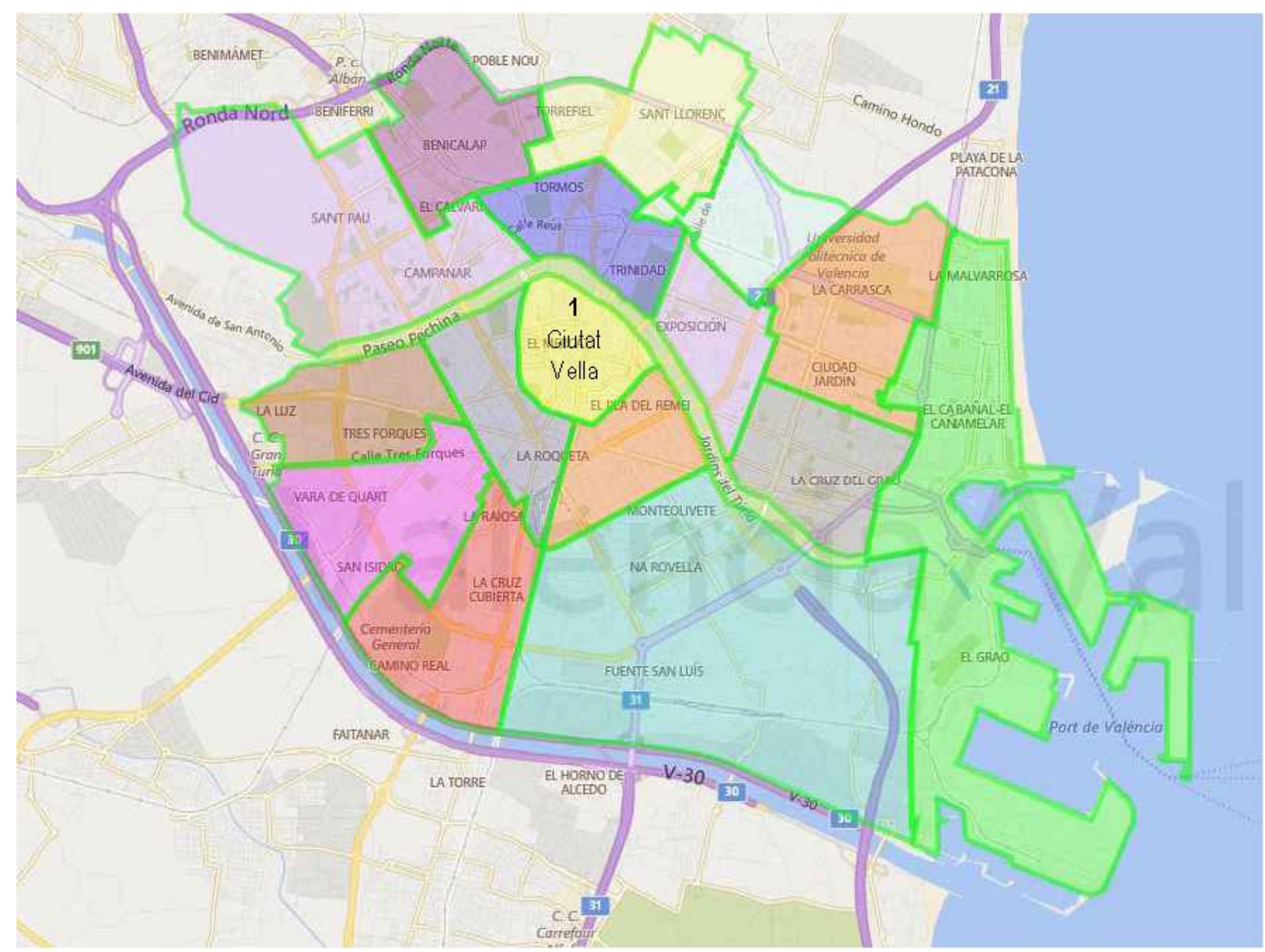

\section{LÍMITES GEOGRÁFICOS.}

C/ Colón, C/ Játiva, C/ Guillém de Castro, C/ Blanquerías, Paseo de la Ciudadela y Avda. Navarro Reverter. 


\section{EVOLUCIÓN DEL 1985-2014}

\section{PLANO UBICACIÓN INDUSTRIAS}

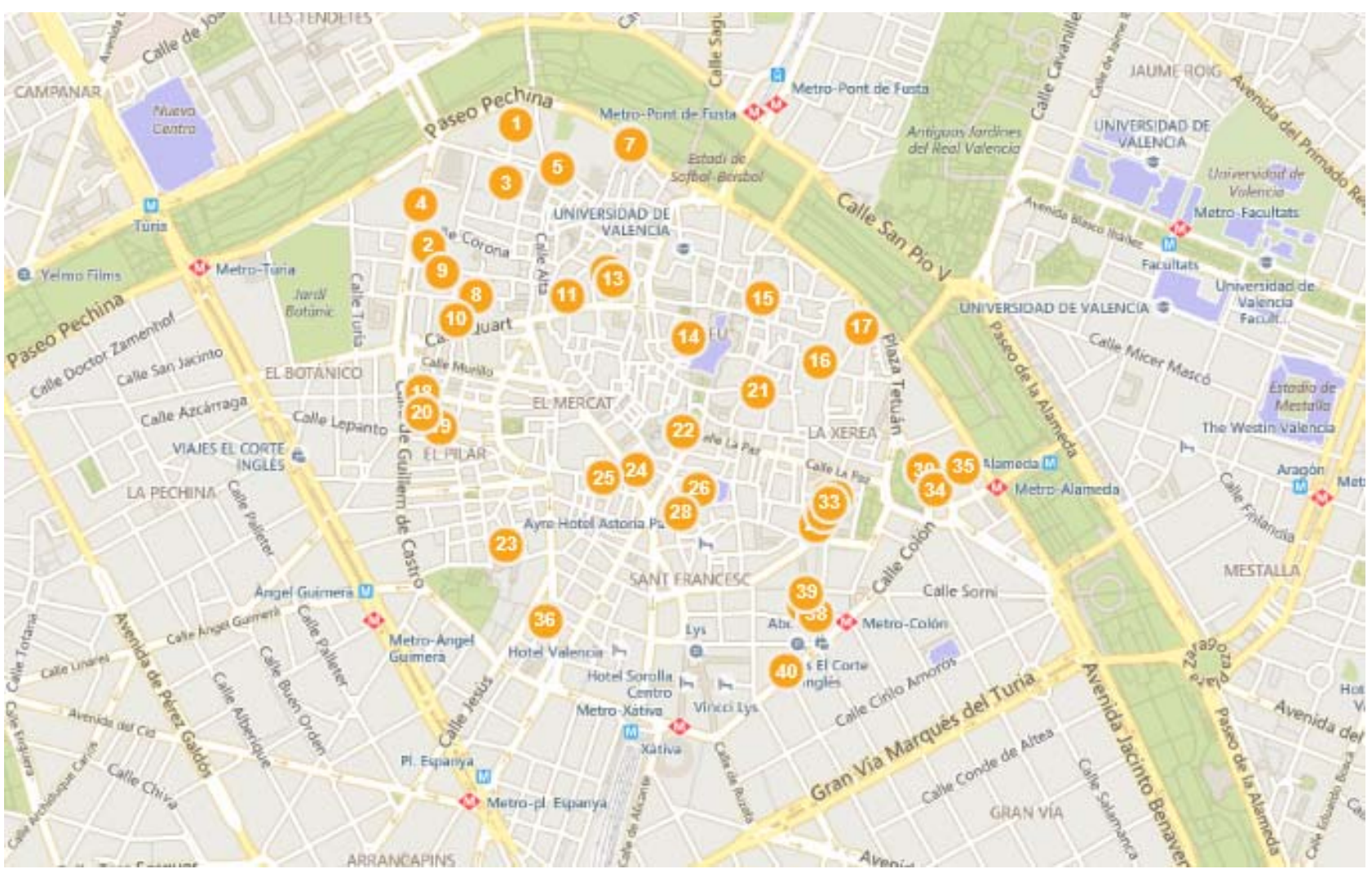

LISTADO DE INDUSTRIAS Y ESTADO ACTUAL .-

1. Romeu Orquin, A.

Solar sin edificar

2. INDUSTRIAS SALUBES, S.A.

Sin actividad

3. HIJOS DE VICENTE DOMINGO VERA, S.L.

Sin actividad

4. IMPRENTA DIPUTACION

IVAM

5. Barrera Mateu, V

Obra nueva.

6. Juan Badal Martínez

Sin actividad 
7. Vidagany Linares, $\mathbf{N}$

Sin actividad

8. García Cortina, J.

Prótesis. En la actualidad: Bar "El Principito"

9. ASCENSORES CENIA S.A.

Peluquería

10. FAYGRA, S.A.

Trajes de valenciana

11. LOS GOLOSOS, S.A.

Solar sin edificar

12. Vicente Gil Galán

Sin actividad

13. Burguera Miñana, $V$

Sin actividad

14. José $M^{\mathrm{a}}$ Montañana

Sin actividad

15. Antonio Morante Ríos

Sin actividad

16. SERIGRADIA VIMA

Mantiene la actividad

17. Sanchis Espallargues, A

Hotel

18. Moret Segura, M.

Comercio de artículos de arte.

19. TECE, S.L.

Sede de Amnistía Internacional.

20. BARBER LORCA Y CIA, S.L.

Arreglos florales

21. Nacher Lluesma, $\mathrm{C}$.

Mantiene la actividad

22. Vda. de Romero Vicente, A.

Horchatería.

23. Collado Pérez, Rafael

Sin actividad

24. LABORATORIOS CUSI, S.A.

Sin datos.

25. ALBEROLA HNOS. S.R.C.

Solar sin edificar.

26. Miralles Guillen, Guillermo

Sin actividad 
27. ANTONIO GUERRERO MECÁNICA S.A.

Sin actividad

28. WARONS, S.A.

Bar.

29. Chuliá Gimenez, J.M. y R.

kiosco.

30. Roig Caballero, Adela

Entidad bancaria.

31. GRÁFICAS CARBAJAL S.A.

Taller de restauración

32. Alonso Hernandez, J.

Sin actividad

33. Sarrión Marco, J.

Sin actividad

34. STANDARD ELÉCTRICA S.A.

Escuela de idiomas.

35. BURROUGHS, S.A.

Mantiene la actividad

36. LABORATORIOS SUBSTANCIA S.A.

Cafetería.

37. Lazaro Chiva, J.

Sin datos.

38. Antonio Llorens Miro

Mantiene la actividad

39. Villanueva Tortajada, V.

Tienda de ropa

40. COINTRA

Tienda de ropa

CARACTERÍSTICAS DEL ASENTAMIENTO INDUSTRIAL.

- Histórico, de carácter artesanal.

- Disperso.

- Homogéneo en cuanto a emplazamiento y tamaño de las industrias

CARACTERÍSTICAS DE LOS LOCALES INDUSTRIALES.

- Pequeña superficie de parcela.

- Situados generalmente en plantas bajas de edificios de viviendas entre medianeras. 
- Habitualmente no reúnen condiciones adecuadas para el desarrollo de actividades industriales.

\section{CARACTERÍSTICAS DE LAS ACTIVIDADES.-}

- De tipo artesanal, muy enraizadas en su entorno.

- Se censaron inicialmente 40 industrias y en el período de vigencia del Plan General han quedado solamente 4 creándose 29 nuevas industrias.

- Las actividades dominantes son calzado y confección, productos metálicos y artes gráficas.

\section{IMPACTO EN EL MEDIO AMBIENTE.-}

- Contaminación ambiental: Prácticamente nula.

- Transporte: escaso, tanto en volumen como en frecuencia. Peligrosidad nula.

- Integración en el entorno: total, por estar situados en los bajos de los edificios de viviendas.

\section{EDIFICIOS INDUSTRIALES DE INTERES.-}

- Imprenta de la Diputación Provincial.

C/ Guillén de Castro, nำ 120.

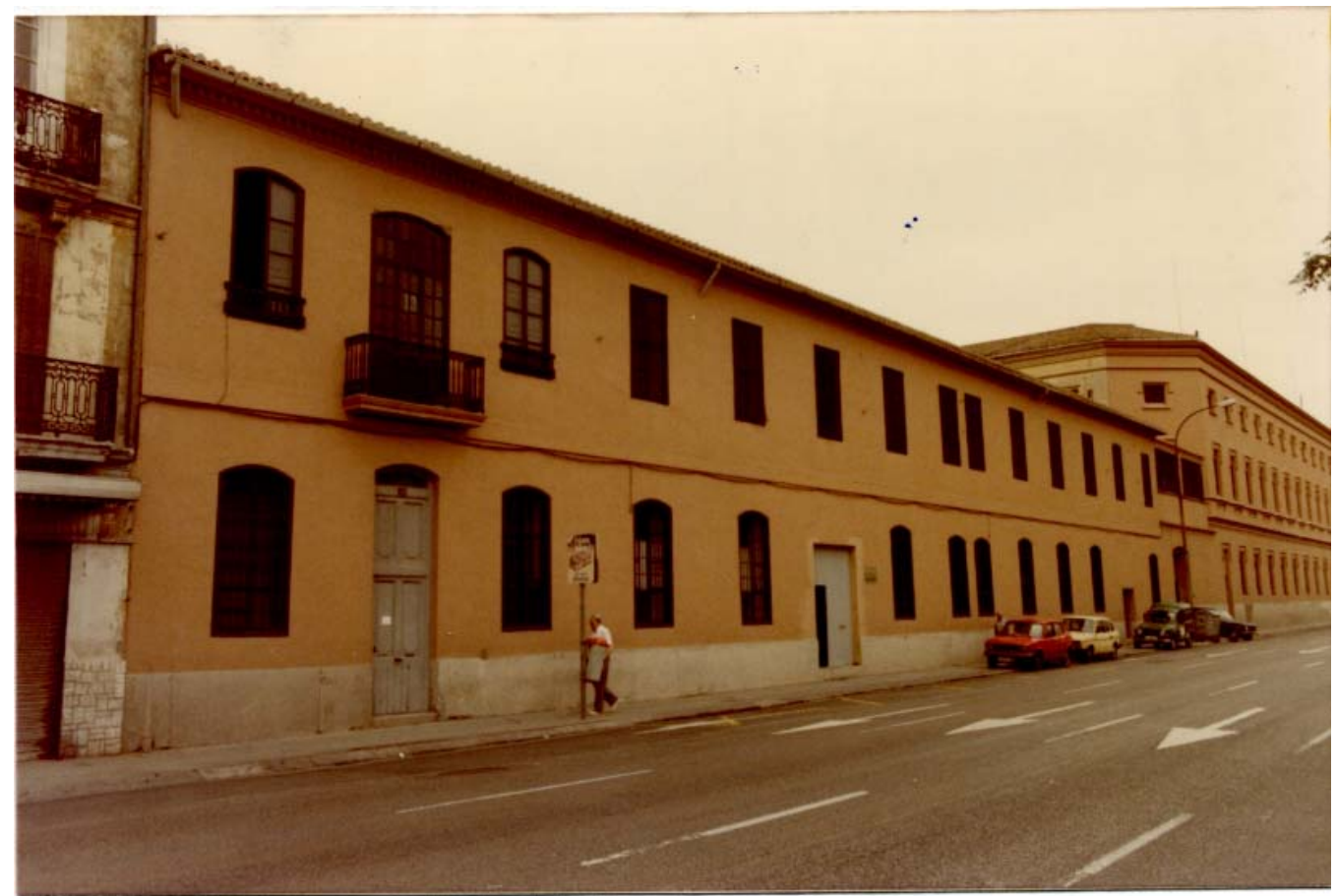

Foto 19: Imprenta de la Diputación Provincial. Calle Guillén de Castro, no 120. Valencia.1985 Fuente: Elaboración propia 
- El Palacio de Justicia fue anteriormente un edificio industrial destinado a la fabricación de tabaco.

TIPOLOGÍA EDIFICACIÓN

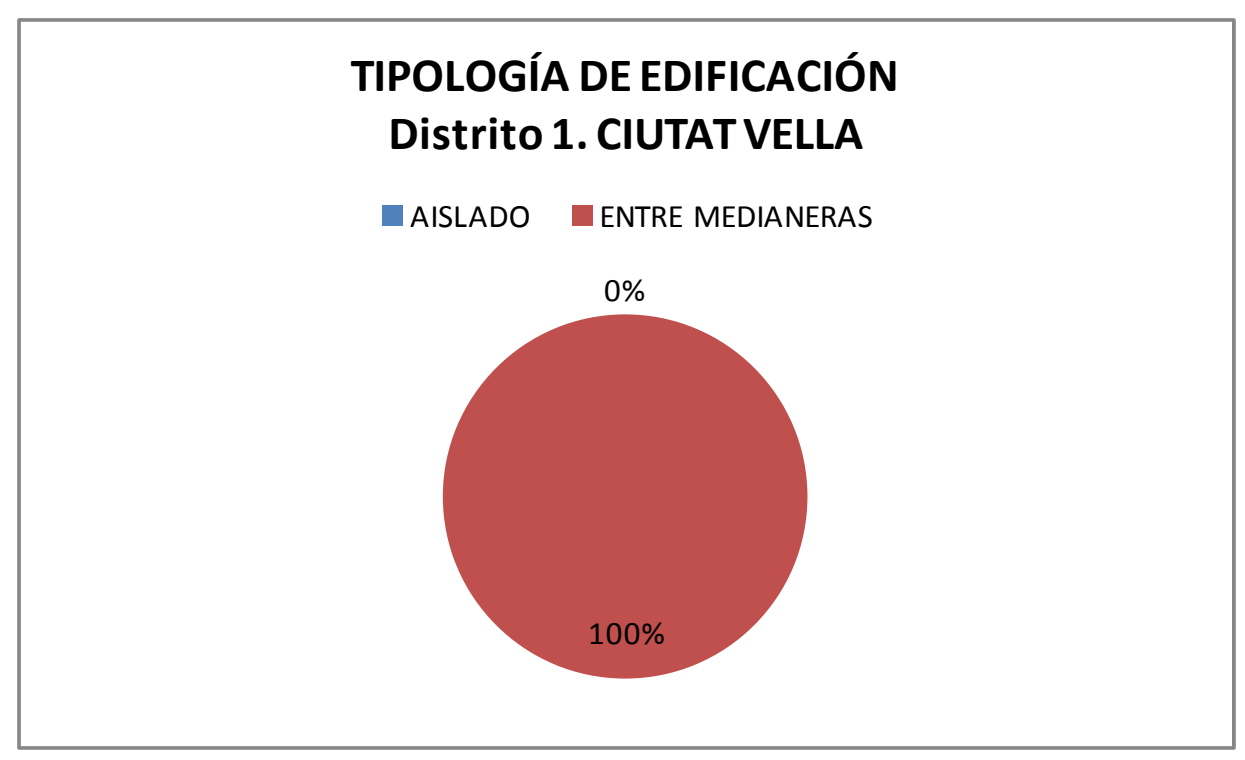




\section{ACTIVIDAD INDUSTRIAL, SUPERFICIE Y EMPLEO}

\begin{tabular}{|c|c|c|c|c|c|}
\hline \multicolumn{6}{|c|}{ DISTRITO 1 - CIUTAT VELLA (ATIVIDAD INDUSTRIAL Y EMPLEO) } \\
\hline ACTIVIDAD & $\begin{array}{l}\text { № } \\
\text { EMPRESAS }\end{array}$ & $\begin{array}{l}\text { SUP. ACTIVIDAD } \\
\text { IND }\left(\mathrm{m}^{2}\right)\end{array}$ & $\begin{array}{l}\text { \% SUP. } \\
\text { INDUSTRIAL }\end{array}$ & $\begin{array}{c}\text { No } \\
\text { EMPLEADOS }\end{array}$ & $\begin{array}{c}\text { DENSIDAD } \\
\text { EMPLEO } \\
\text { (empleados } / \mathrm{m}^{2} \\
\text { actividad) }\end{array}$ \\
\hline INDUSTRIAS DE PRODUCTOS MINERALES NO METÁLICOS & 1 & 80 & 0,61 & 8 & 0,1000 \\
\hline INDUSTRIA QUÍMICA & 2 & 280 & 2,13 & 16 & 0,0571 \\
\hline FABRICACIÓN DE PRODUCTOS METÁLICOS & 3 & 1960 & 14,88 & 60 & 0,0306 \\
\hline CONSTRUCCIÓN DE MÁQUINAS DE OFICINA Y ORDENADORES & 1 & 208 & 1,58 & 6 & 0,0288 \\
\hline CONSTRUCCIÓN DE MAQUINARIA Y MATERIAL ELÉCTRICO & 2 & 800 & 6,07 & 17 & 0,0213 \\
\hline FABRICACIÓN DE MATERIAL ELECTRÓNICO & 1 & 545 & 4,14 & 42 & 0,0771 \\
\hline FABRICACIÓN DE INSTRUMENTOS DE PRECISIÓN, ÓPTICA Y SIMILARES & 4 & 398 & 3,02 & 60 & 0,1508 \\
\hline INDUSTRIAS DE PRODUCTOS ALIMENTICIOS, BEBIDAS Y TABACO & 3 & 480 & 3,64 & 21 & 0,0438 \\
\hline INDUSTRIAS DE PRODUCTOS ALIMENTICIOS, BEBIDAS Y TABACO & 1 & 425 & 3,23 & 3 & 0,0071 \\
\hline INDUSTRIA TEXTIL & 1 & 300 & 2,28 & 12 & 0,0400 \\
\hline INDUSTRIA DEL CALZADO Y DEL VESTIDO Y OTRAS CONFECCIONES & 7 & 3708 & 28,15 & 149 & 0,0402 \\
\hline INDUSTRIAS DE MADERA, CORCHO Y MUEBLES DE MADERA & 2 & 1060 & 8,05 & 30 & 0,0283 \\
\hline $\begin{array}{l}\text { INDUSTRIA DEL PAPEL Y FABRICACIÓN DE ARTÍCULOS DE PAPEL, ARTES GRÁFICAS } \\
\text { Y EDICIÓN }\end{array}$ & 6 & 1830 & 13,89 & 73 & 0,0399 \\
\hline OTRAS INDUSTRIAS MANUFACTURERAS & 3 & 780 & 5,92 & 41 & 0,0526 \\
\hline CONSTRUCCIÓN & 3 & 320 & 2,43 & 38 & 0,1188 \\
\hline TOTAL & 40 & 13174 & 100 & 576 & 0,0437 \\
\hline
\end{tabular}

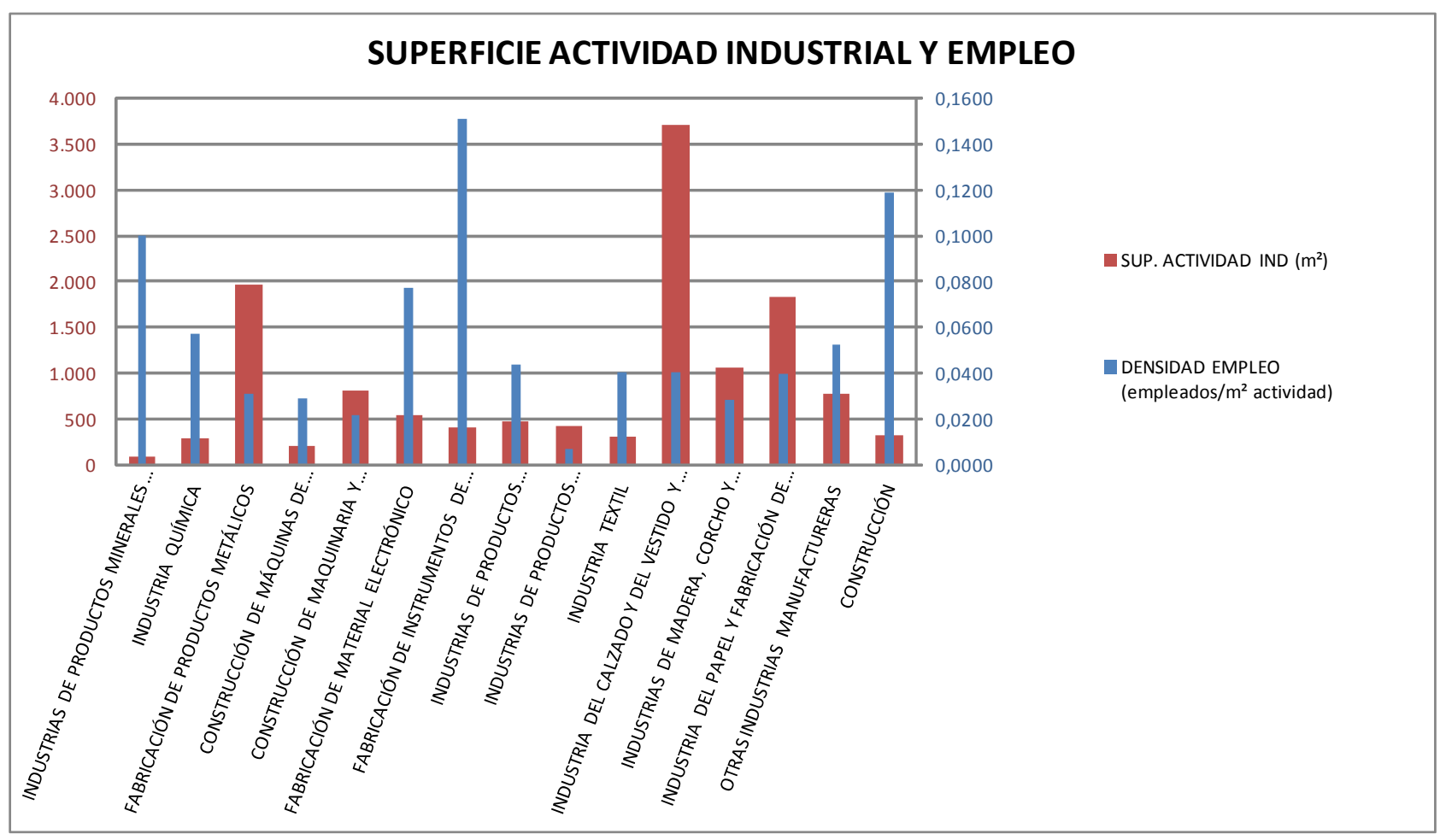


IMPACTO AMBIENTAL

\begin{tabular}{|c|c|c|c|c|c|}
\hline \multicolumn{6}{|c|}{ DISTRITO 1 - CIUTAT VELLA (INFORMACIÓN URBANÍSTICA) } \\
\hline ACTIVIDAD & $\begin{array}{l}\text { No } \\
\text { EMPRESAS }\end{array}$ & $\begin{array}{c}\text { ENTRE } \\
\text { MEDIANERAS }\end{array}$ & RUIDOSAS & $\begin{array}{c}\text { EMPRESAS } \\
\text { CON } \\
\text { CHIMENEA }\end{array}$ & $\begin{array}{l}\text { RUIDOSAS Y } \\
\text { CHIMENEA }\end{array}$ \\
\hline INDUSTRIAS DE PRODUCTOS MINERALES NO METÁLICOS & 1 & 1 & 0 & 0 & 0 \\
\hline INDUSTRIA QUÍMICA & 2 & 2 & 2 & 0 & 0 \\
\hline FABRICACIÓN DE PRODUCTOS METÁLICOS & 3 & 3 & 1 & 0 & 0 \\
\hline CONSTRUCCIÓN DE MÁQUINAS DE OFICINA Y ORDENADORES & 1 & 1 & 0 & 0 & 0 \\
\hline CONSTRUCCIÓN DE MAQUINARIA Y MATERIAL ELÉCTRICO & 2 & 2 & 0 & 0 & 0 \\
\hline FABRICACIÓN DE MATERIAL ELECTRÓNICO & 1 & 1 & 0 & 0 & 0 \\
\hline FABRICACIÓN DE INSTRUMENTOS DE PRECISIÓN, ÓPTICA Y SIMILARES & 4 & 4 & 4 & 0 & 0 \\
\hline INDUSTRIAS DE PRODUCTOS ALIMENTICIOS, BEBIDAS Y TABACO & 3 & 3 & 1 & 1 & 0 \\
\hline INDUSTRIAS DE PRODUCTOS ALIMENTICIOS, BEBIDAS Y TABACO & 1 & 1 & 0 & 0 & 0 \\
\hline INDUSTRIA TEXTIL & 1 & 1 & 0 & 0 & 0 \\
\hline INDUSTRIA DEL CALZADO Y DEL VESTIDO Y OTRAS CONFECCIONES & 7 & 7 & 1 & 0 & 0 \\
\hline INDUSTRIAS DE MADERA, CORCHO Y MUEBLES DE MADERA & 2 & 2 & 2 & 0 & 0 \\
\hline $\begin{array}{l}\text { INDUSTRIA DEL PAPEL Y FABRICACIÓN DE ARTÍCULOS DE PAPEL, ARTES GRÁFICAS } \\
\text { Y EDICIÓN }\end{array}$ & 6 & 6 & 5 & 0 & 0 \\
\hline OTRAS INDUSTRIAS MANUFACTURERAS & 3 & 3 & 0 & 1 & 0 \\
\hline CONSTRUCCIÓN & 3 & 3 & 0 & 1 & 0 \\
\hline TOTAL & 40 & 40 & 16 & 3 & 0 \\
\hline
\end{tabular}

\section{IMPACTO EN EL MEDIO URBANO}

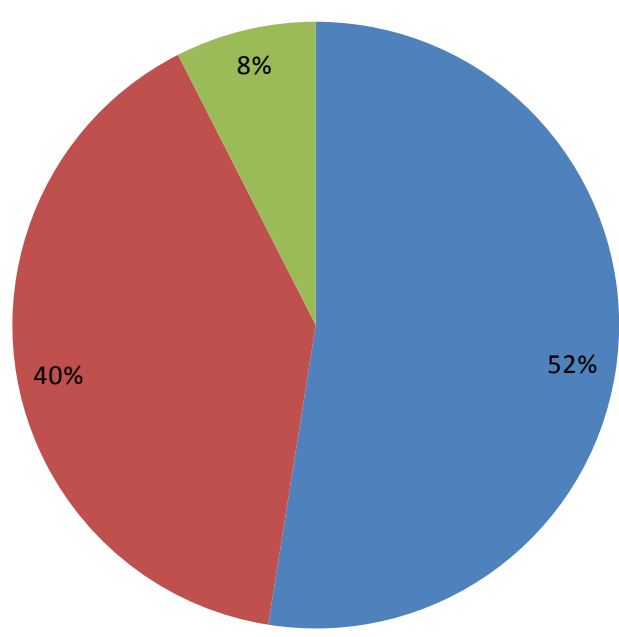

EMPRESAS INOCUAS

EMPRESAS RUIDOSAS

EMPRESAS CON CHIMENEA 


\section{FICHAS TIPO \\ FICHA DATOS DE LA INDUSTRIA}

LOCALIZACION ACTUALIZADA DE ACTIVIDADES INDUSTRIALES EN EL MEDIO URBANO DE VALENCIA

\begin{tabular}{|c|c|c|c|c|c|c|c|}
\hline \multirow{5}{*}{ 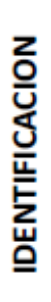 } & \multirow{2}{*}{\multicolumn{2}{|c|}{$\begin{array}{c}\text { NOMBRE } \\
\text { EMPLAZAMIENTO }\end{array}$}} & \multicolumn{5}{|c|}{ ROMEU ORQUIN, A. } \\
\hline & & & \multicolumn{3}{|l|}{ C/ Liria no 22} & C.P. & \\
\hline & \multirow{2}{*}{ CNAE } & \multirow{2}{*}{461} & \multirow{2}{*}{ DESCRIPCION } & \multicolumn{4}{|c|}{ INDUSTRIA DE LA MADERA, CORCHO Y MUEBLES } \\
\hline & & & & \multicolumn{4}{|c|}{ Aserradero } \\
\hline & DISTRITO & 1 & \multicolumn{5}{|c|}{ CIUTAT VELLA } \\
\hline & \multicolumn{2}{|c|}{ SUPERFICIES } & $\begin{array}{l}\text { Sup. Parcela: } \\
460 \mathrm{~m}^{2}\end{array}$ & $\begin{array}{l}\text { Sup. Ocupada: } \\
460 \mathrm{~m}^{2}\end{array}$ & $\begin{array}{l}\text { Sup. Construida: } \\
460 \mathrm{~m}^{2}\end{array}$ & EMP & $\begin{array}{l}\text { EADOS: } \\
5\end{array}$ \\
\hline
\end{tabular}
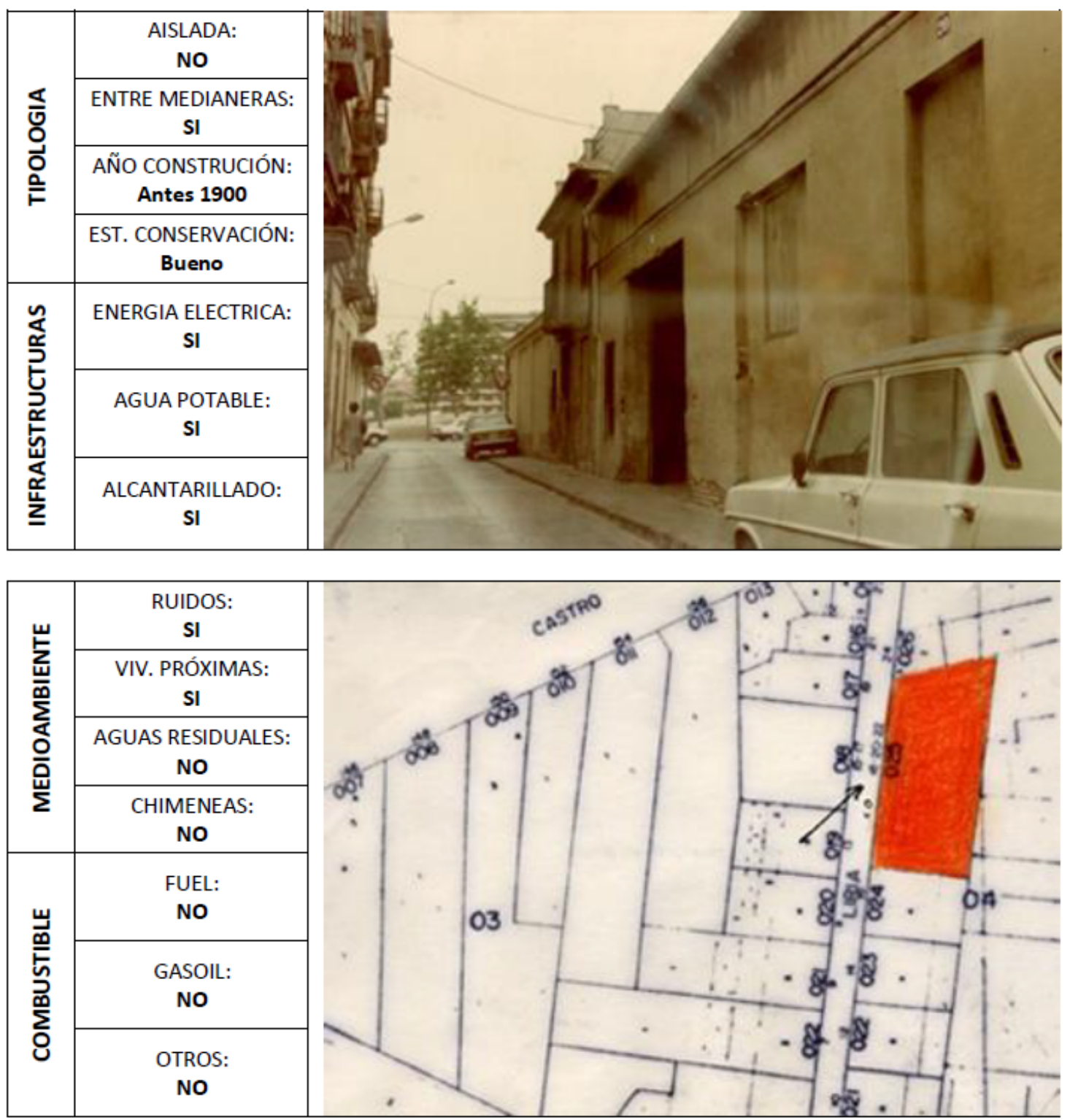


\section{FICHA DATOS DE LA INDUSTRIA}

LOCALIZACION ACTUALIZADA DE ACTIVIDADES INDUSTRIALES EN EL MEDIO URBANO DE VALENCIA

\begin{tabular}{|c|c|c|c|c|c|c|c|}
\hline \multirow{5}{*}{ 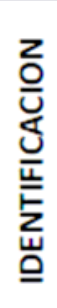 } & \multirow{2}{*}{\multicolumn{2}{|c|}{$\begin{array}{c}\text { NOMBRE } \\
\text { EMPLAZAMIENTO }\end{array}$}} & \multicolumn{5}{|c|}{ INDUSTRIAS SALUBES, S.A. } \\
\hline & & & \multicolumn{3}{|c|}{ C/ Guillen de Castro $n \cong 110$} & C.P. & \\
\hline & \multirow{2}{*}{ CNAE } & \multirow{2}{*}{316} & \multirow{2}{*}{ DESCRIPCION } & \multicolumn{4}{|c|}{ FABRICACIÓN DE PRODUCTOS METÁLICOS } \\
\hline & & & & \multicolumn{4}{|c|}{ Matriculas } \\
\hline & DISTRITO & 1 & \multicolumn{5}{|c|}{ CIUTAT VELLA } \\
\hline & \multicolumn{2}{|c|}{ SUPERFICIES } & $\begin{array}{c}\text { Sup. Parcela: } \\
1600 \mathrm{~m}^{2}\end{array}$ & $\begin{array}{c}\text { Sup. Ocupada: } \\
1600 \mathrm{~m}^{2}\end{array}$ & $\begin{array}{l}\text { Sup. Construida: } \\
1600 \mathrm{~m}^{2}\end{array}$ & EMP & $\begin{array}{l}\text { EADOS: } \\
49\end{array}$ \\
\hline
\end{tabular}
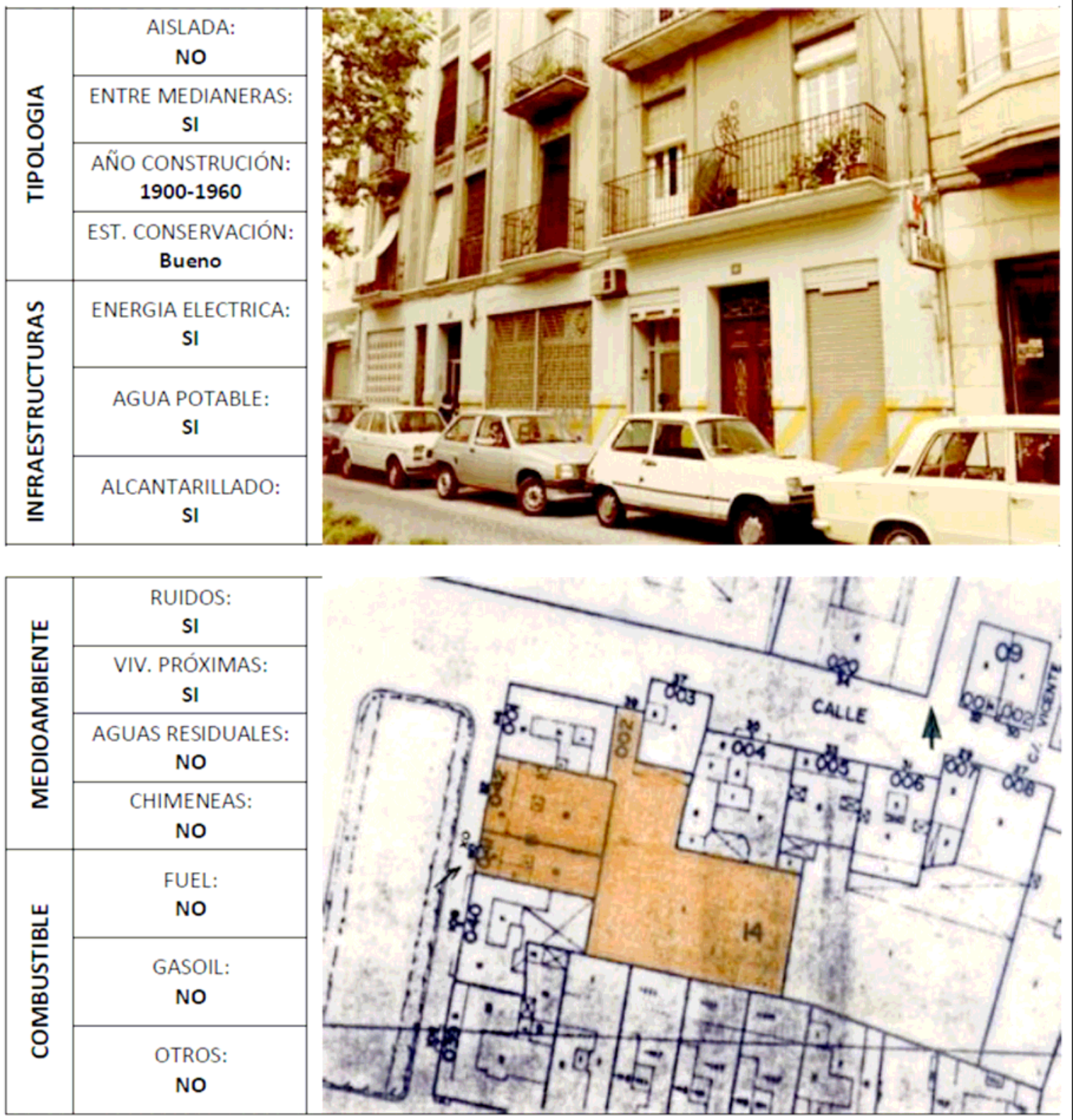


\section{FICHA DATOS DE LA INDUSTRIA}

\section{LOCALIZACION ACTUALIZADA DE ACTIVIDADES INDUSTRIALES EN EL MEDIO URBANO DE VALENCIA}

\begin{tabular}{|c|c|c|c|c|c|c|}
\hline \multirow{5}{*}{ 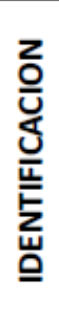 } & \multirow{2}{*}{\multicolumn{2}{|c|}{$\begin{array}{c}\text { NOMBRE } \\
\text { EMPLAZAMIENTO }\end{array}$}} & \multicolumn{4}{|c|}{ IMPRENTA DIPUTACIÓN } \\
\hline & & & \multicolumn{3}{|c|}{ C/ Guillen de Castro $n=120$} & C.P. \\
\hline & \multirow{2}{*}{ CNAE } & \multirow{2}{*}{474} & \multirow{2}{*}{ DESCRIPCION } & \multicolumn{3}{|c|}{ IND. PAPEL, ARTES GRAFICAS, ETC. } \\
\hline & & & & \multicolumn{3}{|c|}{ Imprenta } \\
\hline & DISTRITO & 1 & \multicolumn{4}{|c|}{ CIUTAT VELLA } \\
\hline \multicolumn{3}{|c|}{ SUPERFICIES } & $\begin{array}{c}\text { Sup. Parcela: } \\
700 \mathrm{~m}^{2}\end{array}$ & $\begin{array}{c}\text { Sup. Ocupada: } \\
700 \mathrm{~m}^{2}\end{array}$ & $\begin{array}{c}\text { Sup. Construida: } \\
1400 \mathrm{~m}^{2}\end{array}$ & $\begin{array}{c}\text { EMPLEADOS: } \\
39 \\
\end{array}$ \\
\hline
\end{tabular}
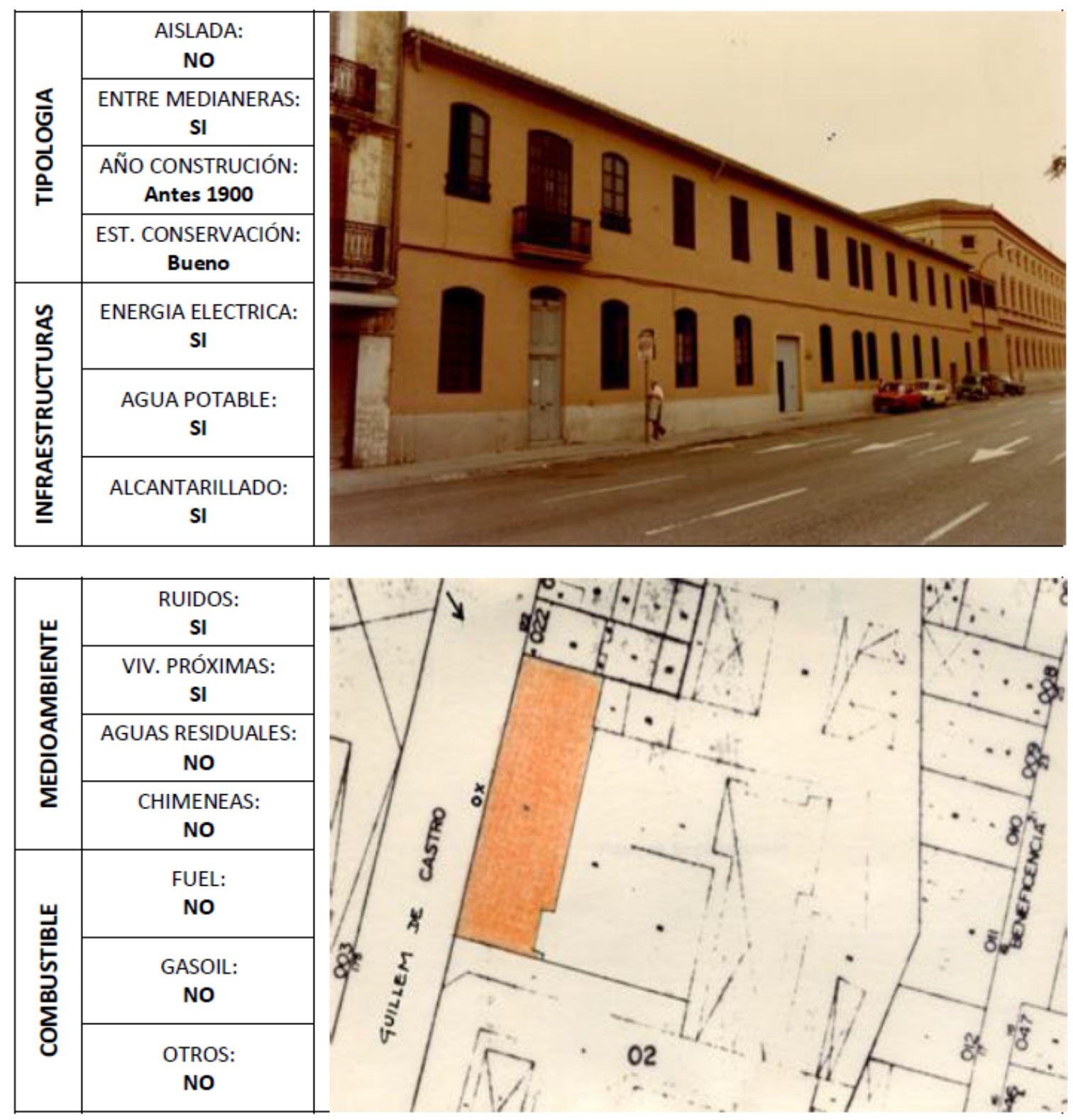


\section{FICHA DATOS DE LA INDUSTRIA}

LOCALIZACION ACTUALIZADA DE ACTIVIDADES INDUSTRIALES EN EL MEDIO URBANO DE VALENCIA

\begin{tabular}{|c|c|c|c|c|c|c|c|}
\hline \multirow{5}{*}{ 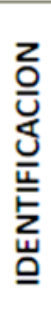 } & \multirow{2}{*}{\multicolumn{2}{|c|}{$\begin{array}{c}\text { NOMBRE } \\
\text { EMPLAZAMIENTO }\end{array}$}} & \multicolumn{5}{|c|}{ ANTONIO LLORENS MIRO } \\
\hline & & & \multicolumn{3}{|c|}{ C/ Perez Bayer $n \cong 3$} & C.P. & \\
\hline & \multirow{2}{*}{ CNAE } & \multirow{2}{*}{347} & \multirow{2}{*}{ DESCRIPCION } & \multicolumn{4}{|c|}{ CONS. DE MAQUINARIA Y MAT. ELECTRICO } \\
\hline & & & & \multicolumn{4}{|c|}{ Instalaciones eléctricas } \\
\hline & DISTRITO & 1 & \multicolumn{5}{|c|}{ CIUTAT VELLA } \\
\hline & \multicolumn{2}{|c|}{ SUPERFICIES } & $\begin{array}{l}\text { Sup. Parcela: } \\
300 \mathrm{~m}^{2}\end{array}$ & $\begin{array}{c}\text { Sup. Ocupada: } \\
300 \mathrm{~m}^{2}\end{array}$ & $\begin{array}{l}\text { Sup. Construida: } \\
300 \mathrm{~m}^{2}\end{array}$ & EMP & $\begin{array}{l}\text { LEADOS: } \\
12\end{array}$ \\
\hline
\end{tabular}
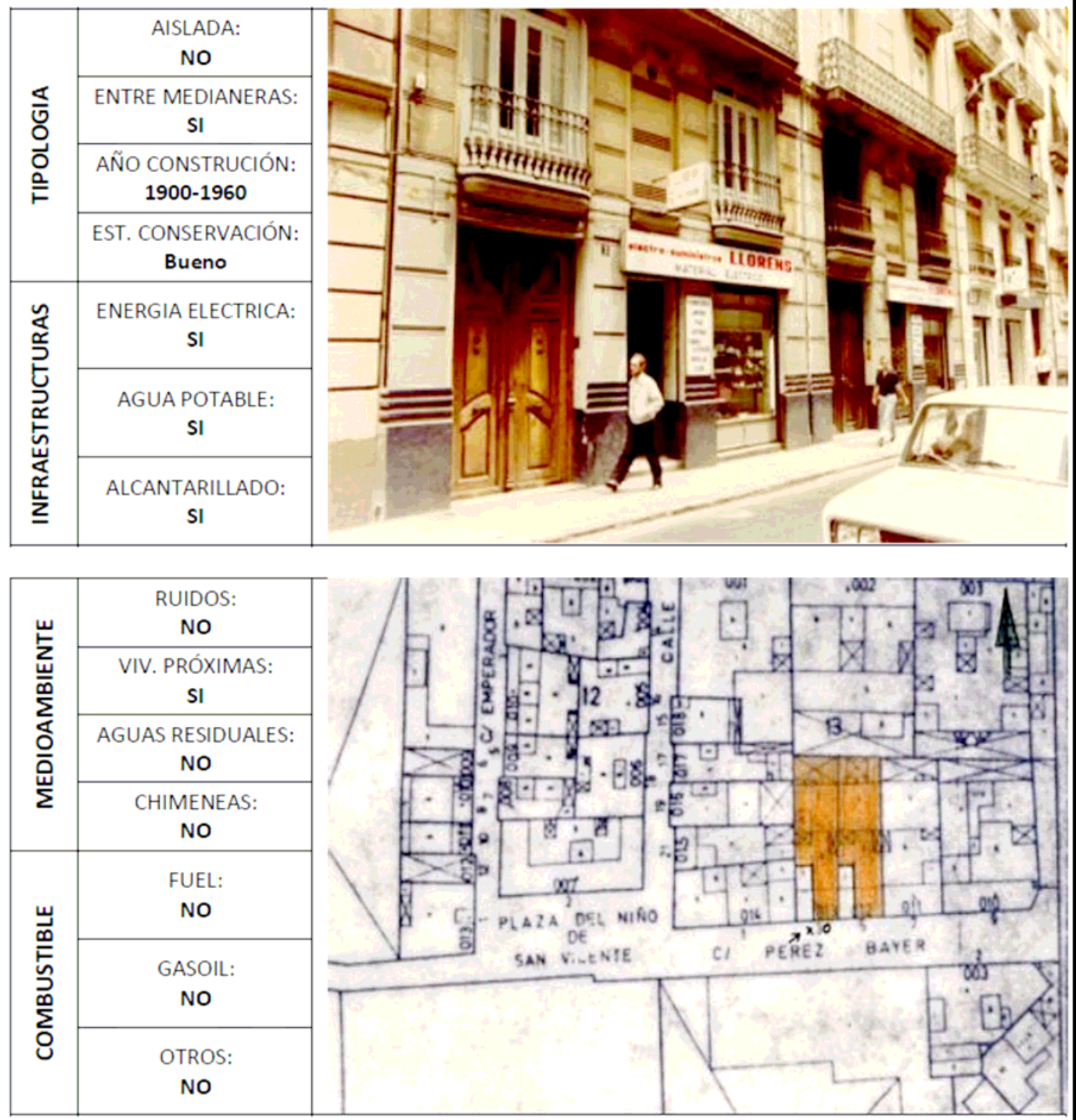

EN LA ACTUALIAD: SE MANTIENE LA ACTIVIDAD 


\section{EVOLUCIÓN}

\section{PLANO UBICACIÓN INDUSTRIAS}

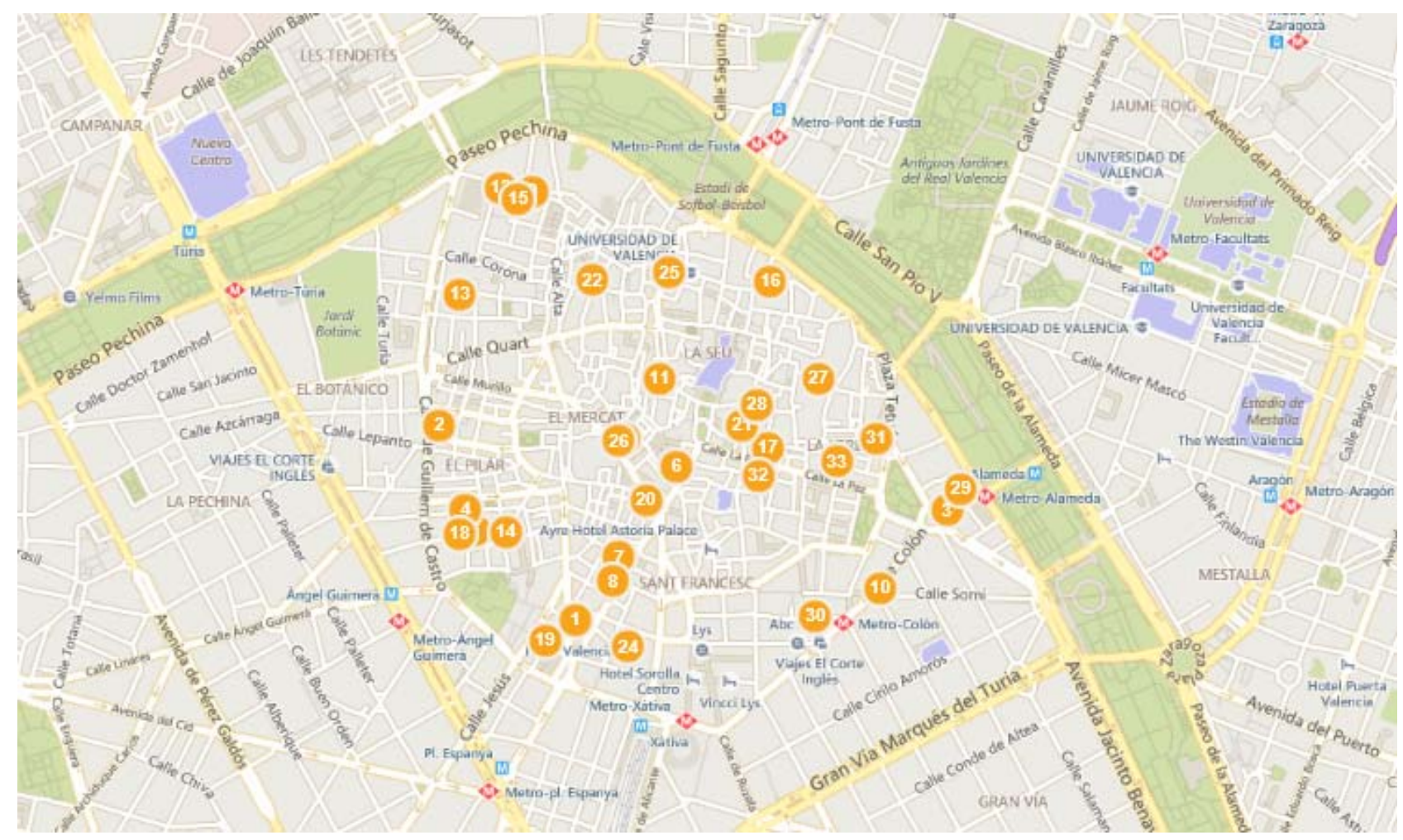

LISTADO DE INDUSTRIAS Y ACTIVIDAD.-

1. Joaquín Martínez Mateu

Fabricación de otros muebles

\section{Ramón Díaz Mocholí}

Fabricación de otros muebles

3. GRIPHUS ESPAÑA, S.A.

Fabricación de otros muebles

4. Rafael Alonso Alvarez

Fabricación de otros muebles

5. HERMANAS SANTAMARIA, C.B.

Fabricación de artículos de joyería y artículos similares

6. Julio José Portet Mas

Fabricación de artículos de joyería y artículos similares

\section{Concepción Vila Berenguer}

Confección de artículos confeccionados con textiles excepto prendas de vestir 
8. UCLE \& SET, S.L.

Fabricación de artículos confeccionados con textiles excepto prendas de vestir

9. BIO SMILING, S.L.

Fabricación de instrumentos y suministros médicos y odontológicos

10. AUDIO TECHNO CLINIC, S.L.

Fabricación instrumentos y suministros médicos y odontológicos

\section{Juan Andrés García Bueno}

Fabricación de cerraduras y herrajes

12. $\mathbf{M}^{\mathrm{a}}$ Teresa Perelló Aleixandre

Fabricación de otros productos metálicos n.c.o.p.

13. Manuel Gómez Galindo

Mantenimiento y reparación de vehículos a motor

14. Fernando Galbis Valero

Fabricación de otros muebles

15. Francisco Moreno Julián

Fabricación de otros muebles

16. Ana Estrella Medrano Andrés

Fabricación de otros productos de madera, artículos de corcho, cestería y espartería

17. Francisco Lozano Pérez

Confección de otras prendas de vestir exteriores

18. ERNESTO DE SOSTEA, C.B.

Confección de otras prendas de vestir exteriores

19. Natividad Cárdenas Hinojosa

Confección de otras prendas de vestir y accesorios

20. José Eduardo Mallent Company

Confección de otras prendas de vestir y accesorios

21. MITRESCO, S.L.

Confección de otras prendas de vestir y accesorios

22. $M^{\mathrm{a}}$ Carmen Ferrando Guillem

Confección de otras prendas de vestir y accesorios

23. Carmen Chanza Giner

Fabricación de pan y productos frescos de panadería y pastelería

24. NUEZCAFE, S.L.

Fabricación de pan y productos frescos de panadería y pastelería

25. Miguel Campillo Blas

Elaboración café, té e infusiones

26. ASTRO FALAFEL, S.L.

Elaboración platos y comidas preparadas

27. SERIGRAFIA VIMA (Existente 16)

CNAE año 1.985 (474) 
28. Naches Huesca, C (Existente 21)

CNAE año 1.985 (474)

29. BURROUGHS, S.A. (Existente 35)

CNAE año 1.985 (330)

30. Antonio Llorens Miró (Existente 38)

CNAE año 1.985 (347)

31. Guijarro Girón Jorge

Otras actividades de impresión y artes gráficas

32. Sales Genovés, Gemma

Otras actividades de impresión y artes gráficas

33. NUMIDIA, C.B.

Otras actividades

\section{ESTADO ACTUAL DE LOS ANTIGUOS EDIFICIOS INDUSTRIALES DE INTERES.-}

- Imprenta de la Diputación Provincial.

C/ Guillén de Castro, ㄲo 120.

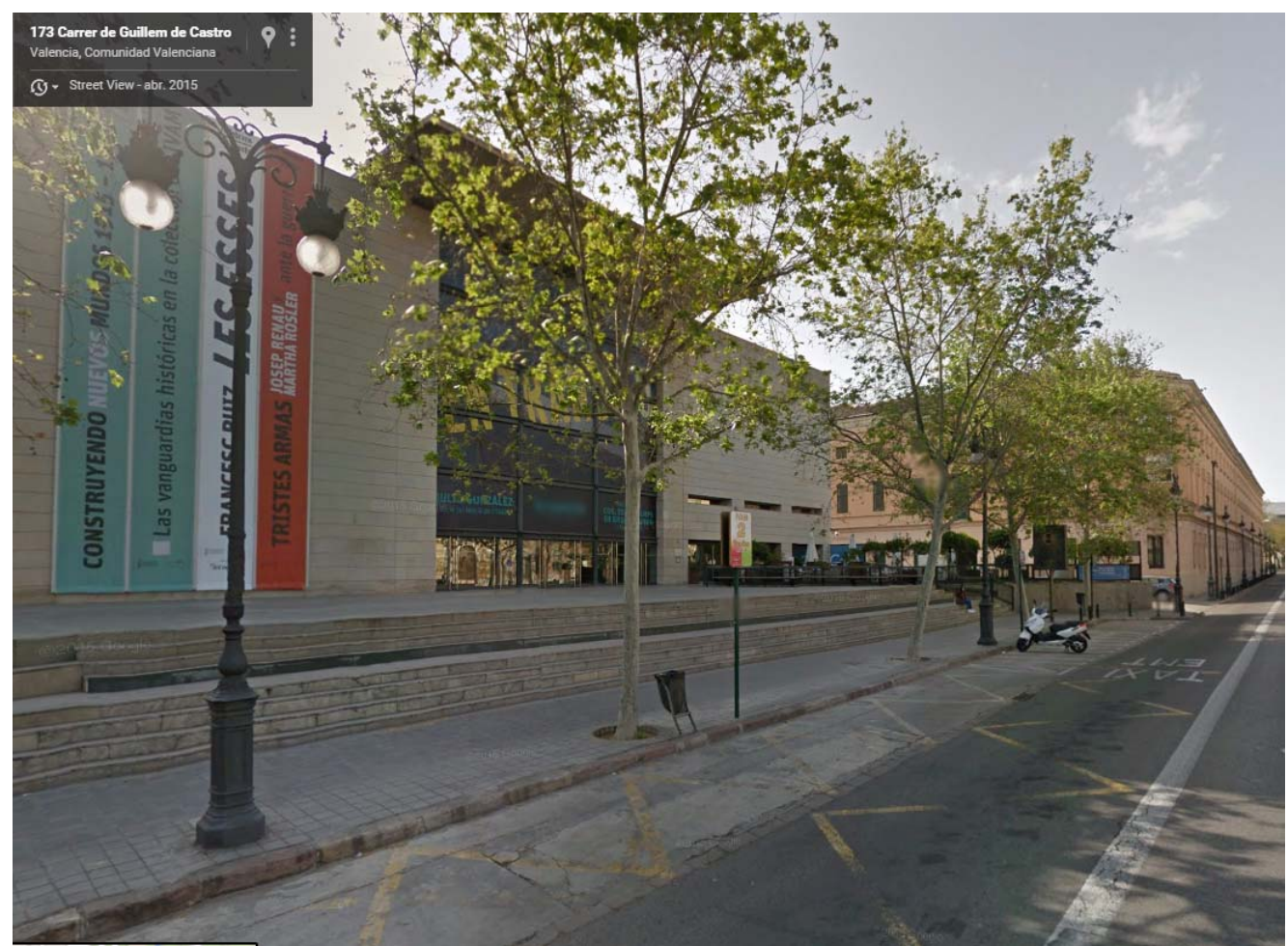

Foto 20: Instituto Valenciano de Arte Moderno IVAM. C/ Guillén de Castro, 173. Valencia. 2015 Fuente: WEB. http://www.google.es/maps (Street View) 


\section{Distrito 1. CIUTAT VELLA}

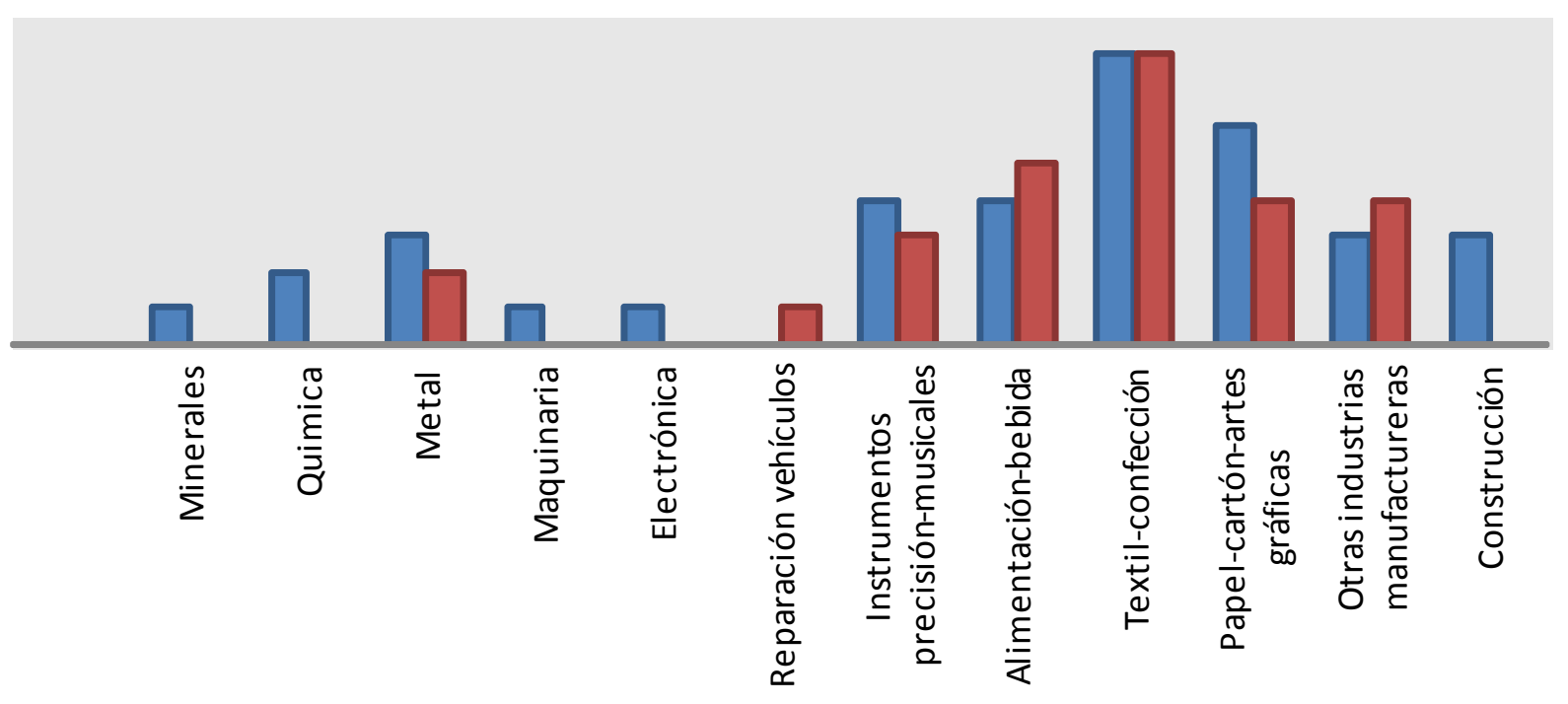

口Actividad Industrial 1985/1990 $\square$ Actividad Industrial 2014

EVOLUCIÓN DEL IMPACTO AMBIENTAL

\section{IMPACTO EN EL MEDIO URBANO Distrito 1. CIUTAT VELLA}

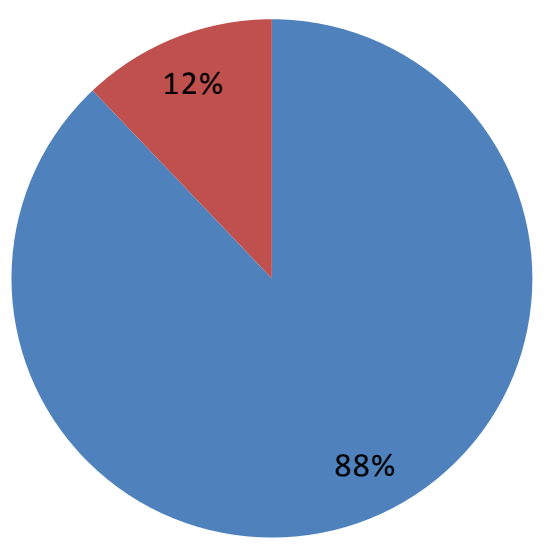

Empresas inocuas

Empresas ruidosas

Empresas ruidosas con chimenea 


\section{FICHAS TIPO \\ FICHA DATOS DE LA INDUSTRIA}

LOCALIZACION ACTUALIZADA DE ACTIVIDADES INDUSTRIALES EN EL MEDIO URBANO DE VALENCIA

\begin{tabular}{|c|c|c|c|c|c|c|c|}
\hline \multirow{5}{*}{ 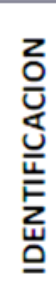 } & \multirow{2}{*}{\multicolumn{2}{|c|}{$\begin{array}{c}\text { NOMBRE } \\
\text { EMPLAZAMIENTO }\end{array}$}} & \multicolumn{5}{|c|}{ ASTRO FALAFEL, S.L. } \\
\hline & & & \multicolumn{3}{|l|}{ C/ ERCILLA, 21} & C.P. & 46001 \\
\hline & \multirow{2}{*}{ CNAE } & \multirow{2}{*}{1085} & \multirow{2}{*}{ DESCRIPCION } & \multicolumn{4}{|c|}{ ALIMENTACION-BEBIDA } \\
\hline & & & & \multicolumn{4}{|c|}{ Elaboración platos y comidas preparadas } \\
\hline & DISTRITO & 1 & \multicolumn{5}{|c|}{ CIUTAT VELLA } \\
\hline \multicolumn{3}{|c|}{ MEDIOAMBIENTE } & RUIDOSAS & NO & CHIMENEAS & & $\mathrm{NO}$ \\
\hline
\end{tabular}

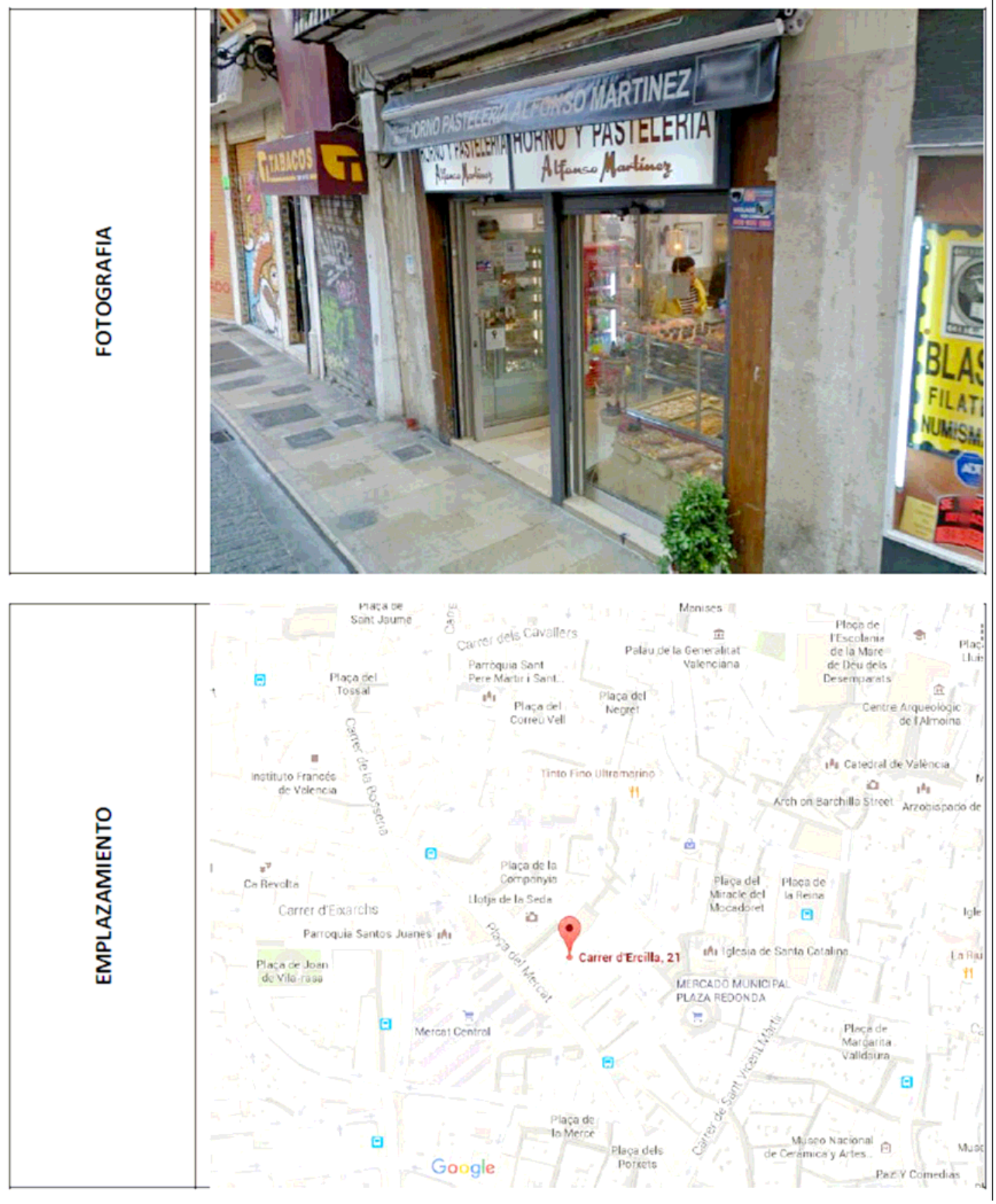




\section{FICHA DATOS DE LA INDUSTRIA}

LOCALIZACION ACTUALIZADA DE ACTIVIDADES INDUSTRIALES EN EL MEDIO URBANO DE VALENCIA

\begin{tabular}{|c|c|c|c|c|c|c|c|}
\hline \multirow{5}{*}{ 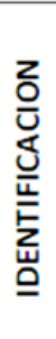 } & \multirow{2}{*}{\multicolumn{2}{|c|}{$\begin{array}{c}\text { NOMBRE } \\
\text { EMPLAZAMIENTO } \\
\end{array}$}} & \multicolumn{5}{|c|}{ HERMANAS SANTAMARIA, C.B. } \\
\hline & & & \multicolumn{3}{|c|}{ C/MALDONADO, 34} & C.P. & 46001 \\
\hline & \multirow[b]{2}{*}{ CNAE } & \multirow[b]{2}{*}{3212} & \multirow[b]{2}{*}{ DESCRIPCION } & \multicolumn{4}{|c|}{ OTRAS INDUSTRIAS MANUFACTURERAS } \\
\hline & & & & \multicolumn{4}{|c|}{$\begin{array}{l}\text { Fabricación de artículos de joyería y artículos } \\
\text { similares }\end{array}$} \\
\hline & DISTRITO & 1 & \multicolumn{5}{|c|}{ CIUTAT VELLA } \\
\hline \multicolumn{3}{|c|}{ MEDIOAMBIENTE } & RUIDOSAS & NO & CHIMENEAS & & 0 \\
\hline
\end{tabular}

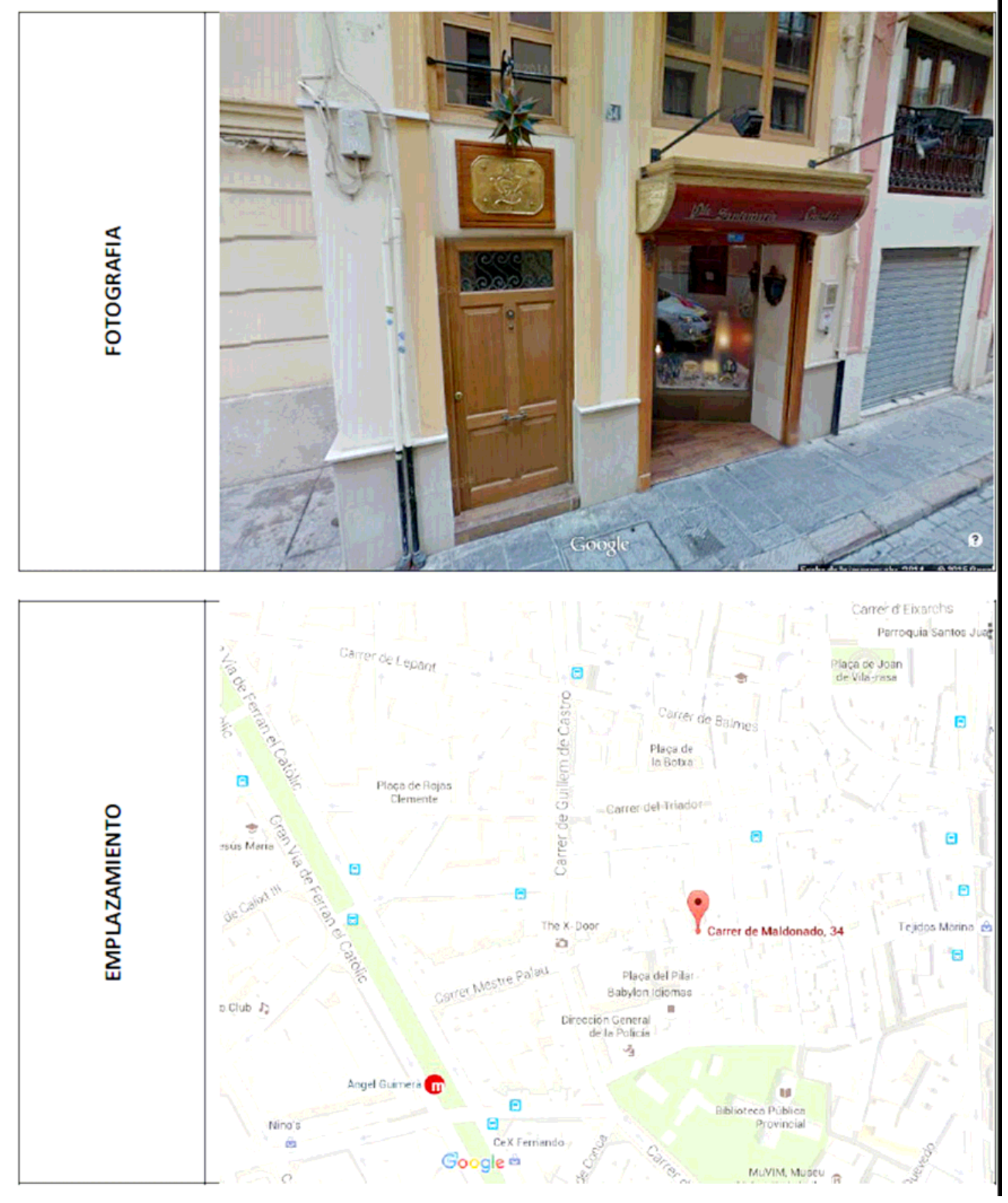




\section{FICHA DATOS DE LA INDUSTRIA}

LOCALIZACION ACTUALIZADA DE ACTIVIDADES INDUSTRIALES EN EL MEDIO URBANO DE VALENCIA

\begin{tabular}{|c|c|c|c|c|c|c|c|}
\hline \multirow{5}{*}{$\begin{array}{l}z \\
\mathrm{O} \\
\mathrm{U} \\
\mathrm{U} \\
\mathrm{E} \\
\mathrm{z} \\
\underline{\mathrm{U}}\end{array}$} & \multirow{2}{*}{\multicolumn{2}{|c|}{$\begin{array}{c}\text { NOMBRE } \\
\text { EMPLAZAMIENTO }\end{array}$}} & \multicolumn{5}{|c|}{ RAFAEL ALONSO ALVAREZ } \\
\hline & & & \multicolumn{3}{|l|}{ C/ BANY, 32} & C.P. & 46001 \\
\hline & \multirow[b]{2}{*}{ CNAE } & \multirow[b]{2}{*}{3109} & \multirow[b]{2}{*}{ DESCRIPCION } & \multicolumn{4}{|c|}{ INDUSTRIA DE LA MADERA, CORCHO Y MUEBLES } \\
\hline & & & & \multicolumn{4}{|c|}{ Fabricación de otros muebles } \\
\hline & DISTRITO & 1 & \multicolumn{5}{|c|}{ CIUTAT VELLA } \\
\hline \multicolumn{3}{|c|}{ MEDIOAMBIENTE } & RUIDOSAS & $\mathrm{SI}$ & CHIMENEAS & & NO \\
\hline
\end{tabular}
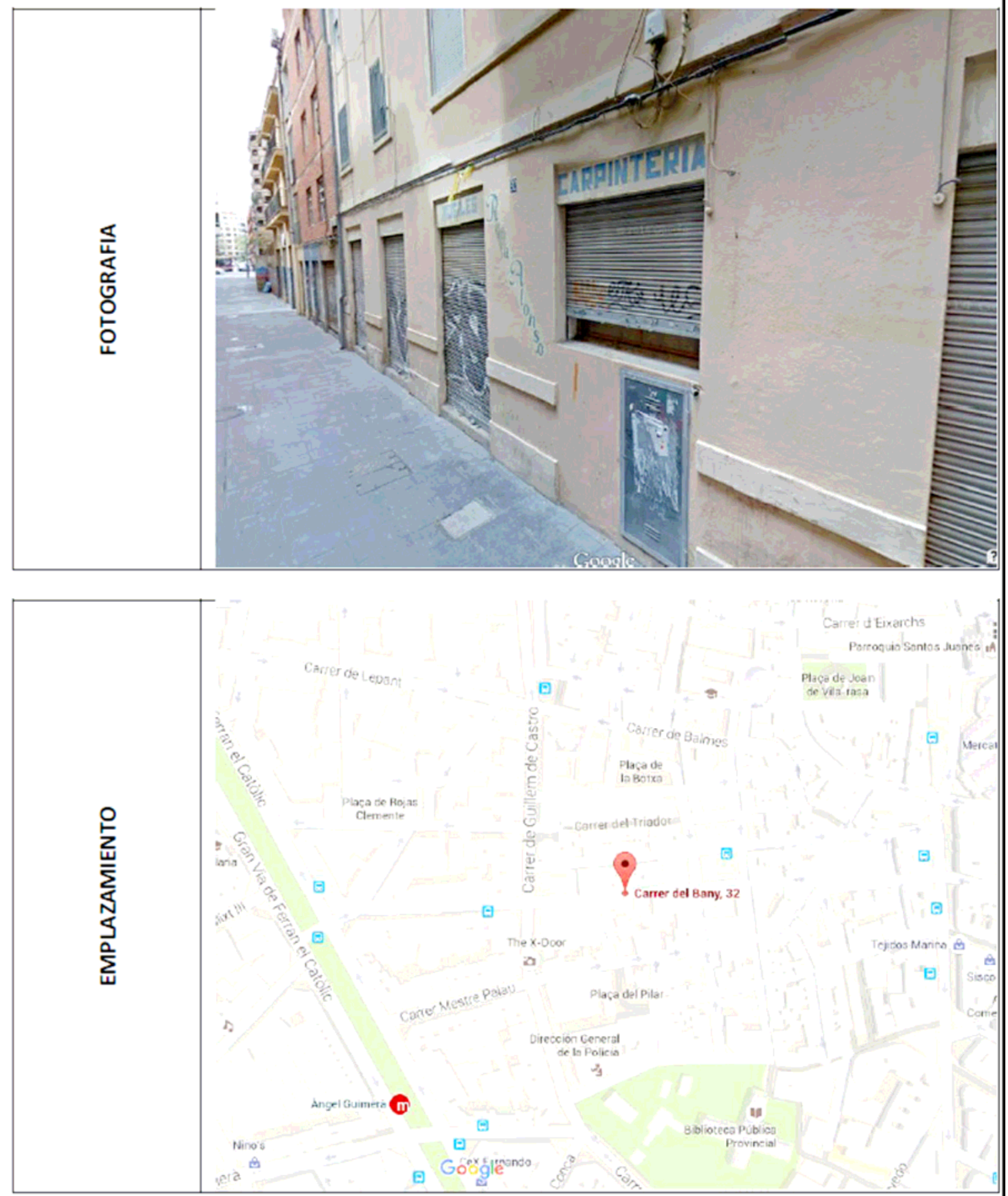


\section{FICHA DATOS DE LA INDUSTRIA}

LOCALIZACION ACTUALIZADA DE ACTIVIDADES INDUSTRIALES EN EL MEDIO URBANO DE VALENCIA

\begin{tabular}{|c|c|c|c|c|c|c|c|}
\hline \multirow{5}{*}{ 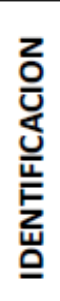 } & \multirow{2}{*}{\multicolumn{2}{|c|}{$\begin{array}{c}\text { NOMBRE } \\
\text { EMPLAZAMIENTO }\end{array}$}} & \multicolumn{5}{|c|}{ MIGUEL CAMPILLO BLAS } \\
\hline & & & \multicolumn{3}{|c|}{ C/ SERRANOS, 20} & C.P. & 46003 \\
\hline & \multirow{2}{*}{ CNAE } & \multirow{2}{*}{1083} & \multirow{2}{*}{ DESCRIPCION } & \multicolumn{4}{|c|}{ ALIMENTACION-BEBIDA } \\
\hline & & & & \multicolumn{4}{|c|}{ Elaboración café, té e infusiones } \\
\hline & DISTRITO & 1 & \multicolumn{5}{|c|}{ CIUTAT VELLA } \\
\hline \multicolumn{3}{|c|}{ MEDIOAMBIENTE } & RUIDOSAS & NO & CHIMENEAS & & $\mathrm{O}$ \\
\hline
\end{tabular}
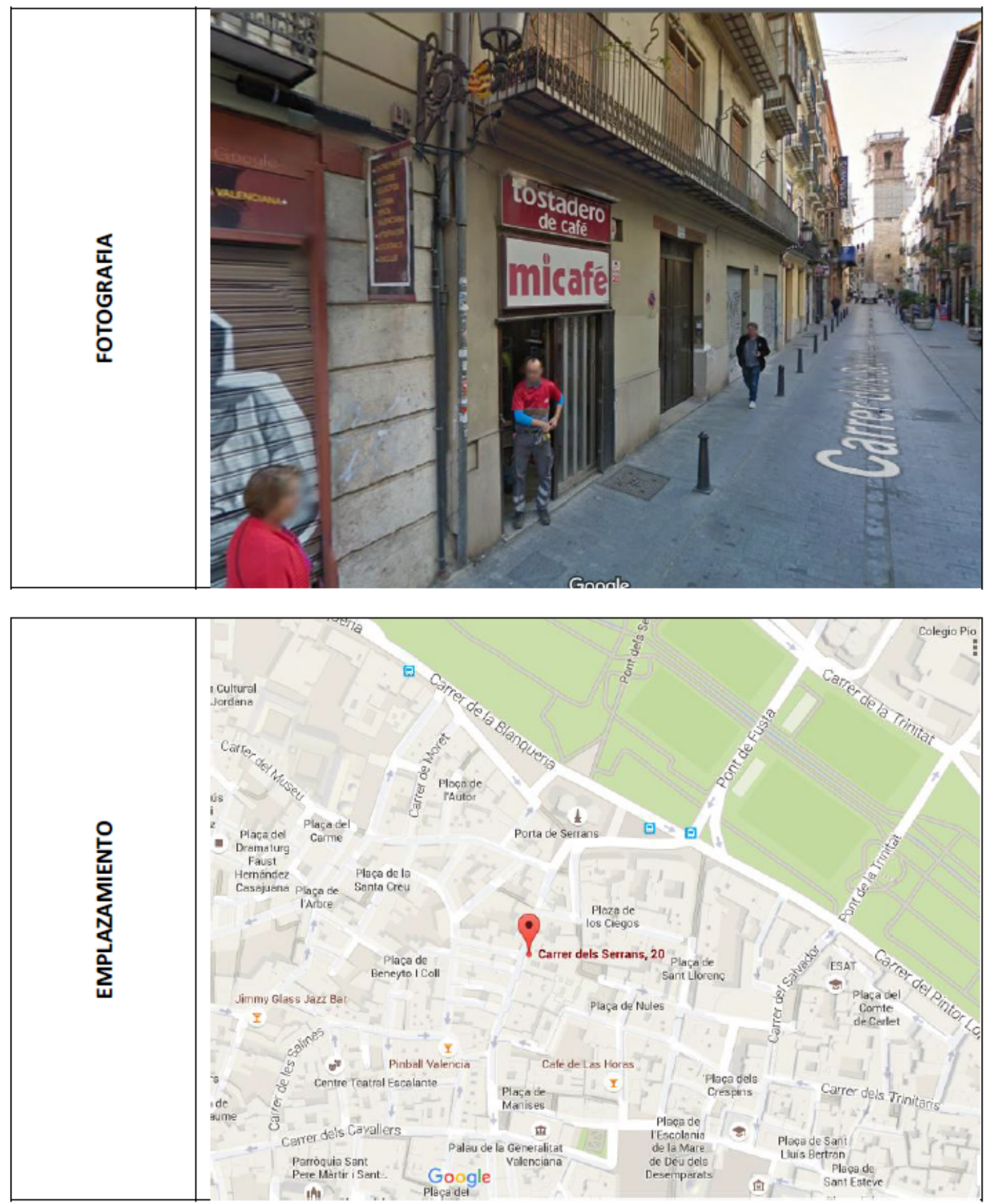
DISTRITO 2.- L'EIXAMPLE

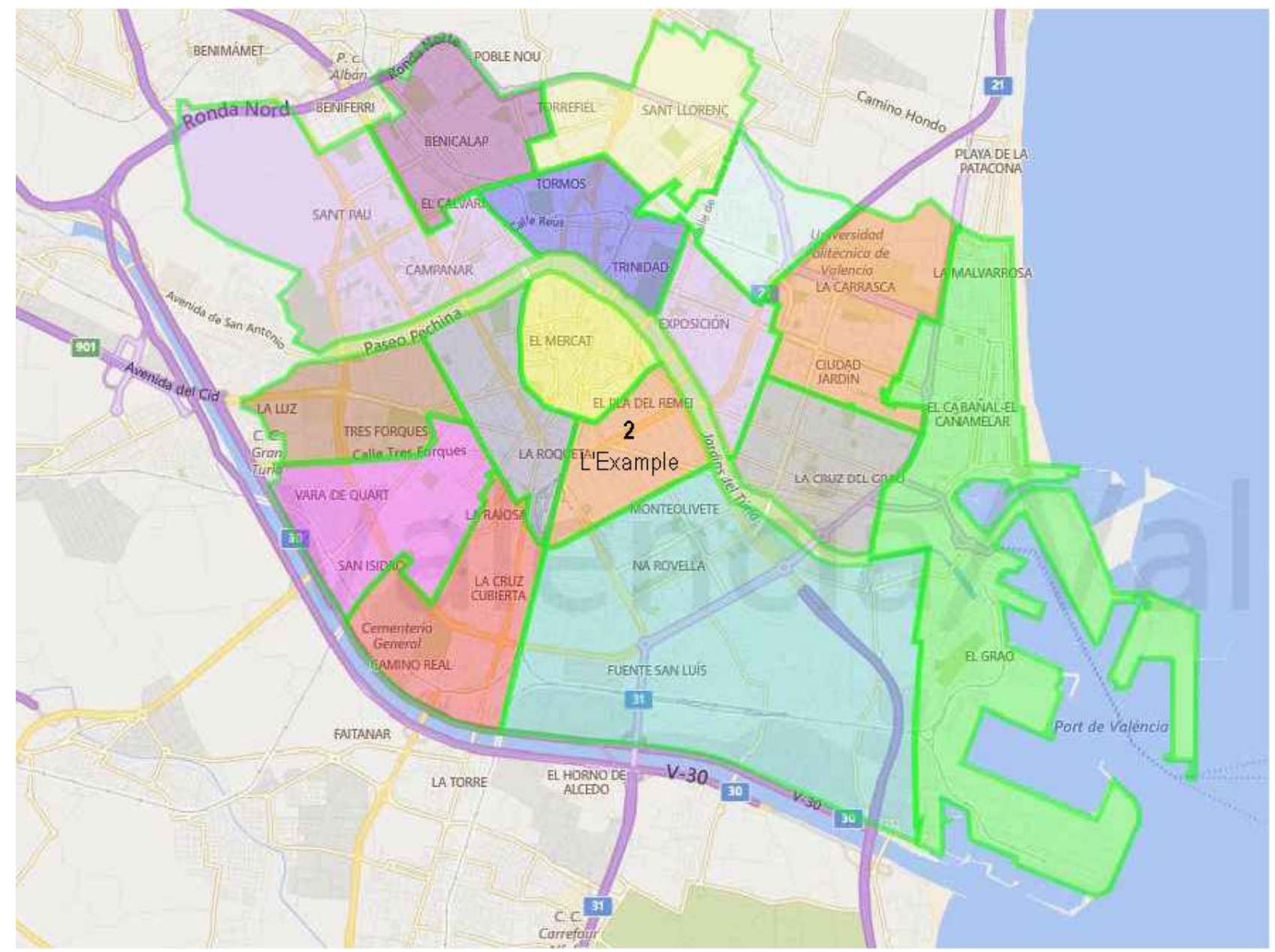

\section{LÍMITES GEOGRÁFICOS.-}

C/ Colón. Avda. Peris y Valero, Cauce viejo del Turia y Estación del Norte 


\section{EVOLUCIÓN DEL 1985-2014}

\section{PLANO UBICACIÓN INDUSTRIAS}

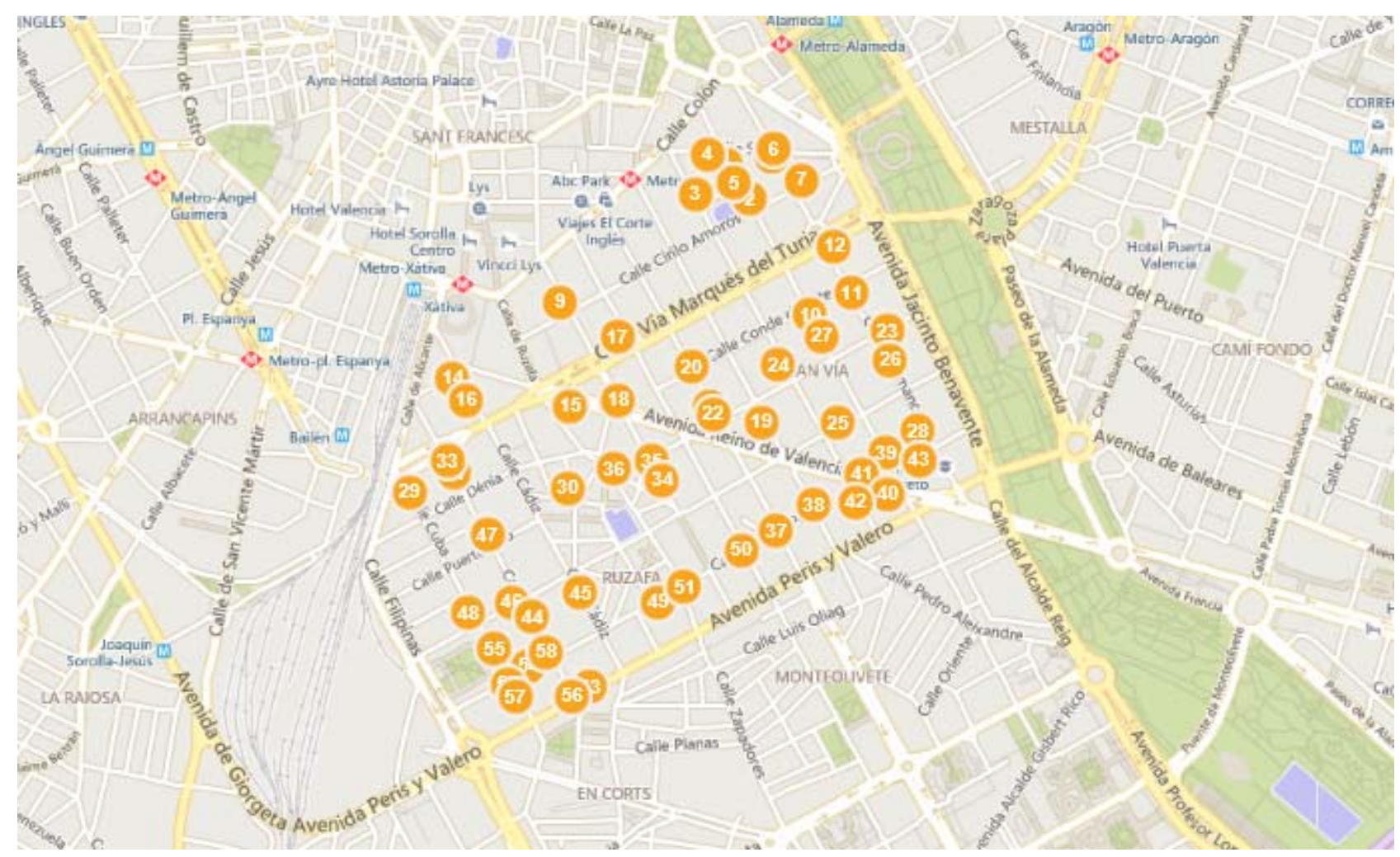

LISTADO DE INDUSTRIAS Y ESTADO ACTUAL .-

1. CANDELA HERMANOS. S.L

Sin actividad

2. José Martínez Agustín

Tienda de confección.

3. CONFECCIONES RUGEN S.A.

Tienda de confección.

4. Manuel Millas Mossi

Tienda de confección.

5. SIGNO GRAFICO, S.L.

Sin actividad

6. Pascual Quiles Pérez

Sin actividad

7. IBERKABA, S.A.

Metales y cerrajería 
8. INFORMATICA MEDITERRANEA, S.A.

Sin actividad

9. ORTO PRONO

Mantiene la actividad

10. BRAUN ESPAÑOLA, S.A.

Restaurante.

11. Aurelio Victorio

Mantiene la actividad

12. Huerta Moreno, Salvador

Mantiene la actividad

13. Carsí Belenguer, Miguel

Tienda al por mayor de suministros.

14. VDA DE PEDRO RUIZ S.A.

Asociación senegalesa valenciana.

15. Ibáñez Martínez, E.

Mantiene la actividad

16. Estelles Nieto, $\mathrm{S}$.

Bar

17. ARTESANIA SELO

Entidad bancaria.

18. NOVA-COMPOSICION, S.A.

Sin actividad

19. Mirabet Garrigos, V.

Bar.

20. Perales Bent, José Luis

Tienda de confección.

21. Francisco Mota Gonzalez

Mantiene la actividad

22. Salvador Nebot Ortega

Sin actividad

23. CLAUSE IBERICA, S.A.

Restaurante.

24. AÑON INDUSTRIAS GRÁFICAS, S.A.

Restaurante.

25. TALLERES RUIZ ASCENSORES, S.L.

Mantiene la actividad

26. Productos selectos del cerdo LA PIARA

Clínica dental.

27. VINAUTO

Mantiene la actividad 
28. NOGUERA Y VINTRO, S.A.

Sin actividad

29. Pastor Raga, F.

Carnicería.

30. IMPRENTA PAU, S.L.

Obra nueva

31. Cardo Lluesma, Vicente

Óptica.

32. INDUSTRIAS MEYRA, S.L.

Sin actividad

33. José Cervera

Mantiene la actividad

34. Aviñó Pérez, E.

Obra nueva

35. TIPOGRAFIA LLEDO

Academia de idiomas

36. PANIFICADORA Y PASTELERIA ESCRIBA, S.A.

Sin actividad

37. GOZALBO, S.L.

Peluquería.

38. REFRIGERACION TERMO MECANIC

Mantiene la actividad

39. ENRIQUE MOLINA, S.L.

Taller infantil de juegos

40. COMERCIAL DE ARTÍCULOS PARA OFICINA, S.L.

Fábrica y tienda de piel

41. R. IBAÑEZ, S.L.

Horno.

42. L.O.S., S.L.

Garaje

43. Fores Mateo, V.M.

Papelería.

44. Pilar Muñoz, J.

Peluquería canina

45. Pedro Juan Cortes Serrano

Resto-cóctel-club NOLITA space

46. LABORATORIOS PENSA, S.A.

Restaurante.

47. CINTAS DUMILA, S.L.

Fabricación de ventanas. 
48. Aznar Climent, V.

Bazar chino.

49. LABORATORIOS LIFASA

Peluquería

50. José Miguel Miguel y cía. S.R.C.

Taller de vehículos.

51. Barbera Martínez, Miguel

Entidad bancaria.

52. INDUSTRIAS BRUGUER, S.A.

Salón de juego.

53. MATEU Y ÁLVAREZ, S.A.

Obra nueva

54. RÁPIDA, S.A.

Excavaciones industriales.

55. PEYCA, S.L.

Sin actividad

56. Arago Mas, $M$.

Tienda de marcos.

57. ARTESANIA VALER

Academia de idiomas

58. Vilaplana Blasco, Francisco

Clínica dental / Clínica veterinaria

CARACTERÍSTICAS DEL ASENTAMIENTO INDUSTRIAL.

- Se inicia a principio de siglo vinculado al crecimiento urbano de la zona.

- Disperso.

- Homogéneo, en cuanto a tamaño y ubicación.

CARACTERÍSTICAS DE LOS LOCALES.

- En bajos de edificios de viviendas y en patios de manzana.

- De mediana y pequeña superficie según se utilice o no el patio de manzana.

CARACTERÍSTICAS DE LAS ACTIVIDADES.

- Compatibles con el uso residencial dominante (pequeños talleres almacenes).

- Se censaron inicialmente 58 industrias y en el período de vigencia del Plan General han quedado solamente 12 creándose 46 nuevas industrias. 
- Las actividades dominantes son artes gráficas, alimentación y bebidas e industrias químicas.

IMPACTO EN EL MEDIO AMBIENTE.-

- Contaminación ambiental: Prácticamente nula, salvo las posibles molestias de tipo acústico derivadas de la proximidad de las viviendas.

- Transporte: de escasa importancia.

- Integración en el entorno: plena, por su emplazamiento inserto en la misma edificación residencial.

EDIFICIOS INDUSTRIALES DE INTERES.-

- No existe edificio específicamente industrial digno de mención.

TIPOLOGÍA EDIFICACIÓN

\section{TIPOLOGÍA DE EDIFICACIÓN \\ Distrito 2. L'EIXAMPLE}

AISLADO ENTRE MEDIANERAS

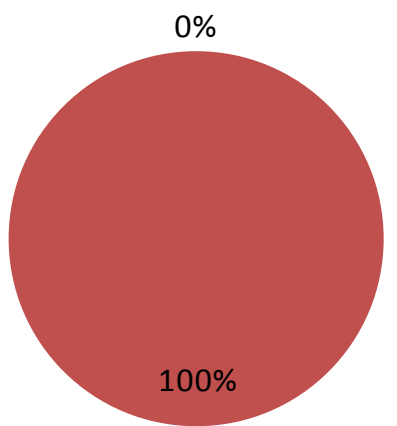




\section{ACTIVIDAD INDUSTRIAL, SUPERFICIE Y EMPLEO}

\begin{tabular}{|c|c|c|c|c|c|}
\hline \multicolumn{6}{|c|}{ DISTRITO 2 - L'EIXAMPLE (ATIVIDAD INDUSTRIAL Y EMPLEO) } \\
\hline ACTIVIDAD & $\begin{array}{c}\text { № } \\
\text { EMPRESAS }\end{array}$ & $\begin{array}{c}\text { SUP. ACTIVIDAD } \\
\text { IND }\left(\mathrm{m}^{2}\right)\end{array}$ & $\begin{array}{c}\text { \% SUP. } \\
\text { INDUSTRIAL }\end{array}$ & $\begin{array}{c}\text { № } \\
\text { EMPLEADOS }\end{array}$ & $\begin{array}{c}\text { DENSIDAD } \\
\text { EMPLEO } \\
\text { (empleados } / \mathrm{m}^{2} \\
\text { actividad) }\end{array}$ \\
\hline SERVICIOS AGRÍCOLAS Y GANADEROS & 1 & 325 & 1,35 & 18 & 0,0554 \\
\hline INDUSTRIA QUÍMICA & 3 & 3325 & 13,79 & 74 & 0,0223 \\
\hline FABRICACIÓN DE PRODUCTOS METÁLICOS & 8 & 2770 & 11,48 & 51 & 0,0184 \\
\hline CONSTRUCCIÓN DE MAQUINARIA Y EQUIPO MECÁNICO & 1 & 400 & 1,66 & 4 & 0,0100 \\
\hline CONSTRUCCIÓN DE MÁQUINAS DE OFICINA Y ORDENADORES & 1 & 250 & 1,04 & 32 & 0,1280 \\
\hline CONSTRUCCIÓN DE MAQUINARIA Y MATERIAL ELÉCTRICO & 6 & 1326 & 5,50 & 67 & 0,0505 \\
\hline FABRICACIÓN DE INSTRUMENTOS DE PRECISIÓN, ÓPTICA Y SIMILARES & 2 & 600 & 2,49 & 33 & 0,0550 \\
\hline INDUSTRIAS DE PRODUCTOS ALIMENTICIOS, BEBIDAS Y TABACO & 12 & 2891 & 11,99 & 105 & 0,0363 \\
\hline INDUSTRIAS DE PRODUCTOS ALIMENTICIOS, BEBIDAS Y TABACO & 1 & 349 & 1,45 & 6 & 0,0172 \\
\hline INDUSTRIA DEL CUERO & 2 & 560 & 2,32 & 21 & 0,0375 \\
\hline INDUSTRIA DEL CALZADO Y DEL VESTIDO Y OTRAS CONFECCIONES TEXTILES & 3 & 950 & 3,94 & 44 & 0,0463 \\
\hline INDUSTRIAS DE MADERA, CORCHO Y MUEBLES DE MADERA & 2 & 2190 & 9,08 & 28 & 0,0128 \\
\hline $\begin{array}{l}\text { INDUSTRIA DEL PAPEL Y FABRICACIÓN DE ARTÍCULOS DE PAPEL, ARTES GRÁFICAS } \\
\text { Y EDICIÓN }\end{array}$ & 12 & 4616 & 19,14 & 135 & 0,0292 \\
\hline INDUSTIAS DE TRANSFORMACIÓN DEL CAUCHO Y MATERIAS PLÁSTICAS & 1 & 230 & 0,95 & 10 & 0,0435 \\
\hline OTRAS INDUSTRIAS MANUFACTURERAS & 1 & 550 & 2,28 & 58 & 0,1055 \\
\hline CONSTRUCCIÓN & 3 & 1550 & 6,43 & 35 & 0,0226 \\
\hline COMERCIO AL POR MAYOR Y ALMACENAMIENTO & 1 & 1237 & 5,13 & 42 & 0,0340 \\
\hline TOTAL & 60 & 24119 & 100 & 763 & 0,0316 \\
\hline
\end{tabular}

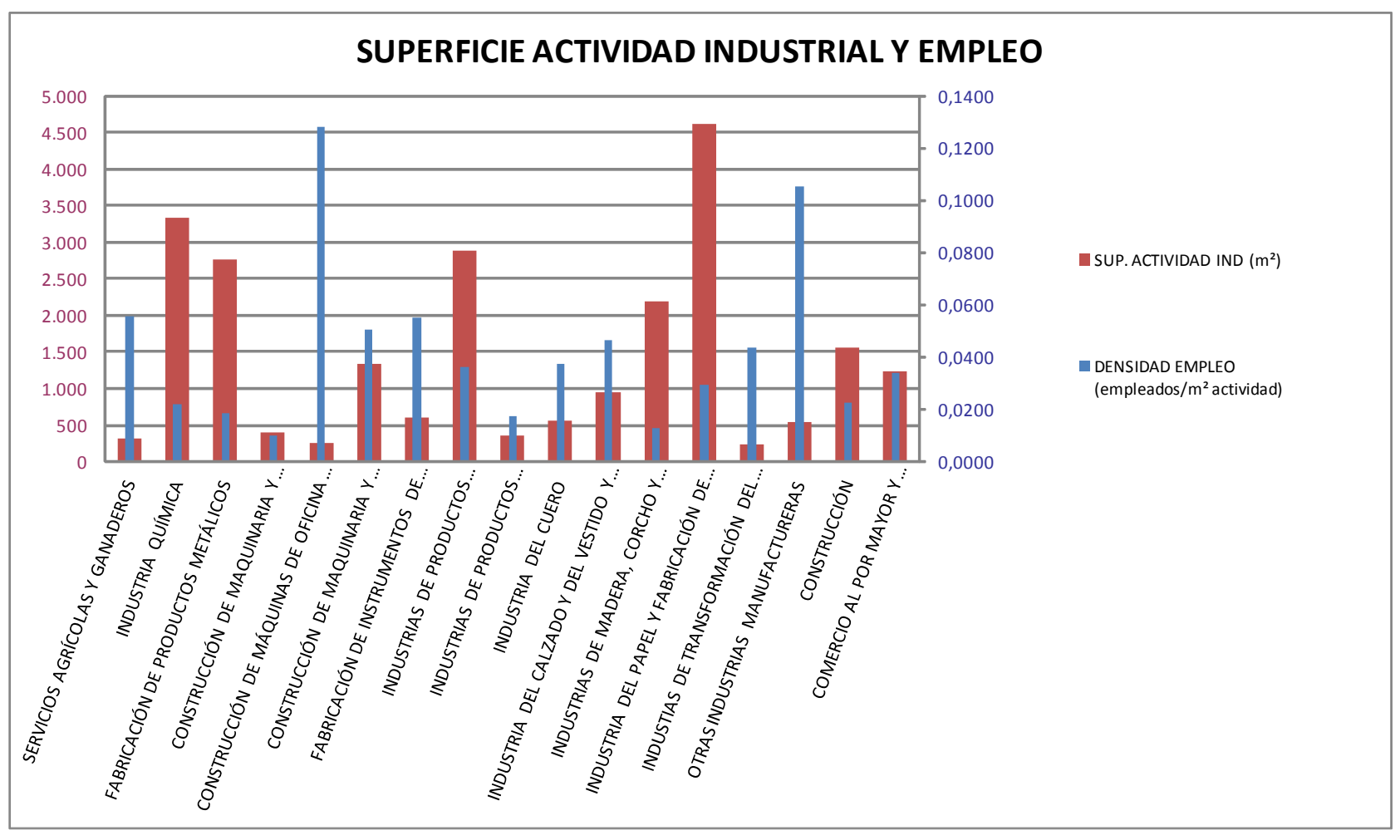




\section{IMPACTO AMBIENTAL}

\begin{tabular}{|c|c|c|c|c|c|}
\hline \multicolumn{6}{|c|}{ DISTRITO 2 - L'EIXAMPLE (INFORMACIÓN URBANÍSTICA) } \\
\hline ACTIVIDAD & $\begin{array}{l}\text { № } \\
\text { EMPRESAS }\end{array}$ & $\begin{array}{c}\text { ENTRE } \\
\text { MEDIANERAS }\end{array}$ & RUIDOSAS & $\begin{array}{c}\text { EMPRESAS } \\
\text { CON } \\
\text { CHIMENEA }\end{array}$ & $\begin{array}{l}\text { RUIDOSAS Y } \\
\text { CHIMENEA }\end{array}$ \\
\hline SERVICIOS AGRÍCOLAS Y GANADEROS & 1 & 1 & 0 & 0 & 0 \\
\hline INDUSTRIA QUÍMICA & 3 & 3 & 0 & 0 & 0 \\
\hline FABRICACIÓN DE PRODUCTOS METÁLICOS & 8 & 8 & 3 & 0 & 0 \\
\hline CONSTRUCCIÓN DE MAQUINARIA Y EQUIPO MECÁNICO & 1 & 1 & 0 & 0 & 0 \\
\hline CONSTRUCCIÓN DE MÁQUINAS DE OFICINA Y ORDENADORES & 1 & 1 & 0 & 0 & 0 \\
\hline CONSTRUCCIÓN DE MAQUINARIA Y MATERIAL ELÉCTRICO & 6 & 6 & 0 & 0 & 0 \\
\hline FABRICACIÓN DE INSTRUMENTOS DE PRECISIÓN, ÓPTICA Y SIMILARES & 2 & 2 & 0 & 0 & 0 \\
\hline INDUSTRIAS DE PRODUCTOS ALIMENTICIOS, BEBIDAS Y TABACO & 12 & 12 & 0 & 7 & 0 \\
\hline INDUSTRIAS DE PRODUCTOS ALIMENTICIOS, BEBIDAS Y TABACO & 1 & 1 & 0 & 1 & 0 \\
\hline INDUSTRIA DEL CUERO & 2 & 2 & 0 & 0 & 0 \\
\hline INDUSTRIA DEL CALZADO Y DEL VESTIDO Y OTRAS CONFECCIONES TEXTILES & 3 & 3 & 0 & 0 & 0 \\
\hline INDUSTRIAS DE MADERA, CORCHO Y MUEBLES DE MADERA & 2 & 2 & 0 & 0 & 0 \\
\hline $\begin{array}{l}\text { INDUSTRIA DEL PAPEL Y FABRICACIÓN DE ARTÍCULOS DE PAPEL, ARTES GRÁFICAS } \\
\text { Y EDICIÓN }\end{array}$ & 12 & 12 & 4 & 0 & 0 \\
\hline INDUSTIAS DE TRANSFORMACIÓN DEL CAUCHO Y MATERIAS PLÁSTICAS & 1 & 1 & 0 & 0 & 0 \\
\hline OTRAS INDUSTRIAS MANUFACTURERAS & 1 & 1 & 1 & 0 & 0 \\
\hline CONSTRUCCIÓN & 3 & 3 & 0 & 0 & 0 \\
\hline COMERCIO AL POR MAYOR Y ALMACENAMIENTO & 1 & 1 & 0 & 0 & 0 \\
\hline TOTAL & 60 & 60 & 8 & 8 & 0 \\
\hline
\end{tabular}

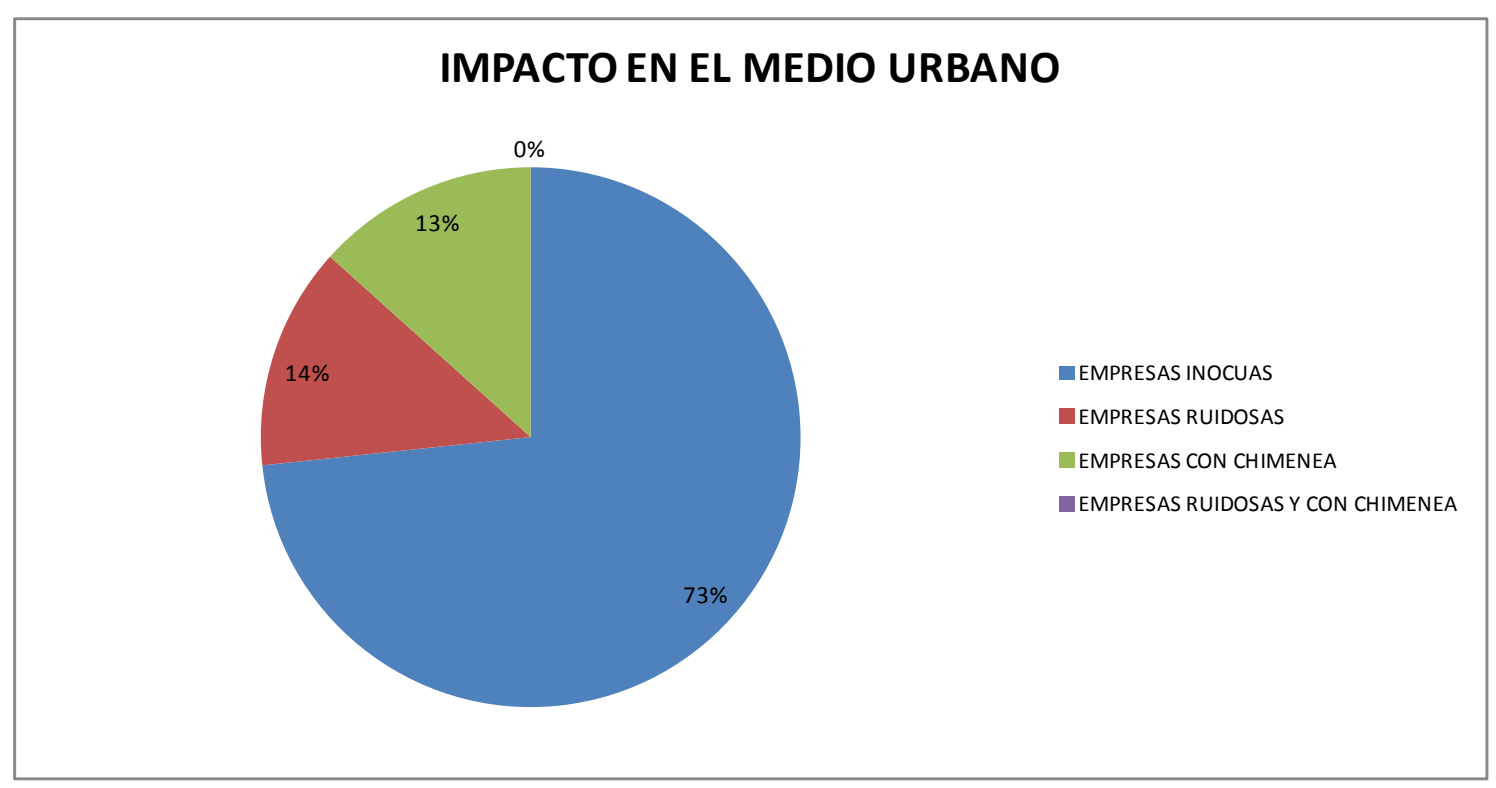




\section{FICHAS TIPO \\ FICHA DATOS DE LA INDUSTRIA}

LOCALIZACION ACTUALIZADA DE ACTIVIDADES INDUSTRIALES EN EL MEDIO URBANO DE VALENCIA

\begin{tabular}{|c|c|c|c|c|c|c|c|}
\hline \multirow{5}{*}{ 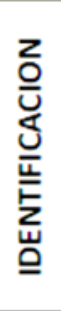 } & \multirow{2}{*}{\multicolumn{2}{|c|}{$\begin{array}{c}\text { NOMBRE } \\
\text { EMPLAZAMIENTO }\end{array}$}} & \multicolumn{5}{|c|}{ CONFECCIONES RUGEN, S.A. } \\
\hline & & & \multicolumn{3}{|c|}{ C/ Jorge Juan $n \cong 13$} & C.P. & \\
\hline & \multirow[b]{2}{*}{ CNAE } & \multirow[b]{2}{*}{453} & \multirow[b]{2}{*}{ DESCRIPCION } & \multicolumn{4}{|c|}{ INDUSTRIAS DEL CALZADO Y VESTIDO } \\
\hline & & & & \multicolumn{4}{|c|}{ Confecciones } \\
\hline & DISTRITO & 2 & \multicolumn{5}{|c|}{ L'EIXAMPLE } \\
\hline \multicolumn{3}{|c|}{ SUPERFICIES } & $\begin{array}{c}\text { Sup. Parcela: } \\
550 \mathrm{~m}^{2}\end{array}$ & $\begin{array}{c}\text { Sup. Ocupada: } \\
550 \mathrm{~m}^{2}\end{array}$ & $\begin{array}{l}\text { Sup. Construida: } \\
550 \mathrm{~m}^{2}\end{array}$ & EMPI & $\begin{array}{l}\text { LEADOS: } \\
20\end{array}$ \\
\hline
\end{tabular}
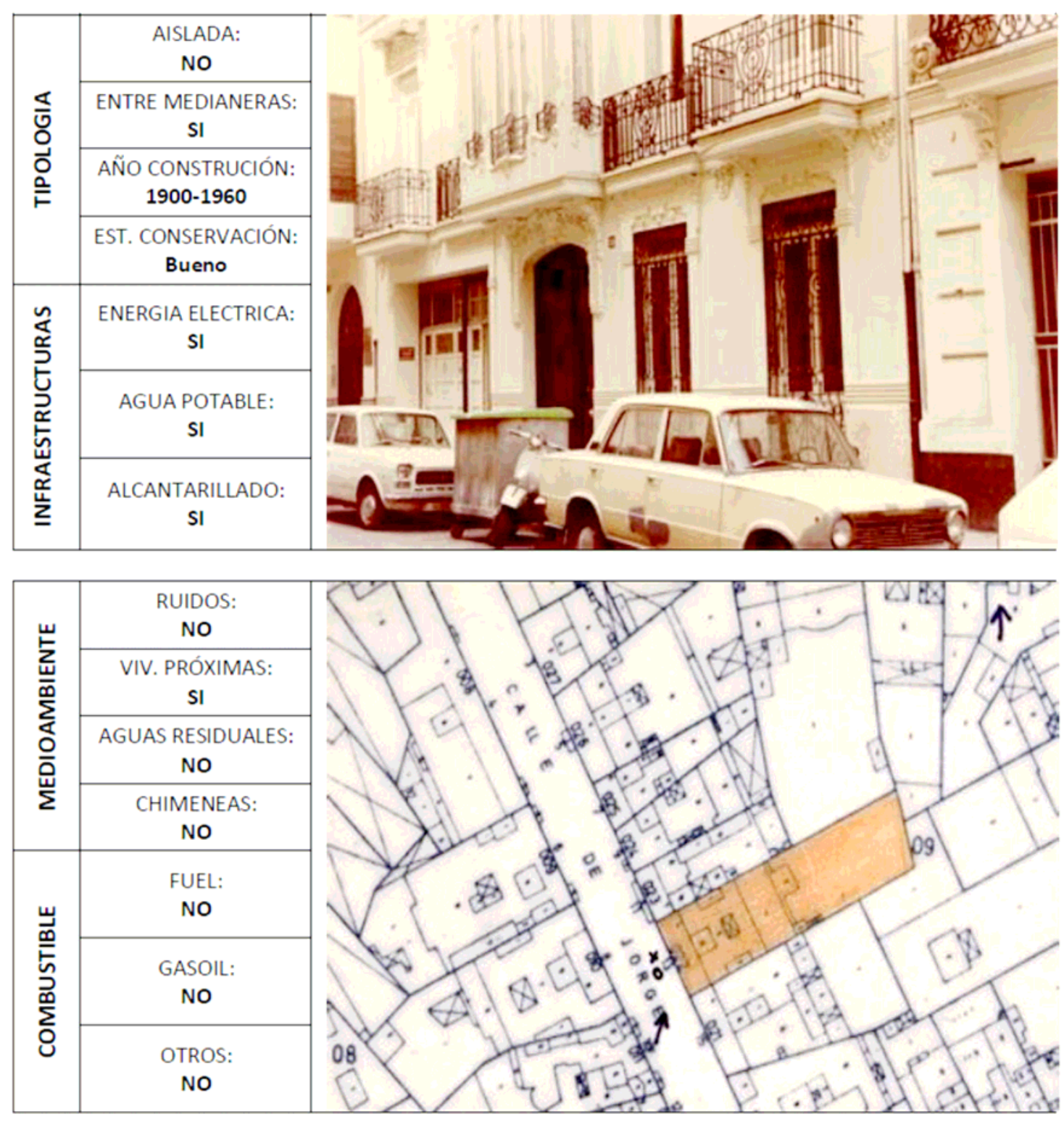

EN LA ACTUALIDAD: Comercio 


\section{FICHA DATOS DE LA INDUSTRIA}

LOCALIZACION ACTUALIZADA DE ACTIVIDADES INDUSTRIALES EN EL MEDIO URBANO DE VALENCIA

\begin{tabular}{|c|c|c|c|c|c|c|c|}
\hline \multirow{5}{*}{ 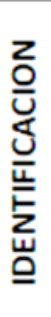 } & \multirow{2}{*}{\multicolumn{2}{|c|}{$\begin{array}{c}\text { NOMBRE } \\
\text { EMPLAZAMIENTO }\end{array}$}} & \multicolumn{5}{|c|}{ CONFECCIONES RUGEN, S.A. } \\
\hline & & & \multicolumn{3}{|c|}{ C/ Cirilo amoros no 77} & C.P. & \\
\hline & \multirow[b]{2}{*}{ CNAE } & \multirow[b]{2}{*}{361} & \multirow[b]{2}{*}{ DESCRIPCION } & \multicolumn{4}{|c|}{ FABRICACIÓN DE PRODUCTOS METÁLICOS } \\
\hline & & & & \multicolumn{4}{|c|}{ Metales y cerragería } \\
\hline & DISTRITO & 2 & \multicolumn{5}{|c|}{ L'EIXAMPLE } \\
\hline & \multicolumn{2}{|c|}{ SUPERFICIES } & $\begin{array}{c}\text { Sup. Parcela: } \\
270 \mathrm{~m}^{2}\end{array}$ & $\begin{array}{c}\text { Sup. Ocupada: } \\
270 \mathrm{~m}^{2}\end{array}$ & $\begin{array}{l}\text { Sup. Construida: } \\
380 \mathrm{~m}^{2}\end{array}$ & EMPI & $\begin{array}{l}\text { EADOS: } \\
11\end{array}$ \\
\hline
\end{tabular}

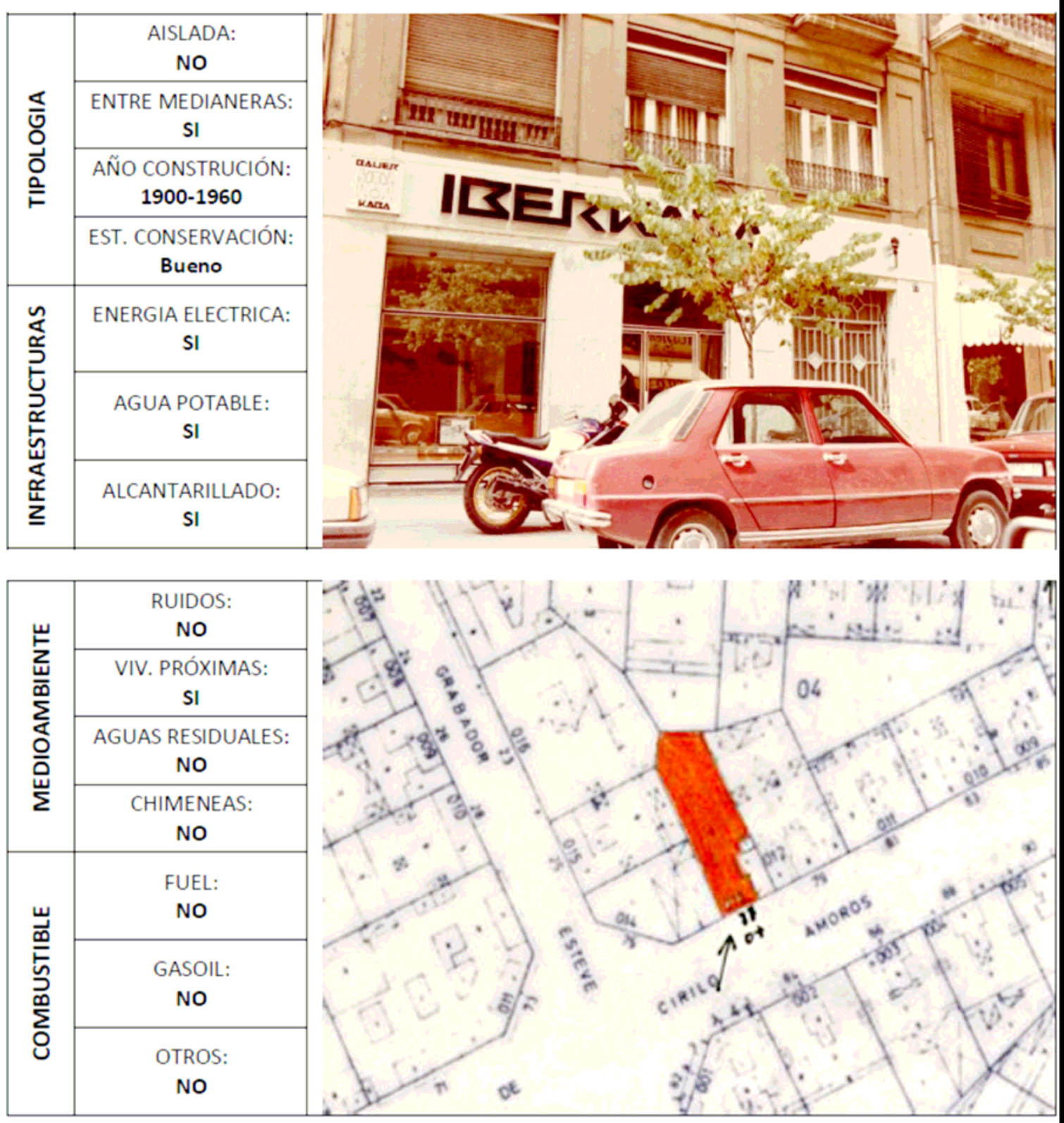




\section{FICHA DATOS DE LA INDUSTRIA}

LOCALIZACION ACTUALIZADA DE ACTIVIDADES INDUSTRIALES EN EL

MEDIO URBANO DE VALENCIA

\begin{tabular}{|c|c|c|c|c|c|c|}
\hline \multirow{5}{*}{ 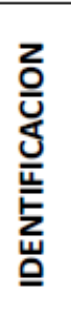 } & \multirow{2}{*}{\multicolumn{2}{|c|}{$\begin{array}{c}\text { NOMBRE } \\
\text { EMPLAZAMIENTO }\end{array}$}} & \multicolumn{4}{|c|}{ IMPRENTA PAU, S.L. } \\
\hline & & & \multicolumn{3}{|l|}{$\mathrm{C} /$ Clero $\mathrm{n} \div 14$} & C.P. \\
\hline & \multirow[b]{2}{*}{ CNAE } & \multirow[b]{2}{*}{474} & \multirow[b]{2}{*}{ DESCRIPCION } & \multicolumn{3}{|c|}{ INDUSTRIAS DEL PAPEL, ARTES GRÁFICAS, ETC. } \\
\hline & & & & \multicolumn{3}{|c|}{ Imprenta } \\
\hline & DISTRITO & 2 & \multicolumn{4}{|c|}{ L'EIXAMPLE } \\
\hline \multicolumn{3}{|c|}{ SUPERFICIES } & $\begin{array}{l}\text { Sup. Parcela: } \\
210 \mathrm{~m}^{2}\end{array}$ & $\begin{array}{c}\text { Sup. Ocupada: } \\
160 \mathrm{~m}^{2}\end{array}$ & $\begin{array}{l}\text { Sup. Construida: } \\
160 \mathrm{~m}^{2}\end{array}$ & $\begin{array}{c}\text { EMPLEADOS: } \\
9\end{array}$ \\
\hline
\end{tabular}

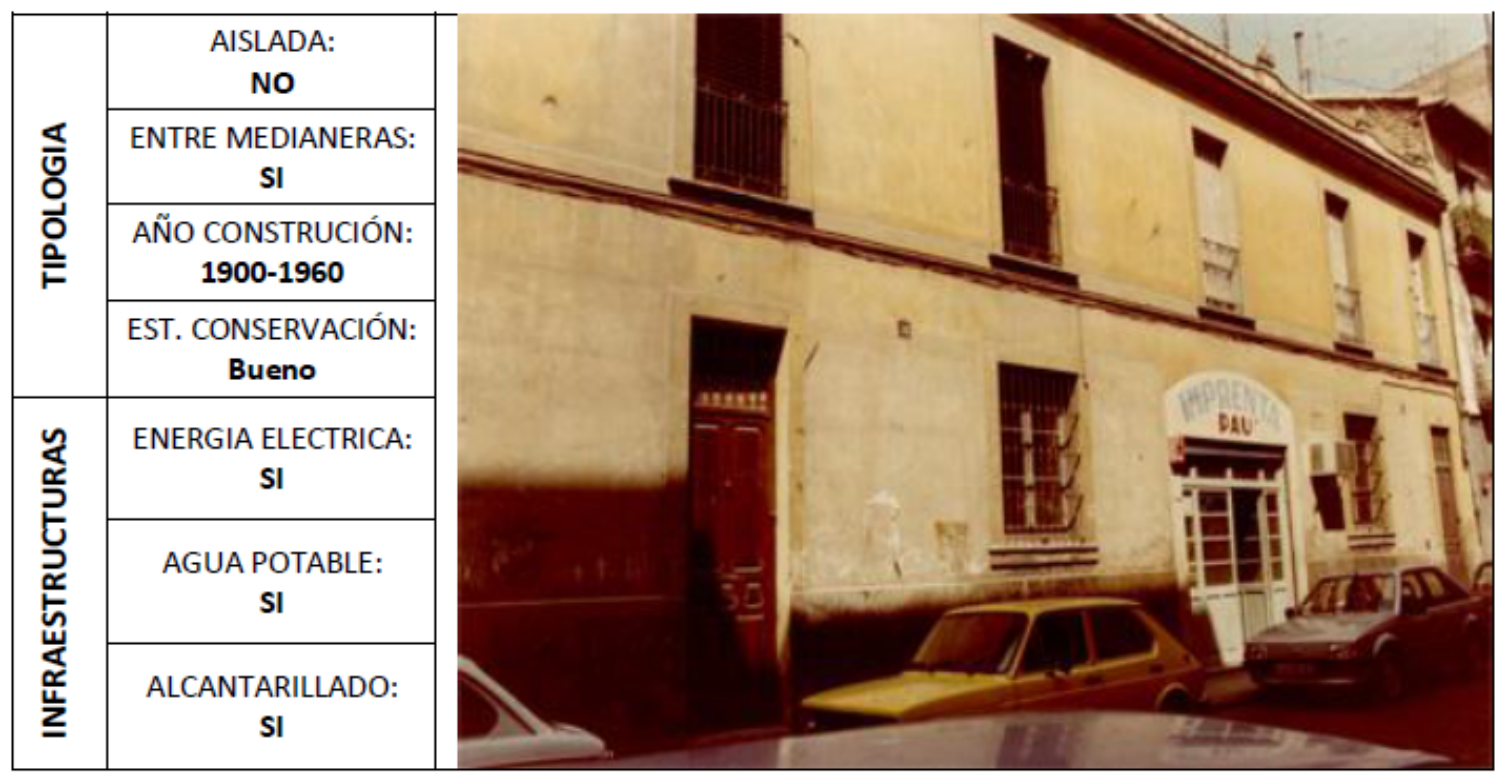

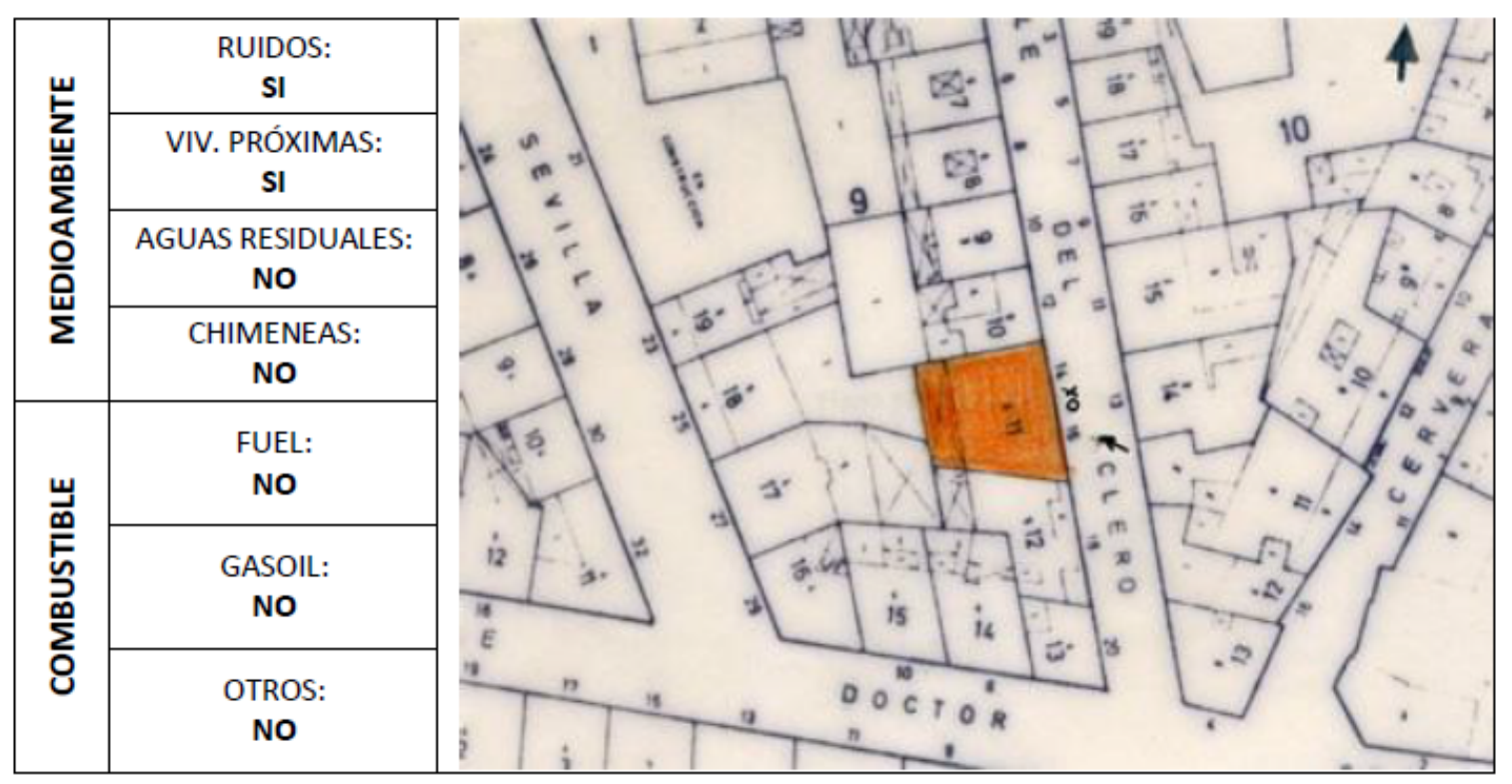

EN LA ACTUALIDAD: EDIFICIO DE VIVIENDAS 


\section{FICHA DATOS DE LA INDUSTRIA}

LOCALIZACION ACTUALIZADA DE ACTIVIDADES INDUSTRIALES EN EL MEDIO URBANO DE VALENCIA

\begin{tabular}{|c|c|c|c|c|c|c|c|}
\hline \multirow{5}{*}{ 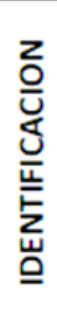 } & \multirow{2}{*}{\multicolumn{2}{|c|}{$\begin{array}{c}\text { NOMBRE } \\
\text { EMPLAZAMIENTO }\end{array}$}} & \multicolumn{5}{|c|}{ LABORATORIOS LIFASA } \\
\hline & & & \multicolumn{3}{|c|}{ C/ Los Centelles no 7} & C.P. & \\
\hline & \multirow[b]{2}{*}{ CNAE } & \multirow[b]{2}{*}{253} & \multirow[b]{2}{*}{ DESCRIPCION } & \multicolumn{4}{|c|}{ INDUSTRIAS QUIMICAS } \\
\hline & & & & \multicolumn{4}{|c|}{$\begin{array}{l}\text { Fabricación de especialidades y otros productos } \\
\text { farmaceuticos }\end{array}$} \\
\hline & DISTRITO & 2 & \multicolumn{5}{|c|}{ L'EIXAMPLE } \\
\hline & \multicolumn{2}{|c|}{ SUPERFICIES } & $\begin{array}{c}\text { Sup. Parcela: } \\
1900 \mathrm{~m}^{2}\end{array}$ & $\begin{array}{c}\text { Sup. Ocupada: } \\
1900 \mathrm{~m}^{2}\end{array}$ & $\begin{array}{c}\text { Sup. Construida: } \\
1900 \mathrm{~m}^{2}\end{array}$ & EMP & $\begin{array}{l}\text { EADOS: } \\
11\end{array}$ \\
\hline
\end{tabular}
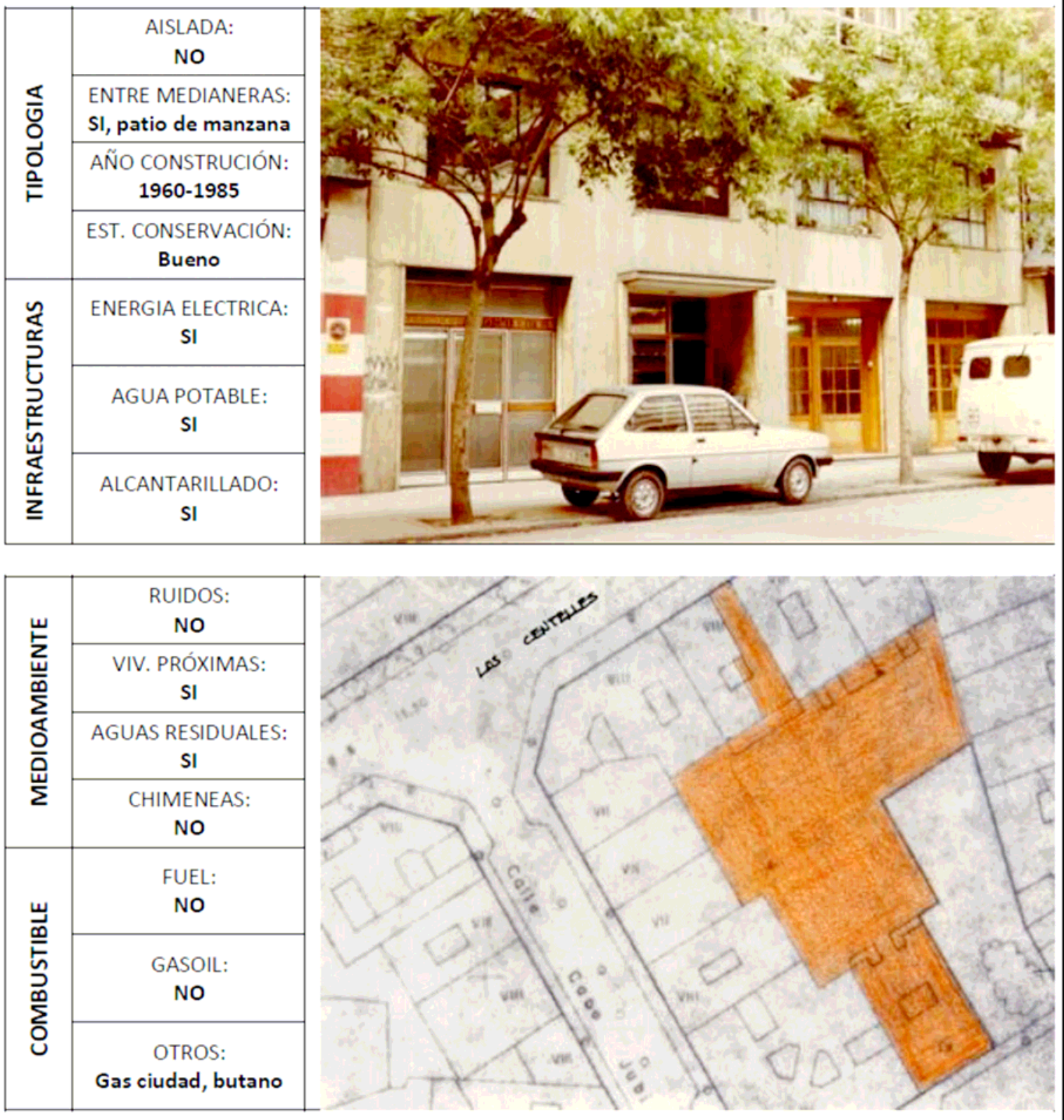


\section{EVOLUCIÓN}

\section{PLANO UBICACIÓN INDUSTRIAS}

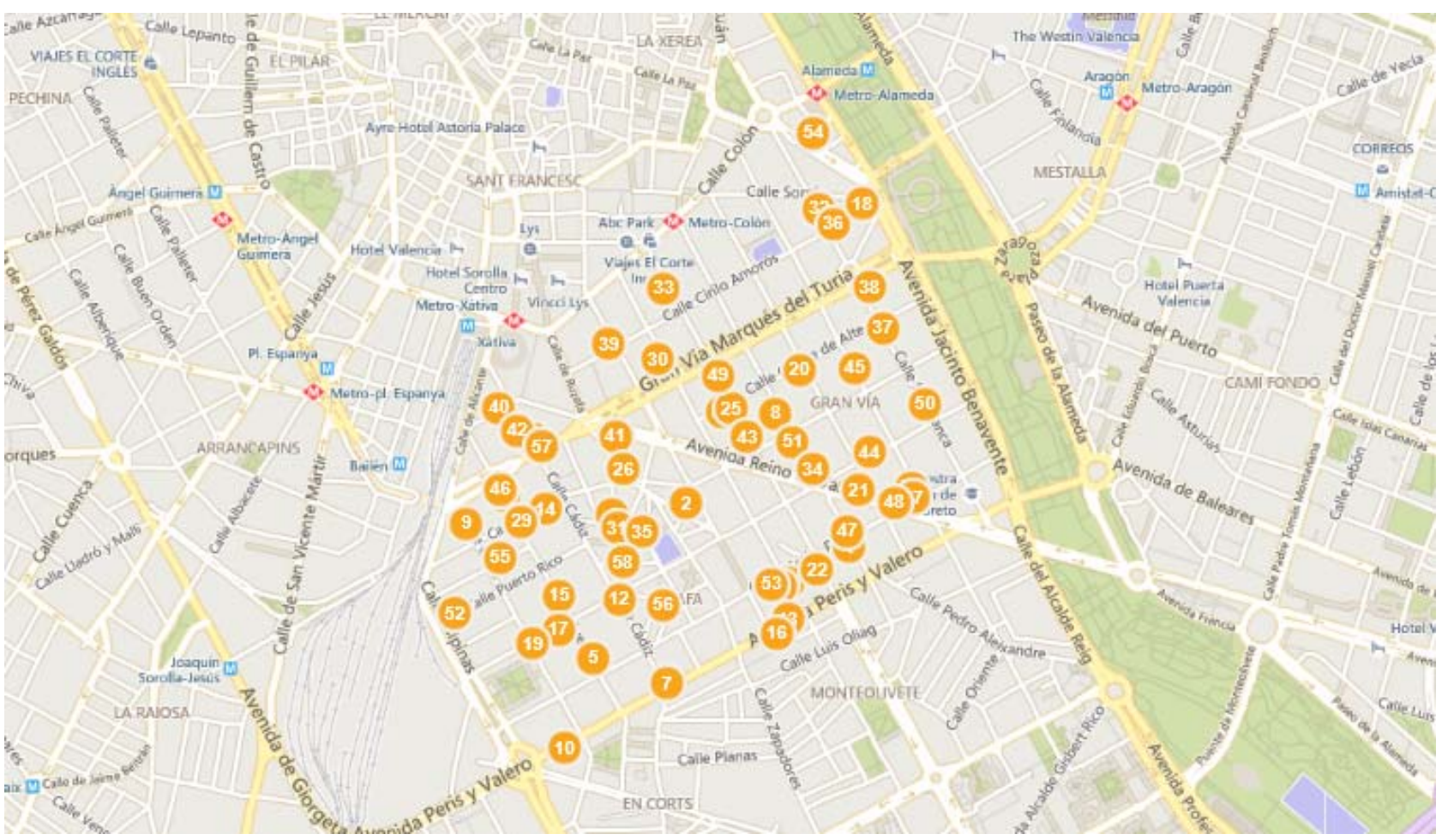

\section{LISTADO DE INDUSTRIAS Y ACTIVIDAD.-}

\section{Sergio Ballester Llopes}

Fabricación de otros muebles

\section{Daniel Vicente Bada Marzo}

Fabricación de artículos de joyería y artículos similares

\section{Lorenzo Sanchez Martínez}

Fabricación de artículos confección con textiles, excepto prendas de vestir

4. LABORATORIO ADELANTADO, S.L.

Fabricación de instrumentos y suministros médicos y odontológicos

5. Francisco Javier Ariño Ferrer

Fabricación de componentes electrónicos

6. DENTAL VIDAGANY, S.L.

Fabricación instrumentos y suministros médicos y odontológicos

7. CLINICAS AUDITIVAS ASIO, S.L.

Fabricación instrumentos y suministros médicos y odontológicos 
8. Vicente José Pastor Irago

Fabricación de envases y embalajes de plástico

9. Gines Lopez Viñes

Mantenimiento y reparación de vehículos a motor

10. Bernardino Martínez Alfaro

Mantenimiento y reparación de vehículos a motor

11. TALLERES SAMAN, C.B.

Mantenimiento y reparación de vehículos a motor

12. MOTOS RAMÓN, C.B.

Mantenimiento y reparación de vehículos a motor

13. ELECTROMOVIL SDAD. COOP. VALENCIANA LIMITADA

Mantenimiento y reparación de vehículos a motor

14. Antonio José Montañana Sales

Mantenimiento y reparación de vehículos a motor

15. Juan Prado Clemente Guillem

Mantenimiento y reparación de vehículos a motor

16. Jonay Cabrera Bustos

Mantenimiento y reparación de vehículos a motor

17. José Gimenez Piera

Mantenimiento y reparación de vehículos a motor

18. Desamparados Mari Beltrán

Mantenimiento y reparación de vehículos a motor

19. Julio Esteban Pardo Ibañez

Fabricación de otros muebles

20. Juan Vicente Comes Alacreu

Fabricación de otros muebles

21. Vicente Marín Maestro

Fabricación de otros productos de madera, artículos de corcho, cestería y espartería

22. Felipe Bravo Rodrigo

Fabricación de otros productos de madera, artículos de corcho, cestería y espartería

23. Juan Andres Mompo Casadella

Confección de otras prendas de vestir exteriores

24. Eva Marquez Linares

Confección de otras prendas de vestir y accesorios

25. AMPARO FABRA, C.B.

Confección de otras prendas de vestir exteriores

26. Julio Berzosa Martínez

Confección de otras prendas de vestir exteriores

27. NURIA CAPON FASHION, S.L.

Confección de otras prendas de vestir y accesorios 
28. Salvador Guillermo Carbonell

Confección de otras prendas de vestir y accesorios

29. Isabel Soria Montfort

Confección de otras prendas de vestir exteriores

30. DOCTOR CRESCENTI, S.L.

Productos alimenticios

31. Jesús Poveda López

Fabricación de pan y productos frescos de panadería y pastelería

32. Serafín Mengod Cardo

Fabricación de pan y productos frescos de panadería y pastelería

33. Carlos Antonio Jericó Montoro

Fabricación galletas y productos de panadería y pastelería de larga duración

34. Rafael Sanchis Cañizares

Fabricación cacao, chocolate y productos de confitería

35. UTOPICK, C.B.

Fabricación cacao, chocolate y productos de confitería

36. IBERKABA, S.A. (Existente 7)

CNAE año 1.985 (316)

37. CAFETERIA HORNO SALAMANCA, S.L. (Existente 11)

CNAE año 1.985 (419)

38. Salvador Huerta Moreno (Existente 12)

CNAE año 1.985 (419)

39. ORTOPRONO (Existente 9)

CNAE año 1.985 (392)

40. Antonio Domenech Bartual

Fabricación de pan y productos frescos de panadería y pastelería

41. E. Ibañez Martinez (Existente 15)

CNAE año 1.985 (419)

42. S. Estelles Nieto (Existente 16)

CNAE año 1.985 (474)

43. Francisco Mota Gonzalez (Existente 21)

CNAE año 1.985 (419)

44. TALLERES RUIZ ASCENSORES, S.L. (Existente 25)

CNAE año 1.985 (504)

45. VINAUTO (Existente 27)

CNAE año 1.985 (319)

46. CRISTALDI SALVATORE (Existente 33)

CNAE año 1.985 (419)

47. REFRIGERACIÓN TERMO MECANIC (Existente 38)

CNAE año 1.985 (316) 
48. IBAÑEZ, S.L. (Existente 41)

CNAE año 1.985 (316)

49. Crespo Sánchez Cañamares, $M^{\mathrm{a}}$ Ángeles

Otras actividades de impresión y artes gráficas

50. GRÁFICAS GENOVES, S.L.

Otras actividades de impresión y artes gráficas

51. Tellas Nacher, Jorge

Otras actividades de impresión y artes gráficas

52. Cerdá Mansilla, Guillermo

Otras actividades de impresión y artes gráficas

53. PROYECTOS INTEGRALES UNICROM, S.L.

Otras actividades de impresión y artes gráficas

54. García Tolosa, Francisco Rafael

Otras actividades de impresión y artes gráficas

55. Francisco Javier Dobón Giménez

Otras actividades de impresión y artes gráficas

56. Fernández Arizmendi, Alejandro

Otras actividades de impresión y artes gráficas

57. SELLOS AIV, S.L.

Otras actividades de impresión y artes gráficas

58. Serra Molla, Salvador

Otras actividades de impresión y artes gráficas 


\section{Distrito 2. L'EIXAMPLE}

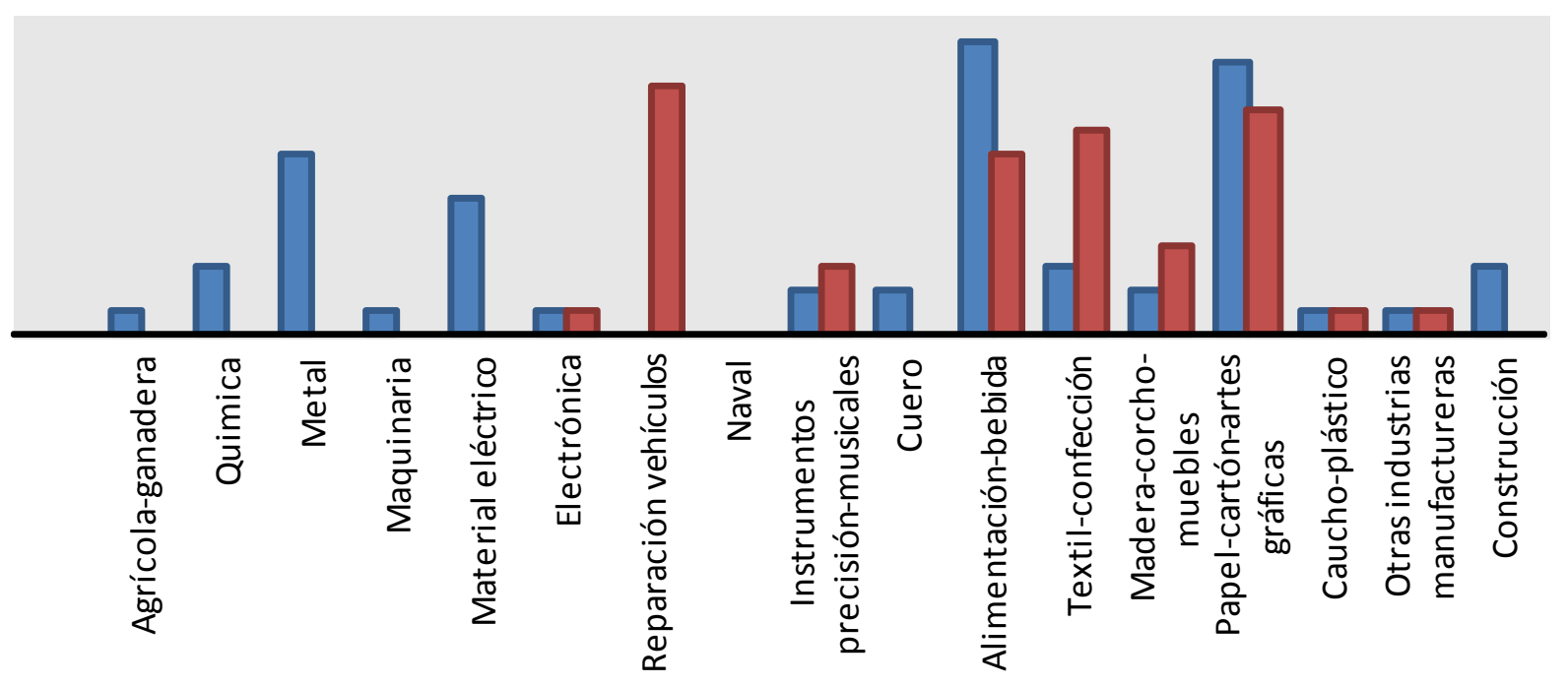

Actividad Industrial 1985/1990

Actividad Industrial 2014

\section{IMPACTO EN EL MEDIO URBANO Distrito 2. L'EIXAMPLE}

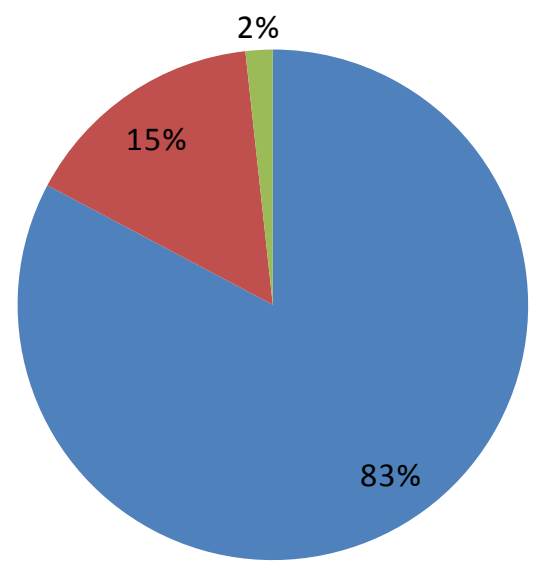

Empresas inocuas

Empresas ruidosas

Empresas ruidosas con chimenea 


\section{FICHAS TIPO \\ FICHA DATOS DE LA INDUSTRIA}

LOCALIZACION ACTUALIZADA DE ACTIVIDADES INDUSTRIALES EN EL

MEDIO URBANO DE VALENCIA

\begin{tabular}{|c|c|c|c|c|c|c|c|}
\hline \multirow{5}{*}{ 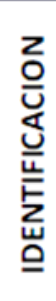 } & \multirow{2}{*}{\multicolumn{2}{|c|}{$\begin{array}{c}\text { NOMBRE } \\
\text { EMPLAZAMIENTO }\end{array}$}} & \multicolumn{5}{|c|}{ DESAMPARADOS MARI BELTRAM } \\
\hline & & & \multicolumn{3}{|c|}{ PLAZA AMERICA, 4} & C.P. & 46004 \\
\hline & \multirow[b]{2}{*}{ CNAE } & \multirow{2}{*}{4520} & \multirow{2}{*}{ DESCRIPCION } & \multicolumn{4}{|c|}{ REPARACIÓN VEHICULOS } \\
\hline & & & & \multicolumn{4}{|c|}{ Mantenimiento y reparación de vehiculos a motor } \\
\hline & DISTRITO & 2 & \multicolumn{5}{|c|}{ L'EIXAMPLE } \\
\hline \multicolumn{3}{|c|}{ MEDIOAMBIENTE } & RUIDOSAS & SI & CHIMENEAS & & $\mathrm{OO}$ \\
\hline
\end{tabular}

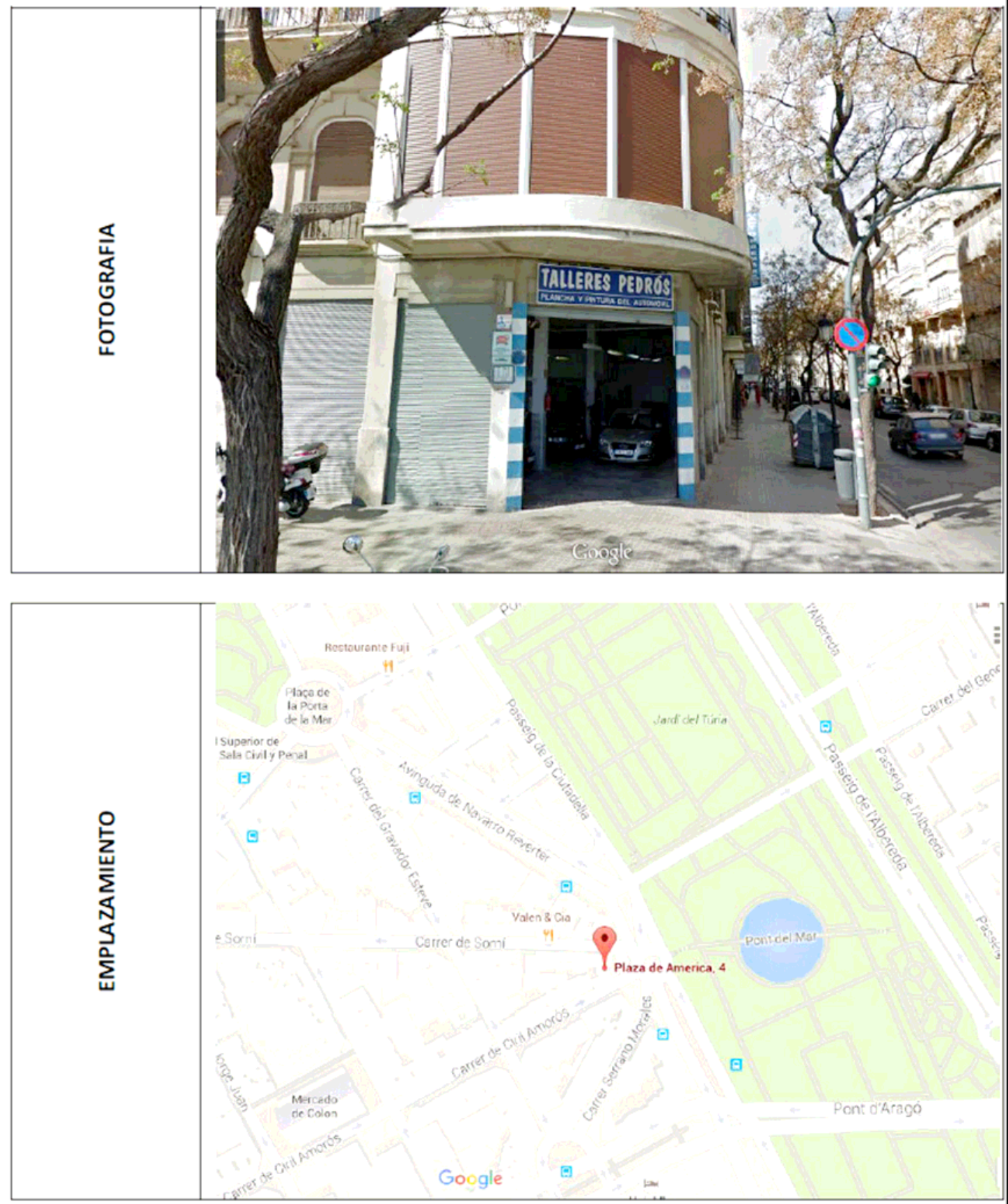




\section{FICHA DATOS DE LA INDUSTRIA}

LOCALIZACION ACTUALIZADA DE ACTIVIDADES INDUSTRIALES EN EL MEDIO URBANO DE VALENCIA

\begin{tabular}{|c|c|c|c|c|c|c|c|}
\hline \multirow{5}{*}{ 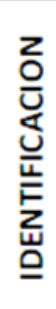 } & \multirow{2}{*}{\multicolumn{2}{|c|}{$\begin{array}{c}\text { NOMBRE } \\
\text { EMPLAZAMIENTO }\end{array}$}} & \multicolumn{5}{|c|}{ ANTONIO DOMENECH BARTUAL } \\
\hline & & & \multicolumn{3}{|l|}{ C/ SEGORBE, 4} & C.P. & 46004 \\
\hline & \multirow[b]{2}{*}{ CNAE } & \multirow[b]{2}{*}{1071} & \multirow[b]{2}{*}{ DESCRIPCION } & \multicolumn{4}{|c|}{ ALIMENTACIÓN-BEBIDA } \\
\hline & & & & \multicolumn{4}{|c|}{$\begin{array}{l}\text { Fabricación de pan y productos frescos de } \\
\text { panadería y pastelería }\end{array}$} \\
\hline & DISTRITO & 2 & \multicolumn{5}{|c|}{ L'EIXAMPLE } \\
\hline \multicolumn{3}{|c|}{ MEDIOAMBIENTE } & RUIDOSAS & NO & CHIMENEAS & & $\mathrm{O}$ \\
\hline
\end{tabular}

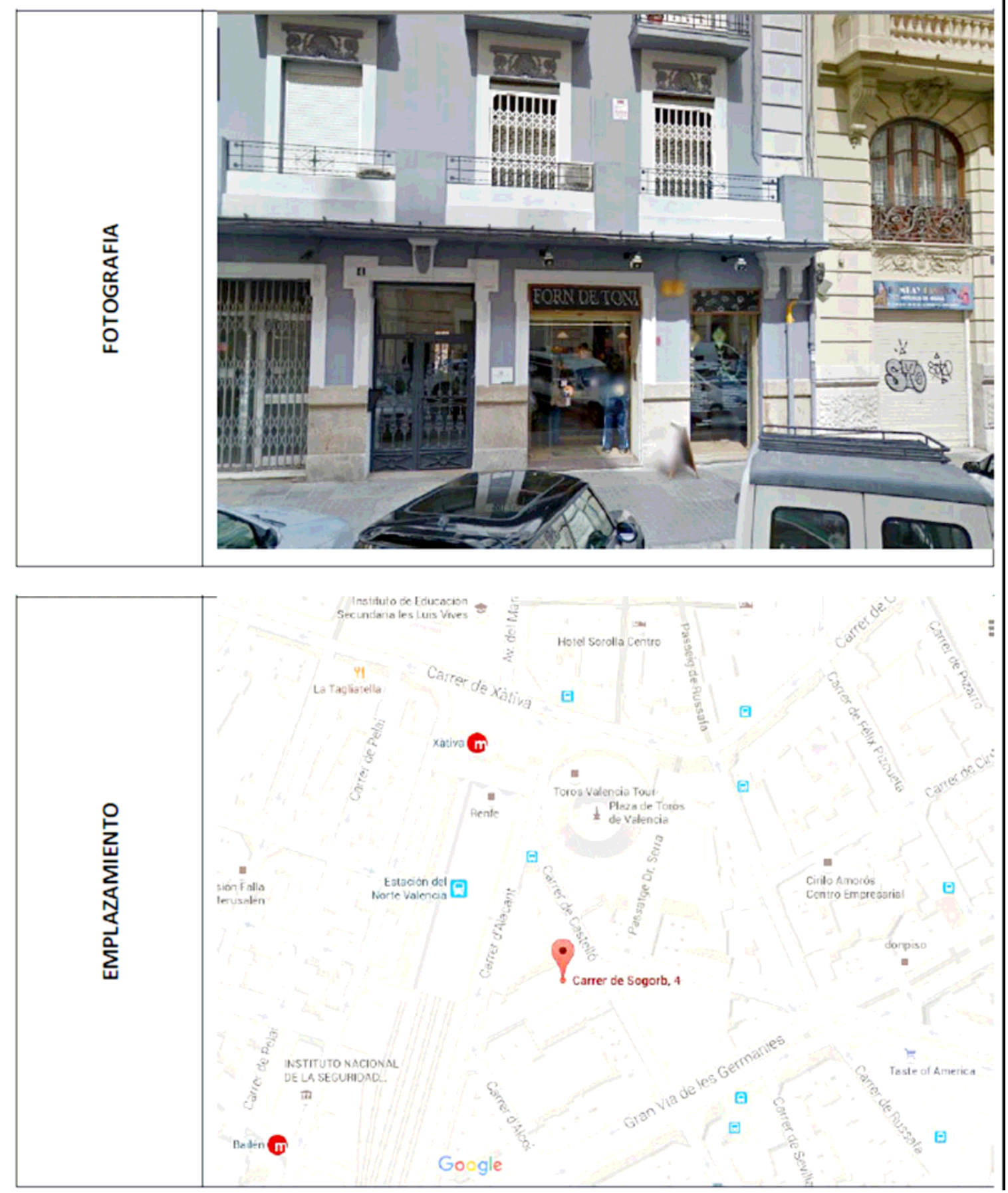




\section{FICHA DATOS DE LA INDUSTRIA}

LOCALIZACION ACTUALIZADA DE ACTIVIDADES INDUSTRIALES EN EL MEDIO URBANO DE VALENCIA

\begin{tabular}{|c|c|c|c|c|c|c|c|}
\hline \multirow{5}{*}{ 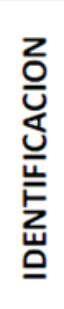 } & \multirow{2}{*}{\multicolumn{2}{|c|}{$\begin{array}{c}\text { NOMBRE } \\
\text { EMPLAZAMIENTO }\end{array}$}} & \multicolumn{5}{|c|}{ JULIO BERZOSA MARTINEZ } \\
\hline & & & \multicolumn{3}{|l|}{ C/ RUZAFA, 51} & C.P. & 46006 \\
\hline & \multirow{2}{*}{ CNAE } & \multirow{2}{*}{1413} & \multirow{2}{*}{ DESCRIPCION } & \multicolumn{4}{|c|}{ TEXTIL-CALZADO-CONFECCIÓN } \\
\hline & & & & \multicolumn{4}{|c|}{ Confección de otras prendas de vestir exteriores } \\
\hline & DISTRITO & 2 & \multicolumn{5}{|c|}{ L'EIXAMPLE } \\
\hline \multicolumn{3}{|c|}{ MEDIOAMBIENTE } & RUIDOSAS & NO & CHIMENEAS & & NO \\
\hline
\end{tabular}

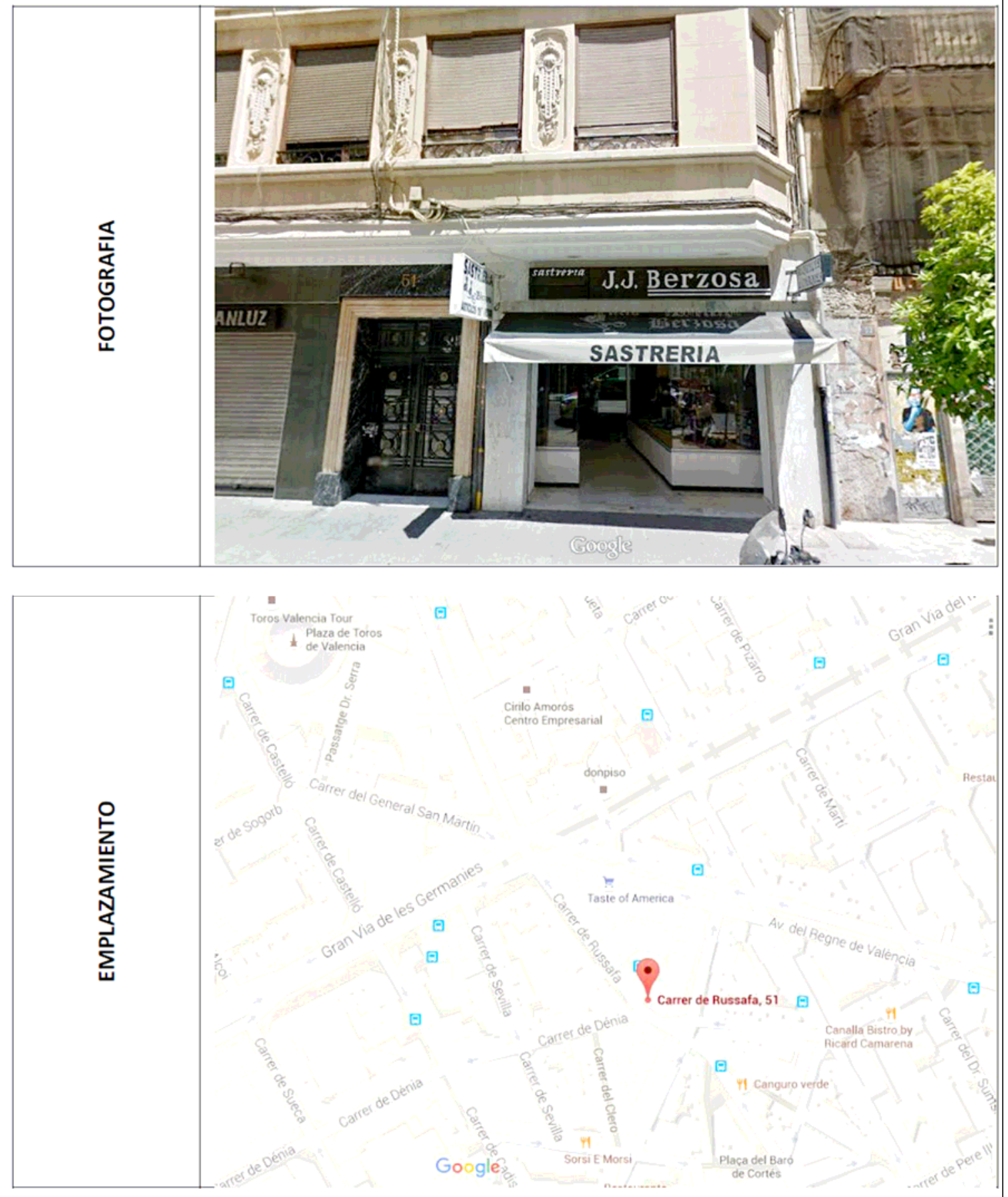




\section{FICHA DATOS DE LA INDUSTRIA}

LOCALIZACION ACTUALIZADA DE ACTIVIDADES INDUSTRIALES EN EL MEDIO URBANO DE VALENCIA

\begin{tabular}{|c|c|c|c|c|c|c|}
\hline \multirow{5}{*}{ 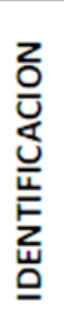 } & \multirow{2}{*}{\multicolumn{2}{|c|}{$\begin{array}{c}\text { NOMBRE } \\
\text { EMPLAZAMIENTO }\end{array}$}} & \multicolumn{4}{|c|}{ FRANCISCO JAVIER DOBÓN GIMÉNEZ } \\
\hline & & & \multicolumn{2}{|c|}{ C/ BUENOS AIRES, 10} & C.P. & 46004 \\
\hline & \multirow{2}{*}{ CNAE } & \multirow{2}{*}{1812} & \multirow{2}{*}{ DESCRIPCION } & \multicolumn{3}{|c|}{ PAPEL-CARTÓN-ARTES GRÁFICAS } \\
\hline & & & & \multicolumn{3}{|c|}{ Otras actividades de impresión y artes gráficas } \\
\hline & DISTRITO & 2 & \multicolumn{4}{|c|}{ L'EIXAMPLE } \\
\hline & \multicolumn{2}{|c|}{ MEDIOAMBIENTE } & RUIDOSAS & NO & & $\mathrm{NO}$ \\
\hline
\end{tabular}
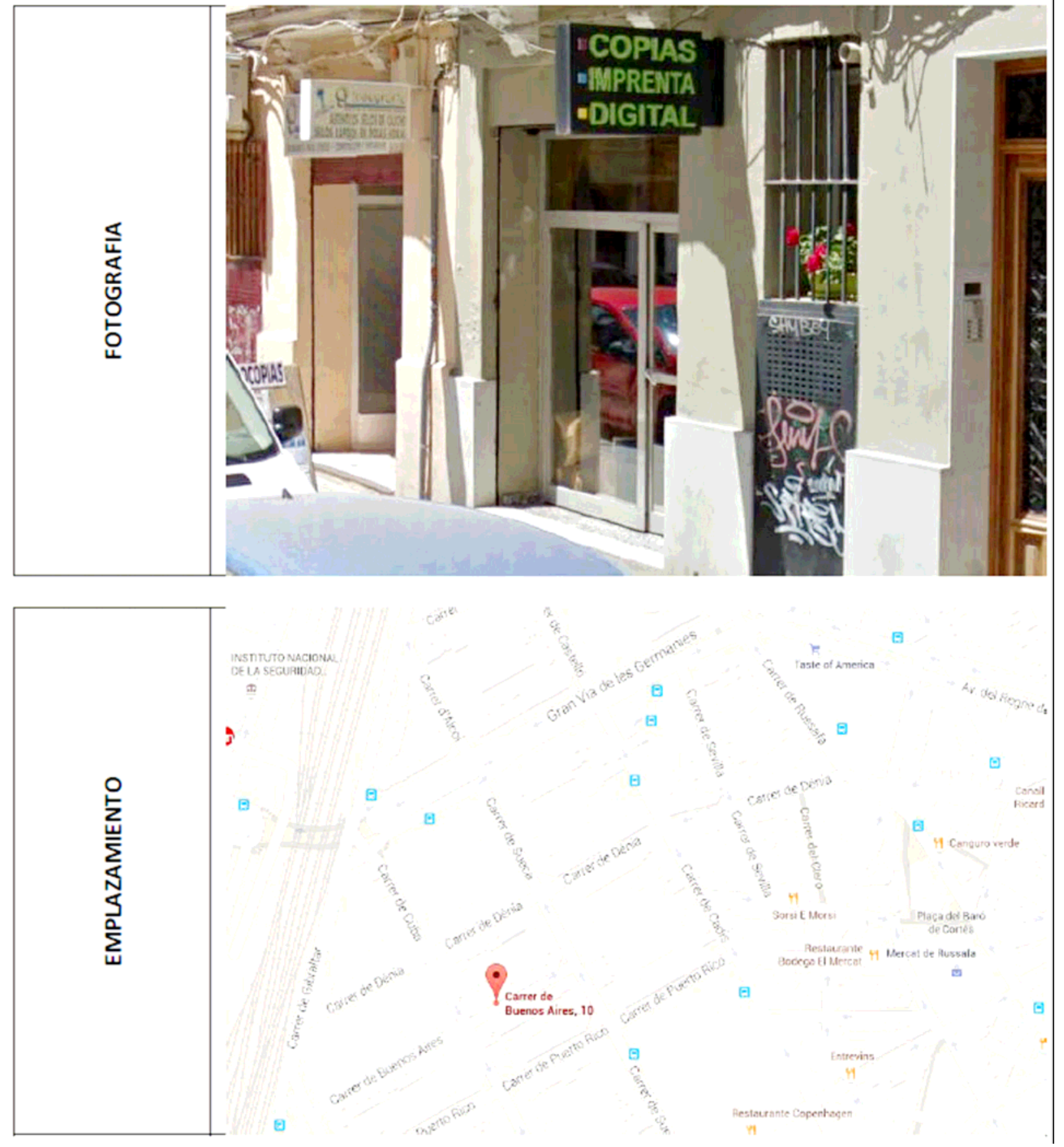
DISTRITO 3.- EXTRAMURS

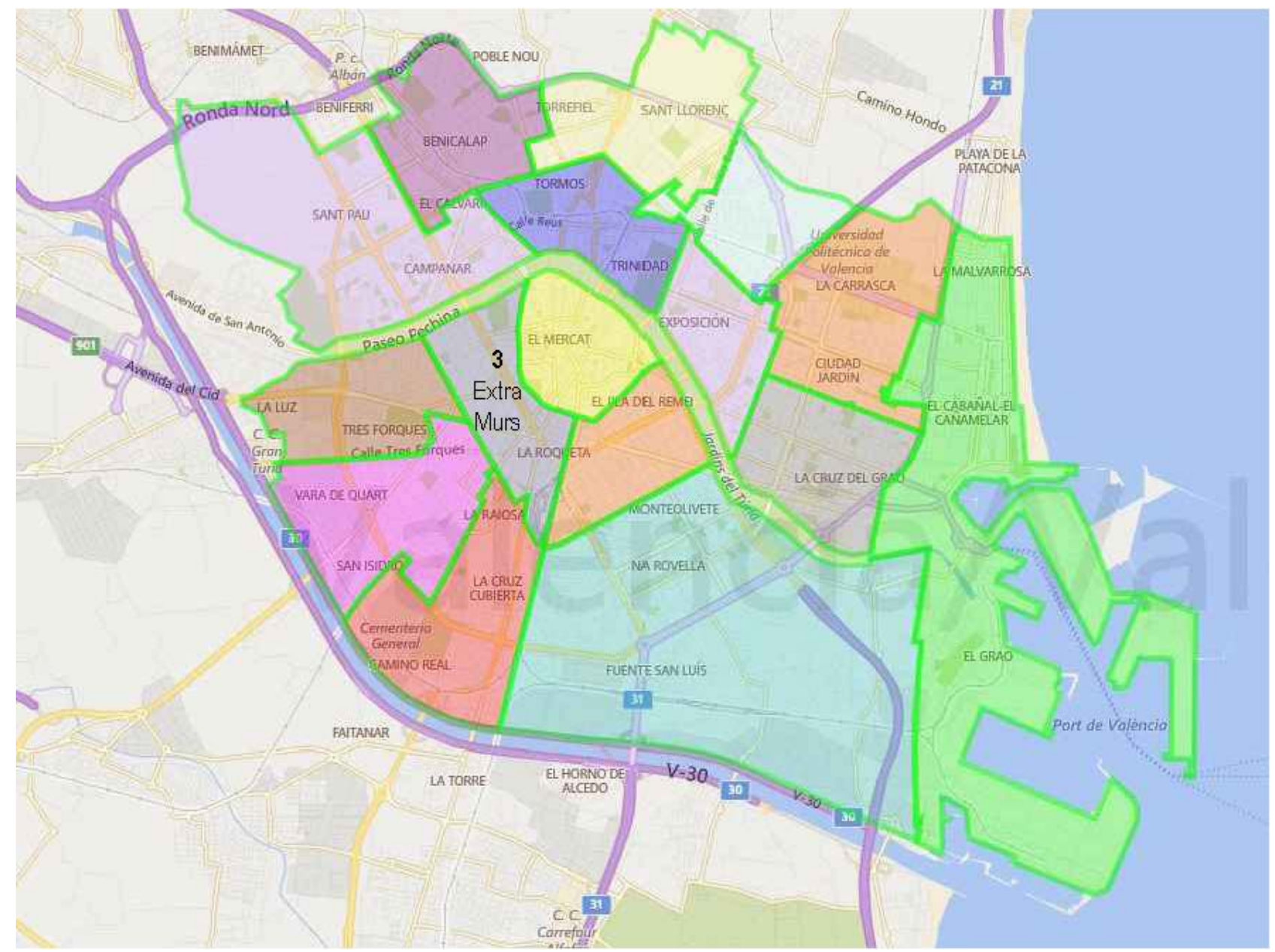

\section{LÍMITES GEOGRÁFICOS.}

Cauce Viejo del Turia, primera y segunda Ronda de Circunvalación y Estación del Norte. 


\section{EVOLUCIÓN DEL 1985-2014}

\section{PLANO UBICACIÓN INDUSTRIAS}

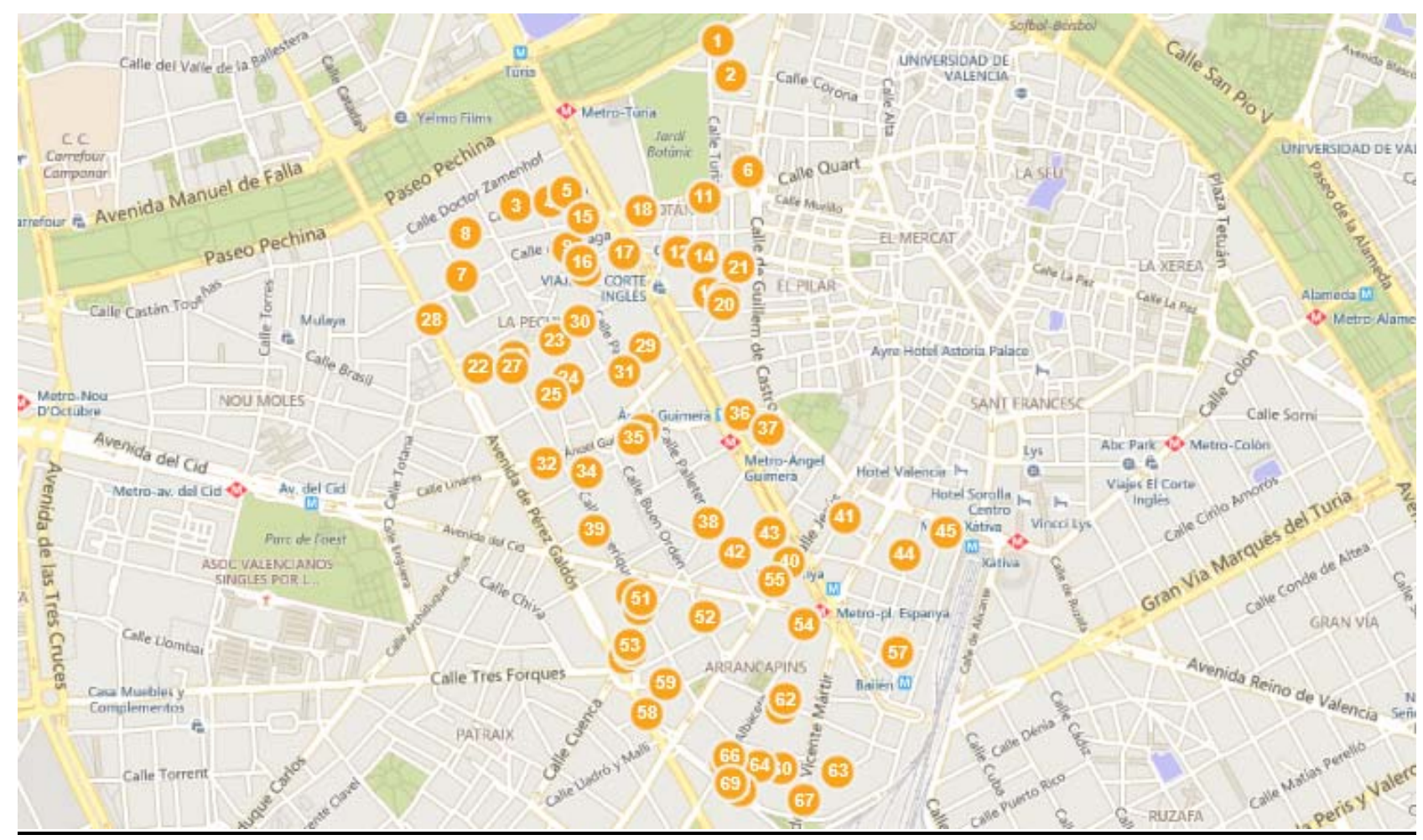

LISTADO DE INDUSTRIAS Y ESTADO ACTUAL .-

\section{Navarro Ripoll, Amparo}

Mantiene la actividad

2. LABORATORIOS LLAMA, S.L.

Tienda de antigüedades

3. CONFECCIONES VALENCIA Y PUCHALT, S.A.

Sin actividad

4. Julio A. Melquizo Folgado

Supermercado

5. Céspedes Valero, G.

Sin actividad

6. Hernández León, A.

Carpintería

\section{Gutiérrez Martínez, Rafael}

Protésico dental 
8. Ferrer Pastor, F.

Escuela náutica

9. Roig Paulis, R.

Obra nueva

10. Carrasco Suay, E.

Sin actividad

11. F. TOMÁS PASCUAL, S.L.

Sin actividad

12. FOTOGRABADOS TETRA, S.A.

Sin actividad

13. TONDA Y KARRUAZ

Sin actividad

14. TECHNIART, S.L.

Taller de vehículos

15. BUCH MÁXIMO, S.A.

Pastelería, cafetería.

16. BLASCO REQUENA, S.A.

Casal fallero

17. Francisco Cortes Cerverón

Abogados

18. CREACIONES JALBI, S.A.

Sin actividad

19. Esteve Carrascosa, R.

Sin actividad

20. Cebriá Bonhome, V.

Asociación

21. ADOLFO MOLTO, S.L.

Marmolista

22. J. Fernández Castillo

Sin actividad

23. Torres Campos, C.

Obra nueva

24. COOPERATIVA OBRERA LA PRODUCTORA

Obra nueva

25. TIPOVAL, S.A.

Supermercado

26. LLORCA HERMANOS, S.L.

Obra nueva

27. SALVADOR COLOMER ORTOL, S.L.

Obra nueva 
28. Manuel Moscardo Ortega

Puertas

29. Catalá Albors, $P$.

Mantiene la actividad

30. HIJA DE BARTUAL BARTUAL, V

Sin actividad

31. TIPOGRAFÍA ARTÍSTICA PUERTES, S.L.

Obra nueva

32. METALES SOLER

Obra nueva

33. SOCIEDAD ESPAÑOLA PRODUCTOS FOTOGRAFICOS "VALCA"

Sin actividad

34. ELECTRODOS K.D., S.A.

Reparación ordenadores

35. HIJOS DE JOAQUIN GIL GOMEZ, S.R.C.

Obra nueva

36. IMPRENTA CORTELL, S.C.L.

Peluquería

37. ORTOPEDIA SOTOS, S.L.

Mantiene la actividad

38. VIUDA DE J.BAYARRI

Obra nueva

39. Ángeles Lucas Ferrandis

Iluminación

40. Miralles Valls, Teresa

Solar sin edificar

41. Josefina Rubio Pascual

Hotel

42. López Mezquina, E.

Sin datos

43. HIJOS DE E.COMEZ SANCHEZ, S.R.C.

Sin actividad

44. V. ALEPUZ, S.L.

Mantiene la actividad

45. Bisbal Gimeno, E.

Kiosco

46. ACRO DESEL

Mantiene la actividad

47. INDUSTRIAL ANDREU, S.L.

Centro de día para mayores 
48. MIGUEL LABROSA ROCA, S.L.

Obra nueva

49. Olmos Ortega, M.

Sin actividad

50. TALLERES GRÁFICOS RIPOLL, S.A.

Sin actividad

51. Hernandiz Pallardo, V. y M.

Sin actividad

52. Rafael Rochina Hernández

Sin actividad

53. INDUSTRIAS ANDREU S.L.

Centro de día para mayores

54. ECHEVESTE Y CIA, S.A.

Mantiene la actividad

55. DOLZ, S.A.

Tienda de ropa

56. Vicente Matali Badia

Médico

57. JULIÁN SÁNCHEZ, S.L.

Productos de peluquería

58. BURAGLIA YUSTE, J. y C.

Sin datos

59. ARGON, S.A.

Sin actividad

60. CREACIONES GIMÉNEZ

Obra nueva

61. Bartual Martínez, F.

Gimnasio

62. GRAUMAR

Colchones/ Calzado

63. AREITO DISTRIBUCIONES, S.A.

Centro Base de Apoyo (CBA)

64. PAPELERIA VILA, S.L.

Sin actividad

65. CONFECCIONES REVI, S.L.

Sin actividad

66. MANUFACTURAS CONDEMO

Kiosco

67. TREFILERÍAS RUIZ, S.A.

Obra nueva 
68. MAINSA

Clínica homeopática

69. A. JORDAN, S.L.

Tienda de fotografía

\section{CARACTERÍSTICAS DEL ASENTAMIENTO INDUSTRIAL.}

- Corresponde a la segunda mitad del Siglo XX.

- Distribución espacial dispersa.

- Uso residencial dominante.

- Relativamente homogéneo en cuanto a emplazamiento y tamaño de las industrias.

\section{CARACTERÍSTICAS DE LOS LOCALES.}

- De mediana y pequeña superficie, situados en bajos de viviendas y patios de manzana.

\section{CARACTERÍSTICAS DE LAS ACTIVIDADES.}

- Se censaron inicialmente 69 industrias y en el período de vigencia del Plan General han quedado solamente 5 creándose 60 nuevas industrias.

- Las actividades dominantes son artes gráficas, industria de la madera, corcho y muebles y productos metálicos.

- Por la superficie ocupada y el nivel de empleo, se trata de pequeña industria con poca incidencia en el carácter residencial del barrio.

IMPACTO EN EL MEDIO AMBIENTE.

- Contaminación ambiental: Prácticamente nula.

- Transporte: De escasa importancia, tanto en volumen como en frecuencia.

- Integración en el entorno: Plena, dada la situación de las industrias formando parte de los edificios de viviendas.

EDIFICIOS INDUSTRIALES DE INTERES.

- No existe edificios específicamente industriales dignos de mención. 
TIPOLOGÍA EDIFICACIÓN

\section{TIPOLOGÍA DE EDIFICACIÓN}

Distrito 3. EXTRAMURS

AISLADO ENTRE MEDIANERAS

$0 \%$

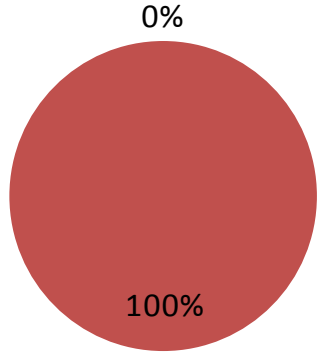




\section{ACTIVIDAD INDUSTRIAL, SUPERFICIE Y EMPLEO}

\begin{tabular}{|c|c|c|c|c|c|}
\hline \multicolumn{6}{|c|}{ DISTRITO 3 - EXTRAMURS (ATIVIDAD INDUSTRIAL Y EMPLEO) } \\
\hline ACTIVIDAD & $\begin{array}{c}\text { № } \\
\text { EMPRESAS }\end{array}$ & $\begin{array}{c}\text { SUP. ACTIVIDAD } \\
\text { IND }\left(\mathrm{m}^{2}\right)\end{array}$ & $\begin{array}{c}\text { \% SUP. } \\
\text { INDUSTRIAL }\end{array}$ & $\begin{array}{c}\text { № } \\
\text { EMPLEADOS }\end{array}$ & $\begin{array}{c}\text { DENSIDAD } \\
\text { EMPLEO } \\
\text { (empleados } / \mathrm{m}^{2} \\
\text { actividad) }\end{array}$ \\
\hline INDUSTRIAS DE PRODUCTOS MINERALES NO METÁLICOS & 4 & 2620 & 6,55 & 79 & 0,0302 \\
\hline INDUSTRIA QUÍMICA & 4 & 4070 & 10,18 & 42 & 0,0103 \\
\hline FABRICACIÓN DE PRODUCTOS METÁLICOS & 14 & 5294 & 13,24 & 184 & 0,0348 \\
\hline CONSTRUCCIÓN DE MAQUINARIA Y EQUIPO MECÁNICO & 2 & 859 & 2,15 & 18 & 0,0210 \\
\hline CONSTRUCCIÓN DE MAQUINARIA Y MATERIAL ELÉCTRICO & 6 & 2690 & 6,73 & 59 & 0,0219 \\
\hline FABRICACIÓN DE INSTRUMENTOS DE PRECISIÓN, ÓPTICA Y SIMILARES & 2 & 790 & 1,98 & 60 & 0,0759 \\
\hline INDUSTRIAS DE PRODUCTOS ALIMENTICIOS, BEBIDAS Y TABACO & 3 & 770 & 1,93 & 42 & 0,0545 \\
\hline INDUSTRIA DEL CUERO & 2 & 435 & 1,09 & 42 & 0,0966 \\
\hline INDUSTRIA DEL CALZADO Y DEL VESTIDO Y OTRAS CONFECCIONES TEXTILES & 6 & 2568 & 6,42 & 102 & 0,0397 \\
\hline INDUSTRIAS DE MADERA, CORCHO Y MUEBLES DE MADERA & 5 & 6414 & 16,05 & 160 & 0,0249 \\
\hline INDUSTRIA DEL PAPEL Y FABRICACIÓN DE ARTÍCULOS DE PAPEL, ARTES GRÁFICAS & 13 & 10087 & 25,23 & 177 & 0,0175 \\
\hline INDUSTIAS DE TRANSFORMACIÓN DEL CAUCHO Y MATERIAS PLÁSTICAS & 1 & 180 & 0,45 & 10 & 0,0556 \\
\hline OTRAS INDUSTRIAS MANUFACTURERAS & 5 & 2910 & 7,28 & 182 & 0,0625 \\
\hline CONSTRUCCIÓN & 2 & 287 & 0,72 & 24 & 0,0836 \\
\hline TOTAL & 69 & 39974 & 100 & 1181 & 0,0295 \\
\hline
\end{tabular}

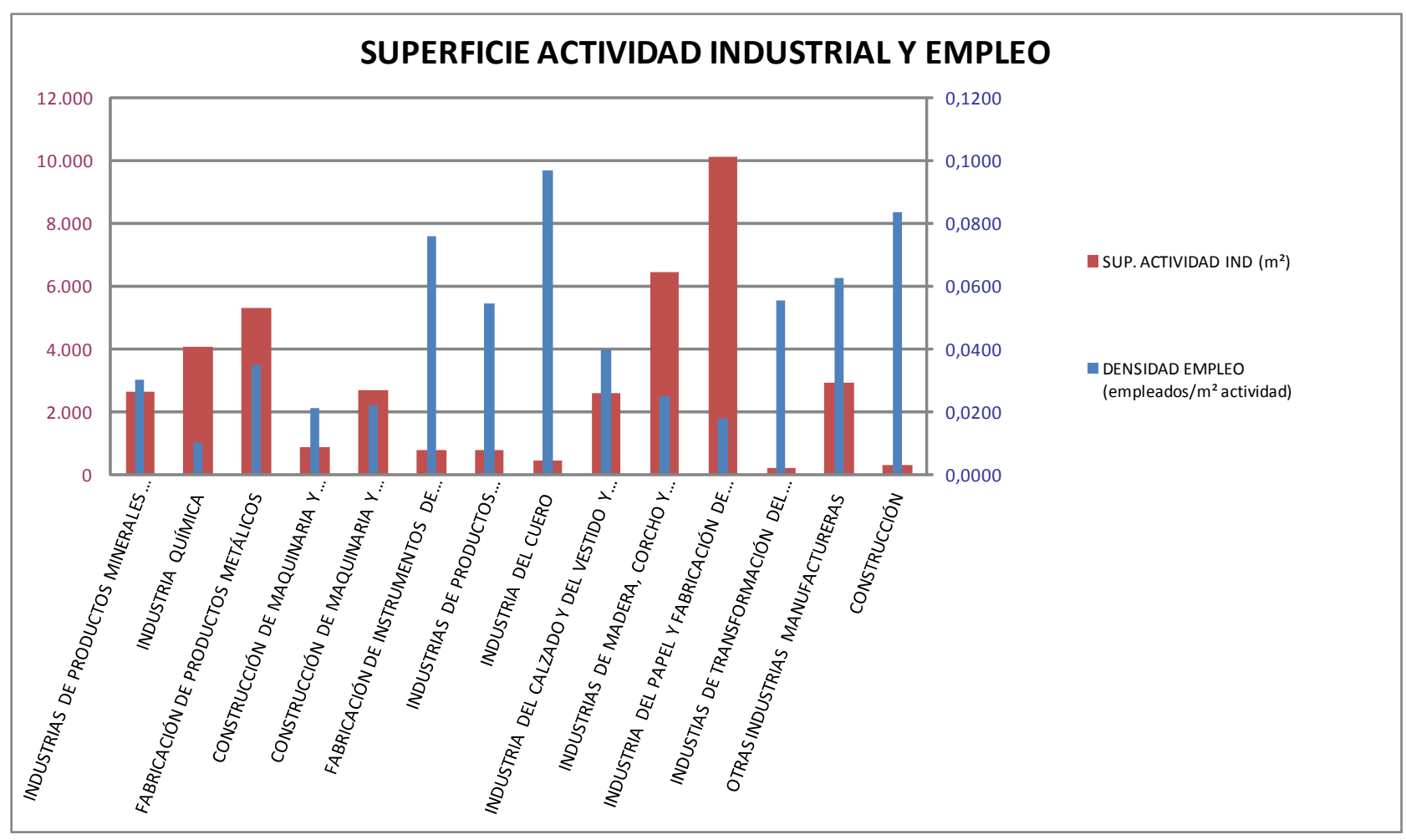




\section{IMPACTO AMBIENTAL}

\begin{tabular}{|c|c|c|c|c|c|}
\hline \multicolumn{6}{|c|}{ DISTRITO 3 - EXTRAMURS (INFORMACIÓN URBANÍSTICA) } \\
\hline ACTIVIDAD & $\begin{array}{c}\text { No } \\
\text { EMPRESAS }\end{array}$ & $\begin{array}{c}\text { ENTRE } \\
\text { MEDIANERAS }\end{array}$ & RUIDOSAS & $\begin{array}{c}\text { EMPRESAS } \\
\text { CON } \\
\text { CHIMENEA }\end{array}$ & $\begin{array}{l}\text { RUIDOSAS Y } \\
\text { CHIMENEA }\end{array}$ \\
\hline INDUSTRIAS DE PRODUCTOS MINERALES NO METÁLICOS & 4 & 4 & 2 & 0 & 0 \\
\hline INDUSTRIA QUÍMICA & 4 & 4 & 0 & 0 & 0 \\
\hline FABRICACIÓN DE PRODUCTOS METÁLICOS & 14 & 14 & 10 & 1 & 0 \\
\hline CONSTRUCCIÓN DE MAQUINARIA Y EQUIPO MECÁNICO & 2 & 2 & 2 & 0 & 0 \\
\hline CONSTRUCCIÓN DE MAQUINARIA Y MATERIAL ELÉCTRICO & 6 & 6 & 0 & 0 & 0 \\
\hline FABRICACIÓN DE INSTRUMENTOS DE PRECISIÓN, ÓPTICA Y SIMILARES & 2 & 2 & 1 & 0 & 0 \\
\hline INDUSTRIAS DE PRODUCTOS ALIMENTICIOS, BEBIDAS Y TABACO & 3 & 3 & 0 & 1 & 0 \\
\hline INDUSTRIA DEL CUERO & 2 & 2 & 0 & 0 & 0 \\
\hline INDUSTRIA DEL CALZADO Y DEL VESTIDO Y OTRAS CONFECCIONES TEXTILES & 6 & 6 & 0 & 0 & 0 \\
\hline INDUSTRIAS DE MADERA, CORCHO Y MUEBLES DE MADERA & 5 & 5 & 2 & 0 & 0 \\
\hline $\begin{array}{l}\text { INDUSTRIA DEL PAPEL Y FABRICACIÓN DE ARTÍCULOS DE PAPEL, ARTES GRÁFICAS } \\
\text { Y EDICIÓN }\end{array}$ & 13 & 13 & 5 & 0 & 0 \\
\hline INDUSTIAS DE TRANSFORMACIÓN DEL CAUCHO Y MATERIAS PLÁSTICAS & 1 & 1 & 0 & 0 & 0 \\
\hline OTRAS INDUSTRIAS MANUFACTURERAS & 5 & 5 & 0 & 0 & 0 \\
\hline CONSTRUCCIÓN & 2 & 2 & 1 & 0 & 0 \\
\hline TOTAL & 69 & 69 & 23 & 2 & 0 \\
\hline
\end{tabular}

\section{IMPACTO EN EL MEDIO URBANO}

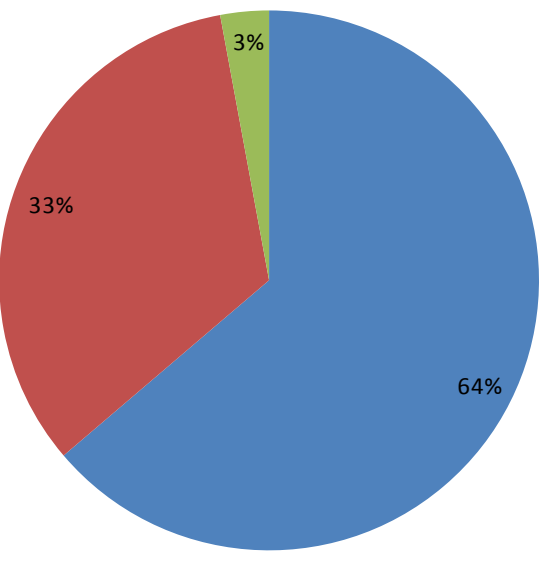




\section{FICHAS TIPO \\ FICHA DATOS DE LA INDUSTRIA}

LOCALIZACION ACTUALIZADA DE ACTIVIDADES INDUSTRIALES EN EL

MEDIO URBANO DE VALENCIA

\begin{tabular}{|c|c|c|c|c|c|c|c|}
\hline \multirow{5}{*}{ 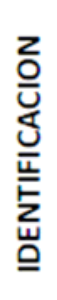 } & \multirow{2}{*}{\multicolumn{2}{|c|}{$\begin{array}{c}\text { NOMBRE } \\
\text { EMPLAZAMIENTO }\end{array}$}} & \multicolumn{5}{|c|}{ CONFECCIONES VALENCIA Y PUCHALT, S.A. } \\
\hline & & & \multicolumn{3}{|c|}{ C/ San Jacinto $n \div 22$} & C.P. & \\
\hline & \multirow{2}{*}{ CNAE } & \multirow{2}{*}{453} & \multirow{2}{*}{ DESCRIPCION } & \multicolumn{4}{|c|}{ INDUSTRIAS DEL CALZADO Y VESTIDO } \\
\hline & & & & \multicolumn{4}{|c|}{ Confección } \\
\hline & DISTRITO & 3 & \multicolumn{5}{|c|}{ EXTRAMURS } \\
\hline & \multicolumn{2}{|c|}{ SUPERFICIES } & $\begin{array}{l}\text { Sup. Parcela: } \\
\qquad 800 \mathrm{~m}^{2}\end{array}$ & $\begin{array}{l}\text { Sup. Ocupada: } \\
800 \mathrm{~m}^{2}\end{array}$ & $\begin{array}{l}\text { Sup. Construida: } \\
800 \mathrm{~m}^{2}\end{array}$ & EMP & $\begin{array}{l}\text { LEADOS: } \\
50\end{array}$ \\
\hline
\end{tabular}
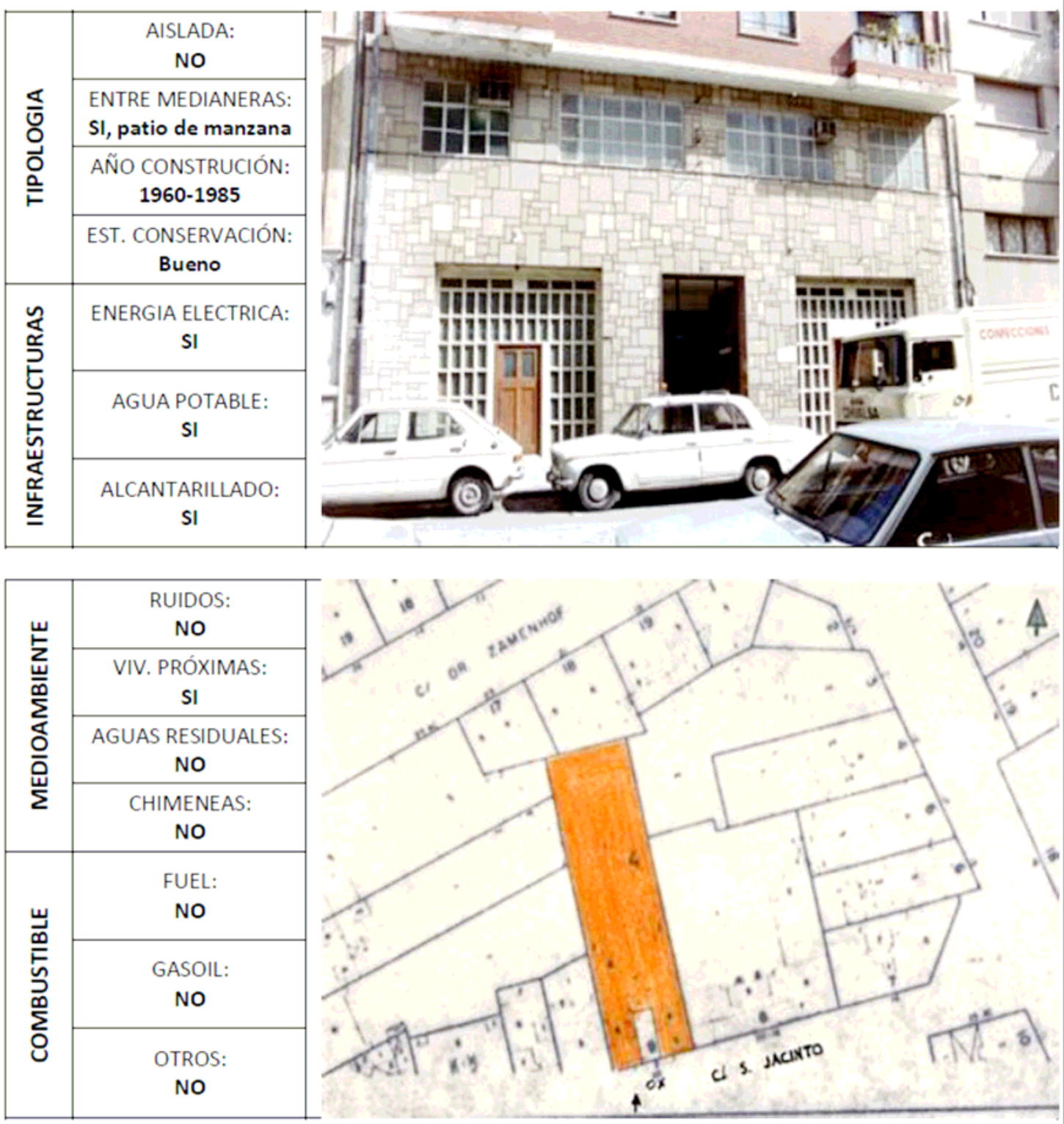

EN LA ACTUALIDAD: SIN ACTIVIDAD 


\section{FICHA DATOS DE LA INDUSTRIA}

LOCALIZACION ACTUALIZADA DE ACTIVIDADES INDUSTRIALES EN EL MEDIO URBANO DE VALENCIA

\begin{tabular}{|c|c|c|c|c|c|c|c|}
\hline \multirow{5}{*}{ 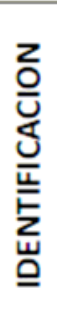 } & \multirow{2}{*}{\multicolumn{2}{|c|}{$\begin{array}{c}\text { NOMBRE } \\
\text { EMPLAZAMIENTO }\end{array}$}} & \multicolumn{5}{|c|}{ BUCH MAXIMO, S.A. } \\
\hline & & & \multicolumn{3}{|c|}{ C/ Quart, $n \cong 114$} & C.P. & \\
\hline & \multirow{2}{*}{ CNAE } & \multirow{2}{*}{467} & \multirow{2}{*}{ DESCRIPCION } & \multicolumn{4}{|c|}{ INDUSTRIA MADERA CORCHO Y MUEBLE } \\
\hline & & & & \multicolumn{4}{|c|}{ Fábrica de brochas } \\
\hline & DISTRITO & 3 & \multicolumn{5}{|c|}{ EXTRAMURS } \\
\hline & \multicolumn{2}{|c|}{ SUPERFICIES } & $\begin{array}{l}\text { Sup. Parcela: } \\
2000 \mathrm{~m}^{2}\end{array}$ & $\begin{array}{c}\text { Sup. Ocupada: } \\
1200 \mathrm{~m}^{2}\end{array}$ & $\begin{array}{l}\text { Sup. Construida: } \\
2000 \mathrm{~m}^{2}\end{array}$ & EMP & $\begin{array}{l}\text { LEADOS: } \\
25\end{array}$ \\
\hline
\end{tabular}

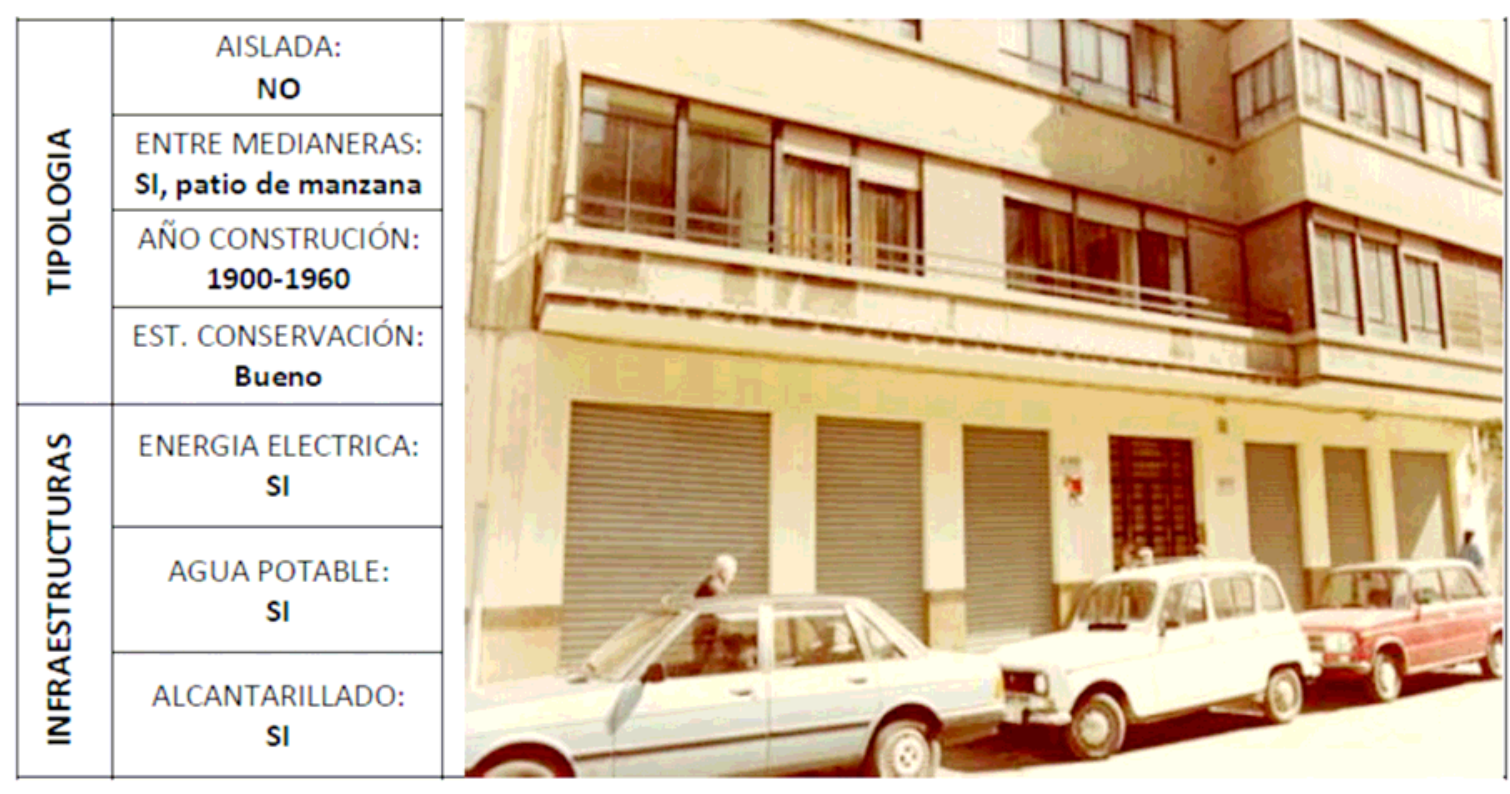

\begin{tabular}{|c|c|}
\hline \multirow{4}{*}{ 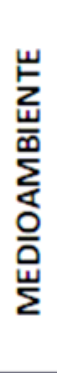 } & $\begin{array}{l}\text { RUIDOS: } \\
\text { NO }\end{array}$ \\
\hline & $\begin{array}{l}\text { VIV. PRÓXIMAS: } \\
\text { SI }\end{array}$ \\
\hline & $\begin{array}{c}\text { AGUAS RESIDUALES: } \\
\text { NO }\end{array}$ \\
\hline & $\begin{array}{l}\text { CHIMENEAS: } \\
\text { NO }\end{array}$ \\
\hline \multirow{3}{*}{ 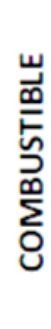 } & $\begin{array}{l}\text { FUEL: } \\
\text { NO }\end{array}$ \\
\hline & $\begin{array}{l}\text { GASOIL: } \\
\text { NO }\end{array}$ \\
\hline & $\begin{array}{l}\text { OTROS: } \\
\text { NO }\end{array}$ \\
\hline
\end{tabular}

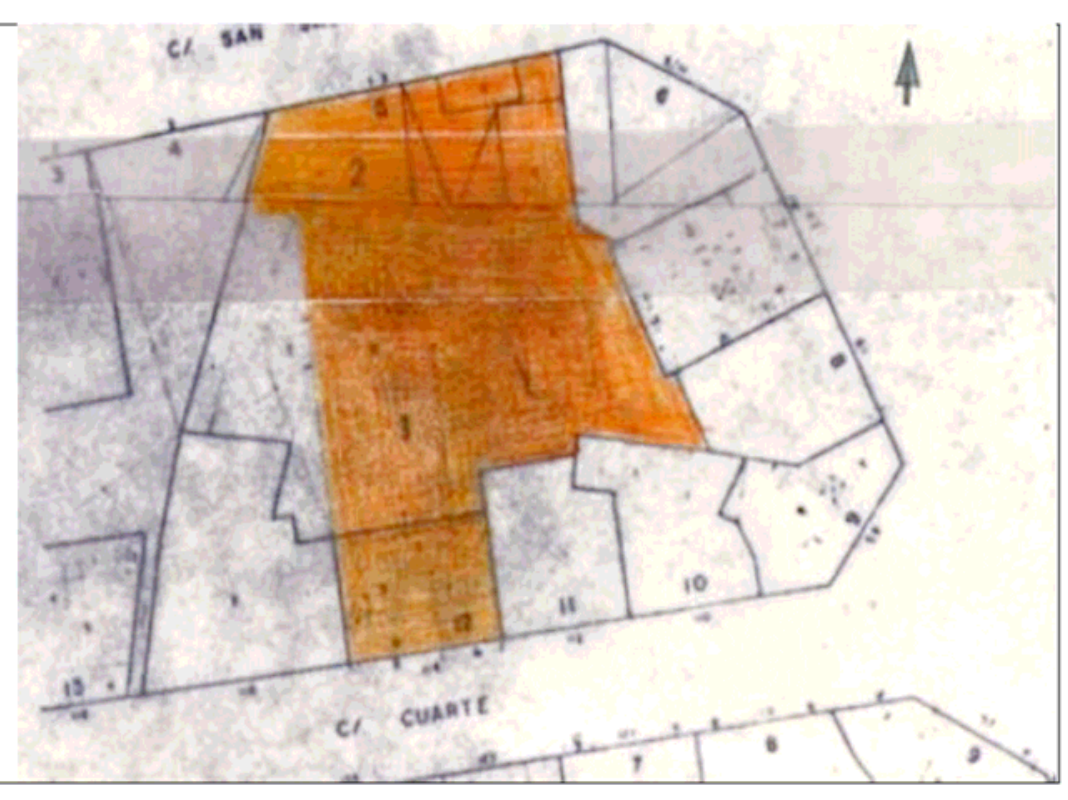

EN LA ACTUALIDAD: CAFETERÍA 


\section{FICHA DATOS DE LA INDUSTRIA}

LOCALIZACION ACTUALIZADA DE ACTIVIDADES INDUSTRIALES EN EL MEDIO URBANO DE VALENCIA

\begin{tabular}{|c|c|c|c|c|c|c|c|}
\hline \multirow{5}{*}{ 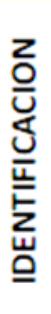 } & \multirow{2}{*}{\multicolumn{2}{|c|}{$\begin{array}{c}\text { NOMBRE } \\
\text { EMPLAZAMIENTO }\end{array}$}} & \multicolumn{5}{|l|}{ ACRO DIESEL } \\
\hline & & & \multicolumn{3}{|c|}{$\mathrm{C} /$ Alberique, $\mathrm{n} \cong 11$} & C.P. & \\
\hline & \multirow{2}{*}{ CNAE } & \multirow{2}{*}{329} & \multirow{2}{*}{ DESCRIPCION } & \multicolumn{4}{|c|}{ CONSTRUCCIÓN DE MAQUINARIA } \\
\hline & & & & \multicolumn{4}{|c|}{ Maquinaria } \\
\hline & DISTRITO & 3 & \multicolumn{5}{|c|}{ EXTRAMURS } \\
\hline & \multicolumn{2}{|c|}{ SUPERFICIES } & $\begin{array}{l}\text { Sup. Parcela: } \\
600 \mathrm{~m}^{2}\end{array}$ & $\begin{array}{c}\text { Sup. Ocupada: } \\
600 \mathrm{~m}^{2}\end{array}$ & $\begin{array}{l}\text { Sup. Construida: } \\
600 \mathrm{~m}^{2}\end{array}$ & EMP & $\begin{array}{l}\text { EADOS: } \\
8\end{array}$ \\
\hline
\end{tabular}
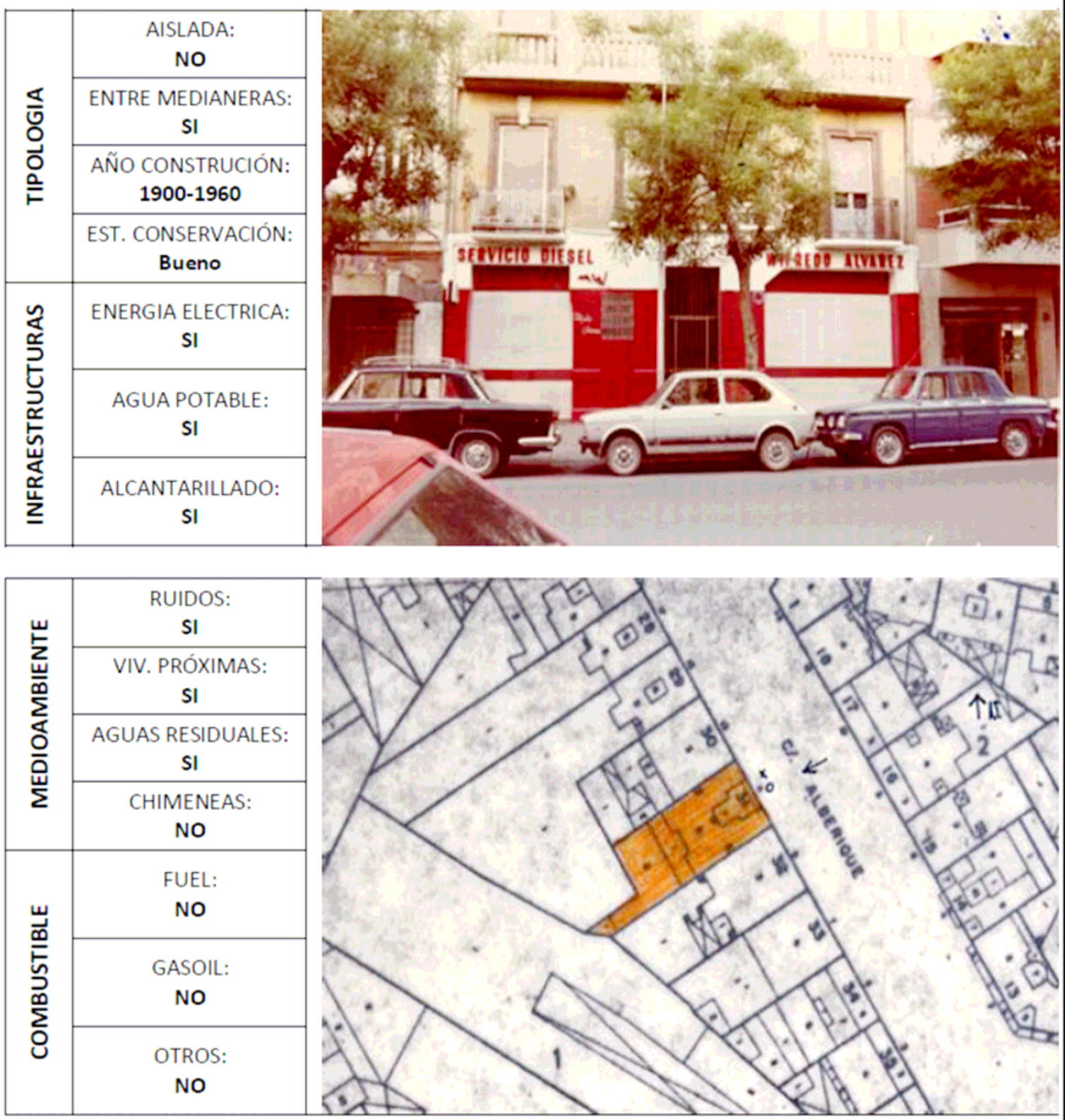

EN LA ACTUALIDAD: SE MANTIENE LA ACTIVIDAD 


\section{FICHA DATOS DE LA INDUSTRIA}

LOCALIZACION ACTUALIZADA DE ACTIVIDADES INDUSTRIALES EN EL MEDIO URBANO DE VALENCIA

\begin{tabular}{|c|c|c|c|c|c|c|}
\hline \multirow{5}{*}{ 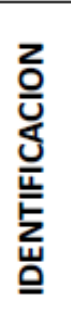 } & \multirow{2}{*}{\multicolumn{2}{|c|}{$\begin{array}{c}\text { NOMBRE } \\
\text { EMPLAZAMIENTO }\end{array}$}} & \multicolumn{4}{|c|}{ TALLERES GRAFICOS RIPOLL, S.A. } \\
\hline & & & \multicolumn{3}{|c|}{ C/ Cuenca, no 57} & C.P. \\
\hline & \multirow{2}{*}{ CNAE } & \multirow{2}{*}{474} & \multirow{2}{*}{ DESCRIPCION } & \multicolumn{3}{|c|}{ INDUSTRIAS DEL PAPEL, ARTES GRAFICAS, ETC. } \\
\hline & & & & \multicolumn{3}{|c|}{ Artes graficas } \\
\hline & DISTRITO & 3 & \multicolumn{4}{|c|}{ EXTRAMURS } \\
\hline \multicolumn{3}{|c|}{ SUPERFICIES } & $\begin{array}{l}\text { Sup. Parcela: } \\
637 \mathrm{~m}^{2}\end{array}$ & $\begin{array}{c}\text { Sup. Ocupada: } \\
637 \mathrm{~m}^{2}\end{array}$ & $\begin{array}{l}\text { Sup. Construida: } \\
637 \mathrm{~m}^{2}\end{array}$ & $\begin{array}{c}\text { EMPLEADOS: } \\
18\end{array}$ \\
\hline
\end{tabular}
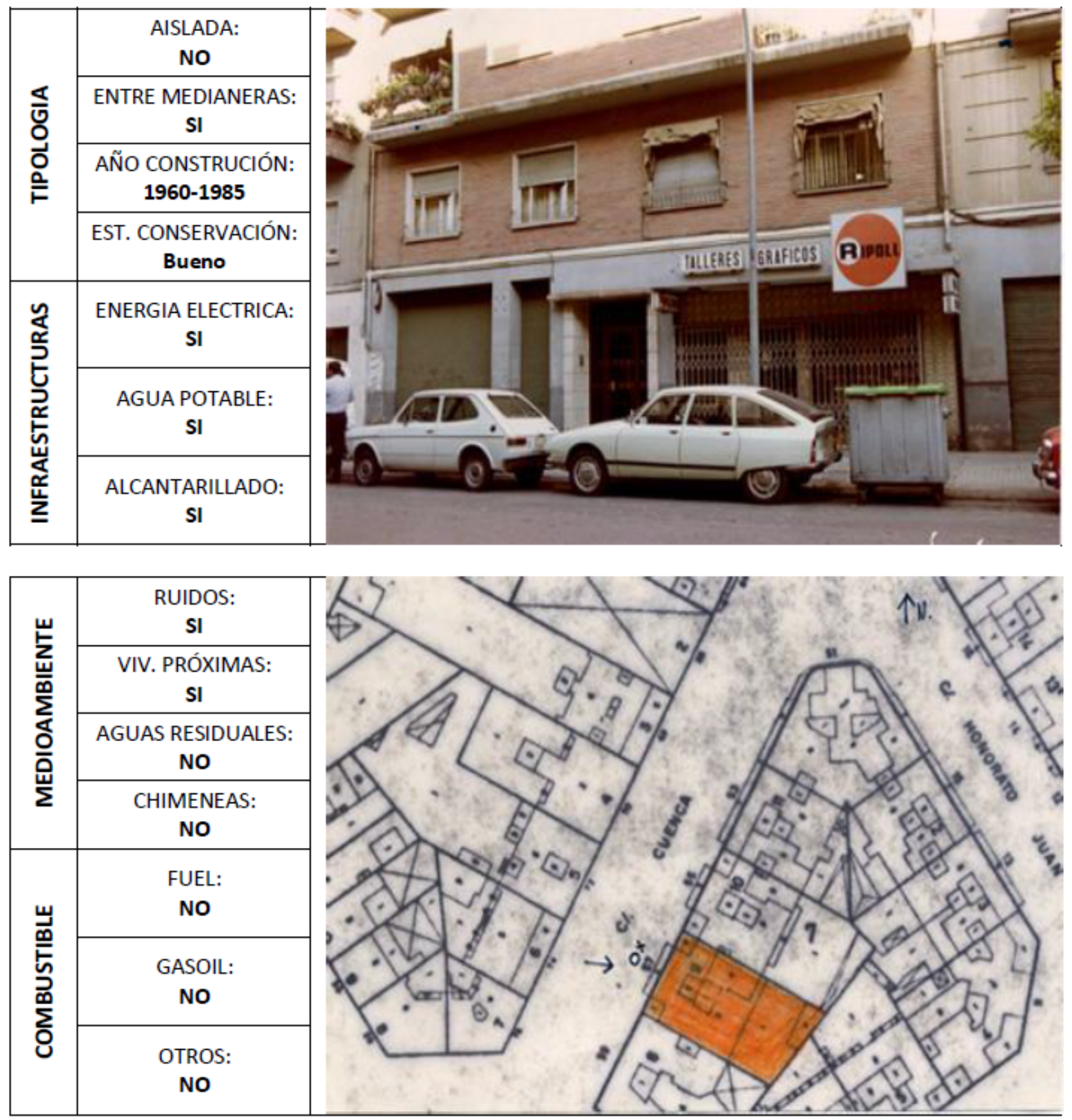


\section{EVOLUCIÓN}

\section{PLANO UBICACIÓN INDUSTRIAS}

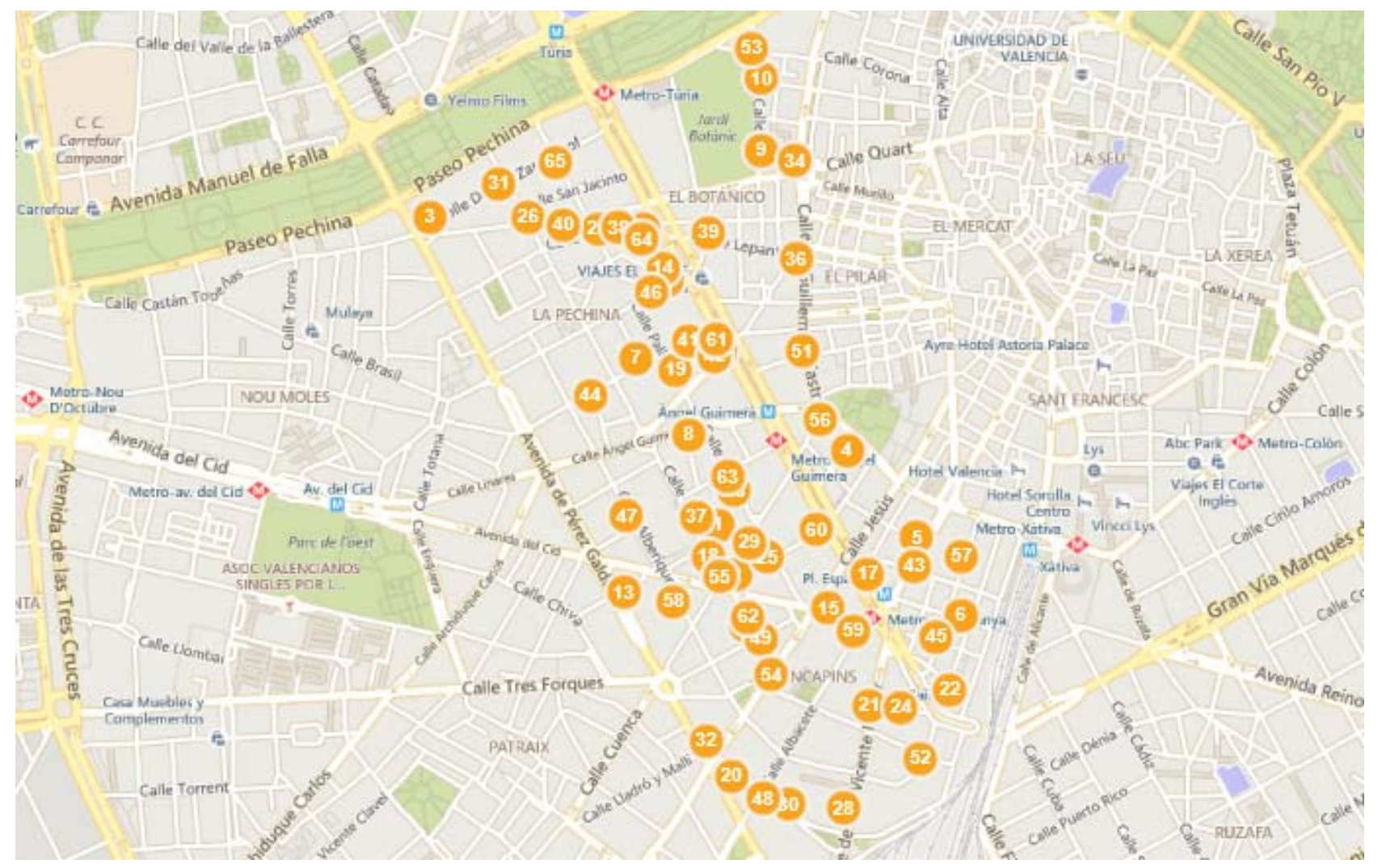

LISTADO DE INDUSTRIAS Y ACTIVIDAD.-

1. ACCESORIOS Y COMPLEMENTOS IDEA MUEBLES, S.L.

Fabricación de otros muebles

2. LA COMPEÑERIA, S.L.

Fabricación de artículos de joyería y artículos similares

3. ORFET, S.L.

Fabricación de artículos de joyería y artículos similares

4. Vicente Pérez Vela

Fabricación de artículos de joyería y artículos similares

5. $M^{\mathrm{a}}$ Dolores Zayas Martínez

Fabricación de artículos de joyería y artículos similares

6. NUESTRO TALISMAN, S.L.

Fabricación de artículos de joyería y artículos similares

7. SABEH MUSHALNAT MORAD

Fabricación de artículos confeccionados con textiles, excepto prendas de vestir 
8. TECNICA DENTAL, C.B.

Fabricación instrumentos y suministros médicos y odontológicos

9. Begoña Minguez Rubio

Fabricación instrumentos y suministros médicos y odontológicos

10. L. PROTESIS DENTALES MOLDENT, S.L.

Fabricación instrumentos y suministros médicos y odontológicos

11. TECNODENT, C.B.

Fabricación instrumentos y suministros médicos y odontológicos

12. AZA, C.B.

Fabricación instrumentos y suministros médicos y odontológicos

13. Salvador Olmos Martínez

Fabricación instrumentos y suministros médicos y odontológicos

14. Rosendo Cuenca Carrasquet

Fabricación instrumentos y suministros médicos y odontológicos

15. OPTICA II 2012, S.L.

Fabricación de instrumentos de óptica y equipo fotográfico

16. PROTESIS DENTAL C. CHUST, S.L.

Fabricación instrumentos y suministros médicos y odontológicos

17. PIETOUCH, S.L.

Fabricación de calzado

18. BTA. Toribio Herrero Juan

Fabricación de otros productos de caucho

19. Alvaro Vila Selles

Fabricación de papel y cartón ondulados; fabricación de envases y embalajes de papel y cartón

20. Arturo Cases Almonacil

Fabricación de otros productos metálicos n.c.o.p.

21. BLUEGENE RESEARCU, S.L.

Fabricación de productos básicos de hierro, acero y ferroaleaciones

22. Ceferino Arenas Sánchez

Mantenimiento y reparación de vehículos a motor

23. José Bustamante Villalonga

Mantenimiento y reparación de vehículos a motor

24. Vicente Pérez Sánchez

Mantenimiento y reparación de vehículos a motor

25. Juan Vicente Gil Galán

Mantenimiento y reparación de vehículos a motor

26. Rafael José Moya García

Mantenimiento y reparación de vehículos a motor

27. Antonio Ceballos Ballesteros

Mantenimiento y reparación de vehículos a motor 
28. Máximo Herraiz Liñares

Mantenimiento y reparación de vehículos a motor

29. Olegov Kirilov Kistiyan

Mantenimiento y reparación de vehículos a motor

30. Fernando Eugenio Rodríguez Garrido

Mantenimiento y reparación de vehículos a motor

31. TALLERES AUTOFRANC, C.B.

Mantenimiento y reparación de vehículos a motor

32. Faustino Leoncio Carcelen Canella

Mantenimiento y reparación de vehículos a motor

33. Guillermo Patricio Rodríguez Matera

Mantenimiento y reparación de vehículos a motor

34. Fernando Bas Grau

Aserradero y cepillado de madera

35. WOOD UK MADERAS UKBANIA, S.L.

Aserrado y cepillado de madera

36. Felipe Ferrer Salom

Fabricación de otras estructuras de madera y piezas de carpintería y ebanistería para la construcción

37. J.M. PINAZO Y J. SAMPER, C.B.

Fabricación de otras estructuras de madera y piezas de carpintería y ebanistería para la construcción

38. Juan Antonio Garrido Tirado

Fabricación de otros muebles

39. TALLER DE TAPICERIA GRIMALT, C.B.

Fabricación de otros muebles

40. Vicente Fernando Bustamante

Fabricación de otros muebles

41. Eduardo Bautista Baza

CNAE año 1.985 (474)

42. ENMARCACIÓN EL TALLER DE ALFONSO, S.L.

Fabricación de otros productos de madera, artículos de corcho, cestería y espartería

43. Manuel Muñoz Sanz

Fabricación de otros productos de madera, artículos de corcho, cestería y espartería

44. Regina Maruenda Alba

Fabricación de otros productos de madera, artículos de corcho, cestería y espartería

45. Francisco Cerezo Lluch

Fabricación de otros productos de madera, artículos de corcho, cestería y espartería

46. EUGENIA PUERTES, C.B.

Confección de otras prendas de vestir exteriores 
47. TARAS, C.B.

Confección de otras prendas de vestir y accesorios

48. $M^{\circ}$ José García Rapa

Confección de otras prendas de vestir exteriores

49. $M^{\mathrm{a}}$ Carmen Millán Puell

Confección de otras prendas de vestir exteriores

50. Rafaela Moles Reyes

Confección de otras prendas de vestir exteriores

51. Evelyna Nersisyan

Confección de otras prendas de vestir exteriores

52. HORNO MORENO PONCE, S.L.

Fabricación de pan y de productos frescos de panadería y pastelería

53. José Alberto Llueca Graneu

Fabricación de pan y de productos frescos de panadería y pastelería

54. PASTELERÍA DULCE DE LECHE, S.L.

Fabricación de pan y de productos frescos de panadería y pastelería

55. $M^{\mathrm{a}}$ Carmen Crespo Monleón

Fabricación de pan y de productos frescos de panadería y pastelería

56. ORTOPEDIA SOTOS, S.L.

CNAE año 1.985 (329)

57. V. ALEPUZ, S.L.

CNA año 1.985 (474)

58. ACRO DIESEL

CNAE año 1.985 (329)

59. ECHEVESTE Y CIA., S.A.

CNAE año 1.985 (246)

60. STARS DISEÑO Y PRODUCCIÓN GRÁFICA, S.L.

Otras actividades de impresión y artes gráficas

61. Ybarra Mora, María

Otras actividades de impresión y artes gráficas

62. Loba Yuste, Pedro

Otras actividades de impresión y artes gráficas

63. GATO GRÁFICOS ESTUDIO, S.L.

Otras actividades de impresión y artes gráficas

64. GHITA NIRGIL PETRISOR

Otras actividades de impresión y artes gráficas

65. PA I DOLÇOS HOGO L'ARTESA

fabricación de pan y otros productos frescos de panadería 


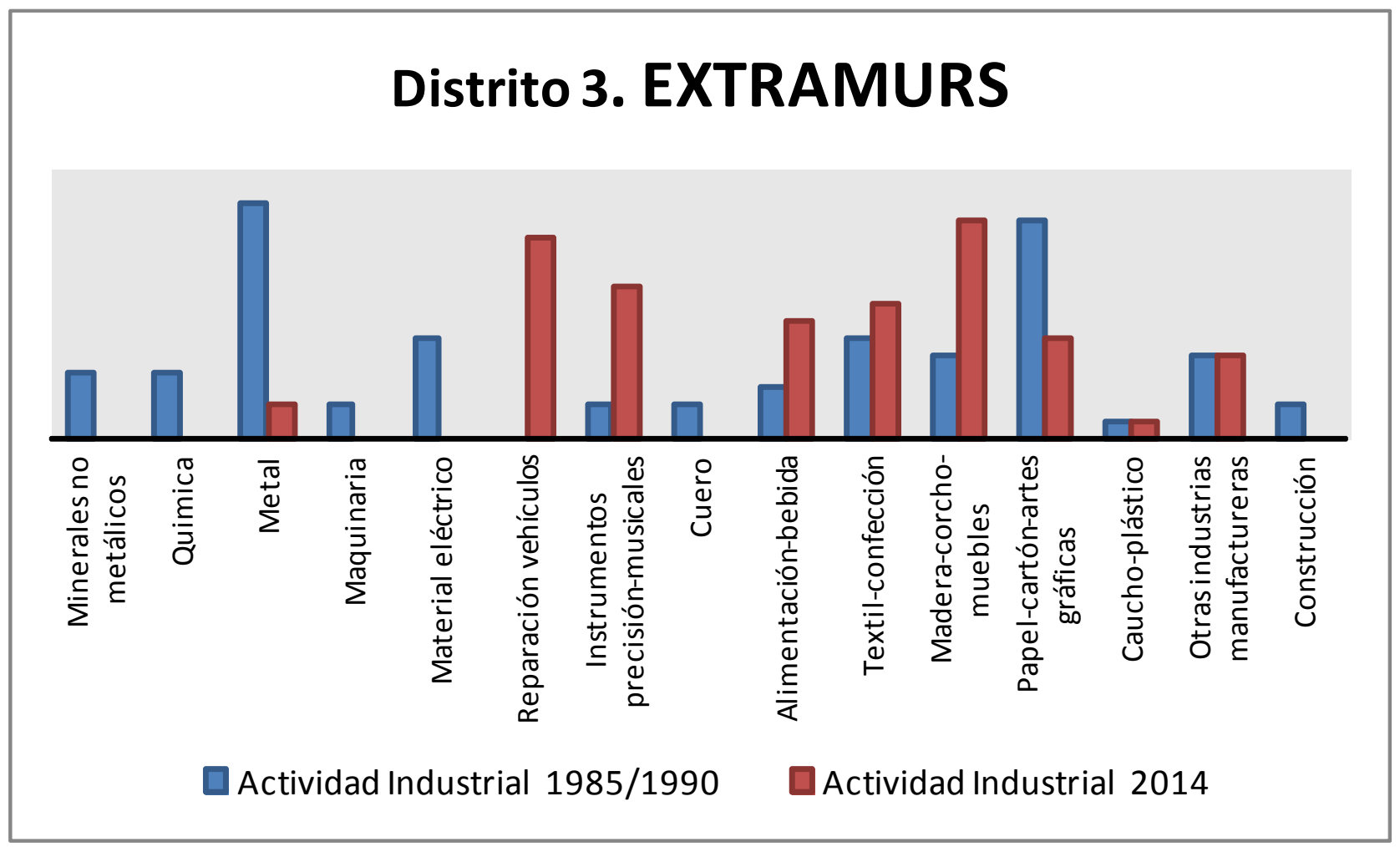

EVOLUCIÓN DEL IMPACTO AMBIENTAL

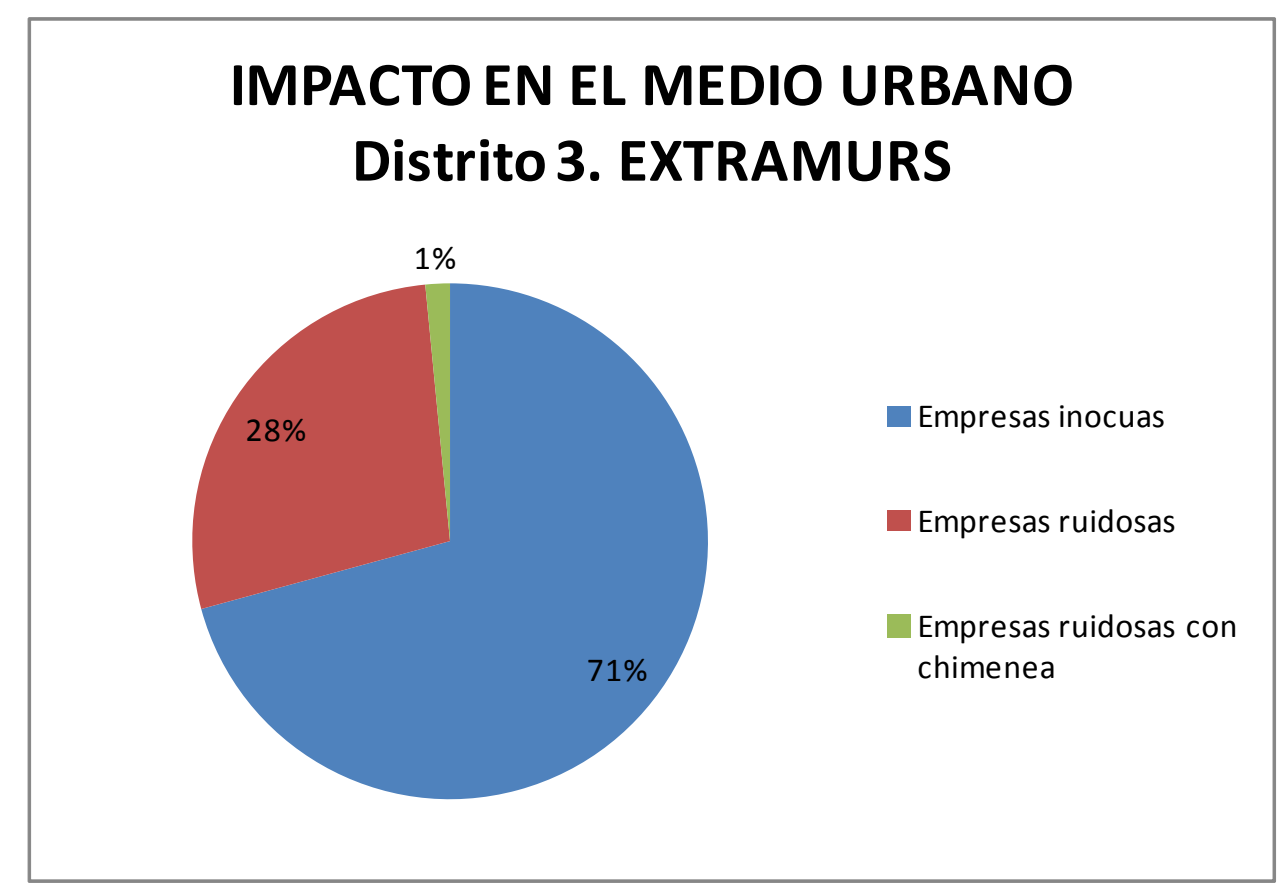




\section{FICHAS TIPO}

\section{FICHA DATOS DE LA INDUSTRIA}

LOCALIZACION ACTUALIZADA DE ACTIVIDADES INDUSTRIALES EN EL

MEDIO URBANO DE VALENCIA

\begin{tabular}{|c|c|c|c|c|c|c|c|}
\hline \multirow{5}{*}{ 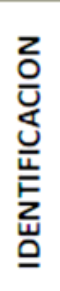 } & \multirow{2}{*}{\multicolumn{2}{|c|}{$\begin{array}{c}\text { NOMBRE } \\
\text { EMPLAZAMIENTO }\end{array}$}} & \multicolumn{5}{|c|}{ ENMARCACIÓN EL TALLER DE ALFONSO, S.L. } \\
\hline & & & \multicolumn{3}{|c|}{ C/ ERUDITO ORELLANA, 4} & C.P. & 46008 \\
\hline & \multirow[b]{2}{*}{ CNAE } & \multirow[b]{2}{*}{1629} & \multirow[b]{2}{*}{ DESCRIPCION } & \multicolumn{4}{|c|}{ MADERA-CORCHO-MUEBLES } \\
\hline & & & & \multicolumn{4}{|c|}{$\begin{array}{l}\text { Fabricación de otros productos de madera, } \\
\text { artículos de corcho cestería y espartería }\end{array}$} \\
\hline & DISTRITO & 3 & \multicolumn{5}{|c|}{ EXTRAMURS } \\
\hline \multicolumn{3}{|c|}{ MEDIOAMBIENTE } & RUIDOSAS & NO & CHIMENEAS & & $\mathrm{O}$ \\
\hline
\end{tabular}
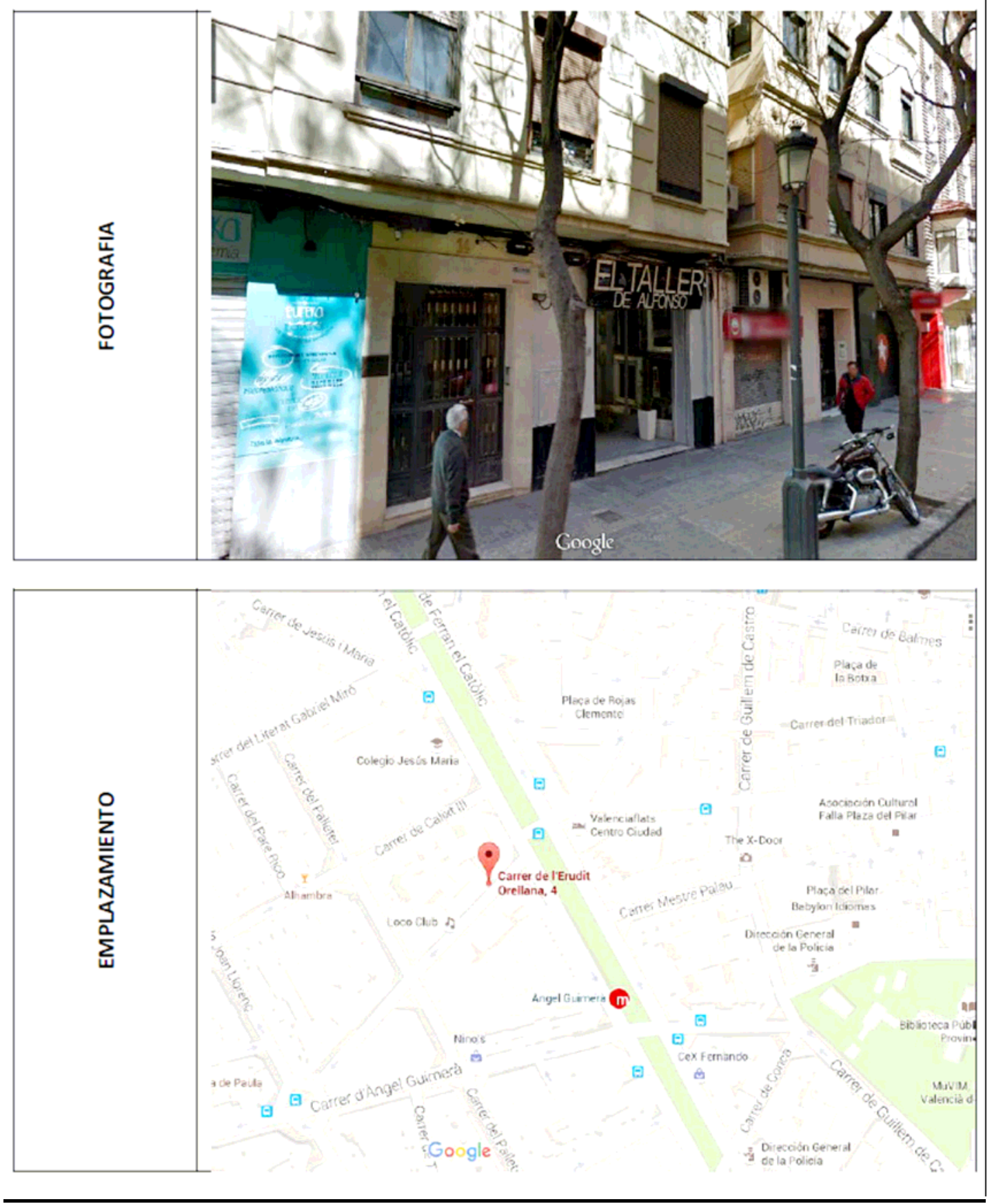


\section{FICHA DATOS DE LA INDUSTRIA}

LOCALIZACION ACTUALIZADA DE ACTIVIDADES INDUSTRIALES EN EL MEDIO URBANO DE VALENCIA

\begin{tabular}{|c|c|c|c|c|c|c|c|}
\hline \multirow{5}{*}{ 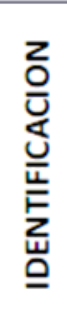 } & \multirow{2}{*}{\multicolumn{2}{|c|}{$\begin{array}{c}\text { NOMBRE } \\
\text { EMPLAZAMIENTO }\end{array}$}} & \multicolumn{5}{|c|}{ HORNO MORENO PONCE, S.L. } \\
\hline & & & \multicolumn{3}{|c|}{ C/ Dr. GIL Y MORTE, 10} & C.P. & 46007 \\
\hline & \multirow[b]{2}{*}{ CNAE } & \multirow[b]{2}{*}{1071} & \multirow[b]{2}{*}{ DESCRIPCION } & \multicolumn{4}{|c|}{ MENTACIÓN-BEBIDA } \\
\hline & & & & \multicolumn{4}{|c|}{$\begin{array}{l}\text { Fabricación de pan y de productos frescos de } \\
\text { panadería y pastelería }\end{array}$} \\
\hline & DISTRITO & 3 & \multicolumn{5}{|c|}{ EXTRAMURS } \\
\hline \multicolumn{3}{|c|}{ MEDIOAMBIENTE } & RUIDOSAS & NO & CHIMENEAS & & 10 \\
\hline
\end{tabular}
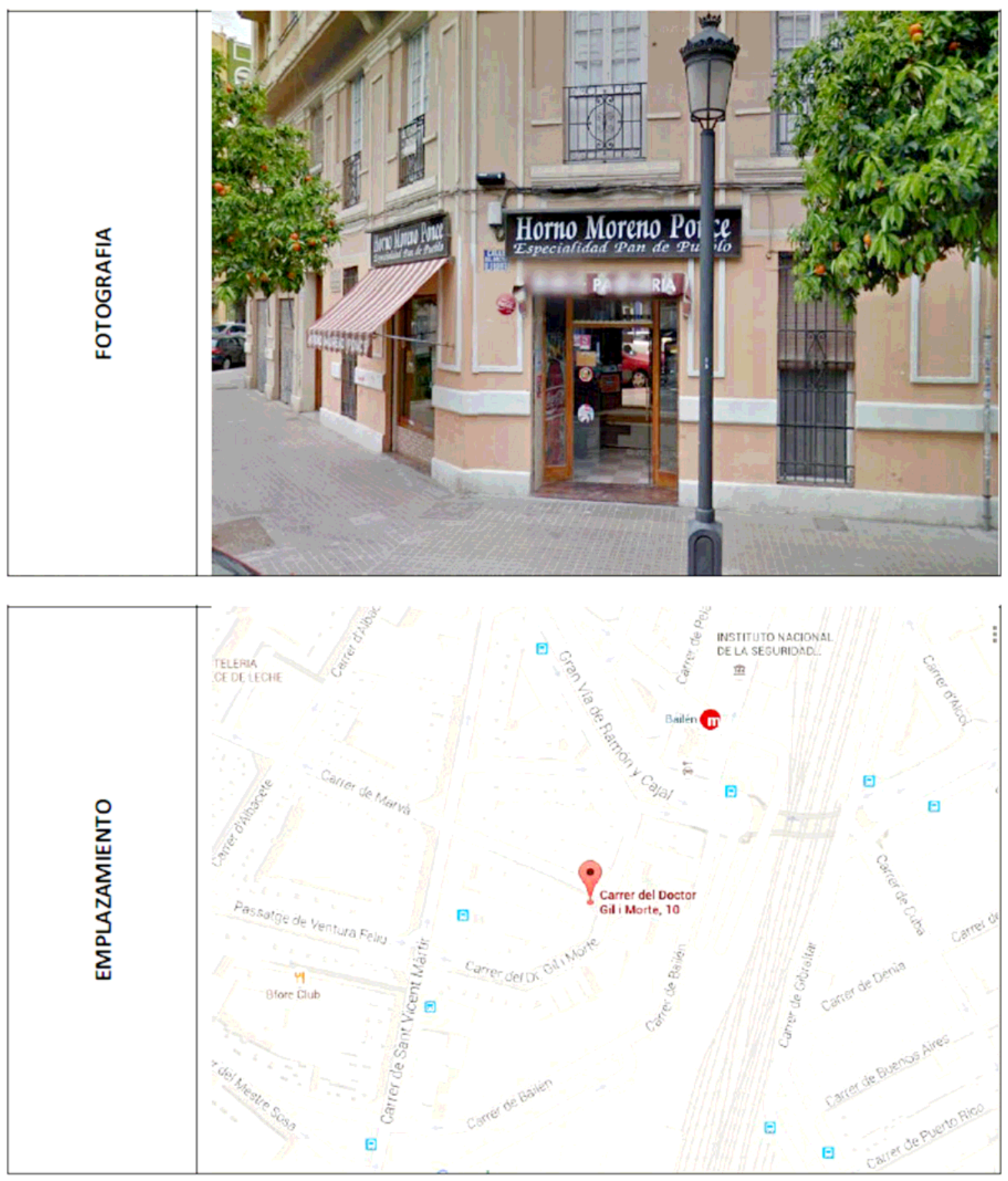


\section{FICHA DATOS DE LA INDUSTRIA}

LOCALIZACION ACTUALIZADA DE ACTIVIDADES INDUSTRIALES EN EL MEDIO URBANO DE VALENCIA

\begin{tabular}{|c|c|c|c|c|c|c|c|}
\hline \multirow{5}{*}{ 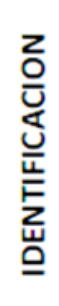 } & \multirow{2}{*}{\multicolumn{2}{|c|}{$\begin{array}{c}\text { NOMBRE } \\
\text { EMPLAZAMIENTO }\end{array}$}} & \multicolumn{5}{|c|}{ SABEH MUSHALNAT MORAD } \\
\hline & & & \multicolumn{3}{|c|}{ C/ PADRE RICO, 14} & C.P. & 46008 \\
\hline & \multirow{2}{*}{ CNAE } & \multirow{2}{*}{1392} & \multirow{2}{*}{ DESCRIPCION } & \multicolumn{4}{|c|}{ TEXTIL-CALZADO-CONFECCIÓN } \\
\hline & & & & \multicolumn{4}{|c|}{$\begin{array}{l}\text { Fabricación de artículos confeccionados con } \\
\text { textiles, excepto prendas de vestir }\end{array}$} \\
\hline & DISTRITO & 3 & \multicolumn{5}{|c|}{ EXTRAMURS } \\
\hline \multicolumn{3}{|c|}{ MEDIOAMBIENTE } & RUIDOSAS & NO & CHIMENEAS & & $\mathrm{O}$ \\
\hline
\end{tabular}

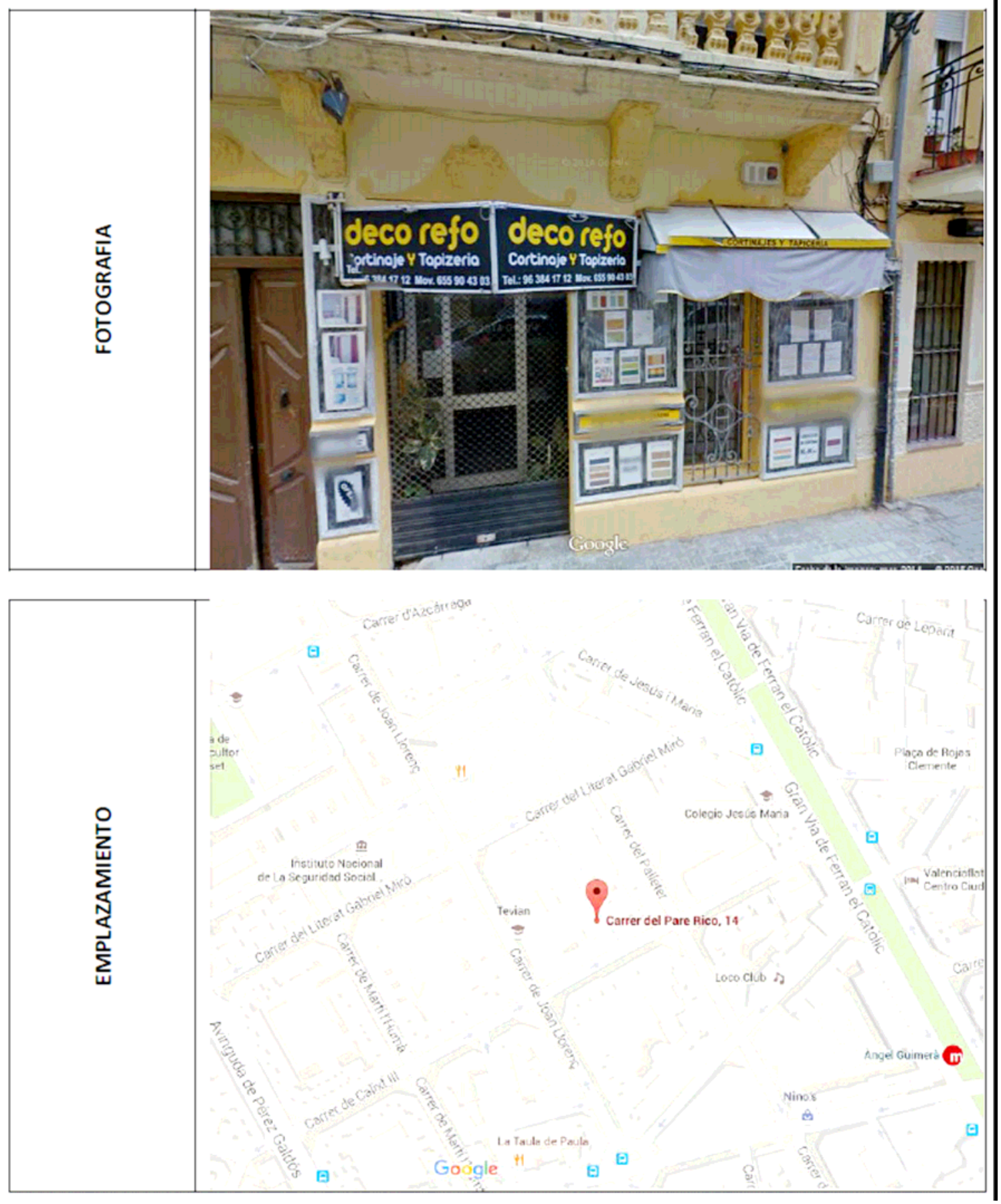




\section{FICHA DATOS DE LA INDUSTRIA}

LOCALIZACION ACTUALIZADA DE ACTIVIDADES INDUSTRIALES EN EL MEDIO URBANO DE VALENCIA

\begin{tabular}{|c|c|c|c|c|c|c|c|}
\hline \multirow{5}{*}{ 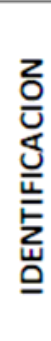 } & \multirow{2}{*}{\multicolumn{2}{|c|}{$\begin{array}{c}\text { NOMBRE } \\
\text { EMPLAZAMIENTO }\end{array}$}} & \multicolumn{5}{|c|}{ ALVARO VILA SELLES } \\
\hline & & & \multicolumn{3}{|c|}{ C/ PALLETER, 40} & C.P. & 46008 \\
\hline & \multirow[b]{2}{*}{ CNAE } & \multirow[b]{2}{*}{1721} & \multirow[b]{2}{*}{ DESCRIPCION } & \multicolumn{4}{|c|}{ PAPEL-CARTON-ARTES GRAFICAS } \\
\hline & & & & \multicolumn{4}{|c|}{$\begin{array}{c}\text { Fabricación de papel y cartón ondulados; } \\
\text { fabricación de envases y embalajes de papel y } \\
\text { cartón }\end{array}$} \\
\hline & DISTRITO & 3 & \multicolumn{5}{|c|}{ EXTRAMURS } \\
\hline \multicolumn{3}{|c|}{ MEDIOAMBIENTE } & RUIDOSAS & NO & CHIMENEAS & & $\mathrm{O}$ \\
\hline
\end{tabular}
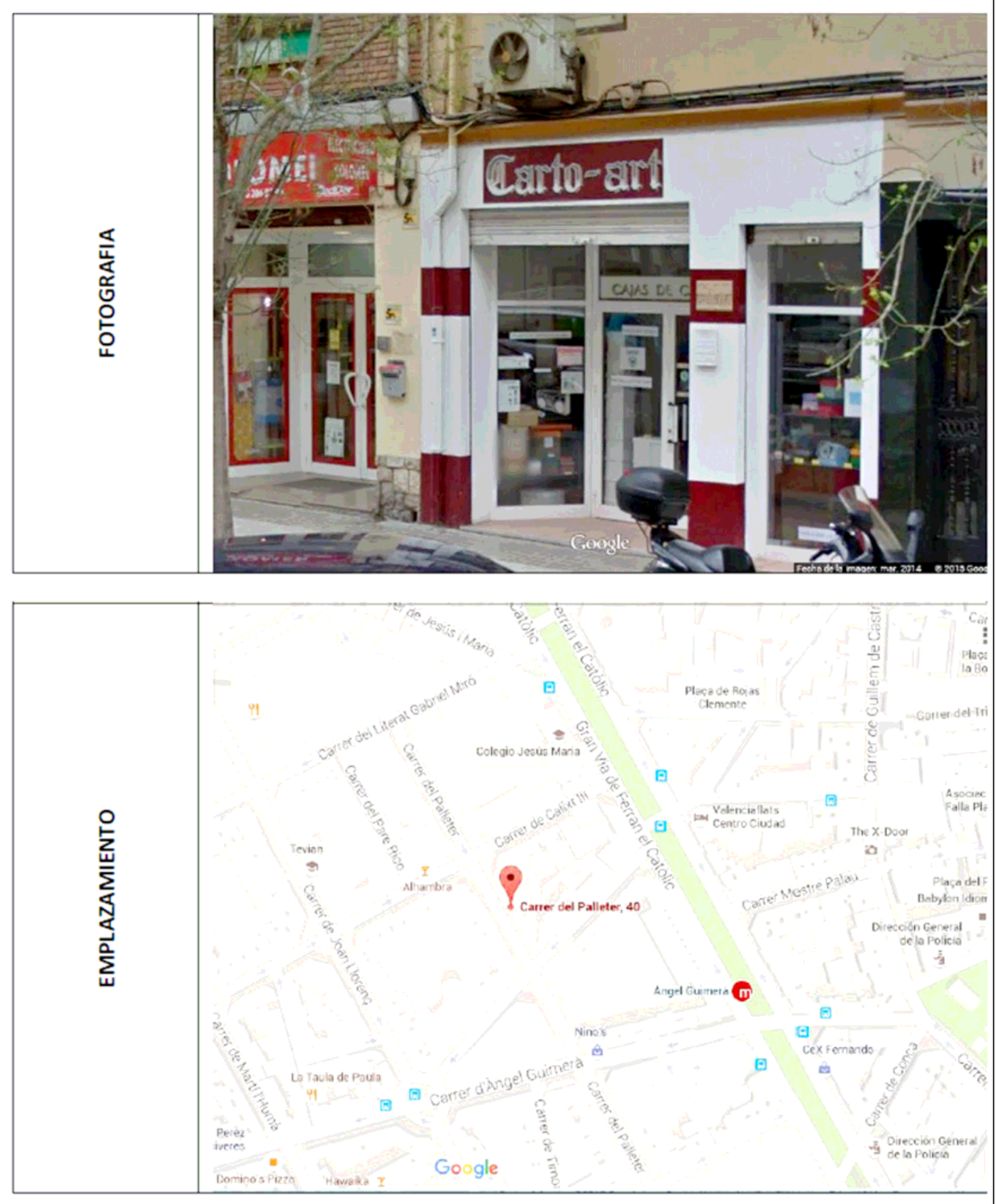
DISTRITO 4.- CAMPANAR

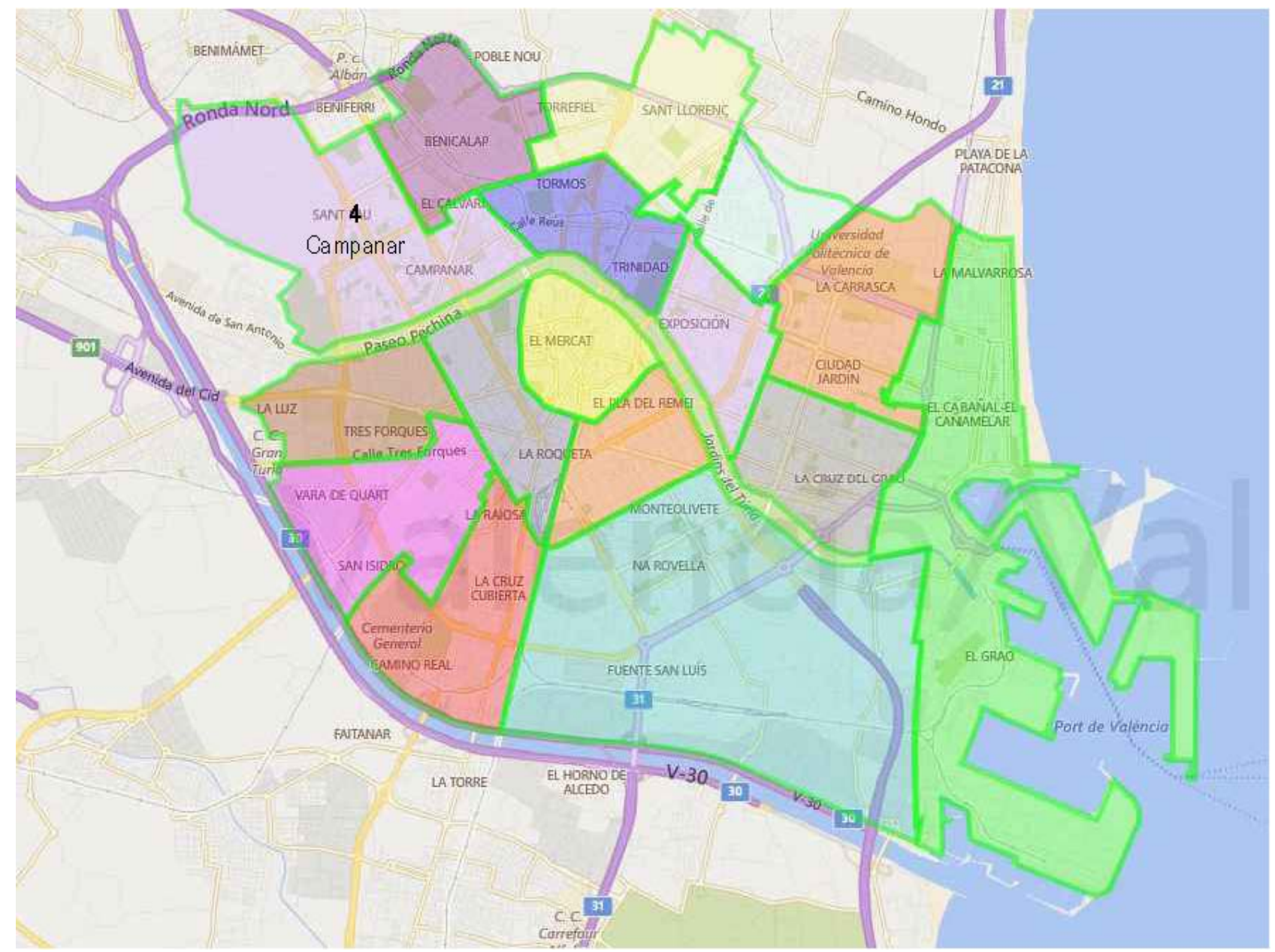

\section{LÍMITES GEOGRÁFICOS.}

- Camino nuevo de Paterna, Avda. de Burjassot, Carretera de Ademuz y Término municipal de Mislata 


\section{PLANO UBICACIÓN INDUSTRIAS}

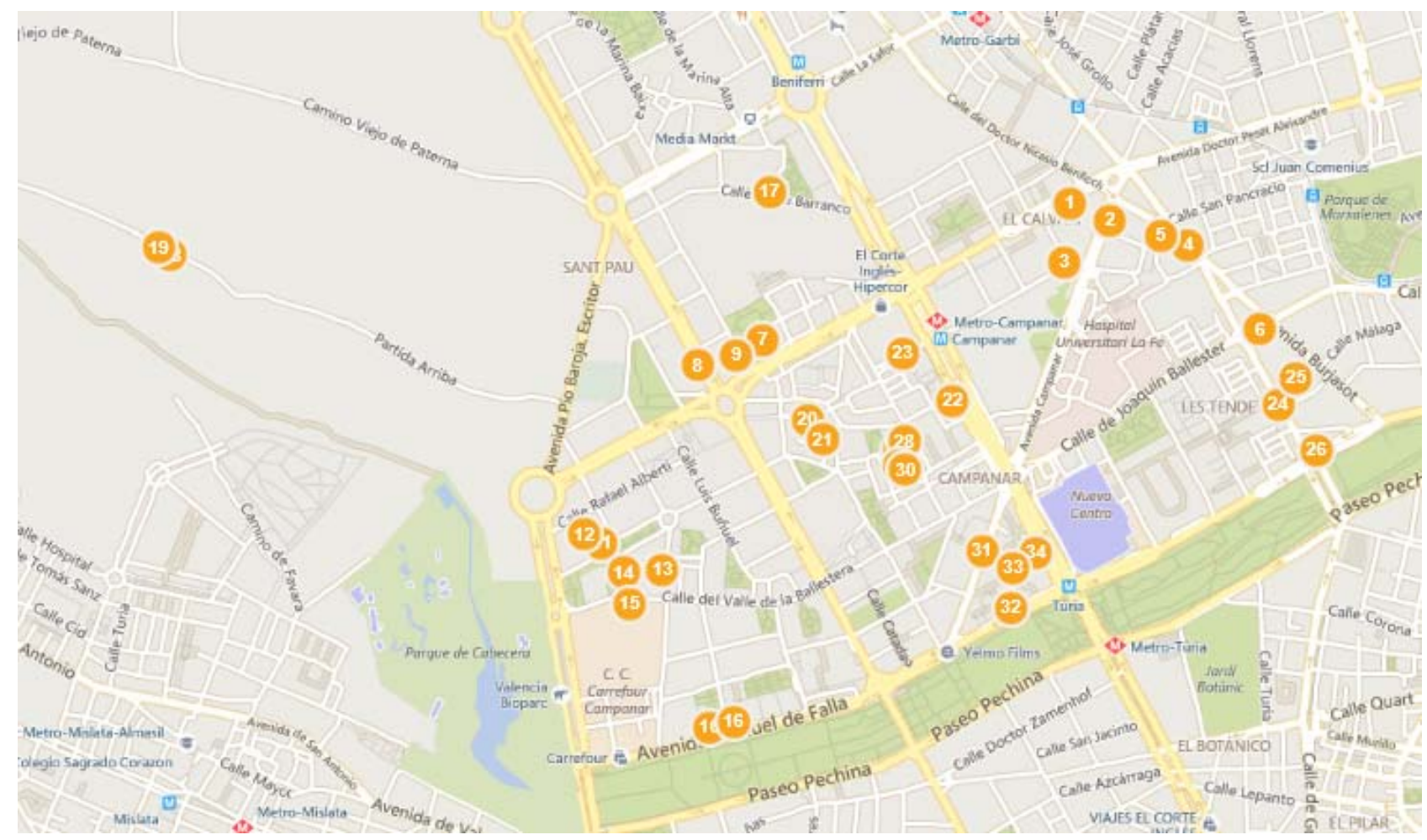

LISTADO DE INDUSTRIAS Y ESTADO ACTUAL .-

1. N.K. ELECTRONICA

Tienda de ropa

2. Vicenta Solaz Zaragoza

Horno-cafetería

3. Vicente Viguer

Otra actividad

4. Gómez Alondiga, J. TALLERES PASCUAL MATEU

Taller

5. Antonio Oficial Montaner

Mantiene la actividad

6. CONFECCIONES JOMABE

Vídeo club / Tintorería

7. HORNO CASANI

Mantiene la actividad 
8. FRIKAL REFRIGERACION

Sin actividad

9. Vicente Llopis, F.

Nueva ordenación - Edificio de viviendas

10. Juan Alberola Calabuig "DAS AUDIO"

Sin actividad

11. Bordes Valls, $\mathbf{R}$.

Nueva ordenación - Calle y zona verde

12. NIS-PIEL, S.L.

Nueva ordenación - Calle y zona verde

13. RAN-MAR, S.L.

Servicio de prevención MAPFRE

14. Juan Manuel Gil Álvarez

Nueva ordenación

15. Sapena Gimeno, Pablo

Almacén Bluespace

16. ASENSI FERRER, S.L.

Sin actividad

17. TALLERES BARUSANZ

Sin actividad

18. PARQUET FLORES DE LA LUNA, S.L.

Sin actividad

19. José Targa Rodríguez

Sin actividad

20. Rafael Ciurana

Mantiene la actividad

21. José Martínez Ferrer

Solar

22. CLEMENTE MARQUES, S.L.

Tienda de juguetes

23. RICARDO SANCHIS Y CIA., S.R.C.

Cafetería

24. Aznar Climent, Eduardo

Horno.

25. AGI-IMSA, S.L.

Supermercado

26. TENERIA INDUSTRIAL LEVANTINA, S.A.

Obra nueva

27. López García, M.

Sin actividad 
28. Carmelo Soler Sánchez

Frutería

29. MORATO Y SILVESTRE

Sin actividad

30. Manaut Galdon, E.

Sin actividad

31. COMERCIAL DIAGA, S.A.

Reparación lunas automóvil

32. SOLYMER, S.L.

Servicio de prevención

33. JULCO

Sin actividad

34. Soler Villanueva, J.

Sin actividad

CARACTERÍSTICAS DEL ASENTAMIENTO INDUSTRIAL.-

- Escasa relevancia industrial.

- Uso residencial dominante.

- Heterogéneo en cuanto a emplazamiento y características de las industrias.

- Disperso.

CARACTERÍSTICAS DE LOS LOCALES.-

- Se distinguen dos tipos:

- De pequeño tamaño situados en los bajos de edificios de viviendas de reciente construcción.

- De mediana superficie en edificación aislada situados en áreas de huerta poco consolidadas por la edificación.

\section{CARACTERÍSTICAS DE LAS ACTIVIDADES.-}

- Se censaron inicialmente 34 industrias y en el período de vigencia del Plan General han quedado solamente 4 creándose 17 nuevas industrias.

- Las actividades dominantes son curtidos y marroquinería, productos metálicos y muebles.

- La industria del cuero es la que mayor número de trabajadores ocupa y por su carácter de actividad molesta (curtidos) se encuentra generalmente alejada de las áreas residenciales. 
IMPACTO EN EL MEDIO AMBIENTE.-

- Contaminación ambiental: De cierta importancia en lo que respecta a las industrias de curtido, puesto que carecen generalmente de alcantarillado y realizan sus vertidos a las acequias.

- Transporte: Escaso dada la poca importancia del asentamiento industrial.

- Integración en el entorno: Plena en las industrias situadas en plantas bajas de edificios de viviendas y claramente fuera de contexto las industrias aisladas enclavadas en áreas de huerta.

EDIFICIOS INDUSTRIALES DE INTERES.-

- Inexistentes

TIPOLOGÍA EDIFICACIÓN

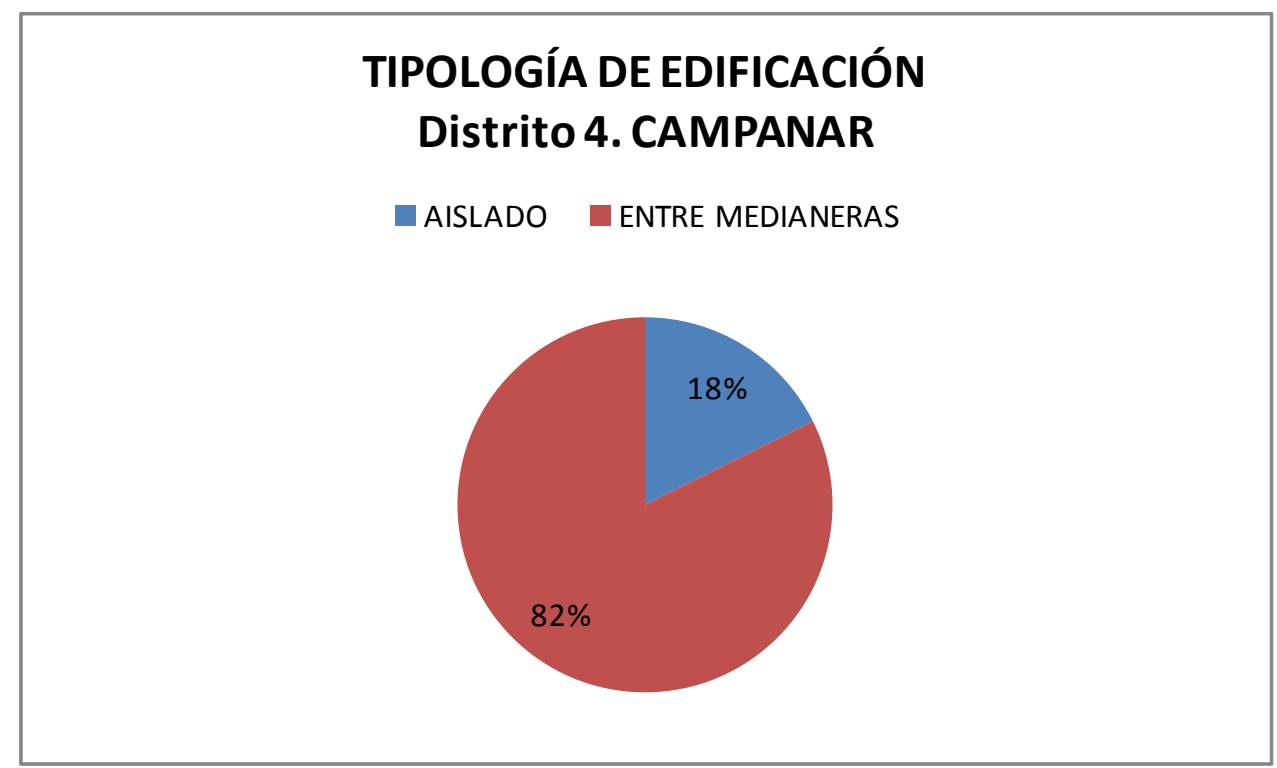




\section{ACTIVIDAD INDUSTRIAL, SUPERFICIE Y EMPLEO}

\begin{tabular}{|c|c|c|c|c|c|}
\hline \multicolumn{6}{|c|}{ DISTRITO 4 - CAMPANAR (ATIVIDAD INDUSTRIAL Y EMPLEO) } \\
\hline ACTIVIDAD & $\begin{array}{c}\text { № } \\
\text { EMPRESAS }\end{array}$ & $\begin{array}{c}\text { SUP. ACTIVIDAD } \\
\text { IND }\left(\mathrm{m}^{2}\right)\end{array}$ & $\begin{array}{c}\text { \% SUP. } \\
\text { INDUSTRIAL }\end{array}$ & $\begin{array}{c}\text { № } \\
\text { EMPLEADOS }\end{array}$ & $\begin{array}{c}\text { DENSIDAD } \\
\text { EMPLEO } \\
\text { (empleados } / \mathrm{m}^{2} \\
\text { actividad) }\end{array}$ \\
\hline INDUSTRIAS DE PRODUCTOS MINERALES NO METÁLICOS & 1 & 1295 & 5,85 & 23 & 0,0178 \\
\hline FABRICACIÓN DE PRODUCTOS METÁLICOS & 5 & 5100 & 23,04 & 65 & 0,0127 \\
\hline FABRICACIÓN DE MATERIAL ELECTRÓNICO & 2 & 530 & 2,39 & 24 & 0,0453 \\
\hline FABRICACIÓN DE INSTRUMENTOS DE PRECISIÓN, ÓPTICA Y SIMILARES & 1 & 1500 & 6,78 & 19 & 0,0127 \\
\hline INDUSTRIAS DE PRODUCTOS ALIMENTICIOS, BEBIDAS Y TABACO & 5 & 1067 & 4,82 & 22 & 0,0206 \\
\hline INDUSTRIA DEL CUERO & 6 & 6176 & 27,90 & 104 & 0,0168 \\
\hline INDUSTRIA DEL CALZADO Y DEL VESTIDO Y OTRAS CONFECCIONES TEXTILES & 2 & 1445 & 6,53 & 35 & 0,0242 \\
\hline INDUSTRIAS DE MADERA, CORCHO Y MUEBLES DE MADERA & 5 & 3570 & 16,13 & 25 & 0,0070 \\
\hline INDUSTRIAS DE TRANSFORMACIÓN DEL CAUCHO Y MATERIAS PLÁSTICAS & 1 & 70 & 0,32 & 3 & 0,0429 \\
\hline OTRAS INDUSTRIAS MANUFACTURERAS & 3 & 1180 & 5,33 & 68 & 0,0576 \\
\hline CONSTRUCCIÓN & 1 & 200 & 0,90 & 8 & 0,0400 \\
\hline TOTAL & 32 & 22133 & 100 & 396 & 0,0179 \\
\hline
\end{tabular}

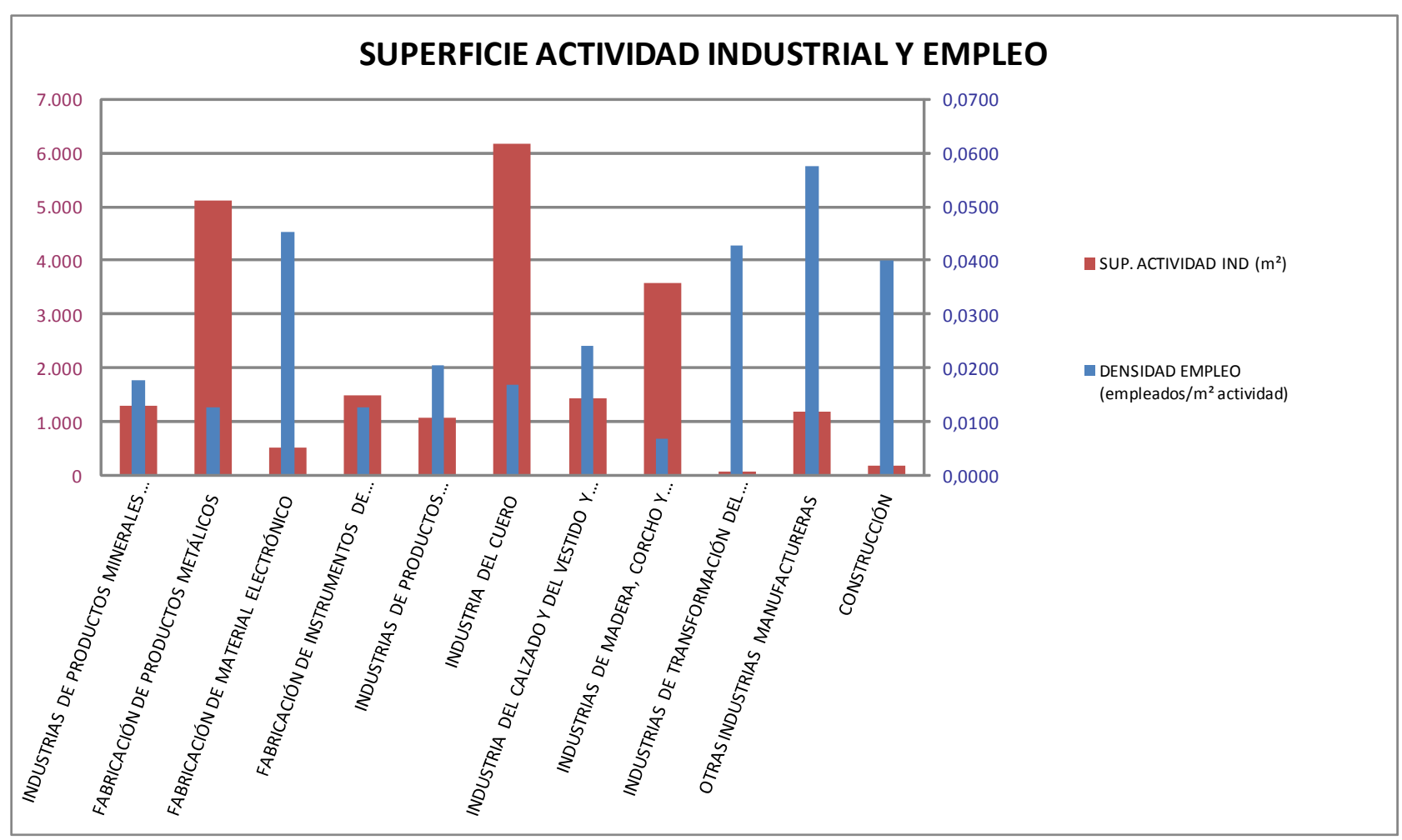


IMPACTO AMBIENTAL

\begin{tabular}{|c|c|c|c|c|c|}
\hline \multicolumn{6}{|c|}{ DISTRITO 4 - CAMPANAR (INFORMACIÓN URBANÍSTICA) } \\
\hline ACTIVIDAD & $\begin{array}{c}\text { No } \\
\text { EMPRESAS }\end{array}$ & $\begin{array}{c}\text { ENTRE } \\
\text { MEDIANERAS }\end{array}$ & RUIDOSAS & $\begin{array}{c}\text { EMPRESAS } \\
\text { CON } \\
\text { CHIMENEA }\end{array}$ & $\begin{array}{c}\text { RUIDOSAS Y } \\
\text { CHIMENEA }\end{array}$ \\
\hline INDUSTRIAS DE PRODUCTOS MINERALES NO METÁLICOS & 1 & 1 & 1 & 0 & 0 \\
\hline FABRICACIÓN DE PRODUCTOS METÁLICOS & 5 & 2 & 5 & 0 & 0 \\
\hline FABRICACIÓN DE MATERIAL ELECTRÓNICO & 2 & 2 & 0 & 0 & 0 \\
\hline FABRICACIÓN DE INSTRUMENTOS DE PRECISIÓN, ÓPTICA Y SIMILARES & 1 & 1 & 1 & 0 & 0 \\
\hline INDUSTRIAS DE PRODUCTOS ALIMENTICIOS, BEBIDAS Y TABACO & 5 & 5 & 0 & 3 & 1 \\
\hline INDUSTRIA DEL CUERO & 6 & 3 & 1 & 1 & 2 \\
\hline INDUSTRIA DEL CALZADO Y DEL VESTIDO Y OTRAS CONFECCIONES TEXTILES & 2 & 2 & 0 & 0 & 0 \\
\hline INDUSTRIAS DE MADERA, CORCHO Y MUEBLES DE MADERA & 5 & 5 & 4 & 0 & 0 \\
\hline INDUSTRIAS DE TRANSFORMACIÓN DEL CAUCHO Y MATERIAS PLÁSTICAS & 1 & 1 & 0 & 0 & 0 \\
\hline OTRAS INDUSTRIAS MANUFACTURERAS & 3 & 3 & 0 & 1 & 0 \\
\hline CONSTRUCCIÓN & 1 & 1 & 0 & 0 & 0 \\
\hline TOTAL & 32 & 26 & 12 & 5 & 3 \\
\hline
\end{tabular}

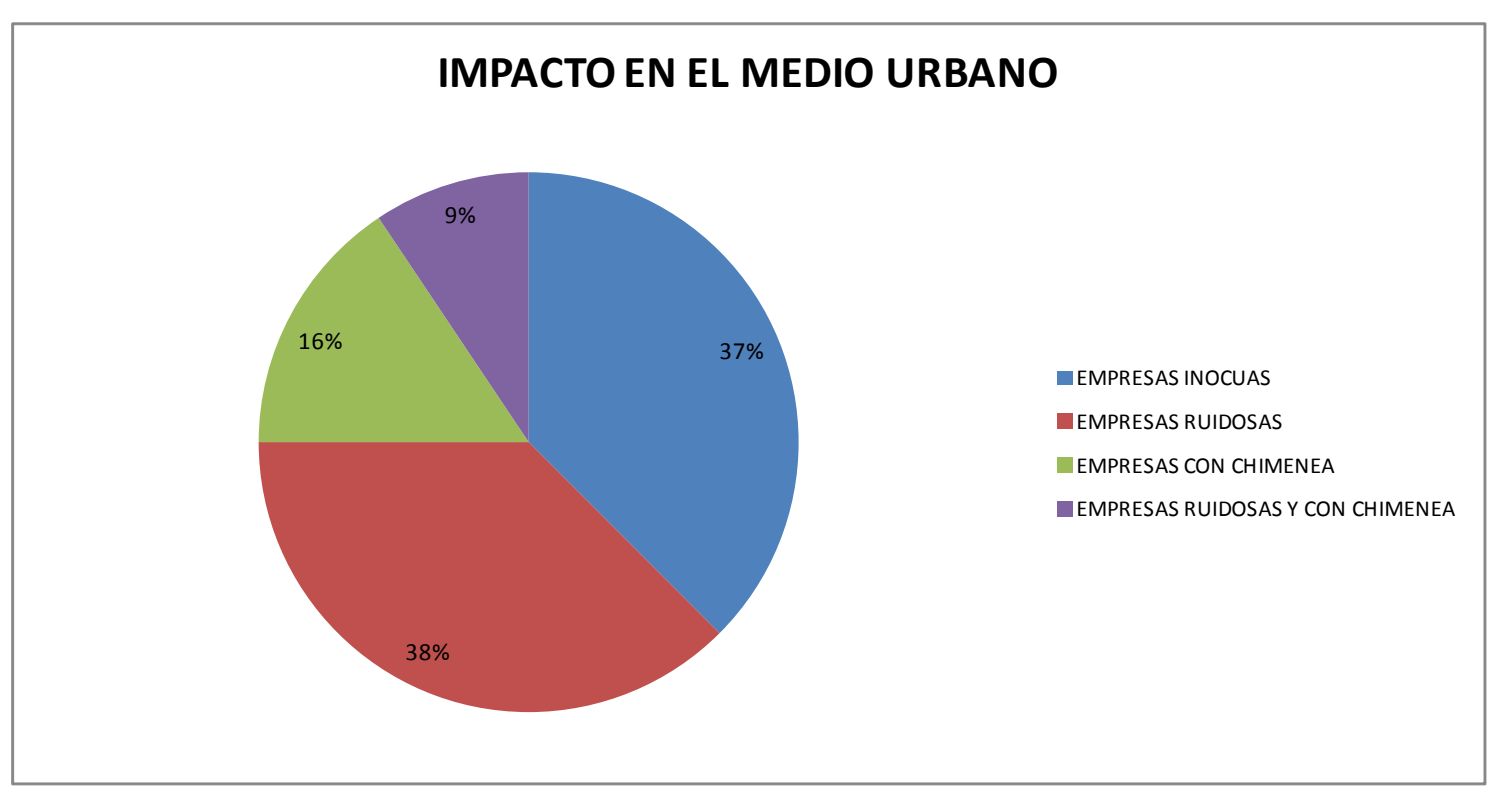


FICHAS TIPO

\section{FICHA DATOS DE LA INDUSTRIA}

LOCALIZACION ACTUALIZADA DE ACTIVIDADES INDUSTRIALES EN EL MEDIO URBANO DE VALENCIA

\begin{tabular}{|c|c|c|c|c|c|c|c|}
\hline \multirow{5}{*}{ 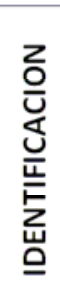 } & \multirow{2}{*}{\multicolumn{2}{|c|}{$\begin{array}{c}\text { NOMBRE } \\
\text { EMPLAZAMIENTO }\end{array}$}} & \multicolumn{5}{|c|}{ GÓMEZ ALÓNDIGA, J. } \\
\hline & & & \multicolumn{3}{|c|}{ Av. Burjasot, 71} & C.P. & \\
\hline & \multirow{2}{*}{ CNAE } & \multirow{2}{*}{316} & \multirow{2}{*}{ DESCRIPCION } & \multicolumn{4}{|c|}{ FABRICACIÓN PRODUCTOS METÁLICOS } \\
\hline & & & & \multicolumn{4}{|c|}{ Metales y cerrajería } \\
\hline & DISTRITO & 4 & \multicolumn{5}{|c|}{ CAMPANAR } \\
\hline & \multicolumn{2}{|c|}{ SUPERFICIES } & $\begin{array}{l}\text { Sup. Parcela: } \\
500 \mathrm{~m}^{2}\end{array}$ & $\begin{array}{l}\text { Sup. Ocupada: } \\
500 \mathrm{~m}^{2}\end{array}$ & $\begin{array}{l}\text { Sup. Construida: } \\
500 \mathrm{~m}^{2}\end{array}$ & EMP & $\begin{array}{l}\text { EADOS: } \\
13\end{array}$ \\
\hline
\end{tabular}

\begin{tabular}{|c|c|}
\hline \multirow{4}{*}{ 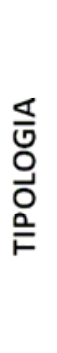 } & $\begin{array}{l}\text { AISLADA: } \\
\text { NO }\end{array}$ \\
\hline & $\begin{array}{c}\text { ENTRE MEDIANERAS: } \\
\text { SI }\end{array}$ \\
\hline & $\begin{array}{c}\text { AÑO CONSTRUCIÓN: } \\
1960-1985\end{array}$ \\
\hline & $\begin{array}{c}\text { EST. CONSERVACIÓN: } \\
\text { Regular }\end{array}$ \\
\hline \multirow{3}{*}{ 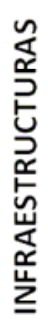 } & $\begin{array}{c}\text { ENERGIA ELECTRICA: } \\
\text { SI }\end{array}$ \\
\hline & $\begin{array}{c}\text { AGUA POTABLE: } \\
\text { SI }\end{array}$ \\
\hline & $\begin{array}{c}\text { ALCANTARILLADO: } \\
\text { SI }\end{array}$ \\
\hline
\end{tabular}

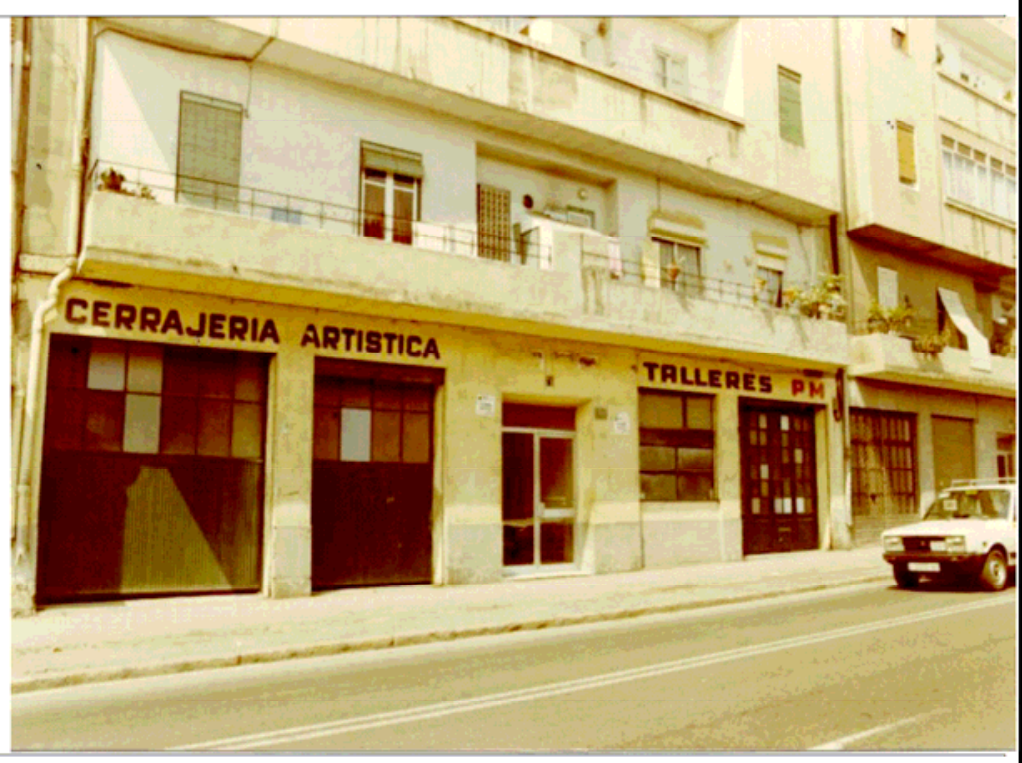

\begin{tabular}{|c|c|}
\hline \multirow{4}{*}{ 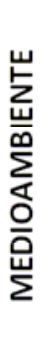 } & $\begin{array}{l}\text { RUIDOS: } \\
\text { SI }\end{array}$ \\
\hline & $\begin{array}{l}\text { VIV. PRÓXIMAS: } \\
\text { SI }\end{array}$ \\
\hline & $\begin{array}{c}\text { AGUAS RESIDUALES: } \\
\text { NO }\end{array}$ \\
\hline & $\begin{array}{l}\text { CHIMENEAS: } \\
\text { NO }\end{array}$ \\
\hline \multirow{3}{*}{ 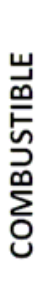 } & $\begin{array}{l}\text { FUEL: } \\
\text { NO }\end{array}$ \\
\hline & $\begin{array}{l}\text { GASOIL: } \\
\text { NO }\end{array}$ \\
\hline & $\begin{array}{l}\text { OTROS: } \\
\text { NO }\end{array}$ \\
\hline
\end{tabular}

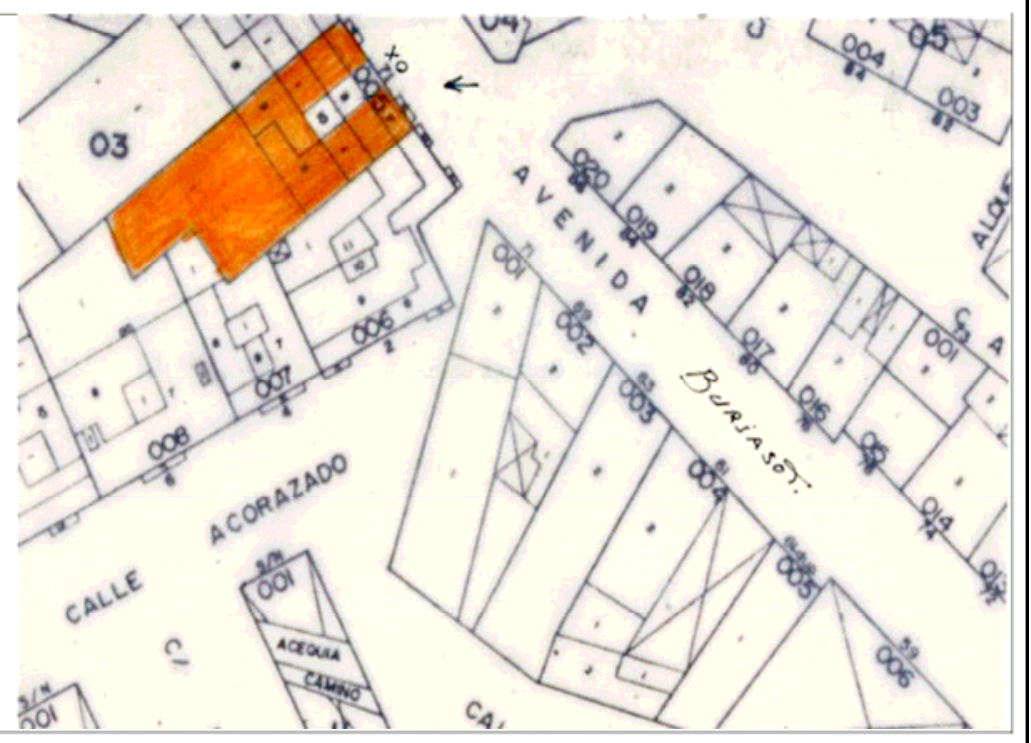




\section{FICHA DATOS DE LA INDUSTRIA}

LOCALIZACION ACTUALIZADA DE ACTIVIDADES INDUSTRIALES EN EL MEDIO URBANO DE VALENCIA

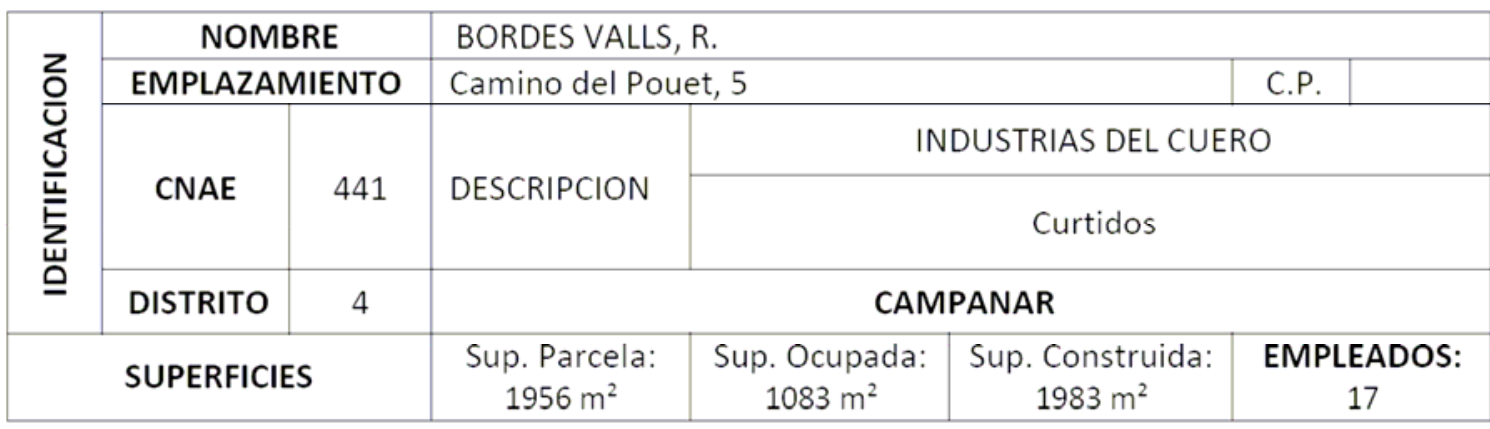
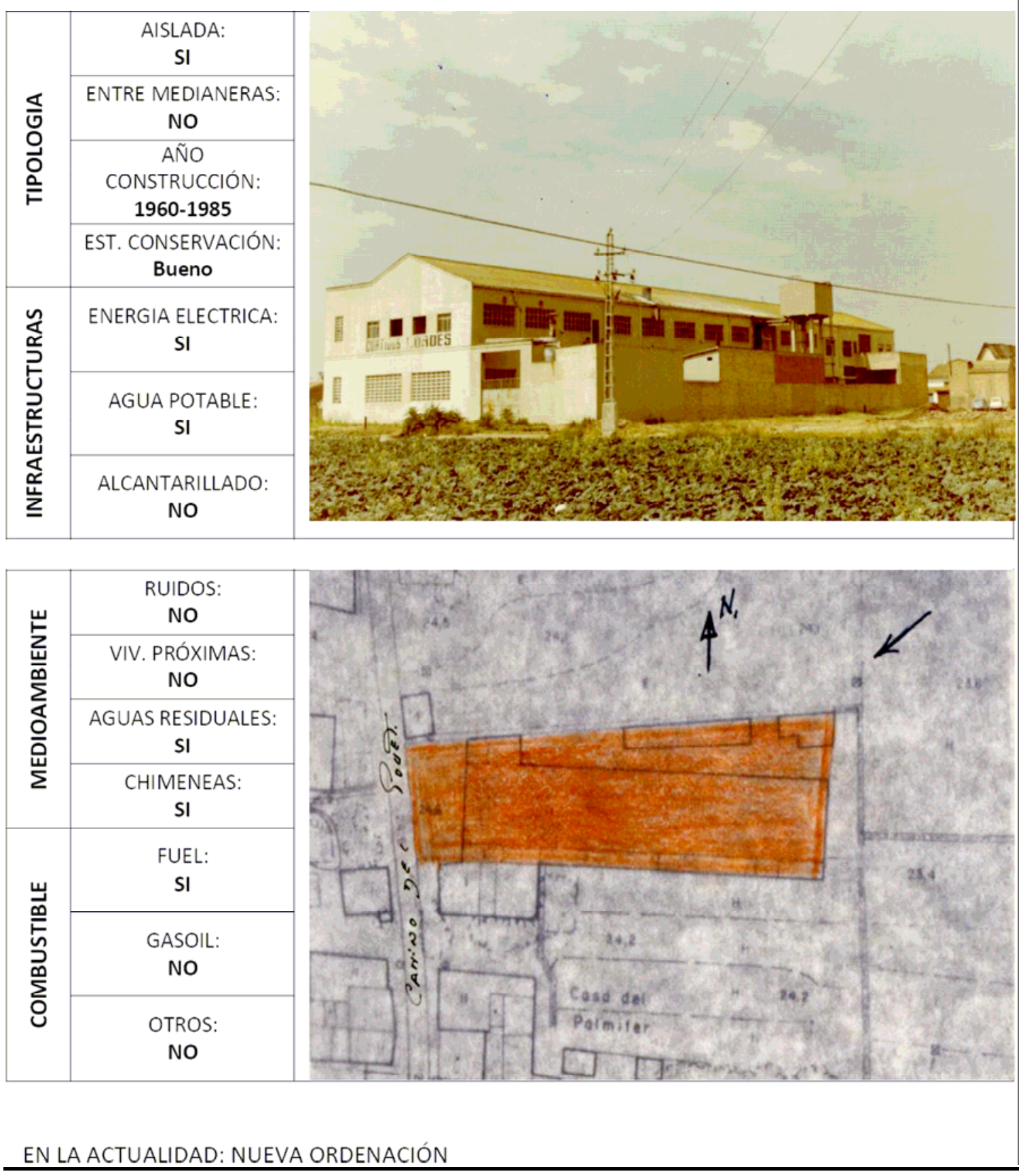


\section{FICHA DATOS DE LA INDUSTRIA}

LOCALIZACION ACTUALIZADA DE ACTIVIDADES INDUSTRIALES EN EL MEDIO URBANO DE VALENCIA

\begin{tabular}{|c|c|c|c|c|c|c|c|}
\hline \multirow{5}{*}{ 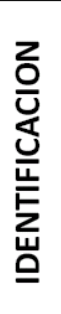 } & \multirow{2}{*}{\multicolumn{2}{|c|}{$\begin{array}{c}\text { NOMBRE } \\
\text { EMPLAZAMIENTO }\end{array}$}} & \multicolumn{5}{|l|}{ RAN-MAR S.L. } \\
\hline & & & \multicolumn{3}{|c|}{ C/ Evaristo Crespo Azorín, 1} & C.P. & \\
\hline & \multirow{2}{*}{ CNAE } & \multirow[b]{2}{*}{442} & \multirow[b]{2}{*}{ DESCRIPCION } & \multicolumn{4}{|c|}{ INDUSTRIAS DEL CUERO } \\
\hline & & & & \multicolumn{4}{|c|}{ Fabricación de artículos de marroquinería y viaje } \\
\hline & DISTRITO & 4 & \multicolumn{5}{|c|}{ CAMPANAR } \\
\hline \multicolumn{3}{|c|}{ SUPERFICIES } & $\begin{array}{l}\text { Sup. Parcela: } \\
1900 \mathrm{~m}^{2}\end{array}$ & $\begin{array}{c}\text { Sup. Ocupada: } \\
1400 \mathrm{~m}^{2}\end{array}$ & $\begin{array}{c}\text { Sup. Construida: } \\
1900 \mathrm{~m}^{2}\end{array}$ & EMPL & $\begin{array}{l}\text { EADOS: } \\
20\end{array}$ \\
\hline
\end{tabular}
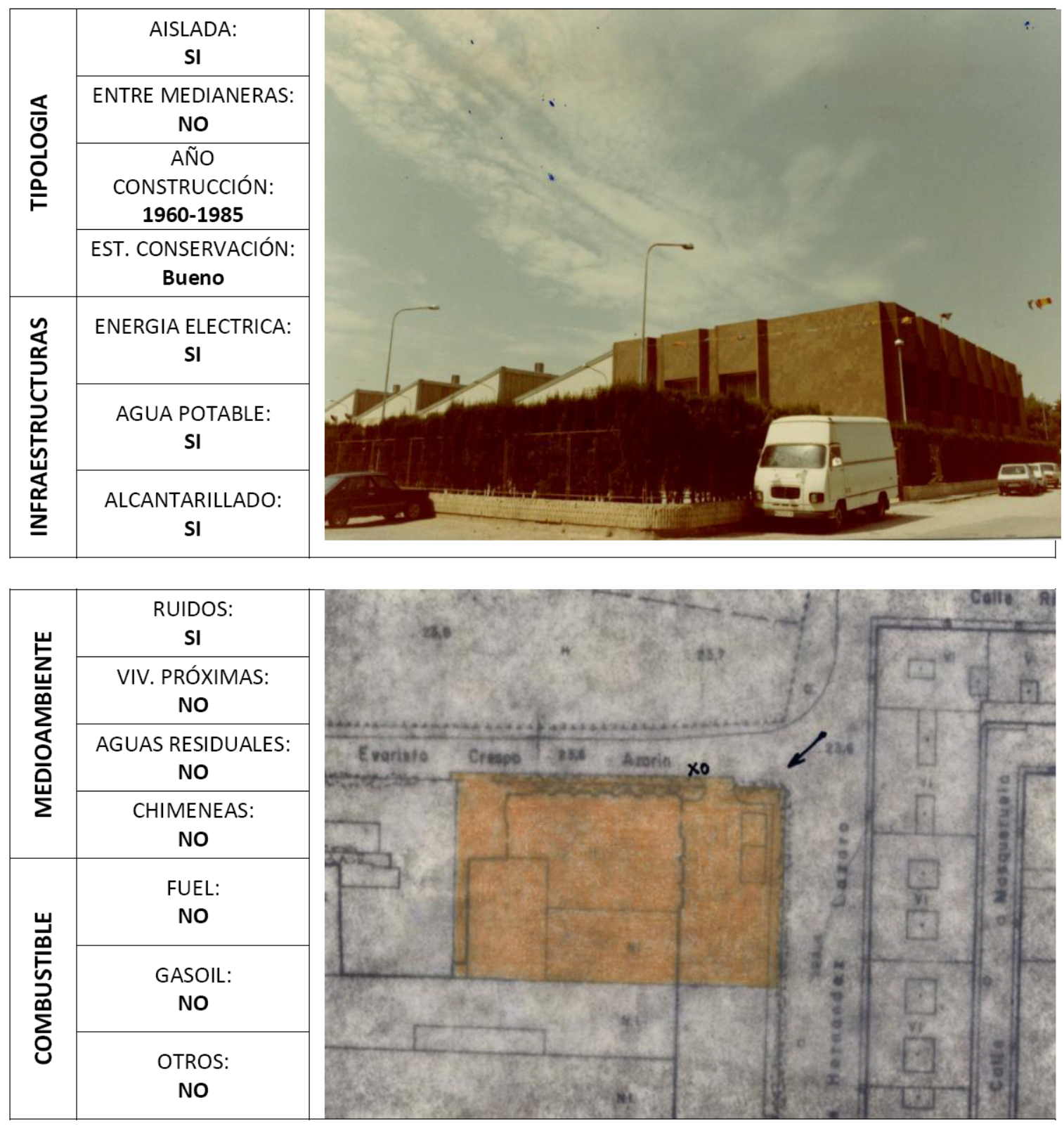


\section{FICHA DATOS DE LA INDUSTRIA}

LOCALIZACION ACTUALIZADA DE ACTIVIDADES INDUSTRIALES EN EL MEDIO URBANO DE VALENCIA

\begin{tabular}{|c|c|c|c|c|c|c|c|}
\hline \multirow{5}{*}{ 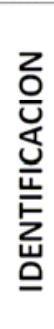 } & \multirow{2}{*}{\multicolumn{2}{|c|}{$\begin{array}{c}\text { NOMBRE } \\
\text { EMPLAZAMIENTO }\end{array}$}} & \multicolumn{5}{|c|}{ CLEMENTE MARQUES S.L. } \\
\hline & & & \multicolumn{3}{|l|}{ C/ Pio XII, 45} & C.P. & \\
\hline & \multirow{2}{*}{ CNAE } & \multirow{2}{*}{247} & \multirow{2}{*}{ DESCRIPCION } & \multicolumn{4}{|c|}{$\begin{array}{l}\text { INDUSTRIA DE PRODUCTOS MINERALES NO } \\
\text { METÁLICOS }\end{array}$} \\
\hline & & & & \multicolumn{4}{|c|}{ Almacén elementos sanitarios } \\
\hline & DISTRITO & 4 & \multicolumn{5}{|c|}{ CAMPANAR } \\
\hline & \multicolumn{2}{|c|}{ SUPERFICIES } & $\begin{array}{l}\text { Sup. Parcela: } \\
1000 \mathrm{~m}^{2}\end{array}$ & $\begin{array}{c}\text { Sup. Ocupada: } \\
1000 \mathrm{~m}^{2}\end{array}$ & $\begin{array}{l}\text { Sup. Construida: } \\
2000 \mathrm{~m}^{2}\end{array}$ & EMP & $\begin{array}{l}\text { LEADOS: } \\
15\end{array}$ \\
\hline
\end{tabular}
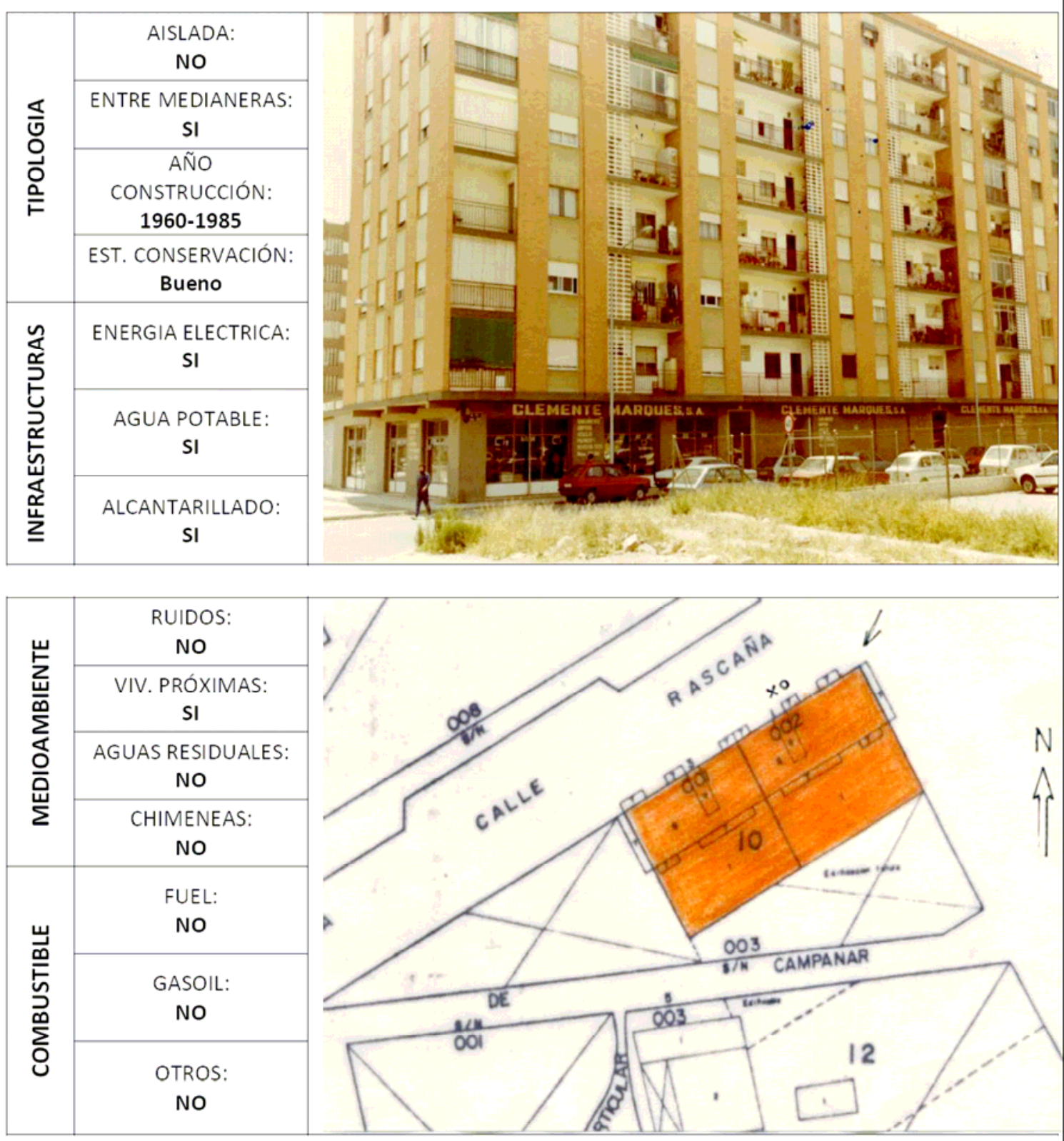


\section{FICHA DATOS DE LA INDUSTRIA}

LOCALIZACION ACTUALIZADA DE ACTIVIDADES INDUSTRIALES EN EL MEDIO URBANO DE VALENCIA

\begin{tabular}{|c|c|c|c|c|c|c|c|}
\hline \multirow{5}{*}{ 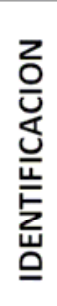 } & \multirow{2}{*}{\multicolumn{2}{|c|}{$\begin{array}{c}\text { NOMBRE } \\
\text { EMPLAZAMIENTO }\end{array}$}} & \multicolumn{5}{|c|}{ FRIKAL REFRIGERACIÓN } \\
\hline & & & \multicolumn{3}{|c|}{ C/ Maestro Rodrigo, 93} & C.P. & \\
\hline & \multirow{2}{*}{ CNAE } & \multirow{2}{*}{504} & \multirow{2}{*}{ DESCRIPCION } & \multicolumn{4}{|c|}{ CONSTRUCCIÓN } \\
\hline & & & & \multicolumn{4}{|c|}{ Refrigeración } \\
\hline & DISTRITO & 4 & \multicolumn{5}{|c|}{ CAMPANAR } \\
\hline \multicolumn{3}{|c|}{ SUPERFICIES } & $\begin{array}{c}\text { Sup. Parcela: } \\
200 \mathrm{~m}^{2}\end{array}$ & $\begin{array}{l}\text { Sup. Ocupada: } \\
200 \mathrm{~m}^{2}\end{array}$ & $\begin{array}{l}\text { Sup. Construida: } \\
200 \mathrm{~m}^{2}\end{array}$ & EMPI & ADOS: \\
\hline
\end{tabular}
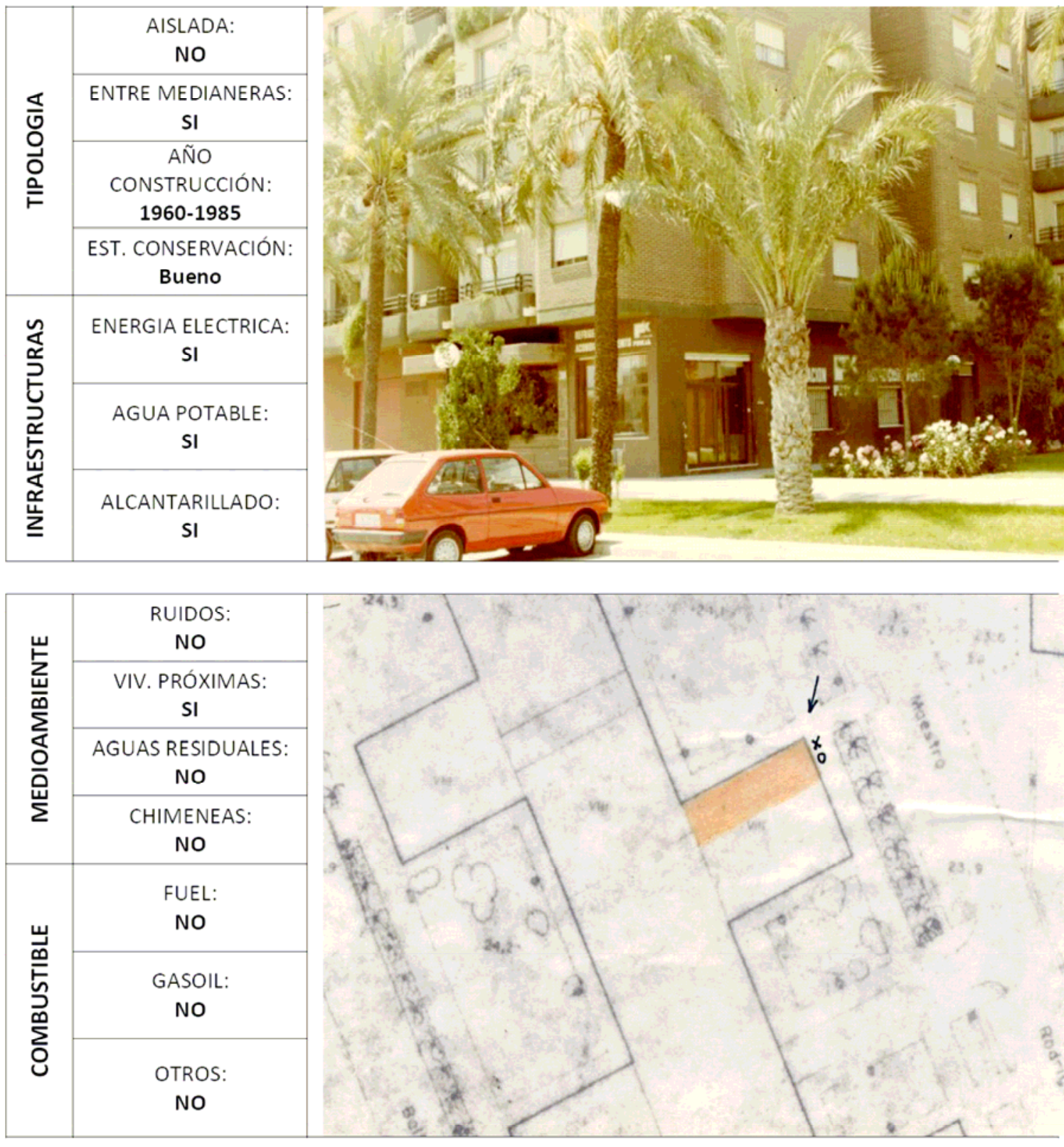


\section{EVOLUCIÓN}

\section{PLANO UBICACIÓN INDUSTRIAS}

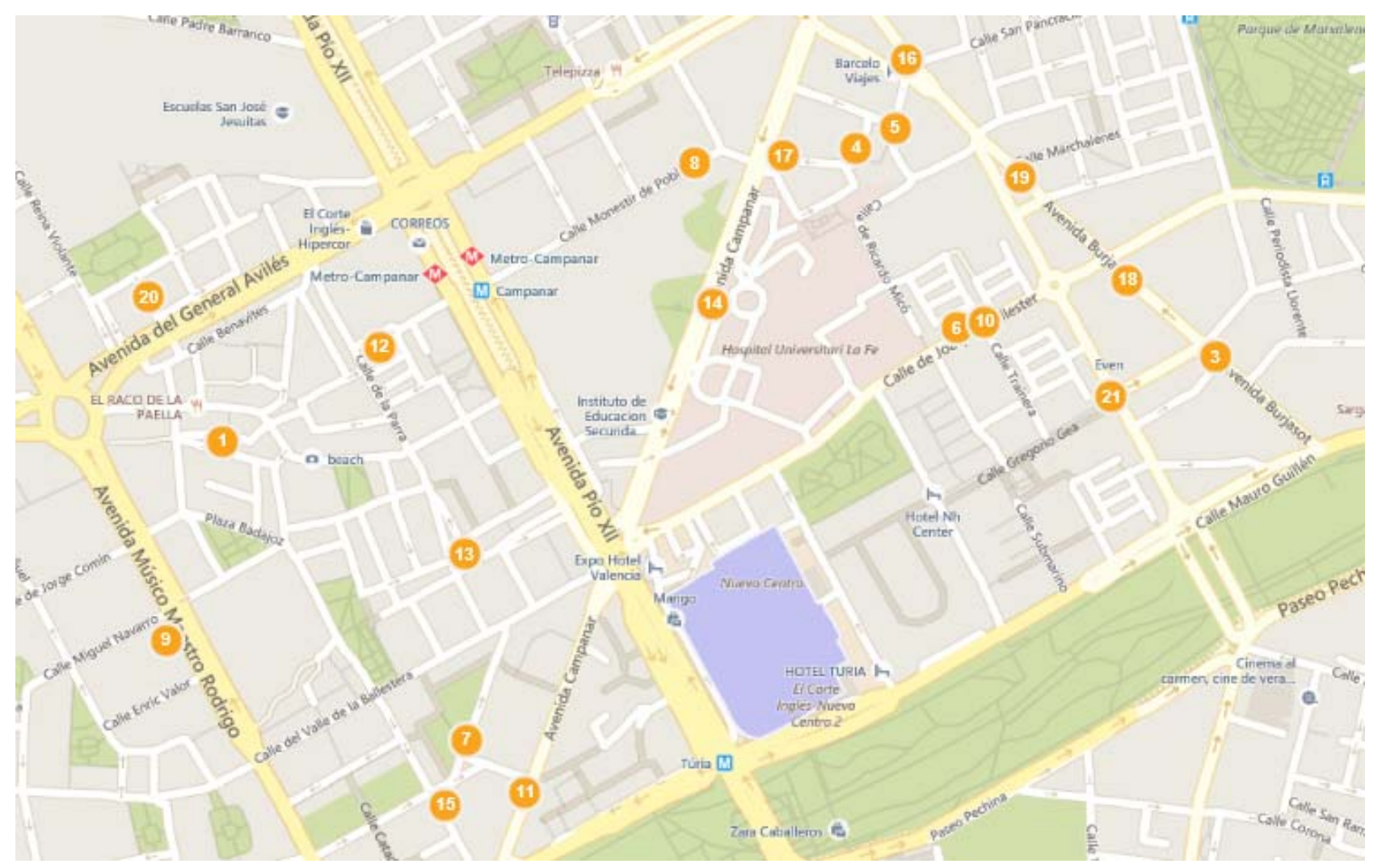

LISTADO DE INDUSTRIAS Y ACTIVIDAD.-

1. SILLAS CIURANA C.B.(existente 20)

CNAE año 1985 (469)

2. Ángel Gómez Pérez

Fabricación de otros muebles.

3. Josep Xavier Santamaría

Fabricación de artículos de joyería y artículos similares.

4. CENTRO ORTOPÉDICO TEC S.L.

Fabricación instrumentos y suministros médicos y odontológicos

5. TALLERES TOGAR S.L.

Mantenimiento y reparación y vehículos a motor.

6. Mariano Martínez Plaza

Mantenimiento y reparación de vehículos a motor.

7. MIGUEL SANCHIS COMPANY Y COMPAÑíA C.B.

Mantenimiento y reparación de vehículos de motor. 
8. VICENTE TATAY LLOP C.B.

Mantenimiento y reparación de vehículos de motor.

9. AUTOMOCION NOU CAMPANAR C.B.

Mantenimiento y reparación de vehículos a motor

10. Antonio Martínez Ballesteros

Mantenimiento y reparación de vehículos a motor

11. Ángel Álvarez Díaz

Mantenimiento y reparación de vehículos a motor.

12. M.B. COMPOSTURAS C.B.

Confección de otras prendas de vestir exteriores.

13. Angélica Pérez Romero

Confección de otras prendas de vestir exteriores

14. CIFRE CREACIONES ARTESANAS C.B.

Fabricación de pan y de productos frescos de panadería y pastelería

15. Ricardo Soriano Genovés

Fabricación de pan y de productos frescos de panadería y pastelería.

16. HEREDEROS ANTONIO REIG MATA C.B.

Otras actividades de impresión y artes gráficas

17. Gallana Mullor, Rosa

Otras actividades de impresión y artes gráficas.

18. García Martínez, Vicente Javier

19. Gómez Alóndiga J. Talleres Pascual Mateu (existente 4)

CNAE año 1985 (316)

20. HORNO CASANI (existente 7)

CNAE año 1985 (419)

21. Aznar Climent, Eduardo (existente 24)

CNAE año 1985 (419) 
EVOLUCIÓN DE LA ACTIVIDAD INDUSTRIAL

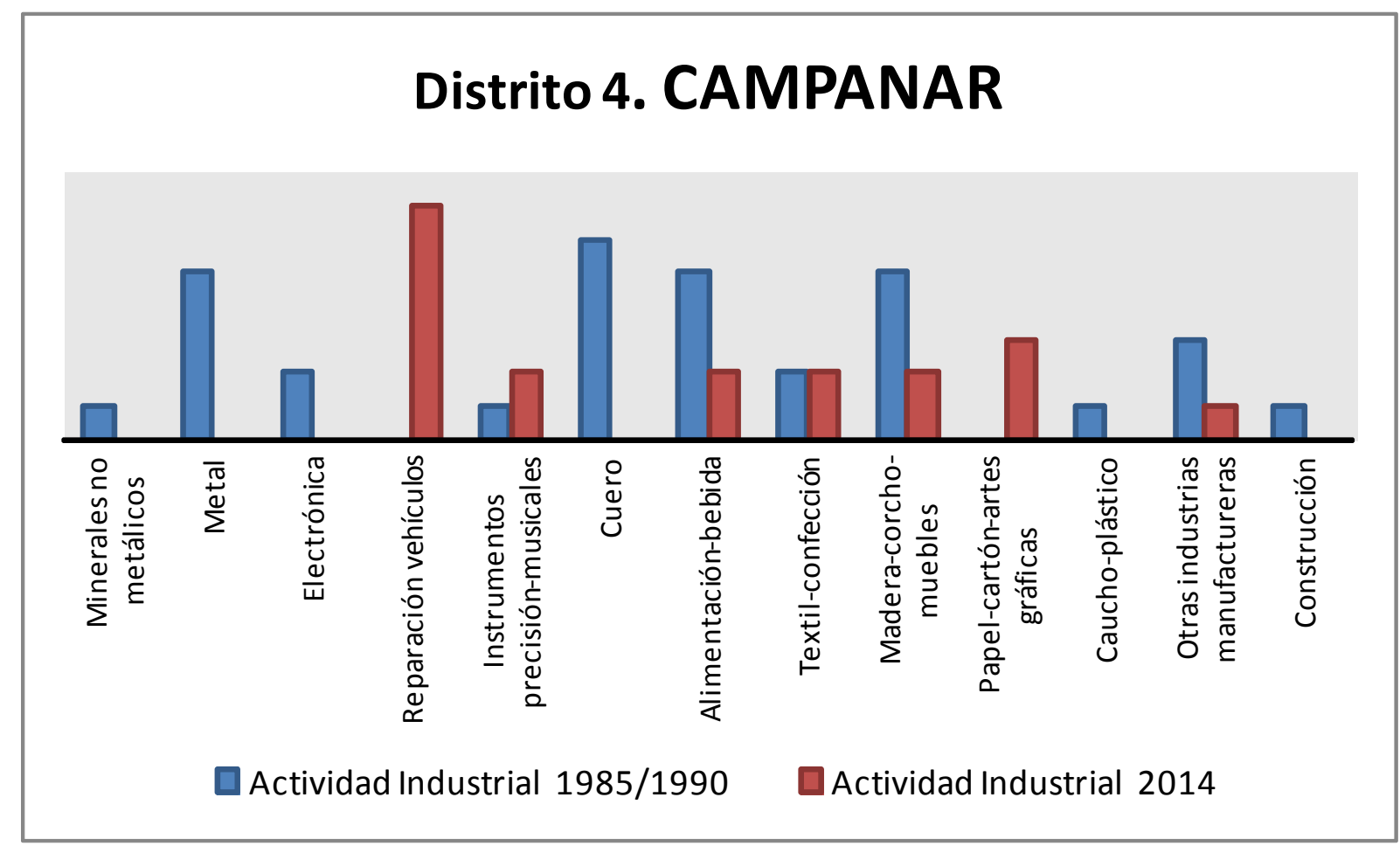

EVOLUCIÓN DEL IMPACTO AMBIENTAL

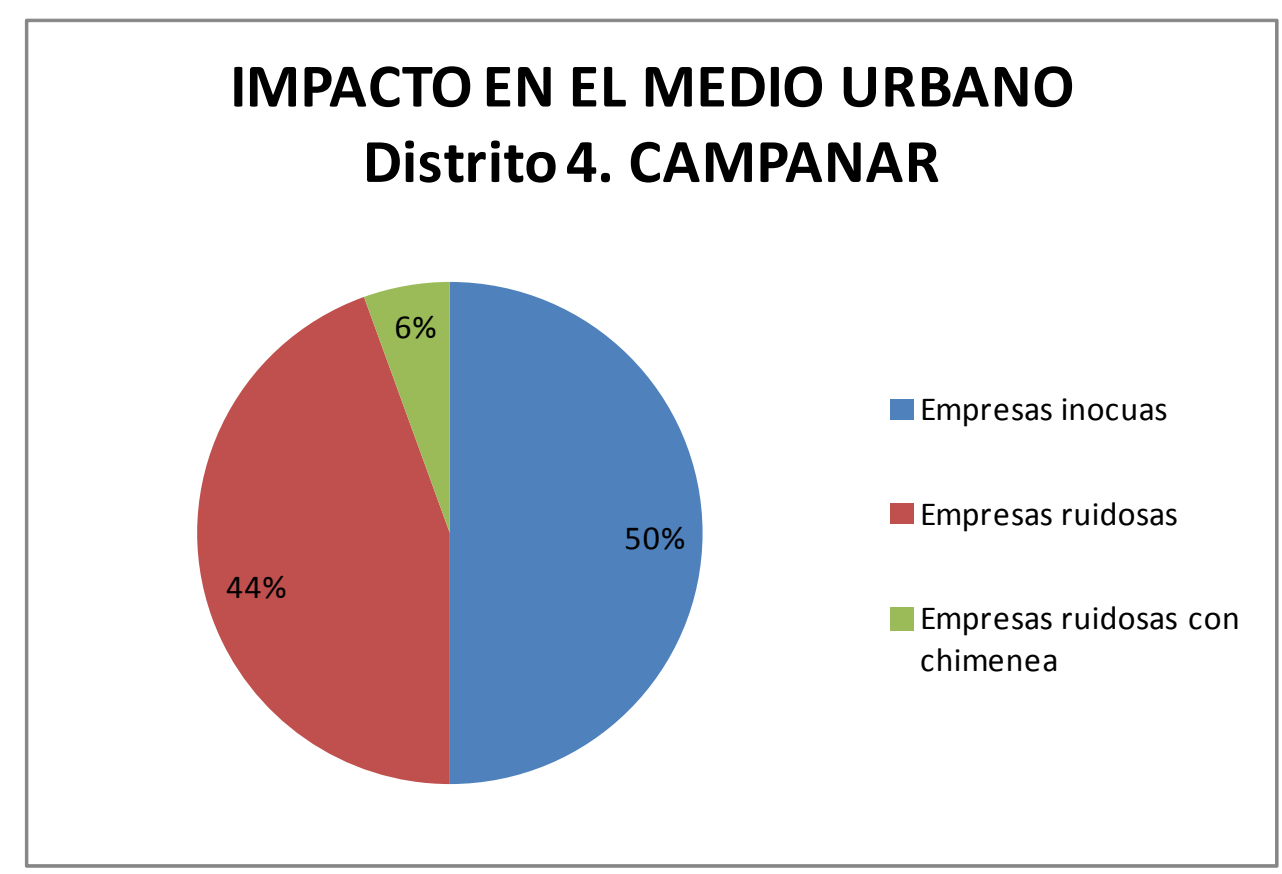




\section{FICHAS TIPO \\ FICHA DATOS DE LA INDUSTRIA}

LOCALIZACION ACTUALIZADA DE ACTIVIDADES INDUSTRIALES EN EL MEDIO URBANO DE VALENCIA

\begin{tabular}{|c|c|c|c|c|c|c|c|}
\hline \multirow{5}{*}{ 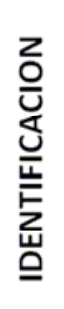 } & \multirow{2}{*}{\multicolumn{2}{|c|}{$\begin{array}{c}\text { NOMBRE } \\
\text { EMPLAZAMIENTO }\end{array}$}} & \multicolumn{5}{|c|}{ ANGELICA PÉREZ ROMERO } \\
\hline & & & \multicolumn{3}{|c|}{ C/VALDELINARES, 12} & C.P. & 46015 \\
\hline & \multirow[b]{2}{*}{ CNAE } & \multirow[b]{2}{*}{1413} & \multirow{2}{*}{ DESCRIPCION } & \multicolumn{4}{|c|}{ TEXTIL-CALZADO-CONFECCIÓN } \\
\hline & & & & \multicolumn{4}{|c|}{ Confección de otras prendas de vestir exteriores } \\
\hline & DISTRITO & 4 & \multicolumn{5}{|c|}{ CAMPANAR } \\
\hline \multicolumn{3}{|c|}{ MEDIOAMBIENTE } & RUIDOSAS & NO & CHIMENEAS & & 0 \\
\hline
\end{tabular}

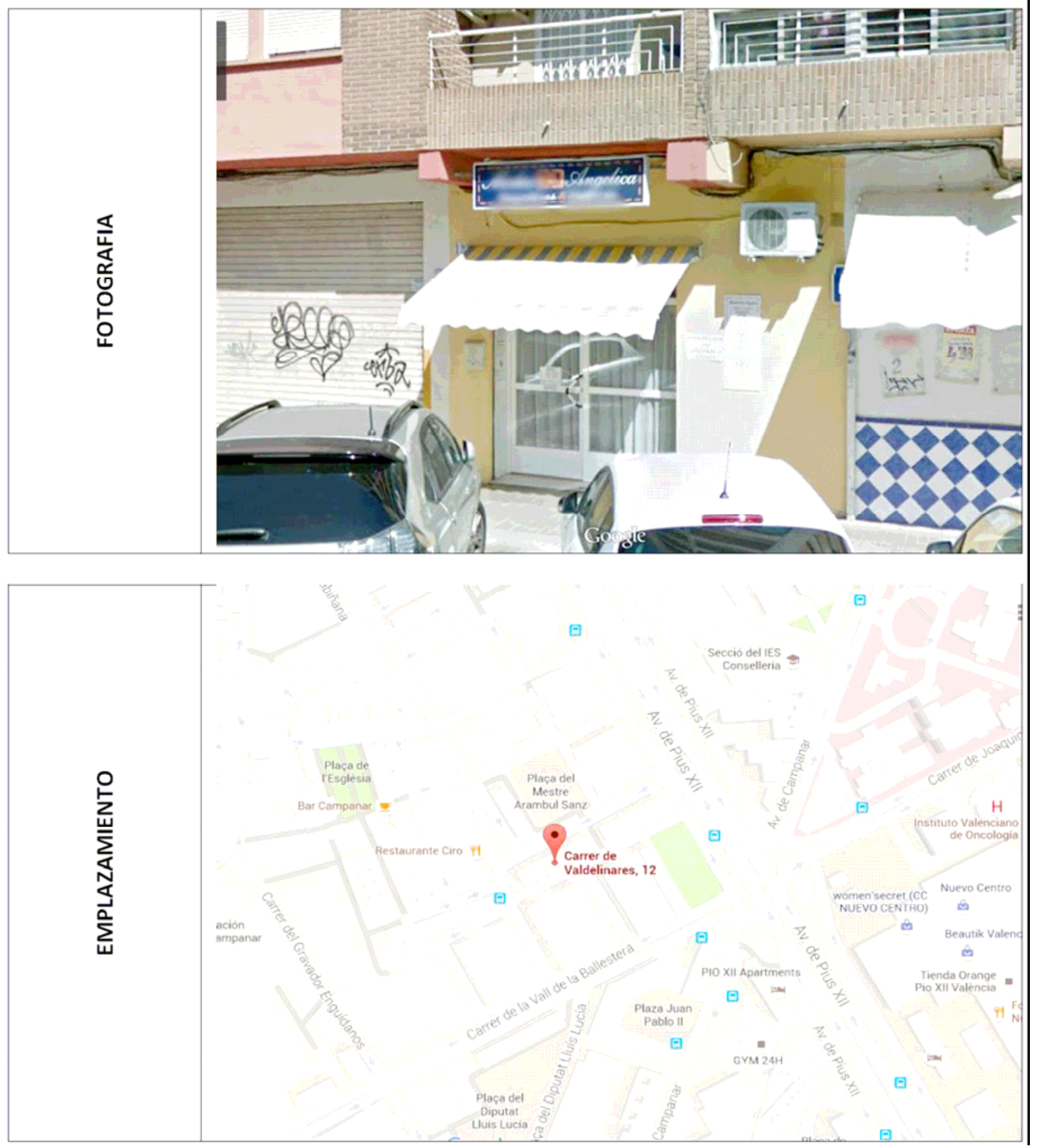




\section{FICHA DATOS DE LA INDUSTRIA}

LOCALIZACION ACTUALIZADA DE ACTIVIDADES INDUSTRIALES EN EL MEDIO URBANO DE VALENCIA

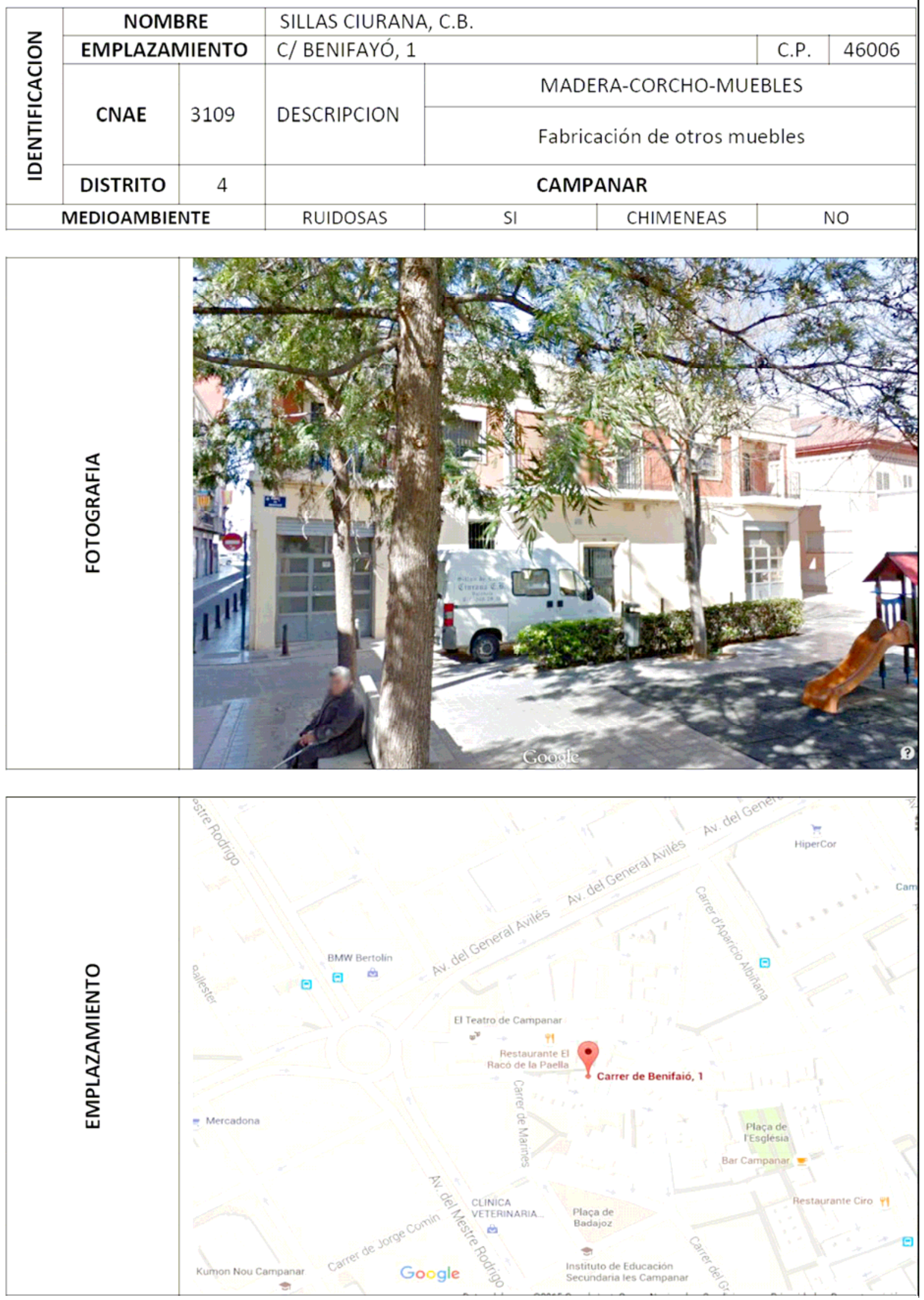




\section{FICHA DATOS DE LA INDUSTRIA}

LOCALIZACION ACTUALIZADA DE ACTIVIDADES INDUSTRIALES EN EL MEDIO URBANO DE VALENCIA

\begin{tabular}{|c|c|c|c|c|c|c|c|}
\hline \multirow{5}{*}{ 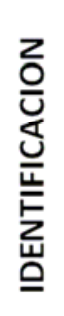 } & \multirow{2}{*}{\multicolumn{2}{|c|}{$\begin{array}{c}\text { NOMBRE } \\
\text { EMPLAZAMIENTO }\end{array}$}} & \multicolumn{5}{|c|}{ MIGUEL SANCHIS COMPANY Y COMPAÑÍA, CB } \\
\hline & & & \multicolumn{3}{|c|}{ PZA. DIPUTAT LLUIS LUCIA, 21} & C.P. & 46015 \\
\hline & \multirow{2}{*}{ CNAE } & \multirow{2}{*}{4520} & \multirow{2}{*}{ DESCRIPCION } & \multicolumn{4}{|c|}{ REPARACIÓN VEHÍCULOS } \\
\hline & & & & \multicolumn{4}{|c|}{ Mantenimiento y reparación de vehículos a motor } \\
\hline & DISTRITO & 4 & \multicolumn{5}{|c|}{ CAMPANAR } \\
\hline \multicolumn{3}{|c|}{ MEDIOAMBIENTE } & RUIDOSAS & SI & CHIMENEAS & & 0 \\
\hline
\end{tabular}

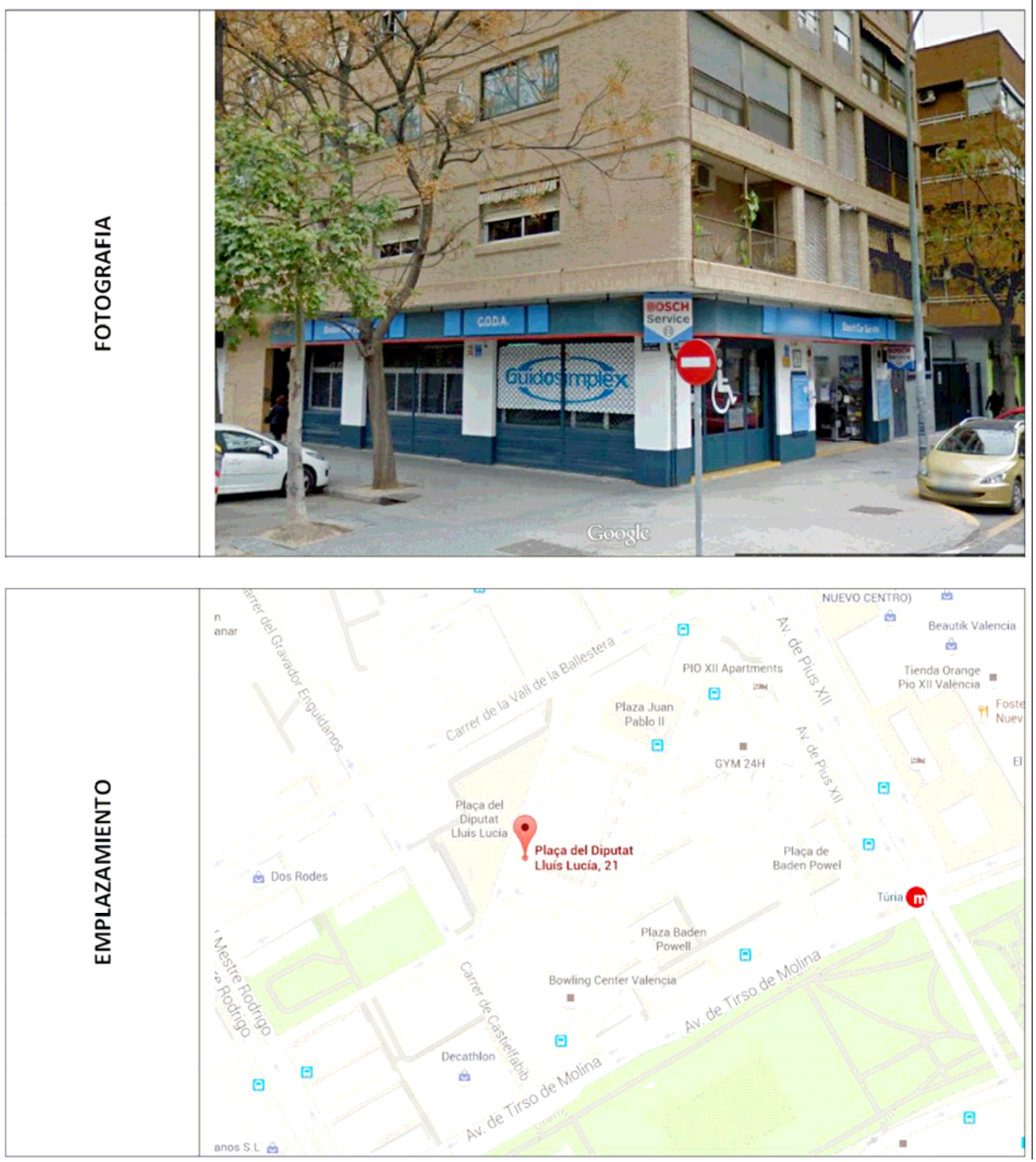




\section{FICHA DATOS DE LA INDUSTRIA}

LOCALIZACION ACTUALIZADA DE ACTIVIDADES INDUSTRIALES EN EL

MEDIO URBANO DE VALENCIA

\begin{tabular}{|c|c|c|c|c|c|c|c|}
\hline \multirow{5}{*}{ 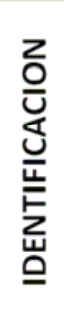 } & \multirow{2}{*}{\multicolumn{2}{|c|}{$\begin{array}{c}\text { NOMBRE } \\
\text { EMPLAZAMIENTO }\end{array}$}} & \multicolumn{5}{|c|}{ M.B. COMPOSTURAS, CB } \\
\hline & & & \multicolumn{3}{|c|}{ C/ MONESTIR DE POBLET, 45} & C.P. & 46015 \\
\hline & \multirow{2}{*}{ CNAE } & \multirow{2}{*}{1413} & \multirow{2}{*}{ DESCRIPCION } & \multicolumn{4}{|c|}{ TEXTIL-CALZADO-CONFECCIÓN } \\
\hline & & & & \multicolumn{4}{|c|}{ Confección de otras prendas de vestir exteriores } \\
\hline & DISTRITO & 4 & \multicolumn{5}{|c|}{ CAMPANAR } \\
\hline \multicolumn{3}{|c|}{ MEDIOAMBIENTE } & RUIDOSAS & NO & CHIMENEAS & & 0 \\
\hline
\end{tabular}
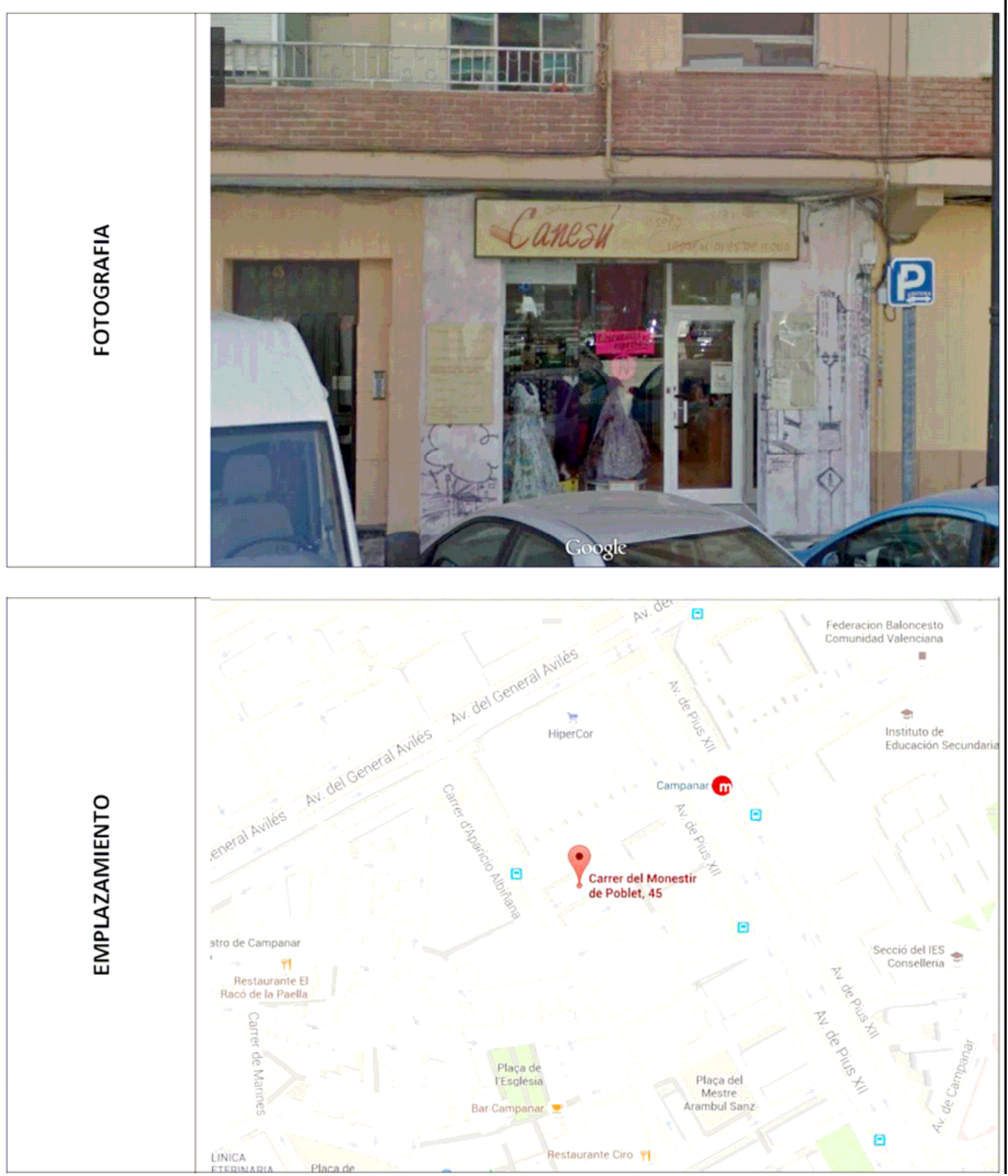


\section{FICHA DATOS DE LA INDUSTRIA}

LOCALIZACION ACTUALIZADA DE ACTIVIDADES INDUSTRIALES EN EL MEDIO URBANO DE VALENCIA

\begin{tabular}{|c|c|c|c|c|c|c|c|}
\hline \multirow{5}{*}{ 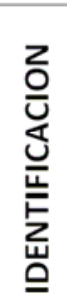 } & \multirow{2}{*}{\multicolumn{2}{|c|}{$\begin{array}{c}\text { NOMBRE } \\
\text { EMPLAZAMIENTO }\end{array}$}} & \multicolumn{5}{|c|}{ CIFRE CREACIONES ARTESANAS, CB } \\
\hline & & & \multicolumn{3}{|c|}{ AV. CAMPANAR, 5} & C.P. & 46009 \\
\hline & \multirow[b]{2}{*}{ CNAE } & \multirow[b]{2}{*}{1071} & \multirow[b]{2}{*}{ DESCRIPCION } & \multicolumn{4}{|c|}{ ALIMENTACIÓN-BEBIDA } \\
\hline & & & & \multicolumn{4}{|c|}{$\begin{array}{l}\text { Fabricación de pan y de productos frescos de } \\
\text { panadería y pastelería }\end{array}$} \\
\hline & DISTRITO & 4 & \multicolumn{5}{|c|}{ CAMPANAR } \\
\hline \multicolumn{3}{|c|}{ MEDIOAMBIENTE } & RUIDOSAS & NO & CHIMENEAS & & 0 \\
\hline
\end{tabular}

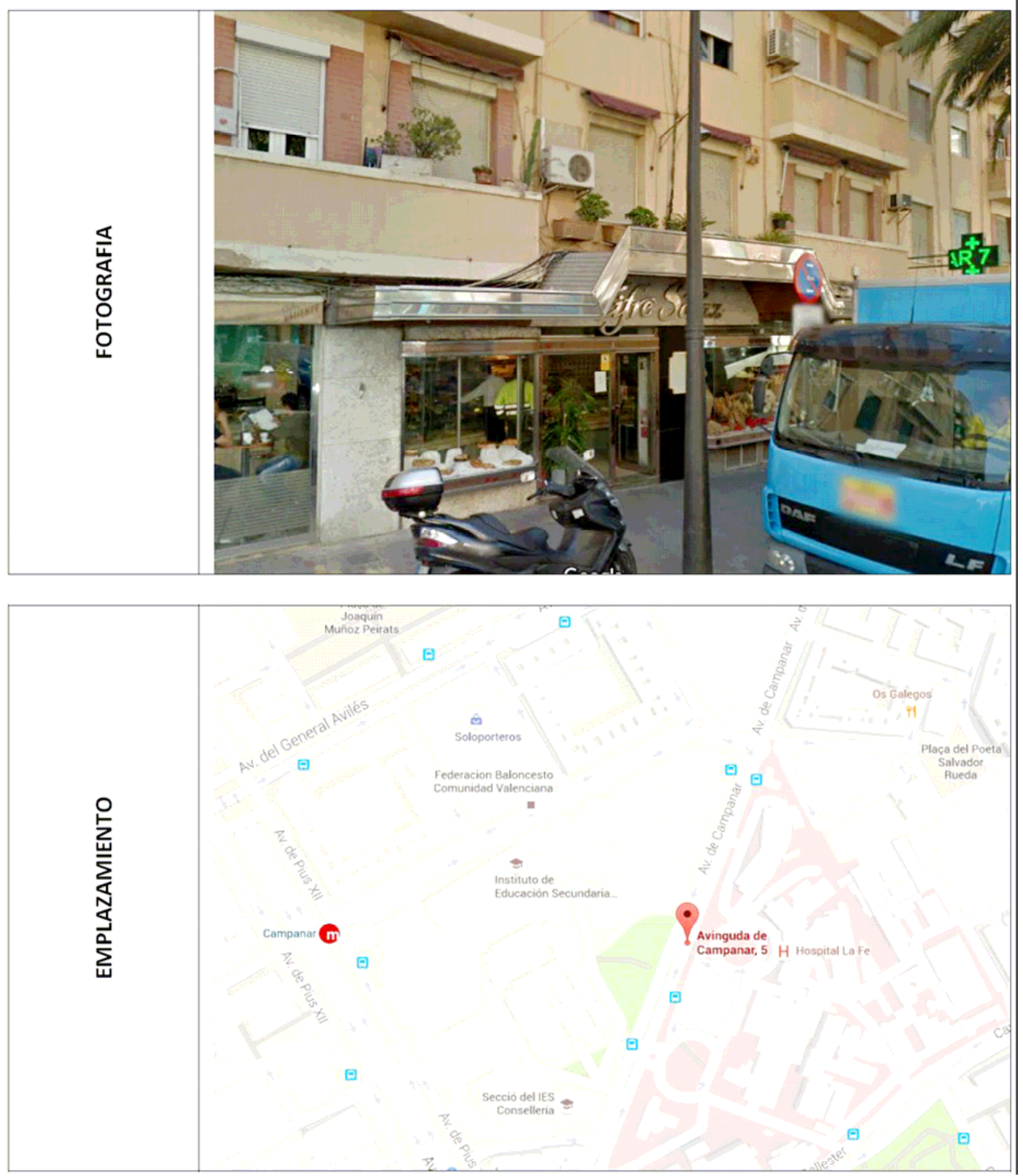


DISTRITO 5.- ZAIDIA

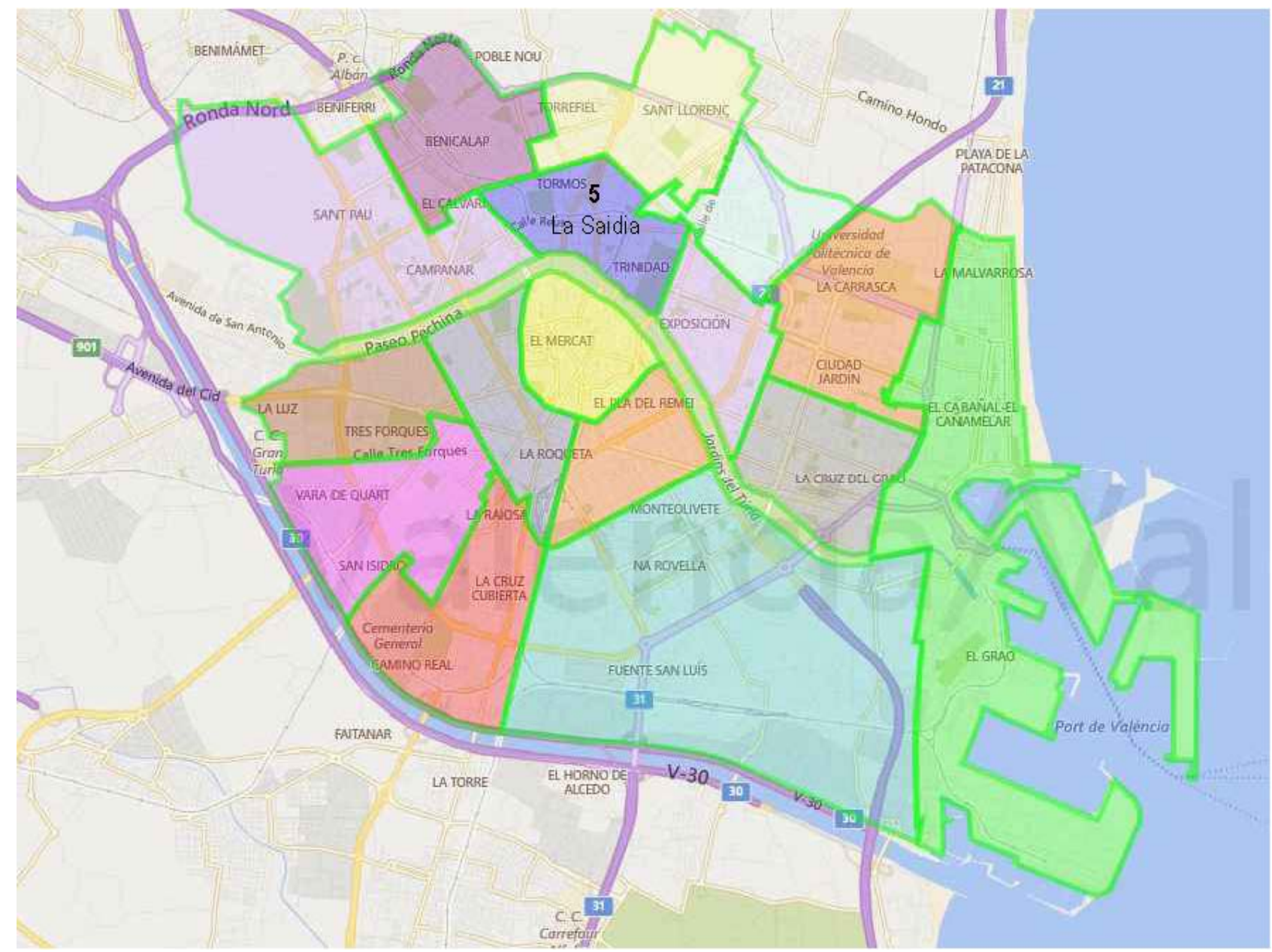

\section{LÍMITES GEOGRÁFICOS.}

-Avda. Dr. Peset Aleixandre, Avda. Primado Reig, C/ Botánico Cavanilles, Cauce viejo del Turia y Avda. de Burjasot. 


\section{EVOLUCIÓN DEL 1985-2014.}

\section{PLANO UBICACIÓN INDUSTRIAS}

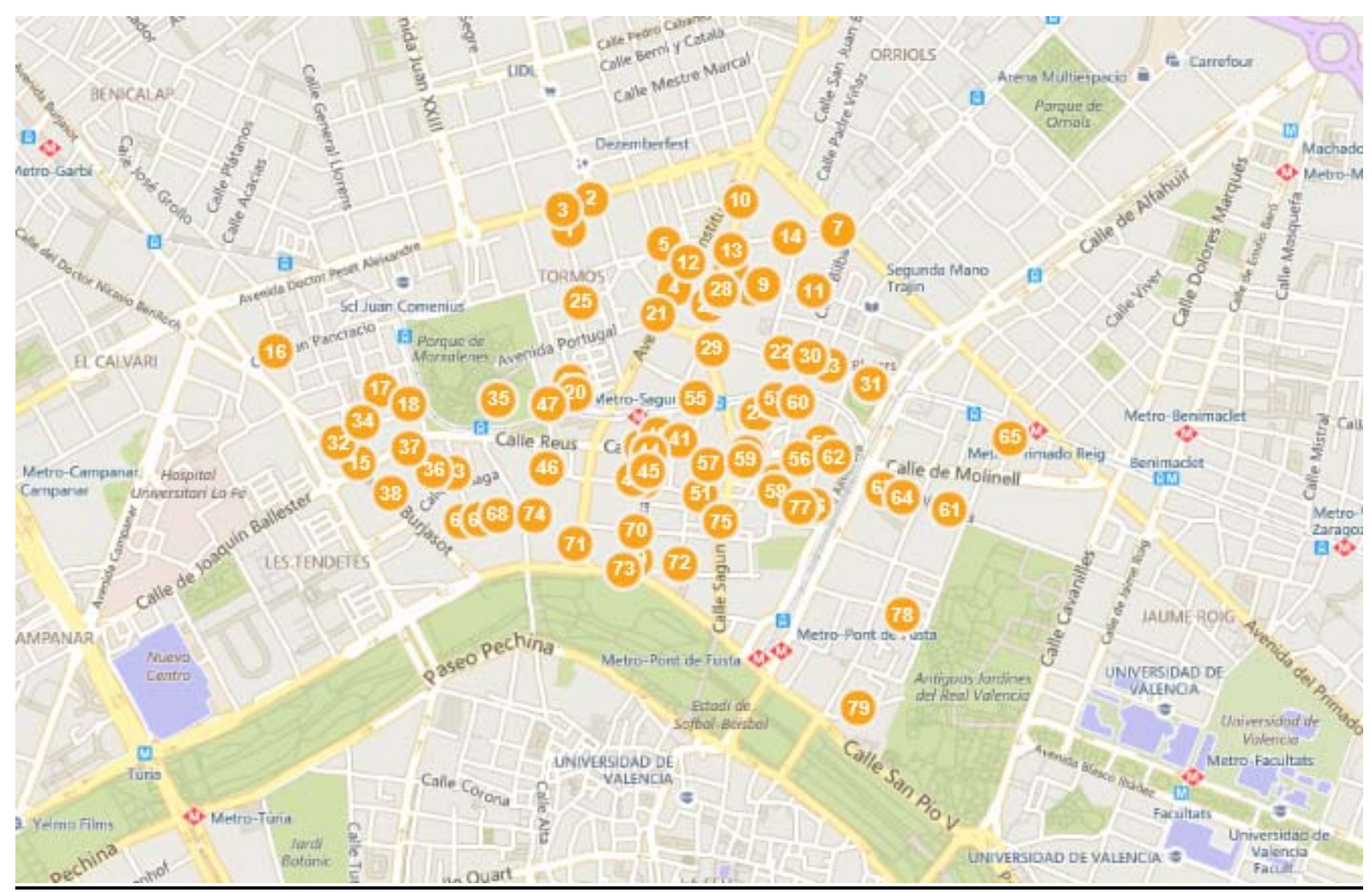

LISTADO DE INDUSTRIAS Y ESTADO ACTUAL .-

1. Querchfels Howahrde, E.J.

Sin actividad

2. TECMAFRI

Tienda de juguetes

3. Matías Villaplana Llorens

Mantiene actividad

4. Safon Lierm, V.

Sin actividad

5. José Álvaro Esteve

Nueva ordenación- Edificio de viviendas

6. Beso Pérez, $v$.

Taller AUTOFECAR 
7. FANDOS BROTHER, S.A.

Tienda de ropa

8. TALLERES FULTON, S.A.

Alquiler de trasteros

9. Lafuente Fayos, R.

Clínica dental/ Trasteros

10. Rafael Martínez Benlloch

Mantiene actividad

11. HERMANOS PRATS, S.L.

Escuela de danza

12. BOMBAS IDEAL

Nueva ordenación- Edificio de viviendas

13. BENLLIURE LIS, S.A.

EDIFESA

14. Francisco Puerta

Sin actividad

15. CARLOS GENS, S.L.

Sin actividad

16. Andreu Querol, L. "JUST"

Mantiene la actividad

17. TEMEL, S.A.

Sin actividad

18. ANTONIO GARCÍA SANCHO, S.A.

Sin actividad

19. Martínez Martínez, Gabriel

Sin actividad

20. Marco Pardo, E.

Taller

21. Adela Bosch Gasco

Nueva ordenación- calle

22. LAMIPLAST, S.A.

Mantiene la actividad

23. CARDELS, S.A.

Tienda de frutos secos

24. FERRANDO GUANTER, S.L.

Sin actividad

25. Salvador Fuster

Sin actividad

26. Forn Aguilar, $\mathbf{J}$.

Obra nueva 
27. Villarroya Costa, D.

Obra nueva

28. Calvet Civer, $\mathbf{J}$.

Obra nueva

29. Barbera Girbes, J.J.

Sin actividad

30. Mercedes Donate Faustino

Otra actividad

31. FEVE - FERROCARRILES DE VALENCIA

Nueva ordenación- Zona verde

32. CONSTRUCCIONES Y APLICACIONES DE LA MADERA

Mantiene la actividad

33. Valkens Waard, W.L.

Sin actividad

34. ANTONIO GARCÍA SANCHO, S.A.

Nueva ordenación- Zona verde

35. Juan Alfonso Alabau

Nueva ordenación- zona verde

36. DAMEL, S.A.

Limpiezas

37. CAIPSA

Supermercado

38. Antonio Giménez Esteban

Solar

39. HERMANOS LUCIA, S.A.

Nueva ordenación- Edificio de viviendas

40. CONTROL Y VERIFICACIÓN, S.A. (C.Y.V.S.A.)

Sin actividad

41. Gallur Calvo, E.

Nueva ordenación- Calle

42. Ripoll Mora, F.

Sin actividad

43. José Castilla Rienda

Sin actividad

44. Aranda Alfonso, S.

Sin actividad

45. SANZ LIMITADA

Casal fallero

46. ELECNOR, S.A.

Sin actividad 
47. IMECA DE VALENCIA S.A.

Nueva ordenación- zona verde

48. COMPEX, S.A.

Sin actividad

49. Miguel García

Nueva ordenación- edificio

50. COSPA, S.L.

Reformas

51. Morera Reig, $\mathrm{V}$.

Obra nueva

52. CONSTRUCCIÓY MAQUINARIA TIRAMAT, S.A.

Sin actividad

53. José Bueso Estellés

Sin actividad

54. JOSE PEREZ BORRULL, S.A.

Fábrica de bolsos

55. METALSOL, S.A.

Pizzería- Kebab

56. HOFMANN, S.A.

Sin actividad

57. Agustín Martínez, J.

Sin actividad

58. LIHETO, S.L.

Sin actividad

59. CONSTRUCCIONES METÁLICAS, M.C., S.L.

Solar

60. MÁRMOLES RAMÓN QUILES

Charcutería

61. Carmelo Casaña

Casal fallero

62. AFILADOS SERRA

Escuela infantil COTO SCHOOL FOR KIDS

63. Enriqueta Campos Borreda

Supermercado

64. BELPLASTINA

Supermercado

65. PROYECTOS MONTAJES ELÉCTRICOS MONTELEC, S.A.

Sin actividad

66. Duran Villarrubi, E.

Solar 
67. RECREATIVOS ENSANCHEZ, S.L.

Sin actividad

68. ISOLAMENTS, S.A.

Tienda de disfraces

69. AFO FRISAL

Autoescuela

70. PROVEEDORES DE METALES, S.A.

Textil

71. Gorrea Fombuena, J.

Solar

72. José María Pérez Cuartiella

Banco

73. Salvador Cebria

Sin actividad

74. COOP. UNION DE FUNDIDORES DE VALENCIA

Solar

75. Sanz Martínez, E.

Mantiene la actividad

76. CONFECCIONES TURIA, S.L.

Obra nueva

77. MARTINEZ Y CATALA, S.L.

Sin actividad

78. GENEROS DE PUNTO JURECA

Solar

79. Perales Castello, J.

Sin actividad

CARACTERÍSTICAS DEL ASENTAMIENTO INDUSTRIAL.

- Tradicional coexistiendo con otro de nueva implantación.

- Disperso.

- Heterogéneo, distinguiéndose dos tipos de industrias según tamaño, emplazamiento y época.

\section{CARACTERÍSTICAS DE LOS LOCALES.}

- Se distinguen dos tipos:

- Edificios industriales de mediana superficie entre medianeras situados junto a las vías importantes del distrito (Avda. Burjasot, C/ Sagunto) cuyo asentamiento data de finales del siglo XIX y principios del XX. 
- De pequeña superficie situados en bajos de viviendas tanto tradicionales como de nueva implantación.

CARACTERÍSTICAS DE LAS ACTIVIDADES.-

- Se censaron inicialmente 79 industrias y en el período de vigencia del Plan General han quedado solamente 4 creándose 45 nuevas industrias.

- Las actividades dominantes son maquinaria y equipo mecánico, material eléctrico e industria de la madera y el mueble.

\section{IMPACTO EN EL MEDIO AMBIENTE.}

- Contaminación ambiental: Escasa dada la existencia de alcantarillado y las características no contaminantes de la mayor parte de las industrias.

- Transporte: de cierta importancia en las empresas de tamaño medio situadas por ello en las proximidades de las vías principales de comunicación, irrelevante en las pequeñas industrias situadas en bajos.

- Integración en el entorno: la industria tradicional de tamaño medio plantea notables problemas de integración en la trama urbana puesto que esta ha ido creciendo sin tener en cuenta las preexistencias de carácter industrial o más bien tratando de eliminarlas. 
EDIFICIOS INDUSTRIALES DE INTERES.-

- CARLOS GENS, S.L.

Avda. de Burjasot, na 54 (Clave 4R-1)

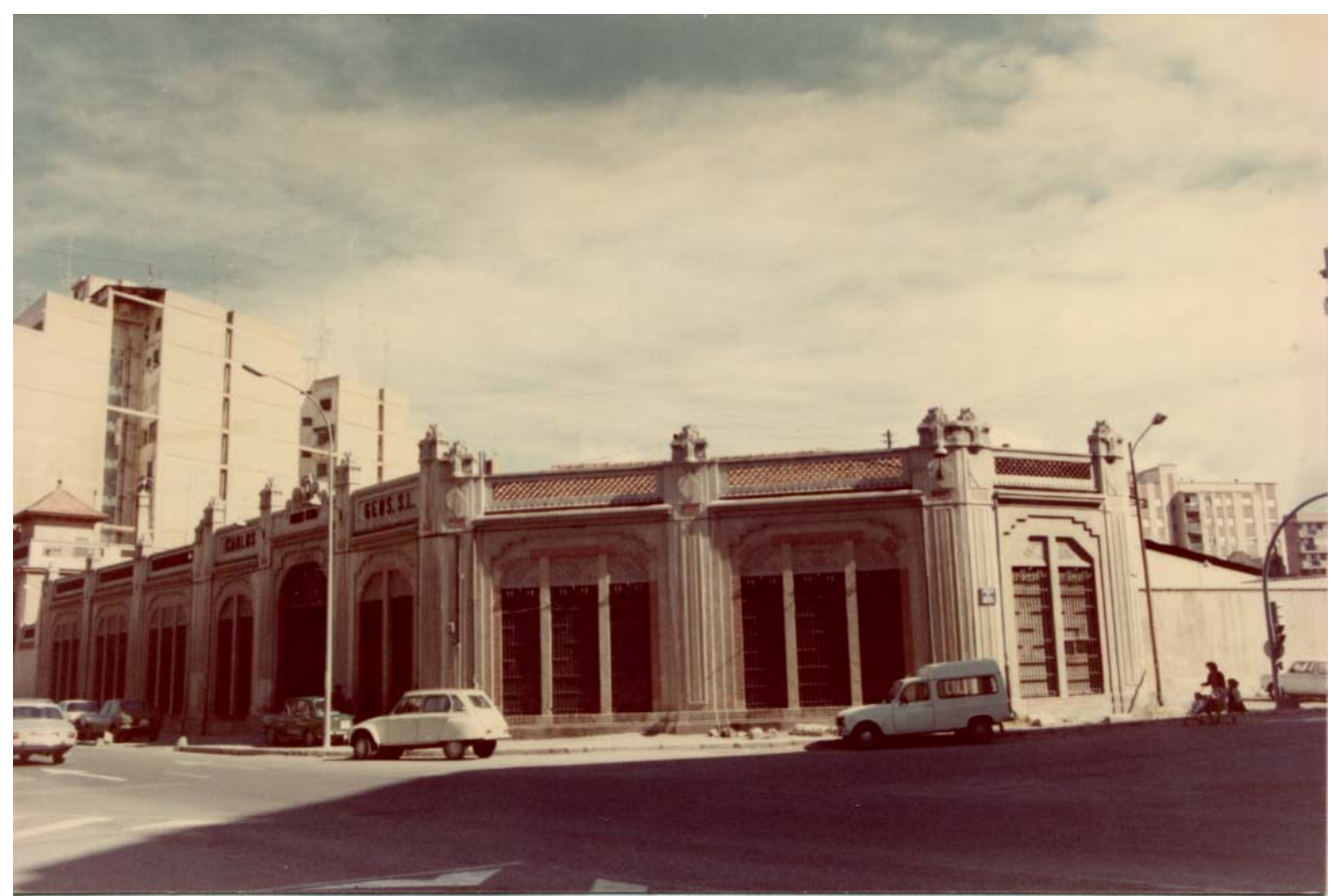

Foto 21: Fábrica de bombas y válvulas Carlos Gens, S.L. Avda. Burjasot, 54. Valencia.1985. Fuente: Elaboración propia

- FEVE, Ferrocarriles de Valencia.

C/ Maximiliano Thous, na 56 (Clave 4K-1)

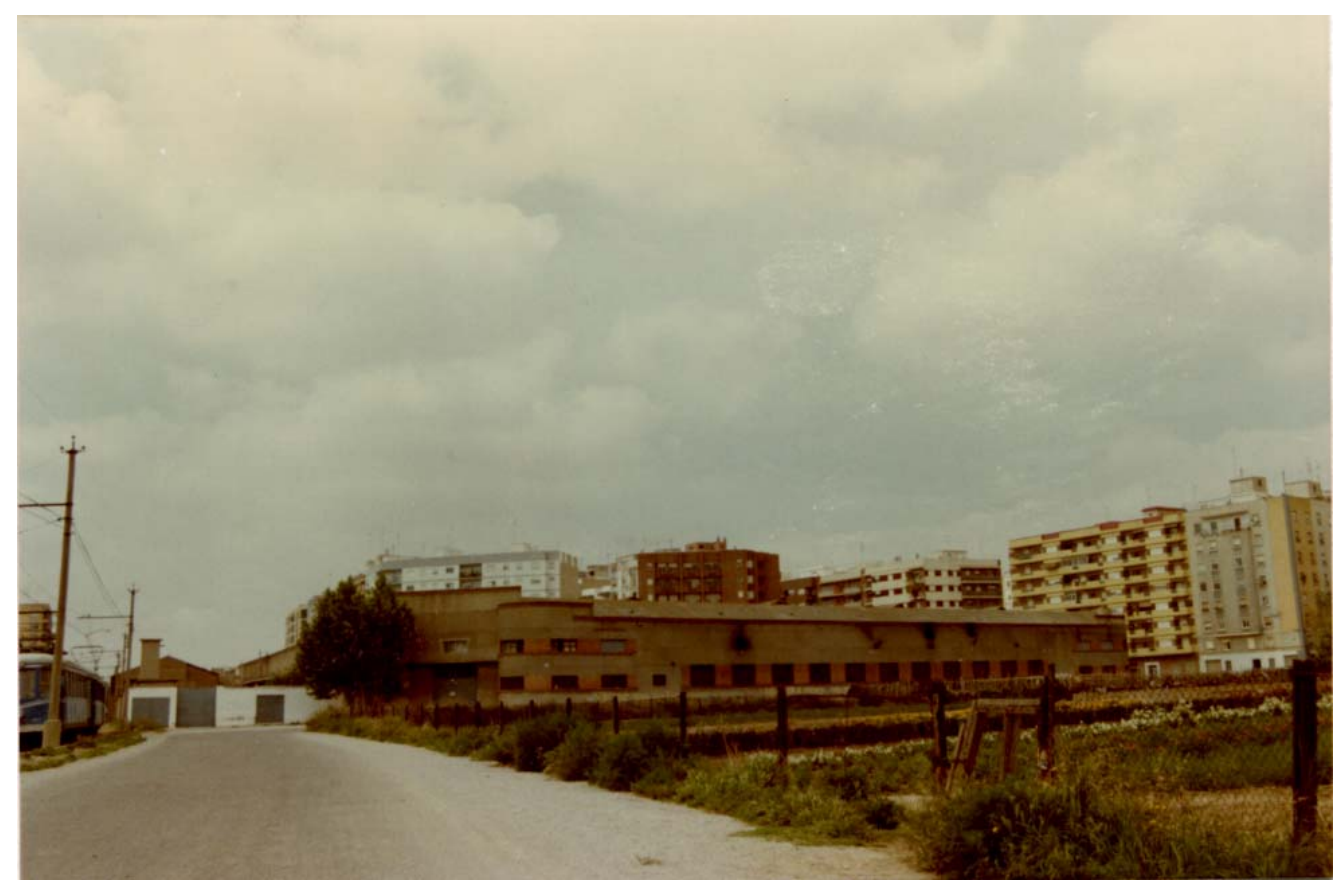

Foto 22: FEVE. Ferrocarriles de Valencia. C/ Maximiliano Thous, 56. Valencia. 1985

Fuente: Elaboración propia 
- $\quad$ TITULAR DESCONOCIDO.

C/ Arzobispo Fabián y Fuero, s/n. (Clave 6L)

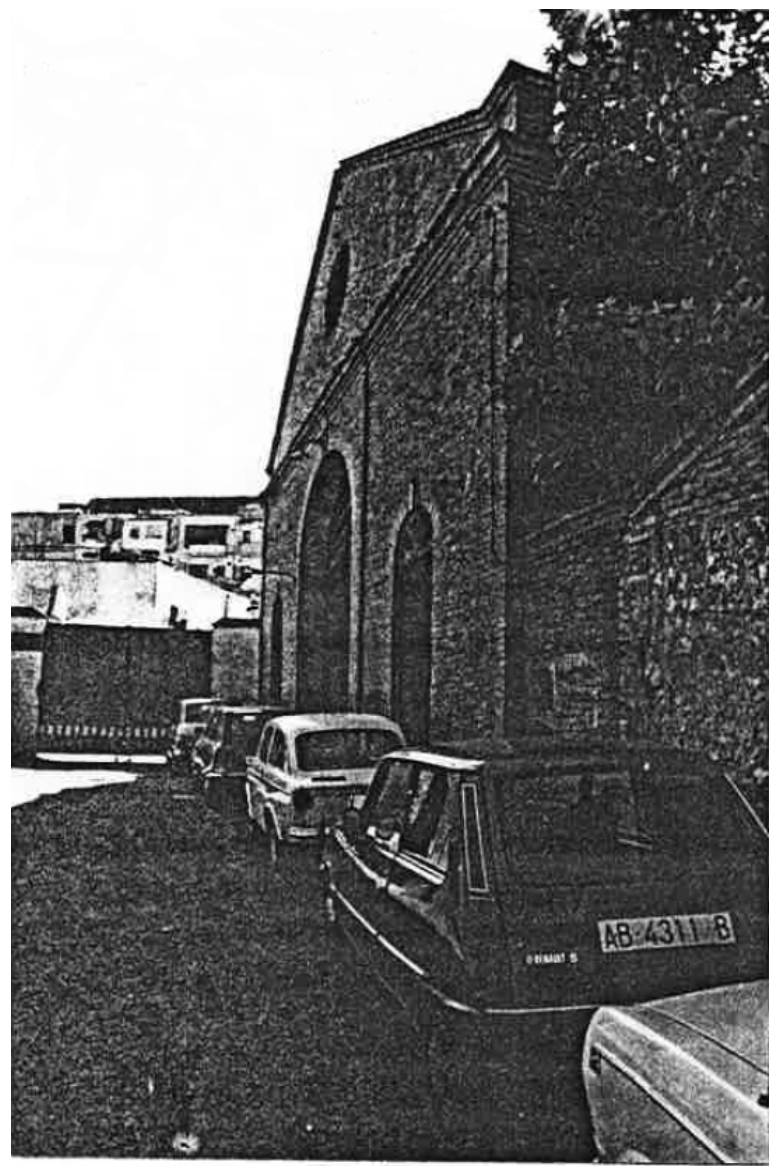

Foto 23: Nave industrial. Cl Arzobispo Fabián y Fuero, s/n.. Valencia. 1985 Fuente: Elaboración propia

TIPOLOGÍA EDIFICACIÓN

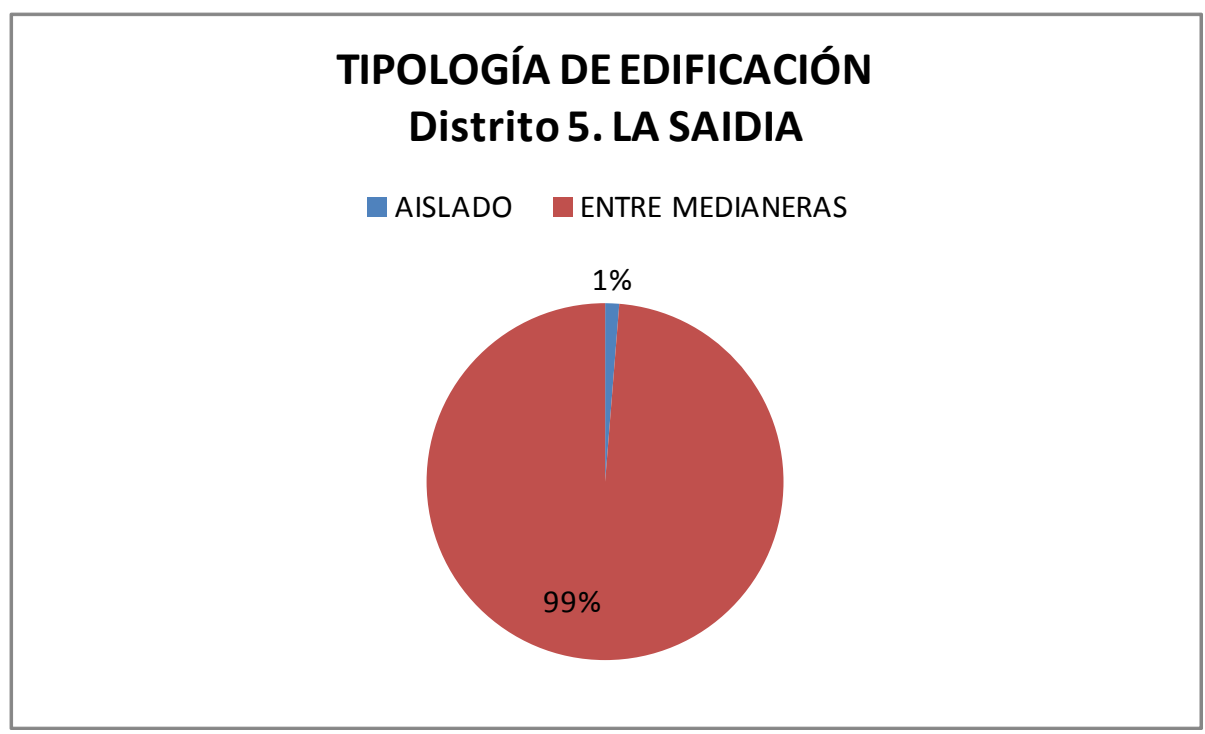




\section{ACTIVIDAD INDUSTRIAL, SUPERFICIE Y EMPLEO}

\begin{tabular}{|c|c|c|c|c|c|}
\hline \multicolumn{6}{|c|}{ DISTRITO 5 - LA SAIDIA (ATIVIDAD INDUSTRIAL Y EMPLEO) } \\
\hline ACTIVIDAD & $\begin{array}{c}\text { № } \\
\text { EMPRESAS }\end{array}$ & $\begin{array}{c}\text { SUP. ACTIVIDAD } \\
\text { IND }\left(\mathrm{m}^{2}\right)\end{array}$ & $\begin{array}{c}\text { \% SUP. } \\
\text { INDUSTRIAL }\end{array}$ & $\begin{array}{c}\text { № } \\
\text { EMPLEADOS }\end{array}$ & \begin{tabular}{|c} 
DENSIDAD \\
EMPLEO \\
(empleados $/ \mathrm{m}^{2}$ \\
actividad) \\
\end{tabular} \\
\hline INDUSTRIAS DE PRODUCTOS MINERALES NO METÁLICOS & 3 & 620 & 0,87 & 19 & 0,0306 \\
\hline FABRICACIÓN DE PRODUCTOS METÁLICOS & 14 & 6032 & 8,42 & 99 & 0,0164 \\
\hline CONSTRUCCIÓN DE MAQUINARIA Y ÉQUIPO MECÁNICO & 7 & 11895 & 16,61 & 229 & 0,0193 \\
\hline CONSTRUCCIÓN DE MAQUINARIA Y MATERIAL ELÉCTRICO & 7 & 2280 & 3,18 & 157 & 0,0689 \\
\hline FABRICACIÓN DE MATERIAL ELECTRÓNICO & 1 & 200 & 0,28 & 12 & 0,0600 \\
\hline CONSTRUCCIÓN DE OTRO MATERIAL DE TRANSPORTE & 1 & 12200 & 17,03 & 123 & 0,0101 \\
\hline INDUSTRIAS DE PRODUCTOS ALIMENTICIOS, BEBIDAS Y TABACO & 8 & 4642 & 6,48 & 101 & 0,0218 \\
\hline INDUSTRIAS DE PRODUCTOS ALIMENTICIOS, BEBIDAS Y TABACO & 2 & 1150 & 1,61 & 5 & 0,0043 \\
\hline INDUSTRIA TEXTIL & 3 & 1250 & 1,75 & 40 & 0,0320 \\
\hline INDUSTRIA DEL CUERO & 5 & 4252 & 5,94 & 72 & 0,0169 \\
\hline INDUSTRIA DEL CALZADO Y DEL VESTIDO Y OTRAS CONFECCIONES TEXTILES & 3 & 730 & 1,02 & 38 & 0,0521 \\
\hline INDUSTRIAS DE MADERA, CORCHO Y MUEBLES DE MADERA & 9 & 13192 & 18,42 & 87 & 0,0066 \\
\hline INDUSTRIA DEL PAPEL Y FABRICACIÓN DE ARTÍCULOS DE PAPEL, ARTES GRÁFICAS & 1 & 1400 & 1,95 & 90 & 0,0643 \\
\hline INDUSTRIAS DE TRANSFORMACIÓN DEL CAUCHO Y MATERIAS PLÁSTICAS & 1 & 120 & 0,17 & 8 & 0,0667 \\
\hline OTRAS INDUSTRIAS MANUFACTURERAS & 1 & 200 & 0,28 & 16 & 0,0800 \\
\hline CONSTRUCCIÓN & 6 & 4770 & 6,66 & 101 & 0,0212 \\
\hline OTROS & 7 & 6690 & 9,34 & 75 & 0,0112 \\
\hline TOTAL & 79 & 71623 & 100 & 1272 & 0,0178 \\
\hline
\end{tabular}

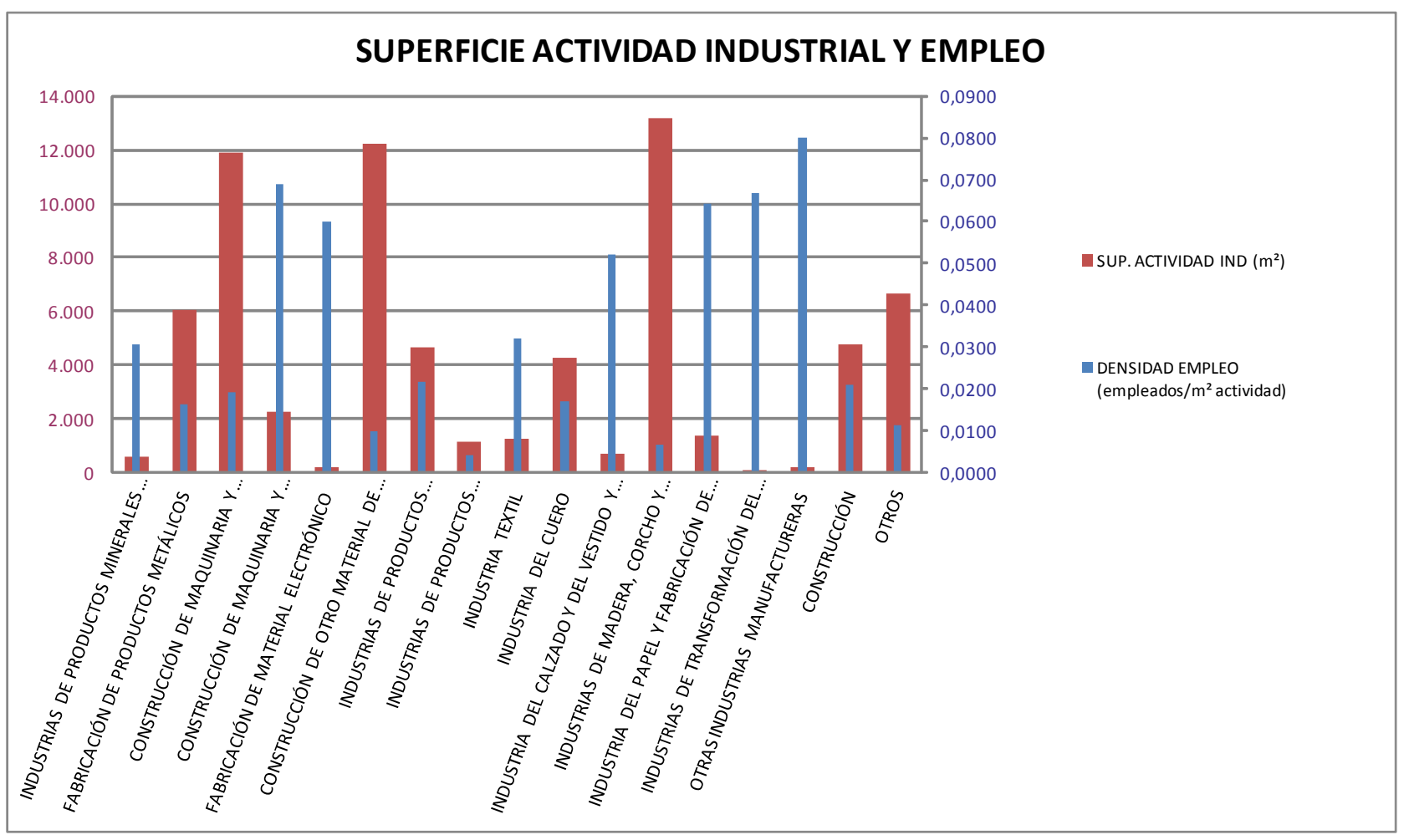




\section{IMPACTO AMBIENTAL}

\begin{tabular}{|c|c|c|c|c|c|}
\hline \multicolumn{6}{|c|}{ DISTRITO 5 - LA SAIDIA (INFORMACIÓN URBANÍSTICA) } \\
\hline ACTIVIDAD & $\begin{array}{l}\text { No } \\
\text { EMPRESAS }\end{array}$ & $\begin{array}{c}\text { ENTRE } \\
\text { MEDIANERAS }\end{array}$ & RUIDOSAS & $\begin{array}{c}\text { EMPRESAS } \\
\text { CON } \\
\text { CHIMENEA }\end{array}$ & $\begin{array}{l}\text { RUIDOSAS Y } \\
\text { CHIMENEA }\end{array}$ \\
\hline INDUSTRIAS DE PRODUCTOS MINERALES NO METÁLICOS & 3 & 3 & 2 & 0 & 0 \\
\hline FABRICACIÓN DE PRODUCTOS METÁLICOS & 14 & 14 & 7 & 2 & 0 \\
\hline CONSTRUCCIÓN DE MAQUINARIA Y ÉQUIPO MECÁNICO & 7 & 7 & 4 & 1 & 0 \\
\hline CONSTRUCCIÓN DE MAQUINARIA Y MATERIAL ELÉCTRICO & 7 & 7 & 2 & 0 & 0 \\
\hline FABRICACIÓN DE MATERIAL ELECTRÓNICO & 1 & 1 & 0 & 0 & 0 \\
\hline CONSTRUCCIÓN DE OTRO MATERIAL DE TRANSPORTE & 1 & 0 & 1 & 0 & 0 \\
\hline INDUSTRIAS DE PRODUCTOS ALIMENTICIOS, BEBIDAS Y TABACO & 8 & 8 & 0 & 5 & 1 \\
\hline INDUSTRIAS DE PRODUCTOS ALIMENTICIOS, BEBIDAS Y TABACO & 2 & 2 & 1 & 0 & 0 \\
\hline INDUSTRIA TEXTIL & 3 & 3 & 2 & 0 & 0 \\
\hline INDUSTRIA DEL CUERO & 5 & 5 & 1 & 1 & 1 \\
\hline INDUSTRIA DEL CALZADO Y DEL VESTIDO Y OTRAS CONFECCIONES TEXTILES & 3 & 3 & 0 & 0 & 0 \\
\hline INDUSTRIAS DE MADERA, CORCHO Y MUEBLES DE MADERA & 9 & 9 & 3 & 0 & 0 \\
\hline $\begin{array}{l}\text { INDUSTRIA DEL PAPEL Y FABRICACIÓN DE ARTÍCULOS DE PAPEL, ARTES GRÁFICAS } \\
\text { Y EDICIÓN }\end{array}$ & 1 & 1 & 0 & 0 & 0 \\
\hline INDUSTRIAS DE TRANSFORMACIÓN DEL CAUCHO Y MATERIAS PLÁSTICAS & 1 & 1 & 1 & 0 & 0 \\
\hline OTRAS INDUSTRIAS MANUFACTURERAS & 1 & 1 & 0 & 0 & 0 \\
\hline CONSTRUCCIÓN & 6 & 6 & 2 & 0 & 0 \\
\hline OTROS & 7 & 0 & 0 & 0 & 0 \\
\hline TOTAL & 79 & 71 & 26 & 9 & 2 \\
\hline
\end{tabular}

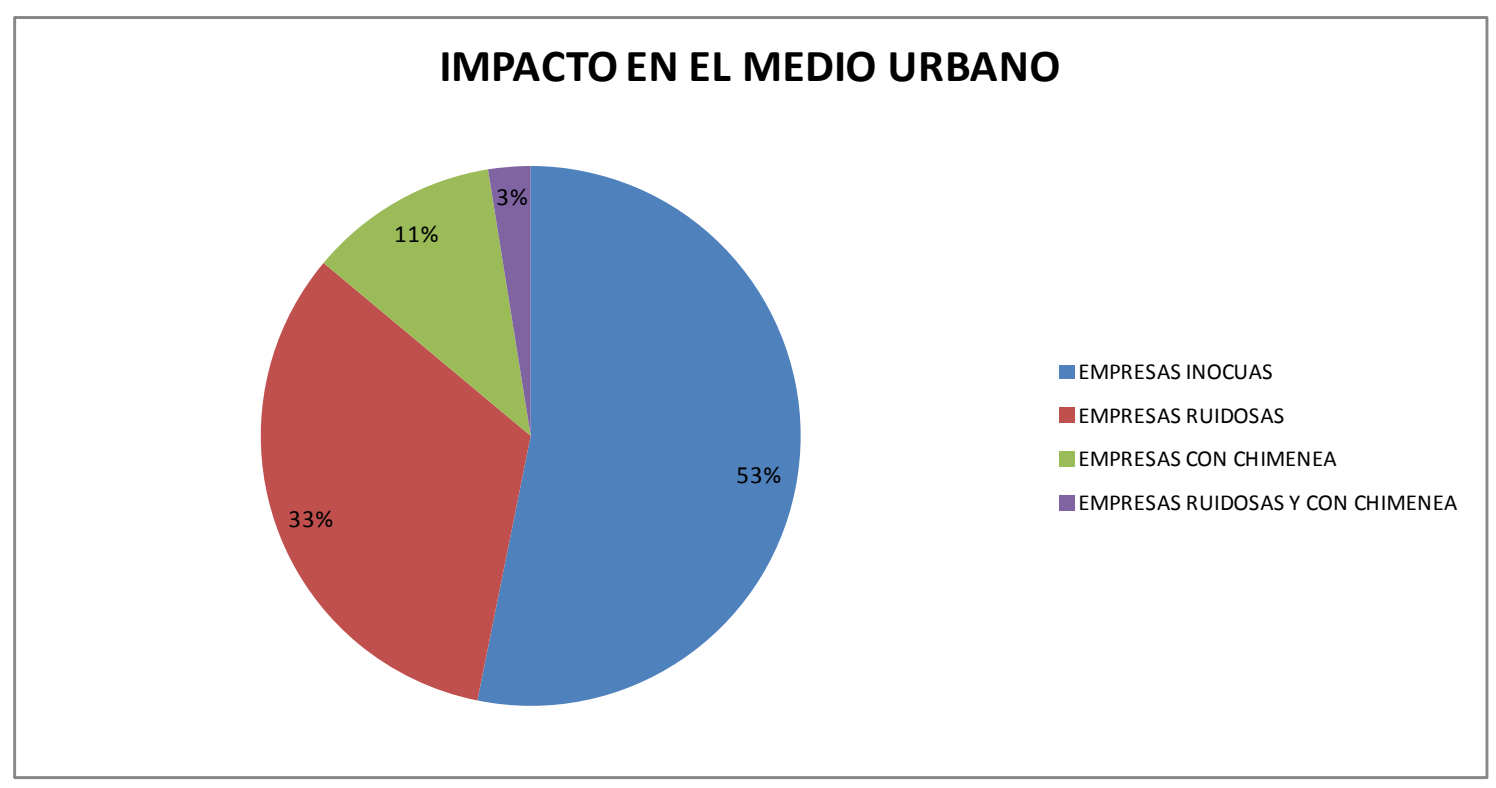




\section{FICHAS TIPO \\ FICHA DATOS DE LA INDUSTRIA}

LOCALIZACION ACTUALIZADA DE ACTIVIDADES INDUSTRIALES EN EL MEDIO URBANO DE VALENCIA

\begin{tabular}{|c|c|c|c|c|c|c|c|}
\hline \multirow{5}{*}{ 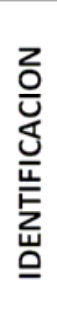 } & \multirow{2}{*}{\multicolumn{2}{|c|}{$\begin{array}{c}\text { NOMBRE } \\
\text { EMPLAZAMIENTO }\end{array}$}} & \multicolumn{5}{|c|}{ CARLOS GENS S.L. } \\
\hline & & & \multicolumn{3}{|l|}{ Av. Burjasot, 54} & C.P. & \\
\hline & \multirow{2}{*}{ CNAE } & \multirow{2}{*}{329} & \multirow{2}{*}{ DESCRIPCION } & \multicolumn{4}{|c|}{$\begin{array}{l}\text { CONSTRUCCIÓN DE MAQUINARIA Y EQUIPO } \\
\text { MECÁNICO }\end{array}$} \\
\hline & & & & \multicolumn{4}{|c|}{ Fabricación de bombas y válvulas } \\
\hline & DISTRITO & 5 & \multicolumn{5}{|c|}{ LA SAIDIA } \\
\hline \multicolumn{3}{|c|}{ SUPERFICIES } & $\begin{array}{l}\text { Sup. Parcela: } \\
5200 \mathrm{~m}^{2}\end{array}$ & $\begin{array}{l}\text { Sup. Ocupada: } \\
4000 \mathrm{~m}^{2}\end{array}$ & $\begin{array}{l}\text { Sup. Construida: } \\
4000 \mathrm{~m}^{2}\end{array}$ & EMPI & $\begin{array}{l}\text { EADOS: } \\
46\end{array}$ \\
\hline
\end{tabular}
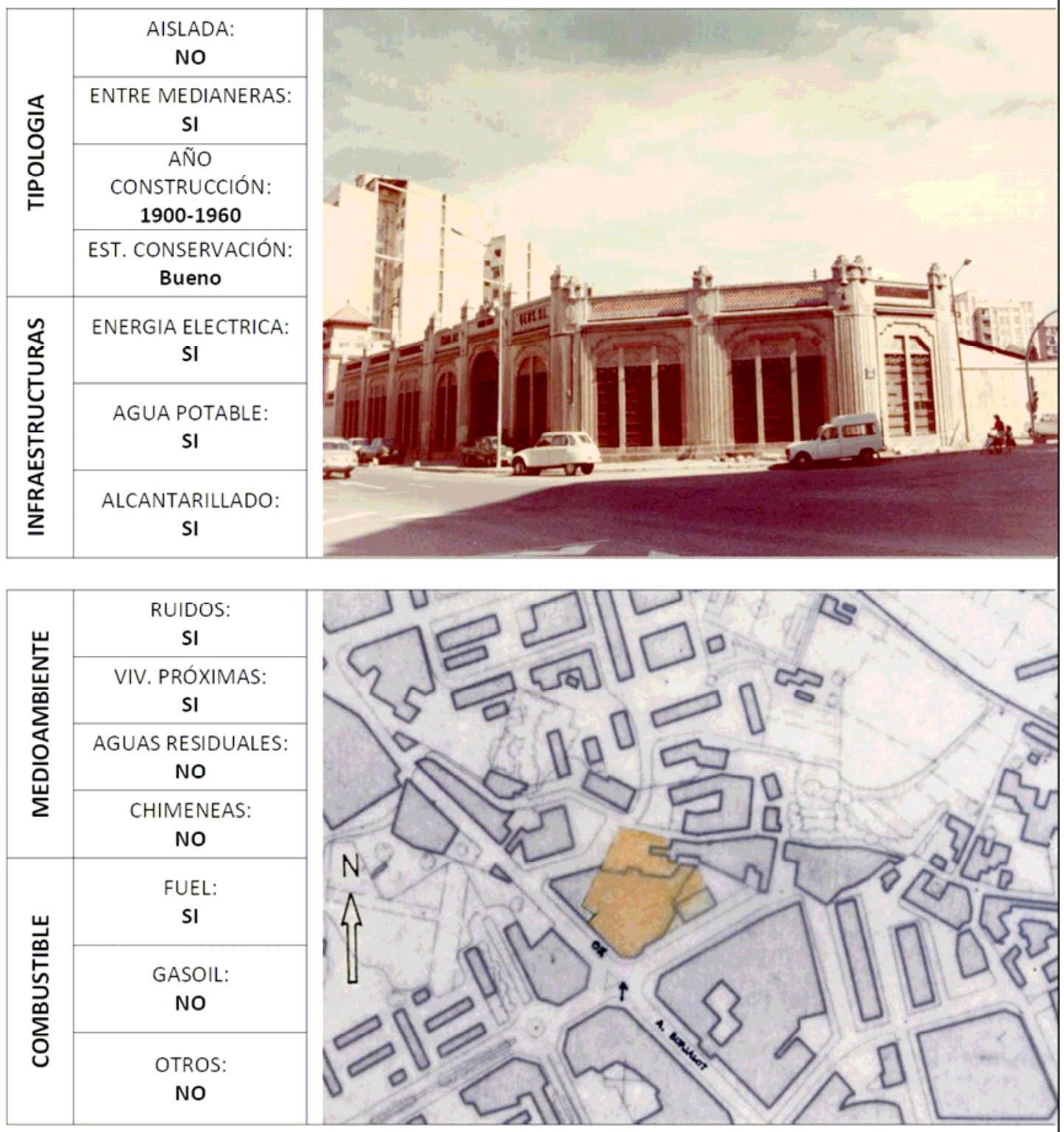


\section{FICHA DATOS DE LA INDUSTRIA}

LOCALIZACION ACTUALIZADA DE ACTIVIDADES INDUSTRIALES EN EL MEDIO URBANO DE VALENCIA

\begin{tabular}{|c|c|c|c|c|c|c|c|}
\hline \multirow{5}{*}{ 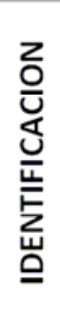 } & \multirow{2}{*}{\multicolumn{2}{|c|}{$\begin{array}{c}\text { NOMBRE } \\
\text { EMPLAZAMIENTO }\end{array}$}} & \multicolumn{5}{|c|}{ IMECA DE VALENCIA S.A. } \\
\hline & & & \multicolumn{3}{|c|}{ C/ Poeta Fernández Heredia, 22} & C.P. & \\
\hline & \multirow[b]{2}{*}{ CNAE } & \multirow[b]{2}{*}{504} & \multirow[b]{2}{*}{ DESCRIPCION } & \multicolumn{4}{|c|}{ CONSTRUCCIÓN } \\
\hline & & & & \multicolumn{4}{|c|}{ Almacén material de construcción } \\
\hline & DISTRITO & 5 & \multicolumn{5}{|c|}{ LA SAIDIA } \\
\hline \multicolumn{3}{|c|}{ SUPERFICIES } & $\begin{array}{l}\text { Sup. Parcela: } \\
3000 \mathrm{~m}^{2}\end{array}$ & $\begin{array}{c}\text { Sup. Ocupada: } \\
3000 \mathrm{~m}^{2}\end{array}$ & $\begin{array}{l}\text { Sup. Construida: } \\
3000 \mathrm{~m}^{2}\end{array}$ & EMPL & ADOS: \\
\hline
\end{tabular}
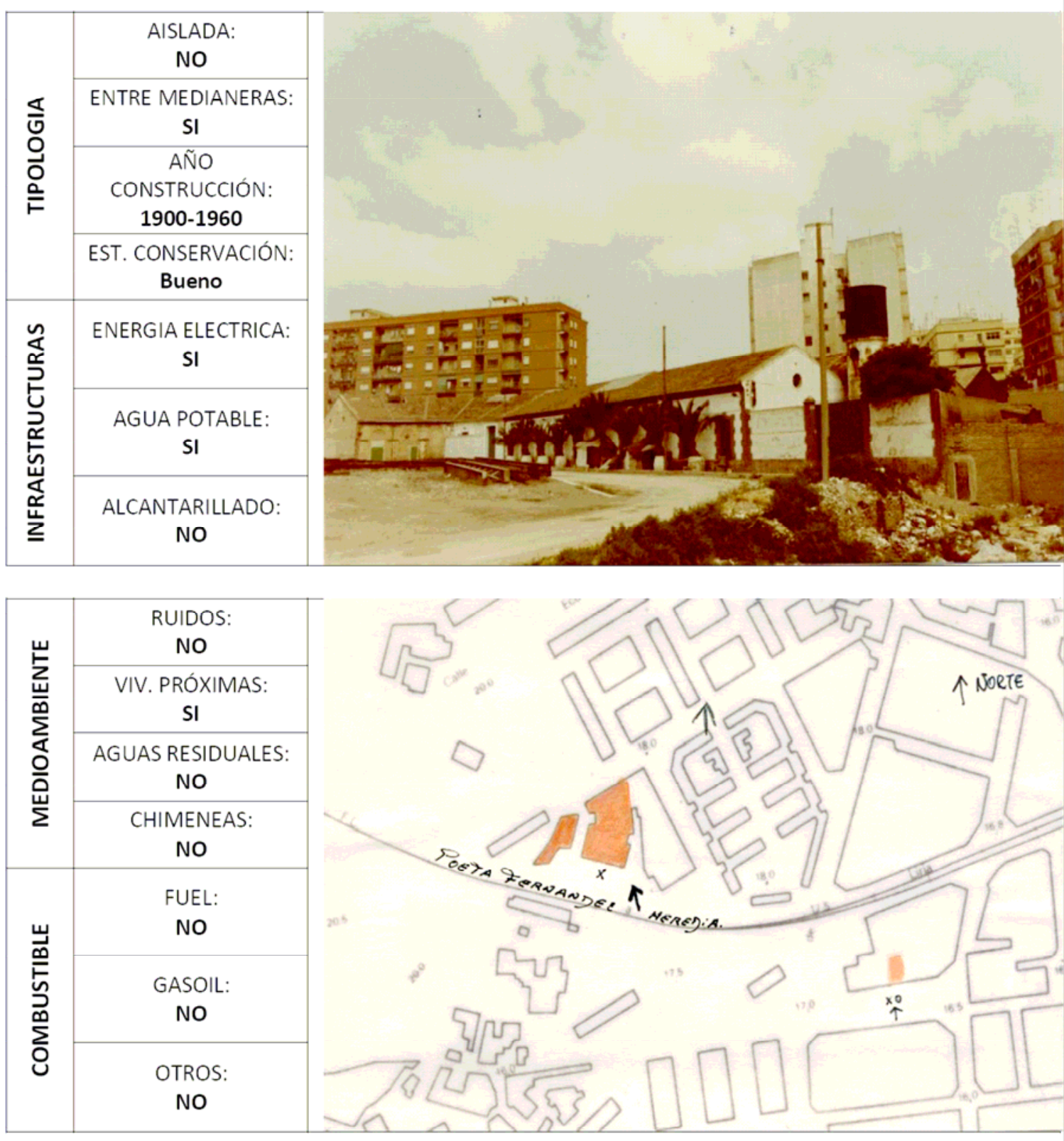


\section{FICHA DATOS DE LA INDUSTRIA}

LOCALIZACION ACTUALIZADA DE ACTIVIDADES INDUSTRIALES EN EL

MEDIO URBANO DE VALENCIA

\begin{tabular}{|c|c|c|c|c|c|c|c|}
\hline \multirow{5}{*}{ 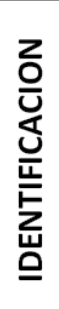 } & \multirow{2}{*}{\multicolumn{2}{|c|}{$\begin{array}{c}\text { NOMBRE } \\
\text { EMPLAZAMIENTO }\end{array}$}} & \multicolumn{5}{|c|}{ DURÁN VILLARUBÍ, E. } \\
\hline & & & \multicolumn{3}{|c|}{ C/ Arzobispo Fabián y Fuero, 31} & C.P. & \\
\hline & \multirow{2}{*}{ CNAE } & \multirow{2}{*}{441} & \multirow{2}{*}{ DESCRIPCION } & \multicolumn{4}{|c|}{ INDUSTRIAS DEL CUERO } \\
\hline & & & & \multicolumn{4}{|c|}{ Curtidos } \\
\hline & DISTRITO & 5 & \multicolumn{5}{|c|}{ LA SAIDIA } \\
\hline & \multicolumn{2}{|c|}{ SUPERFICIES } & $\begin{array}{l}\text { Sup. Parcela: } \\
2500 \mathrm{~m}^{2}\end{array}$ & $\begin{array}{c}\text { Sup. Ocupada: } \\
2000 \mathrm{~m}^{2}\end{array}$ & $\begin{array}{l}\text { Sup. Construida: } \\
2750 \mathrm{~m}^{2}\end{array}$ & EMF & $\begin{array}{l}\text { EADOS: } \\
22\end{array}$ \\
\hline
\end{tabular}
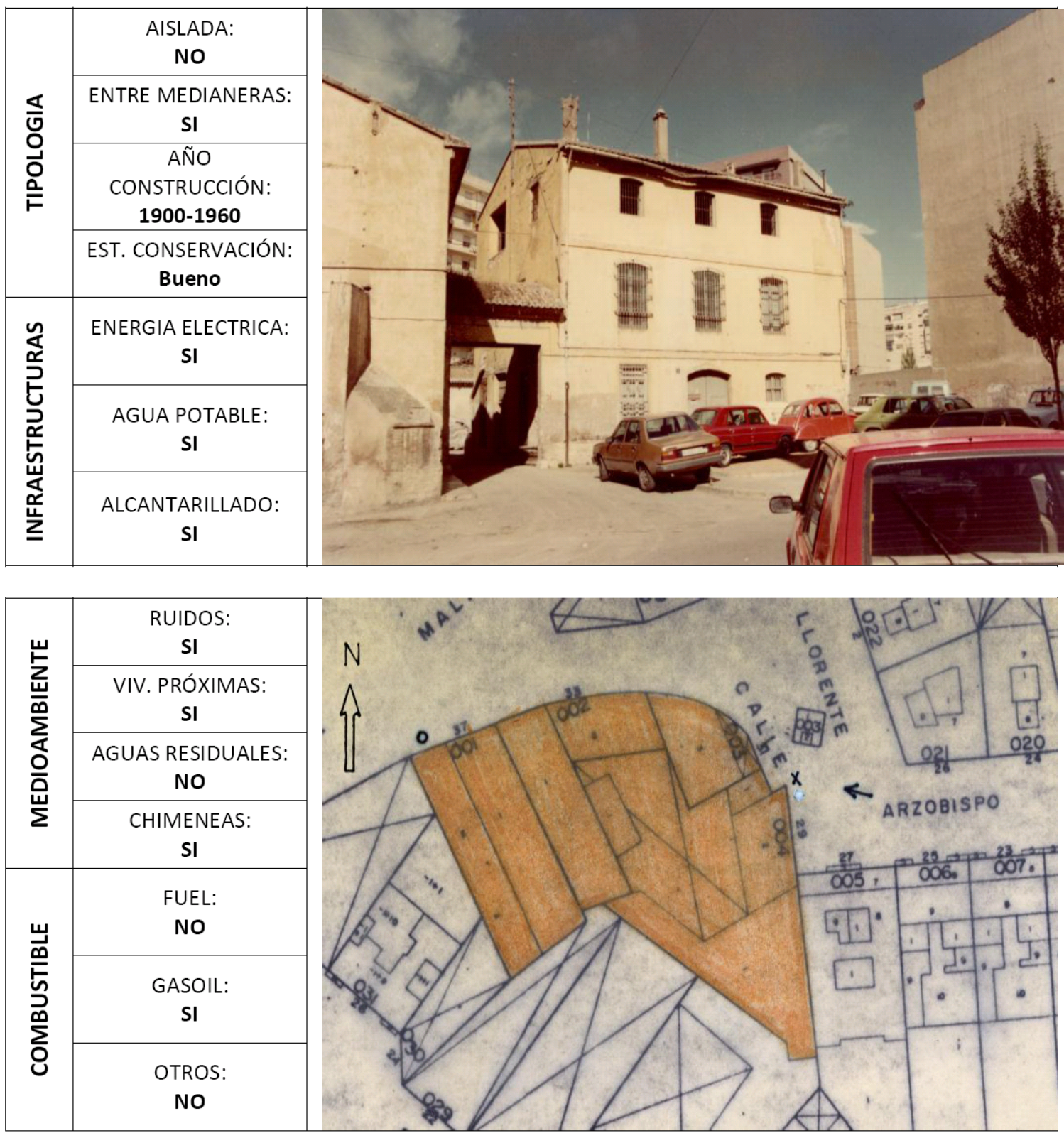

EN LA ACTUALIDAD: SOLAR 


\section{FICHA DATOS DE LA INDUSTRIA}

LOCALIZACION ACTUALIZADA DE ACTIVIDADES INDUSTRIALES EN EL

MEDIO URBANO DE VALENCIA

\begin{tabular}{|c|c|c|c|c|c|c|c|}
\hline \multirow{5}{*}{ 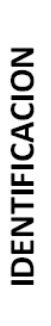 } & \multirow{2}{*}{\multicolumn{2}{|c|}{$\begin{array}{c}\text { NOMBRE } \\
\text { EMPLAZAMIENTO }\end{array}$}} & \multicolumn{5}{|c|}{ SANZ MARTÍNEZ, E. } \\
\hline & & & \multicolumn{3}{|l|}{ C/ Sagunto, 37} & C.P. & \\
\hline & \multirow{2}{*}{ CNAE } & \multirow{2}{*}{419} & \multirow{2}{*}{ DESCRIPCION } & \multicolumn{4}{|c|}{$\begin{array}{l}\text { INDUSTRIA DE PRODUCTOS ALIMENTICIOS, } \\
\text { BEBIDA, ETC. }\end{array}$} \\
\hline & & & & \multicolumn{4}{|c|}{ Horno } \\
\hline & DISTRITO & 5 & \multicolumn{5}{|c|}{ LA SAIDIA } \\
\hline & \multicolumn{2}{|c|}{ SUPERFICIES } & $\begin{array}{l}\text { Sup. Parcela: } \\
120 \mathrm{~m}^{2}\end{array}$ & $\begin{array}{l}\text { Sup. Ocupada: } \\
120 \mathrm{~m}^{2}\end{array}$ & $\begin{array}{l}\text { Sup. Construida: } \\
120 \mathrm{~m}^{2}\end{array}$ & EMP & $\begin{array}{l}\text { LEADOS: } \\
6\end{array}$ \\
\hline
\end{tabular}
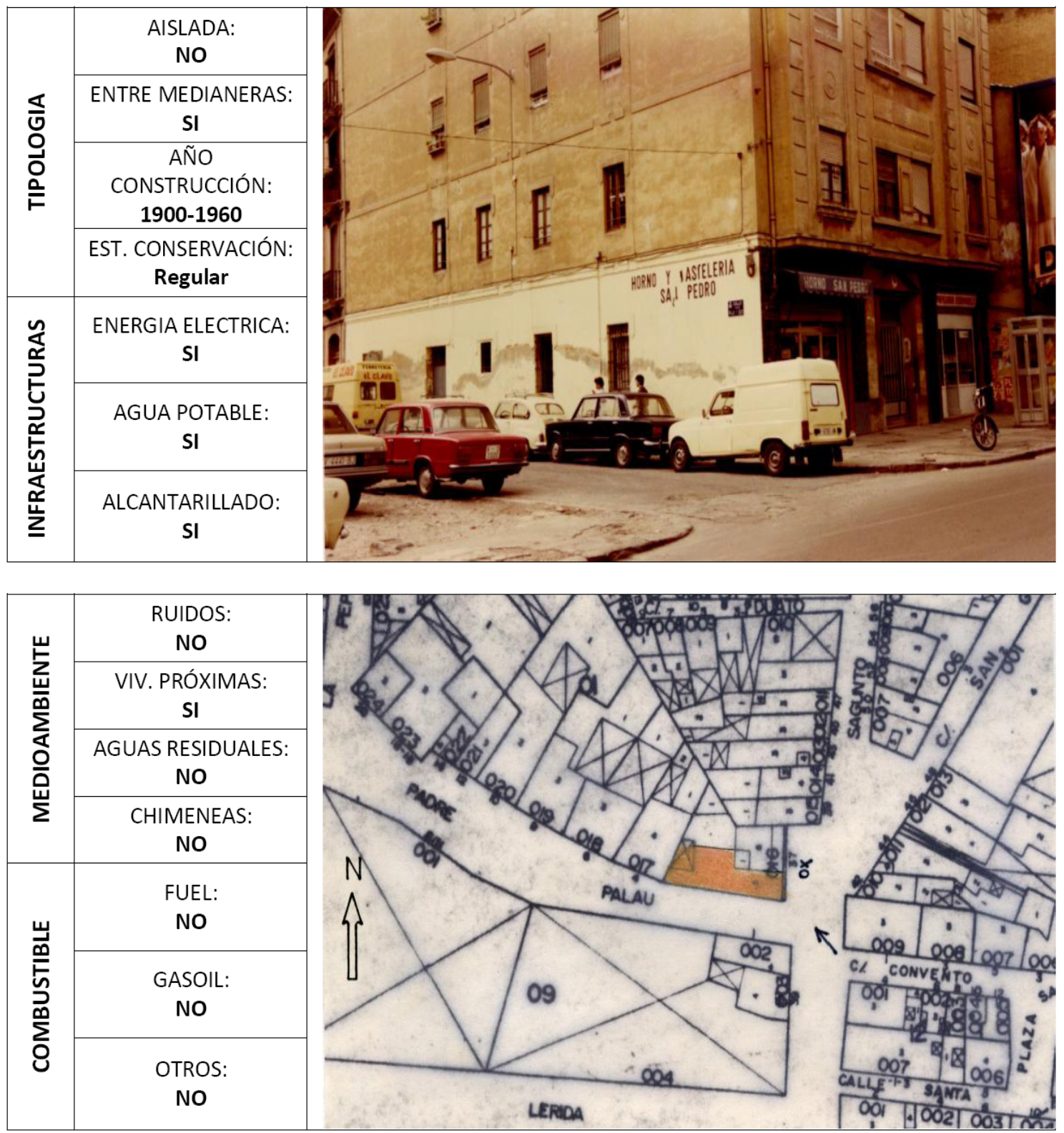


\section{EVOLUCIÓN}

\section{PLANO UBICACIÓN INDUSTRIAS}

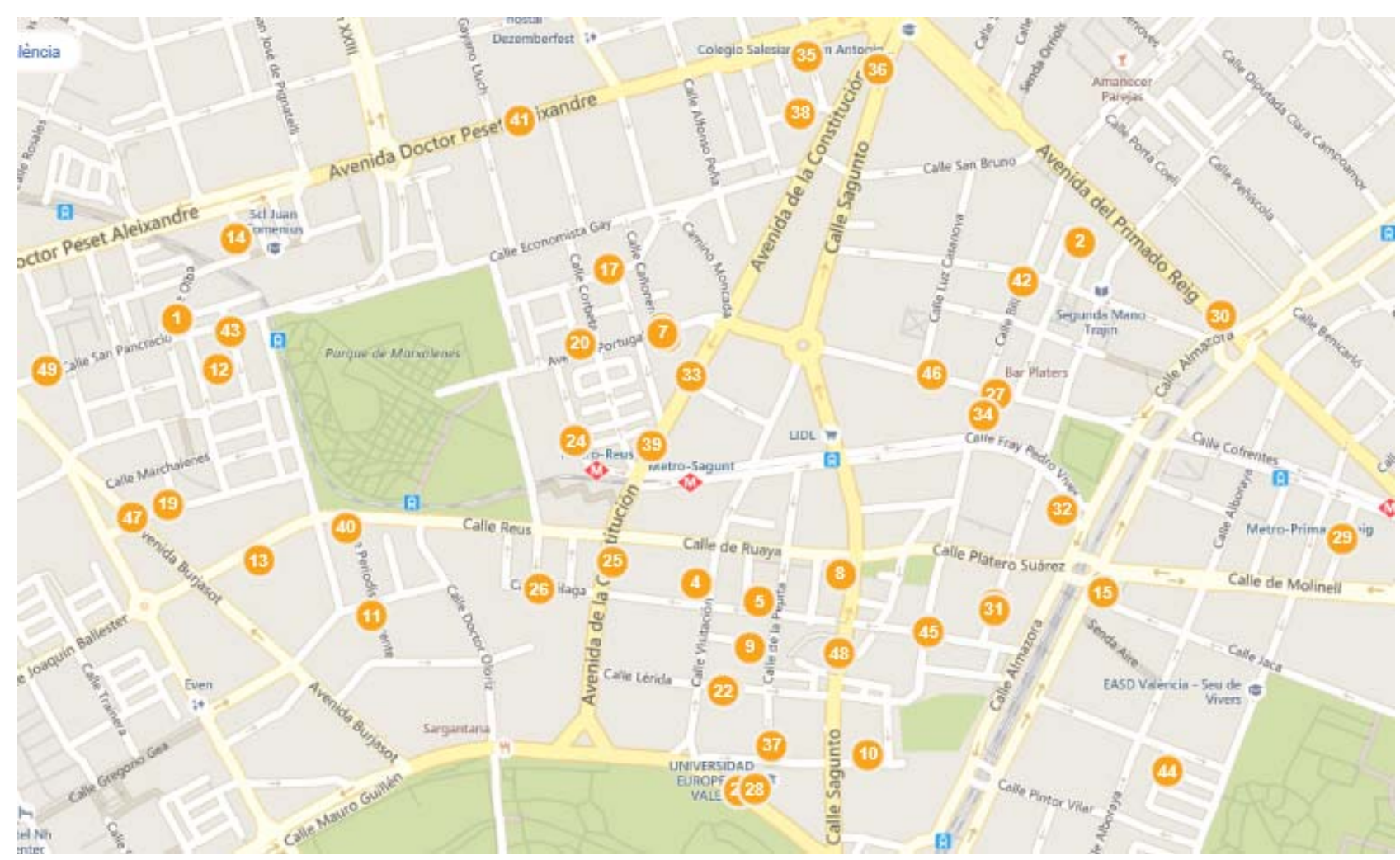

LISTADO DE INDUSTRIAS Y ACTIVIDAD.-

1. José María Escribano Alarcón

Fabricación de otros muebles

2. GRUPO ORIENTACION DISEÑO

Fabricación de muebles de oficina y de establecimientos comerciales

3. COLORES BONIC, 2000 S.L.

Fabricación de otros muebles

4. Antonio Mateos Romero

Fabricación de otros muebles

5. Miguel Rodilla Medina

Fabricación de otros muebles

6. Manuel Pérez Almonacil

Fabricación de artículos de joyería y artículos similares

\section{José Andrés Alós}

Fabricación de artículos confeccionados con textiles, excepto prendas de vestir 


\section{Julián Jerez Lezcano}

Fabricación de artículos confeccionados de textiles, excepto prendas de vestir.

9. Agustín Ibáñez Cuerda

Fabricación instrumentos y suministros médicos y odontológicos.

10. Silviano Pérez Luján

Fabricación instrumentos y suministros médicos y odontológicos

\section{Matías Olivares Lara}

Fabricación de carpintería metálica

12. VALPREMAQ 2014 S.L.

Fabricación de productos básicos de hierro, acero y ferro aleaciones.

13. José Sevilla Albaladejo

Mantenimiento y reparación de vehículos de motor

14. José Carlos Soriano Campos

Mantenimiento y reparación de vehículos de motor

\section{Francisco Giménez Romero}

Mantenimiento y reparación de vehículos de motor

16. Javier García García

Mantenimiento y reparación de vehículos de motor

17. Ricardo Pérez García

Mantenimiento y reparación de vehículos de motor

18. TALLERES BANCADA C.B.

Mantenimiento y reparación de vehículos de motor

19. Gregorio Manzanera Peña

Mantenimiento y reparación de vehículos de motor

20. Lisardo Alfredo Río Rodríguez

Mantenimiento y reparación de vehículos de motor

21. Ángel Pedroche Martínez

Mantenimiento y reparación de vehículos de motor

22. Vicente Pico Ramón

Mantenimiento y reparación de vehículos de motor

23. TALLERES CUBAS C.B.

Mantenimiento y reparación de vehículos de motor

24. TALLERES BANCADA C.B.

Mantenimiento y reparación de vehículos de motor

25. MARCO Y MÉNDEZ C.B.

Mantenimiento y reparación de vehículos de motor

26. Vicente Belenguer Belenguer

Mantenimiento y reparación de vehículos de motor

27. Francisco Martín Gómez

Mantenimiento y reparación de vehículos de motor 


\section{Alonso Martínez Espasa}

Mantenimiento y reparación de vehículos de motor

29. Pablo Ros Ros

Mantenimiento y reparación de vehículos de motor

30. TALLERES R\&J C.B.

Mantenimiento y reparación de vehículos de motor

\section{Silverio Cubas Cantos}

Mantenimiento y reparación de vehículos de motor

32. Alejandro Real Valles

Fabricación de otros productos de madera; artículos de corcho, cestería y espartería

33. $M^{\mathrm{a}}$ Luisa Ortiz Lacomba

Confección de otras prendas de vestir exteriores

34. Emilio Fornas Casamayor

Confección de otras prendas de vestir y accesorios

\section{Alberto Candel Martínez}

Confección de otras prendas de vestir y accesorios

36. Pablo Arribas Buendía

Confección de otras prendas de vestir exteriores

37. JOSE RUZMAR CONFECCIONES S.L.

Confección de otras prendas de vestir exteriores

38. LOMA PIEL S.C.P.

Fabricación de artículos de peletería

39. HERMANO CORTES C.B.

Fabricación de pan y de productos frescos de panadería y pastelería

40. HORNO LOFER S.L.

Fabricación de pan y de productos frescos de panadería y pastelería.

41. PANADERÍA PASTELERÍA RAFAEL LORENTE S.L.

Fabricación de pan y de productos frescos de panadería y pastelería.

42. JOPANA, 7 S.L.

Fabricación de pan y de productos frescos de panadería y pastelería.

43. Manuel Fernández Ibáñez

Fabricación de pan y de productos frescos de panadería y pastelería.

44. LABORATORIOS LOGAR C.B.

Fabricación de perfumes y cosméticos

45. Tortajada Díaz, Manuel

Otras actividades de impresión y artes gráficas

46. LAMIPLAST S.A. (Existente 22)

CNAE año 1985 (468)

47. Construcciones y aplicaciones de la madera (Existente 32)

CNAE año 1985 (462) 
48. Sanz Martínez, E. (Existente 75)

CNAE año 1985 (419)

49. Andreu Querol, L. "JUST" (existente 16)

CNAE año 1985 (346)

ESTADO ACTUAL DE LOS ANTIGUOS EDIFICIOS INDUSTRIALES DE INTERES.-

- CARLOS GENS, S.L.

Avda. de Burjasot, na 54 (Clave 4R-1)

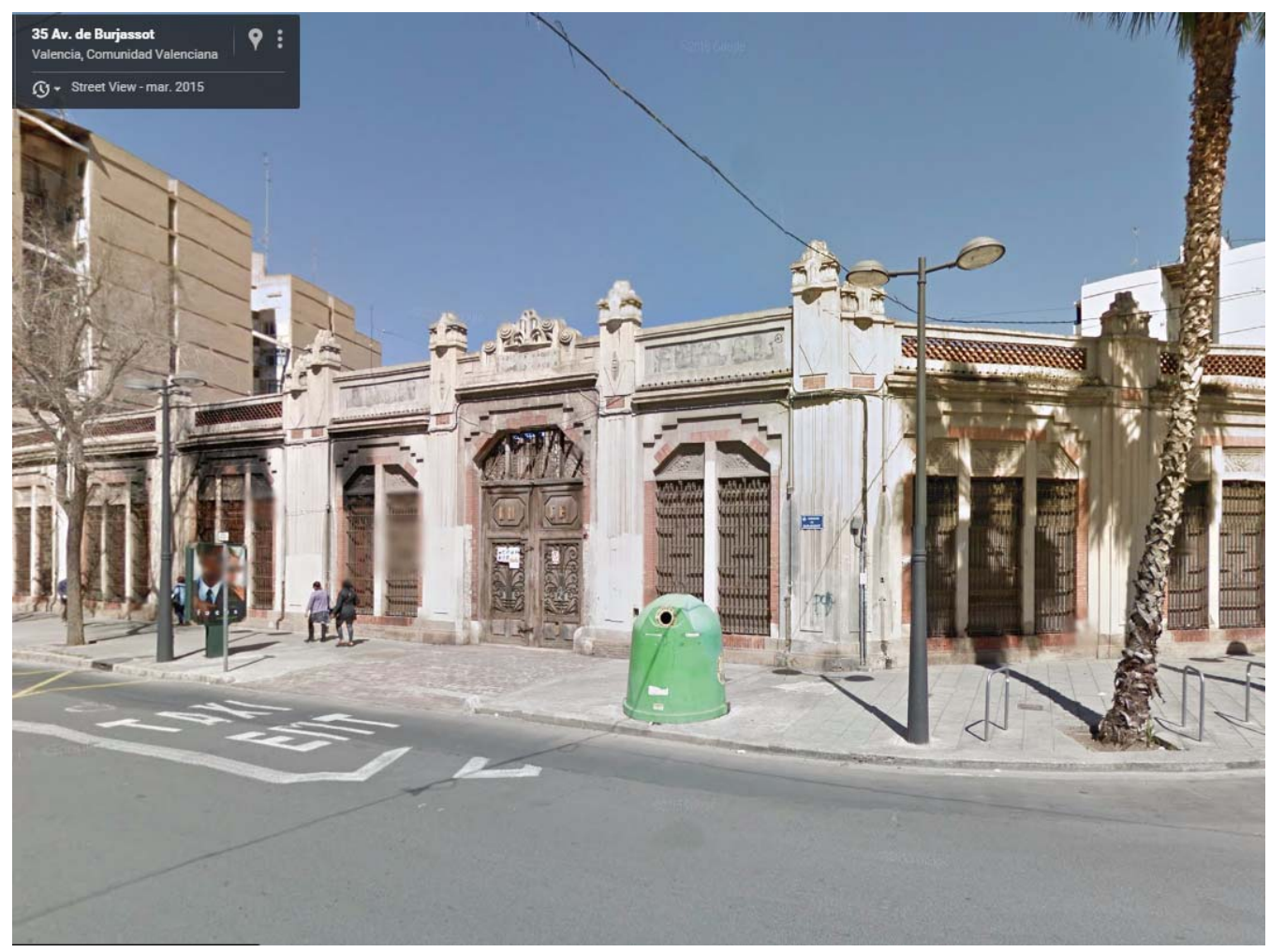

Foto 24: Antigua fábrica de bombas y válvulas Carlos Gens, S.L. Avda. Burjasot, 54. Valencia.2015 Fuente: WEB. http://www.google.es/maps (Street View) 
- FEVE, Ferrocarriles de Valencia.

C/ Maximiliano Thous, na 56 (Clave 4K-1)

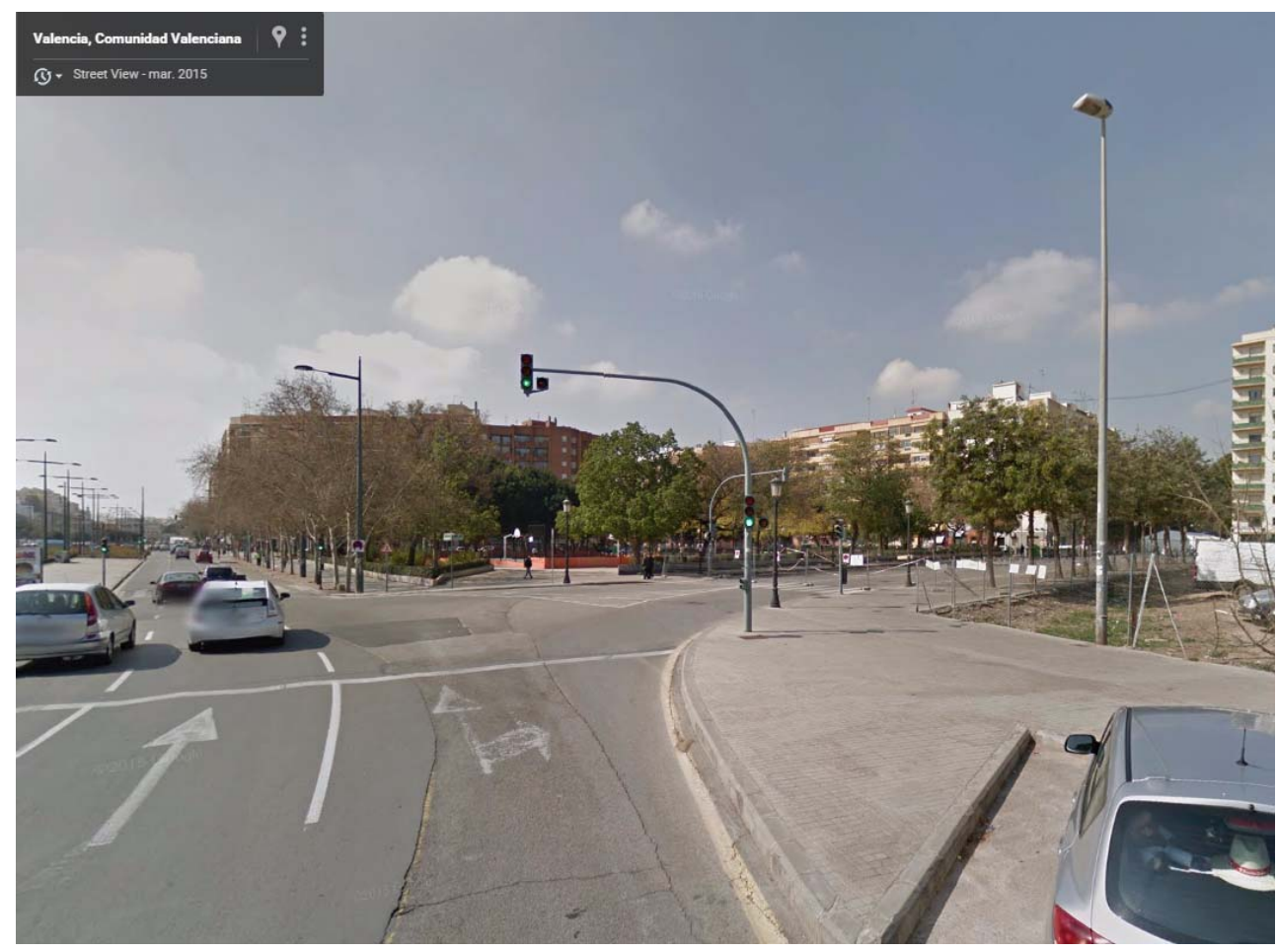

Foto 24: Antigua ubicación FEVE. Ferrocarriles de Valencia. C/ Maximiliano Thous, 56. Valencia.2015 Fuente: WEB. http://www.google.es/maps (Street View)

- TITULAR DESCONOCIDO.

C/ Arzobispo Fabián y Fuero, s/n. (Clave 6L)

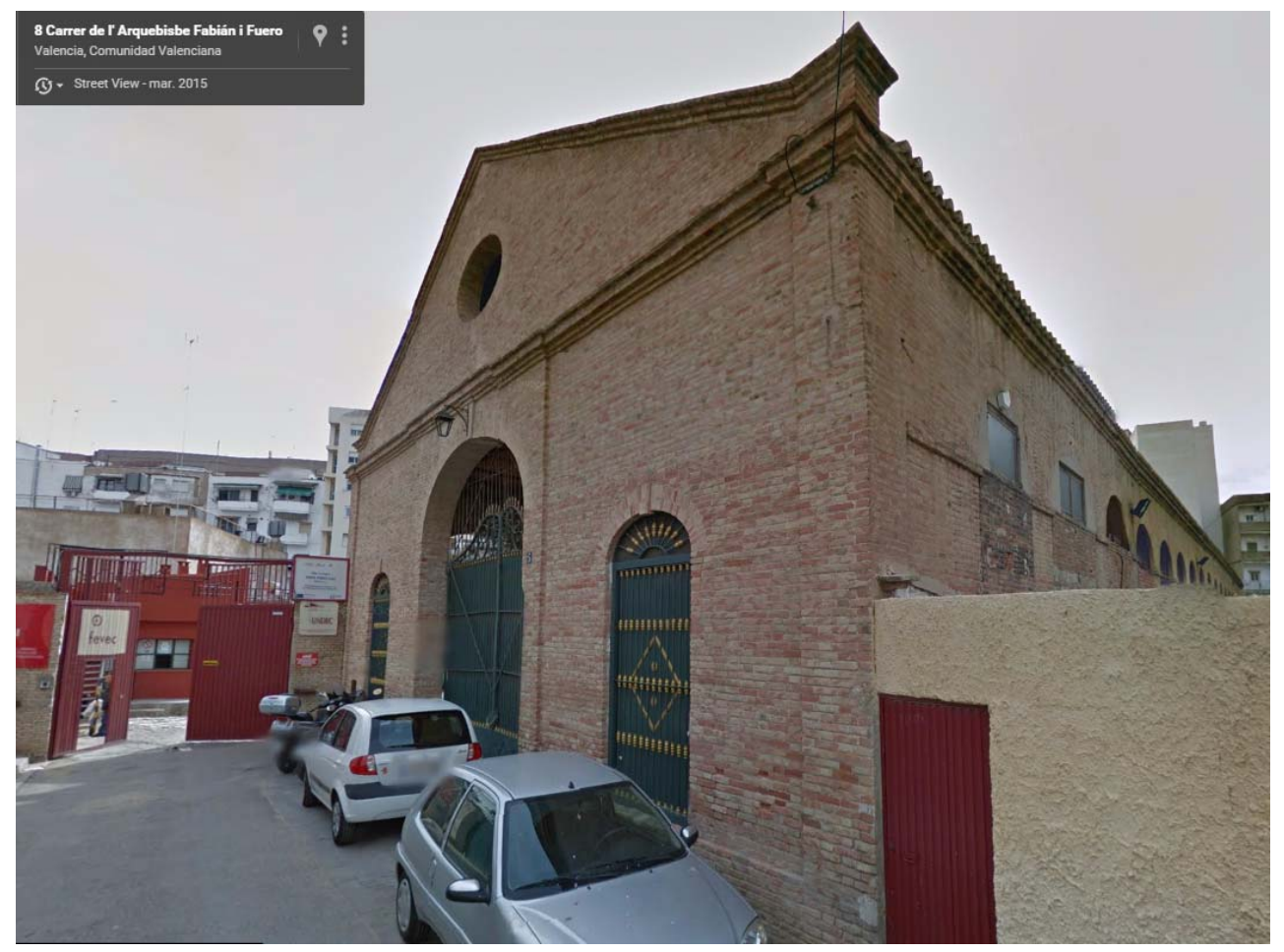

Foto 25: Nave industrial. Cl Arzobispo Fabián y Fuero, s/n.. Valencia.2015

Fuente: WEB. http://www.google.es/maps (Street View) 


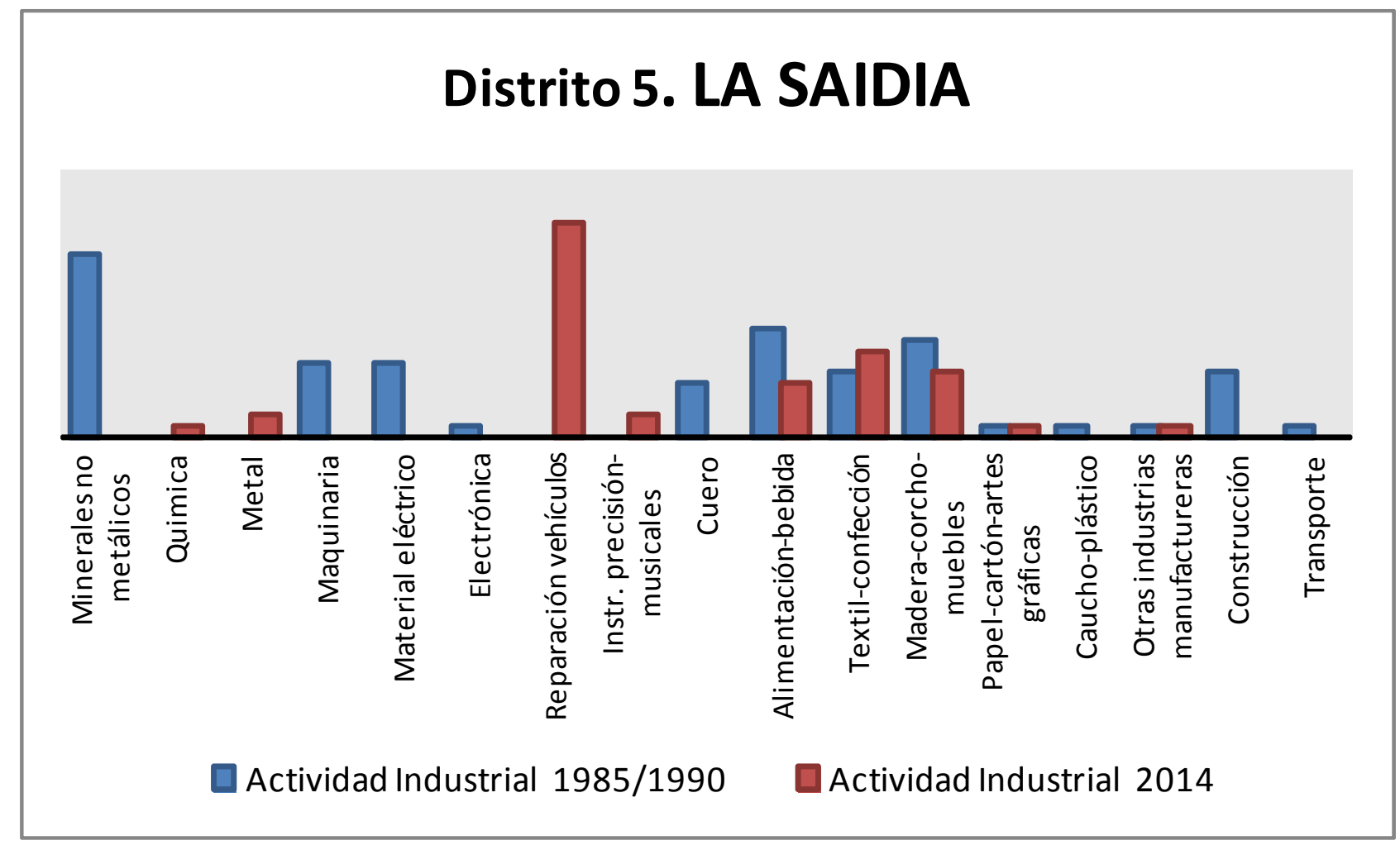

EVOLUCIÓN DEL IMPACTO AMBIENTAL

\section{IMPACTO EN EL MEDIO URBANO Distrito 5. LA SAIDIA}

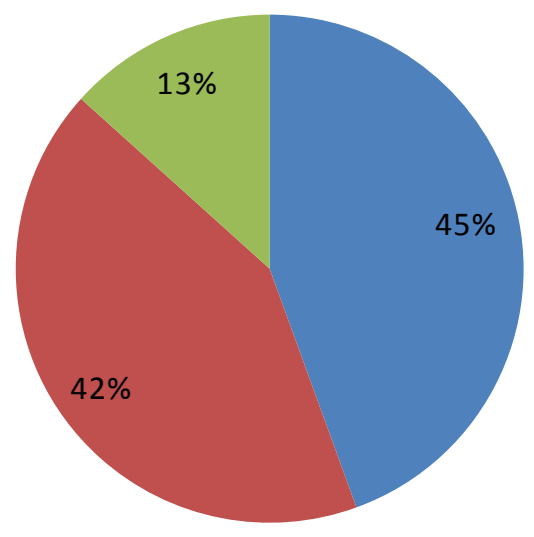

Empresas inocuas

Empresas ruidosas

Empresas ruidosas con chimenea 


\section{FICHAS TIPO \\ FICHA DATOS DE LA INDUSTRIA}

LOCALIZACION ACTUALIZADA DE ACTIVIDADES INDUSTRIALES EN EL MEDIO URBANO DE VALENCIA

\begin{tabular}{|c|c|c|c|c|c|c|c|}
\hline \multirow{5}{*}{ 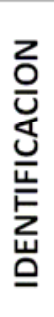 } & \multirow{2}{*}{\multicolumn{2}{|c|}{$\begin{array}{c}\text { NOMBRE } \\
\text { EMPLAZAMIENTO }\end{array}$}} & \multicolumn{5}{|c|}{ ALONSO MARTÍNEZ ESPASA } \\
\hline & & & \multicolumn{3}{|c|}{ C/ GUADALAVIAR, 7} & C.P. & 46009 \\
\hline & \multirow{2}{*}{ CNAE } & \multirow{2}{*}{4520} & \multirow{2}{*}{ DESCRIPCION } & \multicolumn{4}{|c|}{ REPARACIÓN VEHÍCULOS } \\
\hline & & & & \multicolumn{4}{|c|}{ Mantenimiento y reparación de vehículos a motor } \\
\hline & DISTRITO & 5 & \multicolumn{5}{|c|}{ LA SAIDIA } \\
\hline \multicolumn{3}{|c|}{ MEDIOAMBIENTE } & RUIDOSAS & SI & CHIMENEAS & & $\mathrm{O}$ \\
\hline
\end{tabular}

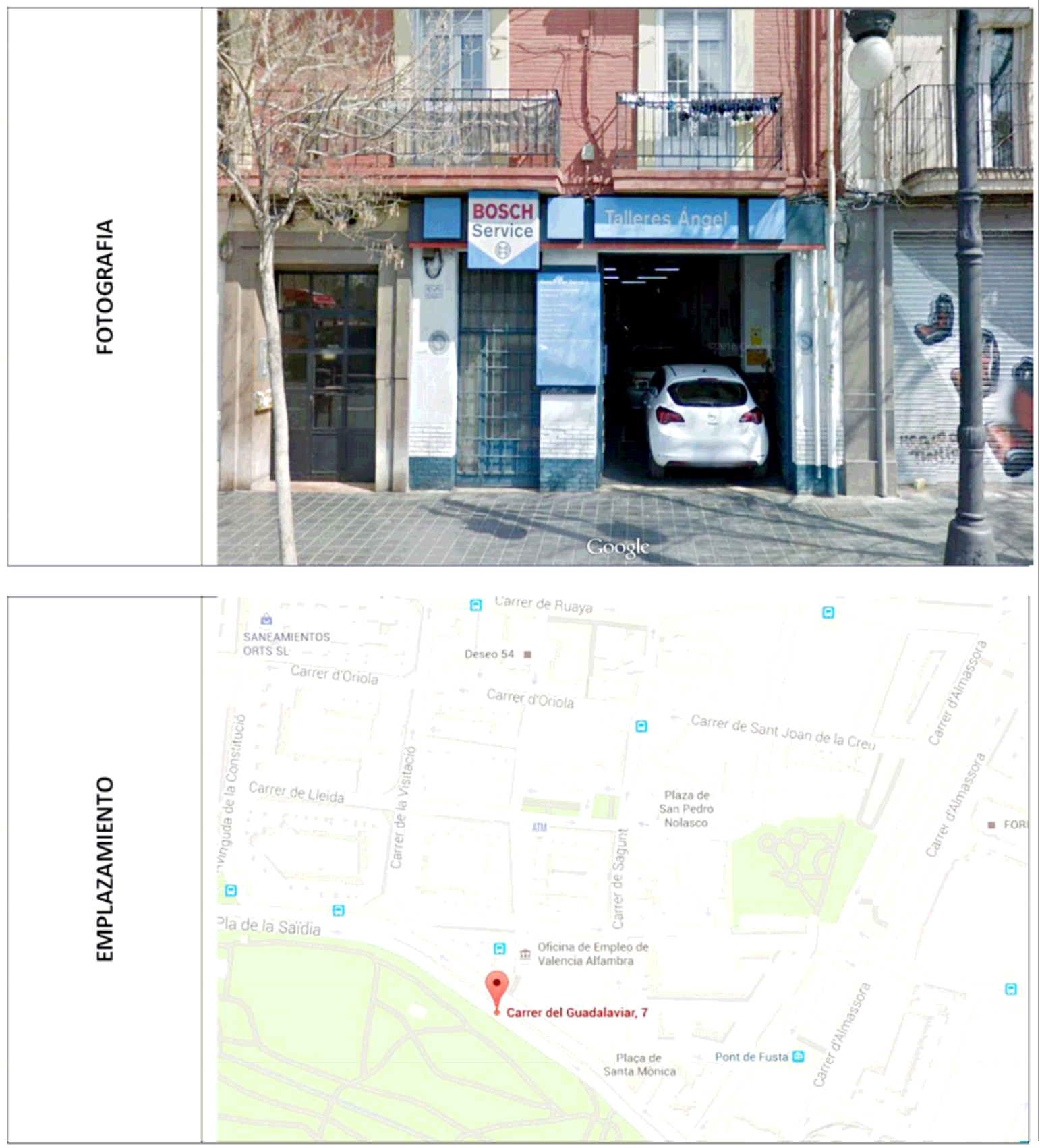




\section{FICHA DATOS DE LA INDUSTRIA}

LOCALIZACION ACTUALIZADA DE ACTIVIDADES INDUSTRIALES EN EL

MEDIO URBANO DE VALENCIA

\begin{tabular}{|c|c|c|c|c|c|c|c|}
\hline \multirow{5}{*}{ 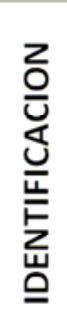 } & \multirow{2}{*}{\multicolumn{2}{|c|}{$\begin{array}{c}\text { NOMBRE } \\
\text { EMPLAZAMIENTO }\end{array}$}} & \multicolumn{5}{|c|}{ MATÍAS OLIVARES LARA } \\
\hline & & & \multicolumn{3}{|c|}{ C/ PERIODISTA LLORENTE, 12} & C.P. & 46009 \\
\hline & \multirow[b]{2}{*}{ CNAE } & \multirow[b]{2}{*}{2512} & \multirow{2}{*}{ DESCRIPCION } & \multicolumn{4}{|c|}{ METAL } \\
\hline & & & & \multicolumn{4}{|c|}{ Fabricación de carpintería metálica } \\
\hline & DISTRITO & 5 & \multicolumn{5}{|c|}{ LA SAIDIA } \\
\hline \multicolumn{3}{|c|}{ MEDIOAMBIENTE } & RUIDOSAS & SI & CHIMENEAS & & NO \\
\hline
\end{tabular}

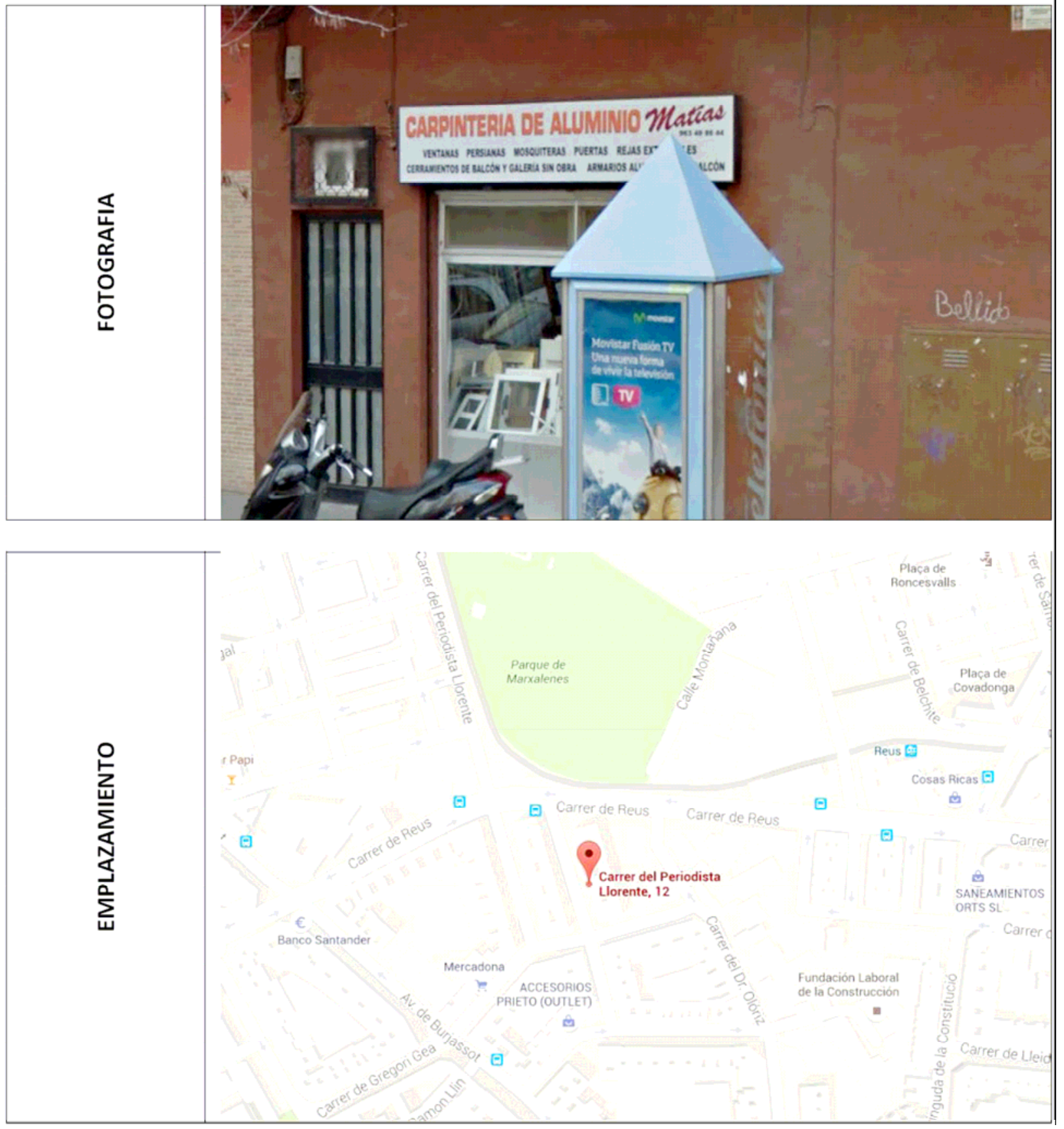




\section{FICHA DATOS DE LA INDUSTRIA}

LOCALIZACION ACTUALIZADA DE ACTIVIDADES INDUSTRIALES EN EL MEDIO URBANO DE VALENCIA

\begin{tabular}{|c|c|c|c|c|c|c|c|}
\hline \multirow{5}{*}{ 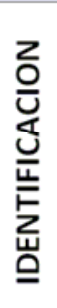 } & \multirow{2}{*}{\multicolumn{2}{|c|}{$\begin{array}{c}\text { NOMBRE } \\
\text { EMPLAZAMIENTO }\end{array}$}} & \multicolumn{5}{|c|}{ MIGUEL RODILLA MEDINA } \\
\hline & & & \multicolumn{3}{|c|}{ C/ ORIHUELA, 18} & C.P. & 46009 \\
\hline & \multirow{2}{*}{ CNAE } & \multirow{2}{*}{3109} & \multirow{2}{*}{ DESCRIPCION } & \multicolumn{4}{|c|}{ MADERA-CORCHO-MUEBLES } \\
\hline & & & & \multicolumn{4}{|c|}{ Fabricación de otros muebles } \\
\hline & DISTRITO & 5 & \multicolumn{5}{|c|}{ LA SAIDIA } \\
\hline \multicolumn{3}{|c|}{ MEDIOAMBIENTE } & RUIDOSAS & SI & CHIMENEAS & & 10 \\
\hline
\end{tabular}
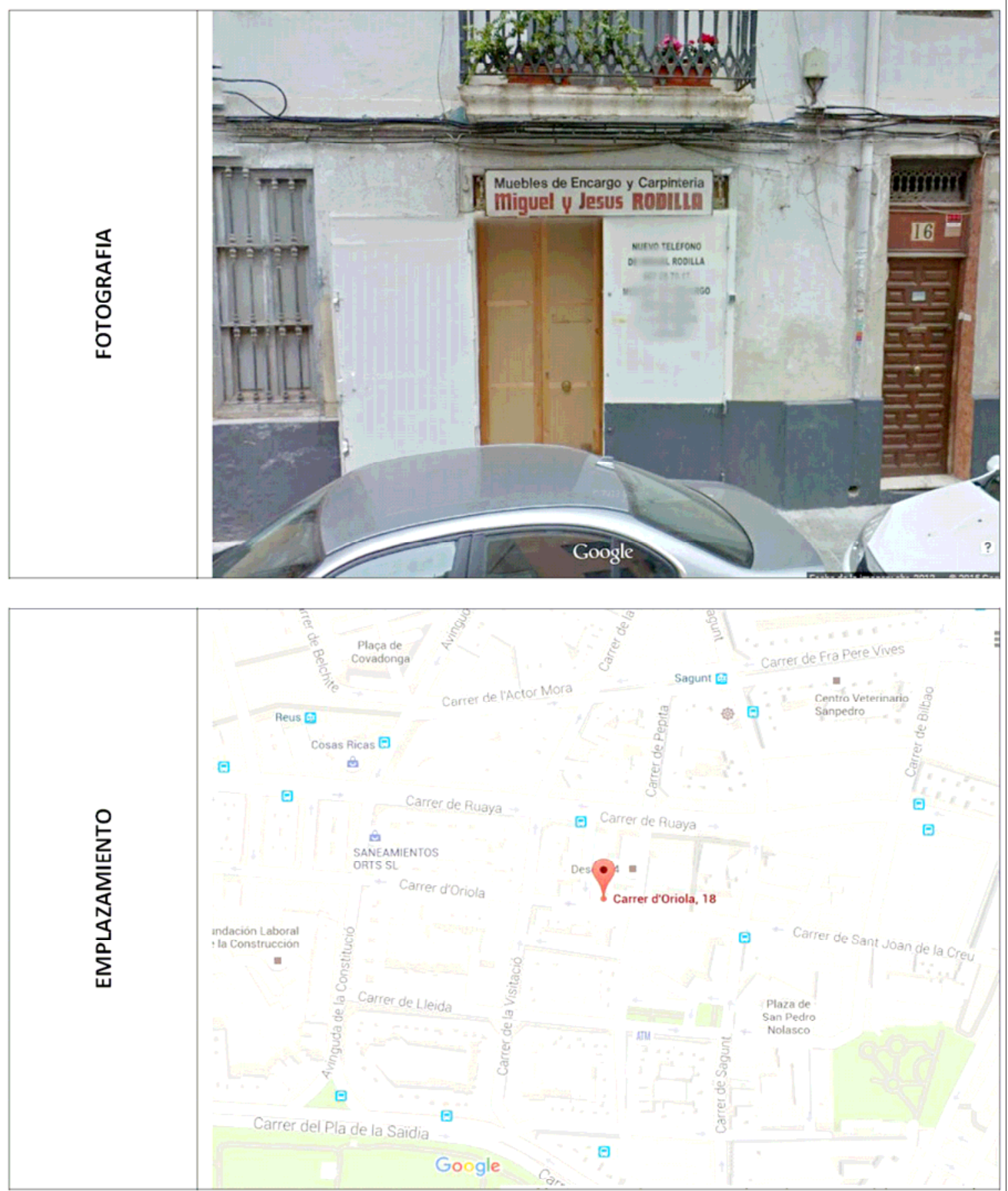


\section{FICHA DATOS DE LA INDUSTRIA}

LOCALIZACION ACTUALIZADA DE ACTIVIDADES INDUSTRIALES EN EL MEDIO URBANO DE VALENCIA

\begin{tabular}{|c|c|c|c|c|c|c|c|}
\hline \multirow{5}{*}{ 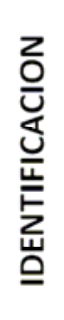 } & \multirow{2}{*}{\multicolumn{2}{|c|}{$\begin{array}{c}\text { NOMBRE } \\
\text { EMPLAZAMIENTO }\end{array}$}} & \multicolumn{5}{|c|}{ JOSE ANDRÉS ALOS } \\
\hline & & & \multicolumn{3}{|c|}{ AV. PORTUGAL, 7} & C.P. & 46009 \\
\hline & \multirow[b]{2}{*}{ CNAE } & \multirow[b]{2}{*}{1392} & \multirow[b]{2}{*}{ DESCRIPCION } & \multicolumn{4}{|c|}{ TEXTIL-CALZADO-CONFECCIÓN } \\
\hline & & & & \multicolumn{4}{|c|}{$\begin{array}{l}\text { Fabricación de artículos confeccionados con } \\
\text { textiles, excepto prendas de vestir }\end{array}$} \\
\hline & DISTRITO & 5 & \multicolumn{5}{|c|}{ LA SAIDIA } \\
\hline \multicolumn{3}{|c|}{ MEDIOAMBIENTE } & RUIDOSAS & NO & CHIMENEAS & & 0 \\
\hline
\end{tabular}

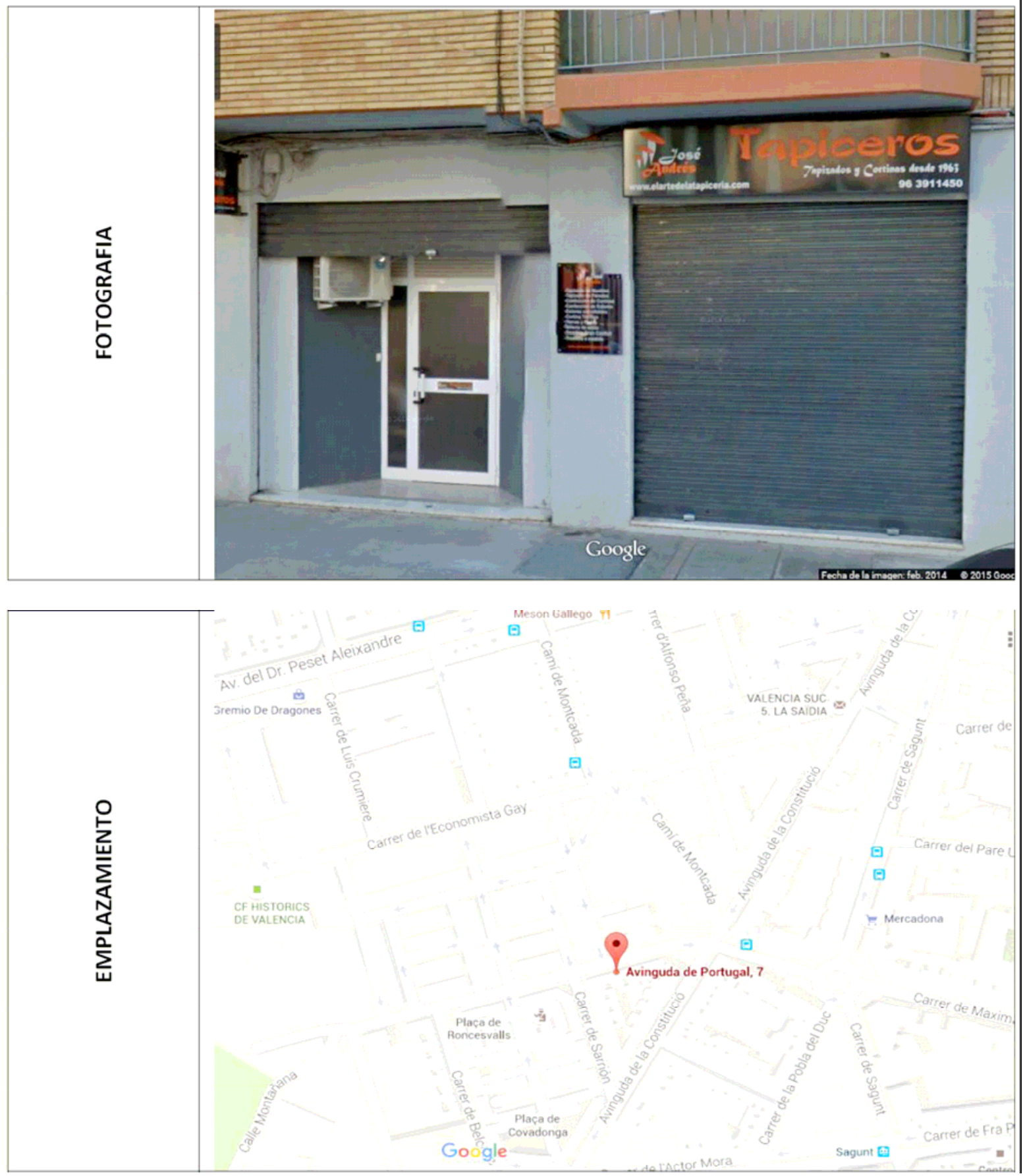




\section{FICHA DATOS DE LA INDUSTRIA}

LOCALIZACION ACTUALIZADA DE ACTIVIDADES INDUSTRIALES EN EL

\begin{tabular}{|c|c|c|c|c|c|c|c|}
\hline \multicolumn{8}{|c|}{ MEDIO URBANO DE VALENCIA } \\
\hline \multirow{5}{*}{ 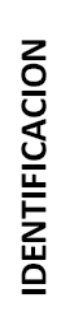 } & \multirow{2}{*}{\multicolumn{2}{|c|}{$\begin{array}{c}\text { NOMBRE } \\
\text { EMPLAZAMIENTO }\end{array}$}} & \multicolumn{5}{|c|}{ PANADERÍA PASTELERÍA RAFAEL LORENTE, S.L. } \\
\hline & & & \multicolumn{3}{|c|}{ AV. PESET ALEIXANDRE, 79} & C.P. & 46009 \\
\hline & \multirow[b]{2}{*}{ CNAE } & \multirow[b]{2}{*}{1071} & \multirow[b]{2}{*}{ DESCRIPCION } & \multicolumn{4}{|c|}{ ALIMENTACIÓN-BEBIDA } \\
\hline & & & & \multicolumn{4}{|c|}{$\begin{array}{l}\text { Fabricación de pan y de productos frescos de } \\
\text { panadería y pastelería }\end{array}$} \\
\hline & DISTRITO & 5 & \multicolumn{5}{|c|}{ LA SAIDIA } \\
\hline & \multicolumn{2}{|c|}{ MEDIOAMBIENTE } & RUIDOSAS & NO & CHIMENEAS & & $\mathrm{O}$ \\
\hline
\end{tabular}
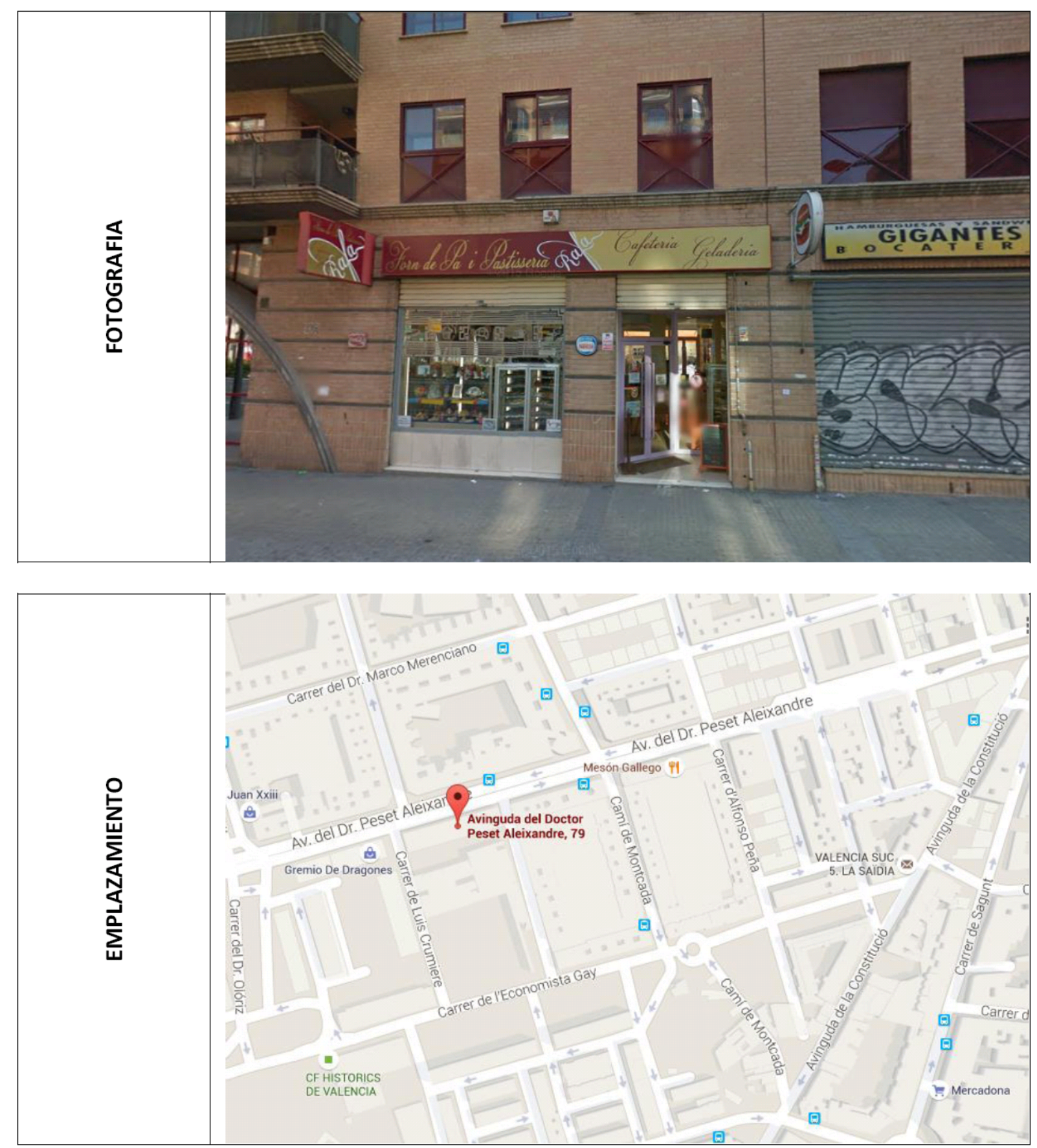
DISTRITO 6.- PLA DEL REAL

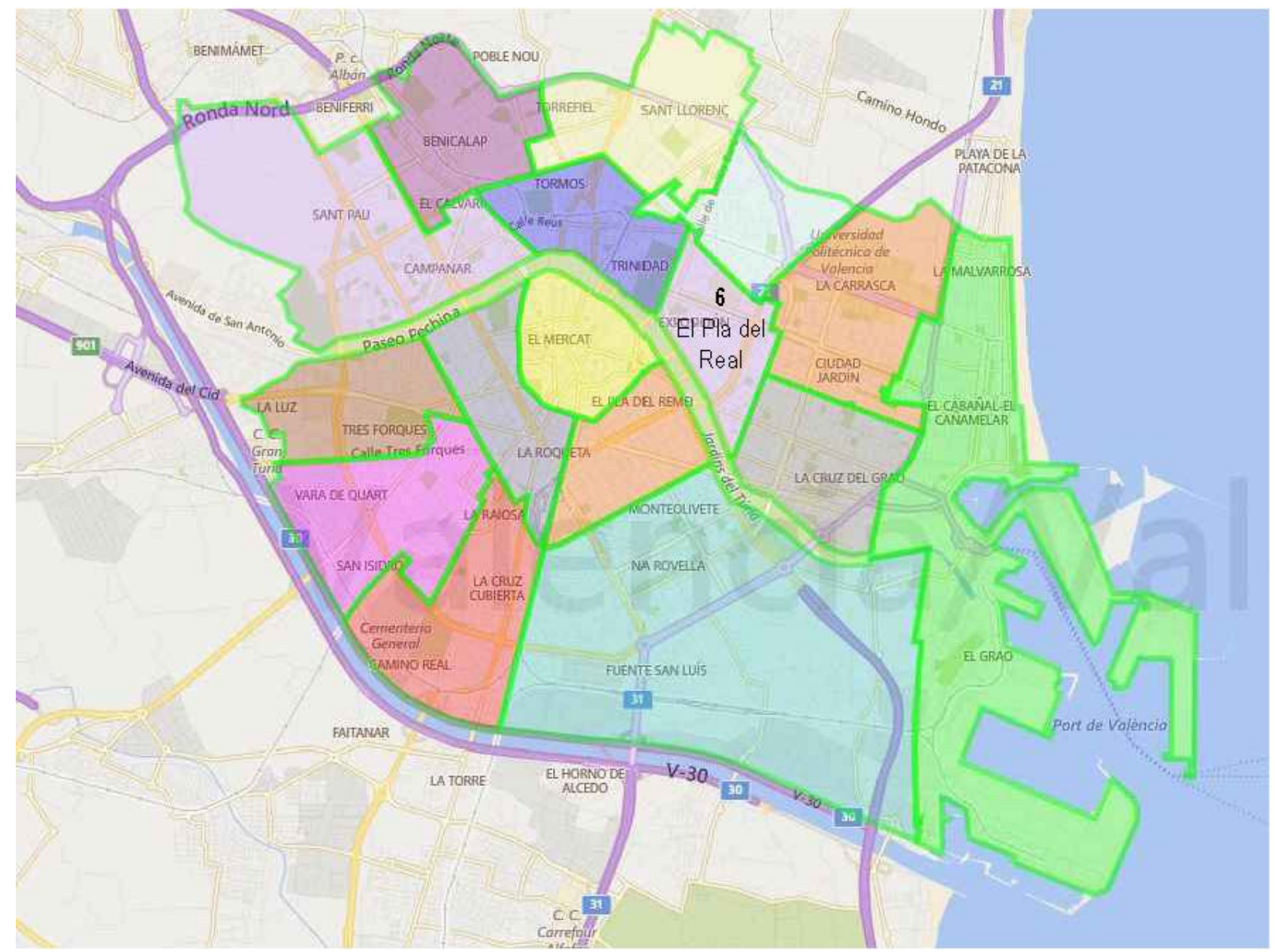

\section{LÍMITES GEOGRÁFICOS.}

- Avda. Primado Reig, Avda. Cardenal Benlloch, C/ Eduardo Bosca, Cauce viejo del Turia y C/ Botánico Cavanilles. 


\section{PLANO UBICACIÓN INDUSTRIAS}

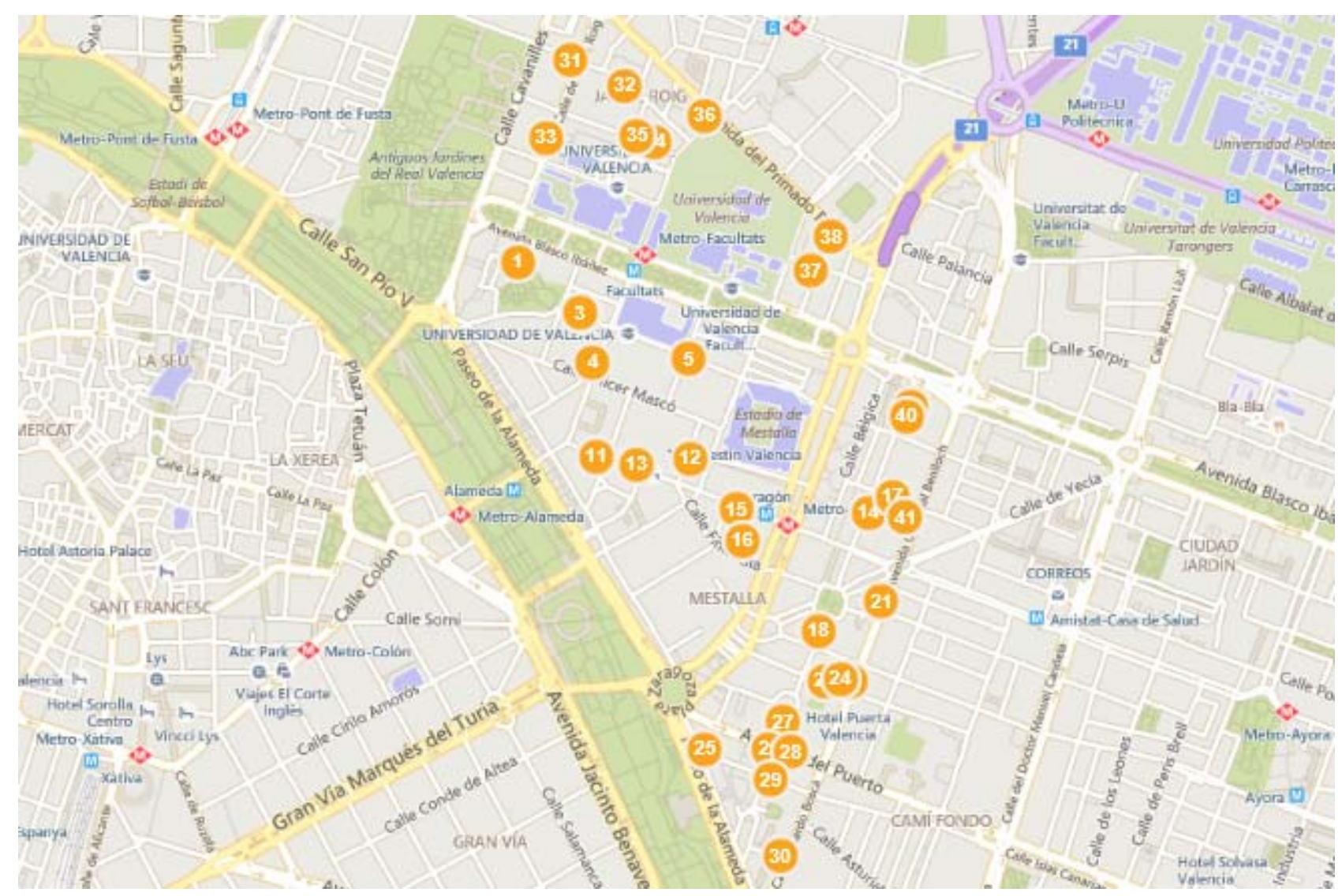

LISTADO DE INDUSTRIAS Y ESTADO ACTUAL .-

1. INTERN. BUSSINES MACHINES

Centro médico

2. LABORATORIOS HUBBER, S.A.

Restaurante

3. IND. FARMACEUTICAS ESPEC., S.A.

Banco

4. WORTHINOTON, S.A.

Cafetería

5. PANIFICADORA MESTALLA

Sin actividad

6. INSTITUTO INVESTIGACIONES CITOLÓGICAS

Universidad Valencia 
7. ELECTROTECNIA MONRABAL, S.L.

Otra industria

8. TABACALERA, S.A.

Ayuntamiento Valencia

9. ROJO TORO, S.A.

Frutería/ Tienda de ropa

10. Lopez, V.

Tienda multiprecio

11. MUEBLES ABAD, S.L.

Nueva ordenación- Edificio de viviendas

12. Gallart Pascual, J.A.

Centro educación infantil

13. IND. AUXILIARES DE ABASTECIMIENTO, S.A.

Garaje

14. CONSTRUCCIONES REFORMAS Y PROYECTOS, S.A.

Restaurante

15. Antonio Roig

Sin actividad

16. Agustín Martínez, A.

Nueva ordenación- Edificio de viviendas

17. JOSE Y LUCIANO RICART, S.L.

Nueva ordenación- Edificio de viviendas

18. CREACIONES MAYE, S.L.

Varios comercios

19. FORESTAL IBERICA

Sin datos

20. Alarcón Seguí, Antonio

Sin actividad

21. MANUEL SERRA, S.A.

Nueva ordenación- Edificio de viviendas

22. DECAM'S DIEL, S.L.

Taller composturas

23. FORJAN, S.A.

Construcción

24. MADERAS ABRAHAM MARTÍNEZ, S.A.

Aparcamiento

25. LUDEX, S.A.

Restaurante

26. PANADERIA ESCRIBA

Banco 
27. Rafael Orguin Almenar

Tintorería

28. INSTITUTO DE AGROQUIMICA Y TECNOLOGÍA DE ALIMENTOS

Instituto biomedicina

29. SECOINSA

Supermercado

30. PANADERÍA ADE

Comercio

31. ISOLUX, S.A.

Mantiene la industria

32. TALLERES HERNANI, S.A:

Obra nueva

33. SERCAM, S.L.

Escuela de español

34. DOWER, S.A.

Taller AUTO AL-VI

35. CERCAS PIEL, S.L.

Academia

36. FRIO Y ACONDICIONAMIENTO, S.A.

Sede PP/ Local en alquiler

37. INSECTICIDAS SERVALESA

Sin actividad

CARACTERÍSTICAS DEL ASENTAMIENTO INDUSTRIAL.

- Se concentra básicamente en el triángulo formado por la antigua estación de Aragón, Avda. Cardenal Benlloch y Cauce viejo del Turia.

- Uso dominante en el distrito residencial y educativo (Universidad).

- Homogéneo en cuanto a tamaño y emplazamiento.

- Tradicional (primera mitad del Siglo XX en el área comprendida entre la antigua estación de Aragón y Cardenal Benlloch).

CARACTERÍSTICAS DE LOS LOCALES.

- Existen dos tipos de locales claramente diferenciados por su situación en el distrito:

. Edificios propiamente industriales entre medianeras, de mediana superficie concentrados entre la antigua estación de Aragón y Cardenal Benlloch. 
. Pequeñas industrias situadas en bajos de edificios de viviendas, en un área de uso eminentemente residencial y educativo, en la que destaca como caso excepcional un edificio industrial de gran superficie: Tabacalera Española.

\section{CARACTERÍSTICAS DE LAS ACTIVIDADES.-}

- Se censaron inicialmente 37 industrias y en el período de vigencia del Plan General han quedado solamente 3 creándose 13 nuevas industrias.

- Las actividades dominantes son alimentación, bebida y tabaco e industria de madera y muebles.

- Hay que destacar la gran importancia de Tabacalera Española en la superficie y nivel de empleo ocupado por la industria en el distrito ya que con sus $23.520 \mathrm{~m} 2 \mathrm{de}$ superficie de parcela, $58.035 \mathrm{~m} 2$ de superficie construida y 555 trabajadores incide decisivamente en la capacidad industrial de este distrito.

\section{INCIDENCIA EN EL MEDIO AMBIENTE.}

- Contaminación ambiental: prácticamente nula excepto la acústica en los alrededores de la Avda. del Puerto donde se concentran industrias ruidosas (aserraderos de madera, carpinterías,...)

- Transporte: Tiene importancia en la concentración industrial del sur del distrito y en Tabacalera, aunque no producen efectos negativos en el tráfico por su baja frecuencia y por la localización de las industrias junto a vías principales.

- Integración en el entorno: La concentración industrial situada al sur de la estación de Aragón ha detenido la expansión del área residencial iniciada en los bordes de la Avda. del Puerto, Avda. de Cardenal Benlloch y Avda. de Eduardo Bosca, dando lugar a una trama urbana confusa y heterogénea, con edificios fuera de ordenación, muy deteriorados, que contrasta con la regularidad y carácter residencial de las nuevas edificaciones en las mencionadas vías de comunicación. Por el contrario, las industrias situadas al norte de la estación de Aragón están perfectamente integradas en su entorno incluyendo el edificio de Tabacalera de notable interés arquitectónico. 
EDIFICIOS INDUSTRIALES DE INTERES

- taBACALERA ESPAÑola, S.A.

C/ Amadeo de Saboya, № 11. (Clave 18 2)

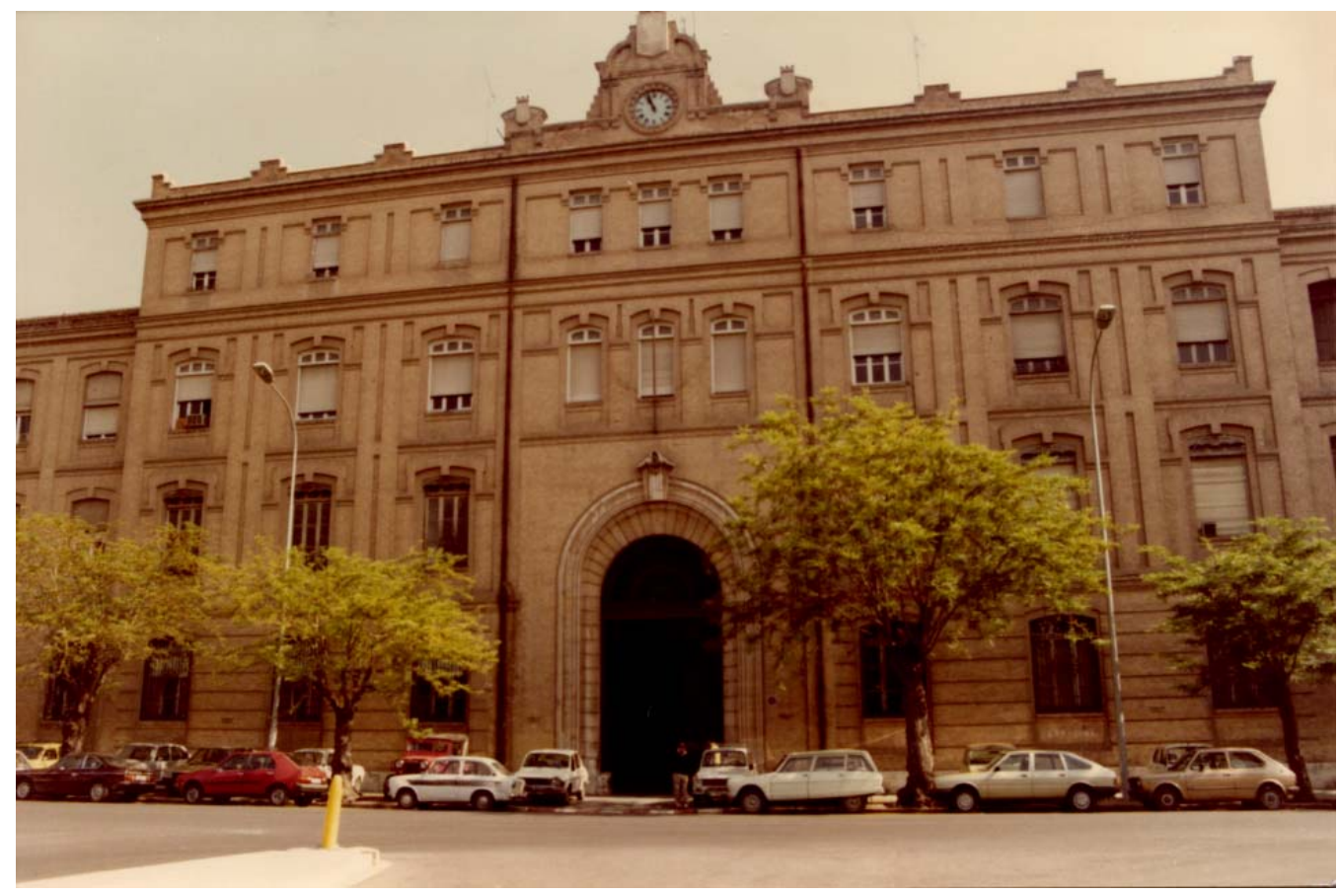

Foto 26: Tabacalera Española, S.A. C/ Amadeo de Saboya, 11. Valencia.1985.

Fuente: Elaboración propia

TIPOLOGÍA EDIFICACIÓN

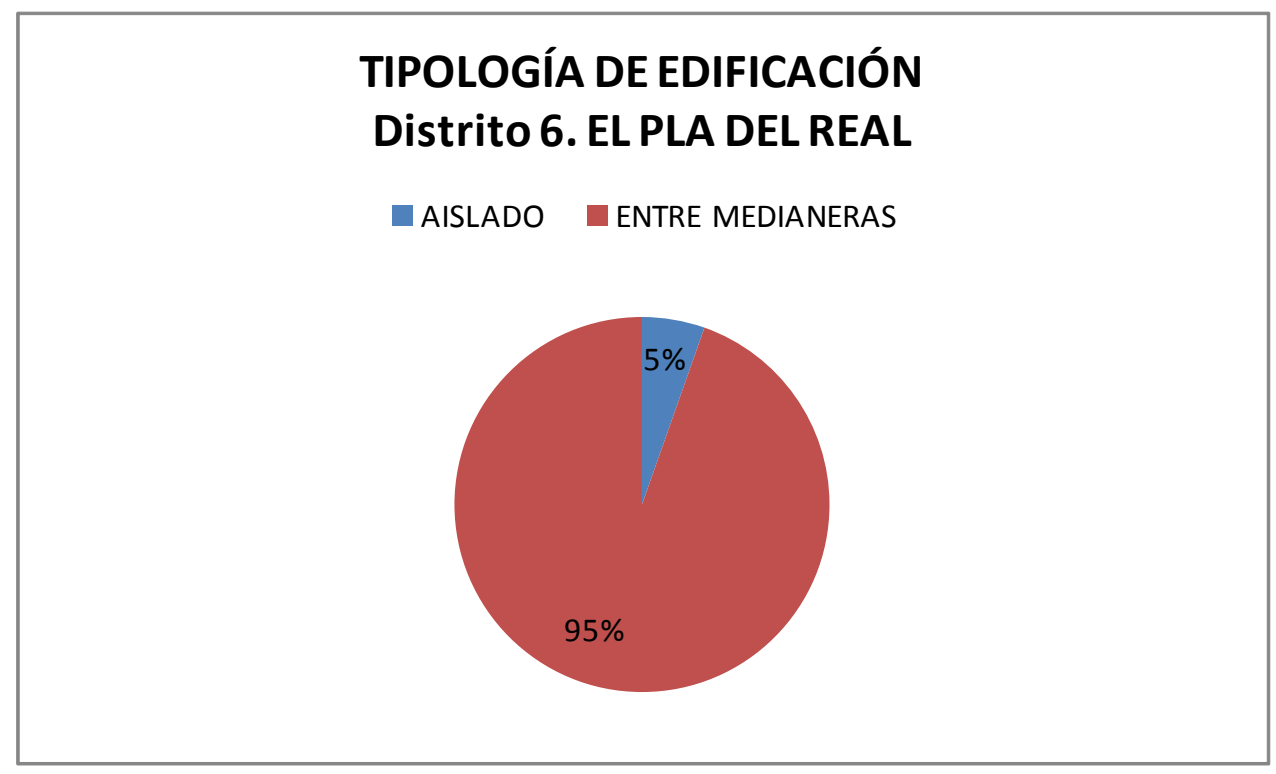




\section{ACTIVIDAD INDUSTRIAL, SUPERFICIE Y EMPLEO}

\begin{tabular}{|c|c|c|c|c|c|}
\hline \multicolumn{6}{|c|}{ DISTRITO 6 - EL PLA DEL REAL (ATIVIDAD INDUSTRIAL Y EMPLEO) } \\
\hline ACTIVIDAD & $\begin{array}{c}\text { № } \\
\text { EMPRESAS }\end{array}$ & $\begin{array}{c}\text { SUP. ACTIVIDAD } \\
\text { IND }\left(\mathrm{m}^{2}\right)\end{array}$ & $\begin{array}{c}\text { \% SUP. } \\
\text { INDUSTRIAL }\end{array}$ & $\begin{array}{c}\text { № } \\
\text { EMPLEADOS }\end{array}$ & $\begin{array}{c}\text { DENSIDAD } \\
\text { EMPLEO } \\
\text { (empleados } / \mathrm{m}^{2} \\
\text { actividad) }\end{array}$ \\
\hline INDUSTRIAS DE PRODUCTOS MINERALES NO METÁLICOS & 1 & 1200 & 2,37 & 2 & 0,0017 \\
\hline INDUSTRIA QUÍMICA & 4 & 546 & 1,08 & 101 & 0,1850 \\
\hline FABRICACIÓN DE PRODUCTOS METÁLICOS & 5 & 1510 & 2,98 & 19 & 0,0126 \\
\hline CONSTRUCCIÓN DE MAQUINARIA Y EQUIPO MECÁNICO & 1 & 70 & 0,14 & 6 & 0,0857 \\
\hline CONSTRUCCIÓN DE MÁQUINAS DE OFICINA Y ORDENADORES & 2 & 2240 & 4,42 & 109 & 0,0487 \\
\hline CONSTRUCCIÓN DE MAQUINARIA Y MATERIAL ELÉCTRICO & 3 & 430 & 0,85 & 78 & 0,1814 \\
\hline CONSTRUCCIÓN DE VEHÍCULOS AUTOMÓVILES Y SUS PIEZAS DE REPUESTO & 1 & 300 & 0,59 & 9 & 0,0300 \\
\hline INDUSTRIAS DE PRODUCTOS ALIMENTICIOS, BEBIDAS Y TABACO & 4 & 545 & 1,08 & 28 & 0,0514 \\
\hline INDUSTRIAS DE PRODUCTOS ALIMENTICIOS, BEBIDAS Y TABACO & 1 & 23520 & 46,42 & 555 & 0,0236 \\
\hline INDUSTRIA DEL CUERO & 1 & 200 & 0,39 & 5 & 0,0250 \\
\hline INDUSTRIA DEL CALZADO Y DEL VESTIDO Y OTRAS CONFECCIONES TEXTILES & 3 & 1140 & 2,25 & 42 & 0,0368 \\
\hline INDUSTRIAS DE MADERA, CORCHO Y MUEBLES DE MADERA & 4 & 12300 & 24,27 & 123 & 0,0100 \\
\hline CONSTRUCCIÓN & 1 & 1000 & 1,97 & 6 & 0,0060 \\
\hline REPARACIONES & 1 & 500 & 0,99 & 9 & 0,0180 \\
\hline OTROS & 4 & 5170 & 10,20 & 236 & 0,0456 \\
\hline TOTAL & 36 & 50671 & 100 & 1328 & 0,0262 \\
\hline
\end{tabular}

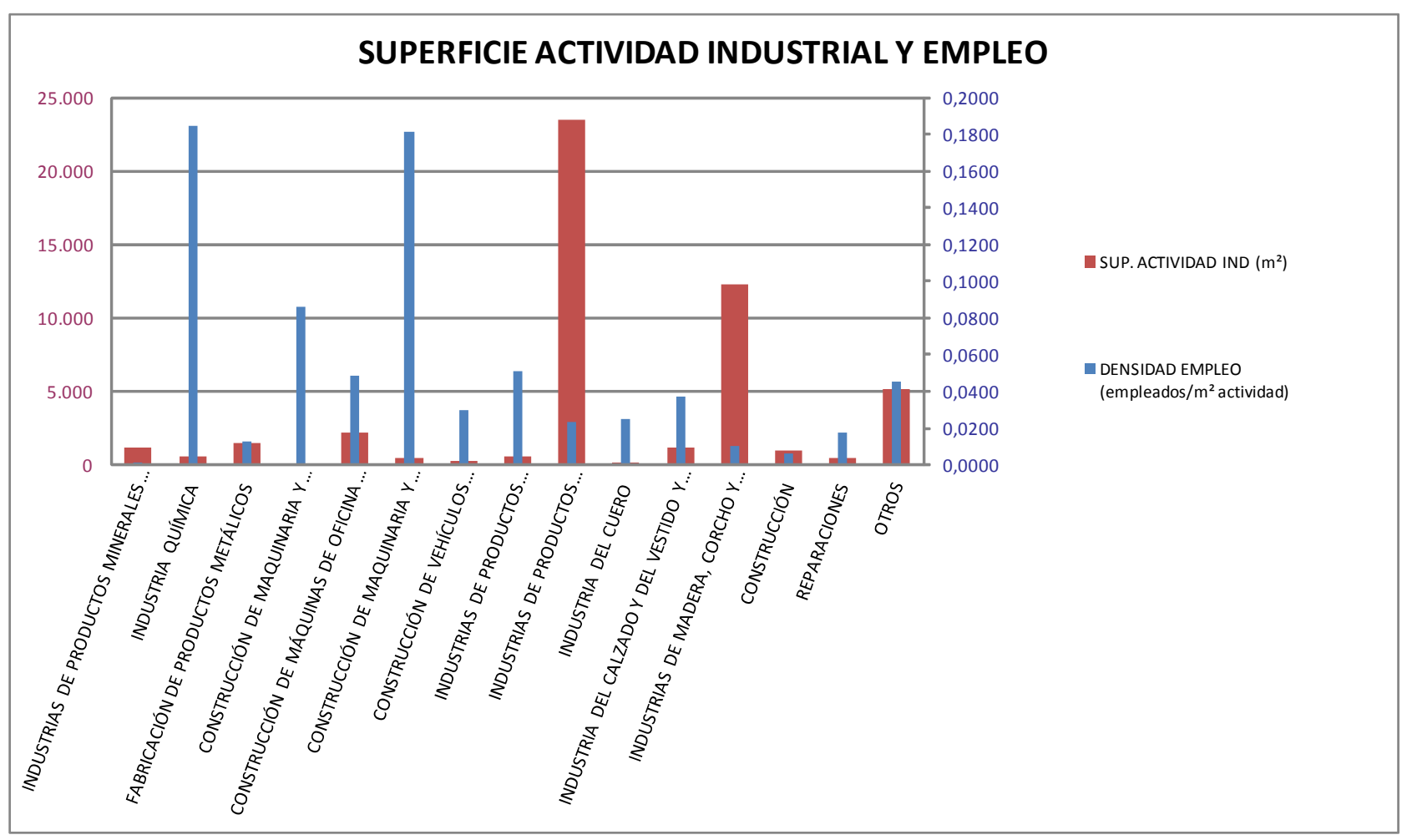


IMPACTO AMBIENTAL

\begin{tabular}{|c|c|c|c|c|c|}
\hline \multicolumn{6}{|c|}{ DISTRITO 6 - EL PLA DEL REAL (INFORMACIÓN URBANÍSTICA) } \\
\hline ACTIVIDAD & $\begin{array}{c}\text { № } \\
\text { EMPRESAS }\end{array}$ & $\begin{array}{c}\text { ENTRE } \\
\text { MEDIANERAS }\end{array}$ & RUIDOSAS & $\begin{array}{c}\text { EMPRESAS } \\
\text { CON } \\
\text { CHIMENEA }\end{array}$ & $\begin{array}{l}\text { RUIDOSAS Y } \\
\text { CHIMENEA }\end{array}$ \\
\hline INDUSTRIAS DE PRODUCTOS MINERALES NO METÁLICOS & 1 & 1 & 0 & 0 & 0 \\
\hline INDUSTRIA QUÍMICA & 4 & 4 & 1 & 0 & 0 \\
\hline FABRICACIÓN DE PRODUCTOS METÁLICOS & 5 & 5 & 2 & 0 & 0 \\
\hline CONSTRUCCIÓN DE MAQUINARIA Y EQUIPO MECÁNICO & 1 & 1 & 0 & 0 & 0 \\
\hline CONSTRUCCIÓN DE MÁQUINAS DE OFICINA Y ORDENADORES & 2 & 2 & 0 & 0 & 0 \\
\hline CONSTRUCCIÓN DE MAQUINARIA Y MATERIAL ELÉCTRICO & 3 & 3 & 0 & 0 & 0 \\
\hline CONSTRUCCIÓN DE VEHÍCULOS AUTOMÓVILES Y SUS PIEZAS DE REPUESTO & 1 & 1 & 1 & 0 & 0 \\
\hline INDUSTRIAS DE PRODUCTOS ALIMENTICIOS, BEBIDAS Y TABACO & 4 & 4 & 0 & 2 & 0 \\
\hline INDUSTRIAS DE PRODUCTOS ALIMENTICIOS, BEBIDAS Y TABACO & 1 & 0 & 0 & 1 & 0 \\
\hline INDUSTRIA DEL CUERO & 1 & 1 & 0 & 0 & 0 \\
\hline INDUSTRIA DEL CALZADO Y DEL VESTIDO Y OTRAS CONFECCIONES TEXTILES & 3 & 3 & 0 & 0 & 0 \\
\hline INDUSTRIAS DE MADERA, CORCHO Y MUEBLES DE MADERA & 5 & 4 & 0 & 2 & 1 \\
\hline CONSTRUCCIÓN & 1 & 1 & 0 & 0 & 0 \\
\hline REPARACIONES & 1 & 1 & 1 & 0 & 0 \\
\hline OTROS & 4 & 4 & 1 & 0 & 0 \\
\hline TOTAL & 37 & 35 & 6 & 5 & 1 \\
\hline
\end{tabular}

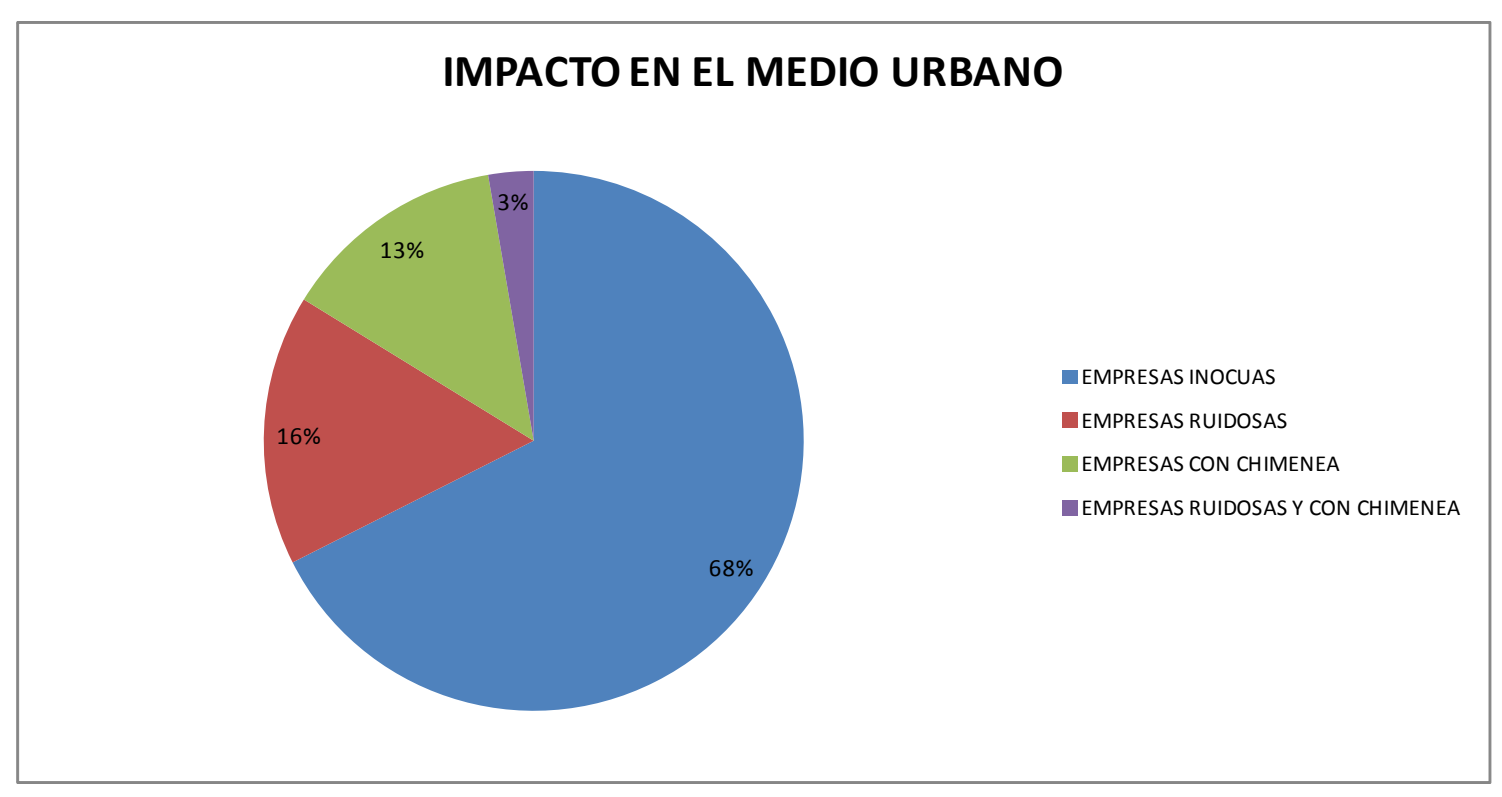


FICHAS TIPO 


\section{FICHA DATOS DE LA INDUSTRIA}

LOCALIZACION ACTUALIZADA DE ACTIVIDADES INDUSTRIALES EN EL MEDIO URBANO DE VALENCIA

\begin{tabular}{|c|c|c|c|c|c|c|c|}
\hline \multirow{5}{*}{ 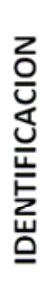 } & \multirow{2}{*}{\multicolumn{2}{|c|}{$\begin{array}{c}\text { NOMBRE } \\
\text { EMPLAZAMIENTO }\end{array}$}} & \multicolumn{5}{|l|}{ SECOIN, S.A. } \\
\hline & & & \multicolumn{3}{|c|}{ C/ Alvaro de Bazan,17 } & C.P. & \\
\hline & \multirow{2}{*}{ CNAE } & \multirow{2}{*}{330} & \multirow{2}{*}{ DESCRIPCION } & \multicolumn{4}{|c|}{ CONST.MMAQUINAS OFICINAS Y ORDENADORES } \\
\hline & & & & \multicolumn{4}{|c|}{ Ordenadores } \\
\hline & DISTRITO & 6 & \multicolumn{5}{|c|}{ EL PLA DEL REAL } \\
\hline & \multicolumn{2}{|c|}{ SUPERFICIES } & $\begin{array}{l}\text { Sup. Parcela: } \\
740 \mathrm{~m}^{2}\end{array}$ & $\begin{array}{l}\text { Sup. Ocupada: } \\
740 \mathrm{~m}^{2}\end{array}$ & $\begin{array}{l}\text { Sup. Construida: } \\
740 \mathrm{~m}^{2}\end{array}$ & EMPL & $\begin{array}{l}\text { EADOS: } \\
12\end{array}$ \\
\hline
\end{tabular}
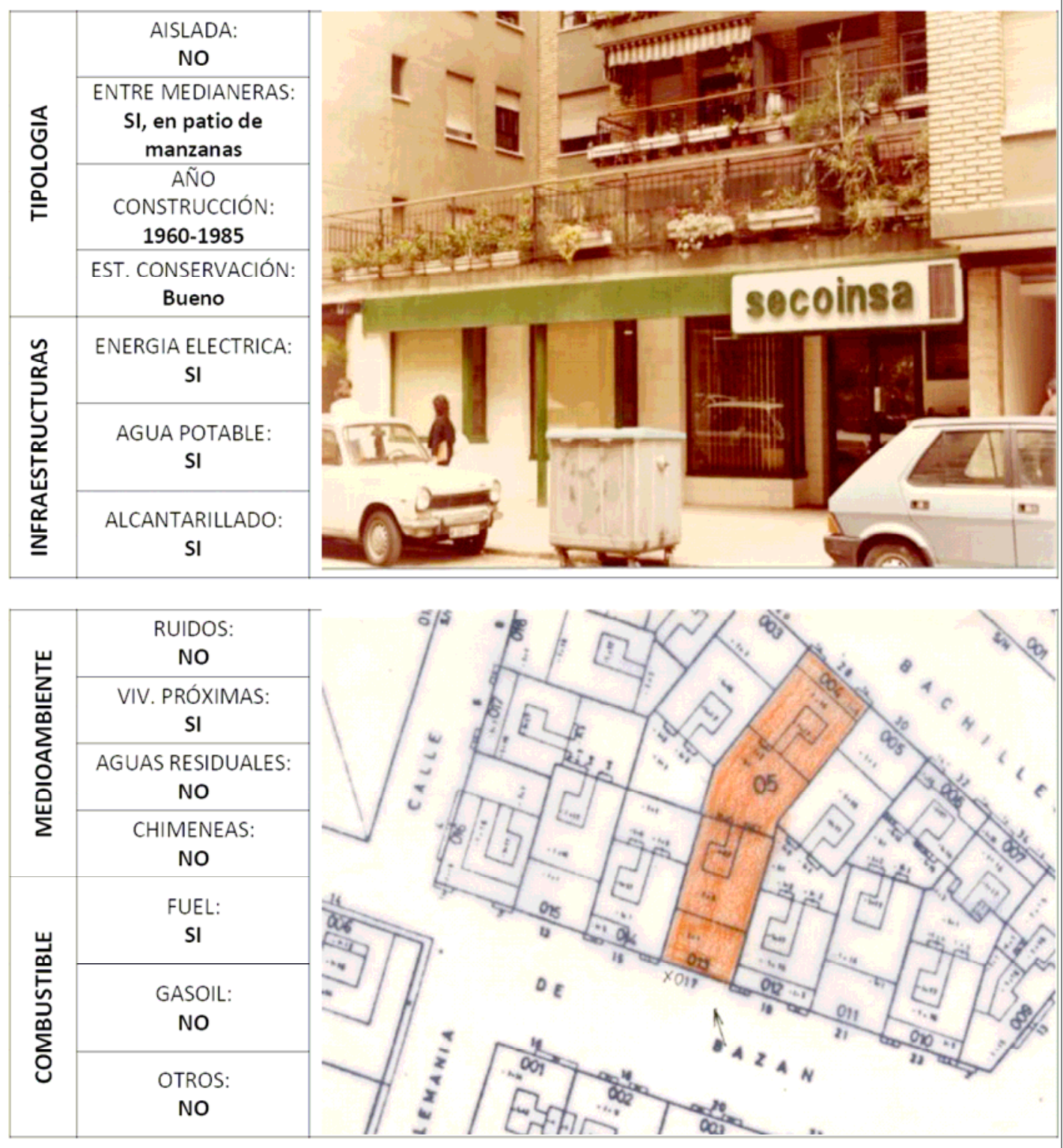

EN LA ACTUALIDAD: SUPERMECADO CONSUM 


\section{FICHA DATOS DE LA INDUSTRIA}

LOCALIZACION ACTUALIZADA DE ACTIVIDADES INDUSTRIALES EN EL MEDIO URBANO DE VALENCIA

\begin{tabular}{|c|c|c|c|c|c|c|c|}
\hline \multirow{5}{*}{ 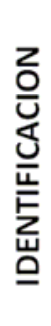 } & \multirow{2}{*}{\multicolumn{2}{|c|}{$\begin{array}{c}\text { NOMBRE } \\
\text { EMPLAZAMIENTO }\end{array}$}} & \multicolumn{5}{|c|}{ INTERN. BUSSINES MACHINES “IBM” } \\
\hline & & & \multicolumn{3}{|c|}{ Plaza Legion Española, 13-1을 } & C.P. & \\
\hline & \multirow{2}{*}{ CNAE } & \multirow{2}{*}{330} & \multirow{2}{*}{ DESCRIPCION } & \multicolumn{4}{|c|}{$\begin{array}{c}\text { CONTRUCCIÓN MAQUINAS OFICINAS Y } \\
\text { ORDENADORES }\end{array}$} \\
\hline & & & & \multicolumn{4}{|c|}{ Ordenadores } \\
\hline & DISTRITO & 6 & \multicolumn{5}{|c|}{ EL PLA DEL REAL } \\
\hline \multicolumn{3}{|c|}{ SUPERFICIES } & $\begin{array}{l}\text { Sup. Parcela: } \\
1500 \mathrm{~m}^{2}\end{array}$ & $\begin{array}{l}\text { Sup. Ocupada: } \\
1500 \mathrm{~m}^{2}\end{array}$ & $\begin{array}{l}\text { Sup. Construida: } \\
1500 \mathrm{~m}^{2}\end{array}$ & EMP & $\begin{array}{l}\text { EADOS: } \\
97\end{array}$ \\
\hline
\end{tabular}
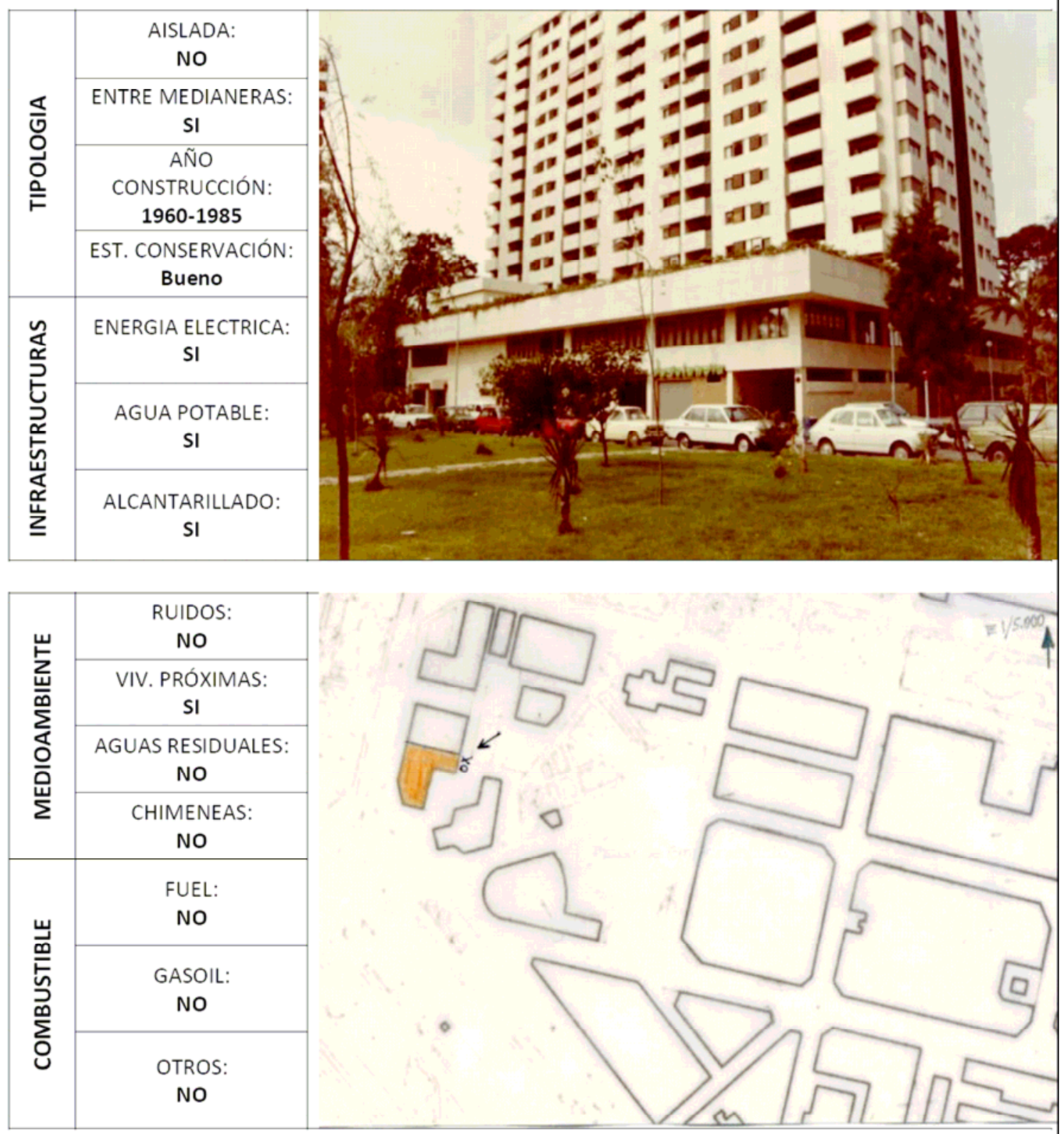


\section{FICHA DATOS DE LA INDUSTRIA}

LOCALIZACION ACTUALIZADA DE ACTIVIDADES INDUSTRIALES EN EL

MEDIO URBANO DE VALENCIA

\begin{tabular}{|c|c|c|c|c|c|c|c|}
\hline \multirow{5}{*}{ 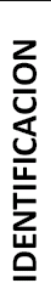 } & \multirow{2}{*}{\multicolumn{2}{|c|}{$\begin{array}{c}\text { NOMBRE } \\
\text { EMPLAZAMIENTO }\end{array}$}} & \multicolumn{5}{|c|}{ MUEBLES ABAD, S.L. } \\
\hline & & & \multicolumn{3}{|c|}{ C/Antonio Suarez, 15} & C.P. & \\
\hline & \multirow{2}{*}{ CNAE } & \multirow{2}{*}{468} & \multirow{2}{*}{ DESCRIPCION } & \multicolumn{4}{|c|}{ IND.MADERA, CORCHO Y MUEBLES } \\
\hline & & & & \multicolumn{4}{|c|}{ Fabricacion mobiliario de madera para el hogar } \\
\hline & DISTRITO & 6 & \multicolumn{5}{|c|}{ EL PLA DEL REAL } \\
\hline & \multicolumn{2}{|c|}{ SUPERFICIES } & $\begin{array}{l}\text { Sup. Parcela: } \\
2.000 \mathrm{~m}^{2}\end{array}$ & $\begin{array}{c}\text { Sup. Ocupada: } \\
1.500 \mathrm{~m}^{2}\end{array}$ & $\begin{array}{c}\text { Sup. Construida: } \\
1.500 \mathrm{~m}^{2}\end{array}$ & EMF & $\begin{array}{l}\text { EADOS: } \\
23\end{array}$ \\
\hline
\end{tabular}
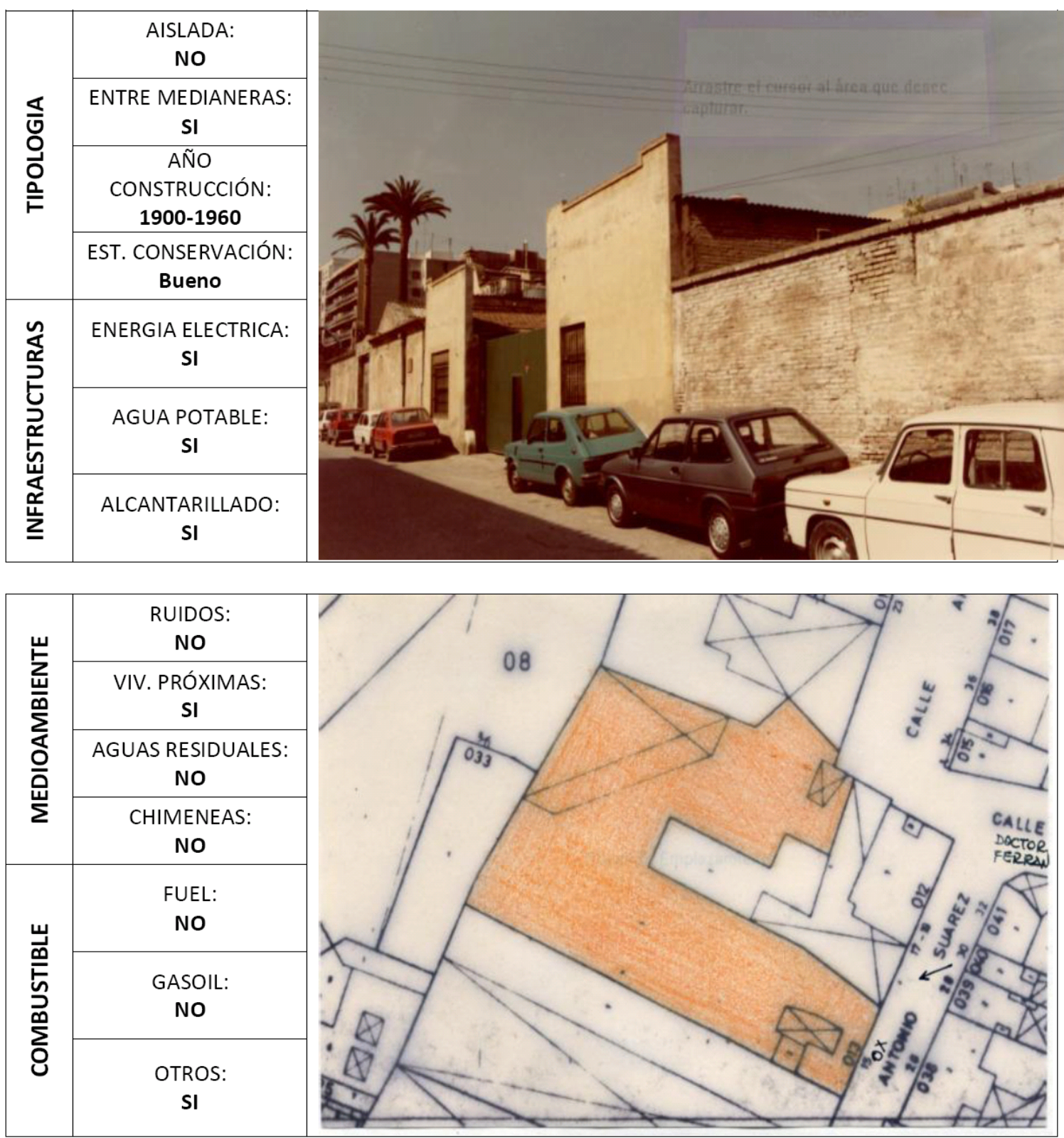

EN LA ACTUALIDAD: EDIFICIO NUEVO. COMERCIOS Y BAR. 


\section{FICHA DATOS DE LA INDUSTRIA}

LOCALIZACION ACTUALIZADA DE ACTIVIDADES INDUSTRIALES EN EL MEDIO URBANO DE VALENCIA

\begin{tabular}{|c|c|c|c|c|c|c|}
\hline \multirow{4}{*}{ 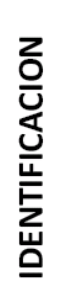 } & \multirow{2}{*}{\multicolumn{2}{|c|}{$\begin{array}{c}\text { NOMBRE } \\
\text { EMPLAZAMIENTO }\end{array}$}} & \multicolumn{4}{|c|}{ INST. DE AGROQUIMICA Y TECNOLOGIA DE ALIMENTOS } \\
\hline & & & \multicolumn{3}{|c|}{ C/Jaime Roig, 11} & C.P. \\
\hline & CNAE & & DESCRIPCION & \multicolumn{3}{|c|}{ Investigación } \\
\hline & DISTRITO & 6 & \multicolumn{4}{|c|}{ EL PLA DEL REAL } \\
\hline & \multicolumn{2}{|c|}{ SUPERFICIES } & $\begin{array}{c}\text { Sup. Parcela: } \\
1.296 \mathrm{~m}^{2}\end{array}$ & $\begin{array}{l}\text { Sup. Ocupada: } \\
700 \mathrm{~m}^{2}\end{array}$ & $\begin{array}{c}\text { Sup. Construida: } \\
3.500 \mathrm{~m}^{2}\end{array}$ & $\begin{array}{c}\text { EMPLEADOS: } \\
180\end{array}$ \\
\hline
\end{tabular}
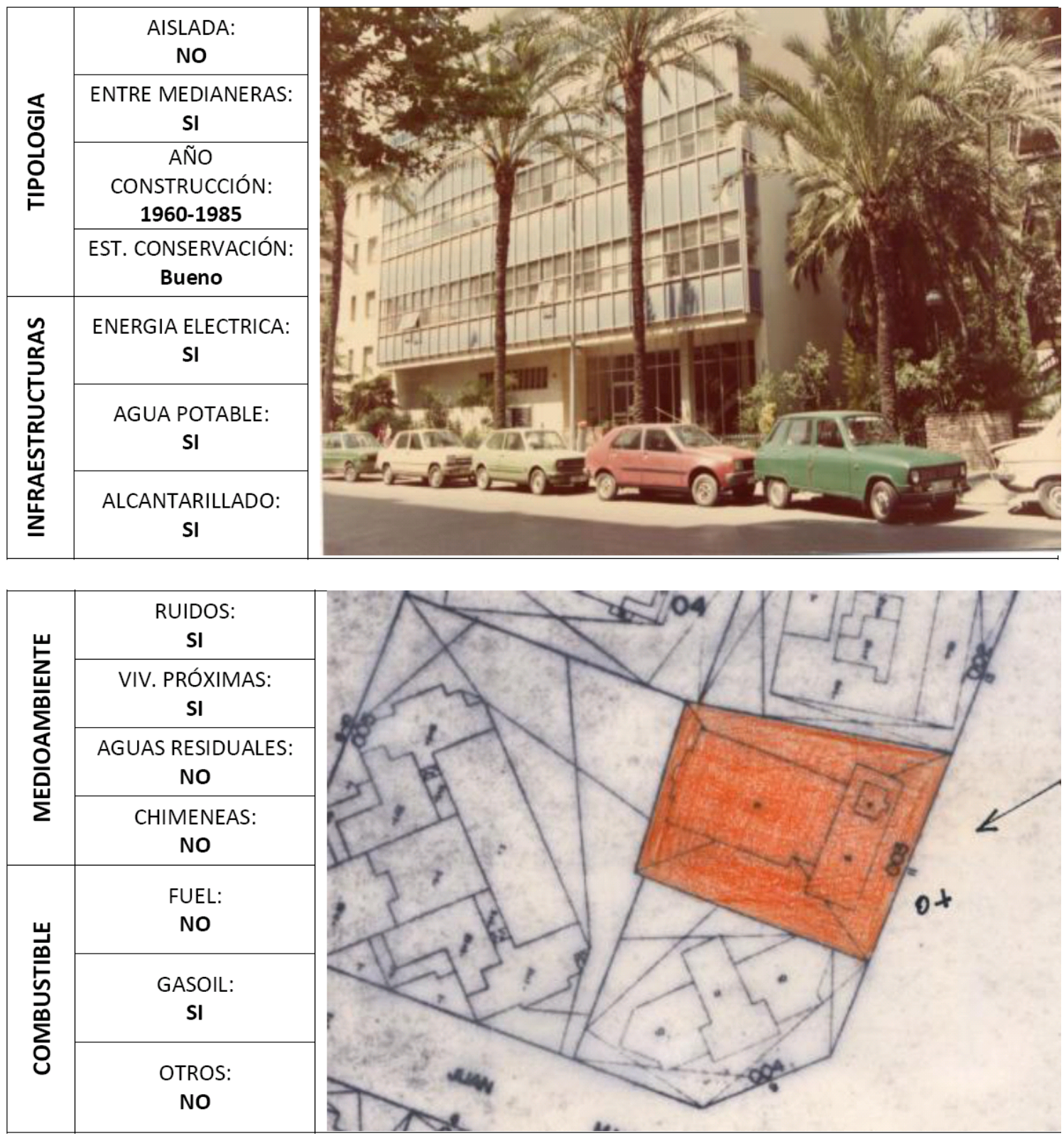

EN LA ACTUALIDAD: SIGUE EN LA ACTUALIDAD LA MISMA EMPRESA. 


\section{FICHA DATOS DE LA INDUSTRIA}

LOCALIZACION ACTUALIZADA DE ACTIVIDADES INDUSTRIALES EN EL

MEDIO URBANO DE VALENCIA

\begin{tabular}{|c|c|c|c|c|c|c|c|}
\hline \multirow{5}{*}{ 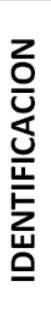 } & \multirow{2}{*}{\multicolumn{2}{|c|}{$\begin{array}{c}\text { NOMBRE } \\
\text { EMPLAZAMIENTO }\end{array}$}} & \multicolumn{5}{|c|}{ TABACALERA, S.L. } \\
\hline & & & \multicolumn{3}{|c|}{ C/Amadeo de Saboya,11 } & C.P. & \\
\hline & \multirow[b]{2}{*}{ CNAE } & \multirow[b]{2}{*}{429} & \multirow[b]{2}{*}{ DESCRIPCION } & \multicolumn{4}{|c|}{ IND.PROD. ALIMENTACIÓN;BEBIDA;ETC. } \\
\hline & & & & \multicolumn{4}{|c|}{ Industria del tabaco } \\
\hline & DISTRITO & 6 & \multicolumn{5}{|c|}{ EL PLA DEL REAL } \\
\hline \multicolumn{3}{|c|}{ SUPERFICIES } & $\begin{array}{l}\text { Sup. Parcela: } \\
23.520 \mathrm{~m}^{2}\end{array}$ & $\begin{array}{l}\text { Sup. Ocupada: } \\
23.520 \mathrm{~m}^{2}\end{array}$ & $\begin{array}{c}\text { Sup. Construida: } \\
58.035 \mathrm{~m}^{2}\end{array}$ & EMP & $\begin{array}{l}\text { LEADOS: } \\
555\end{array}$ \\
\hline
\end{tabular}
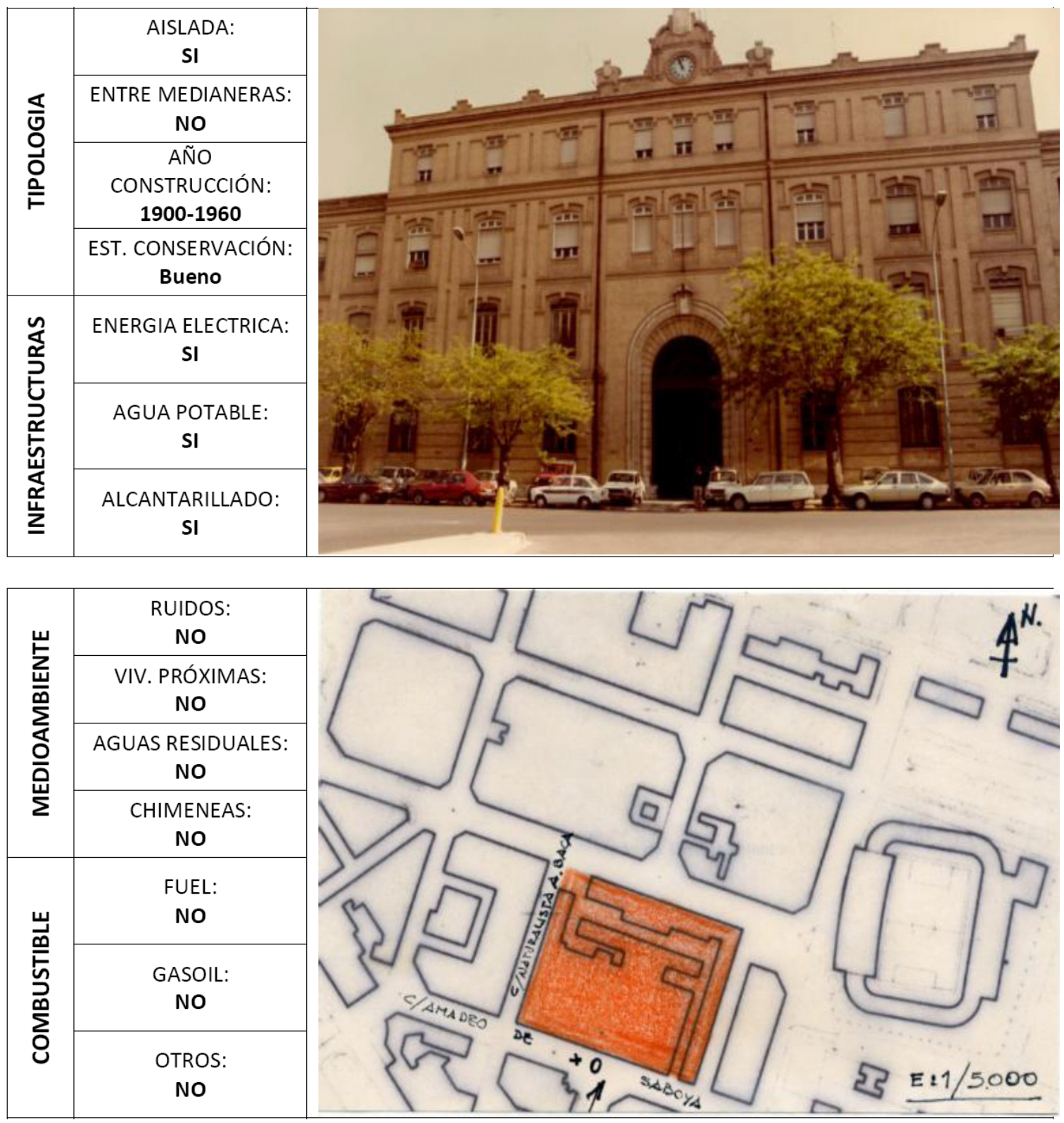

EN LA ACTUALIDAD: AYUNTAMIENTO 


\section{EVOLUCIÓN}

\section{PLANO UBICACIÓN INDUSTRIAS}

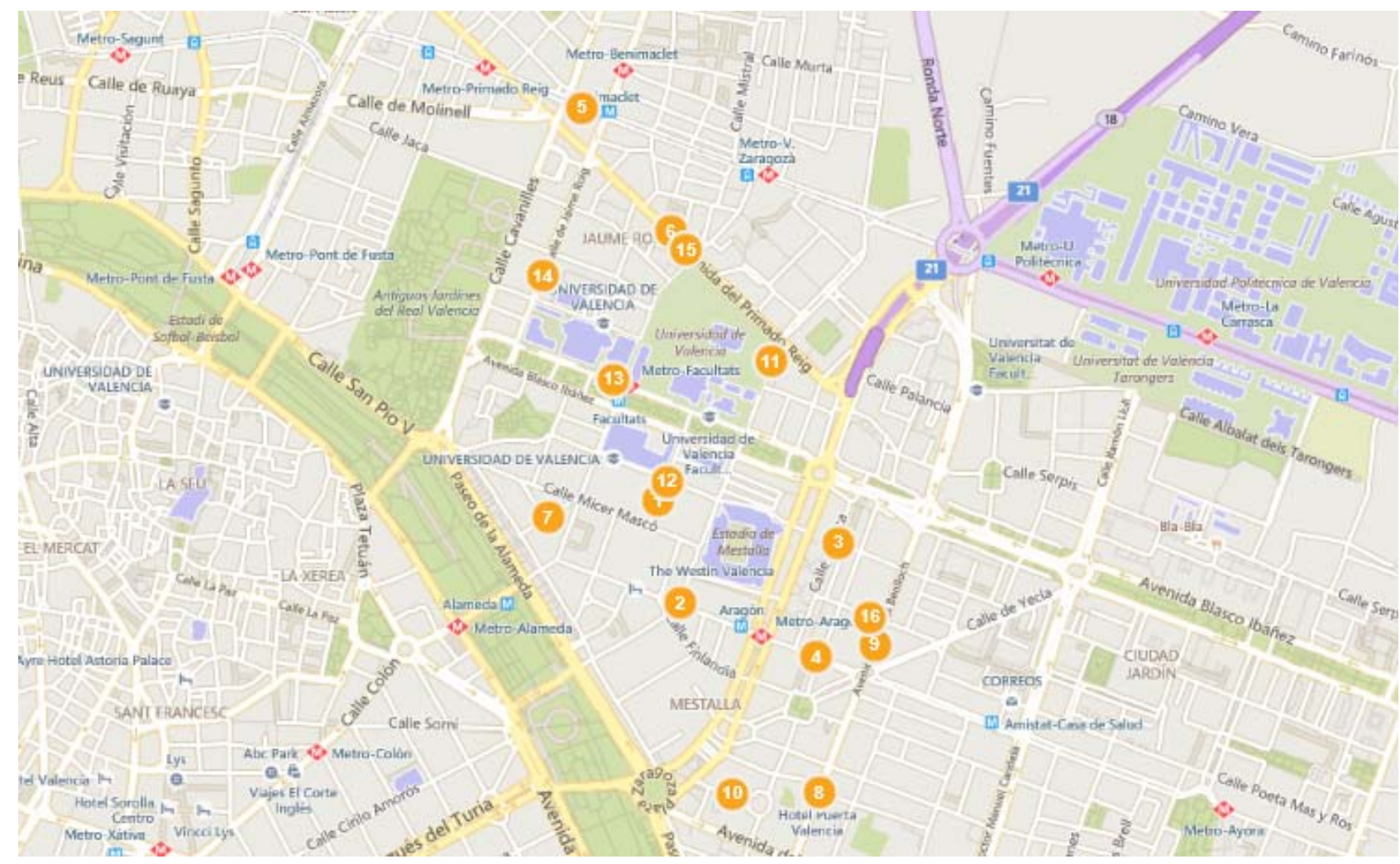

LISTADO DE INDUSTRIAS Y ACTIVIDAD.-

1. TURBODIESEL LEVANTE S.L.

Mantenimiento y reparación de vehículos de motor

2. TALLERES MICO C.B.

Mantenimiento y reparación de vehículos de motor

3. Esteban López Gasco

Mantenimiento y reparación de vehículos de motor

4. Francisco Torralba Ferrer

Mantenimiento y reparación de vehículos de motor

5. José María Pérez Moreno

Fabricación de otras estructuras de madrea y piezas de carpintería y ebanistería para la construcción.

6. Manuel Farto Alba

Confección de otras prendas de vestir exteriores 
7. DESING \& PATTERNS S.L.

Confección de otras prendas de vestir y accesorios

8. Vicente Pérez Torres

Confección de otras prendas de vestir exteriores

9. PANADERIA MASANET C.B.

Fabricación de pan y productos frescos de panadería y pastelería.

10. SUPER RECARGA S.L.

Otras actividades de impresión y artes gráficas.

11. Carrillo Baeza, Ángeles

Otras actividades de impresión y artes gráficas.

12. TINK FACTORÍA COLOR S.L.

Otras actividades de impresión y artes gráficas.

13. COPIES C.B.

Otras actividades de impresión y artes gráficas.

14. INST. DE AGROQUIMICA Y TECNOLOGIA DE ALIMENTOS

(Existente 28) CNAE año 1985 (sin datos)

15. ISOLUX S.A. (Existente 31)

CNAE año 1985 (347)

16. DOVER S.A. (Existente 37)

CNAE año 1985 (672) 
ESTADO ACTUAL DE LOS ANTIGUOS EDIFICIOS INDUSTRIALES DE INTERES.-

- TABACALERA ESPAÑOLA, S.A.

$\mathrm{C} /$ Amadeo de Saboya, № 11. (Clave 18 2)

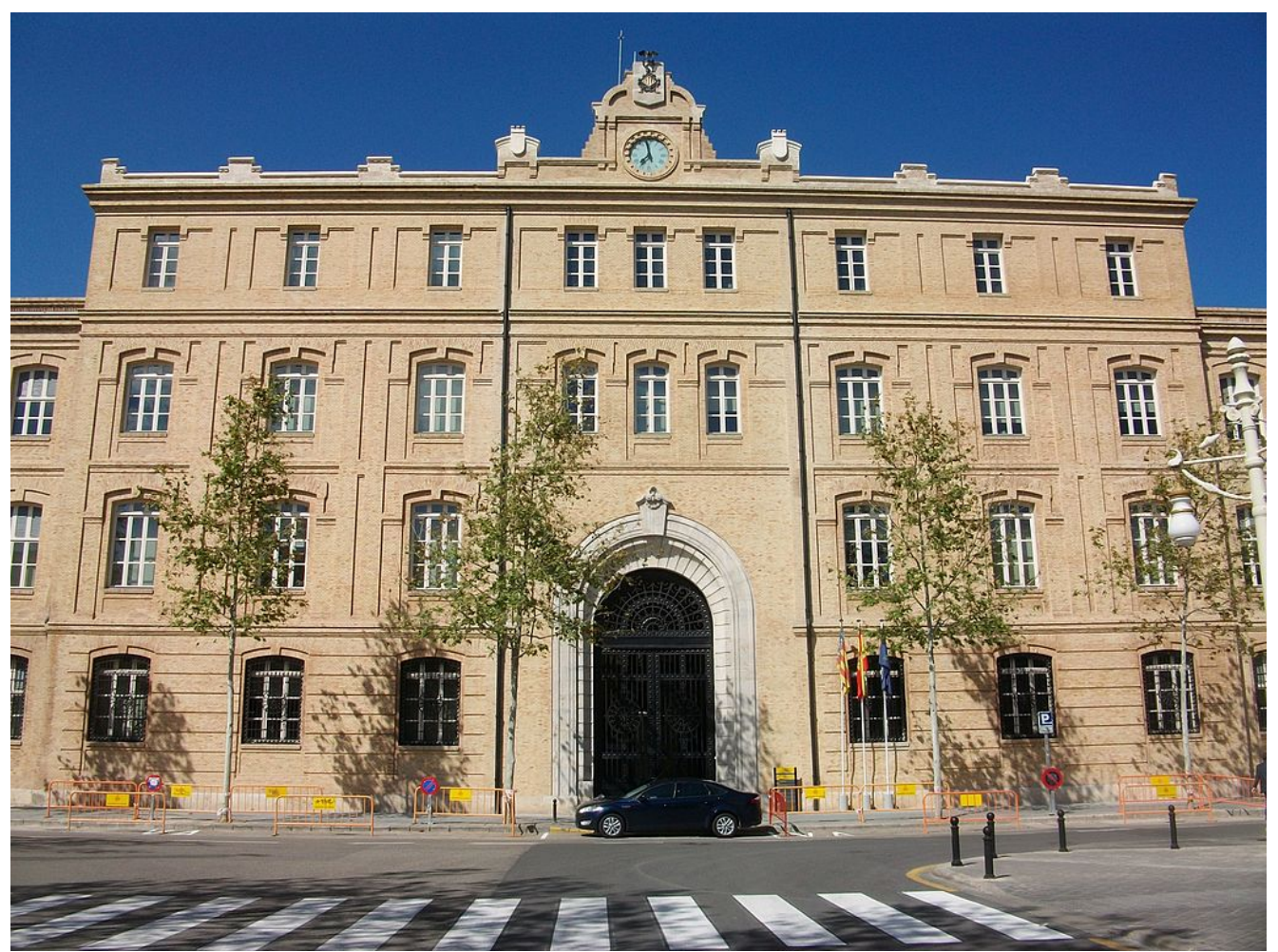

Foto 27: Ayuntamiento de Valencia (Antigua Tabacalera) C/ Amadeo de Saboya, 11. Valencia 2015 Fuente: WEB. http://www.google.es/maps (Street View) 


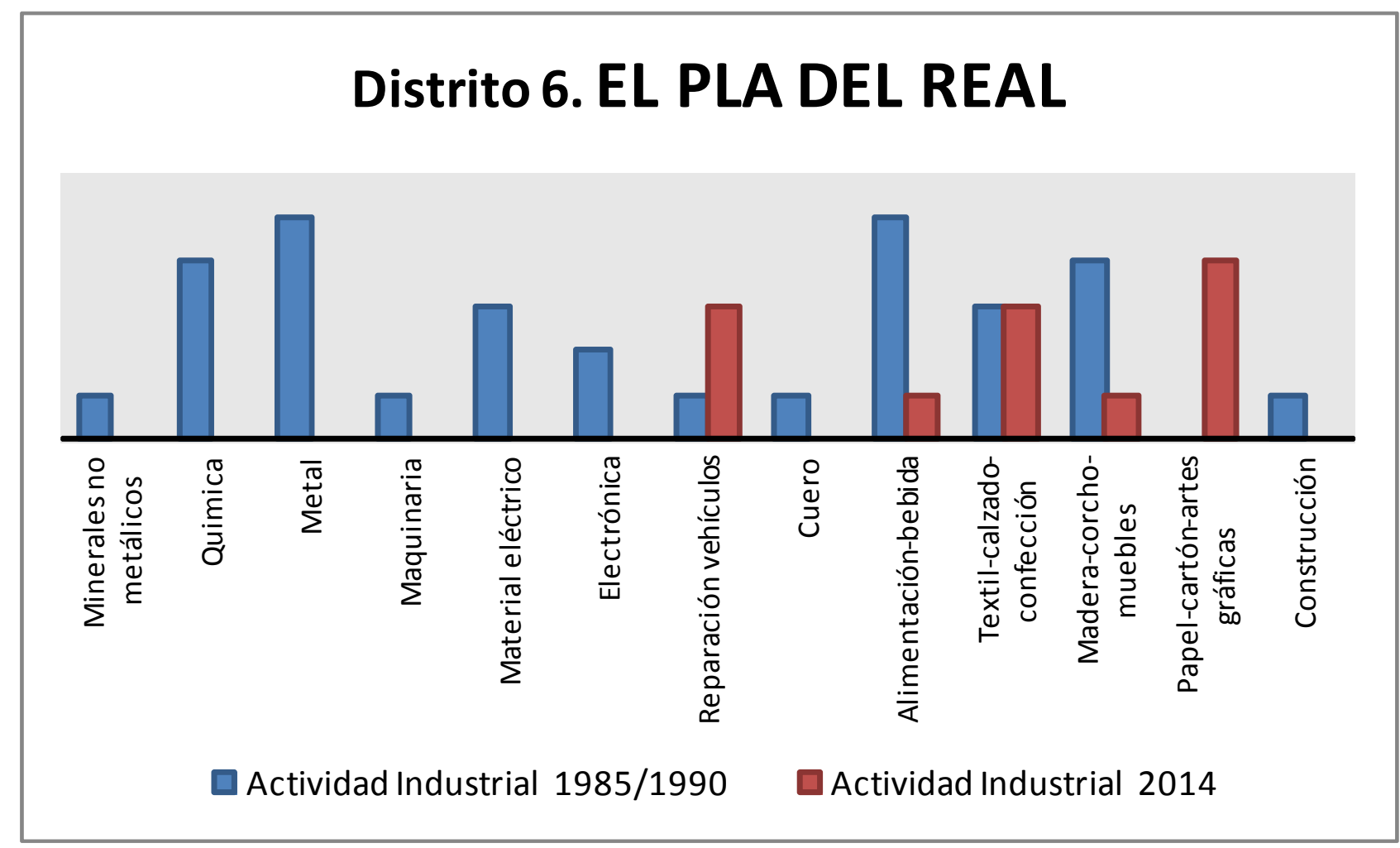

EVOLUCIÓN DEL IMPACTO AMBIENTAL

\section{IMPACTO EN EL MEDIO URBANO Distrito 6. EL PLA DEL REAL}

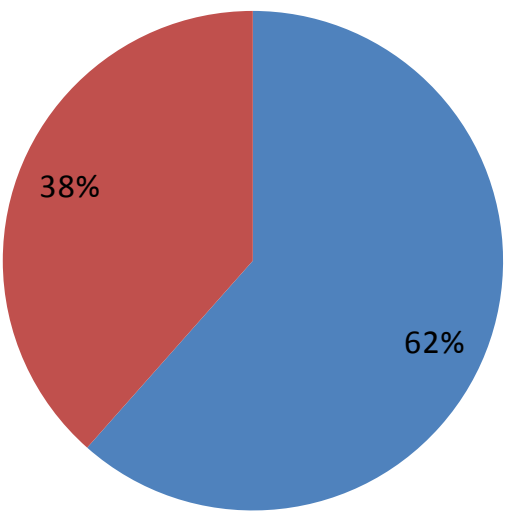

Empresas inocuas

Empresas ruidosas

Empresas ruidosas con chimenea 


\section{FICHAS TIPO}

\section{FICHA DATOS DE LA INDUSTRIA}

LOCALIZACION ACTUALIZADA DE ACTIVIDADES INDUSTRIALES EN EL

MEDIO URBANO DE VALENCIA

\begin{tabular}{|c|c|c|c|c|c|c|c|}
\hline \multirow{5}{*}{ 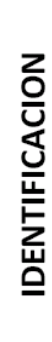 } & \multirow{2}{*}{\multicolumn{2}{|c|}{$\begin{array}{c}\text { NOMBRE } \\
\text { EMPLAZAMIENTO } \\
\end{array}$}} & \multicolumn{5}{|c|}{ JOSE Mạ PÉREZ MORENO } \\
\hline & & & \multicolumn{3}{|c|}{ C/ DR. VICENTE ZARAGOZA, 14} & C.P. & 46020 \\
\hline & \multirow[b]{2}{*}{ CNAE } & \multirow[b]{2}{*}{1623} & \multirow[b]{2}{*}{ DESCRIPCION } & \multicolumn{4}{|c|}{ MADERA-CORCHO-MUEBLES } \\
\hline & & & & \multicolumn{4}{|c|}{$\begin{array}{c}\text { Fabricación de otras estructuras de madera y } \\
\text { piezas de carpintería y ebanistería para la } \\
\text { construcción }\end{array}$} \\
\hline & DISTRITO & 6 & \multicolumn{5}{|c|}{ EL PLA DEL REAL } \\
\hline & \multicolumn{2}{|c|}{ MEDIOAMBIENTE } & RUIDOSAS & SI & CHIMENEAS & & 10 \\
\hline
\end{tabular}
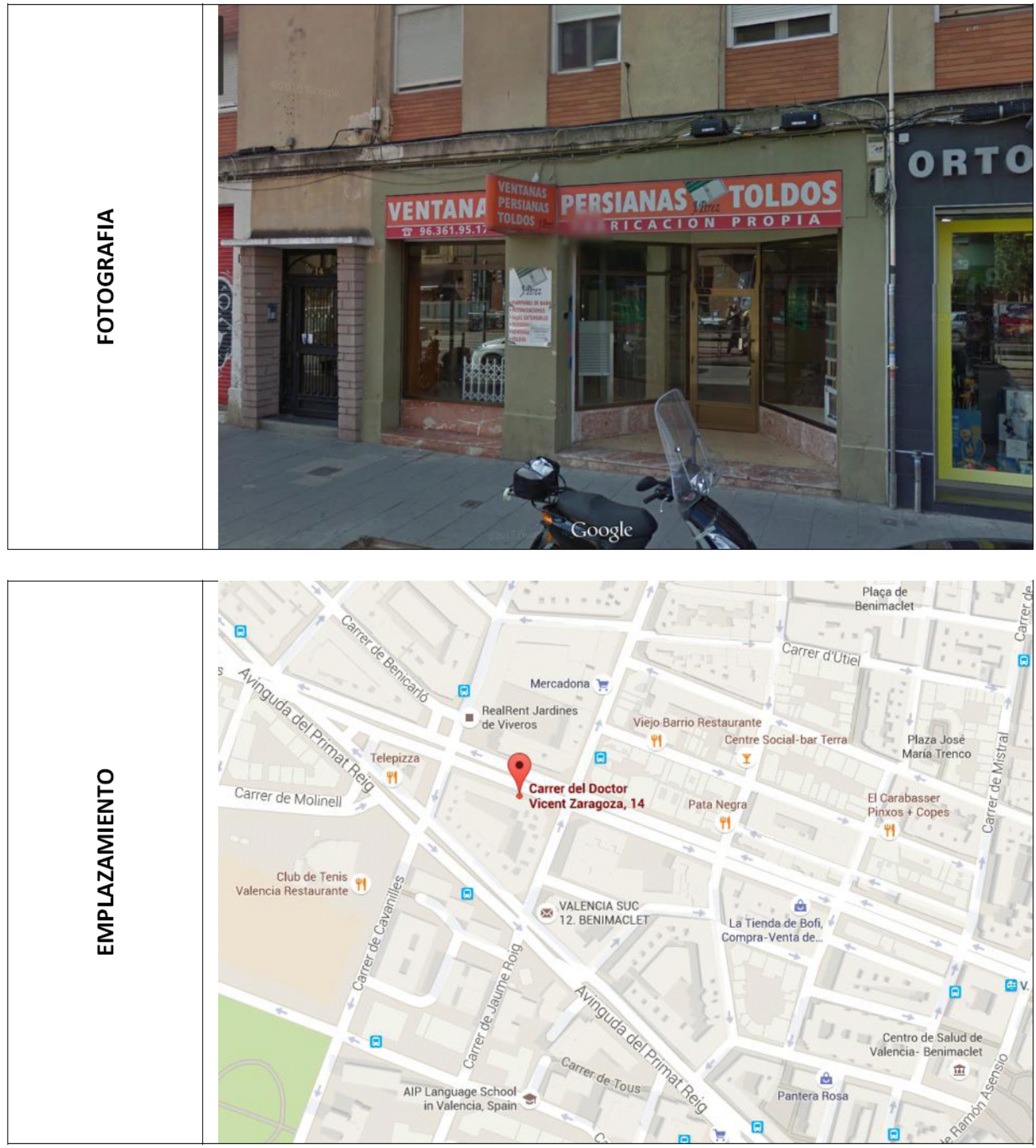


\section{FICHA DATOS DE LA INDUSTRIA}

LOCALIZACION ACTUALIZADA DE ACTIVIDADES INDUSTRIALES EN EL

MEDIO URBANO DE VALENCIA

\begin{tabular}{|c|c|c|c|c|c|c|c|}
\hline \multirow{5}{*}{ 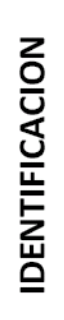 } & \multirow{2}{*}{\multicolumn{2}{|c|}{$\begin{array}{c}\text { NOMBRE } \\
\text { EMPLAZAMIENTO }\end{array}$}} & \multicolumn{5}{|c|}{ VICENTE PÉREZ TORRES } \\
\hline & & & \multicolumn{3}{|c|}{ AV. CARDENAL BENLLOCH, 31} & C.P. & 46021 \\
\hline & \multirow{2}{*}{ CNAE } & \multirow{2}{*}{1413} & \multirow{2}{*}{ DESCRIPCION } & \multicolumn{4}{|c|}{ TEXTIL-CALZADO-CONFECCIÓN } \\
\hline & & & & \multicolumn{4}{|c|}{ Confección de otras prendas de vestir exteriores } \\
\hline & DISTRITO & 6 & \multicolumn{5}{|c|}{ EL PLA DEL REAL } \\
\hline \multicolumn{3}{|c|}{ MEDIOAMBIENTE } & RUIDOSAS & NO & CHIMENEAS & & 0 \\
\hline
\end{tabular}
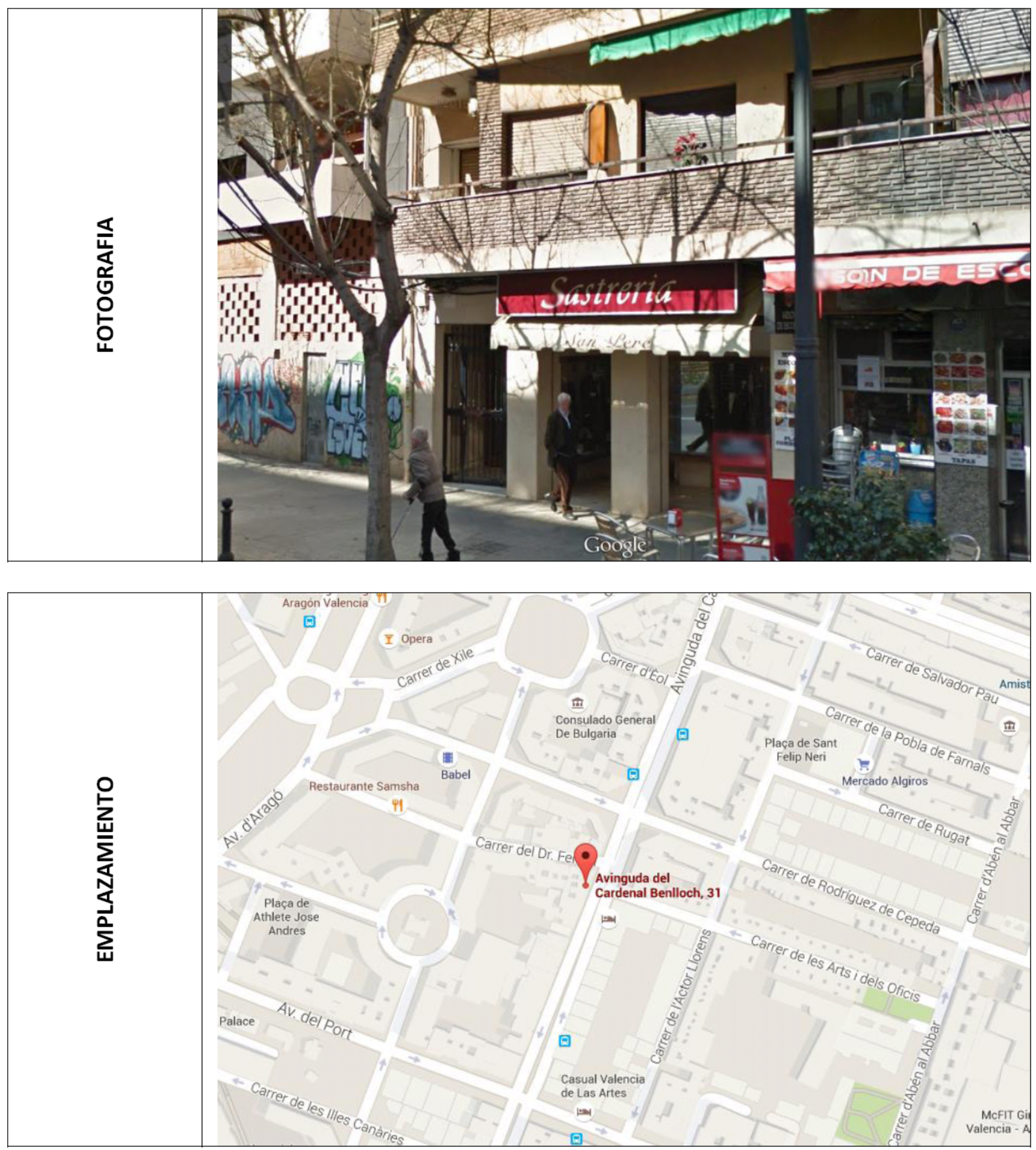


\section{FICHA DATOS DE LA INDUSTRIA}

LOCALIZACION ACTUALIZADA DE ACTIVIDADES INDUSTRIALES EN EL MEDIO URBANO DE VALENCIA

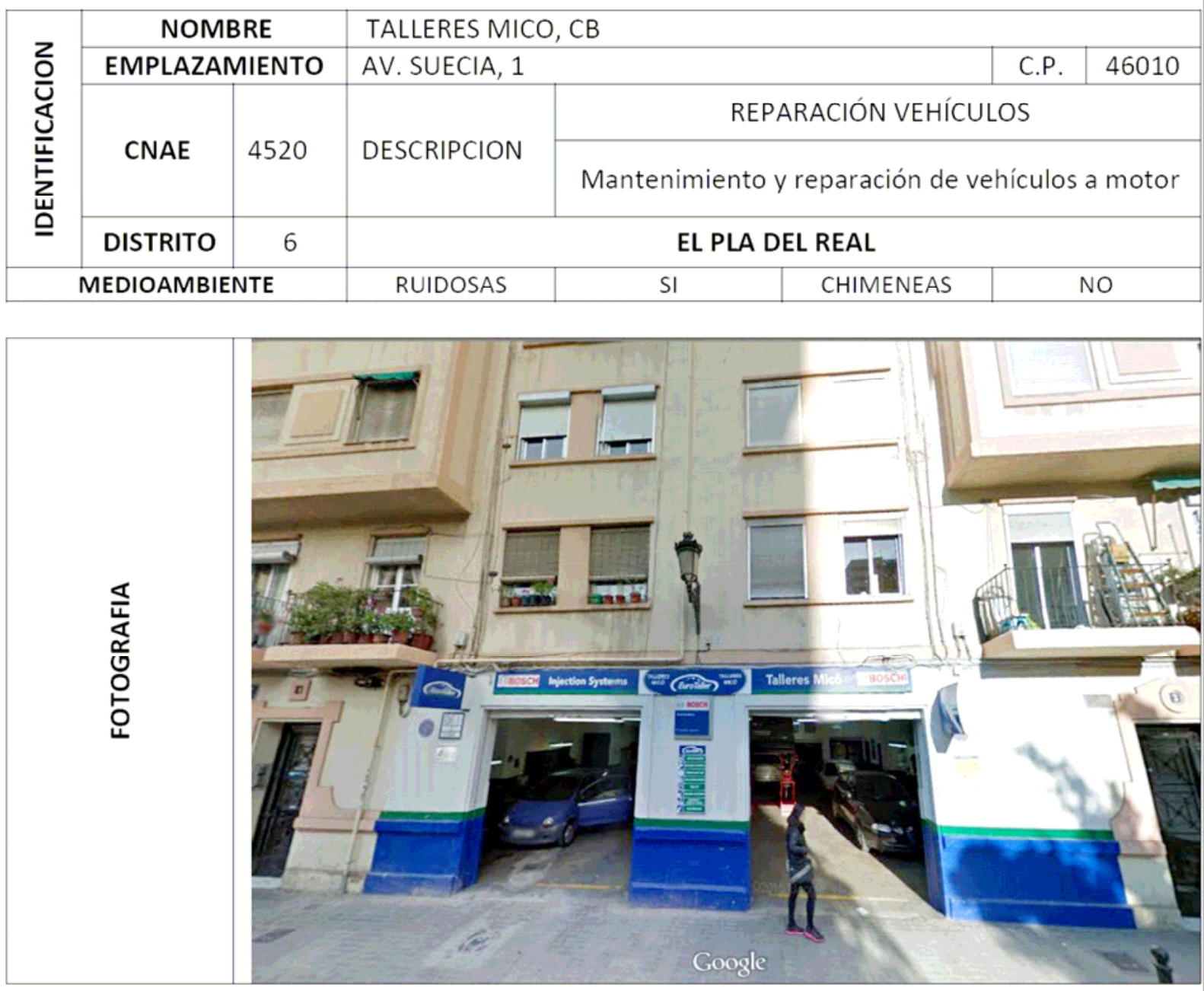

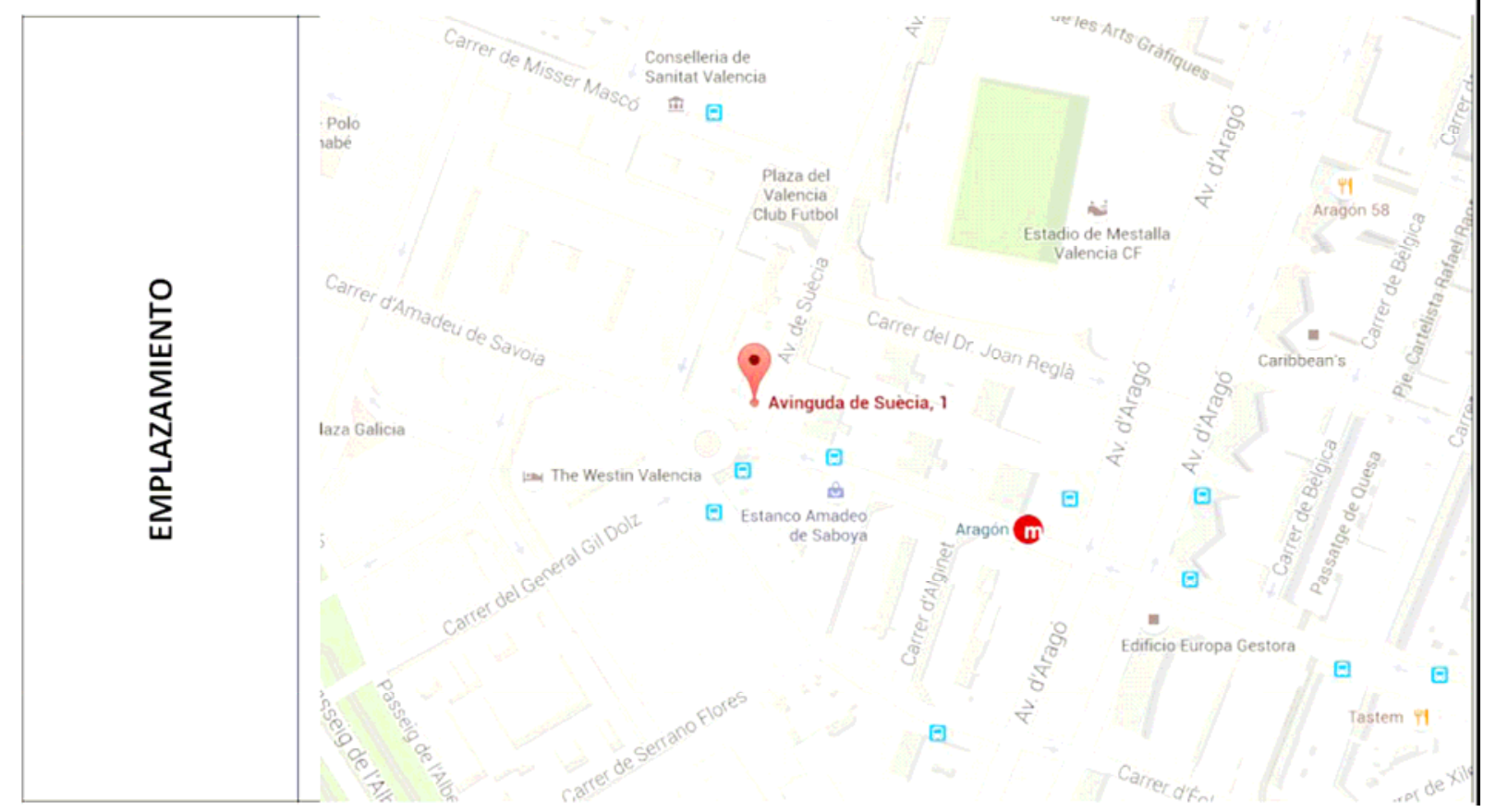




\section{FICHA DATOS DE LA INDUSTRIA}

LOCALIZACION ACTUALIZADA DE ACTIVIDADES INDUSTRIALES EN EL MEDIO URBANO DE VALENCIA

\begin{tabular}{|c|c|c|c|c|c|c|c|}
\hline \multirow{5}{*}{ 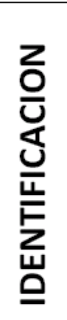 } & \multirow{2}{*}{\multicolumn{2}{|c|}{$\begin{array}{c}\text { NOMBRE } \\
\text { EMPLAZAMIENTO }\end{array}$}} & \multicolumn{5}{|c|}{ CARRILLO BAEZA ÁNGELES } \\
\hline & & & \multicolumn{3}{|c|}{ C/ GASCÓ OLIAG, 25} & C.P. & 46010 \\
\hline & \multirow{2}{*}{ CNAE } & \multirow{2}{*}{1812} & \multirow{2}{*}{ DESCRIPCION } & \multicolumn{4}{|c|}{ PAPEL-CARTÓN-ARTES GRÁFICAS } \\
\hline & & & & \multicolumn{4}{|c|}{ Otras actividades de impresión y artes gráficas } \\
\hline & DISTRITO & 6 & \multicolumn{5}{|c|}{ EL PLA DEL REAL } \\
\hline \multicolumn{3}{|c|}{ MEDIOAMBIENTE } & RUIDOSAS & NO & CHIMENEAS & & 0 \\
\hline
\end{tabular}
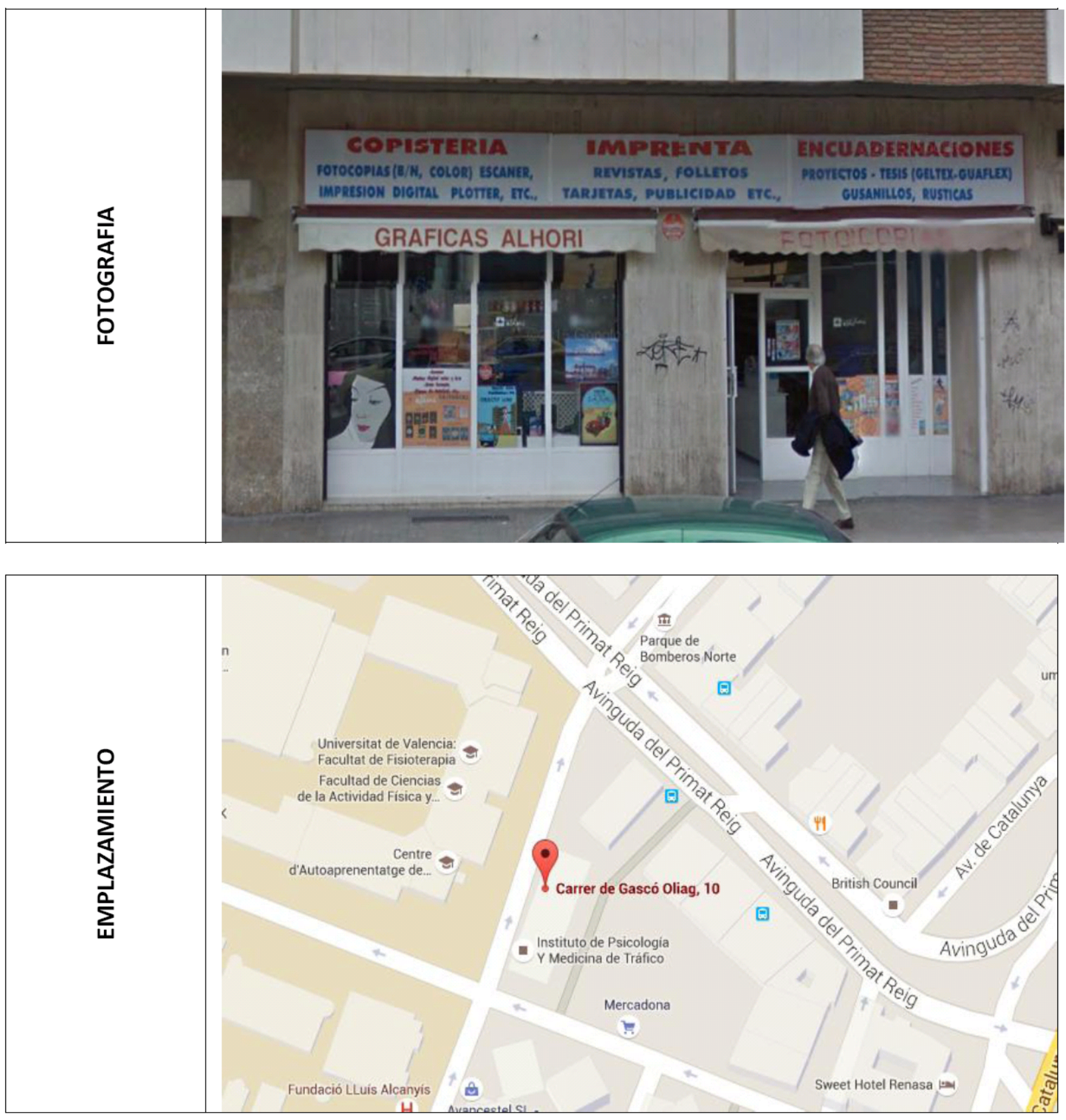


\section{FICHA DATOS DE LA INDUSTRIA}

LOCALIZACION ACTUALIZADA DE ACTIVIDADES INDUSTRIALES EN EL MEDIO URBANO DE VALENCIA

\begin{tabular}{|c|c|c|c|c|c|c|c|}
\hline \multirow{5}{*}{ 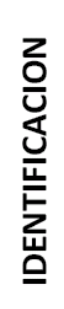 } & \multirow{2}{*}{\multicolumn{2}{|c|}{$\begin{array}{c}\text { NOMBRE } \\
\text { EMPLAZAMIENTO }\end{array}$}} & \multicolumn{5}{|c|}{ PANADERÍA MASANET, CB } \\
\hline & & & \multicolumn{3}{|c|}{ AV. CARDENAL BENLLOCH, 71} & C.P. & 46021 \\
\hline & \multirow[b]{2}{*}{ CNAE } & \multirow[b]{2}{*}{1071} & \multirow[b]{2}{*}{ DESCRIPCION } & \multicolumn{4}{|c|}{ ALIMENTACIÓN-BEBIDA } \\
\hline & & & & \multicolumn{4}{|c|}{$\begin{array}{c}\text { Fabricación de pan y de productos frescos de } \\
\text { panadería y pastelería }\end{array}$} \\
\hline & DISTRITO & 6 & \multicolumn{5}{|c|}{ EL PLA DEL REAL } \\
\hline \multicolumn{3}{|c|}{ MEDIOAMBIENTE } & RUIDOSAS & NO & CHIMENEAS & & NO \\
\hline
\end{tabular}
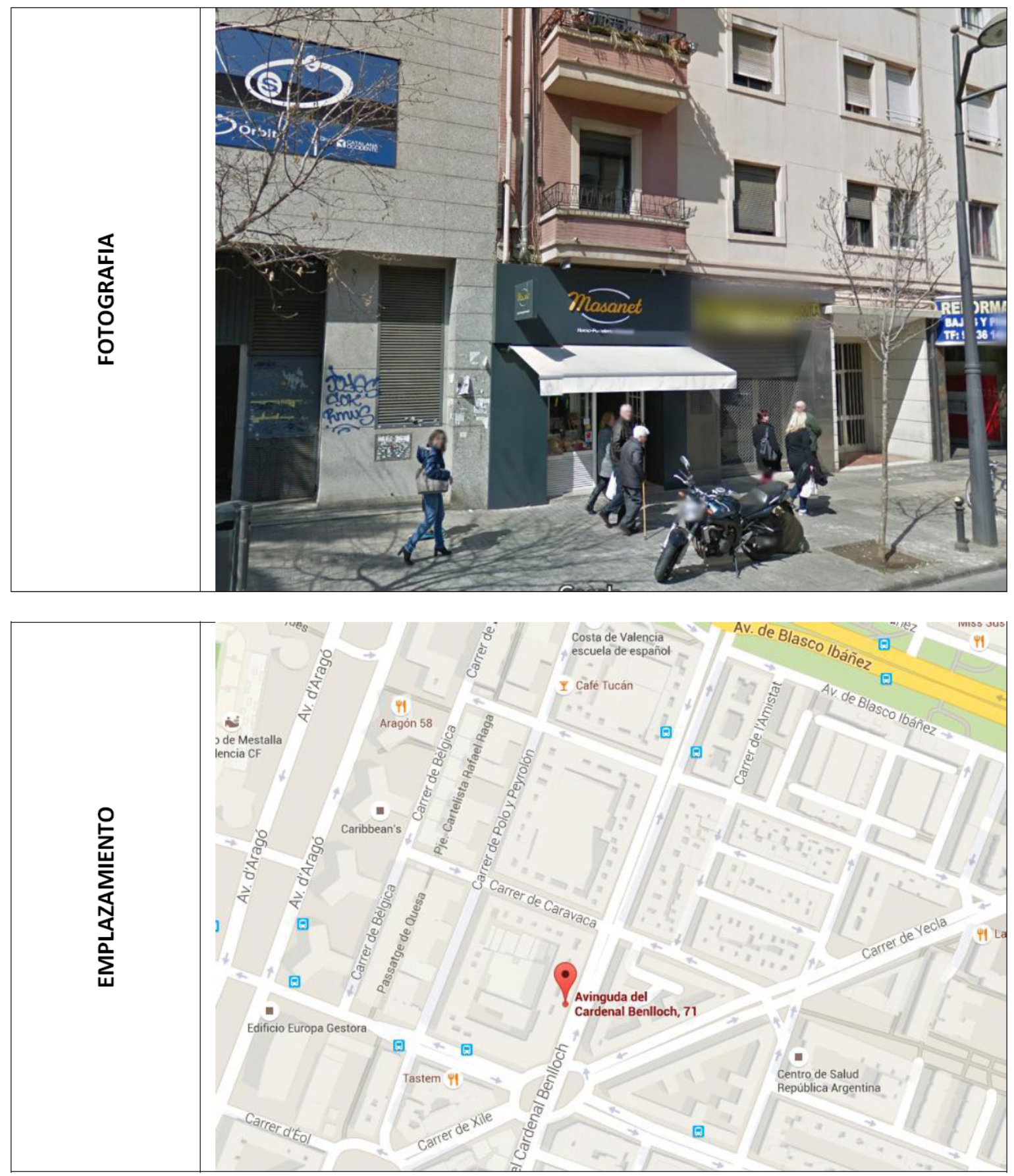


\section{DISTRITO 7.- $\quad$ OLIVERETA}

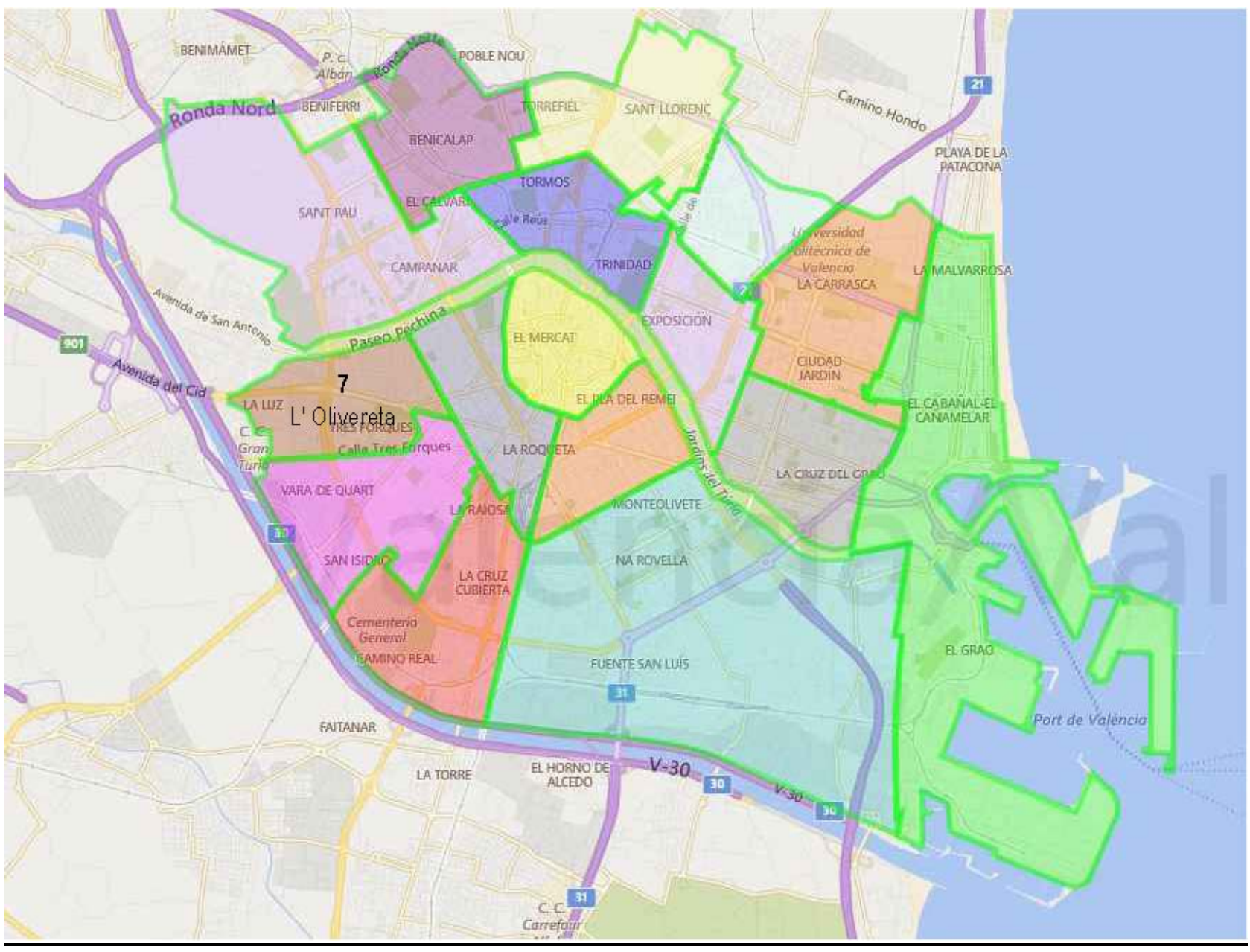

\section{LÍMITES GEOGRÁFICOS}

Cauce Viejo del Turia, término municipal de Mislata, C/ Tres Forques y Avda. Pérez Galdós. 


\section{EVOLUCIÓN DEL 1985-2014}

\section{PLANO UBICACIÓN INDUSTRIAS}

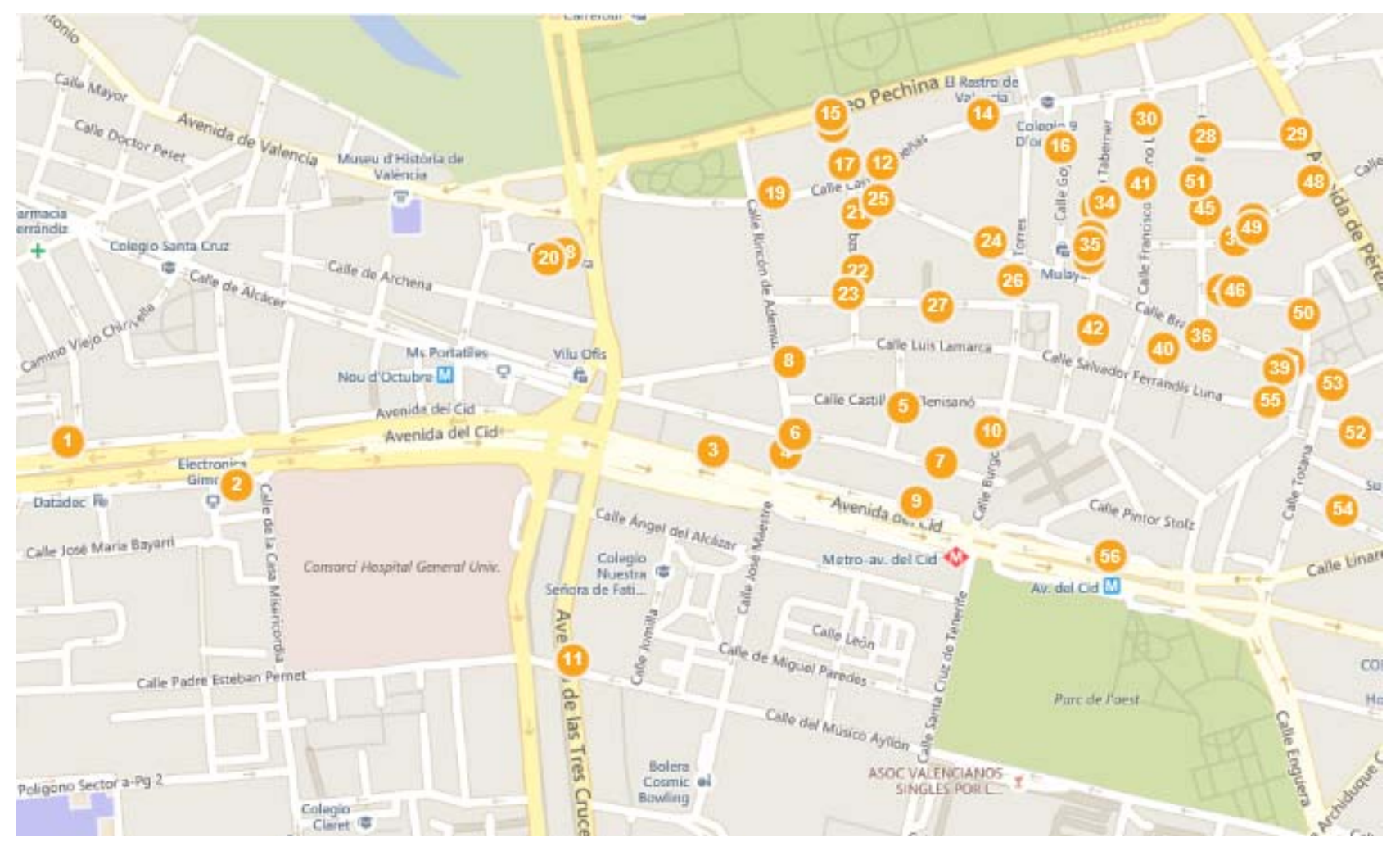

LISTADO DE INDUSTRIAS Y ESTADO ACTUAL :-

1. DIARIO LEVANTE

Oficinas CGT

2. Julián Graullera Olmos

Taller de vehículos

3. ORTA, S.L.

Centro deportivo

4. Llopis Oliver, José $\mathbf{M}^{\mathrm{a}}$.

Obra nueva

5. VELA JOYEROS, S.A.

Confección de cortinas/ Peluquería

6. Cuñat Roig, Ricardo

Obra nueva

7. EDITORIAL MAGA, S.L.

Supermercado 
8. Luis Gijón Moreno

Sin actividad

9. Sancho García, Juana

Varios comercios

10. ESTABLECIMIENTOS NOEL, S.A.

Loterías

11. Mariano Segura Salvador

Obra nueva

12. CANDEL Y COSIN, S.A.

Music dance

13. Carmen Rodríguez

Construcciones

14. GIMNER, S.A.

Peluquería

15. UNIBOTON

Sin actividad

16. MANUFACTURAS HEIDI, S.L.

Obra nueva

17. Miguel Ángel Gómez Planas

Taller de vehículos

18. José $\mathbf{M}^{\mathrm{a}}$ Gil Roger

Sin datos

19. Venancio Simón, J.

Sin actividad

20. ELECTRÓNICA VALENCIANA DEL MUEBLE, S.L.

Escuela de educación infantil

21. Tregón Florentín, Saturnino

Sin actividad

22. OLIVETTI, S.A.

Sin actividad

23. JAZ ESPAÑOLA, S.A.

Entidad bancaria

24. LAMPISTER

Sin actividad

25. Crespo Timoner, $\mathrm{C}$.

Sin actividad

26. CADSER, S.A.

Multibazar

27. Laserna Jiménez, Salvador

Sin actividad 
28. HORNO JOSE SANIA

Obra nueva

29. CONSTRUCCIONES ARGENTE, S.L.

Parking

30. Manuel Longas Muñoz

Obra nueva

31. Jaime Sobricases Vines

Mantiene la actividad

32. OGABAN, S.L.

Sin actividad

33. Peñalver Hernández, Antonio

Sin actividad

34. Llorens Fuster, Enrique

Ins. de protección contra incendios

35. DETENERIA SOCIEDAD COOPERATIVA

Sin actividad

36. HORNO BRASIL

Sin actividad

37. NELAY, S.A.

Iglesia cristiana evangélica

38. Baixauli Marín, F.

Sin actividad

39. Rufino Araco, $F$.

Sin actividad

40. MANUFACTURAS GRÁFICAS NAVARRO CAMPOS, S.A.

Sin actividad

41. Díaz Llacer, F.

Protección contra incendios

42. SUC. DE JOSÉ RODRÍGUEZ SEDAMO, S.L.

Alquiler y venta de disfraces

43. HIJOS R. FERNÁNDEZ BLANQUER, S.A.

Mantiene la actividad

44. MATÍAS JIMÉNEZ FRUTOS, S.A.

Sin actividad

45. Buendía Guix, G.

Sin actividad

46. PRENDAS DEPORTIVAS RESSY, S.A.

Sin datos

47. ALAN-COAR, S.A.

Mantiene la actividad 
48. Ribes Mateu, Jaime Mantiene la actividad

49. GÉNEROS DE PUNTO ESCRIVA, S.A.

Trasteros en alquiler

50. Alfredo Wollstein Alcaraz

Servicio técnico televisión

51. ARTES GRAFICAS SOLER, S.A.

Artes gráficas

52. VICENTE CASQUEL RAUSELL, S.L.

Mantiene la actividad

53. HORNO ENRIQUE ALPERA

Horno

54. JOSÉ CUBES, S.L.

Imprenta

55. PEGUIMAR, S.A.

Bisutería

56. UVEX, S.L.

Confección

CARACTERÍSTICAS DEL ASENTAMIENTO INDUSTRIAL.

- Uso dominante en el distrito: residencial

- Asentamiento industrial homogéneo, de poca relevancia, concentrado en el área próxima a la confluencia del viejo cauce del Turia con la Avd. Pérez Galdós.

- Industria escasa, de pequeña superficie, situada en los bajos de edificios de viviendas, entre medianeras, en su mayoría construidos en las últimas décadas.

\section{CARACTERÍSTICAS DE LOS LOCALES}

- De pequeña superficie.

- Situados en bajos de edificios de viviendas entre medianeras, de reciente construcción.

CARACTERISTICAS DE LAS ACTIVIDADES.

Se censaron inicialmente 56 industrias y en el período de vigencia del Plan General han quedado solamente 8 creándose 51 nuevas industrias.

Las actividades dominantes son calzado y confección, papel y artes gráficas y productos metálicas. 
La escasa superficie ocupada por la actividad industrial y el discreto número de trabajadores empleados demuestra su poca importancia relativa en el contexto industrial municipal.

IMPACTO EN EL MEDIO AMBIENTE URBANO.-

- Industria de características no contaminantes.

- Existe red de alcantarillado en su práctica totalidad.

- La industria emplazada en este distrito no genera transporte de importancia, a excepción del Diario Levante, aunque si se da a través de algunas de sus vías, Avd. del Cid, Avd. Pérez Galdós, C/ Tres Forques, por las que discurre un tráfico de vehículos y mercancías muy notable.

- La integración en este entorno es prácticamente total, dado el emplazamiento de la industria en los bajos de los edificios de vivienda. Es destacable sin embargo el problema creado por el trazado de la Avd. de Tres Cruces al ignorar la edificación preexistente, cuya consecuencia se evidencia en el estrangulamiento de dicha vía por el molino de Picó.

\section{EDIFICIOS INDUSTRIALES DE INTERES:}

- Molino de Picó.

Avd. Tres Cruces no 25 (AV-1)

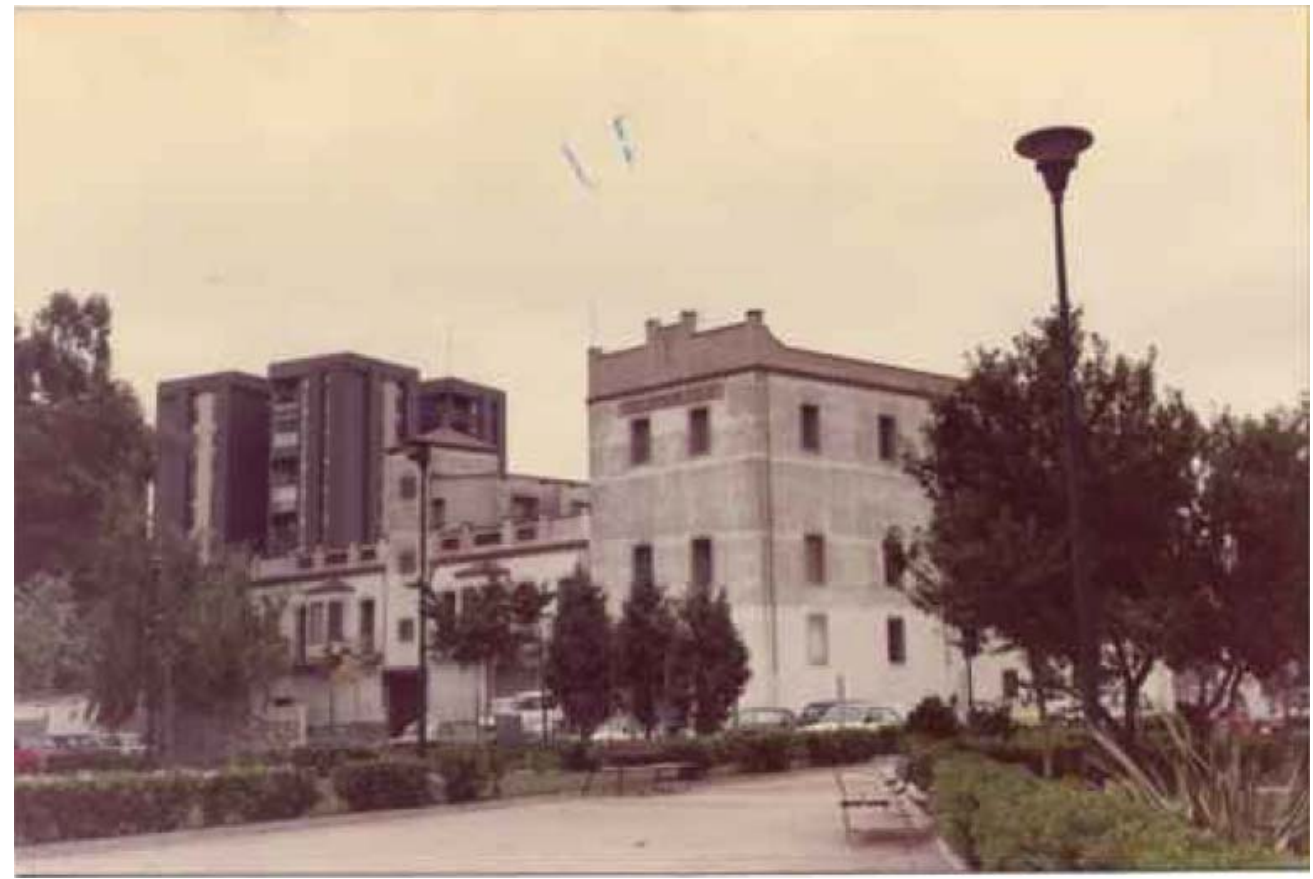

Foto 27: Molino de Picó. Fábrica de harina. Avda. Tres Cruces, 25. Valencia.1985 
TIPOLOGÍA EDIFICACIÓN

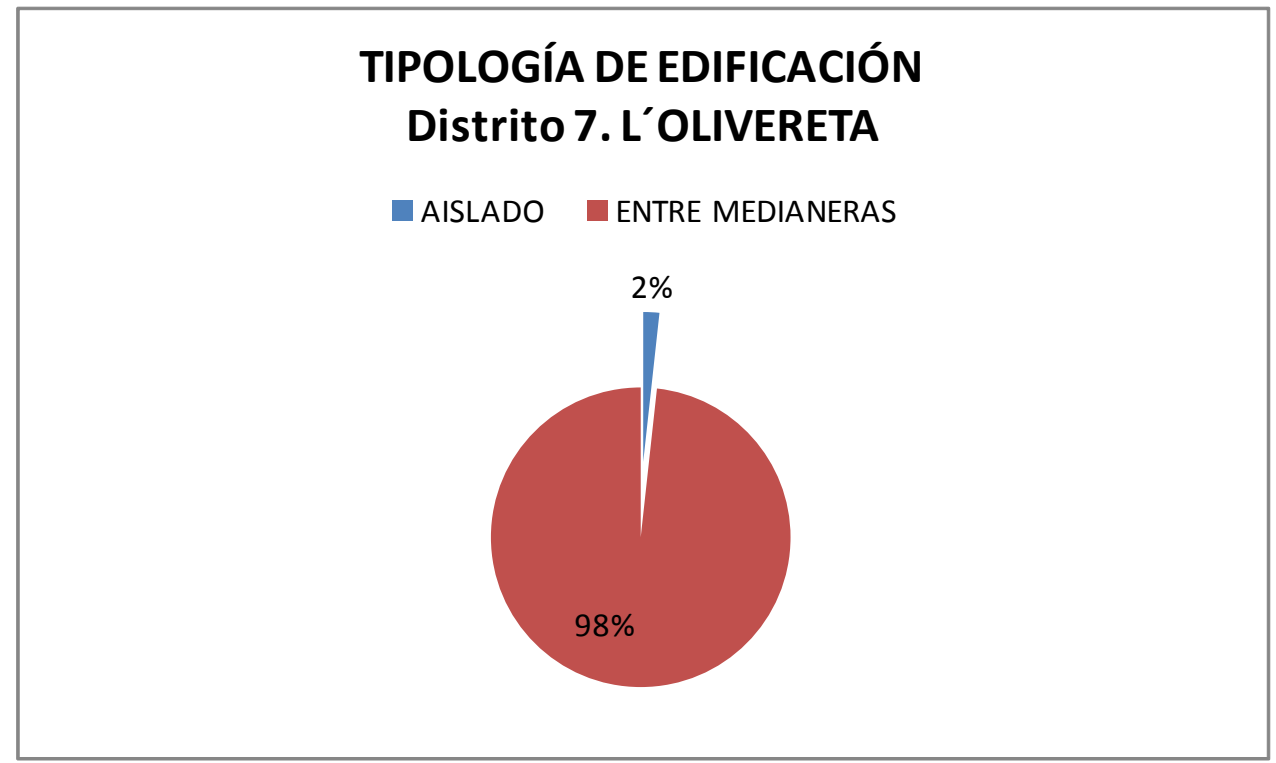




\section{ACTIVIDAD INDUSTRIAL, SUPERFICIE Y EMPLEO}

\begin{tabular}{|c|c|c|c|c|c|}
\hline \multicolumn{6}{|c|}{ DISTRITO 7 - L'OLIVERETA (ATIVIDAD INDUSTRIAL Y EMPLEO) } \\
\hline ACTIVIDAD & $\begin{array}{c}\text { № } \\
\text { EMPRESAS }\end{array}$ & $\begin{array}{c}\text { SUP. ACTIVIDAD } \\
\text { IND }\left(\mathrm{m}^{2}\right)\end{array}$ & $\begin{array}{c}\text { \% SUP. } \\
\text { INDUSTRIAL }\end{array}$ & $\begin{array}{c}\text { № } \\
\text { EMPLEADOS }\end{array}$ & $\begin{array}{c}\text { DENSIDAD } \\
\text { EMPLEO } \\
\text { (empleados } / \mathrm{m}^{2} \\
\text { actividad) }\end{array}$ \\
\hline INDUSTRIA QUÍMICA & 1 & 474 & 1,70 & 8 & 0,0169 \\
\hline FABRICACIÓN DE PRODUCTOS METÁLICOS & 8 & 2055 & 7,37 & 50 & 0,0243 \\
\hline CONSTRUCCIÓN DE MAQUINARIA Y EQUIPO MECÁNICO & 1 & 200 & 0,72 & 1 & 0,0050 \\
\hline CONSTRUCCIÓN DE MÁQUINAS DE OFICINA Y ORDENADORES & 1 & 1027 & 3,68 & 40 & 0,0389 \\
\hline CONSTRUCCIÓN DE MAQUINARIA Y MATERIAL ELÉCTRICO & 2 & 686 & 2,46 & 65 & 0,0948 \\
\hline FABRICACIÓN DE MATERIAL ELECTRÓNICO & 1 & 150 & 0,54 & 6 & 0,0400 \\
\hline FABRICACIÓN DE INSTRUMENTOS DE PRECISIÓN, ÓPTICA Y SIMILARES & 2 & 491 & 1,76 & 45 & 0,0916 \\
\hline INDUSTRIAS DE PRODUCTOS ALIMENTICIOS, BEBIDAS Y TABACO & 10 & 6590 & 23,62 & 54 & 0,0082 \\
\hline INDUSTRIAS DE PRODUCTOS ALIMENTICIOS, BEBIDAS Y TABACO & 1 & 839 & 3,01 & 12 & 0,0143 \\
\hline INDUSTRIA TEXTIL & 1 & 860 & 3,08 & 34 & 0,0395 \\
\hline INDUSTRIA DEL CUERO & 1 & 240 & 0,86 & 6 & 0,0250 \\
\hline INDUSTRIA DEL CALZADO Y DEL VESTIDO Y OTRAS CONFECCIONES TEXTILES & 11 & 6448 & 23,11 & 153 & 0,0237 \\
\hline INDUSTRIAS DE MADERA, CORCHO Y MUEBLES DE MADERA & 1 & 800 & 2,87 & 23 & 0,0288 \\
\hline INDUSTRIA DEL PAPEL Y FABRICACIÓN DE ARTÍCULOS DE PAPEL, ARTES GRÁFICAS & 7 & 2251 & 8,07 & 179 & 0,0795 \\
\hline INDUSTRIAS DE TRANSFORMACIÓN DEL CAUCHO Y MATERIAS PLÁSTICAS & 2 & 1200 & 4,30 & 39 & 0,0325 \\
\hline OTRAS INDUSTRIAS MANUFACTURERAS & 4 & 1865 & 6,69 & 46 & 0,0247 \\
\hline CONSTRUCCIÓN & 3 & 1720 & 6,17 & 49 & 0,0285 \\
\hline TOTAL & 57 & 27896 & 100 & 810 & 0,0290 \\
\hline
\end{tabular}

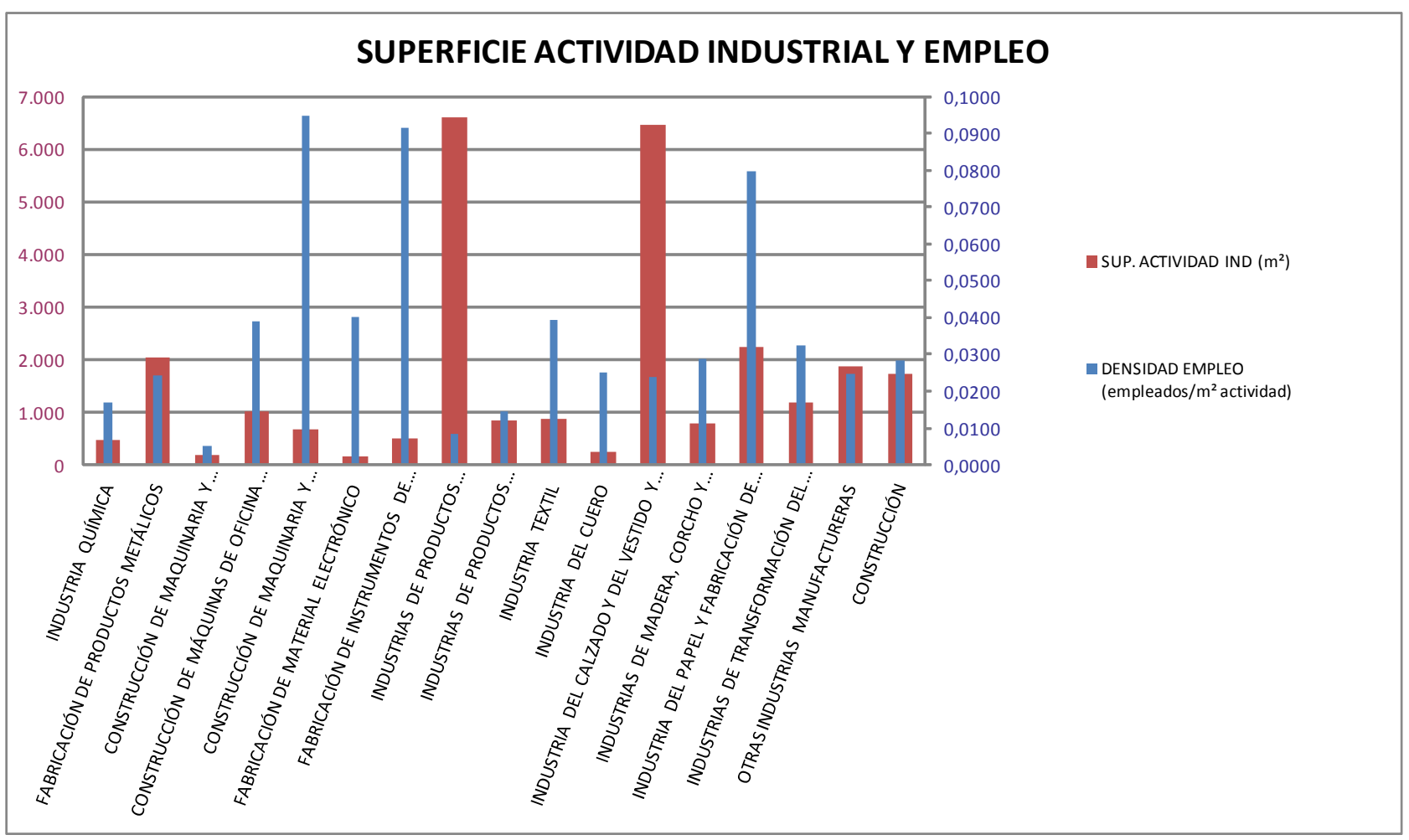




\section{IMPACTO AMBIENTAL}

\begin{tabular}{|c|c|c|c|c|c|}
\hline \multicolumn{6}{|c|}{ DISTRITO 7 - L'OLIVERETA (INFORMACIÓN URBANÍSTICA) } \\
\hline ACTIVIDAD & $\begin{array}{c}\text { No } \\
\text { EMPRESAS }\end{array}$ & $\begin{array}{c}\text { ENTRE } \\
\text { MEDIANERAS }\end{array}$ & RUIDOSAS & $\begin{array}{c}\text { EMPRESAS } \\
\text { CON } \\
\text { CHIMENEA }\end{array}$ & $\begin{array}{l}\text { RUIDOSAS Y } \\
\text { CHIMENEA }\end{array}$ \\
\hline INDUSTRIA QUÍMICA & 1 & 1 & 0 & 0 & 0 \\
\hline FABRICACIÓN DE PRODUCTOS METÁLICOS & 8 & 8 & 5 & 1 & 0 \\
\hline CONSTRUCCIÓN DE MAQUINARIA Y EQUIPO MECÁNICO & 1 & 1 & 0 & 0 & 0 \\
\hline CONSTRUCCIÓN DE MÁQUINAS DE OFICINA Y ORDENADORES & 1 & 1 & 0 & 0 & 0 \\
\hline CONSTRUCCIÓN DE MAQUINARIA Y MATERIAL ELÉCTRICO & 2 & 2 & 0 & 0 & 0 \\
\hline FABRICACIÓN DE MATERIAL ELECTRÓNICO & 1 & 1 & 0 & 0 & 0 \\
\hline FABRICACIÓN DE INSTRUMENTOS DE PRECISIÓN, ÓPTICA Y SIMILARES & 2 & 2 & 0 & 0 & 0 \\
\hline INDUSTRIAS DE PRODUCTOS ALIMENTICIOS, BEBIDAS Y TABACO & 10 & 9 & 1 & 7 & 1 \\
\hline INDUSTRIAS DE PRODUCTOS ALIMENTICIOS, BEBIDAS Y TABACO & 1 & 1 & 0 & 0 & 1 \\
\hline INDUSTRIA TEXTIL & 1 & 1 & 1 & 0 & 0 \\
\hline INDUSTRIA DEL CUERO & 1 & 1 & 0 & 0 & 1 \\
\hline INDUSTRIA DEL CALZADO Y DEL VESTIDO Y OTRAS CONFECCIONES TEXTILES & 11 & 11 & 6 & 0 & 0 \\
\hline INDUSTRIAS DE MADERA, CORCHO Y MUEBLES DE MADERA & 1 & 1 & 0 & 0 & 0 \\
\hline $\begin{array}{l}\text { INDUSTRIA DEL PAPEL Y FABRICACIÓN DE ARTÍCULOS DE PAPEL, ARTES GRÁFICAS } \\
\text { Y EDICIÓN }\end{array}$ & 7 & 7 & 6 & 0 & 0 \\
\hline INDUSTRIAS DE TRANSFORMACIÓN DEL CAUCHO Y MATERIAS PLÁSTICAS & 2 & 2 & 1 & 0 & 0 \\
\hline OTRAS INDUSTRIAS MANUFACTURERAS & 4 & 4 & 1 & 0 & 0 \\
\hline CONSTRUCCIÓN & 3 & 3 & 0 & 0 & 0 \\
\hline TOTAL & 57 & 56 & 21 & 8 & 3 \\
\hline
\end{tabular}

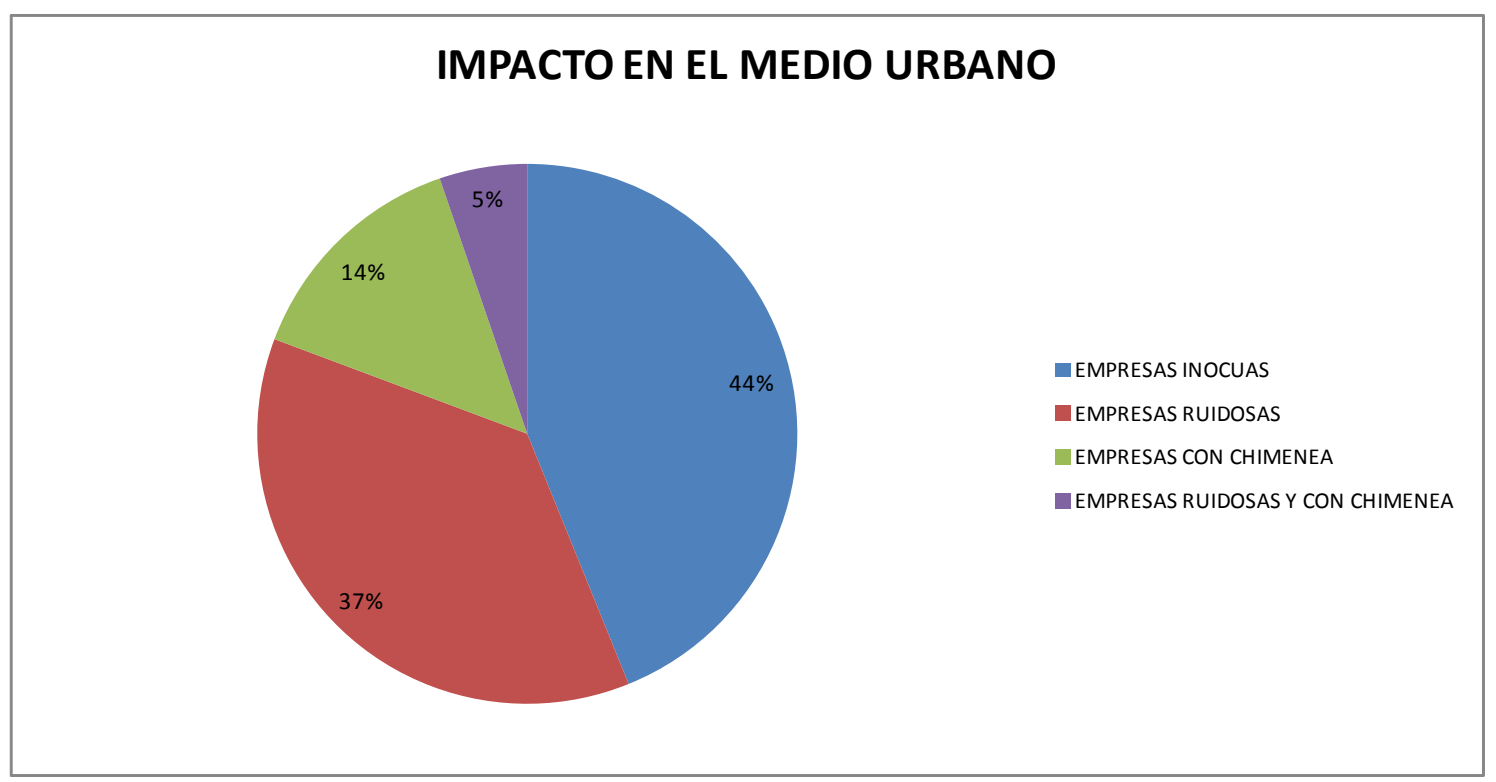




\section{FICHAS TIPO \\ FICHA DATOS DE LA INDUSTRIA}

LOCALIZACION ACTUALIZADA DE ACTIVIDADES INDUSTRIALES EN EL MEDIO URBANO DE VALENCIA

\begin{tabular}{|c|c|c|c|c|c|c|c|}
\hline \multirow{5}{*}{ 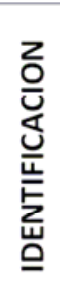 } & \multirow{2}{*}{\multicolumn{2}{|c|}{$\begin{array}{c}\text { NOMBRE } \\
\text { EMPLAZAMIENTO }\end{array}$}} & \multicolumn{5}{|l|}{ ORTA S.L. } \\
\hline & & & \multicolumn{3}{|l|}{ Av. del Cid, 112} & C.P. & \\
\hline & \multirow{2}{*}{ CNAE } & \multirow{2}{*}{504} & \multirow{2}{*}{ DESCRIPCION } & \multicolumn{4}{|c|}{ CONSTRUCCIÓN } \\
\hline & & & & \multicolumn{4}{|c|}{ Instalaciones aire acondicionado } \\
\hline & DISTRITO & 7 & \multicolumn{5}{|c|}{ L'OLIVERETA } \\
\hline & \multicolumn{2}{|c|}{ SUPERFICIES } & $\begin{array}{c}\text { Sup. Parcela: } \\
1000 \mathrm{~m}^{2}\end{array}$ & $\begin{array}{l}\text { Sup. Ocupada: } \\
1000 \mathrm{~m}^{2}\end{array}$ & $\begin{array}{l}\text { Sup. Construida: } \\
1000 \mathrm{~m}^{2}\end{array}$ & EMPI & $\begin{array}{l}\text { EADOS: } \\
25\end{array}$ \\
\hline
\end{tabular}
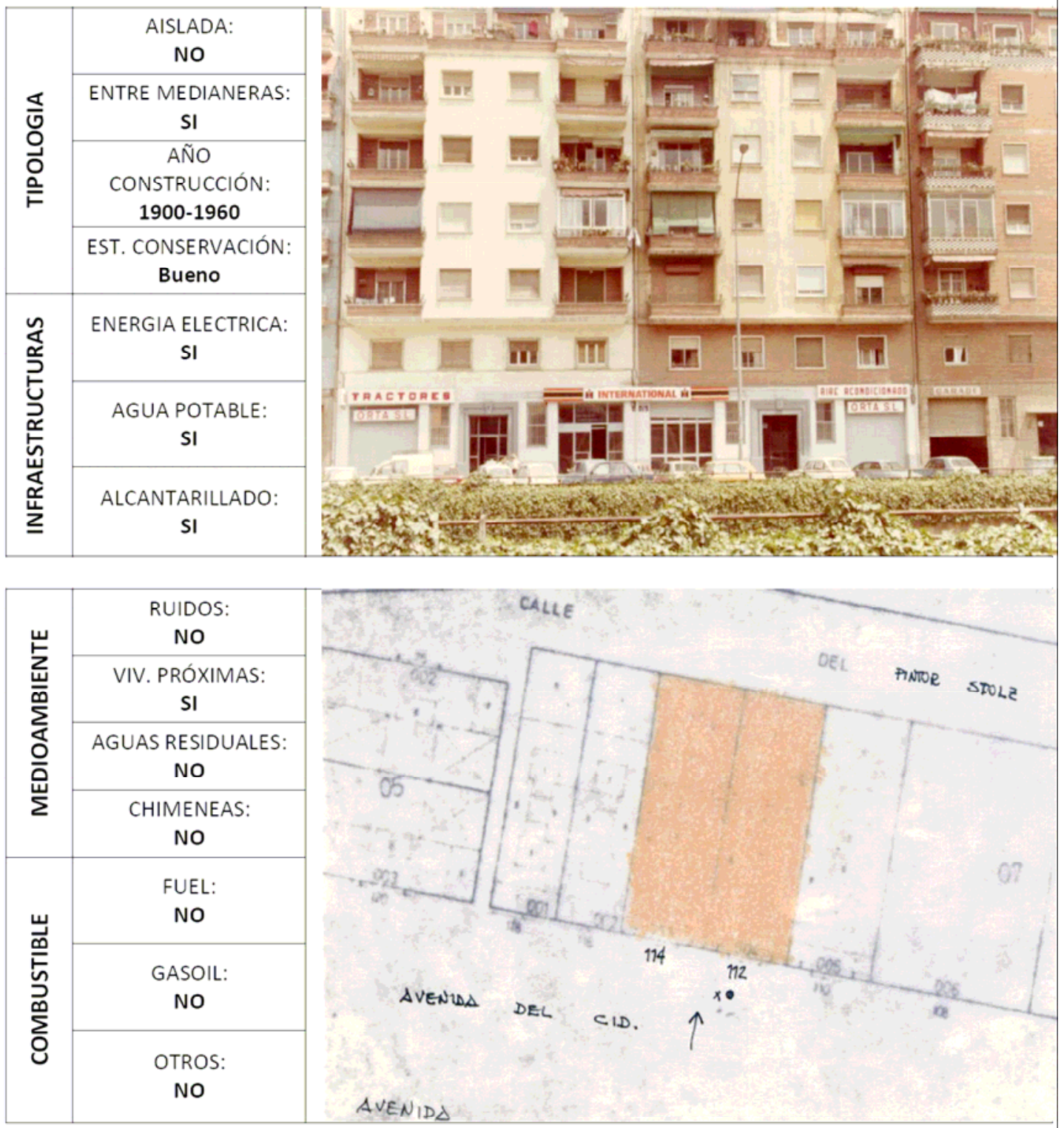

EN LA ACTUALIDAD: CENTRO DEPORTIVO 


\section{FICHA DATOS DE LA INDUSTRIA}

LOCALIZACION ACTUALIZADA DE ACTIVIDADES INDUSTRIALES EN EL MEDIO URBANO DE VALENCIA

\begin{tabular}{|c|c|c|c|c|c|c|c|}
\hline \multirow{5}{*}{$\begin{array}{l}\text { 으 } \\
\text { 은 } \\
\text { 언 } \\
\text { 늘 } \\
\text { 늠 }\end{array}$} & \multirow{2}{*}{\multicolumn{2}{|c|}{$\begin{array}{c}\text { NOMBRE } \\
\text { EMPLAZAMIENTO }\end{array}$}} & \multicolumn{5}{|c|}{ JAIME SOBRICASES VINES } \\
\hline & & & \multicolumn{3}{|c|}{ C/ Manolo Taberner, 26-28 } & C.P. & \\
\hline & \multirow{2}{*}{ CNAE } & \multirow{2}{*}{423} & \multirow{2}{*}{ DESCRIPCION } & \multicolumn{4}{|c|}{$\begin{array}{l}\text { INDUSTRIA DE PRODUCTOS ALIMENTICIOS, } \\
\text { BEBIDAS, ETC. }\end{array}$} \\
\hline & & & & \multicolumn{4}{|c|}{ Tostadero de café } \\
\hline & DISTRITO & 7 & \multicolumn{5}{|c|}{ L'OLIVERETA } \\
\hline \multicolumn{3}{|c|}{ SUPERFICIES } & $\begin{array}{c}\text { Sup. Parcela: } \\
839 \mathrm{~m}^{2}\end{array}$ & $\begin{array}{c}\text { Sup. Ocupada: } \\
839 \mathrm{~m}^{2}\end{array}$ & $\begin{array}{l}\text { Sup. Construida: } \\
1200 \mathrm{~m}^{2}\end{array}$ & EMPI & $\begin{array}{l}\text { LEADOS: } \\
12\end{array}$ \\
\hline
\end{tabular}
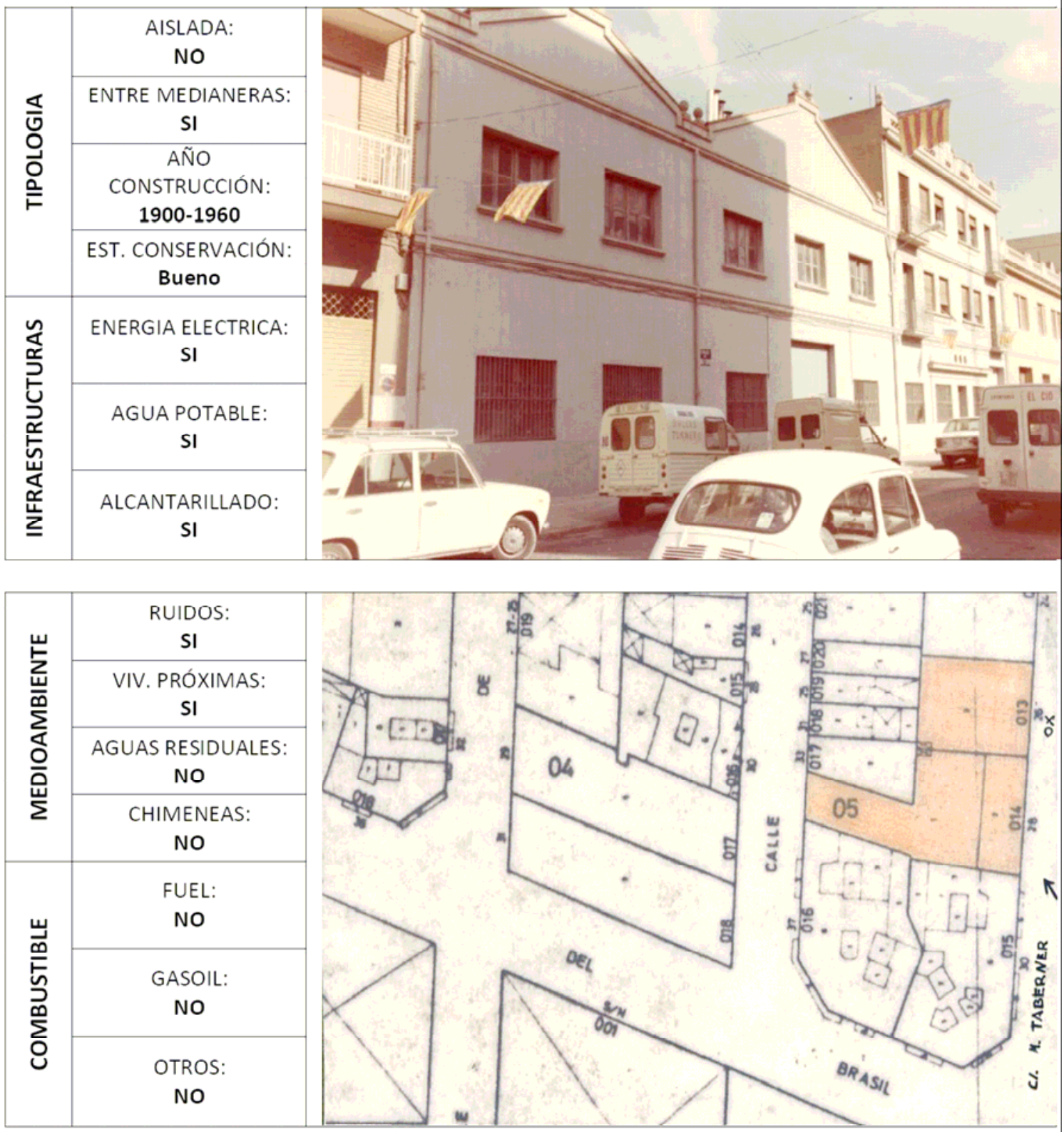


\section{FICHA DATOS DE LA INDUSTRIA}

LOCALIZACION ACTUALIZADA DE ACTIVIDADES INDUSTRIALES EN EL MEDIO URBANO DE VALENCIA

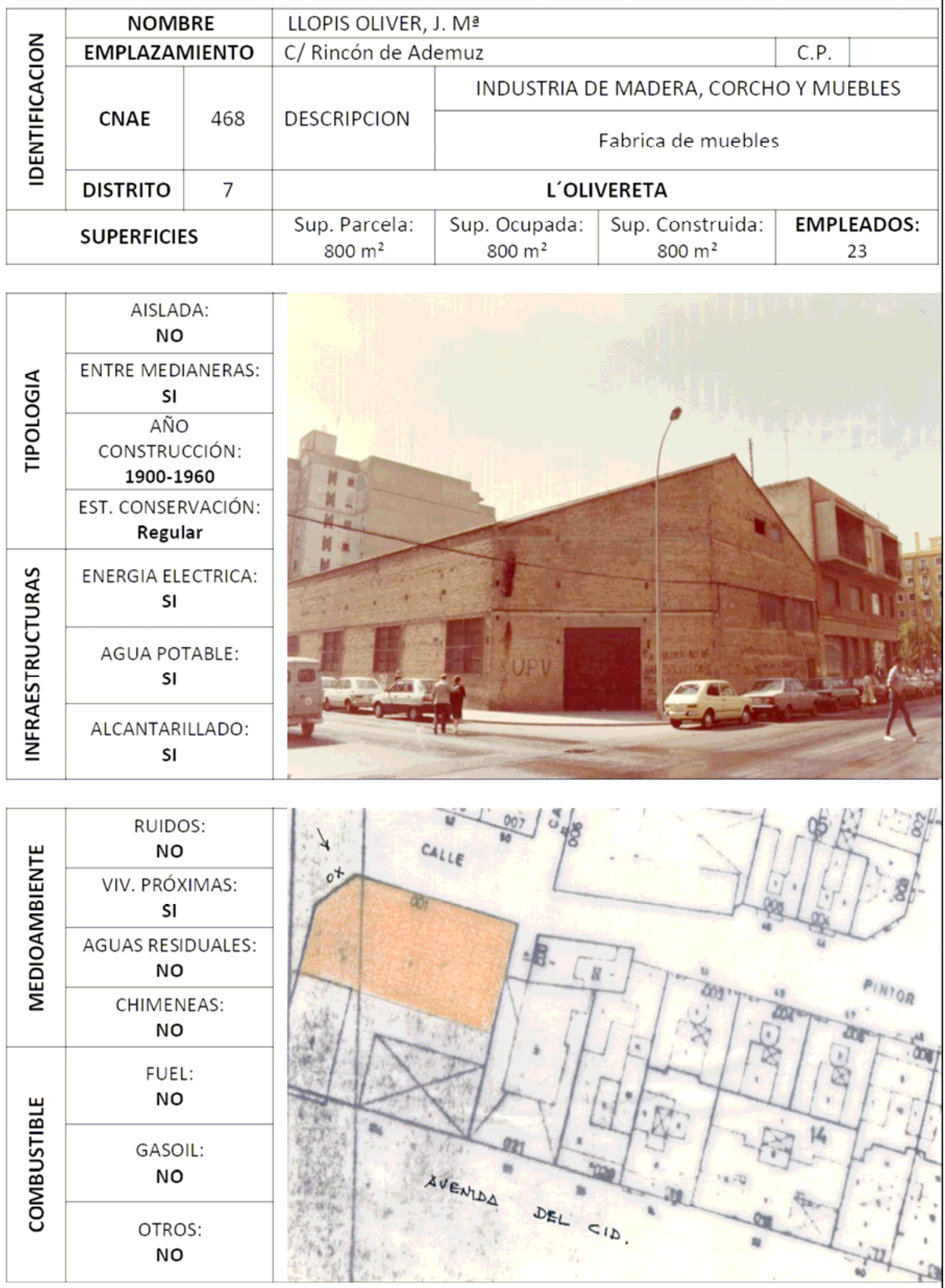




\section{FICHA DATOS DE LA INDUSTRIA}

LOCALIZACION ACTUALIZADA DE ACTIVIDADES INDUSTRIALES EN EL

MEDIO URBANO DE VALENCIA

\begin{tabular}{|c|c|c|c|c|c|c|c|}
\hline \multirow{5}{*}{ 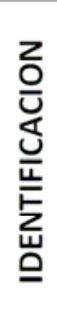 } & \multirow{2}{*}{\multicolumn{2}{|c|}{$\begin{array}{c}\text { NOMBRE } \\
\text { EMPLAZAMIENTO }\end{array}$}} & \multicolumn{5}{|c|}{ VICENTE CASQUEL RAUSELL S.L. } \\
\hline & & & \multicolumn{3}{|c|}{ C/ Ferrandis Luna, 17} & C.P. & \\
\hline & \multirow{2}{*}{ CNAE } & \multirow{2}{*}{453.9} & \multirow{2}{*}{ DESCRIPCION } & \multicolumn{4}{|c|}{ INDUSTRIA DE CALZADO Y VESTIDO } \\
\hline & & & & \multicolumn{4}{|c|}{ Venta y almacén de bordados } \\
\hline & DISTRITO & 7 & \multicolumn{5}{|c|}{ L'OLIVERETA } \\
\hline \multicolumn{3}{|c|}{ SUPERFICIES } & $\begin{array}{l}\text { Sup. Parcela: } \\
\quad 830 \mathrm{~m}^{2}\end{array}$ & $\begin{array}{c}\text { Sup. Ocupada: } \\
830 \mathrm{~m}^{2}\end{array}$ & $\begin{array}{l}\text { Sup. Construida: } \\
830 \mathrm{~m}^{2}\end{array}$ & EMP & ADOS: \\
\hline
\end{tabular}
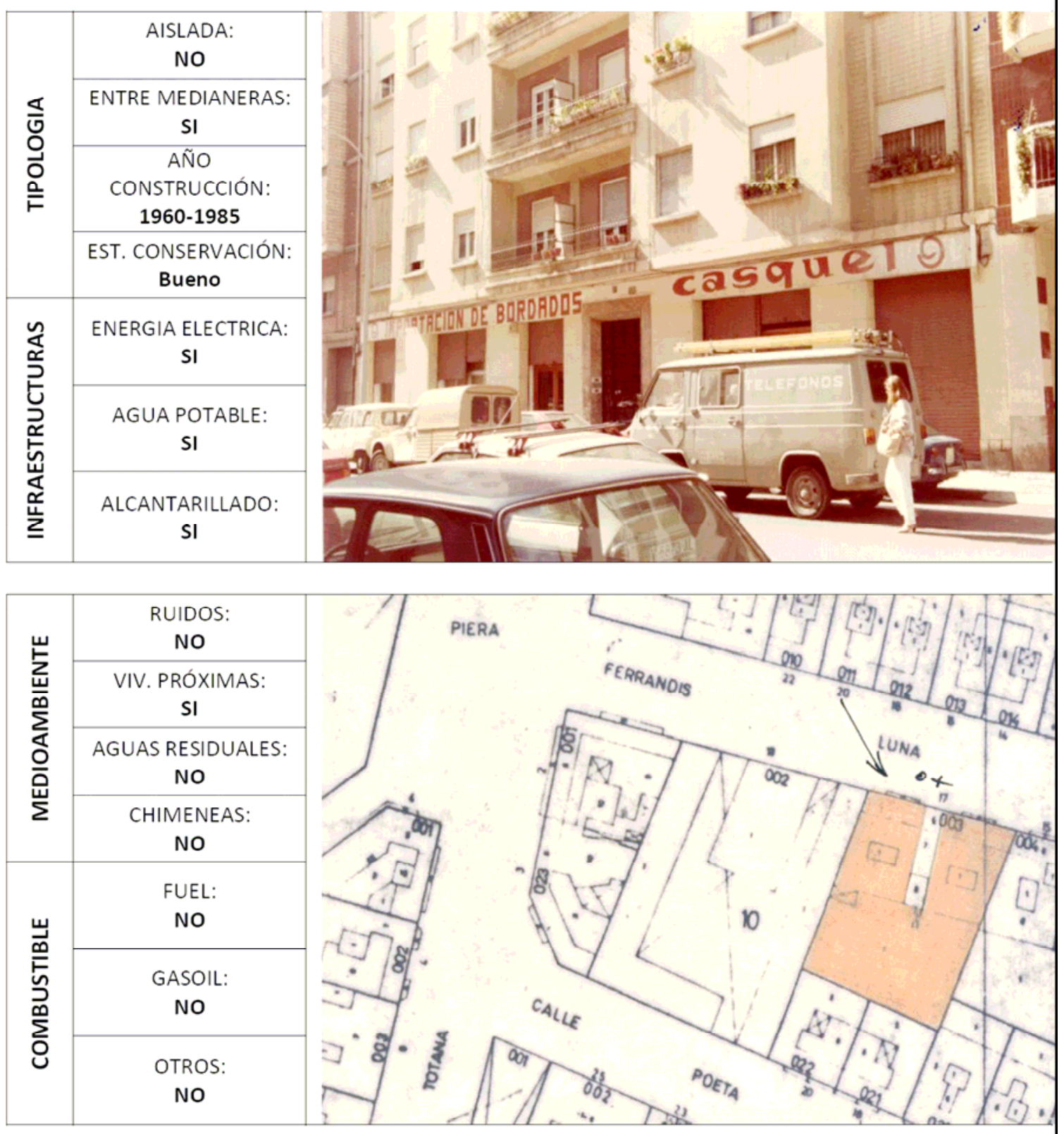


\section{FICHA DATOS DE LA INDUSTRIA}

LOCALIZACION ACTUALIZADA DE ACTIVIDADES INDUSTRIALES EN EL

MEDIO URBANO DE VALENCIA

\begin{tabular}{|c|c|c|c|c|c|c|c|}
\hline \multirow{5}{*}{ 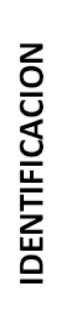 } & \multirow{2}{*}{\multicolumn{2}{|c|}{$\begin{array}{c}\text { NOMBRE } \\
\text { EMPLAZAMIENTO }\end{array}$}} & \multicolumn{5}{|c|}{ CUÑAT ROIG, RICARDO } \\
\hline & & & \multicolumn{3}{|c|}{ C/ Pintor Stolz, 55} & C.P. & \\
\hline & \multirow{2}{*}{ CNAE } & \multirow{2}{*}{419} & \multirow{2}{*}{ DESCRIPCION } & \multicolumn{4}{|c|}{$\begin{array}{l}\text { INDUSTRIA DE PRODUCTOS ALIMENTICIOS, } \\
\text { BEBIDAS, ETC. }\end{array}$} \\
\hline & & & & \multicolumn{4}{|c|}{ Horno } \\
\hline & DISTRITO & 7 & \multicolumn{5}{|c|}{ L'OLIVERETA } \\
\hline & \multicolumn{2}{|c|}{ SUPERFICIES } & $\begin{array}{l}\text { Sup. Parcela: } \\
650 \mathrm{~m}^{2}\end{array}$ & $\begin{array}{l}\text { Sup. Ocupada: } \\
400 \mathrm{~m}^{2}\end{array}$ & $\begin{array}{l}\text { Sup. Construida: } \\
400 \mathrm{~m}^{2}\end{array}$ & EMPI & $\begin{array}{l}\text { EADOS: } \\
8\end{array}$ \\
\hline
\end{tabular}
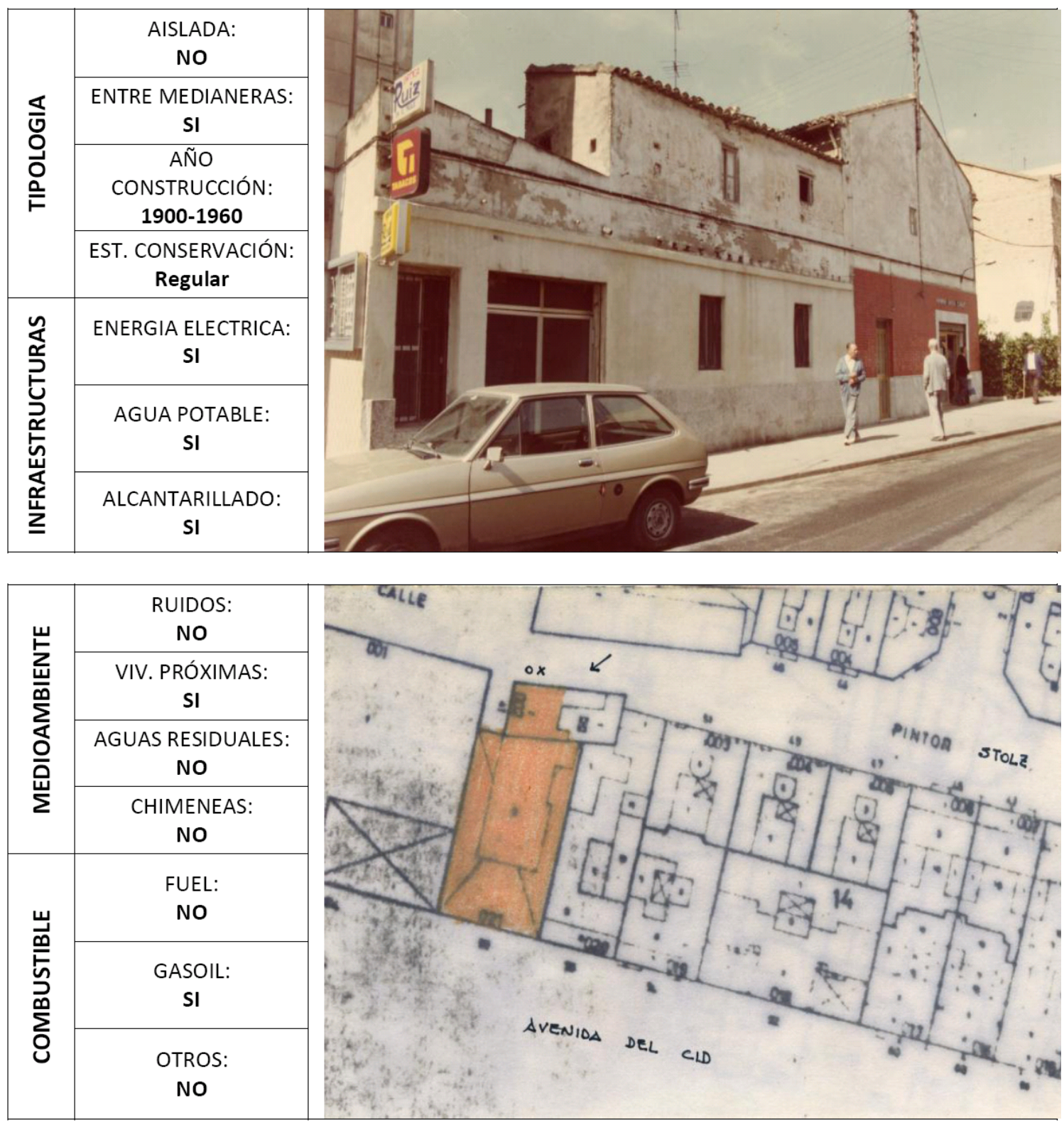


\section{EVOLUCIÓN}

\section{PLANO UBICACIÓN INDUSTRIAS}

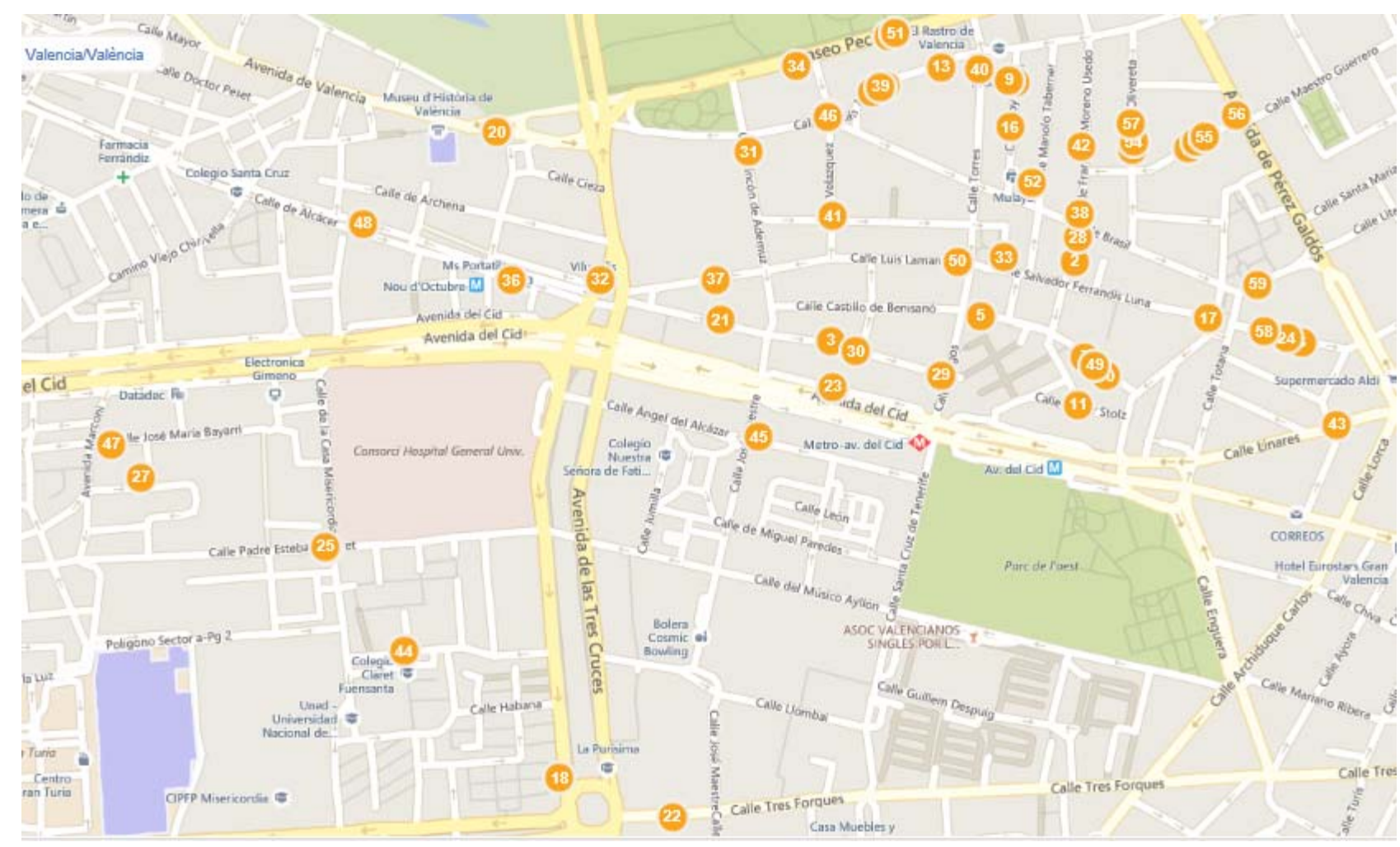

LISTADO DE INDUSTRIAS Y ACTIVIDAD.-

1. Pedro Bonache Melia

Fabricación de otros muebles

2. Fco. Javier Gómez Nieto

Fabricación de otros muebles

3. RESILIENCE Y EQUIPOS DE DESCANSO

Fabricación de colchones

4. Alfonso Landete Núñez

Fabricación de artículos de joyería y artículos similares

5. CREACIONES SERRES C.B.

Fabricación de artículos de joyería y artículos smilares

6. PUBLIAP C.B.

Acabado de textiles

7. SUSA CONFECCIONES

Fabricación de tejidos textiles 
8. CENTRO ORTOPÉDICO SANITARIO S.L.

Fabricación de instrumentos y suministros médicos y odontológicos

9. Cristina Gómez Polo

Fabricación de instrumentos y suministros médicos y odontológicos

10. Juan Ignacio Martínez San Andrés

Fabricación de instrumentos y suministros médicos y odontológicos

11. Francisco Carrasco Rodríguez

Fabricación de artículos de marroquinería, viajes y de guarnicionería y talabartería

12. Tomás Pérez Martí

Fabricación de envases y embalajes de plástico

13. VENCETEC S.L.

Fabricación de carpintería metálica

14. CERRAJERÍA ARTíSTICA OLMOS C.B.

Fabricación de cerraduras y herrajes

15. RIVOLUZ S.L.

Fabricación de otros productos metálicos n.c.o.p.

16. TALLERES BETA S.L.

Mantenimiento y reparación de vehículos a motor

17. Santiago Hurtado López

Mantenimiento y reparación de vehículos a motor

18. TALLERES TRES CRUCES S.L.

Mantenimiento y reparación de vehículos a motor

19. TALLERES DANSI S.L.

Mantenimiento y reparación de vehículos a motor

20. LAMBDA UNO INGENIEROS MECÁNICOS S.C.P.

Mantenimiento y reparación de vehículos a motor

21. Diego Amador Conejo Magro

Mantenimiento y reparación de vehículos a motor

22. TALLERES GASVAL C.B.

Mantenimiento y reparación de vehículos a motor

23. TALLERES MUELAS C.B.

Mantenimiento y reparación de vehículos a motor

24. TALLERES DUQUE C.B.

Mantenimiento y reparación de vehículos a motor

25. Sergio Chozas Gaytán

Mantenimiento y reparación de vehículos a motor

26. Antonio Conejero Millán

Mantenimiento y reparación de vehículos a motor

27. Francisco Polo Carbonell

Mantenimiento y reparación de vehículos a motor 
28. Leonardo Antonio Mata García

Mantenimiento y reparación de vehículos a motor

29. Pedro Antonio Villar Montañes

Mantenimiento y reparación de vehículos a motor

30. TALLERES STOLZ C.B.

Mantenimiento y reparación de vehículos a motor

31. FULL RACING MOTOR S.L.

Mantenimiento y reparación de vehículos a motor

32. Francisco Julián Martínez Miralles

Mantenimiento y reparación de vehículos a motor

33. Emilov Radoslavov

Mantenimiento y reparación de vehículos a motor

34. HERMANOS GARCÍA RACING C.B.

Mantenimiento y reparación de vehículos a motor

35. Julio José Navarro Ramírez

Mantenimiento y reparación de vehículos a motor

36. Carlos Luis Núñez López

Fabricación de otros muebles

37. Julián Gómez Díaz

Fabricación de otros muebles

38. TALLER ARTESANO ANTONIO Y PALMIRA C.B.

Fabricación de otros productos de madera, artículos de corcho, casería y espartería

39. Pedro García Llorca

Confección de otras prendas de vestir y accesorios

40. José Sánchez Ribera

Confección de otras prendas de vestir y accesorios

41. Fomina Rayisa

Confección de otras prendas de vestir y accesorios

42. HERMANOS MIRALLES S.L.

Fabricación de pan y productos frescos de panadería y pastelería

43. OBRADOR DE LEVANTE S.L.

Fabricación de pan y productos frescos de panadería y pastelería

44. GRUPO FABRICACIÓN INTERNACIONAL DE PAN S.L.

Fabricación de pan y productos frescos de panadería y pastelería

45. COOPERATIVA VALENCIANA OBREROS PANADEROS

Fabricación de pan y productos frescos de panadería y pastelería

46. FORN CUÑAT Y TORTOLA S.L.

Fabricación de pan y productos frescos de panadería y pastelería

47. ESPACIO GOURMET 2015 S.L.

Fabricación de pan y productos frescos de panadería y pastelería 
48. MORNERO DEL SOL S.L.

Elaboración de otros productos alimenticios

49. RIFF-RAFF VALENCIA S.L.

Otras actividades de impresión y artes gráficas

50. GRABADOS BERTOMEU S.L.

Reproducción de soportes grabados

51. Agostino Hernan Marcelo

Otras actividades de impresión y artes gráficas

52. Jaime Sobricases Vines (Existente 31)

CNAE año 1985 (423)

53. HIJOS R. FERNÁNDEZ BALAGUER S.A. (Existente 43)

CNAE año 1985 (455)

54. Buendía Guix, G. (Existente 45)

CNAE año 1985 (313)

55. ALAN-COAR S.A. (Existente 47)

CNAE año 1985 (255)

56. Ribes Mateu Jaime (Existente 48)

CNAE año 1985 (419)

57. ARTES GRÁFICAS SOLER, S.A. (Existente 51)

CNAE año 1985 (474)

58. VICENTE CASQUEL RAUSELL S.L. (Existe 52)

CNAE año 1985 (453.9)

59. HORNO ENRIQUE ALPERA (Existente 53)

CNAE año 1985 (419) 
ESTADO ACTUAL DE LOS ANTIGUOS EDIFICIOS INDUSTRIALES DE INTERES.-

- Molino de Picó.

Avd. Tres Cruces no 25 (AV-1)

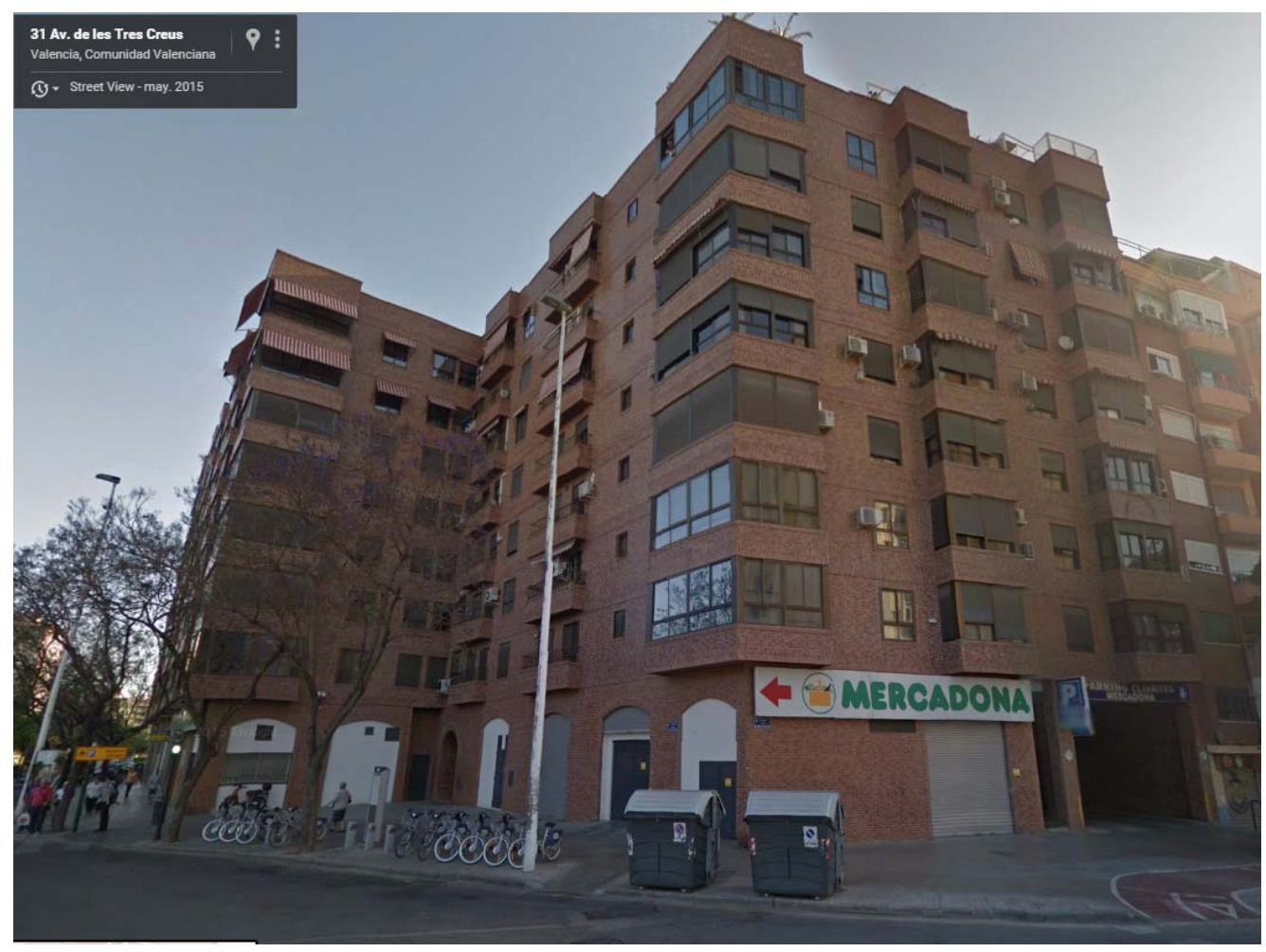

Foto 28: Edificio residencial. Avda. Tres Cruces, 25. Valencia.2015

Fuente: WEB. http://Www.google.es/maps (Street View). 


\section{Distrito 7. L'OLIVERETA}

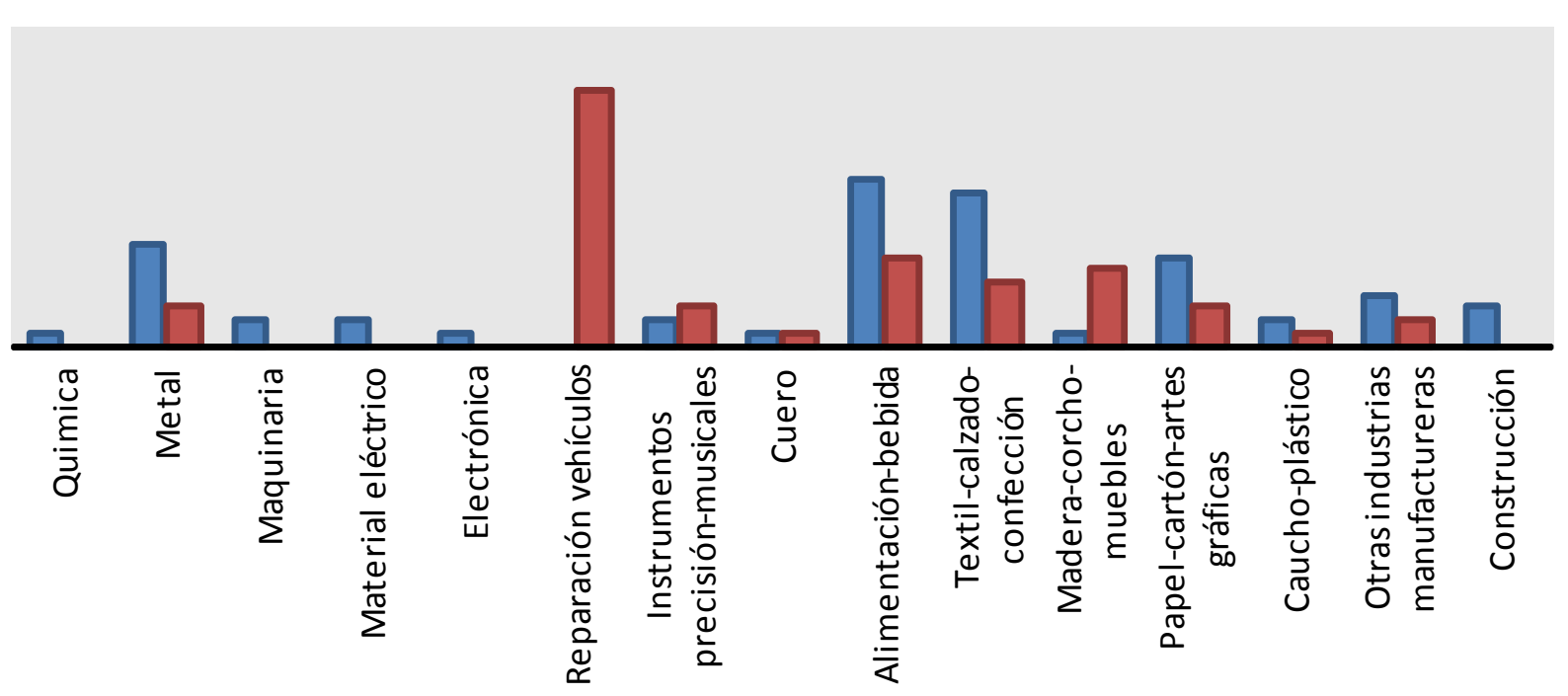

Actividad Industrial 1985/1990 Actividad Industrial 2014

EVOLUCIÓN DEL IMPACTO AMBIENTAL

\section{IMPACTO EN EL MEDIO URBANO Distrito 7. L'OLIVERETA}

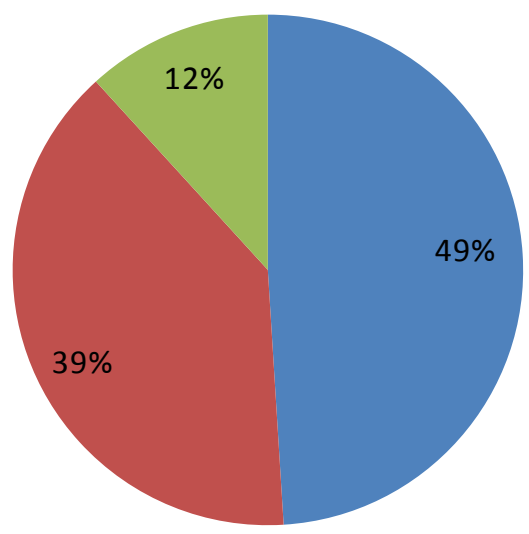

Empresas inocuas

Empresas ruidosas

Empresas ruidosas con chimenea 


\section{FICHAS TIPO}

\section{FICHA DATOS DE LA INDUSTRIA}

LOCALIZACION ACTUALIZADA DE ACTIVIDADES INDUSTRIALES EN EL MEDIO URBANO DE VALENCIA

\begin{tabular}{|c|c|c|c|c|c|c|c|}
\hline \multirow{5}{*}{ 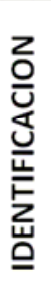 } & \multirow{2}{*}{\multicolumn{2}{|c|}{$\begin{array}{c}\text { NOMBRE } \\
\text { EMPLAZAMIENTO }\end{array}$}} & \multicolumn{5}{|c|}{ SERGIO CHOZAS GAYTÁN } \\
\hline & & & \multicolumn{3}{|c|}{ C/PADRE ESTEBAN PERNET, 4} & C.P. & 46014 \\
\hline & \multirow[b]{2}{*}{ CNAE } & \multirow[b]{2}{*}{4520} & \multirow[b]{2}{*}{ DESCRIPCION } & \multicolumn{4}{|c|}{ REPARACIÓN VEHÍCULOS } \\
\hline & & & & \multicolumn{4}{|c|}{ Mantenimiento y reparación de vehículos a motor } \\
\hline & DISTRITO & 7 & \multicolumn{5}{|c|}{ L'OLIVERETA } \\
\hline \multicolumn{3}{|c|}{ MEDIOAMBIENTE } & RUIDOSAS & $\mathrm{SI}$ & CHIMENEAS & & $\mathrm{OO}$ \\
\hline
\end{tabular}

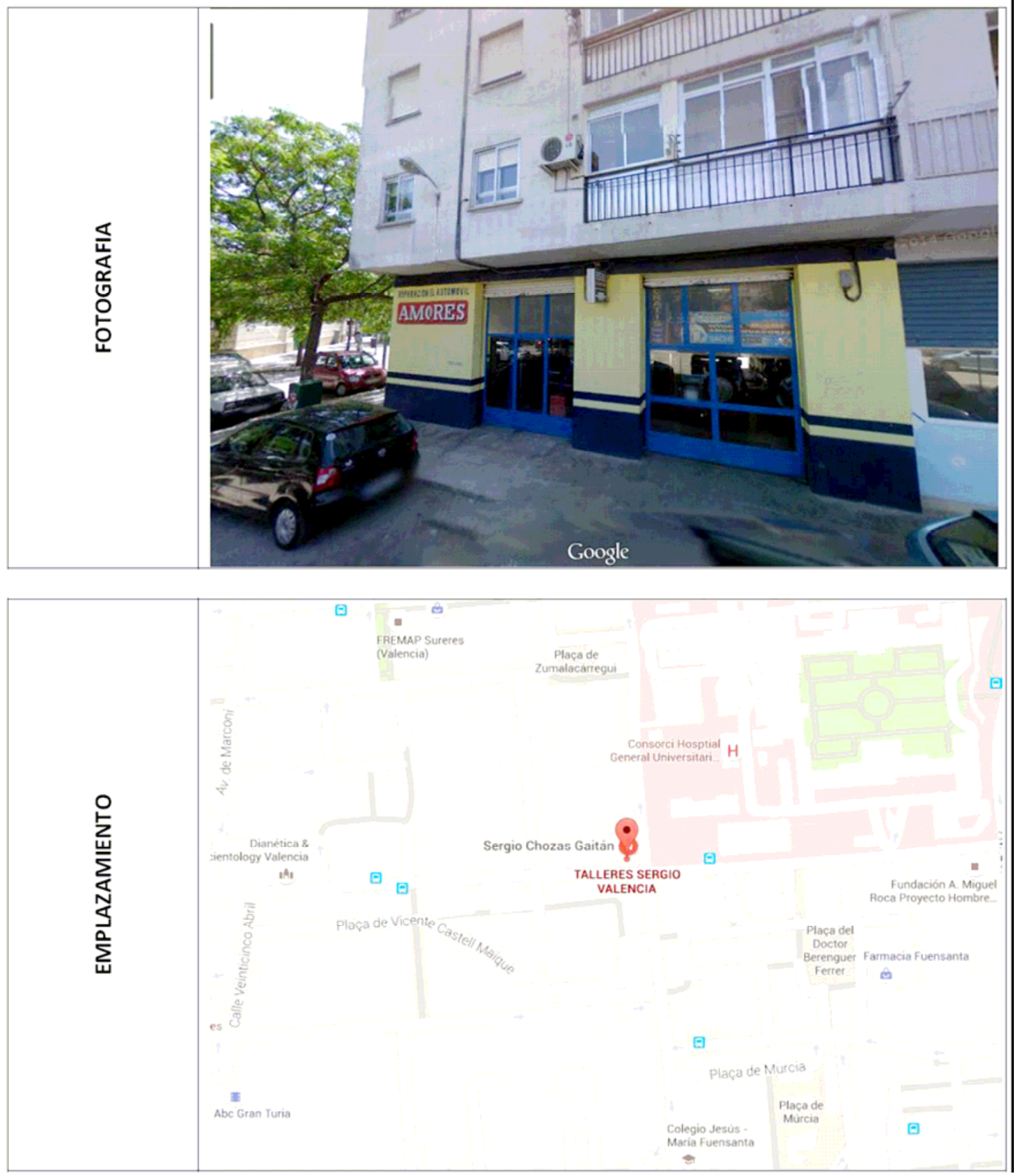




\section{FICHA DATOS DE LA INDUSTRIA}

LOCALIZACION ACTUALIZADA DE ACTIVIDADES INDUSTRIALES EN EL

MEDIO URBANO DE VALENCIA

\begin{tabular}{|c|c|c|c|c|c|c|c|}
\hline \multirow{5}{*}{ 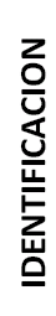 } & \multirow{2}{*}{\multicolumn{2}{|c|}{$\begin{array}{c}\text { NOMBRE } \\
\text { EMPLAZAMIENTO }\end{array}$}} & \multicolumn{5}{|c|}{ CERRAJERÍA ARTÍSTICA OLMOS, CB. } \\
\hline & & & \multicolumn{3}{|c|}{ C/ CASTÁN TOBEÑAS, 53} & C.P. & 46018 \\
\hline & \multirow[b]{2}{*}{ CNAE } & \multirow[b]{2}{*}{2572} & \multirow[b]{2}{*}{ DESCRIPCION } & \multicolumn{4}{|c|}{ METAL } \\
\hline & & & & \multicolumn{4}{|c|}{ Fabricación de cerraduras y herrajes } \\
\hline & DISTRITO & 7 & \multicolumn{5}{|c|}{ L'OLIVERETA } \\
\hline \multicolumn{3}{|c|}{ MEDIOAMBIENTE } & RUIDOSAS & $\mathrm{SI}$ & CHIMENEAS & & NO \\
\hline
\end{tabular}
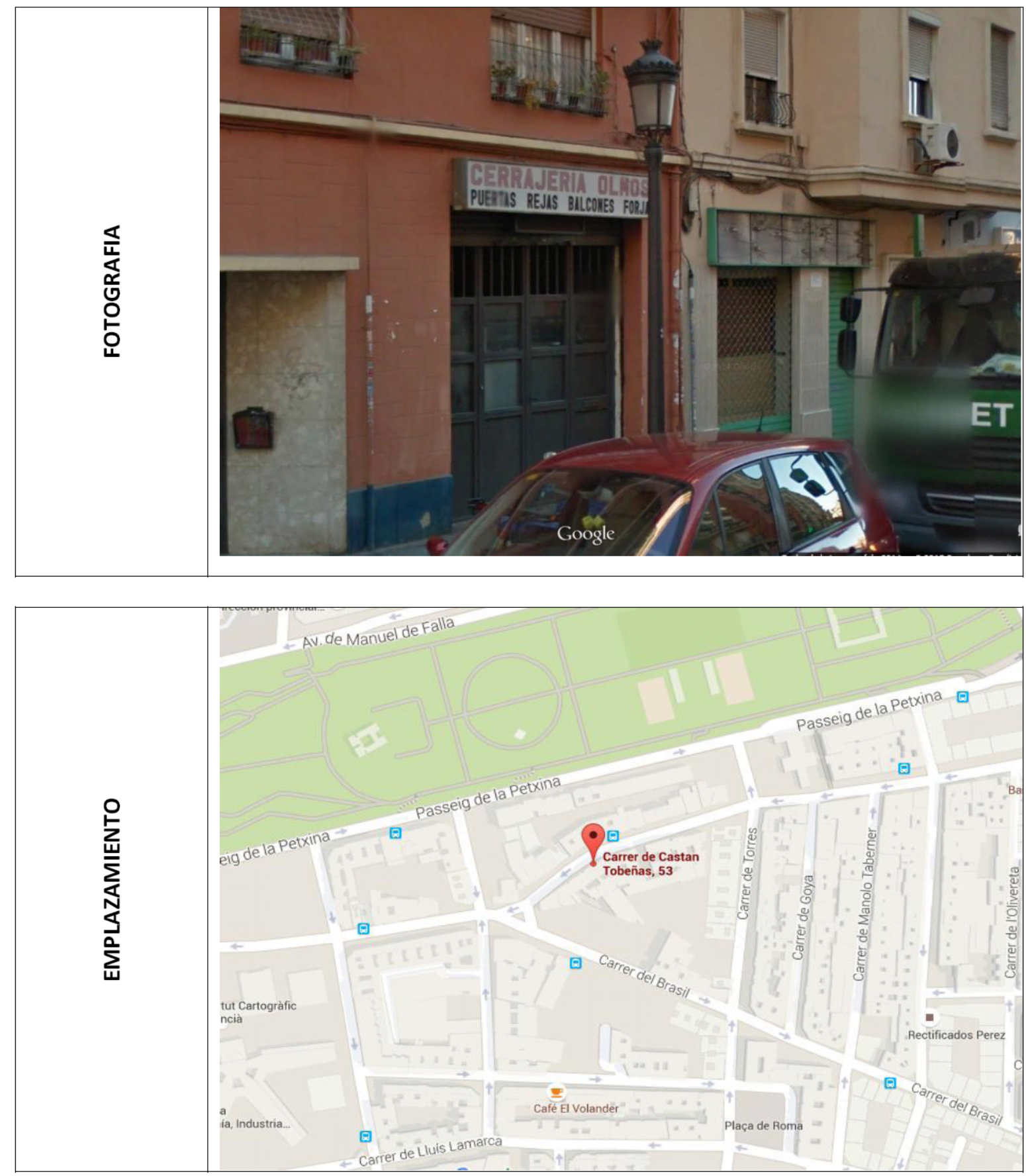


\section{FICHA DATOS DE LA INDUSTRIA}

LOCALIZACION ACTUALIZADA DE ACTIVIDADES INDUSTRIALES EN EL MEDIO URBANO DE VALENCIA

\begin{tabular}{|c|c|c|c|c|c|c|c|}
\hline \multirow{5}{*}{ 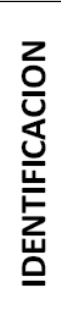 } & \multirow{2}{*}{\multicolumn{2}{|c|}{$\begin{array}{c}\text { NOMBRE } \\
\text { EMPLAZAMIENTO }\end{array}$}} & \multicolumn{5}{|c|}{ COOPERATIVA VALENCIANA OBREROS PANADEROS } \\
\hline & & & \multicolumn{3}{|c|}{ C/ÁNGEL DEL ALCÁZAR, 14} & C.P. & 46018 \\
\hline & \multirow[b]{2}{*}{ CNAE } & \multirow[b]{2}{*}{1071} & \multirow[b]{2}{*}{ DESCRIPCION } & \multicolumn{4}{|c|}{ ALIMENTACIÓN-BEBIDA } \\
\hline & & & & \multicolumn{4}{|c|}{$\begin{array}{c}\text { Fabricación de pan y de productos frescos de } \\
\text { panadería y pastelería }\end{array}$} \\
\hline & DISTRITO & 7 & \multicolumn{5}{|c|}{ L'OLIVERETA } \\
\hline \multicolumn{3}{|c|}{ MEDIOAMBIENTE } & RUIDOSAS & NO & CHIMENEAS & & $\mathrm{O}$ \\
\hline
\end{tabular}
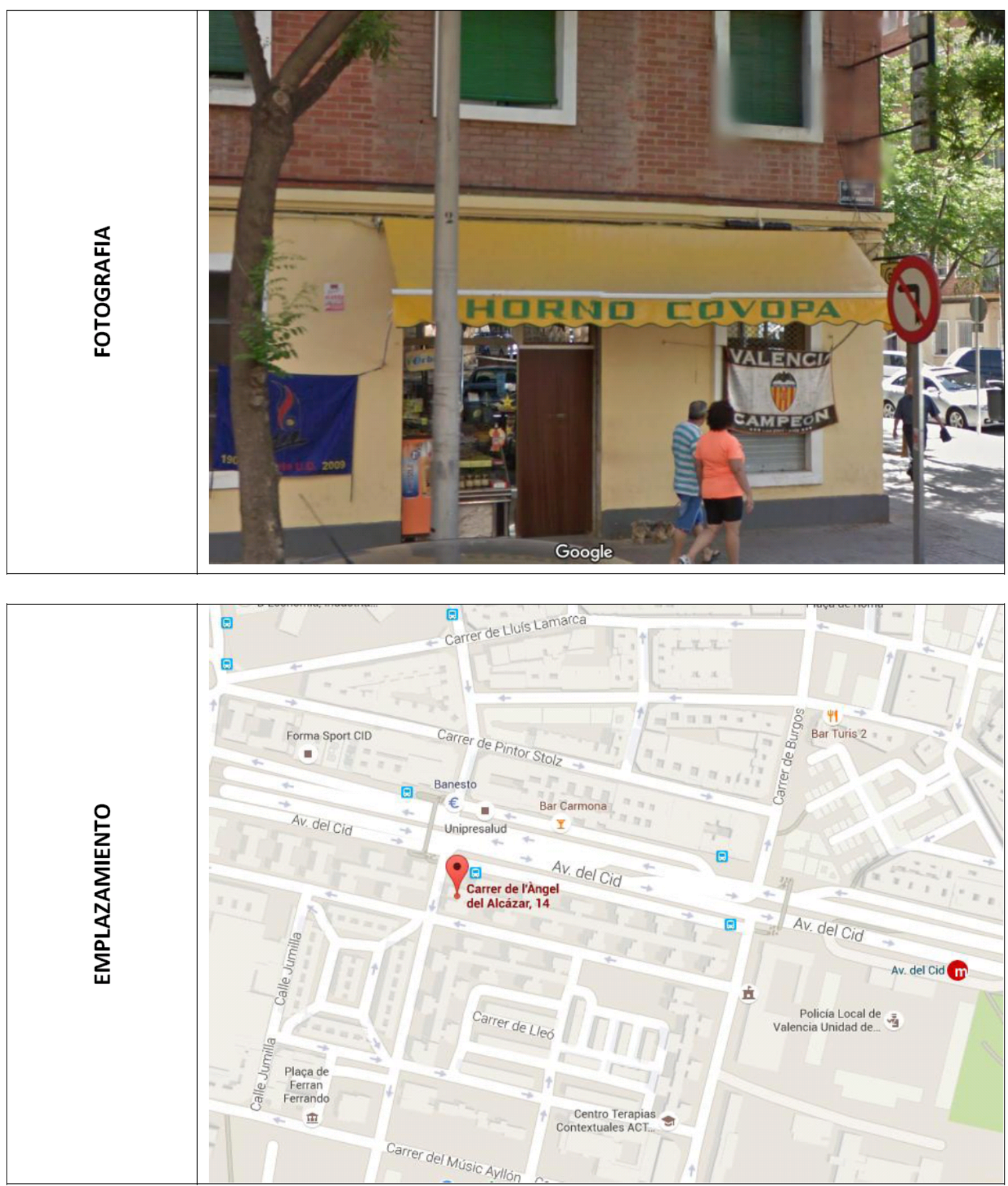


\section{FICHA DATOS DE LA INDUSTRIA}

LOCALIZACION ACTUALIZADA DE ACTIVIDADES INDUSTRIALES EN EL MEDIO URBANO DE VALENCIA

\begin{tabular}{|c|c|c|c|c|c|c|c|}
\hline \multirow{5}{*}{ 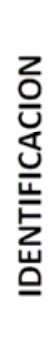 } & \multirow{2}{*}{\multicolumn{2}{|c|}{$\begin{array}{c}\text { NOMBRE } \\
\text { EMPLAZAMIENTO }\end{array}$}} & \multicolumn{5}{|c|}{ CENTRO ORTOPÉDICO SANITARIO, S.L. } \\
\hline & & & \multicolumn{3}{|c|}{ C/ PADRE ESTEBAN PERNET, 21} & C.P. & 46014 \\
\hline & \multirow[b]{2}{*}{ CNAE } & \multirow[b]{2}{*}{3250} & \multirow[b]{2}{*}{ DESCRIPCION } & \multicolumn{4}{|c|}{ INSTRUMENTOS PRECISIÓN-MUSICALES } \\
\hline & & & & \multicolumn{4}{|c|}{$\begin{array}{c}\text { Fabricación instrumentos y suministros médicos y } \\
\text { odontológicos }\end{array}$} \\
\hline & DISTRITO & 7 & \multicolumn{5}{|c|}{ L'OLIVERETA } \\
\hline \multicolumn{3}{|c|}{ MEDIOAMBIENTE } & RUIDOSAS & NO & CHIMENEAS & & 0 \\
\hline
\end{tabular}
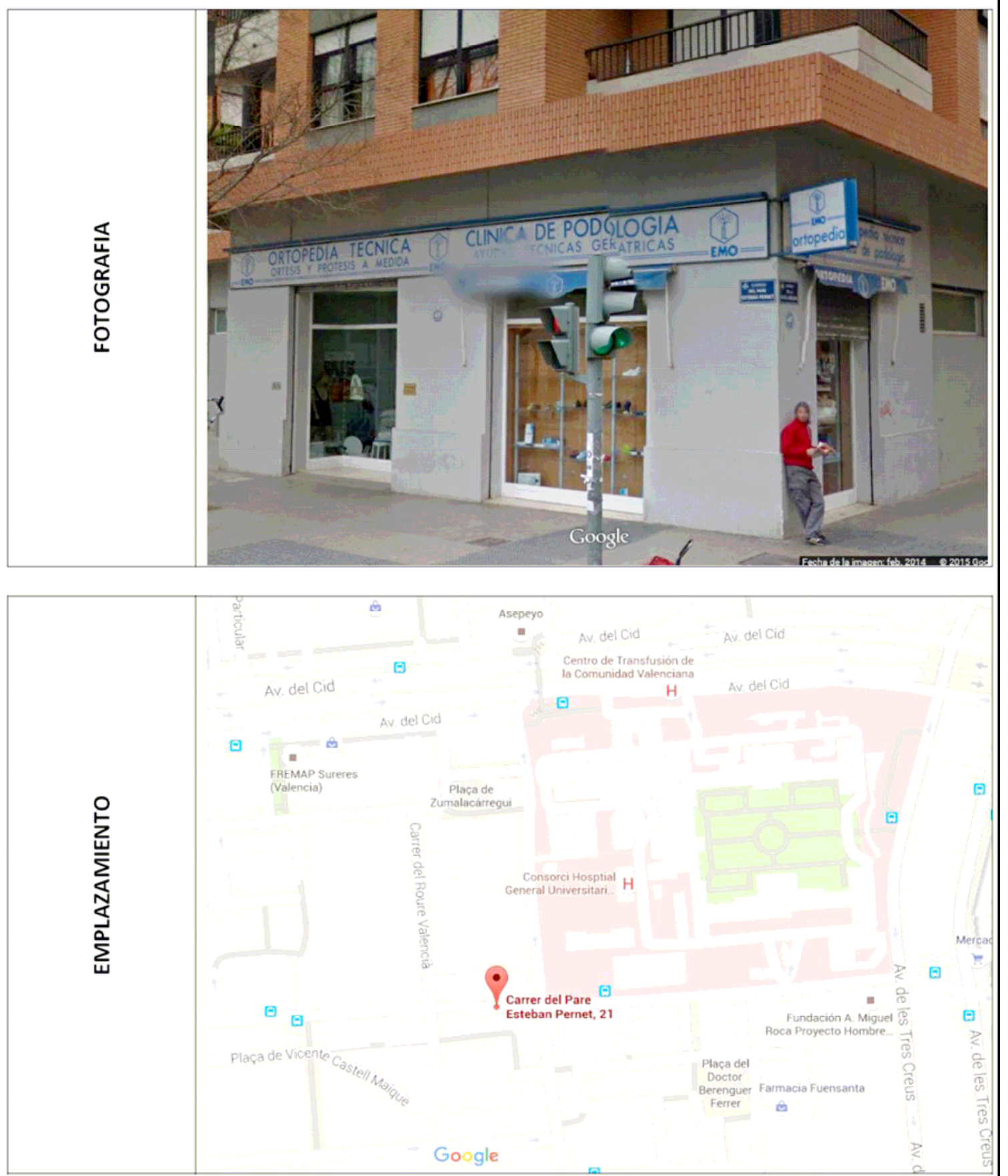
DISTRITO 8.- PATRAIX

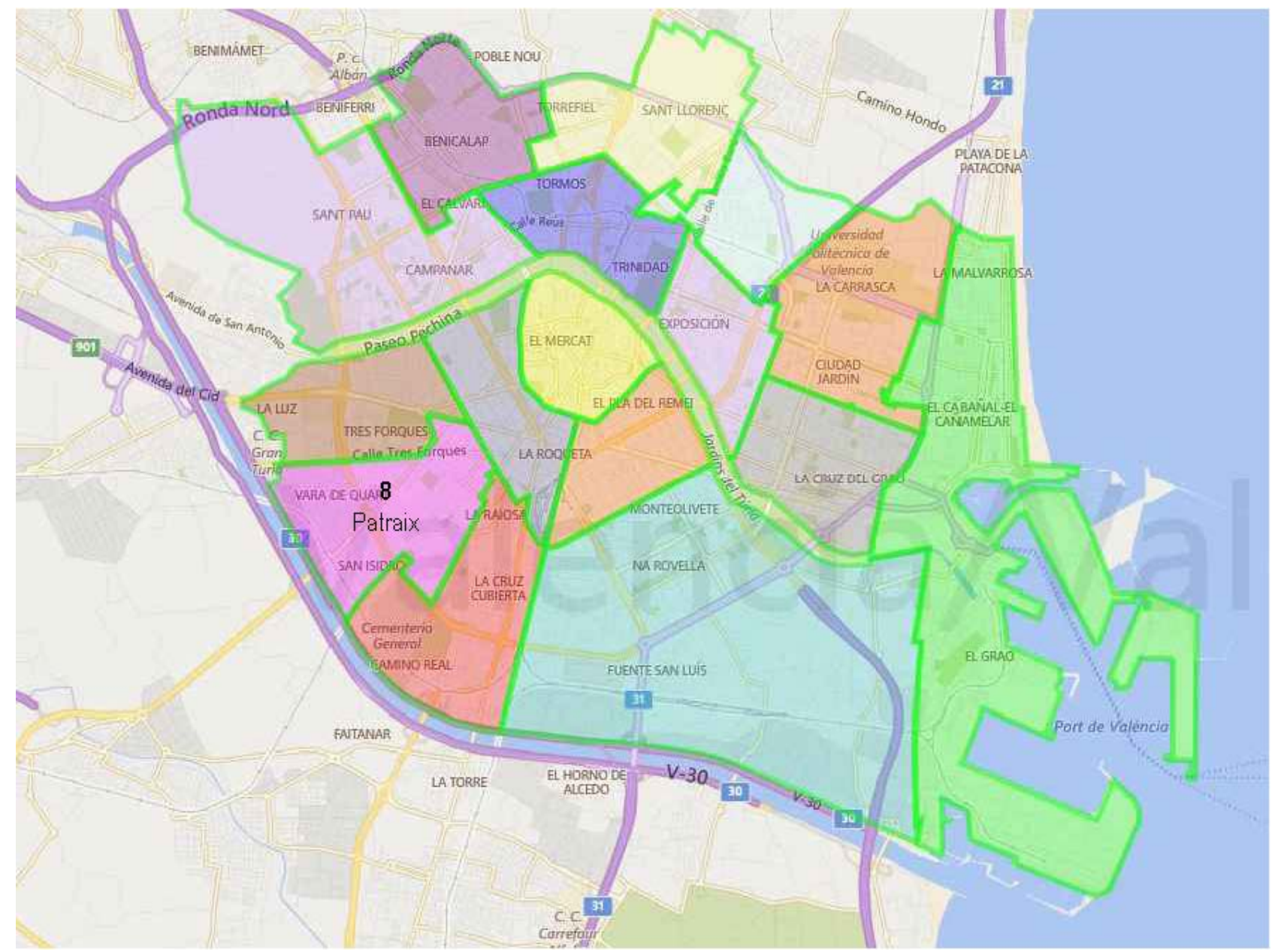

\section{LÍMITES GEOGRÁFICOS}

C/ Tres Forques, C/ Enguera, Avd. del Cid, Avd. Pérez Galdós, C/ Campos Crespo, C/ Soriano, C/ Gaspar Aguilar y Nuevo Cauce del Turia. 


\section{PLANO UBICACIÓN INDUSTRIAS}

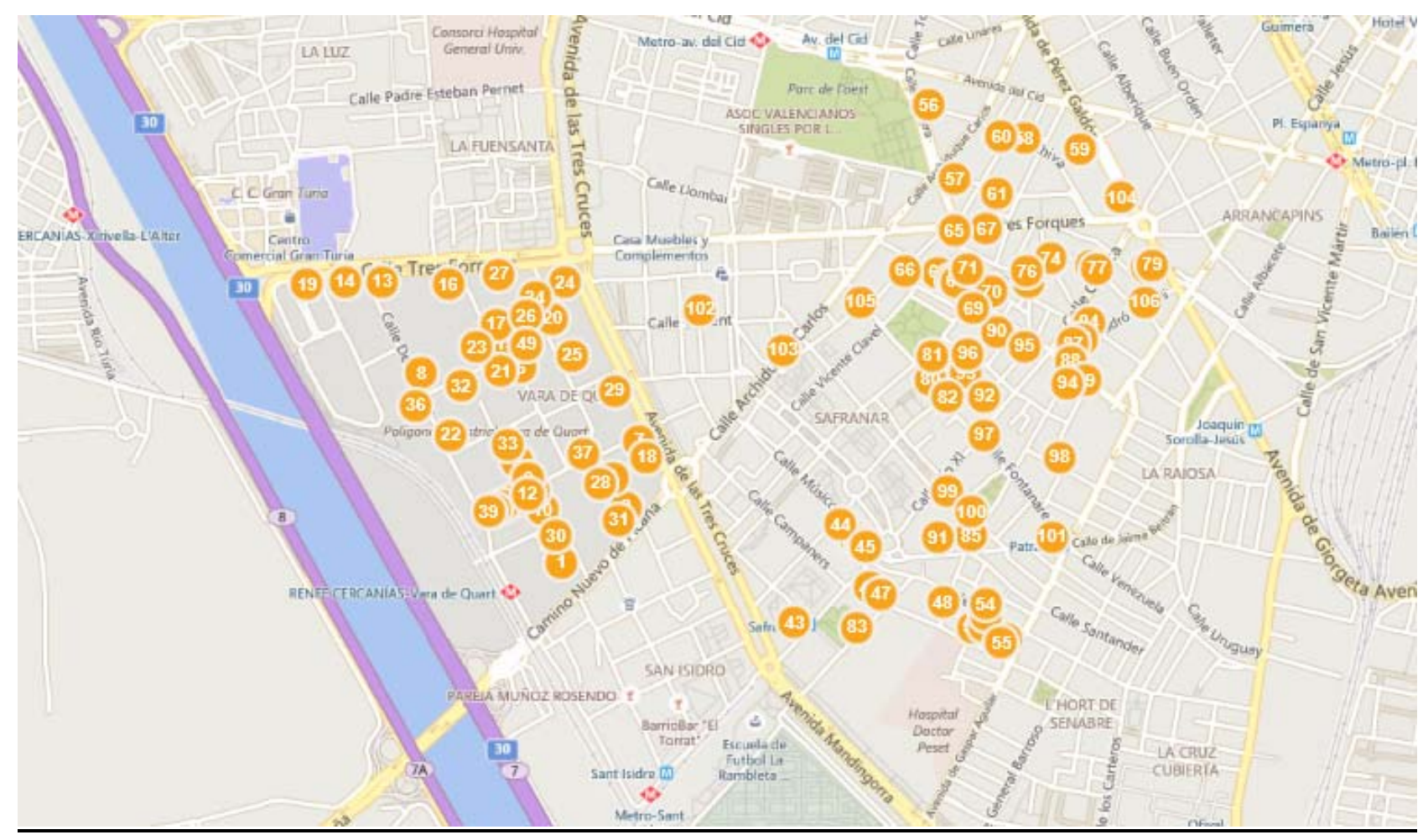

LISTADO DE INDUSTRIAS Y ESTADO ACTUAL .-

1. NUSICO

Supermercado

2. UBESA

Supermercado

3. SOCIEDAD DE AGUAS POTABLES DE VALENCIA, S.A.

Mantiene la actividad

4. ALSIMET

Mantiene la actividad

5. ALMACENES BOLUDA S.A.

Distribución fontanería

6. PRASA

Obra nueva 
7. HENKEL IBERICA, S.A.

Concesionario

8. TRAVENOL, S.A.

Solar

9. CENTRO FARMACEUTICO, S.A.

Mantiene la actividad

10. COOP. DE DROGAS Y PERFUMES "EL PROGRESO"

Droguería y perfumería

11. Pablo Vives Roig

Sin datos

12. Emilio Muñoz Espi

Mantenimiento instalaciones climatización

13. HELESA

Obra nueva

14. HIERROS DEL TURIA

Solar

15. CONSTRUCCIONES MECÁNICAS CHIVA, S.A.

Sin actividad

16. HIERROS ALFONSO

Hierros y aceros

17. TALLERES PONT

Sin actividad

18. INDUSTRIAS YUK, S.A.

Concesionario

19. FRANCISCO ROS CASARES, S.A.

Nueva ordenación- edificio de viviendas

20. Rafael Almenar Valls

Concesionario

21. YOPLAIT

Almacén mayorista productos eléctricos

22. INDUSTRIAS LACTEAS CERVERA, S.A.

Sin actividad

23. Juan Alfonso Puchades

Mantiene la actividad

24. ALGOSA, S.A.

Concesionario

25. CITRINAS Y REFRESCANTES, S.A. TRINARANJUS

Concesionario

26. CEYLAN

Especies 
27. FADITEX, S.A.

Sin datos

28. Carlos Meri Ferrando

Aluminio- Hierro

29. MADERAS BONET

Servicios de arquitectura

30. INDUSTRIAS MARTORELL, S.A.

Sin actividad

31. Mariano García

Nueva ordenación- Gasolinera

32. VDA. DE HURTADO, S.A.

Construcción

33. GARCíA SIMÓN, S.A. "GASISA"

Sin actividad

34. ESTRAMA, S.A.

Sin actividad

35. GRUPO DISTRIBUIDOR EDITORIAL

Sin actividad

36. LAS PROVINCIAS

Mantiene la actividad

37. EDITORIAL PLANETA, S.A.

Distribuidora prensa y revistas

38. CIDONCHA, S.A.

Diseño y construcción

39. TURIA LINCE, S.A.

Sin actividad

40. JAMONES DE ARAGÓN, S.L.

Sin datos

41. DIFRANJO, S.L.

SAU Jardinería

42. Villalba Fuenmayor, P.M.

Sin actividad

43. MECANTEX, S.A.

Nueva ordenación- Zona verde

44. ELEMENTOS FRIGORÍFICOS, S.L.

Materiales para la construcción

45. CONSTRUCCIONES FCO. MATEU, S.L.

Sin actividad

46. REFRIGERACIÓN GURGOS, S.L.

Sin datos 
47. RAMIRO HERMANOS, S.L.

Mantiene la actividad

48. METALES Y PLATERÍA RIBERA, S.A.

Supermercado

49. ALFREDO ARLANDIS MOMPÓ, S.A.

Restauración y pintura rápida

50. Olmos Ruiz, M.

Obra nueva

51. Construcciones mecánicas A y M

Sin actividad

52. Pastor Guerrero, María

Obra nueva

53. Olivares Cantero, A.

Solar

54. Cabañes Fornas, J.

Taller mecánico

55. INDUSTRIAS CAROEN

Extintores

56. MADAVI, S.A.

Confección

57. RIMAT, S.L.

Metales y cerrajería

58. CONFECCIONES PELETERAS, S.A.

Sin datos

59. C. POSTIGO LOPEZ, S.A.

Confección

60. ROCADOR, S.A.

Sin datos

61. José Llorens

Confección

62. VICENTE ESCOBAR, S.L.

Bronces

63. Poveda Americo, J.

Toldos

64. CRYSLAN, S.A.

Lámparas

65. Domenech Domenech, C.

Marmoles

66. PUERTAS NAVARRO, S.A.

Carpintería 
67. FERMAX ELECTRONICA, S.A.E.

Porteros electrónicos

68. Real Benlloch, J.

Chapas

69. FOMENTO AVICOLA, S.A.

Fábrica de piensos

70. Martínez Martínez, J.

Carpintería

71. CAFELCE, S.A.

Tostadero de café

72. Egea Ventura, V.

Electricidad

73. Jesús Ballesteros Saenz

Carpintería

74. LOPEZ GARRIDO, S.A.

Material para lámparas

75. Sarrio Verdu, F.

Cartón ondulado

76. CREACIONES RELIEVE

Confección

77. RICARDO MARIN, S.A.

Trofeos

78. Enrique Genoves Santodomingo

Maquinaria agrícola

79. Miguel Cuenca Sánchez

Confección

80. ETRA, S.A. (ELECTRONIC TRAFIC, S.A.)

Sin datos

81. VALENCIANA DE SEÑALIZACIONES, S.A.

Sin datos

82. BACER, S.A.

Instalaciones eléctricas

83. FABRELEC, S.A.

Electrodomésticos

84. GRAFICAS TOSCAN, S.L.

Sin datos

85. GRAFICAS VIMAR, S.L.

Sin datos

86. TURGOL, S.L.

Porteros automáticos 
87. Bort García, Rafael

Bronces

88. Parra Asensi, A.

Fábrica de muebles

89. Arnau Tamboreno, M.

Imprenta

90. Vicente Solves Vicent

Confección

91. ESTRAMA, S.A.

Chapas

92. VERDU y Cia, S.A.

Maquinaria

93. Maria Belllot Moreno

Cortinas

94. Granell Bellver, V.

Mármoles

95. SHYK, S.A.

Fábrica de bolsas de aseo

96. EGUREN SOCIEDAD COOPERATIVA

Reparación de ascensores

97. HERMANOS CATALA, S.A.

Almacén de madera

98. HIJAS DE FRANCO TORMO

Tableros de madera

99. AUDIPLAST

Plásticos

100. INTERPLASTICA, S.A.

Sin datos

101. SEDESA, S.A.

Tejidos

102. CREACIONES PATRI, S.L.

Sin datos

103. COMERCIAL AUTO TURIA, S.A.

Venta de recambios y accesorios de automóvil

104. INDUSTRIAS ANDREU

Torneado de metales

105. Giménez Izquierdo, A.

Plásticos

106. HIBEROLACTO MONROIG

Productos de alimentación 


\section{CARACTERÍSTICAS DEL ASENTAMIENTO INDUSTRIAL.}

Distrito caracterizado por la existencia en el mismo del Polígono Industrial "Vara de Quart " que merece un tratamiento diferenciado del resto del distrito.

Por tanto distinguimos dos zonas:

ZONA 1.

(Polígono): la constituye el Polígono Industrial "Vara de Quart ", situado al Oeste del distrito.

Sus características son las siguientes:

- Uso Industrial, incluyendo en este termino los almacenes y otros centros de distribución.

- Asentamiento homogéneo en cuanto al tamaño de las industrias y características de los edificios

- Industria agrupada de tamaño medio y grande, con un buen nivel de infraestructura y servicios urbanísticos.

- Asentamiento planificado "ad hoc" (único en todo el término municipal de Valencia).

ZONA 2:

La constituye el resto del Distrito, aunque la industria se concentra en su parte Este.

Sus características son:

- Dominio del uso residencial, especialmente en el centro del Distrito, con edificios de reciente construcción que están acabando con las bolsas de huerta preexistentes, y crean una trama urbana desordenada y dispersa.

- Asentamientos heterogéneos, con industrias de dos tipos: . Industria de pequeña superficie, situada en edificios de viviendas entre medianeras y concentrada sobre el primitivo núcleo urbano de Patraix.

- Industria de mediana y gran superficie con edificios de tipología industrial, aislados $\mathrm{y} / \mathrm{o}$ entre medianeras, agrupados en las proximidades de la confluencia de la Avda. de Gaspar Aguilar con 
el ferrocarril de Villanueva de Castellón a Valencia.

Su construcción aunque reciente es previa a la realización del Polígono Vara de Quart.

\section{CARACTERÍSTICAS DE LOS LOCALES INDUSTRIALES:}

ZONA 1 (Polígono)

- Edificios de tipología industrial, de muy reciente construcción, generalmente aislados, sobre parcelas de tamaño medio generalmente.

ZONA 2 (Resto del distrito).

Existen dos tipos de locales industriales que ya han sido descritos en el punto anterior.

\section{CARACTERÍSTICAS DE LAS ACTIVIDADES.-}

Se censaron inicialmente 106 industrias y en el período de vigencia del Plan General han quedado solamente 5 creándose 48 nuevas industrias.

Las actividades dominantes son madera y muebles, productos metálicos, industria química y alimentación y bebidas.

\section{IMPACTO EN EL MEDIO AMBIENTE.-}

La contaminación ambiental es en conjunto escasa, tanto en el Polígono "Vara de Quart " como en el resto, a excepción de casos aislados de industrias de tamaño medio situadas en las proximidades del ferrocarril de Villanueva de Castellón, que carecen de alcantarillado y realizan sus vertidos a acequias, o que producen humos y ruidos mas o menos molestos para las viviendas próximas.

El transporte generado por el Polígono Vara de Quart es de gran importancia, y ha sido este uno de los factores de su localización junto al Nuevo Cauce (III Cinturón de Ronda), a la Avd. Tres Cruces y C/ Tres Forques. No cabe hablar de integración en la trama urbana en un distrito donde esta es confusa y casi inexistente, salvo en el núcleo de Patraix y Polígono Vara de Quart, sin embargo es evidente que los mayores problemas de integración funcional y formal se plantearán en el área industrial próxima a Gaspar Aguilar y Ferrocarril de Villanueva de Castellón. 
EDIFICIOS INDUSTRIALES DE INTERES.-

- Travenol, S.A.

C/ Dels Gremis no 7 6E/5000-6

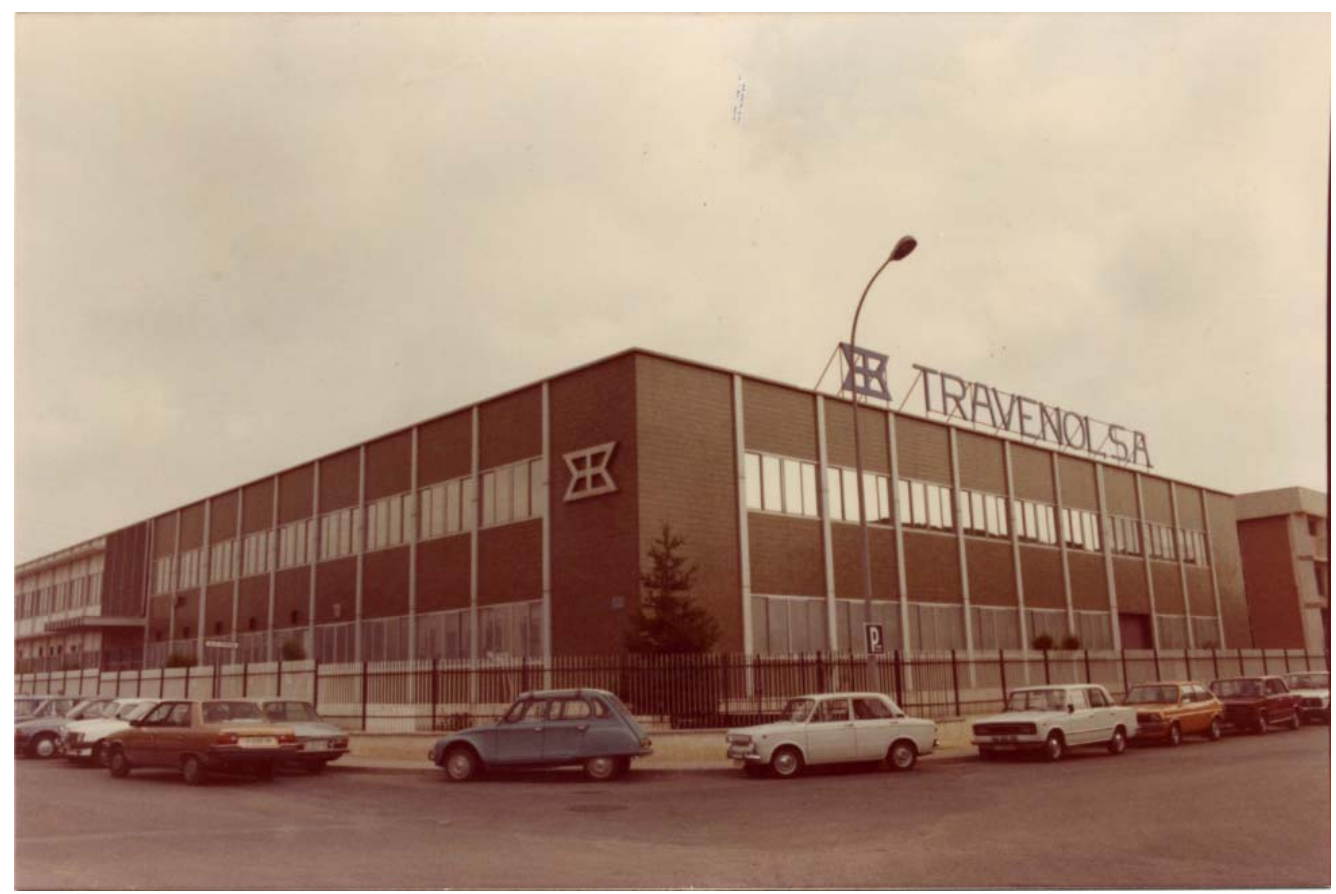

Foto 29: Laboratorio farmacéutico TRAVENOL, S.A. C/ dels Gremis, 7. Polígono industrial Vara de Quart Valencia.1985. Fuente: Elaboración propia

- Vda. de Hurtado

C/ Dels Fusters ํำ 6B/S00J-32

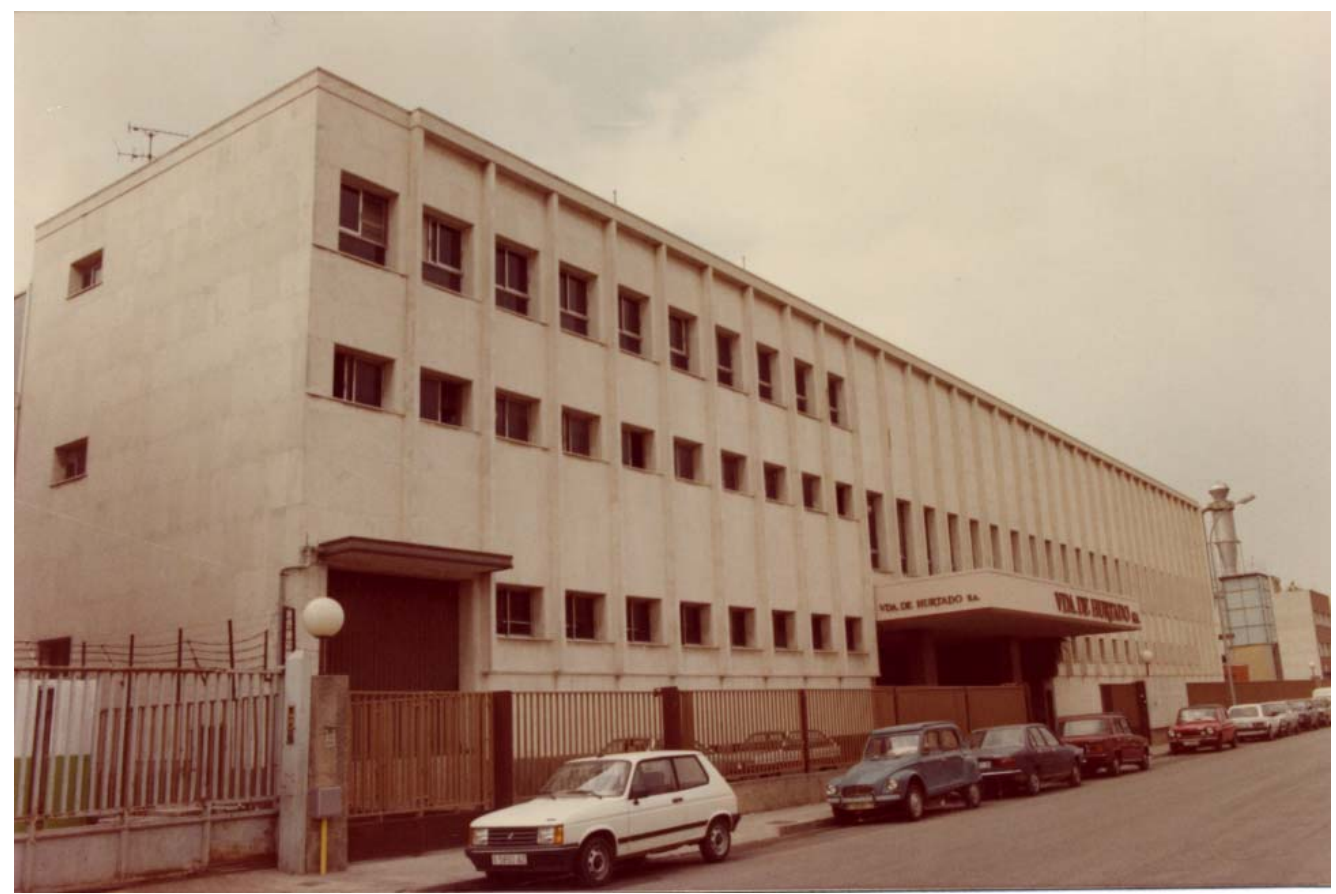

Foto 30: Fábrica de muebles Vda. De Hurtado. C/ dels Fusters, 1. Polígono industrial Vara de Quart Valencia.1985. Fuente: Elaboración propia 
- Las Provincias

C/ Dels Gremis no 4 6E/5000-36

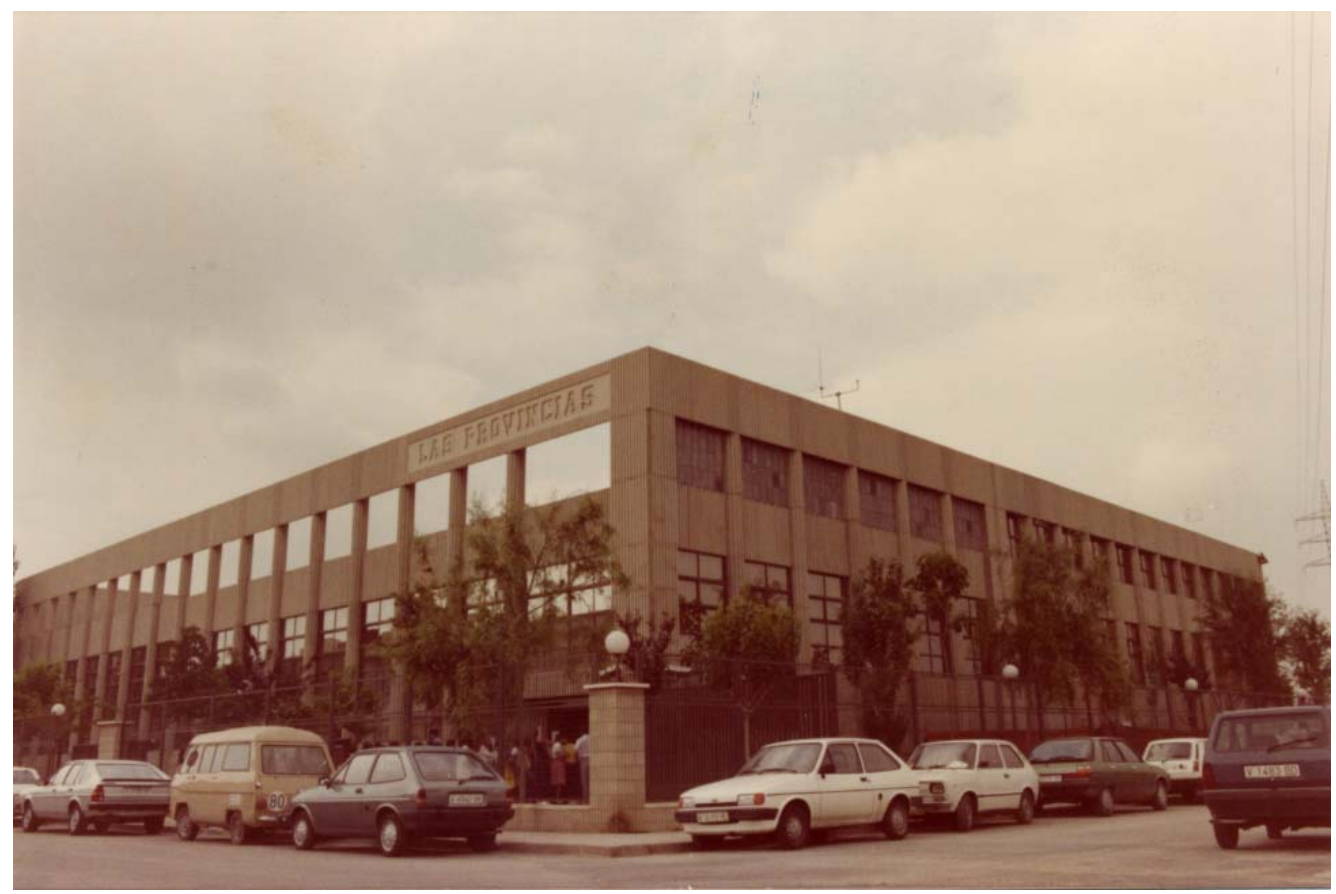

Foto 31: Periódico "Las Provincias". C/ dels Gremis, 4. Polígono industrial Vara de Quart. Valencia.1985. Fuente: Elaboración propia

- Varios edificios

C/ Velluters del no 2 al 14 6E/5000

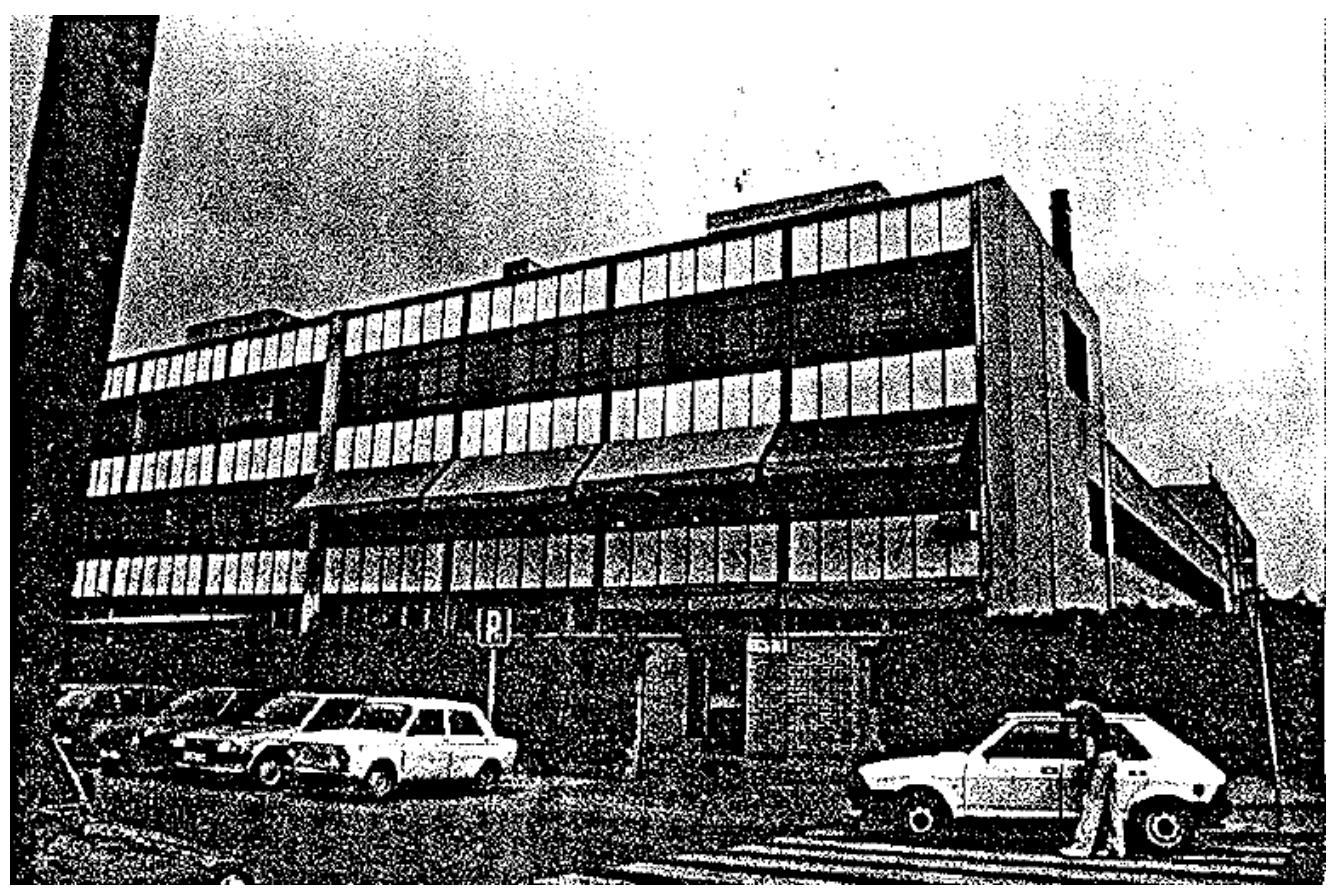

Foto 32: Fábrica de joyería. Cidoncha, S.A. C/ Velluters, 2. Valencia.1985.

Fuente: Elaboración propia 
- Fomento Agrícola, S.A.

C/ Marques de Elche № 22 61-3

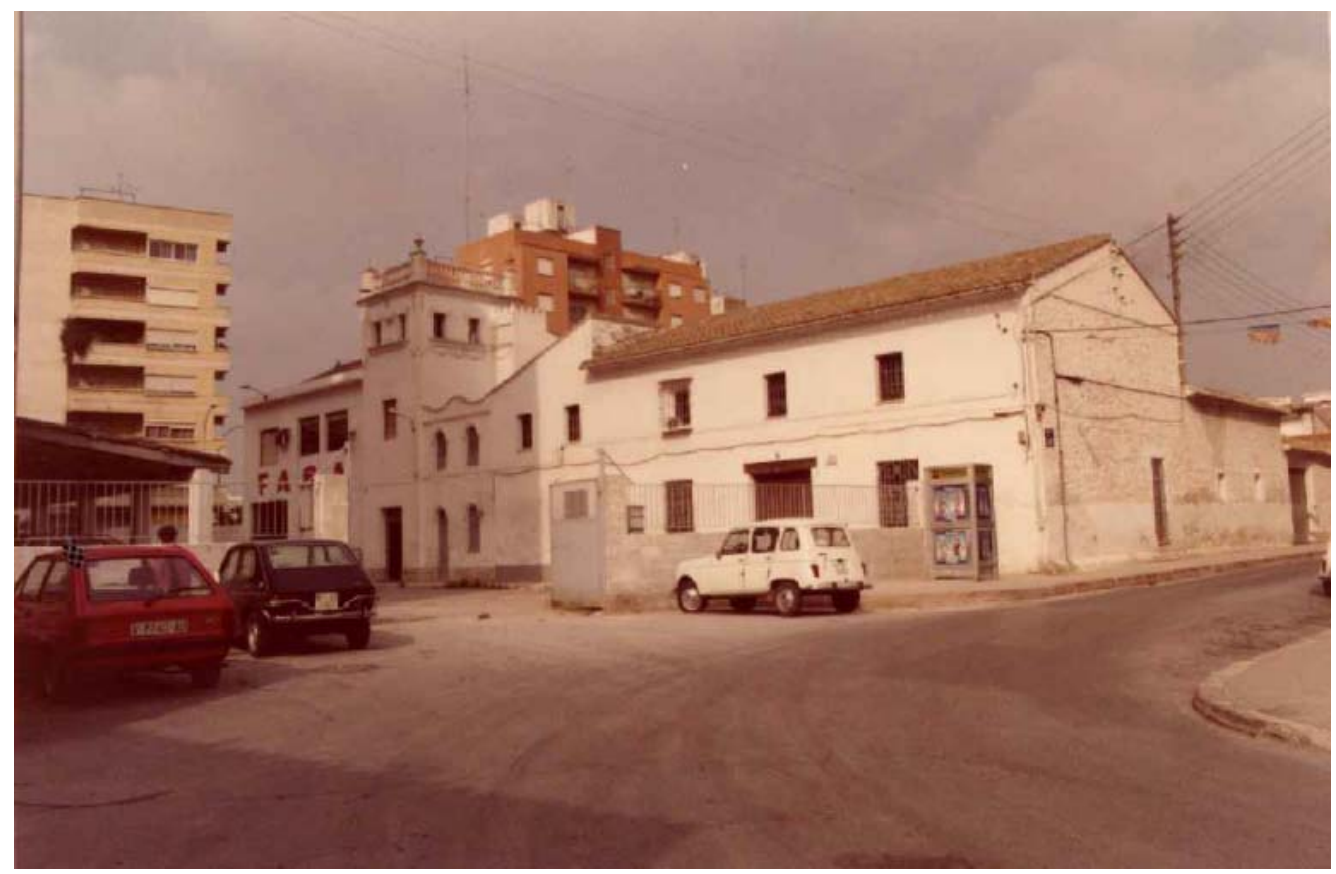

Foto 33: Fábrica de piensos. Fomento agrícola. C/ Merqués de Elche, 22. Valencia.1985. Fuente: Elaboración propia

- Martínez Martínez, J.

\section{C/ Alcudia de Carlet no $3 \quad 61-4$}

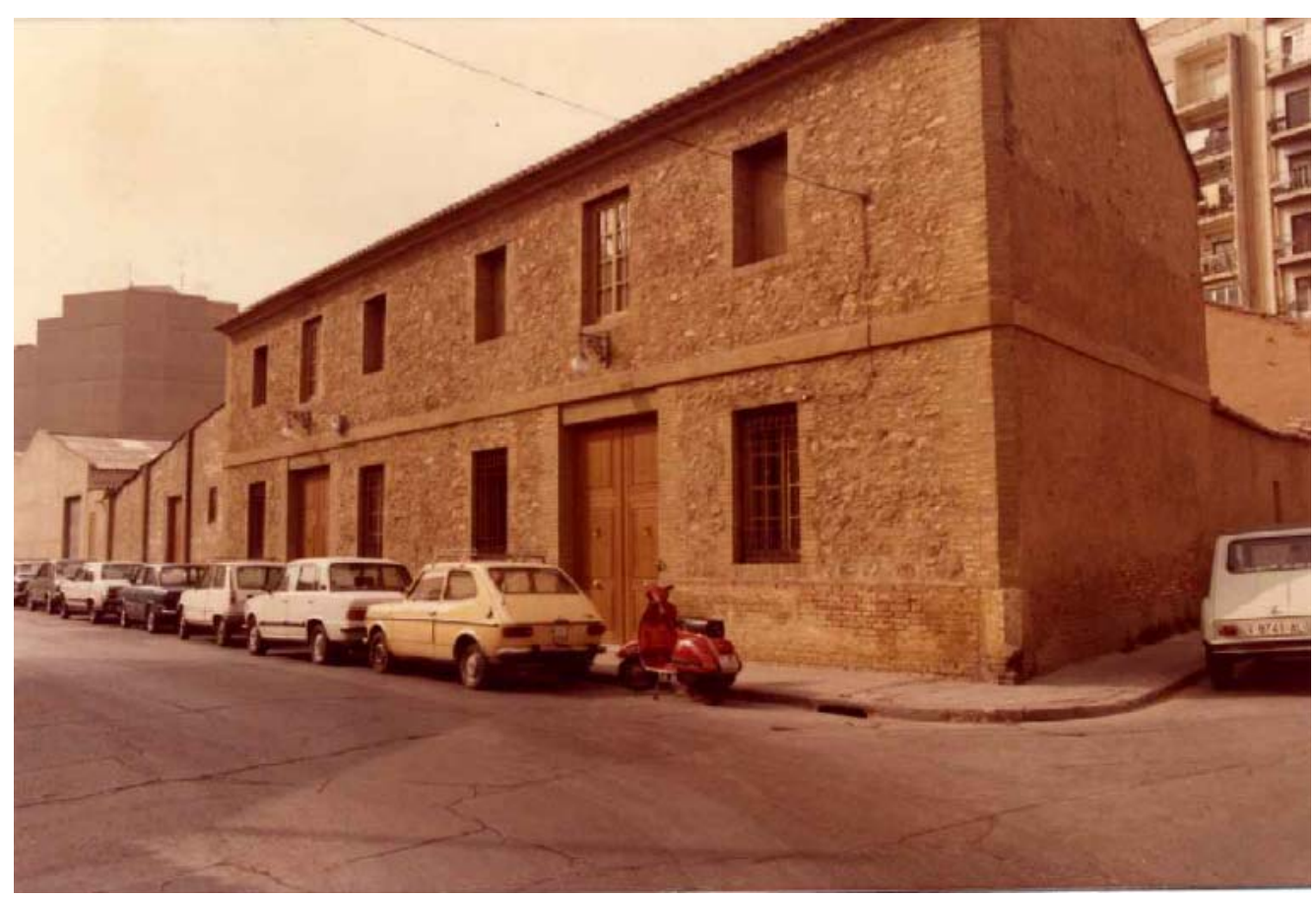

Foto 34: Carpintería. Martínez Martínez, J. C/ Alcudia de Carlet, 3. Valencia.1985. Fuente: Elaboración propia 
- Verdu y Cia. S.A.

C/ Azagador de las Monjas $\mathrm{n}^{\circ} 2$ 71-10

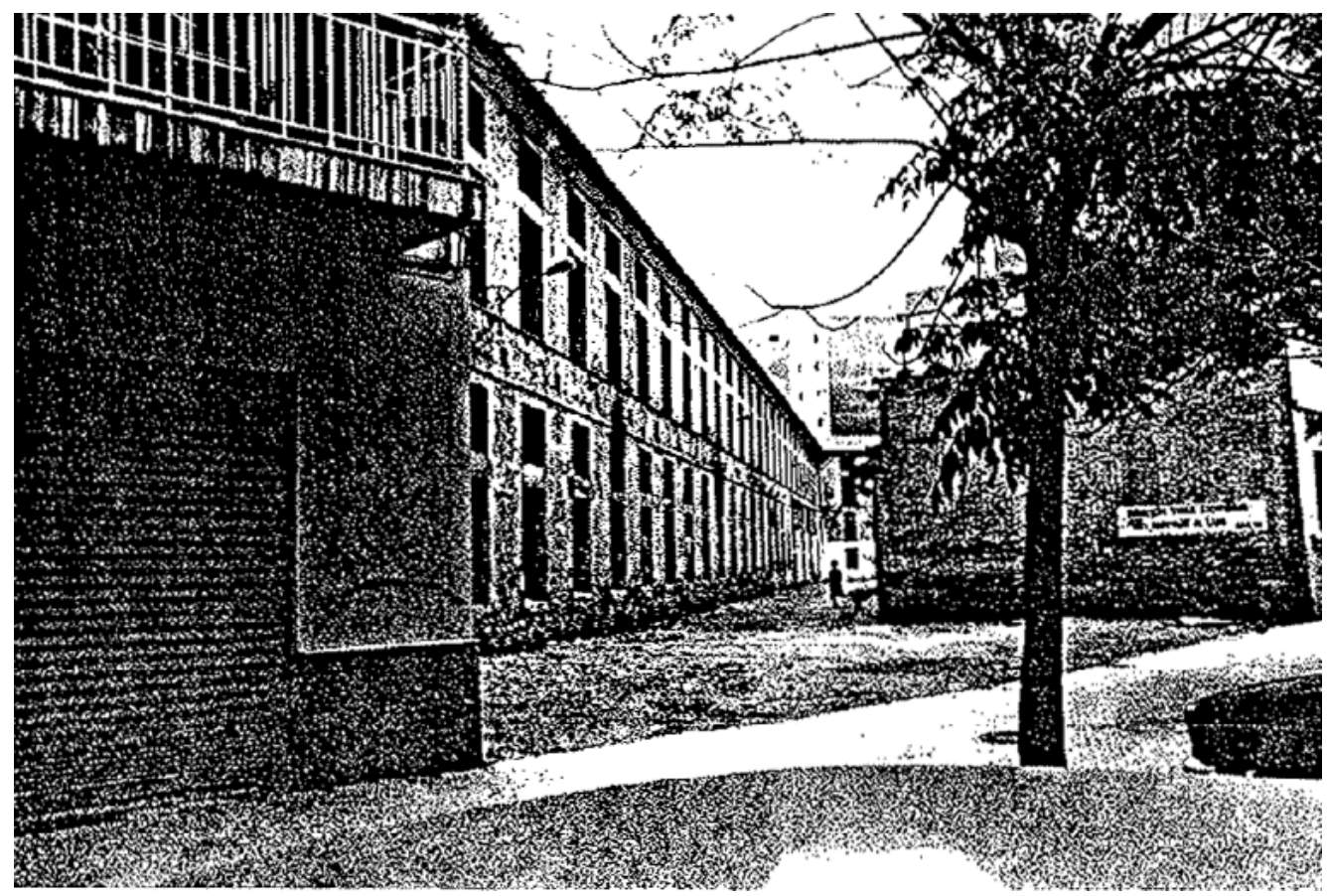

Foto 35: Industria de maquinaria. Verdú y Cia, S.A. C/ Azagador de las monjas, 2. Valencia.1985. Fuente: Elaboración propia

- Mico Estelles, S.A.

C/ Dels Traglners ํㅜ 7 6G-5000

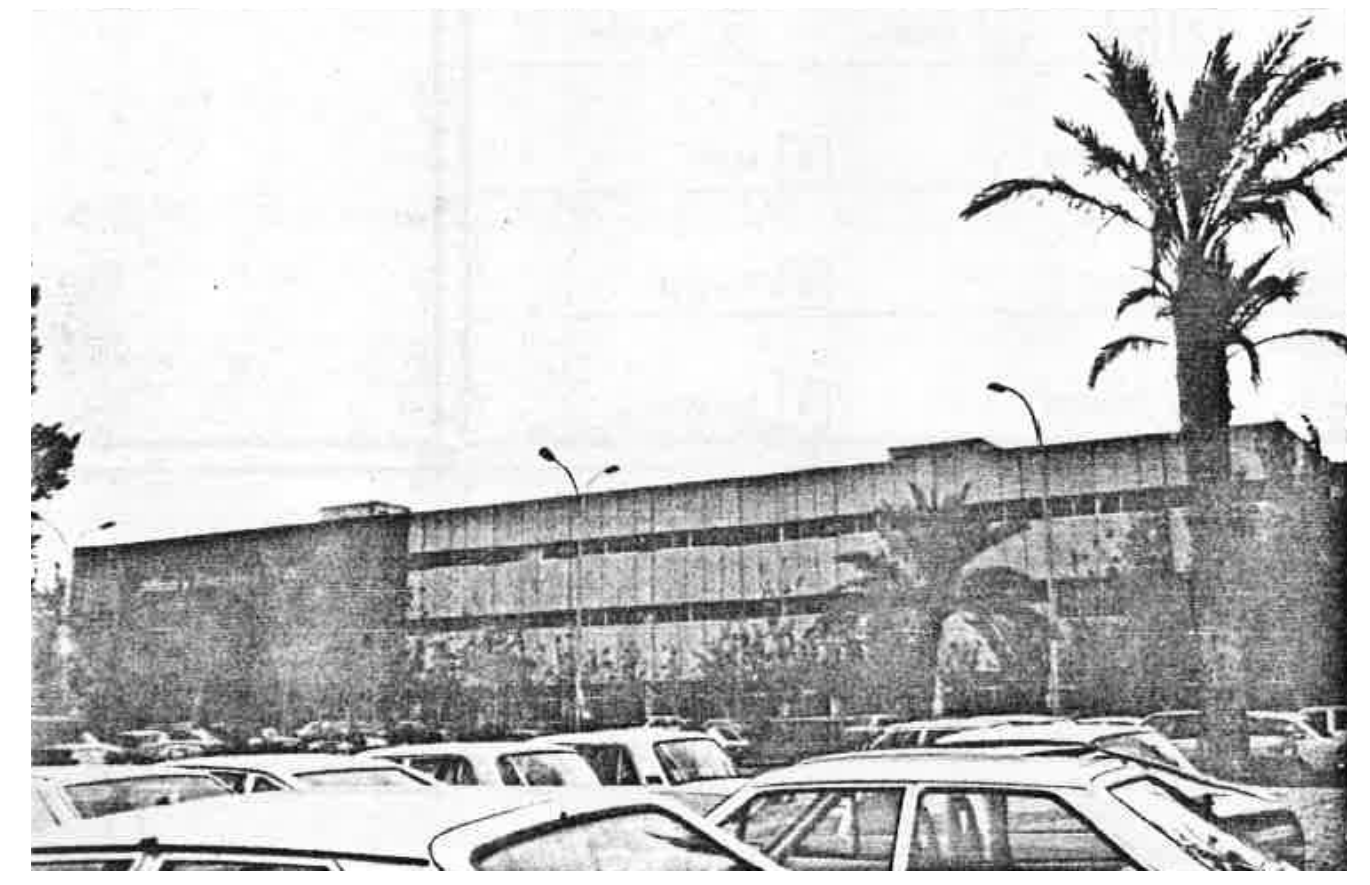

Foto 36: Micó Estelles, S.A. C/ dels Traginers, 7. Polígono industrial Vara de Quart. Valencia.1985. Fuente: Elaboración propia 
- Guzman

C/ Dels Traginers n9 6G-S000

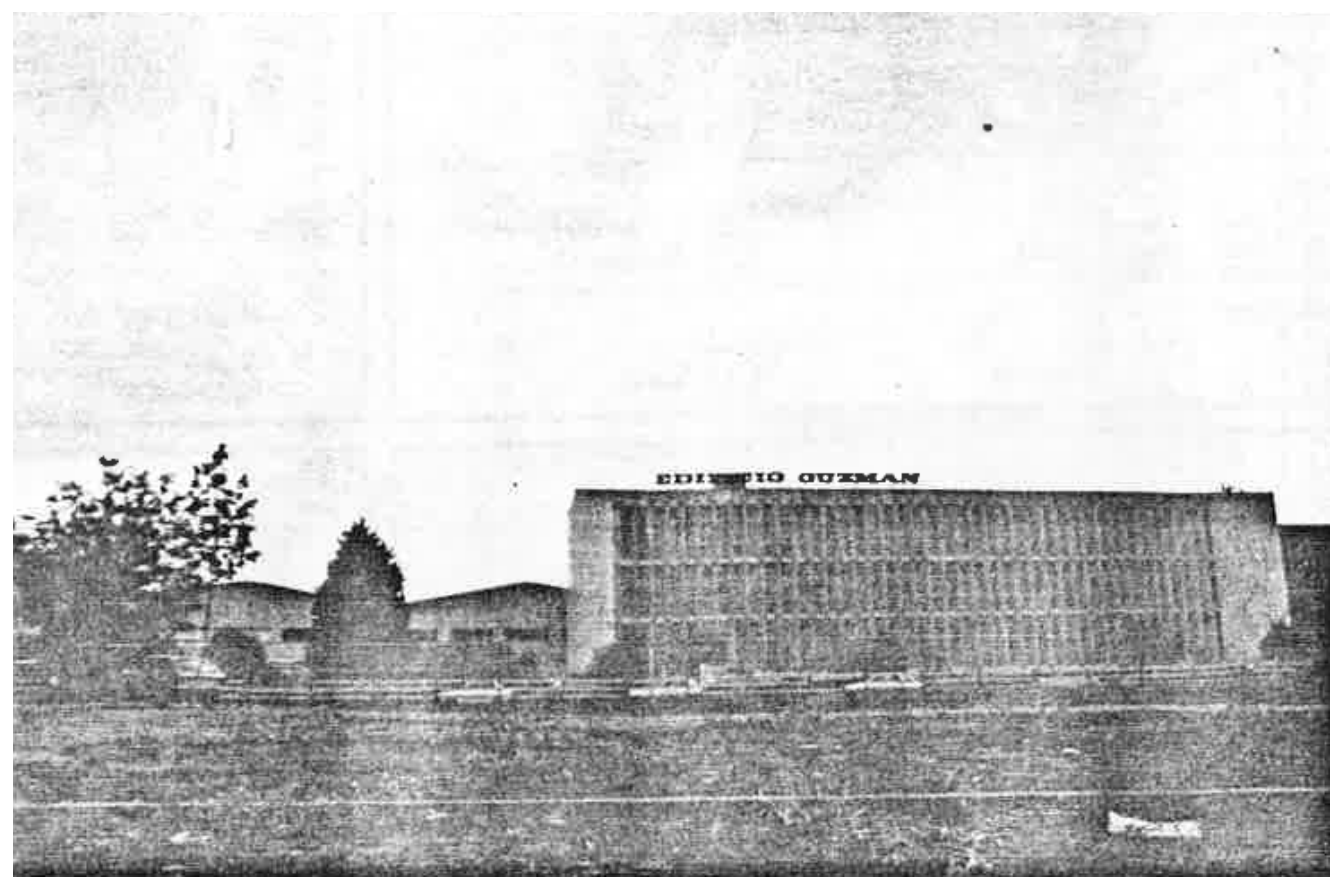

Foto 37: Edificio Guzmán. C/ dels Traginers, 9.Polígono industrial Vara de Quart. Valencia.1985.

Fuente: Elaboración propia

- Mecano Textil

Avd. Gaspar Aguilar nº 2091

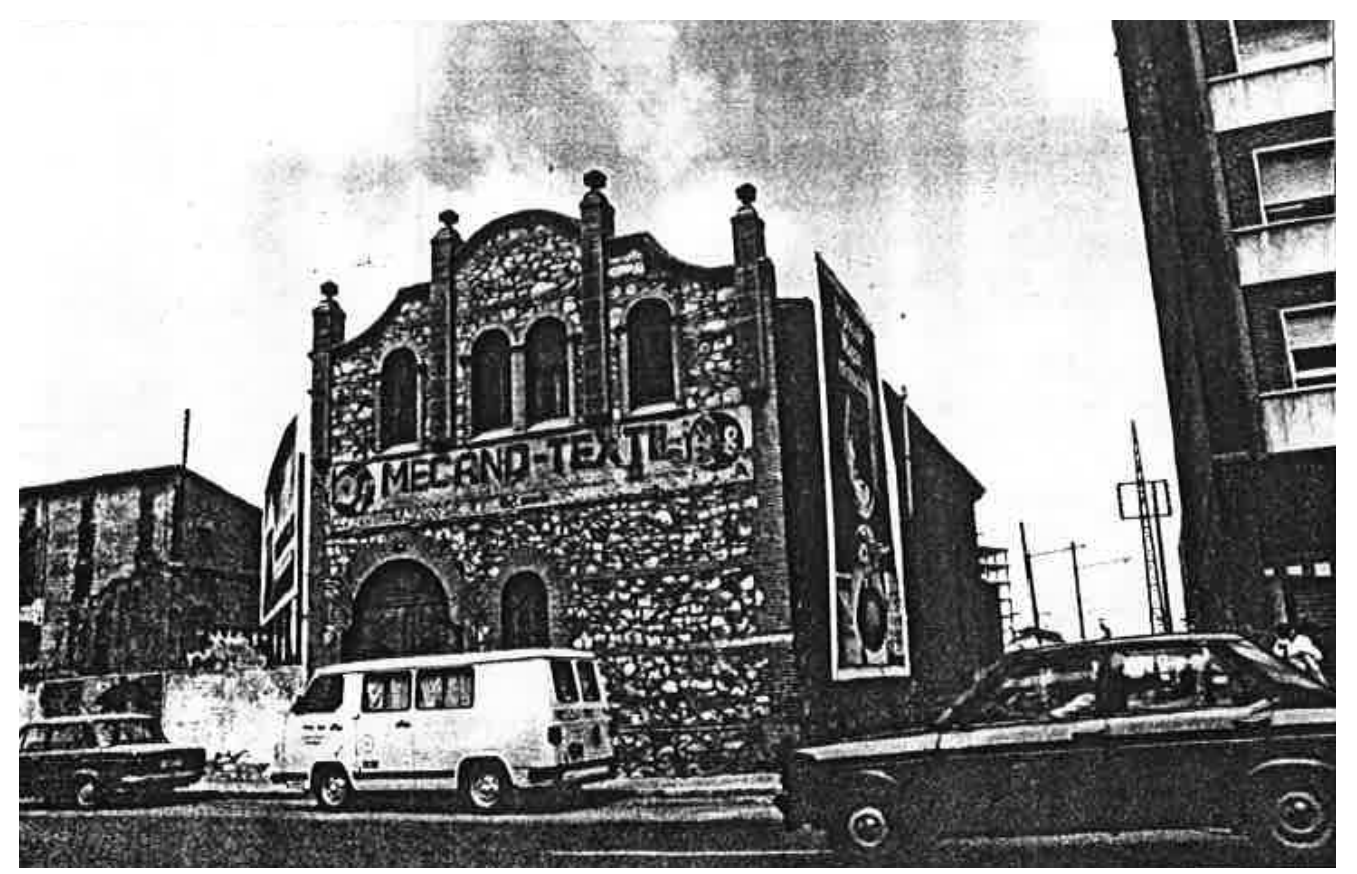

Foto 38: Mecano textil. Avda. Gaspar Aguilar, 20. Valencia.1985.

Fuente: Elaboración propia 
TIPOLOGÍA EDIFICACIÓN

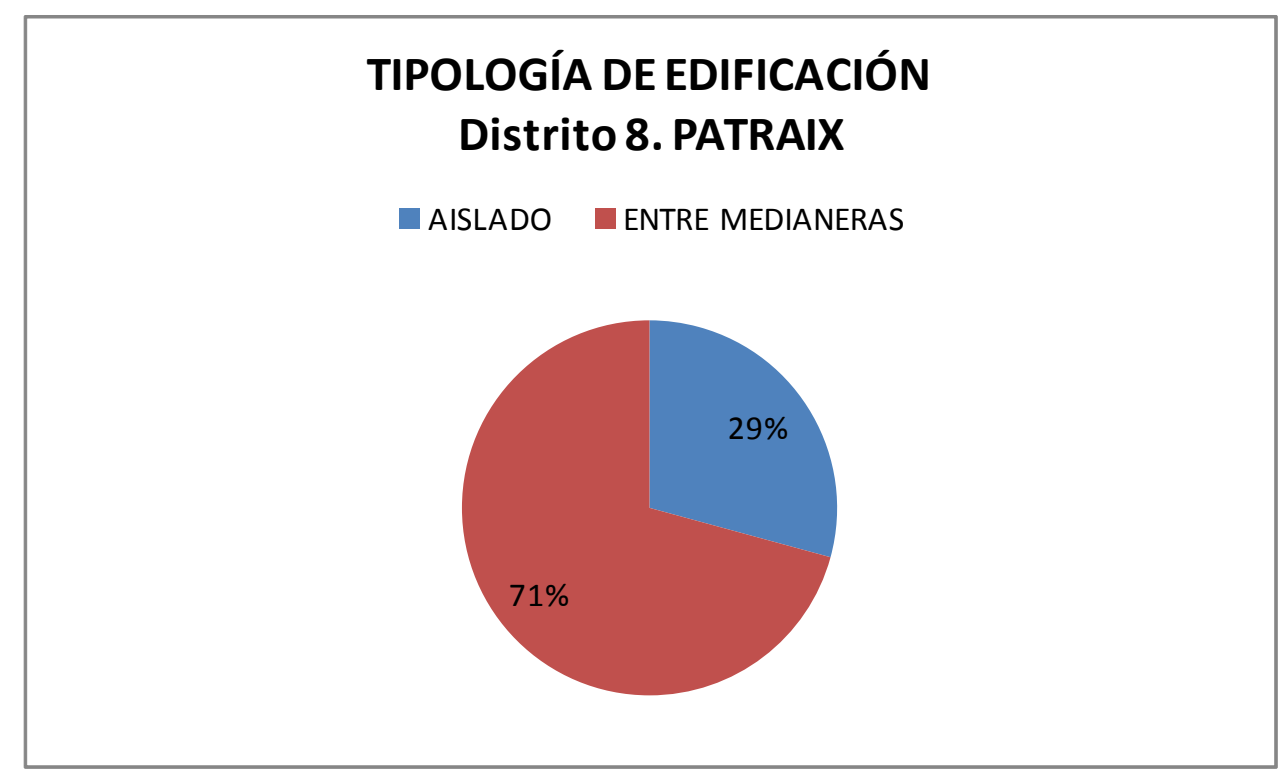




\section{ACTIVIDAD INDUSTRIAL, SUPERFICIE Y EMPLEO}

\begin{tabular}{|c|c|c|c|c|c|}
\hline \multicolumn{6}{|c|}{ DISTRITO 8 - PATRAIX (ATIVIDAD INDUSTRIAL Y EMPLEO) } \\
\hline ACTIVIDAD & $\begin{array}{c}\text { № } \\
\text { EMPRESAS }\end{array}$ & $\begin{array}{c}\text { SUP. ACTIVIDAD } \\
\text { IND }\left(\mathrm{m}^{2}\right)\end{array}$ & $\begin{array}{c}\text { \% SUP. } \\
\text { INDUSTRIAL }\end{array}$ & $\begin{array}{c}\text { № } \\
\text { EMPLEADOS }\end{array}$ & $\begin{array}{c}\text { DENSIDAD } \\
\text { EMPLEO } \\
\text { (empleados } / \mathrm{m}^{2} \\
\text { actividad) }\end{array}$ \\
\hline CAPTACIÓN Y DEPURACIÓN DE AGUAS & 1 & 10000 & 2,51 & 200 & 0,0200 \\
\hline PRODUCCIÓN Y PRIMERA TRANSFORMACIÓN DE METALES & 1 & 8000 & 2,01 & 60 & 0,0075 \\
\hline INDUSTRIAS DE PRODUCTOS MINERALES NO METÁLICOS & 4 & 2520 & 0,63 & 25 & 0,0099 \\
\hline INDUSTRIA QUÍMICA & 8 & 53999 & 13,54 & 462 & 0,0086 \\
\hline FABRICACIÓN DE PRODUCTOS METÁLICOS & 18 & 89480 & 22,44 & 432 & 0,0048 \\
\hline CONSTRUCCIÓN DE MAQUINARIA Y ÉQUIPO MECÁNICO & 5 & 6845 & 1,72 & 84 & 0,0123 \\
\hline CONSTRUCCIÓN DE MAQUINARIA Y MATERIAL ELÉCTRICO & 4 & 17410 & 4,37 & 49 & 0,0028 \\
\hline FABRICACIÓN DE MATERIAL ELECTRÓNICO & 2 & 1160 & 0,29 & 74 & 0,0638 \\
\hline CONSTRUCCIÓN DE VEHÍCULOS AUTMÓVILES Y SUS PIEZAS DE REPUESTO & 1 & 3200 & 0,80 & 70 & 0,0219 \\
\hline INDUSTRIAS DE PRODUCTOS ALIMENTICIOS, BEBIDAS Y TABACO & 4 & 30901 & 7,75 & 347 & 0,0112 \\
\hline INDUSTRIAS DE PRODUCTOS ALIMENTICIOS, BEBIDAS Y TABACO & 5 & 24100 & 6,04 & 110 & 0,0046 \\
\hline INDUSTRIA TEXTIL & 1 & 3950 & 0,99 & 7 & 0,0018 \\
\hline INDUSTRIA DEL CUERO & 2 & 724 & 0,18 & 16 & 0,0221 \\
\hline INDUSTRIA DEL CALZADO Y DEL VESTIDO Y OTRAS CONFECCIONES TEXTILES & 11 & 11143 & 2,79 & 185 & 0,0166 \\
\hline INDUSTRIAS DE MADERA, CORCHO Y MUEBLES DE MADERA & 14 & 79831 & 20,02 & 720 & 0,0090 \\
\hline $\begin{array}{l}\text { INDUSTRIA DEL PAPEL Y FABRICACIÓN DE ARTÍCULOS DE PAPEL, ARTES GRÁFICAS } \\
\text { Y EDICIÓN }\end{array}$ & 8 & 7810 & 1,96 & 252 & 0,0323 \\
\hline INDUSTRIAS DE TRANSFORMACIÓN DEL CAUCHO Y MATERIAS PLÁSTICAS & 4 & 8190 & 2,05 & 68 & 0,0083 \\
\hline OTRAS INDUSTRIAS MANUFACTURERAS & 4 & 3124 & 0,78 & 103 & 0,0330 \\
\hline CONSTRUCCIÓN & 6 & 5746 & 1,44 & 149 & 0,0259 \\
\hline COMERCIO AL POR MENOR & 1 & 22000 & 5,52 & 95 & 0,0043 \\
\hline TRANSPORTES TERRESTRES & 1 & 8600 & 2,16 & 40 & 0,0047 \\
\hline TOTAL & 105 & 398733 & 100 & 3548 & 0,0089 \\
\hline
\end{tabular}

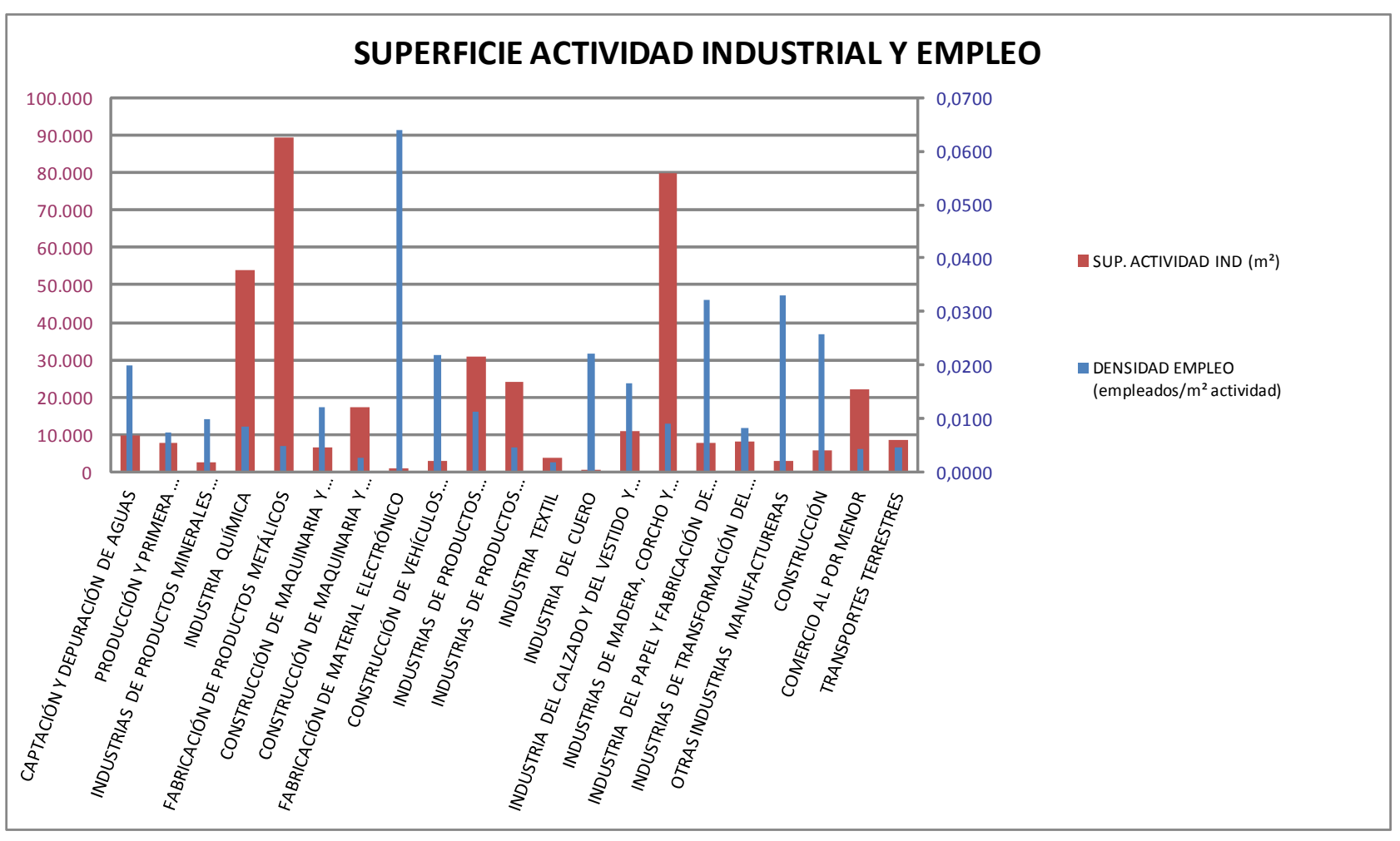


IMPACTO AMBIENTAL

\begin{tabular}{|c|c|c|c|c|c|}
\hline \multicolumn{6}{|c|}{ DISTRITO 8 - PATRAIX (INFORMACIÓN URBANÍSTICA) } \\
\hline ACTIVIDAD & $\begin{array}{c}\text { No } \\
\text { EMPRESAS }\end{array}$ & $\begin{array}{c}\text { ENTRE } \\
\text { MEDIANERAS }\end{array}$ & RUIDOSAS & $\begin{array}{c}\text { EMPRESAS } \\
\text { CON } \\
\text { CHIMENEA }\end{array}$ & $\begin{array}{l}\text { RUIDOSAS Y } \\
\text { CHIMENEA }\end{array}$ \\
\hline CAPTACIÓN Y DEPURACIÓN DE AGUAS & 1 & 1 & 0 & 0 & 0 \\
\hline PRODUCCIÓN Y PRIMERA TRANSFORMACIÓN DE METALES & 1 & 0 & 0 & 0 & 0 \\
\hline INDUSTRIAS DE PRODUCTOS MINERALES NO METÁLICOS & 4 & 4 & 3 & 0 & 0 \\
\hline INDUSTRIA QUÍMICA & 8 & 3 & 0 & 3 & 0 \\
\hline FABRICACIÓN DE PRODUCTOS METÁLICOS & 18 & 11 & 5 & 1 & 2 \\
\hline CONSTRUCCIÓN DE MAQUINARIA Y ÉQUIPO MECÁNICO & 5 & 5 & 1 & 0 & 0 \\
\hline CONSTRUCCIÓN DE MAQUINARIA Y MATERIAL ELÉCTRICO & 4 & 4 & 1 & 0 & 0 \\
\hline FABRICACIÓN DE MATERIAL ELECTRÓNICO & 2 & 2 & 0 & 0 & 0 \\
\hline CONSTRUCCIÓN DE VEHÍCULOS AUTMÓVILES Y SUS PIEZAS DE REPUESTO & 1 & 0 & 1 & 0 & 0 \\
\hline INDUSTRIAS DE PRODUCTOS ALIMENTICIOS, BEBIDAS Y TABACO & 4 & 1 & 0 & 3 & 0 \\
\hline INDUSTRIAS DE PRODUCTOS ALIMENTICIOS, BEBIDAS Y TABACO & 5 & 2 & 1 & 2 & 0 \\
\hline INDUSTRIA TEXTIL & 1 & 1 & 0 & 0 & 0 \\
\hline INDUSTRIA DEL CUERO & 2 & 2 & 0 & 0 & 0 \\
\hline INDUSTRIA DEL CALZADO Y DEL VESTIDO Y OTRAS CONFECCIONES TEXTILES & 11 & 9 & 5 & 0 & 0 \\
\hline INDUSTRIAS DE MADERA, CORCHO Y MUEBLES DE MADERA & 14 & 8 & 1 & 4 & 4 \\
\hline $\begin{array}{l}\text { INDUSTRIA DEL PAPEL Y FABRICACIÓN DE ARTÍCULOS DE PAPEL, ARTES GRÁFICAS } \\
\text { Y EDICIÓN }\end{array}$ & 8 & 6 & 2 & 0 & 0 \\
\hline INDUSTRIAS DE TRANSFORMACIÓN DEL CAUCHO Y MATERIAS PLÁSTICAS & 4 & 4 & 2 & 0 & 0 \\
\hline OTRAS INDUSTRIAS MANUFACTURERAS & 4 & 4 & 1 & 1 & 0 \\
\hline CONSTRUCCIÓN & 7 & 7 & 1 & 0 & 0 \\
\hline COMERCIO AL POR MENOR & 1 & 0 & 0 & 0 & 0 \\
\hline TRANSPORTES TERRESTRES & 1 & 0 & 0 & 0 & 0 \\
\hline TOTAL & 106 & 74 & 24 & 14 & 6 \\
\hline
\end{tabular}

\section{IMPACTO EN EL MEDIO URBANO}

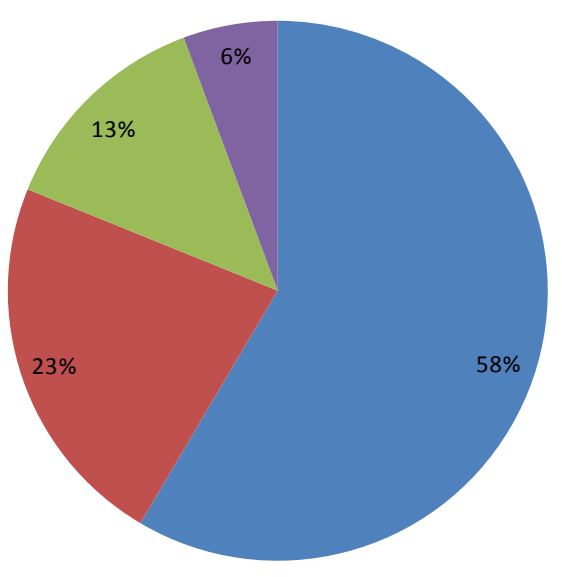

- EMPRESAS INOCUAS

- EMPRESAS RUIDOSAS

- EMPRESAS CON CHIMENEA

EMPRESAS RUIDOSAS Y CON CHIMENEA 


\section{FICHAS TIPO \\ FICHA DATOS DE LA INDUSTRIA}

LOCALIZACION ACTUALIZADA DE ACTIVIDADES INDUSTRIALES EN EL MEDIO URBANO DE VALENCIA

\begin{tabular}{|c|c|c|c|c|c|c|c|}
\hline \multirow{5}{*}{ 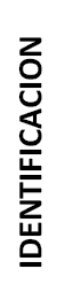 } & \multirow{2}{*}{\multicolumn{2}{|c|}{$\begin{array}{c}\text { NOMBRE } \\
\text { EMPLAZAMIENTO }\end{array}$}} & \multicolumn{5}{|l|}{ ALSIMET } \\
\hline & & & \multicolumn{3}{|c|}{ C/ dels Coeters s/n } & C.P. & \\
\hline & \multirow[b]{2}{*}{ CNAE } & \multirow[b]{2}{*}{221} & \multirow[b]{2}{*}{ DESCRIPCION } & \multicolumn{4}{|c|}{ PROD. Y 1a TRANS. METALES } \\
\hline & & & & \multicolumn{4}{|c|}{ Metalurgia } \\
\hline & DISTRITO & 8 & \multicolumn{5}{|c|}{ PATRAIX } \\
\hline & \multicolumn{2}{|c|}{ SUPERFICIES } & $\begin{array}{l}\text { Sup. Parcela: } \\
8.000 \mathrm{~m}^{2}\end{array}$ & $\begin{array}{l}\text { Sup. Ocupada: } \\
5.000 \mathrm{~m}^{2}\end{array}$ & $\begin{array}{l}\text { Sup. Construida: } \\
5.500 \mathrm{~m}^{2}\end{array}$ & EMPL & $\begin{array}{l}\text { LEADOS: } \\
60\end{array}$ \\
\hline
\end{tabular}
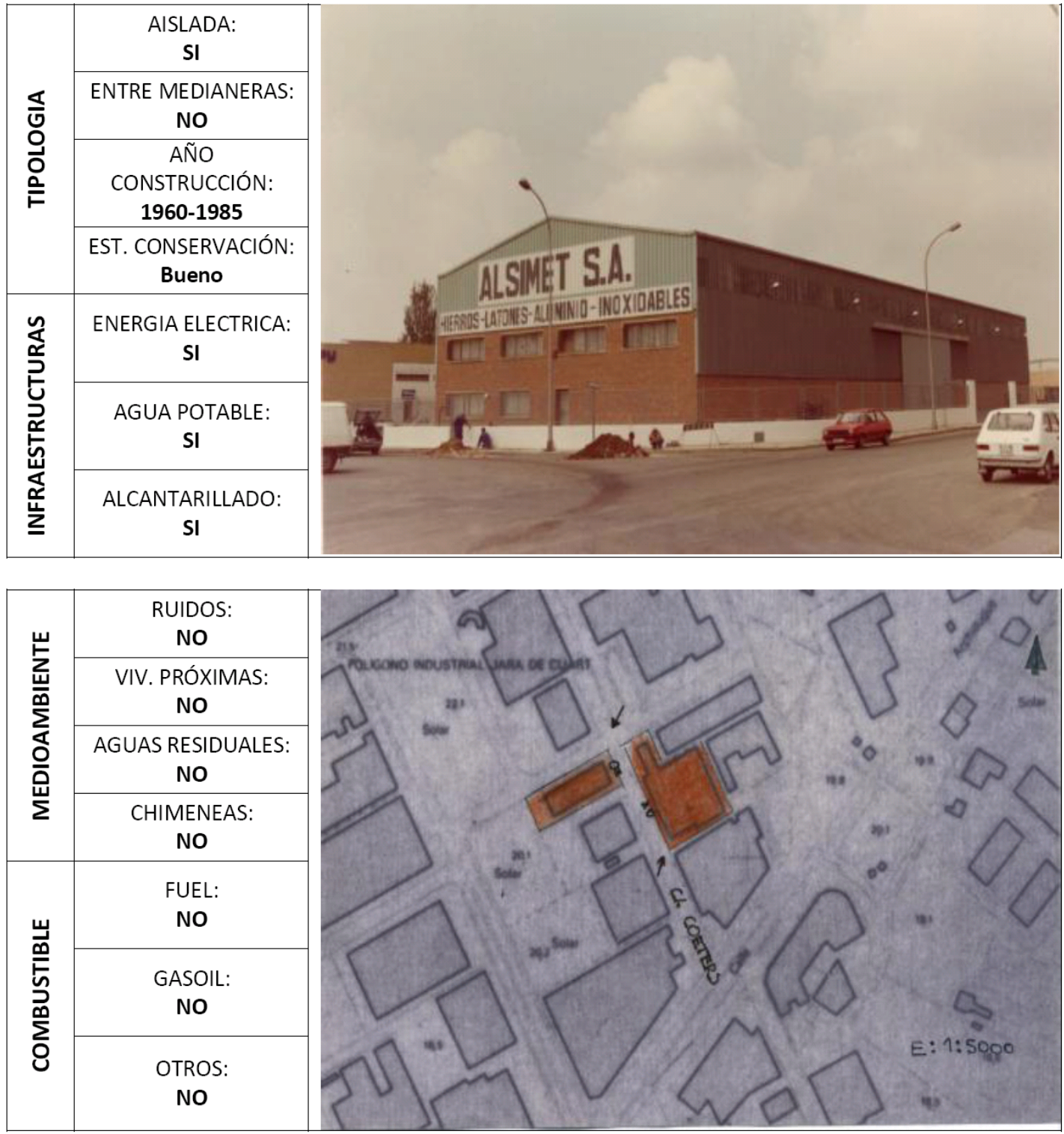


\section{FICHA DATOS DE LA INDUSTRIA}

LOCALIZACION ACTUALIZADA DE ACTIVIDADES INDUSTRIALES EN EL MEDIO URBANO DE VALENCIA

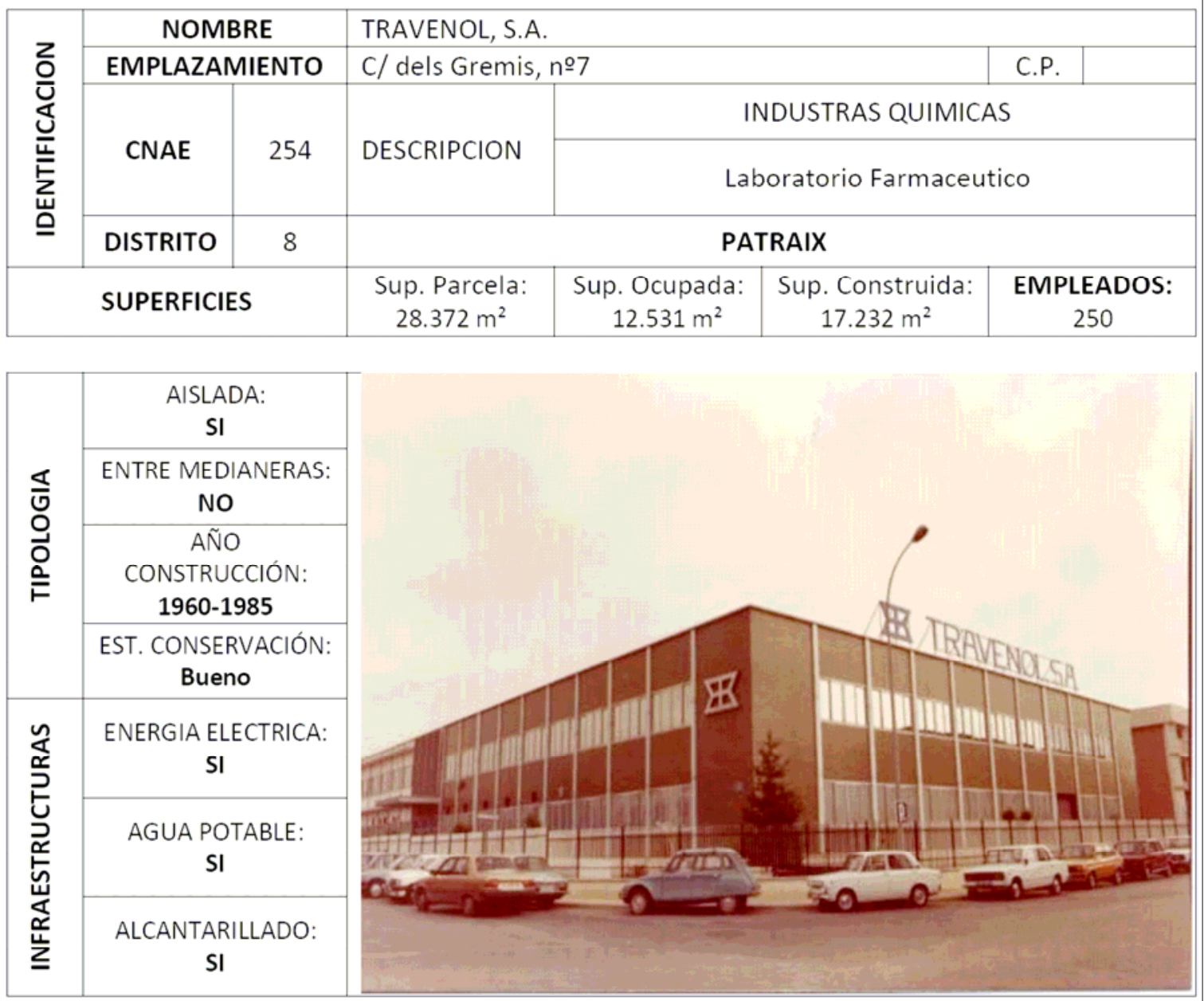

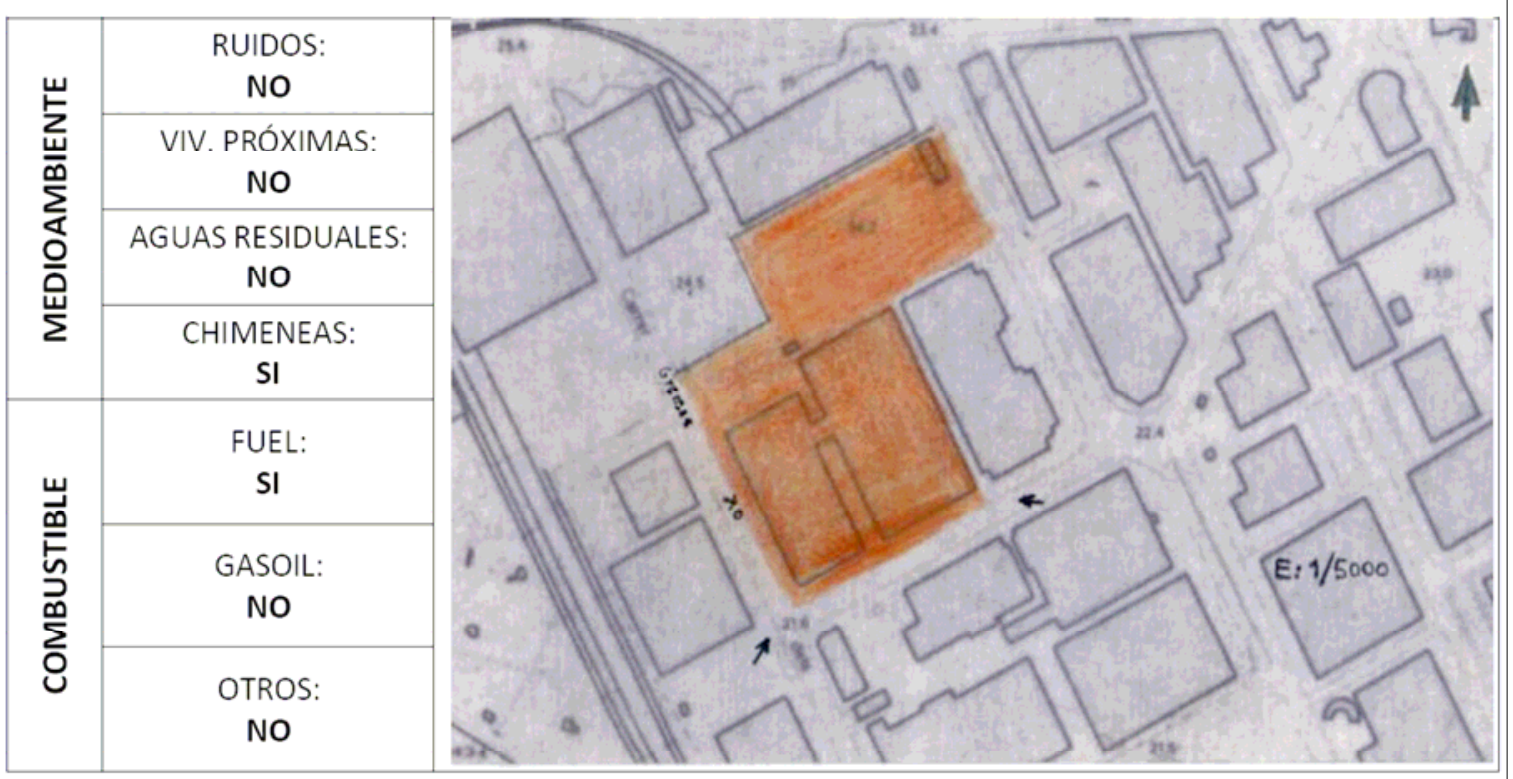




\section{FICHA DATOS DE LA INDUSTRIA}

LOCALIZACION ACTUALIZADA DE ACTIVIDADES INDUSTRIALES EN EL MEDIO URBANO DE VALENCIA

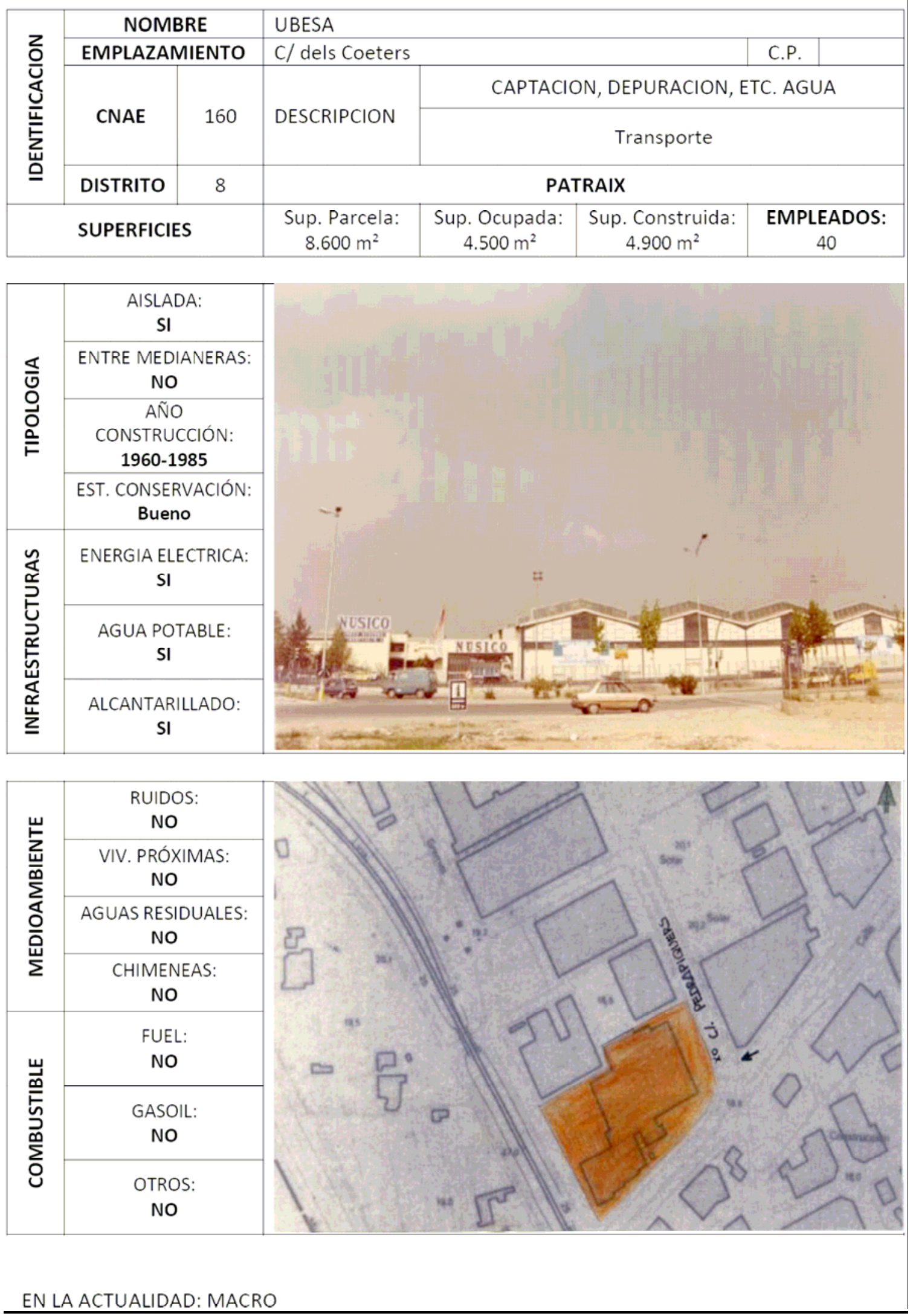




\section{FICHA DATOS DE LA INDUSTRIA}

LOCALIZACION ACTUALIZADA DE ACTIVIDADES INDUSTRIALES EN EL MEDIO URBANO DE VALENCIA

\begin{tabular}{|c|c|c|c|c|c|c|c|}
\hline \multirow{5}{*}{ 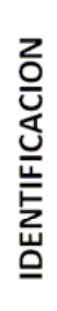 } & \multirow{2}{*}{\multicolumn{2}{|c|}{$\begin{array}{c}\text { NOMBRE } \\
\text { EMPLAZAMIENTO }\end{array}$}} & \multicolumn{5}{|c|}{ MECANTEX, S.A. } \\
\hline & & & \multicolumn{3}{|c|}{ C/Campos Crespo, no54 } & C.P. & \\
\hline & \multirow{2}{*}{ CNAE } & \multirow{2}{*}{322} & \multirow{2}{*}{ DESCRIPCION } & \multicolumn{4}{|c|}{ CONSTRUCCIÓN MAQUINARIA } \\
\hline & & & & \multicolumn{4}{|c|}{ Fabricantes de reductores de velocidad } \\
\hline & DISTRITO & 8 & \multicolumn{5}{|c|}{ PATRAIX } \\
\hline & \multicolumn{2}{|c|}{ SUPERFICIES } & $\begin{array}{c}\text { Sup. Parcela: } \\
1.300 \mathrm{~m}^{2}\end{array}$ & $\begin{array}{c}\text { Sup. Ocupada: } \\
1.300 \mathrm{~m}^{2}\end{array}$ & $\begin{array}{c}\text { Sup. Construida: } \\
1.300 \mathrm{~m}^{2}\end{array}$ & EMPI & $\begin{array}{l}\text { EADOS: } \\
35\end{array}$ \\
\hline
\end{tabular}
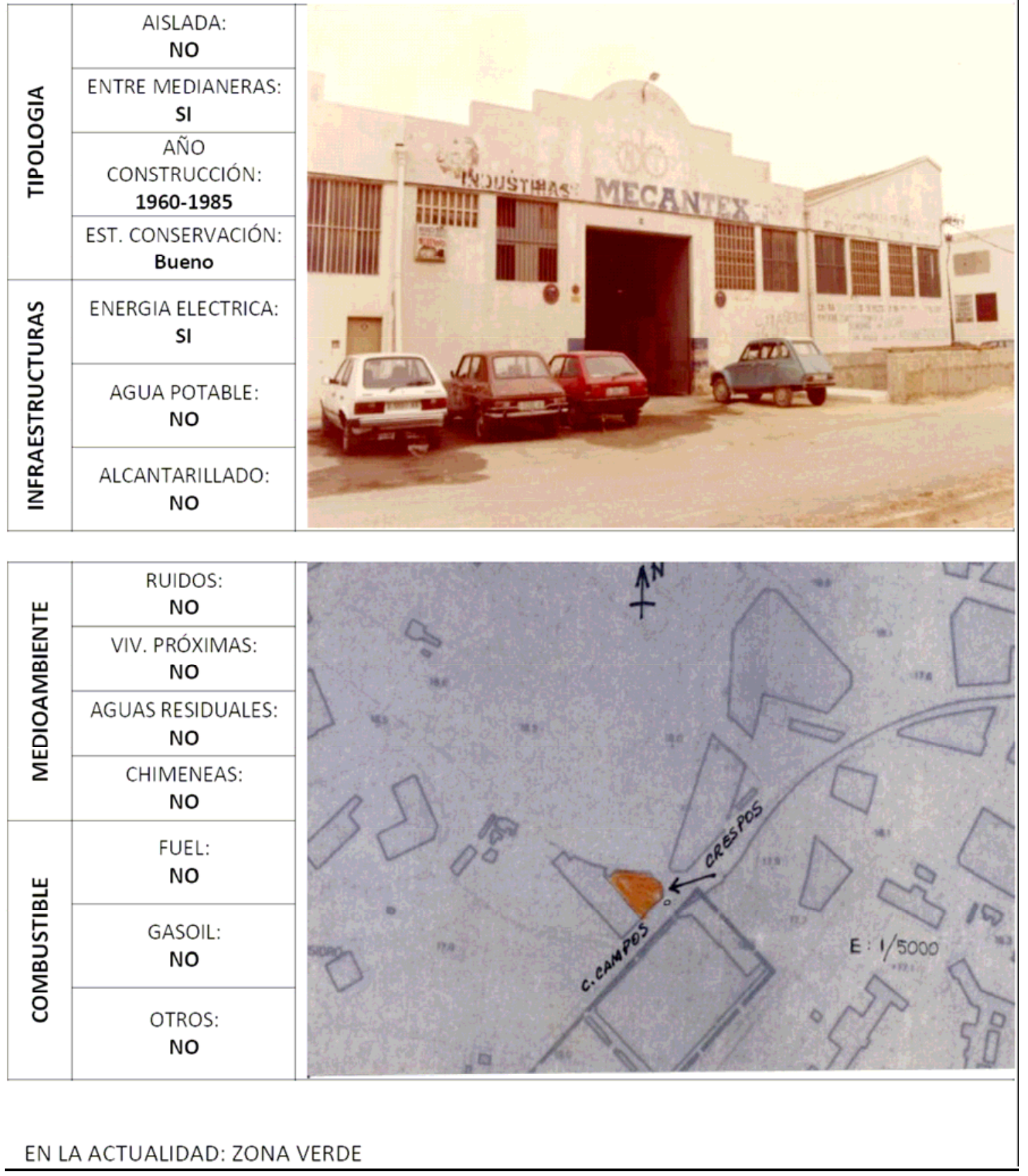


\section{FICHA DATOS DE LA INDUSTRIA}

LOCALIZACION ACTUALIZADA DE ACTIVIDADES INDUSTRIALES EN EL MEDIO URBANO DE VALENCIA

\begin{tabular}{|c|c|c|c|c|c|c|c|}
\hline \multirow{5}{*}{ 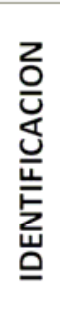 } & \multirow{2}{*}{\multicolumn{2}{|c|}{$\begin{array}{c}\text { NOMBRE } \\
\text { EMPLAZAMIENTO }\end{array}$}} & \multicolumn{5}{|c|}{ FERMAX ELECTRONICA, S.A.E. } \\
\hline & & & \multicolumn{3}{|c|}{ C/ Tres forques, $n=41$} & C.P. & \\
\hline & \multirow[b]{2}{*}{ CNAE } & \multirow[b]{2}{*}{351} & \multirow[b]{2}{*}{ DESCRIPCION } & \multicolumn{4}{|c|}{ MATERIAL ELECTRÓNICO } \\
\hline & & & & \multicolumn{4}{|c|}{ Porteros electrónicos } \\
\hline & DISTRITO & 8 & \multicolumn{5}{|c|}{ PATRAIX } \\
\hline & \multicolumn{2}{|c|}{ SUPERFICIES } & $\begin{array}{l}\text { Sup. Parcela: } \\
900 \mathrm{~m}^{2}\end{array}$ & $\begin{array}{l}\text { Sup. Ocupada: } \\
900 \mathrm{~m}^{2}\end{array}$ & $\begin{array}{l}\text { Sup. Construida: } \\
900 \mathrm{~m}^{2}\end{array}$ & EMPI & $\begin{array}{l}\text { LEADOS: } \\
57\end{array}$ \\
\hline
\end{tabular}
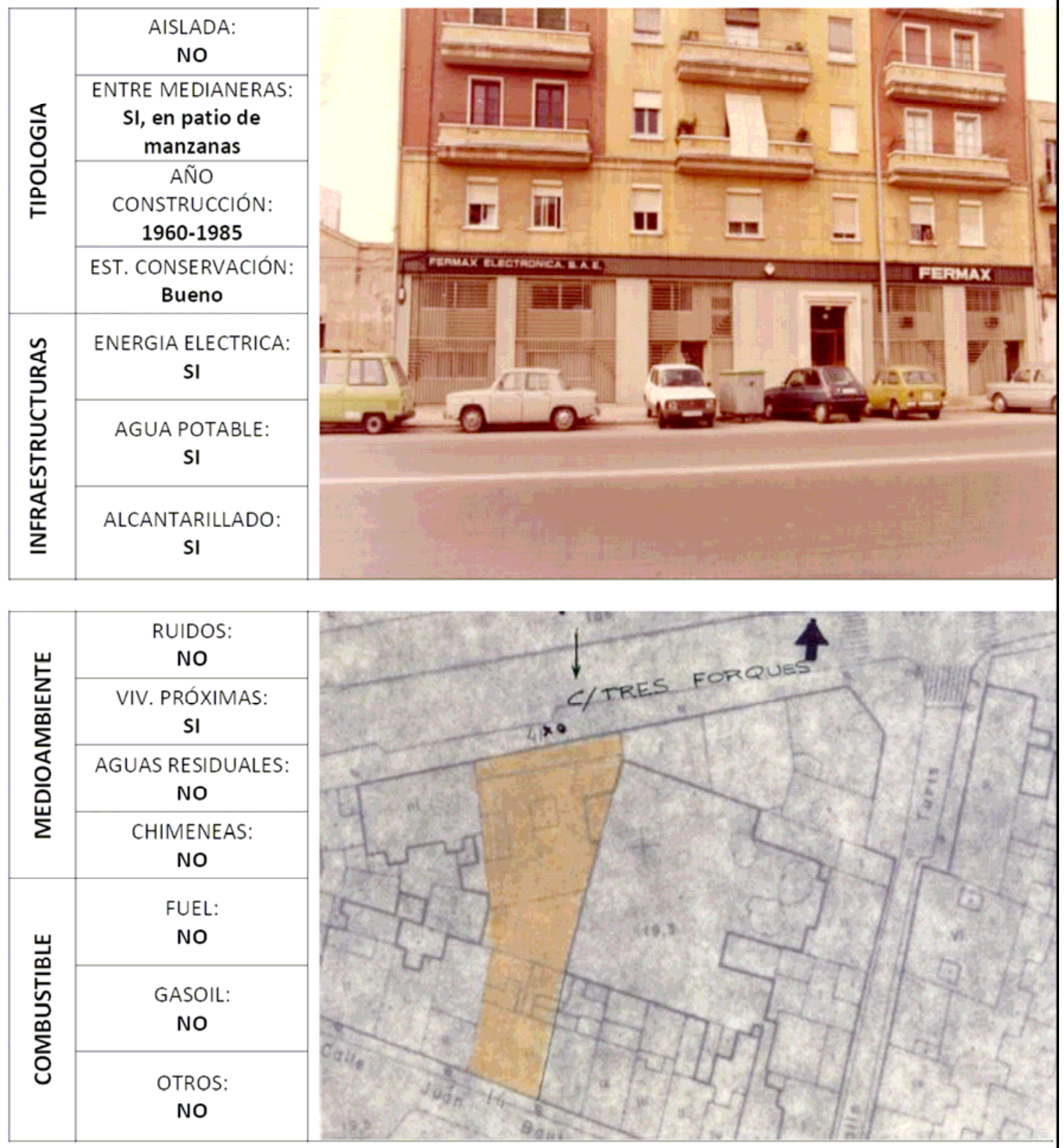


\section{EVOLUCIÓN}

\section{PLANO UBICACIÓN INDUSTRIAS}

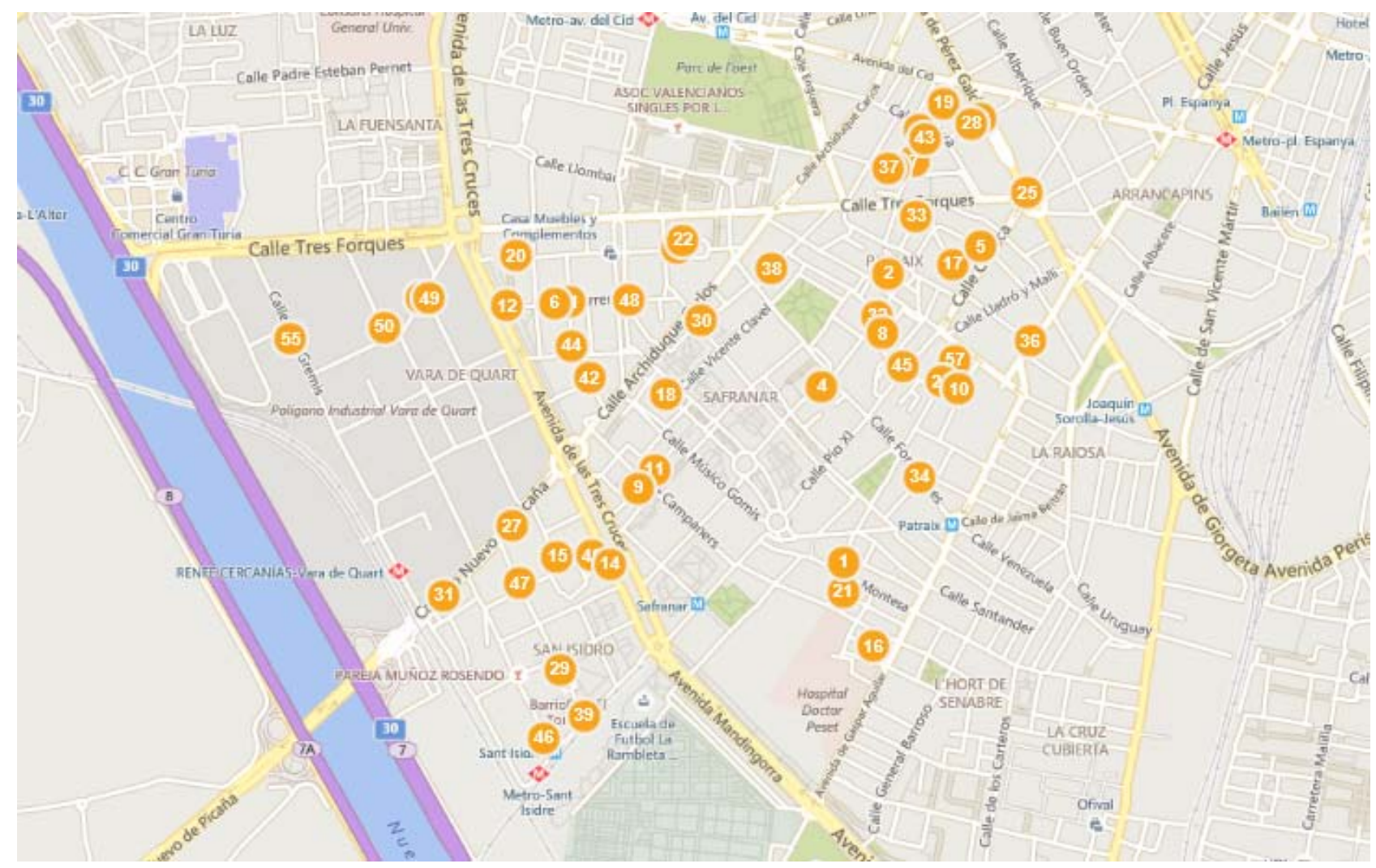

\section{LISTADO DE INDUSTRIAS Y ACTIVIDAD.-}

\section{Manuel Martínez Martinez}

Fabricación de otros muebles

\section{HEREDERAS PEPE MARTINEZ}

Fabricación de otros muebles

3. $M^{a}$ Carmen Martínez Blasco

Fabricación de artículos de joyería y artículos similares

\section{José Valenciano Silvestre}

Fabricación de artículos de joyería y artículos similares

\section{5. $\mathbf{M}^{\mathrm{a}}$ Carmen Pérez Gutiérrez}

Acabado textiles

6. GUDAR ORTODONCIA S.L.

Fabricación instrumentos y suministros médicos y odontológicos 
7. PRÓTESIS DENTAL CARRASQUER S.C.P.

Fabricación instrumentos y suministros médicos y odontológicos

8. Pedro Porras Encinar

Fabricación instrumentos y suministros médicos y odontológicos

9. ARTDENTAL C.B.

Fabricación instrumentos y suministros médicos y odontológicos

10. José Diestro Contreras

Fabricación instrumentos y suministros médicos y odontológicos

11. ART 4 YOU LAB, S.L.

Fabricación instrumentos y suministros médicos y odontológicos

12. MINIBIKE MOTOS S.L.

Mantenimiento y reparación de vehículos a motor

13. Vicente Bruno Lloret Borrás

Mantenimiento y reparación de vehículos a motor

14. Julio Alarcón Gascón

Mantenimiento y reparación de vehículos a motor

15. TALLERES PLANELLS C.B.

Mantenimiento y reparación de vehículos a motor

16. MIGUEL BONET C.B.

Mantenimiento y reparación de vehículos a motor

17. MONFERAUTO S.L.

Mantenimiento y reparación de vehículos a motor

18. ANTÓN AUTOCENTER S.L.

Mantenimiento y reparación de vehículos a motor

19. Pedro Montoro Rus

Mantenimiento y reparación de vehículos a motor

20. Abbas Ghulam

Mantenimiento y reparación de vehículos a motor

21. TALLERES AUTO RAFER C.B.

Mantenimiento y reparación de vehículos a motor

22. RUEDAS RÁPIDAS C.B.

Mantenimiento y reparación de vehículos a motor

23. GASODIEL ABBAS S.L.

Mantenimiento y reparación de vehículos a motor

24. José Miguel Navarro Soriano

Mantenimiento y reparación de vehículos a motor

25. Francisco Silvestre Molina

Mantenimiento y reparación de vehículos a motor 
26. José Francisco Trujillo Giménez

Mantenimiento y reparación de vehículos a motor

27. Ricardo Guijarro Conejo

Mantenimiento y reparación de vehículos a motor

28. BARBER Y BARBER S.L.

Mantenimiento y reparación de vehículos a motor

29. Francisco José González Argente

Mantenimiento y reparación de vehículos a motor

30. Pedro Vicente Marco Carrascosa

Mantenimiento y reparación de vehículos a motor

31. TALLER DE COCHES RÁPIDO S.L.

Mantenimiento y reparación de vehículos a motor

32. Francisco Javier Villalba Aguilar

Fabricación de otras estructuras madera y piezas de carpintería y ebanistería para la construcción

33. Luis Mateo Monterde Viñas

Fabricación de otros productos de madera; artículos de corcho, cestería y espartería.

34. Ana Isabel Navalón Escamilla

Confección de otras prendas de vestir exteriores

35. RIGANS INFANTIL S.L.

Confección de otras prendas de vestir y accesorios

36. $M^{\mathrm{a}}$ Carmen Jiménez Felguera

Confección de otras prendas de vestir exteriores

37. José Eleuterio Llorens Monteagudo

Confección de otras prendas de vestir y accesorios

38. $M^{a}$ José Cañada Sáez

Confección de otras prendas de vestir exteriores

39. David Manzanera Izquierdo

Mantenimiento y reparación de vehículos a motor

40. Salvador Leonardo García Romero

Fabricación de pan y productos frescos de panadería y pastelería

41. José Manuel Rodríguez Rabanete

Fabricación de pan y productos frescos de panadería y pastelería

42. SEBASTIÁN TATAY Y CIA C.B.

Fabricación de pan y productos frescos de panadería y pastelería

43. Armando Vicente Ribes Andrés

Fabricación de pan y productos frescos de panadería y pastelería

44. Jorge Plume Padrón

Fabricación de galletas y productos de panadería y pastelería de larga duración

45. Corredor Boix, Enrique

Otras actividades de impresión y artes gráficas 
46. Rodríguez García, Juan Antonio

Otras actividades de impresión y artes gráficas

47. González Gómez, Francisco

Otras actividades de impresión y artes gráficas

48. Palma Tomás, Luis

Otras actividades de impresión y artes gráficas

49. Rafael Almenar Valls (Existente 20)

CNAE año 1985 (363)

50. Juan Alfonso Puchades (Existente 23)

CNAE año 1985 (411)

51. CEYLAN (Existente 26)

CNAE año 1985 (423)

52. LAS PROVINCIAS (Existente 36)

CNAE año 1985 (475)

53. Granell Bellver, V. (Existente 94)

CNAE año 1985 (244)

ESTADO ACTUAL DE LOS ANTIGUOS EDIFICIOS INDUSTRIALES DE INTERES.-

- Travenol, S.A.

C/ Dels Gremis no 7 6E/5000-6

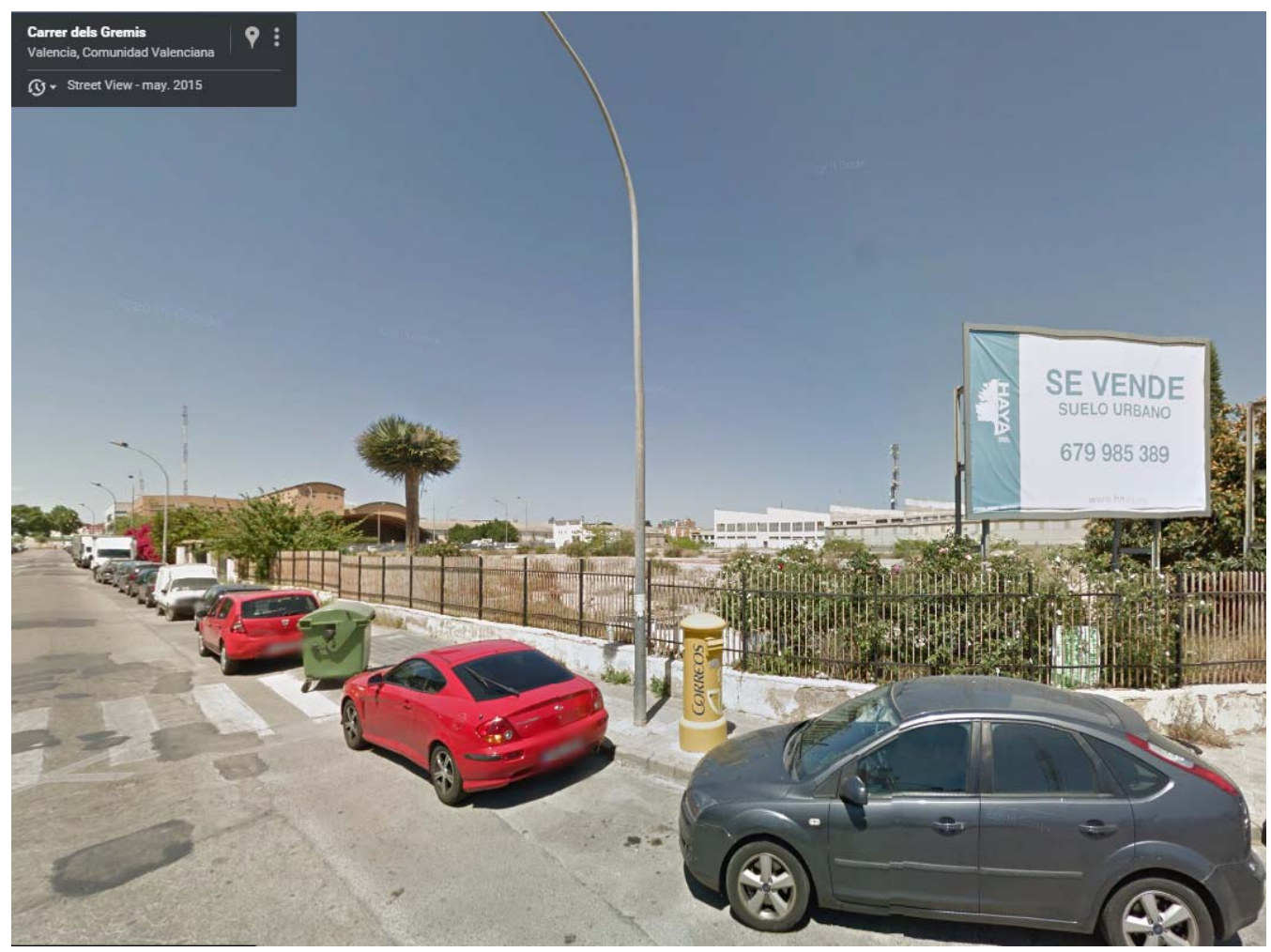

Foto 39: Solar. C/ dels Gremis, 7. Polígono industrial Vara de Quart Valencia.2015.

Fuente: WEB. http://www.google.es/maps (Street View). 
- Vda. de Hurtado C/ Dels Fusters no 1 6B/S00J-32

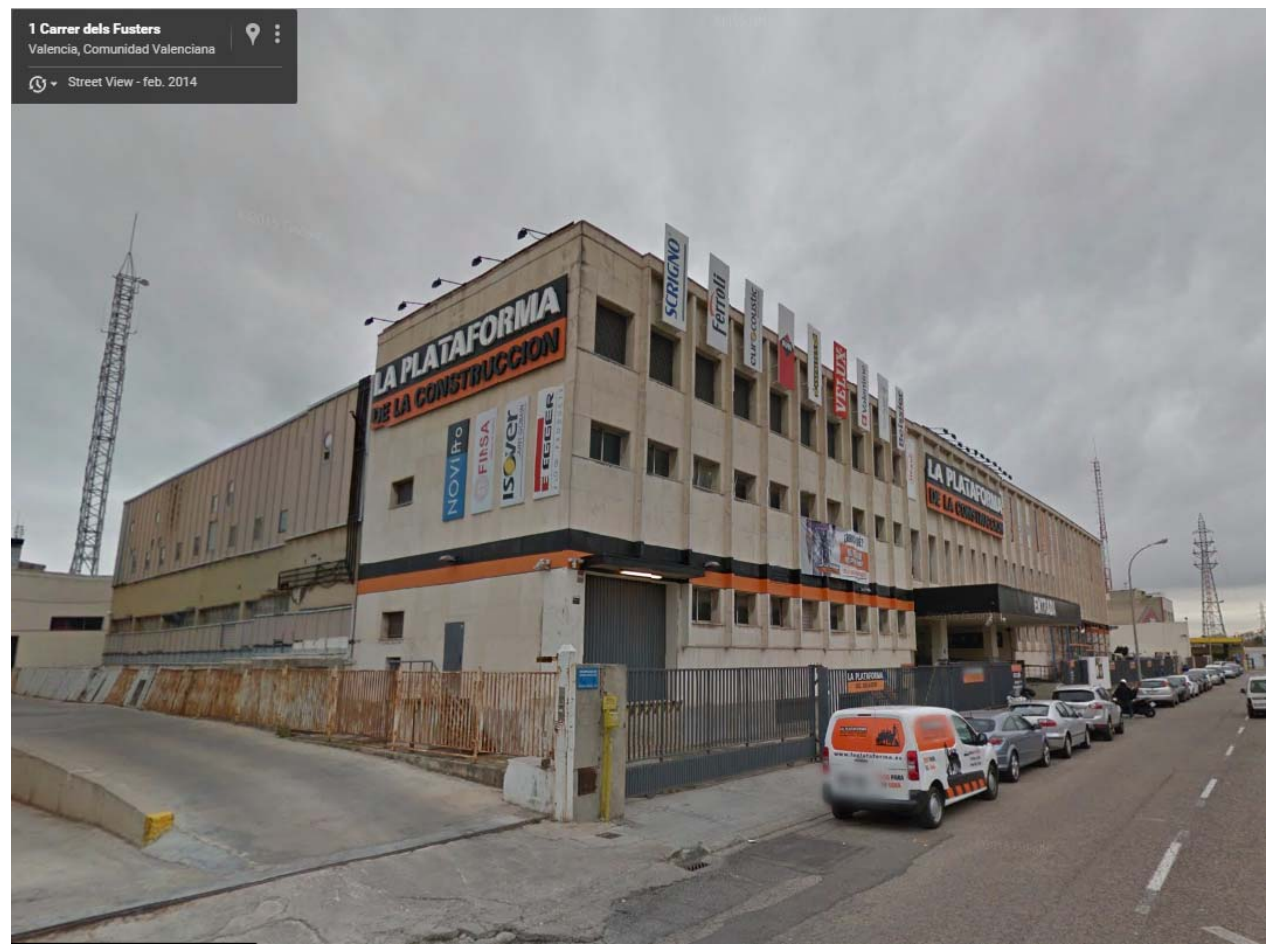

Foto 40: Edificio industrial. C/ dels Gremis, 7. Polígono industrial Vara de Quart Valencia.2014. Fuente: WEB. http://www.google.es/maps (Street View).

- Las Provincias C/ Dels Gremis no 4 6E/5000-36

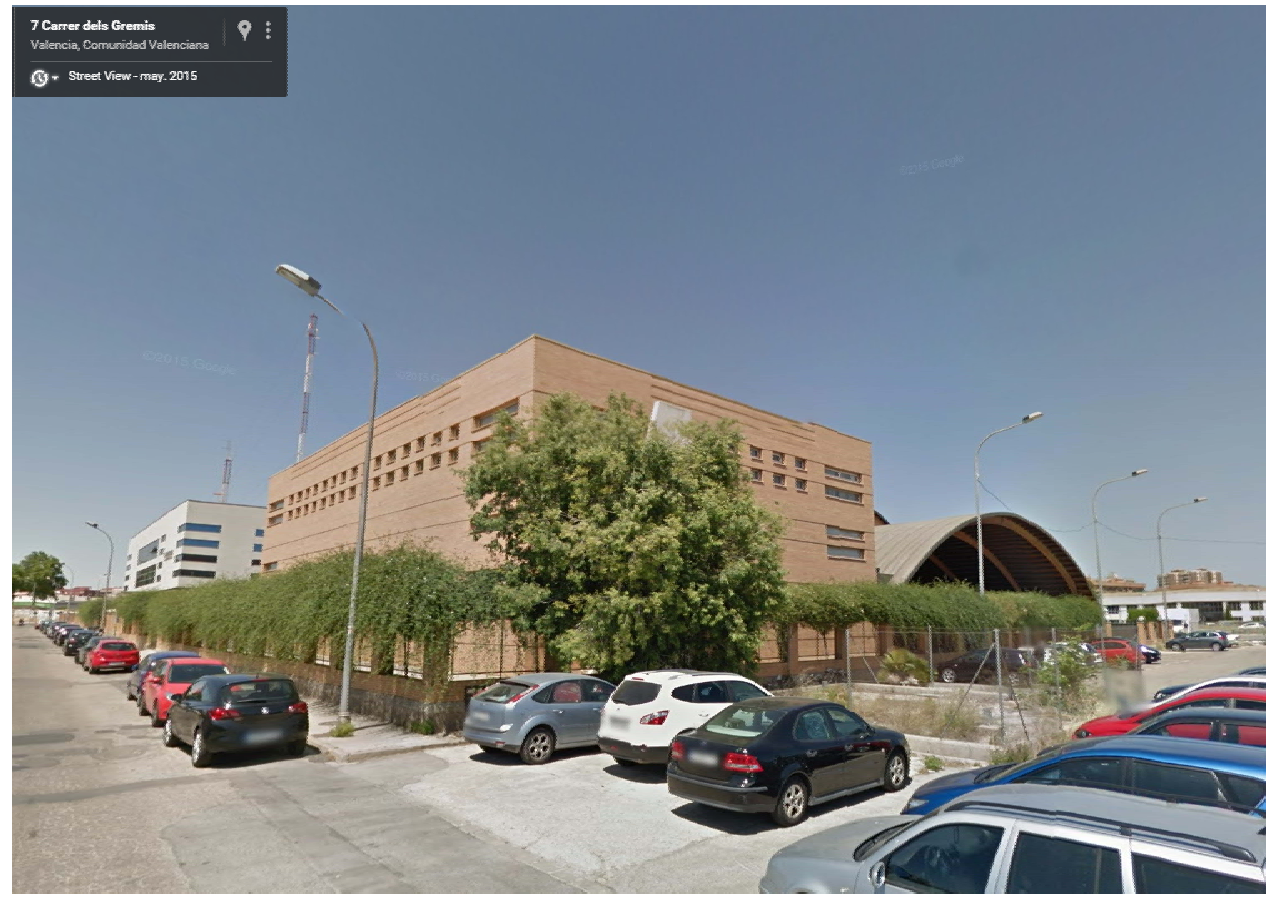

Foto 41: Periódico "Las Provincias". C/ dels Gremis, 4. Polígono industrial Vara de Quart Valencia.2015. Fuente: WEB. http://www.google.es/maps (Street View). 
- Varios edificios

$\mathrm{C} /$ Veluters del $\mathrm{n} \cong 2$ al $14 \quad 6 \mathrm{E} / 5000$

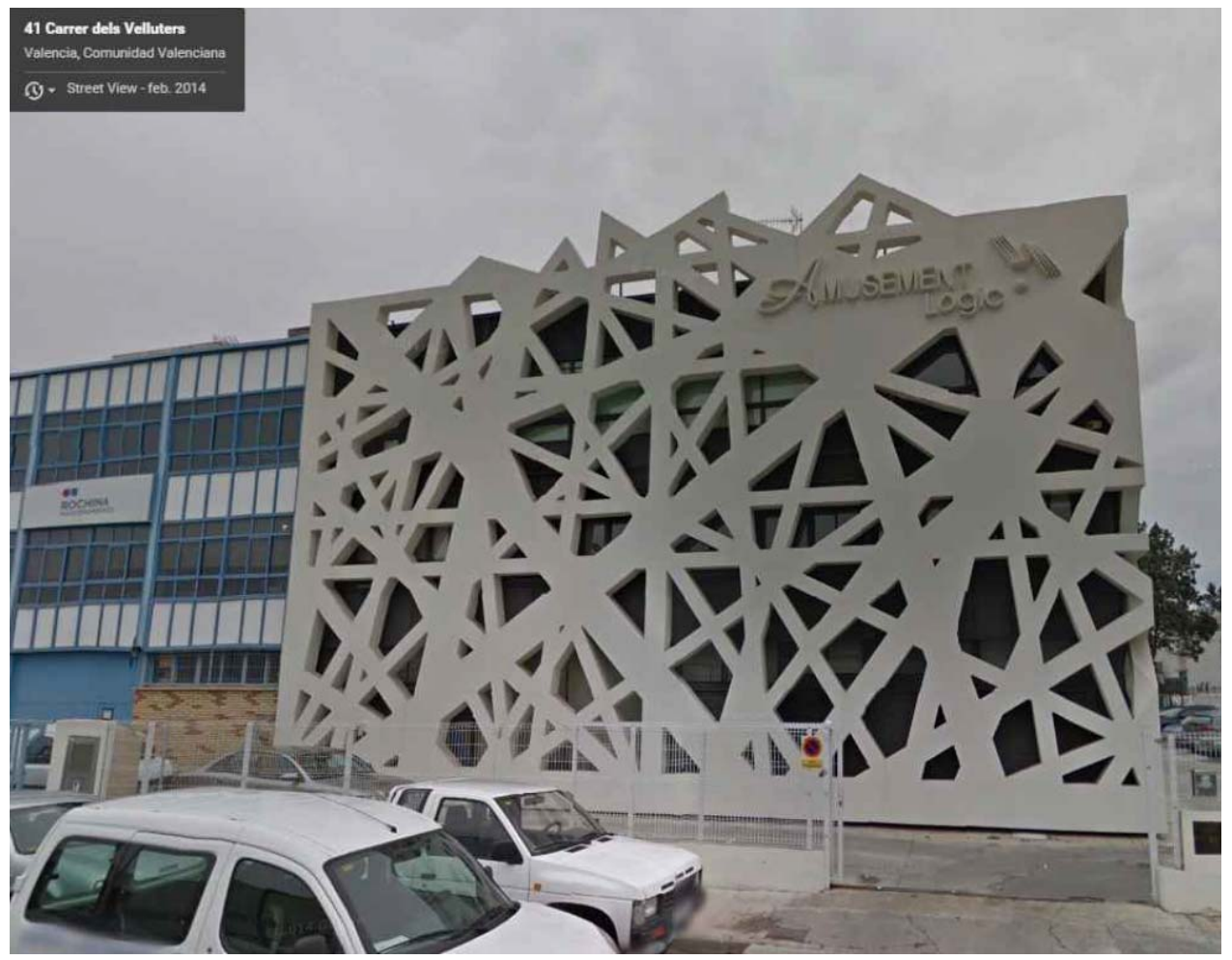

Foto 42: Edificio industrial. C/ Velluters, 2. Polígono industrial Vara de Quart Valencia.2014. Fuente: WEB. http://www.google.es/maps (Street View).

- Fomento Agrícola, S.A.

$\mathrm{C} /$ Marques de Elche $\mathrm{n}^{0} 22$ 61-3

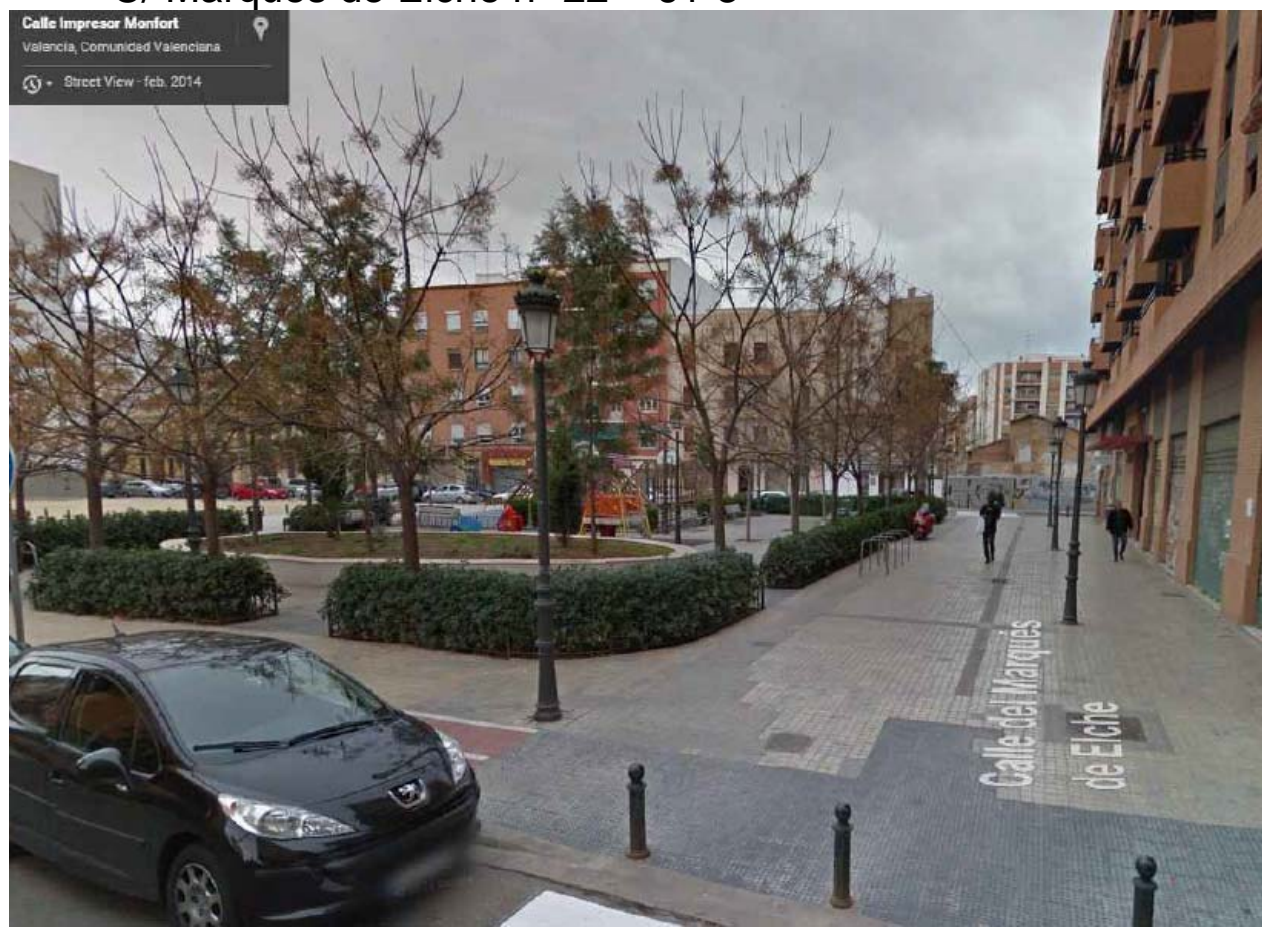

Foto 43: Zona peatonal entre edificios residenciales. C/ Marqués de Elche. Valencia. 2014 Fuente: WEB. http://www.google.es/maps (Street View). 
- Martínez Martínez, J. C/ Alcudia de Carlet nํ $3 \quad 61-4$

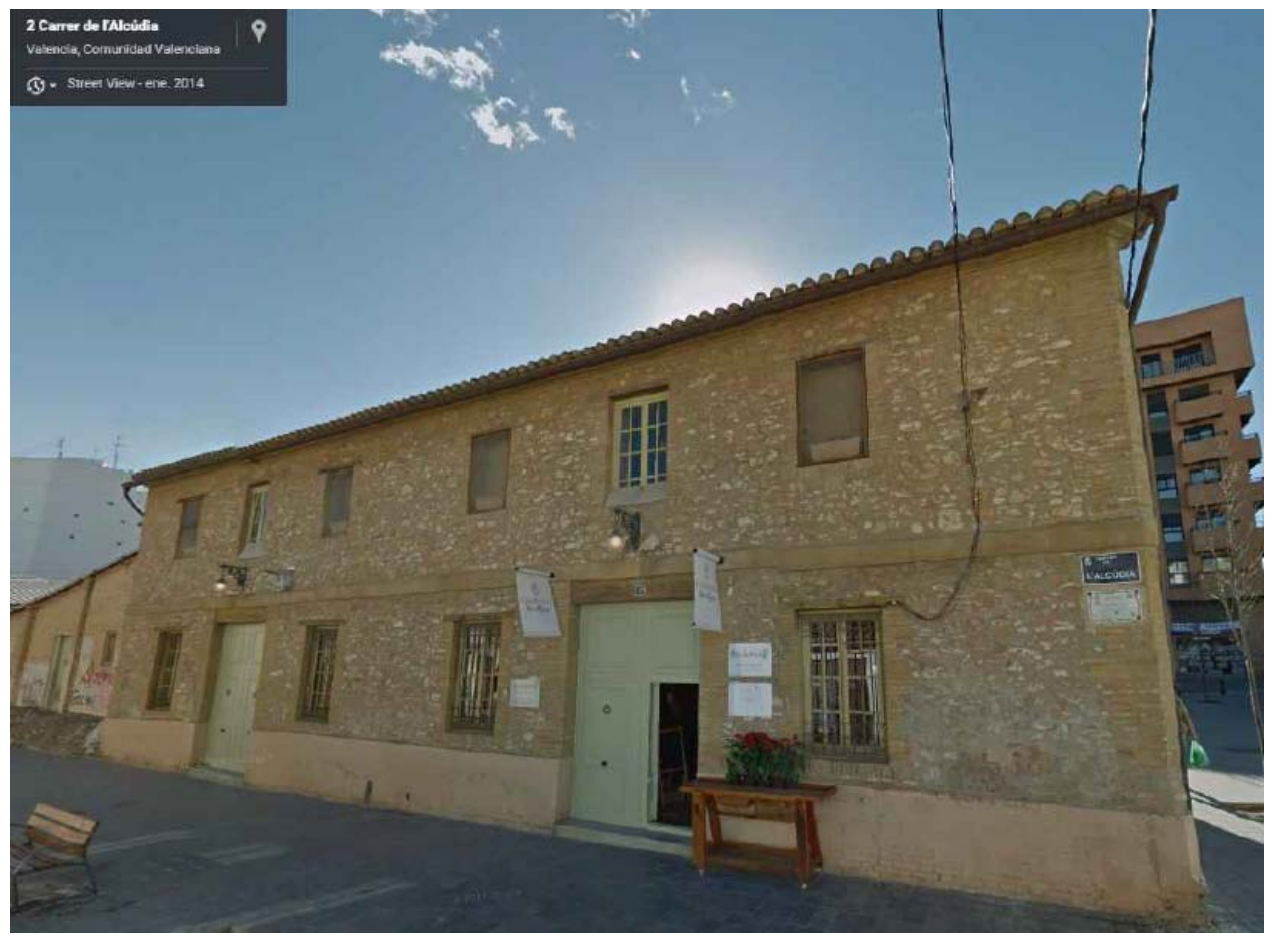

Foto 44: Edificio industrial. C/ Alcudia de Carlet, 3. Valencia. 2014 Fuente: WEB. http://Www.google.es/maps (Street View).

- Verdu y Cia. S.A. C/ Azagador de las Monjas $n \cong 2$ 71-10

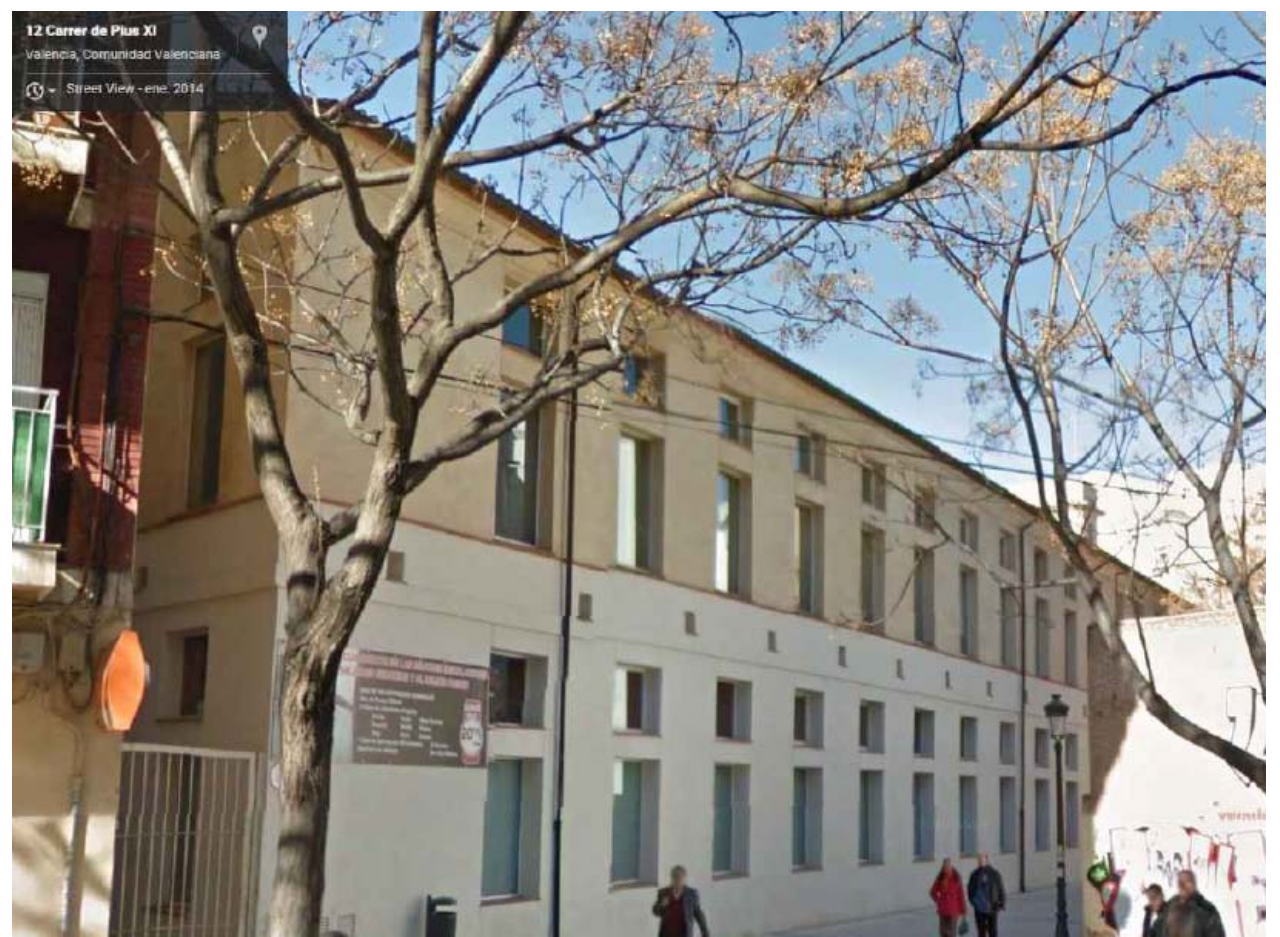

Foto 45: Complejo deportivo-cultural Patraix. C/ Pio XI. Valencia. 2014 Fuente: WEB. http://Www.google.es/maps (Street View). 
- Mico Estelles, S.A.

C/ Deis Traglners no 7 6G-5000

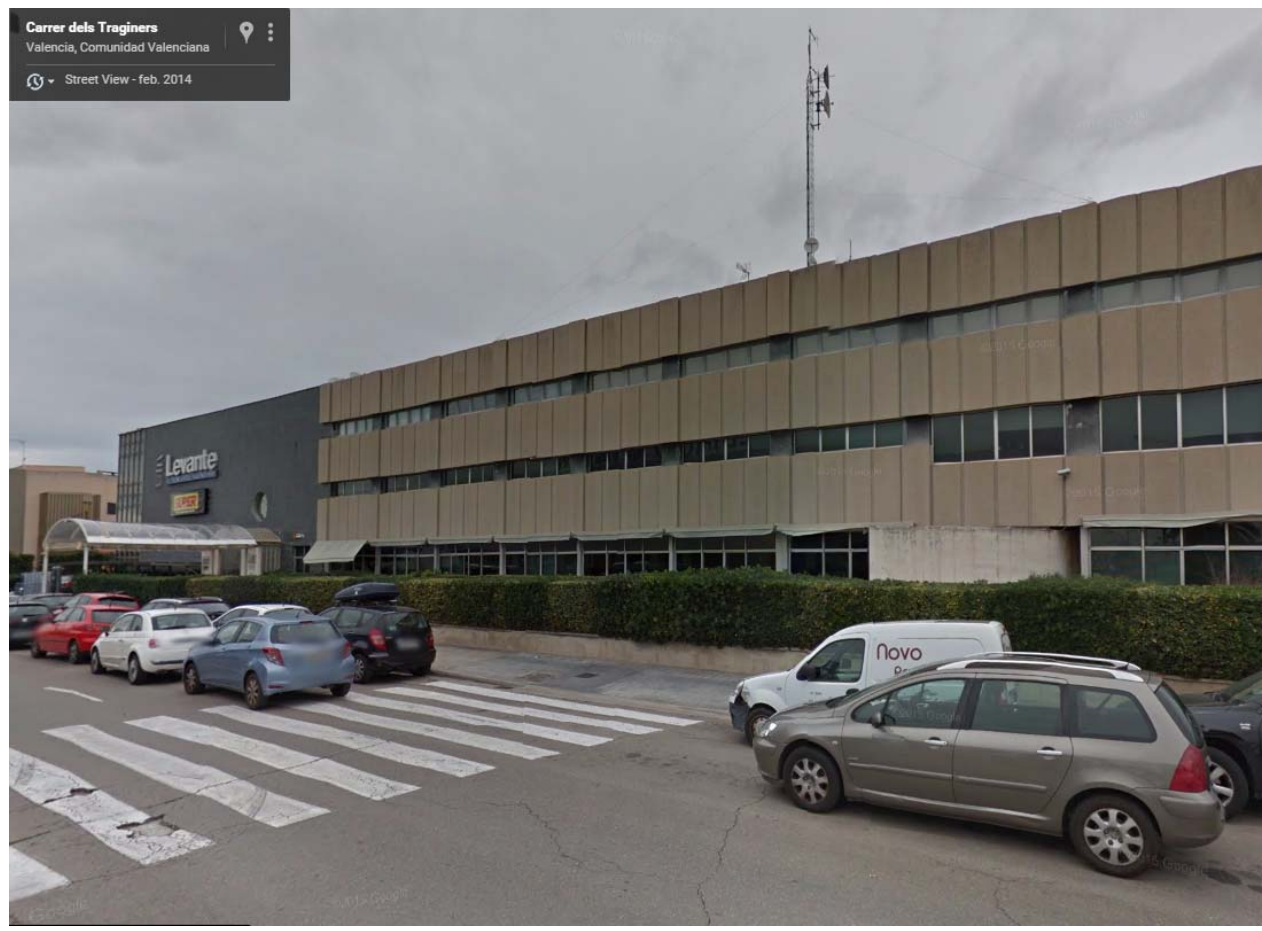

Foto 46: Editorial Periódico Levante. C/ dels Traginers, 7. Valencia. 2014

Fuente: WEB. http://www.google.es/maps (Street View).

- Guzman

C/ Dels Traginers n 9 6G-S000

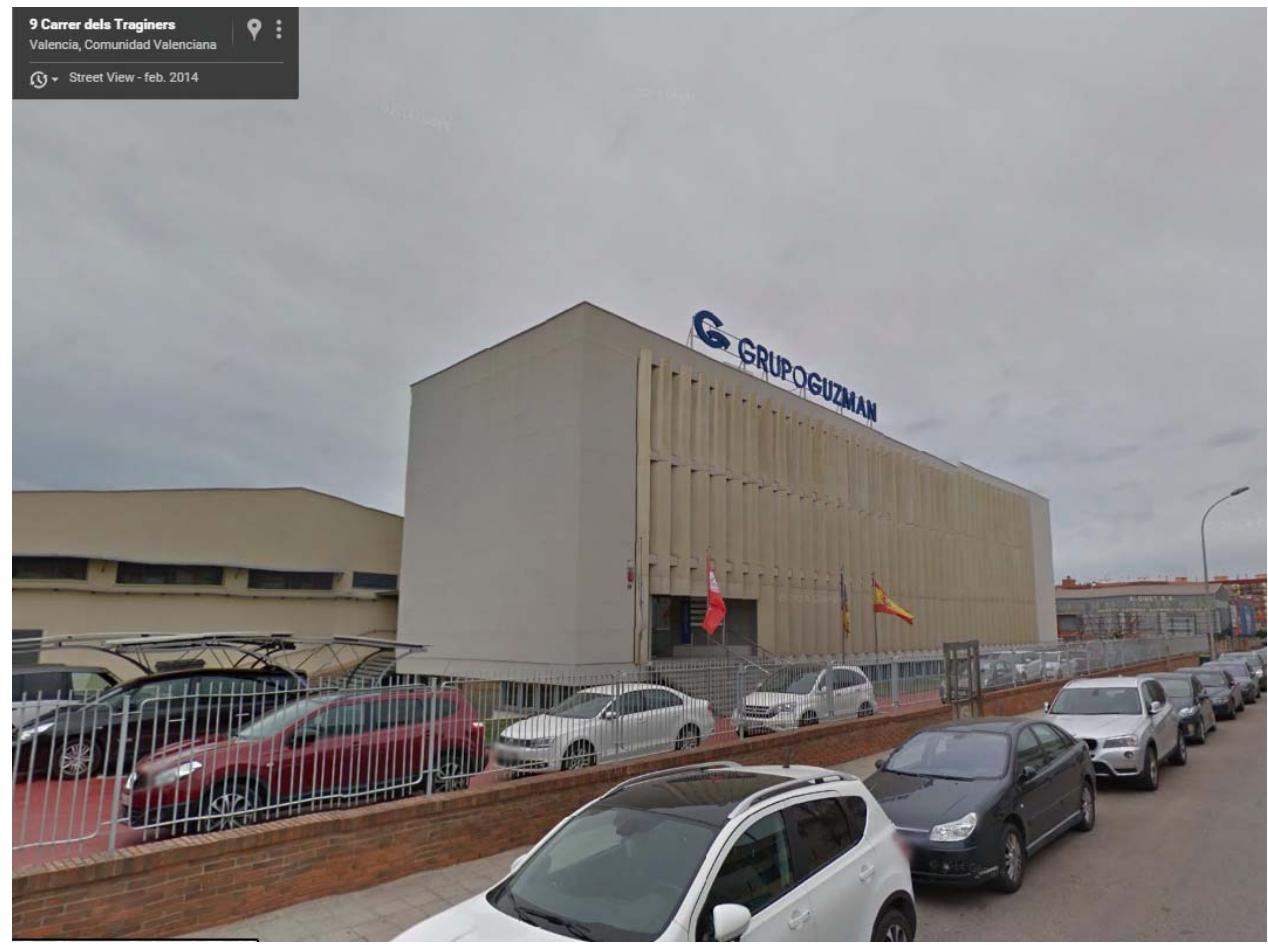

Foto 47: Edificio industrial. Grupo Guzman. Cl dels Traginers, 9. Valencia. 2014 Fuente: WEB. http://Www.google.es/maps (Street View). 
- Mecano Textil

Avd. Gaspar Aguilar oㅡ 2091

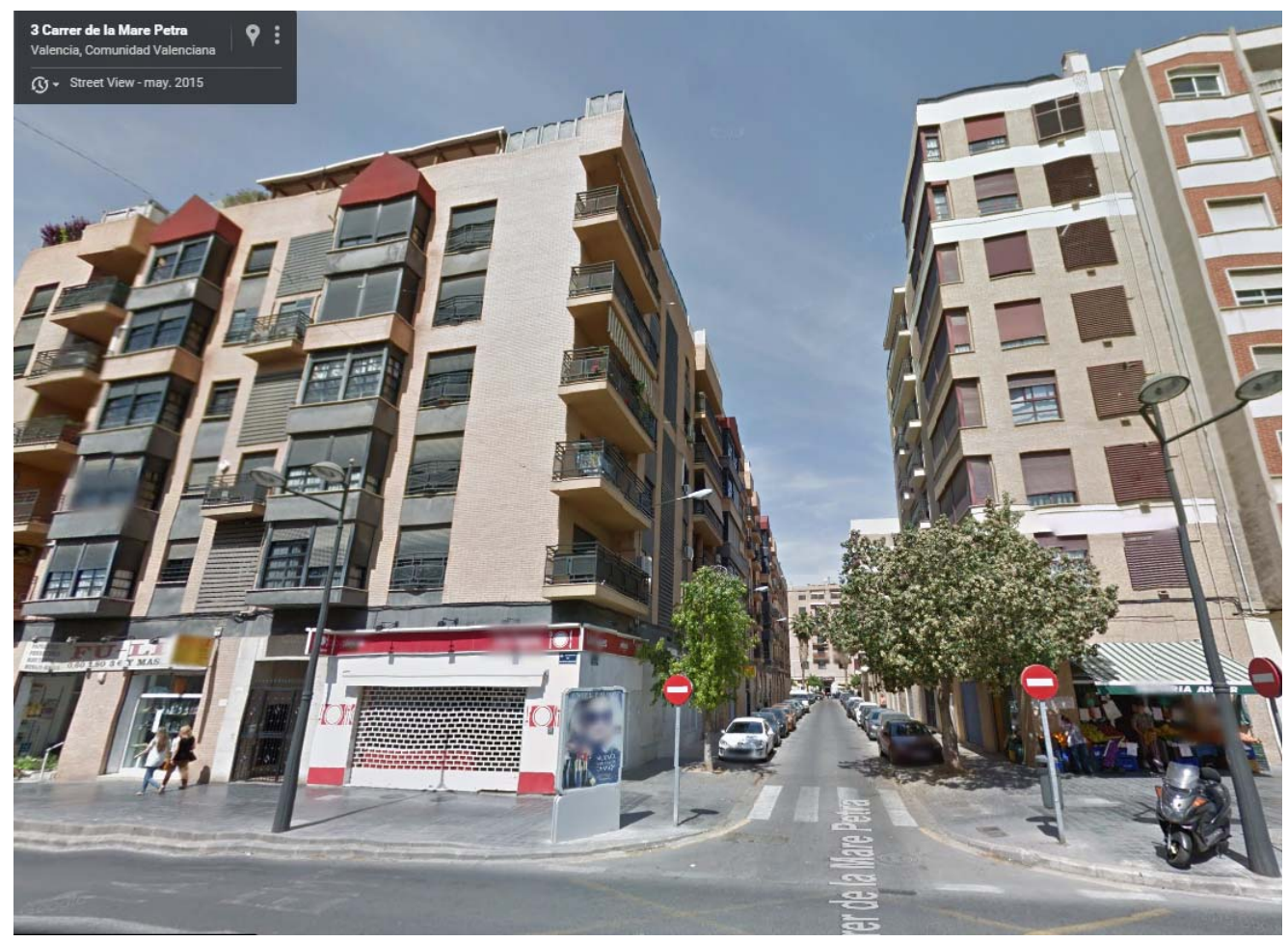

Foto 48: Edificio residencial. Avda. Gaspar Aguilar, 20.. Valencia. 2015

Fuente: WEB. http://www.google.es/maps (Street View). 


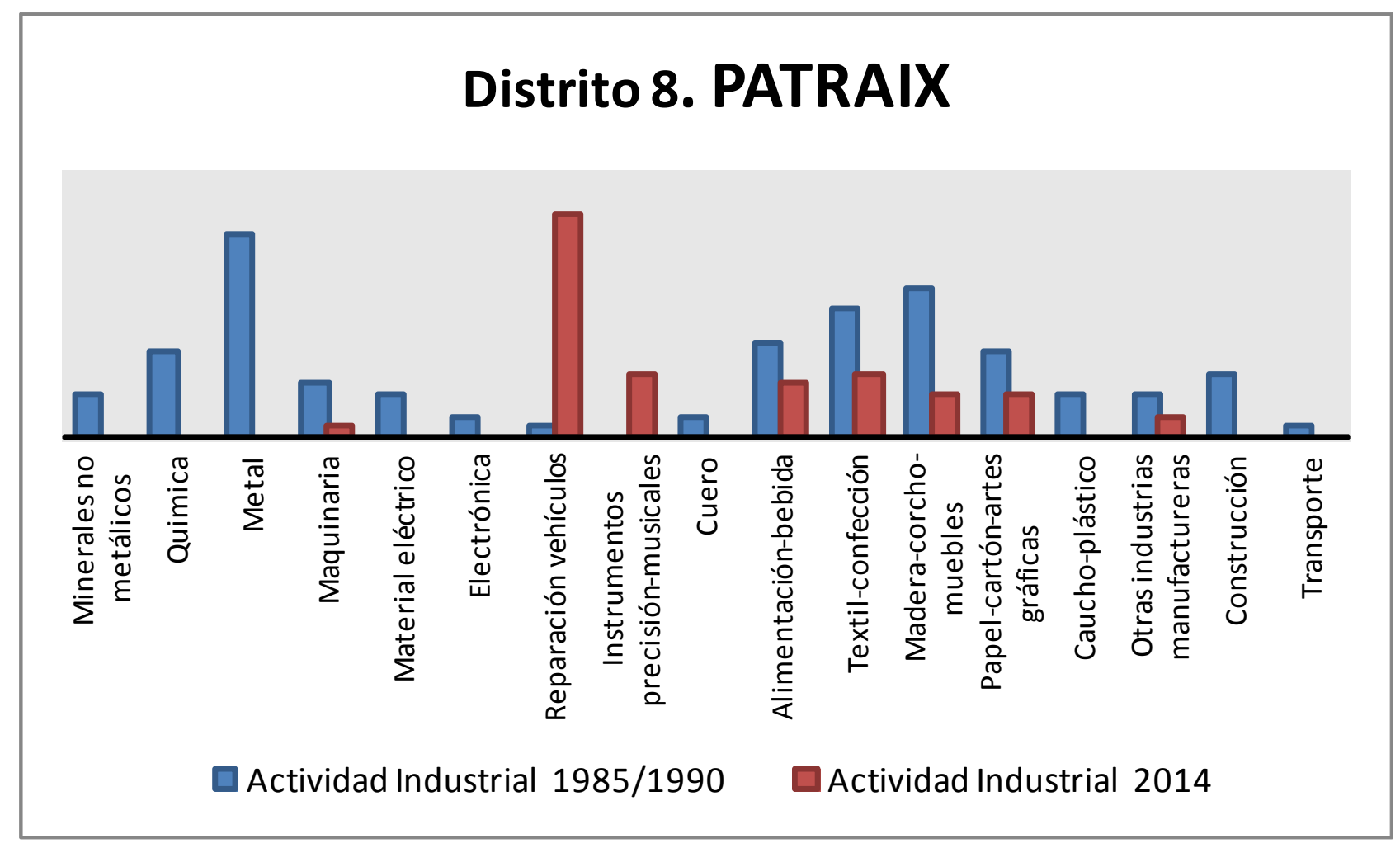

EVOLUCION DEL IMPACTO AMBIENTAL

\section{IMPACTO EN EL MEDIO URBANO Distrito 8. PATRAIX}

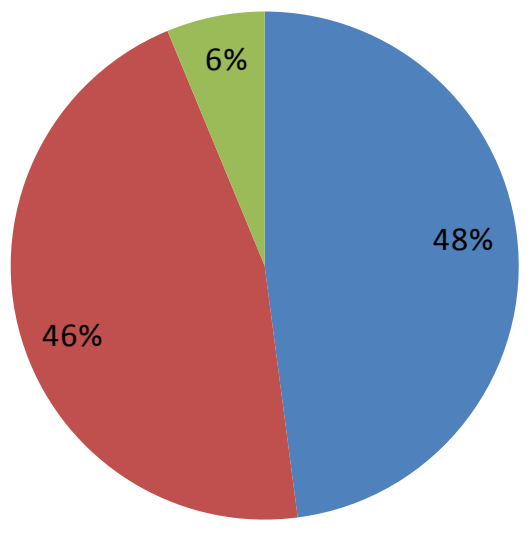

Empresas inocuas

Empresas ruidosas

Empresas ruidosas con chimenea 


\section{FICHAS TIPO \\ FICHA DATOS DE LA INDUSTRIA}

LOCALIZACION ACTUALIZADA DE ACTIVIDADES INDUSTRIALES EN EL MEDIO URBANO DE VALENCIA

\begin{tabular}{|c|c|c|c|c|c|c|c|}
\hline \multirow{5}{*}{ 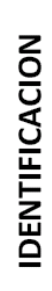 } & \multirow{2}{*}{\multicolumn{2}{|c|}{$\begin{array}{c}\text { NOMBRE } \\
\text { EMPLAZAMIENTO }\end{array}$}} & \multicolumn{5}{|c|}{ Ma CARMEN PÉREZ GUTIÉRREZ } \\
\hline & & & \multicolumn{3}{|c|}{ C/ CALAMOCHA, 19} & C.P. & 46018 \\
\hline & \multirow[b]{2}{*}{ CNAE } & \multirow[b]{2}{*}{1330} & \multirow[b]{2}{*}{ DESCRIPCION } & \multicolumn{4}{|c|}{ TEXTIL-CALZADO-CONFECCIÓN } \\
\hline & & & & \multicolumn{4}{|c|}{ Acabado de textiles } \\
\hline & DISTRITO & 8 & \multicolumn{5}{|c|}{ PATRAIX } \\
\hline \multicolumn{3}{|c|}{ MEDIOAMBIENTE } & RUIDOSAS & NO & CHIMENEAS & & NO \\
\hline
\end{tabular}
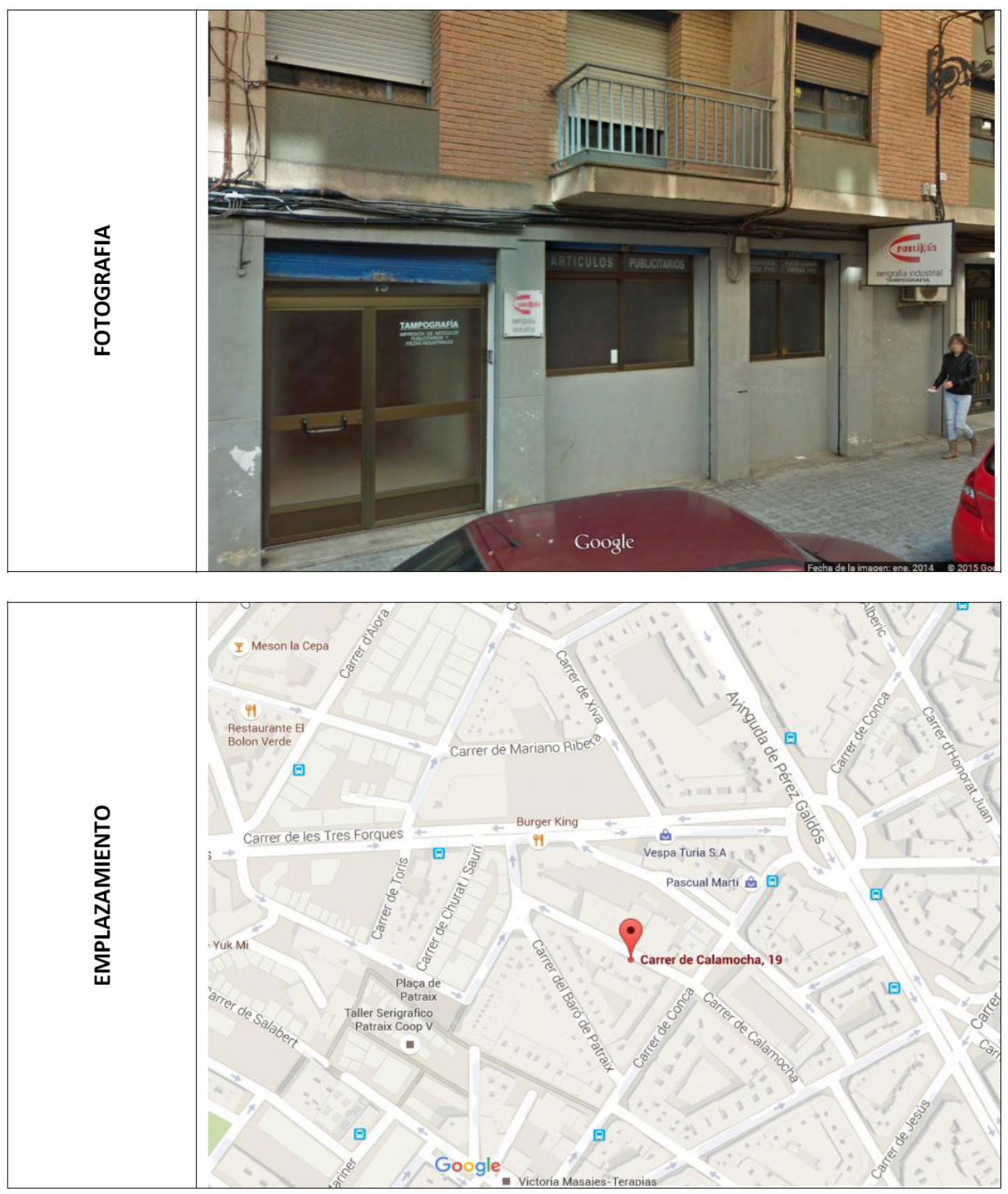


\section{FICHA DATOS DE LA INDUSTRIA}

LOCALIZACION ACTUALIZADA DE ACTIVIDADES INDUSTRIALES EN EL MEDIO URBANO DE VALENCIA

\begin{tabular}{|c|c|c|c|c|c|c|c|}
\hline \multirow{5}{*}{ 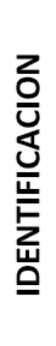 } & \multirow{2}{*}{\multicolumn{2}{|c|}{$\begin{array}{c}\text { NOMBRE } \\
\text { EMPLAZAMIENTO }\end{array}$}} & \multicolumn{5}{|c|}{ ARTDENTAL, CB } \\
\hline & & & \multicolumn{3}{|c|}{ C/ PROFESOR BLANCO, 17} & C.P. & 46014 \\
\hline & \multirow[b]{2}{*}{ CNAE } & \multirow[b]{2}{*}{3250} & \multirow[b]{2}{*}{ DESCRIPCION } & \multicolumn{4}{|c|}{ INSTRUMENTOS PRECISIÓN-MUSICALES } \\
\hline & & & & \multicolumn{4}{|c|}{$\begin{array}{c}\text { Fabricación instrumentos y suministros médicos y } \\
\text { odontológicos }\end{array}$} \\
\hline & DISTRITO & 8 & \multicolumn{5}{|c|}{ PATRAIX } \\
\hline \multicolumn{3}{|c|}{ MEDIOAMBIENTE } & RUIDOSAS & NO & CHIMENEAS & & 0 \\
\hline
\end{tabular}
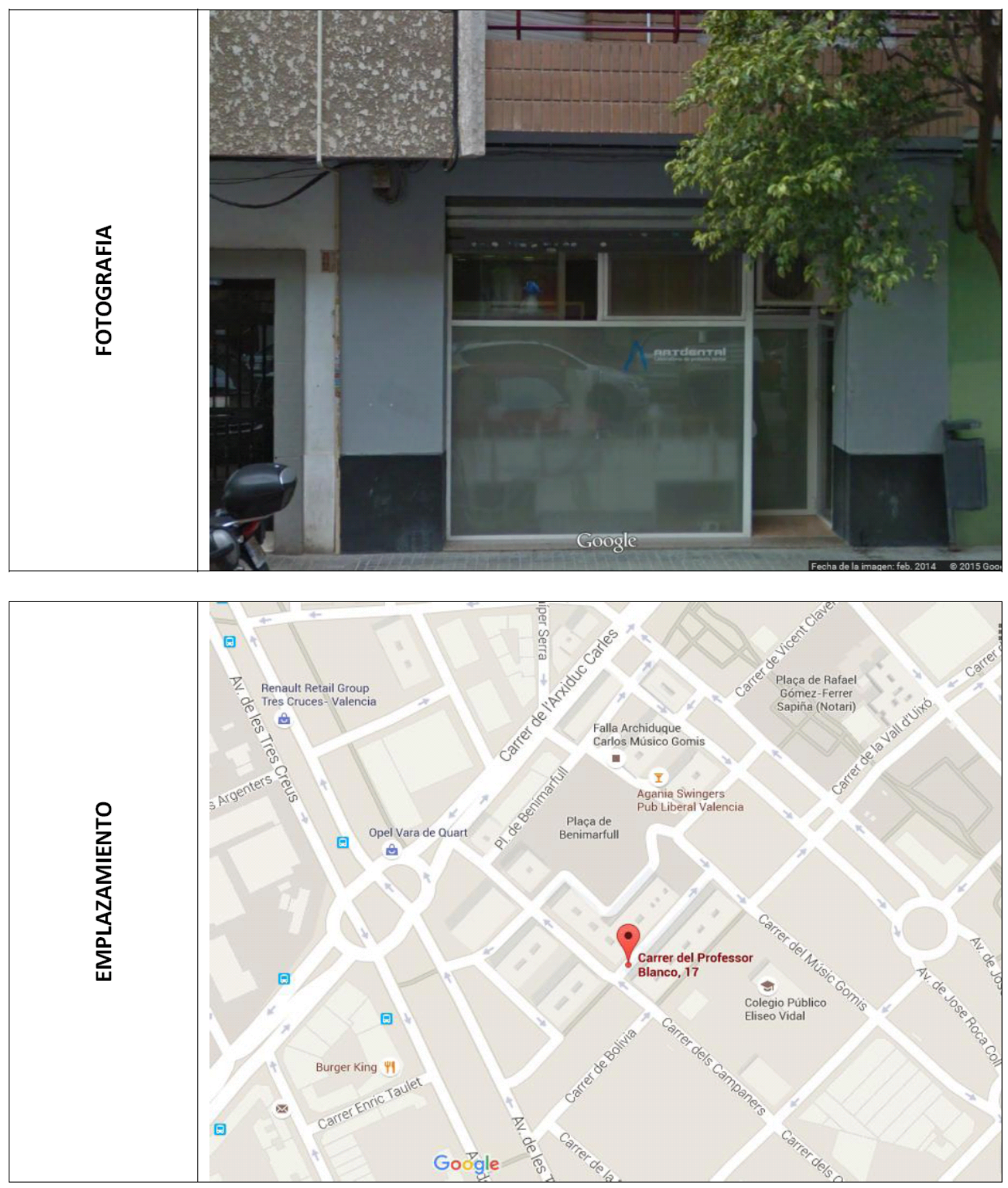


\section{FICHA DATOS DE LA INDUSTRIA}

LOCALIZACION ACTUALIZADA DE ACTIVIDADES INDUSTRIALES EN EL MEDIO URBANO DE VALENCIA
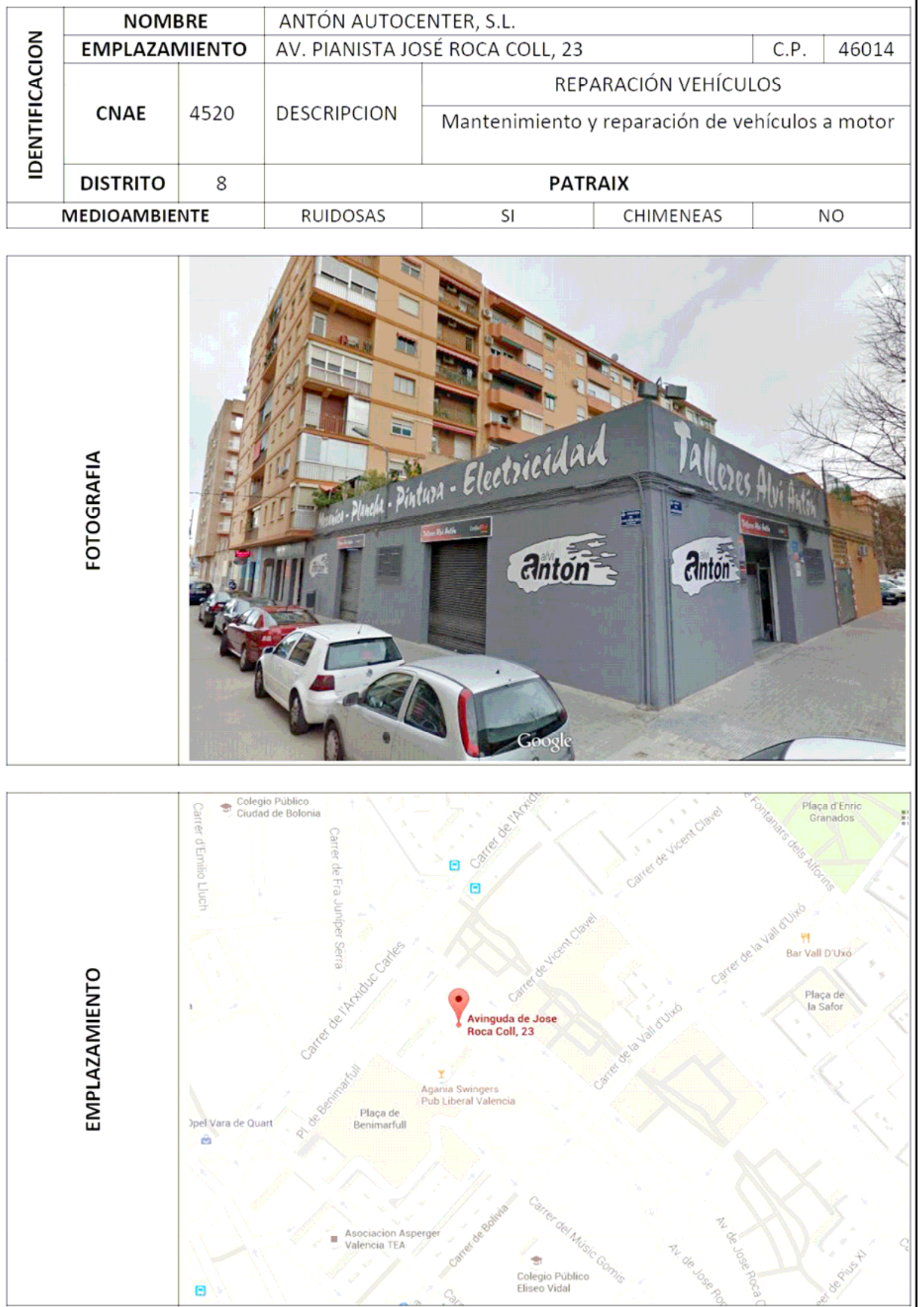


\section{FICHA DATOS DE LA INDUSTRIA}

LOCALIZACION ACTUALIZADA DE ACTIVIDADES INDUSTRIALES EN EL MEDIO URBANO DE VALENCIA

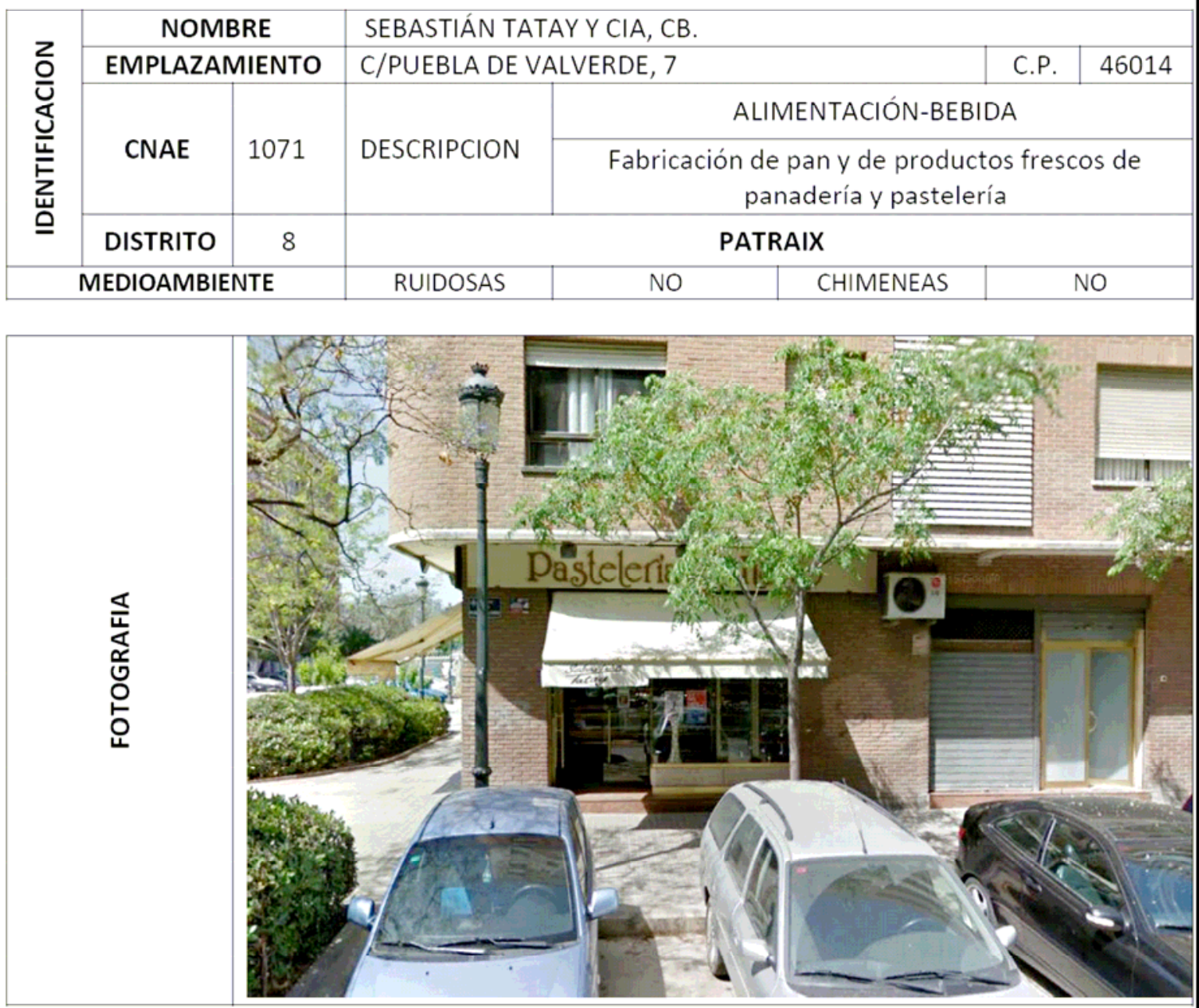

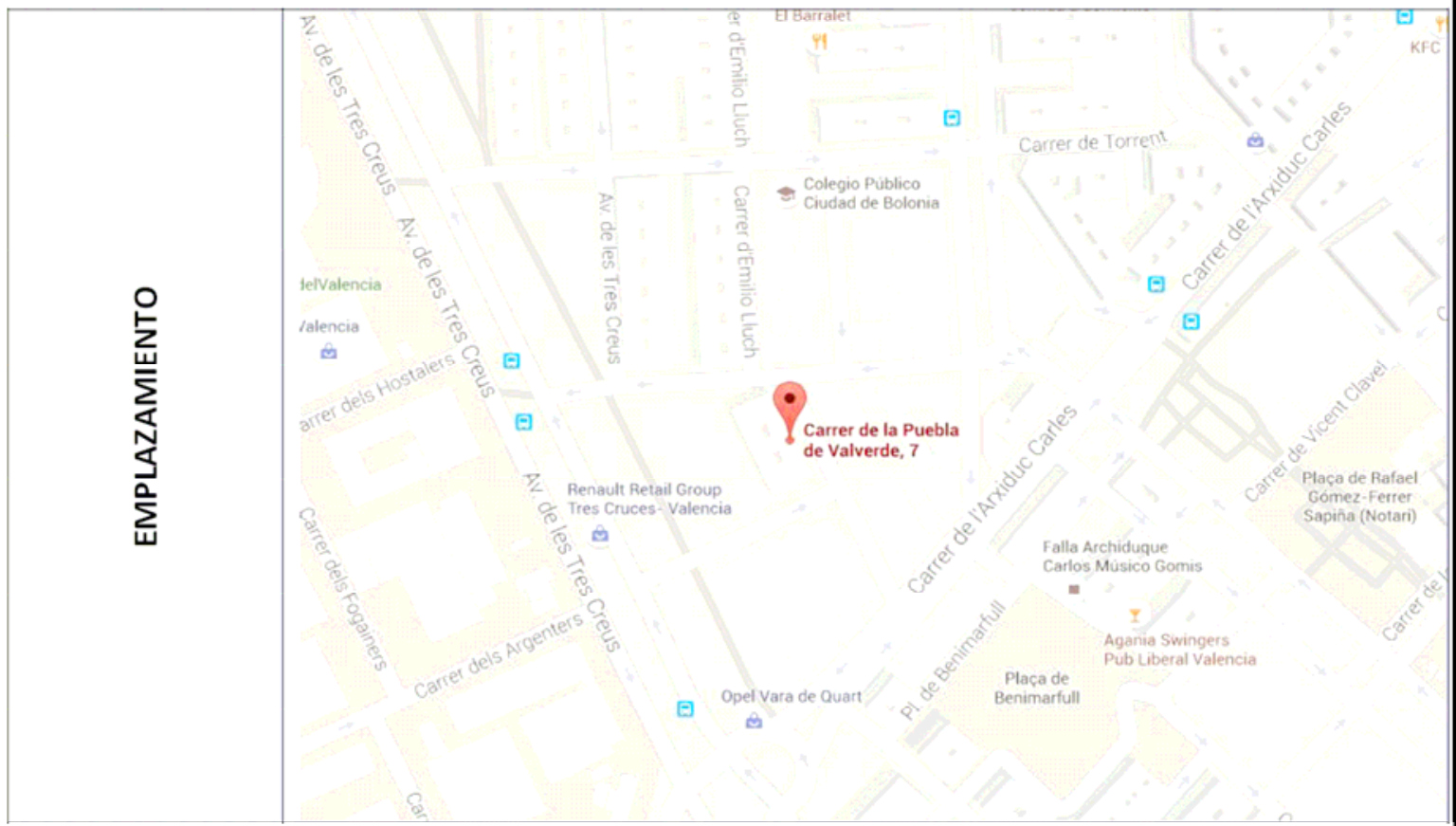




\section{FICHA DATOS DE LA INDUSTRIA}

LOCALIZACION ACTUALIZADA DE ACTIVIDADES INDUSTRIALES EN EL MEDIO URBANO DE VALENCIA

\begin{tabular}{|c|c|c|c|c|c|c|c|}
\hline \multirow{5}{*}{ 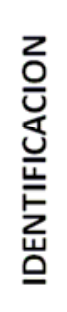 } & \multirow{2}{*}{\multicolumn{2}{|c|}{$\begin{array}{c}\text { NOMBRE } \\
\text { EMPLAZAMIENTO }\end{array}$}} & \multicolumn{5}{|c|}{ ANA ISABEL NAVALÓN ESCAMILLA } \\
\hline & & & \multicolumn{3}{|c|}{ C/FONTANARES, 16} & C.P. & 46007 \\
\hline & \multirow{2}{*}{ CNAE } & \multirow{2}{*}{1413} & \multirow{2}{*}{ DESCRIPCION } & \multicolumn{4}{|c|}{ TEXTIL-CALZADO-CONFECCIÓN } \\
\hline & & & & \multicolumn{4}{|c|}{ Confección de otras prendas de vestir exteriores } \\
\hline & DISTRITO & 8 & \multicolumn{5}{|c|}{ PATRAIX } \\
\hline \multicolumn{3}{|c|}{ MEDIOAMBIENTE } & RUIDOSAS & NO & CHIMENEAS & & 0 \\
\hline
\end{tabular}
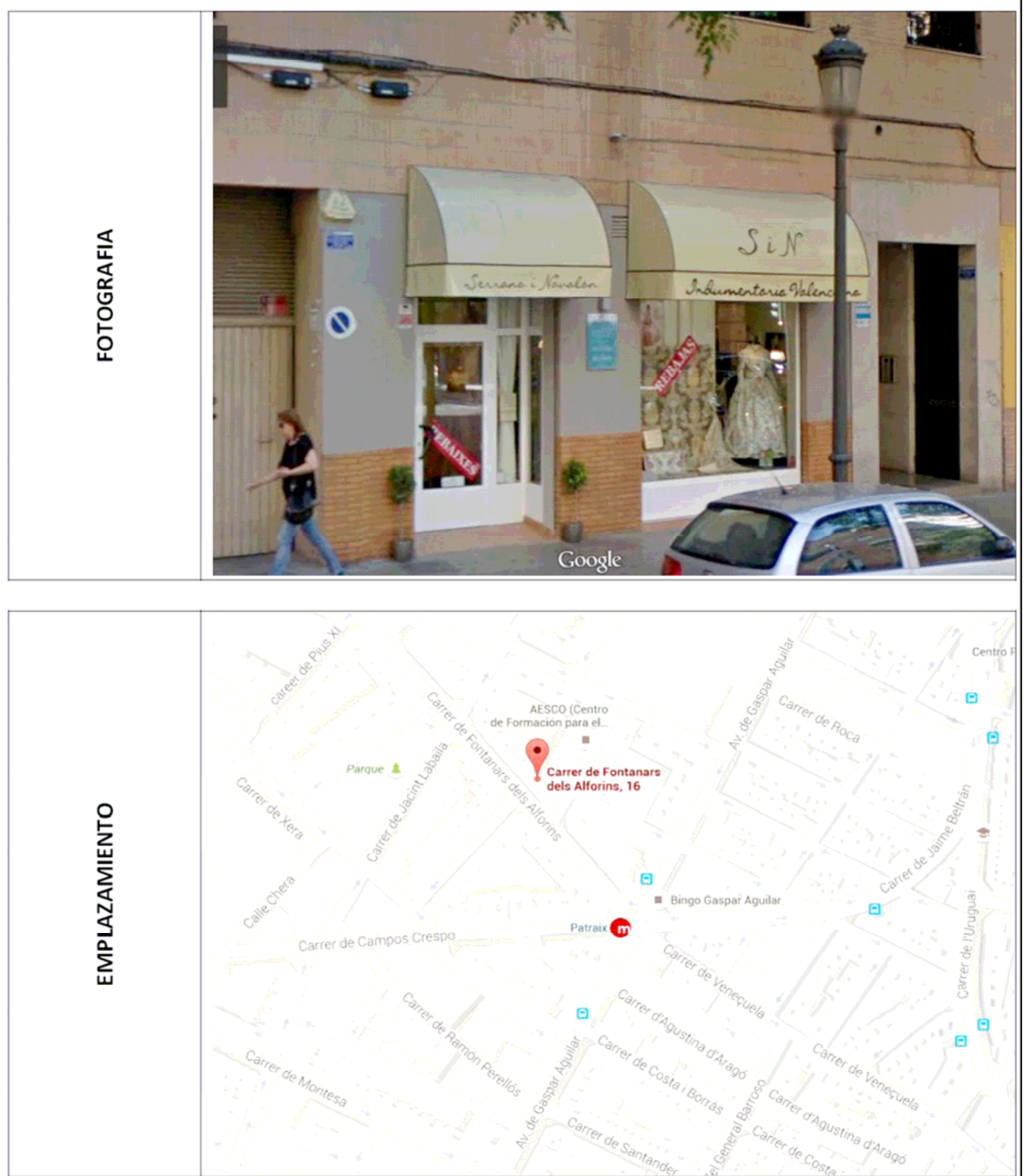
DISTRITO 9.- JESUS

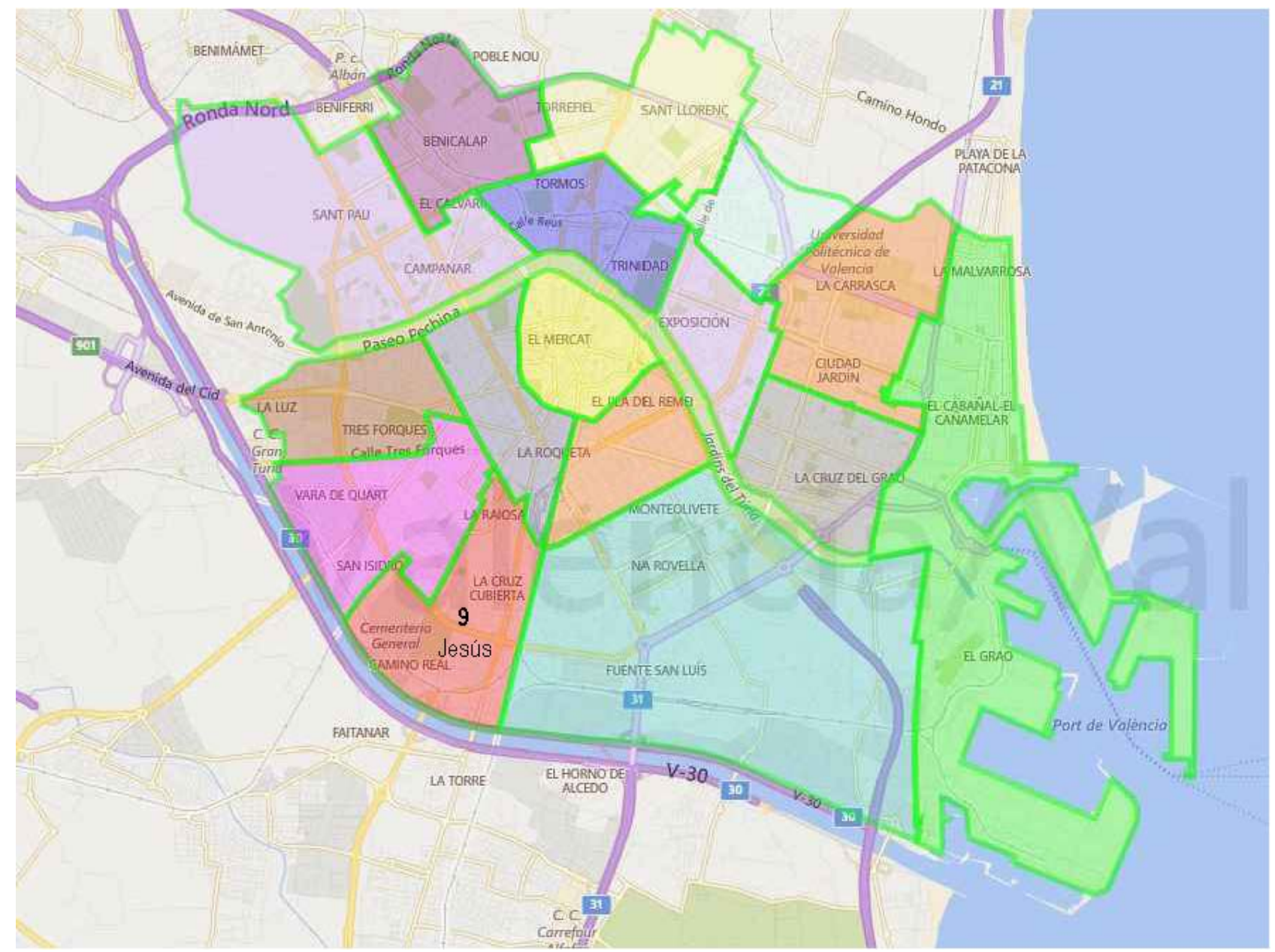

\section{LÍMITES GEOGRÁFICOS.}

Avd. Giorgeta, Nuevo Cauce del Turia, Ferrocarril, Madrid, C/ Campos Crespo y Avd. Gaspar Aguilar. 


\section{EVOLUCIÓN DEL 1985-2014}

\section{PLANO UBICACIÓN INDUSTRIAS}

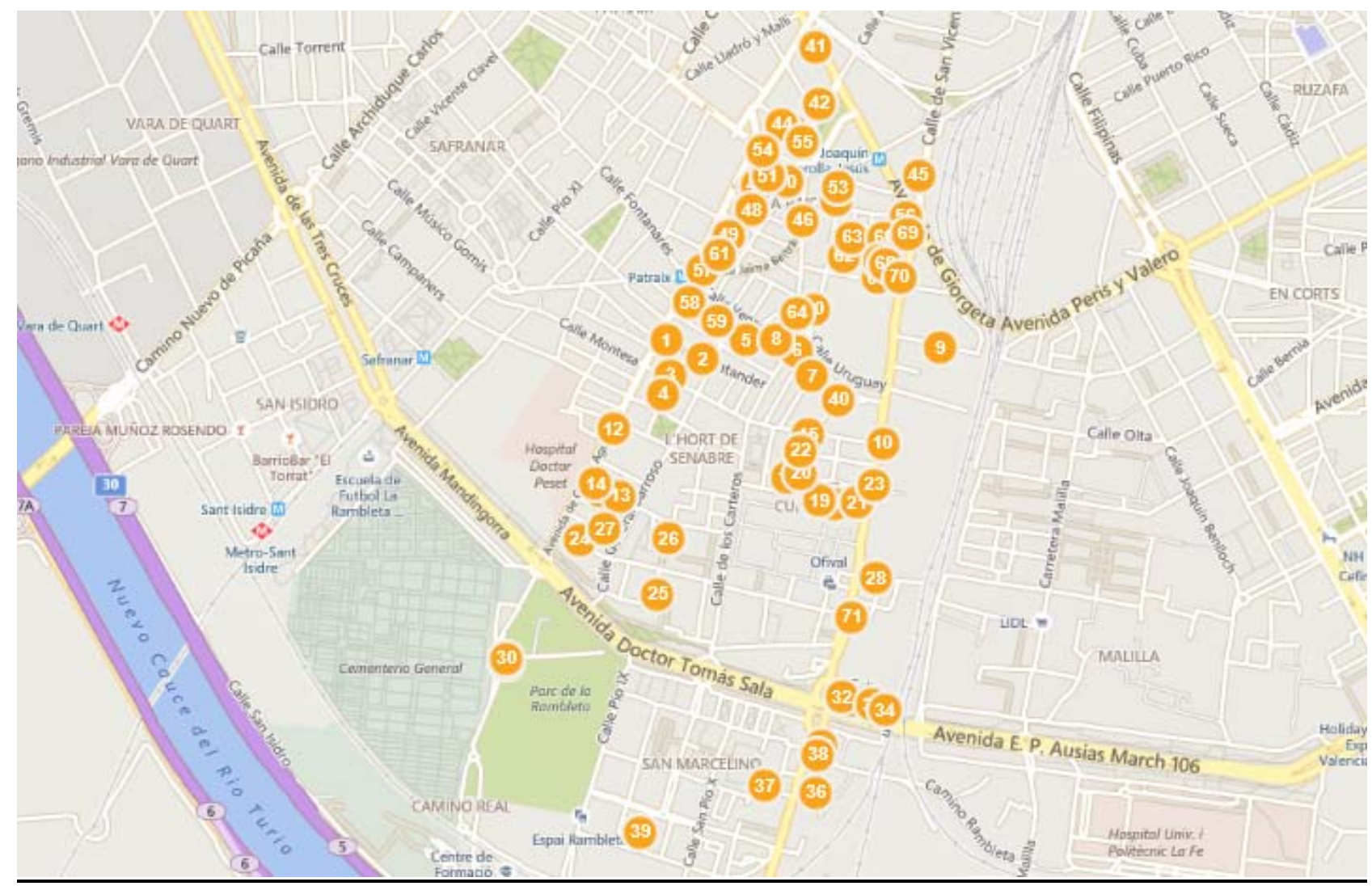

LISTADO DE INDUSTRIAS Y ESTADO ACTUAL :-

1. Romeu Olmos, M.

Sin actividad

2. SANTIAGO VALLES, S.A.

Sin actividad

3. Alcantud Real, A

Supermercado

4. ALPIFOR, S.L.

Sin datos

5. Barroso Serra, J.

Mecanizados 
6. Fuertes Saez, V.

Sin actividad

7. INDUSTRIAS J. LOPEZ, S.L.

Plancha y pintura del automóvil

8. Garces Gómez, José

Sin actividad

9. Manuel Sebastià Martí

Sin actividad

10. MACOSA

Sin actividad

11. FAJOVAL, S.L.

Sin actividad

12. OBJETOS DE ARTE BURRO, S.L.

Ortopedia/ Trasteros/ Garaje

13. MANUFACTURAS BRAYAN, S.A.

Sin datos

14. LUCIO NAVARRO, S.A.

Sin actividad

15. PANIFICADORA AUTOMÁTICA JESÚS, S.L.

Sala cultural

16. CONFECCIONES ZETA, S.L.

Sin actividad

17. MIGUEL SANCHIS PASTOR, S.A.

Solar sin edificar

18. TORTOSA HNOS, S.L.

Sin actividad

19. TALLERES ELECTROMAC BEGA, S.L.

Puertas metálicas

20. Añón Soucase, Juan "LA REGIONAL"

Droguería industrial

21. Puchades Arce, M.

Sin actividad

22. Palop Arcon, J.M.

Sin actividad

23. BELENGUER, S.A.

Sinn actividad

24. TÉCNICA Y PLÁSTICOS, S.A.

Obra nueva

25. CRISTALMET, S.L.

Supermercado 
26. CREACIONES LUZZY, S.L.

Sin actividad

27. Espert Sifre, V

Sin actividad

28. Ferrer Estrems, F.

Sin actividad

29. MÁRMOLES ARTISTICOS CHOVER, S.A.

Mantiene la actividad

30. Rafael Flores Raya

Mantiene la actividad

31. Tamarit Olmos, F.

Nueva ordenación

32. Alcantarilla Domínguez, Manuel

Sin datos

33. Martínez Carrascosa, Vicente

Sin datos

34. Puigcerver Mengual, J.

Sin datos

35. NOVOALU, S.L.

Sin actividad

36. Calaforra Moreno, Aurelio

Sin actividad

37. VICENTE RAGA ESPLUGUES, S.A.

Solar sin edificar

38. Iranzo García, J.

Imprenta

39. CONFECCIONES KIRBY, S.A.

Oficinas

40. Antonio Castello Pico

Sin actividad

41. FANCHUILA, S.A.

Sin actividad

42. Muñoz Guijarro, T.

Paquetería

43. ASCENSORES ELEVA VALENCIA, S.L.

Centro de capacitación

44. Esteve Calvo, Pascual

Obra nueva

45. INDUSTRIAS M.A.G.

Sin actividad 
46. Merino Gómez, F.

Supermercado

47. Palmero Dubón, B.

Mármoles y granitos

48. Verdejo Sabater, $M$.

Obra nueva

49. ESTUDIO GRAFICO BONET LOPEZ

Obra nueva

50. Aguado Martínez, F.

Pizzería

51. Molla Jorda, A.

Sin actividad

52. Martínez David, L.

Oficinas

53. Regal Bruno, J.V.

Kiosco/ Certificados médicos

54. REFLEX-PLAC

Comercios

55. CONFECCIÓN INFANTIL ARTESANÍA, S.A.

Farmacia

56. CONFECCIONES JILTON, S.L.

Tienda de ropa

57. COOP. OBRERA PRODUCCIÓN ARTES GRÁFICAS

Mantiene la actividad

58. BRONCELUZ, SOC. COOP. LMT.

Sin actividad

59. Carlos Roso Aznar

Obra nueva

60. Biosca Ángel, $\mathbf{R}$.

Sin actividad

61. Juan y Rosa Ruiz Alonso

Sin actividad

62. Valiente Blasco, J.

Sin actividad

63. SIST. INSTA. TELECMUNICACIONES

Estanterías metálicas/ Sin actividad

64. Jesús Carrión del Valle

Tienda de ropa

65. CABLES Y ESLINGAS, S.A.

Recambios del automóvil 
66. Palazón Lozano, Francisco

Obra nueva

67. Tarazona Ballester, D.

Solar sin edificar

68. Hernani del Castillo, Víctor

Obra nueva

69. AGRA, S.A. Ácidos Grasos

Sin actividad

70. AGEVAL, S.A.

Olivetti, ordenadores

71. EL TURIA FÁBRICA DE CERVEZA, S.A.

Sin actividad

\section{CARACTERÍSTICAS DEL ASENTAMIENTO INDUSTRIAL.-}

- Domina el uso residencial en el distrito, aunque existe una importante actividad industrial, concentrada básicamente en dos grandes empresas, MACOSA y Cervezas EL TURIA.

- En general y exceptuando las dos empresas mencionadas y algunas naves industriales entre medianeras situadas en sus alrededores, la industria esta dispersa, es de pequeña superficie y está situada generalmente en bajos de edificios de viviendas.

- Ha habido un importante proceso de desplazamiento y sustitución de la industria por viviendas, en el área próxima a la C/ San Vicente y de consolidación de la trama urbana con edificación residencial con el conjunto del distrito.

\section{CARACTERÍSTICAS DE LOS LOCALES.-}

- Son numéricamente mayoritarios los locales de pequeña superficie, situados en plantas bajas de edificios de viviendas, aunque tienen mayor Importancia en cuanto a nivel de empleo y superficie ocupada, la concentra clon industrial formada por dos grandes empresas, MACOSA y Cervezas EL TURIA, y una pequeña formación de naves entre medianeras situadas a su alrededor que, como las anteriores, han quedado integradas en la trama urbana. 


\section{CARACTERÍSTICAS DE LAS ACTIVIDADES.}

Se censaron inicialmente 71 industrias y en el período de vigencia del Plan General han quedado solamente 3 creándose 55 nuevas industrias.

Las actividades dominantes son construcción de maquinaria y equipo mecánico, alimentación y bebida, industria de la madera y calzado y confección.

A la vista de estos datos deben hacerse las siguientes consideraciones:

1.- La gran incidencia en el sector do maquinarla de la industria MACOSA con $66.000 \mathrm{~m} 2$ de parcela y 1.088 trabajadores y en el sector de la alimentación de la Fábrica de Cervezas El Turia, con 33.200 n2 de parcela y 317 trabajadores.

2.- La importancia de algunos edificios, que ocupan una superficie notable que no ha sido computada en las tablas, este es el caso de Ricardo Soriano, S.A. (Clave 6E) e Industria de la Chapa F. Palmero (Clave DA), ambas cerradas actualmente, o el de H. Miguel Mateu (clave 6P/S100) de la que no se han podido obtener datos.

\section{IMPACTO EN EL MEDIO AMBIENTE.}

La contaminación ambiental se reduce prácticamente a la acústica ya que, pese a la existencia de grandes empresas, las características de estas y la existencia de infraestructura y servicios urbanísticos aparentemente suficientes, reducen la posible contaminación o las molestias que pueden ocasionar a las viviendas próximas como consecuencia de los ruidos que producen tanto las industrias como el ferrocarril.

Tanto Macosa como Cervezas El Turia generan un transporte importante que se canaliza a lo largo de la C/ San Vicente, aunque la proximidad del II y III Cinturón de Ronda (Avd. Giorgeta y Nuevo Cauce del Turia, respectivamente) localizan el problema derivado del transporte en el interior del distrito, en un tramo viario relativamente corto.

Dadas sus características urbanas, la industria de este distrito queda integrada en la trama urbana, incluyendo las dos grandes empresas, MACOSA y Cervezas EL TURIA, -que pese a su tamaño han quedado absorbidas y relativamente integradas en la trama urbana. 
EDIFICIOS INDUSTRIALES DE INTERES:

- MACOSA

C/ San Vicente Mártir no 269 (FA-2)

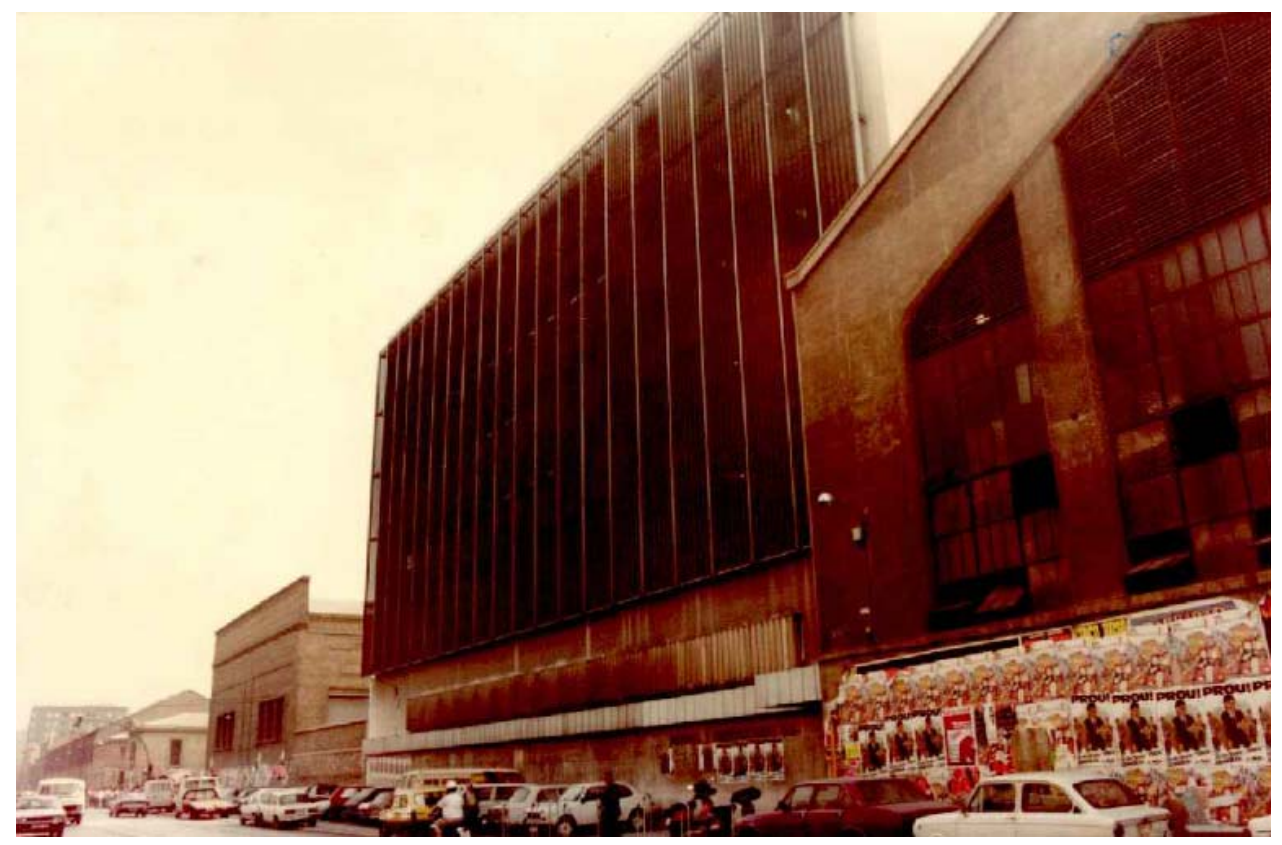

Foto 49: Industria de material de construcción. MACOSA. C/ San Vicente Mártir, 269. Valencia.1985. Fuente: Elaboración propia

- EL TURIA

C/ San Vicente Mártir no 271 (FC-1)

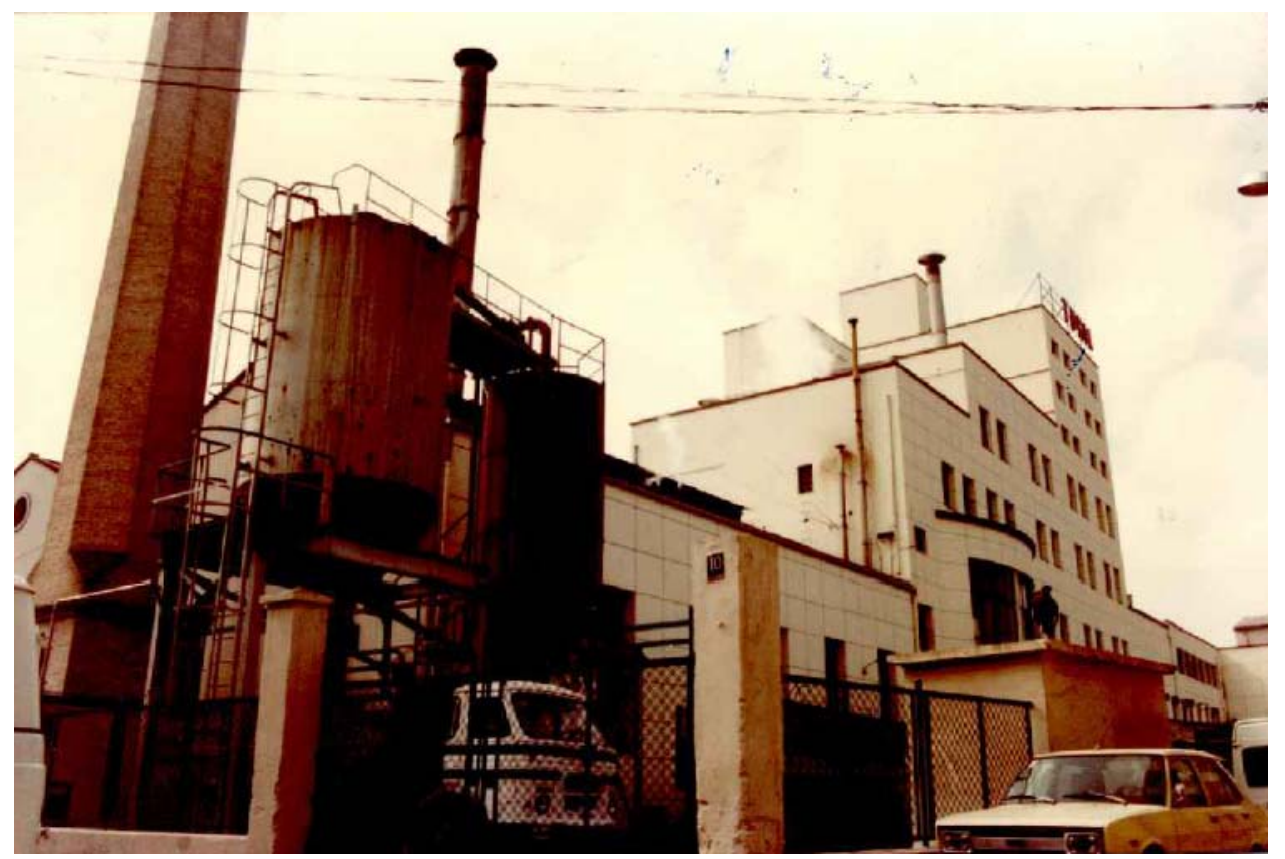

Foto 50: Fábrica de cervezas. El Turia, S.A. C/ San Vicente Mártir, 299.

Valencia.1985. Fuente: Elaboración propia 
- BELENGUER

C/ San Vicente Mártir no 299 (6F/5000-1)

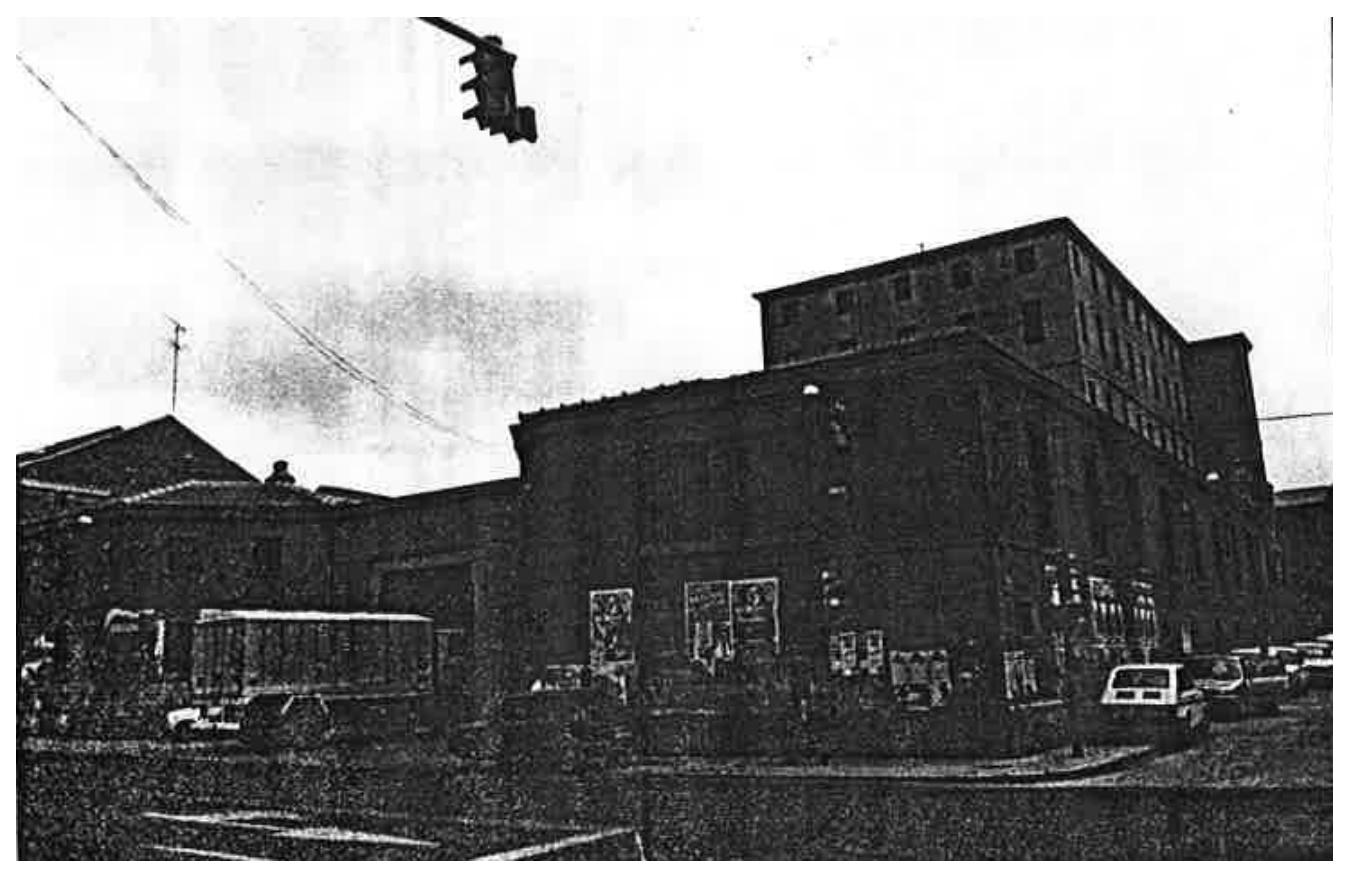

Foto 51: Industria de harina. BELENGUER, S.A.. C/ San Vicente Mártir, 271. Valencia.1985. Fuente: Elaboración propia

TIPOLOGÍA EDIFICACIÓN

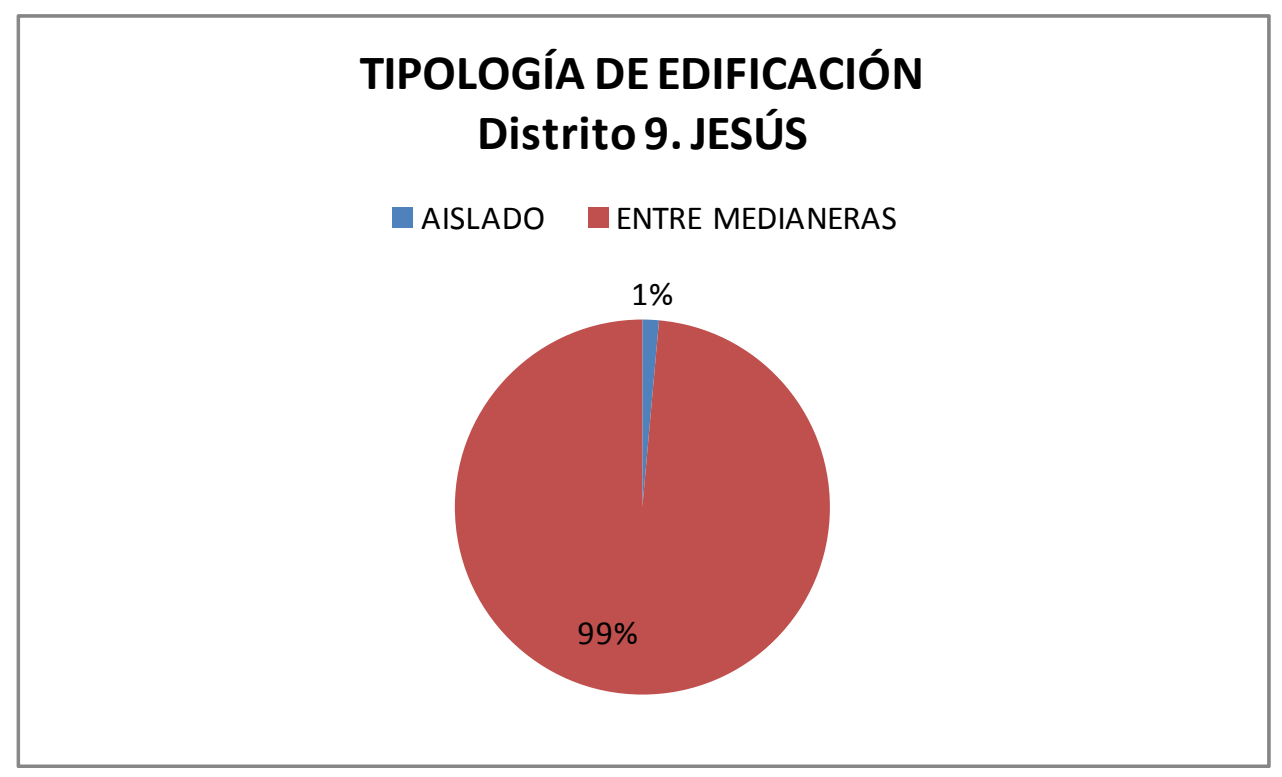




\section{ACTIVIDAD INDUSTRIAL, SUPERFICIE Y EMPLEO}

\begin{tabular}{|c|c|c|c|c|c|}
\hline \multicolumn{6}{|c|}{ DISTRITO 9 - JESUS (ATIVIDAD INDUSTRIAL Y EMPLEO) } \\
\hline ACTIVIDAD & $\begin{array}{c}\text { № } \\
\text { EMPRESAS }\end{array}$ & $\begin{array}{c}\text { SUP. ACTIVIDAD } \\
\text { IND }\left(\mathrm{m}^{2}\right)\end{array}$ & $\begin{array}{c}\text { \% SUP. } \\
\text { INDUSTRIAL }\end{array}$ & $\begin{array}{c}\text { № } \\
\text { EMPLEADOS }\end{array}$ & $\begin{array}{c}\text { DENSIDAD } \\
\text { EMPLEO } \\
\text { (empleados } / \mathrm{m}^{2} \\
\text { actividad) }\end{array}$ \\
\hline INDUSTRIAS DE PRODUCTOS MINERALES NO METÁLICOS & 2 & 2650 & 1,90 & 38 & 0,0143 \\
\hline FABRICACIÓN DE PRODUCTOS METÁLICOS & 12 & 3433 & 2,46 & 90 & 0,0262 \\
\hline CONSTRUCCIÓN DE MAQUINARIA Y EQUIPO MECÁNICO & 6 & 67900 & 48,64 & 1114 & 0,0164 \\
\hline CONSTRUCCIÓN DE MAQUINARIA Y MATERIAL ELÉCTRICO & 4 & 2310 & 1,65 & 56 & 0,0242 \\
\hline FABRICACIÓN DE MATERIAL ELECTRÓNICO & 1 & 240 & 0,17 & 53 & 0,2208 \\
\hline INDUSTRIAS DE PRODUCTOS ALIMENTICIOS, BEBIDAS Y TABACO & 3 & 6550 & 4,69 & 58 & 0,0089 \\
\hline INDUSTRIAS DE PRODUCTOS ALIMENTICIOS, BEBIDAS Y TABACO & 2 & 33600 & 24,07 & 318 & 0,0095 \\
\hline INDUSTRIA TEXTIL & 3 & 1374 & 0,98 & 81 & 0,0590 \\
\hline INDUSTRIA DEL CUERO & 2 & 568 & 0,41 & 26 & 0,0458 \\
\hline INDUSTRIA DEL CALZADO Y DEL VESTIDO Y OTRAS CONFECCIONES TEXTILES & 8 & 3147 & 2,25 & 182 & 0,0578 \\
\hline INDUSTRIAS DE MADERA, CORCHO Y MUEBLES DE MADERA & 13 & 13630 & 9,76 & 175 & 0,0128 \\
\hline INDUSTRIA DEL PAPEL Y FABRICACIÓN DE ARTíCULOS DE PAPEL, ARTES GRÁFICAS & 5 & 1280 & 0,92 & 115 & 0,0898 \\
\hline INDUSTRIAS DE TRANSFORMACIÓN DEL CAUCHO Y MATERIAS PLÁSTICAS & 1 & 530 & 0,38 & 13 & 0,0245 \\
\hline OTRAS INDUSTRIAS MANUFACTURERAS & 4 & 1010 & 0,72 & 45 & 0,0446 \\
\hline CONSTRUCCIÓN & 4 & 1385 & 0,99 & 82 & 0,0592 \\
\hline TOTAL & 70 & 139607 & 100 & 2446 & 0,0175 \\
\hline
\end{tabular}

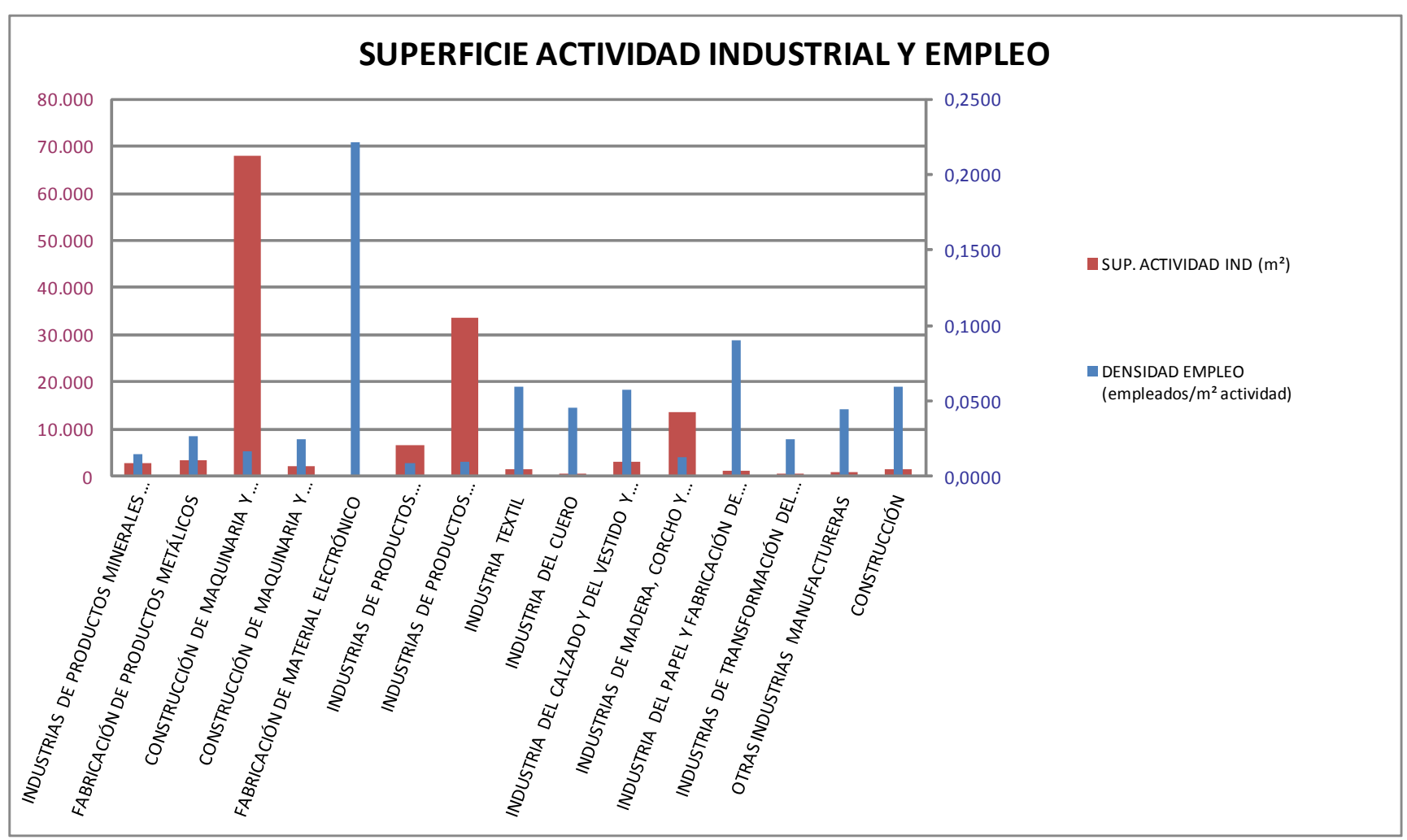


IMPACTO AMBIENTAL

\begin{tabular}{|c|c|c|c|c|c|}
\hline \multicolumn{6}{|c|}{ DISTRITO 9 - JESUS (INFORMACIÓN URBANÍSTICA) } \\
\hline ACTIVIDAD & $\begin{array}{l}\text { No } \\
\text { EMPRESAS }\end{array}$ & $\begin{array}{c}\text { ENTRE } \\
\text { MEDIANERAS }\end{array}$ & RUIDOSAS & $\begin{array}{c}\text { EMPRESAS } \\
\text { CON } \\
\text { CHIMENEA }\end{array}$ & $\begin{array}{l}\text { RUIDOSAS Y } \\
\text { CHIMENEA }\end{array}$ \\
\hline INDUSTRIAS DE PRODUCTOS MINERALES NO METÁLICOS & 2 & 2 & 1 & 0 & 0 \\
\hline FABRICACIÓN DE PRODUCTOS METÁLICOS & 12 & 12 & 7 & 0 & 0 \\
\hline CONSTRUCCIÓN DE MAQUINARIA Y EQUIPO MECÁNICO & 6 & 6 & 1 & 0 & 1 \\
\hline CONSTRUCCIÓN DE MAQUINARIA Y MATERIAL ELÉCTRICO & 4 & 4 & 2 & 0 & 0 \\
\hline FABRICACIÓN DE MATERIAL ELECTRÓNICO & 1 & 1 & 0 & 0 & 0 \\
\hline INDUSTRIAS DE PRODUCTOS ALIMENTICIOS, BEBIDAS Y TABACO & 3 & 3 & 1 & 1 & 0 \\
\hline INDUSTRIAS DE PRODUCTOS ALIMENTICIOS, BEBIDAS Y TABACO & 2 & 1 & 0 & 0 & 1 \\
\hline INDUSTRIA TEXTIL & 3 & 3 & 2 & 0 & 0 \\
\hline INDUSTRIA DEL CUERO & 2 & 2 & 0 & 0 & 0 \\
\hline INDUSTRIA DEL CALZADO Y DEL VESTIDO Y OTRAS CONFECCIONES TEXTILES & 8 & 8 & 3 & 0 & 0 \\
\hline INDUSTRIAS DE MADERA, CORCHO Y MUEBLES DE MADERA & 13 & 13 & 4 & 4 & 1 \\
\hline $\begin{array}{l}\text { INDUSTRIA DEL PAPEL Y FABRICACIÓN DE ARTÍCULOS DE PAPEL, ARTES GRÁFICAS } \\
\text { Y EDICIÓN }\end{array}$ & 5 & 5 & 3 & 0 & 0 \\
\hline INDUSTRIAS DE TRANSFORMACIÓN DEL CAUCHO Y MATERIAS PLÁSTICAS & 1 & 1 & 1 & 0 & 0 \\
\hline OTRAS INDUSTRIAS MANUFACTURERAS & 4 & 4 & 1 & 0 & 0 \\
\hline CONSTRUCCIÓN & 4 & 4 & 0 & 0 & 0 \\
\hline TOTAL & 70 & 69 & 26 & 5 & 3 \\
\hline
\end{tabular}

\section{IMPACTO EN EL MEDIO URBANO}

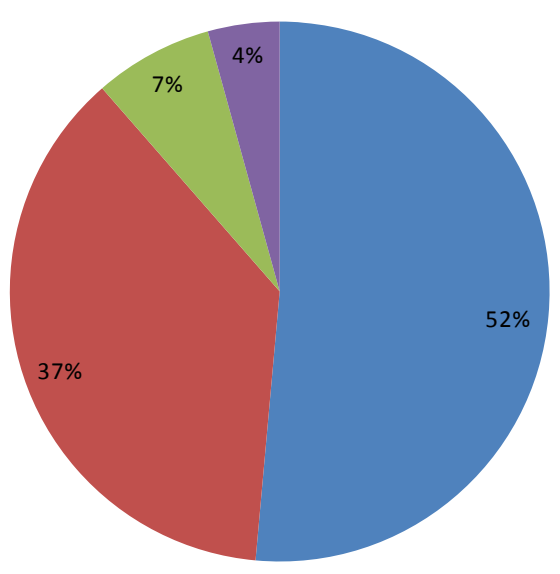

EMPRESAS INOCUAS

EMPRESAS RUIDOSAS

- EMPRESAS CON CHIMENEA

- EMPRESAS RUIDOSAS Y CON CHIMENEA 


\section{FICHAS TIPO \\ FICHA DATOS DE LA INDUSTRIA}

LOCALIZACION ACTUALIZADA DE ACTIVIDADES INDUSTRIALES EN EL

MEDIO URBANO DE VALENCIA

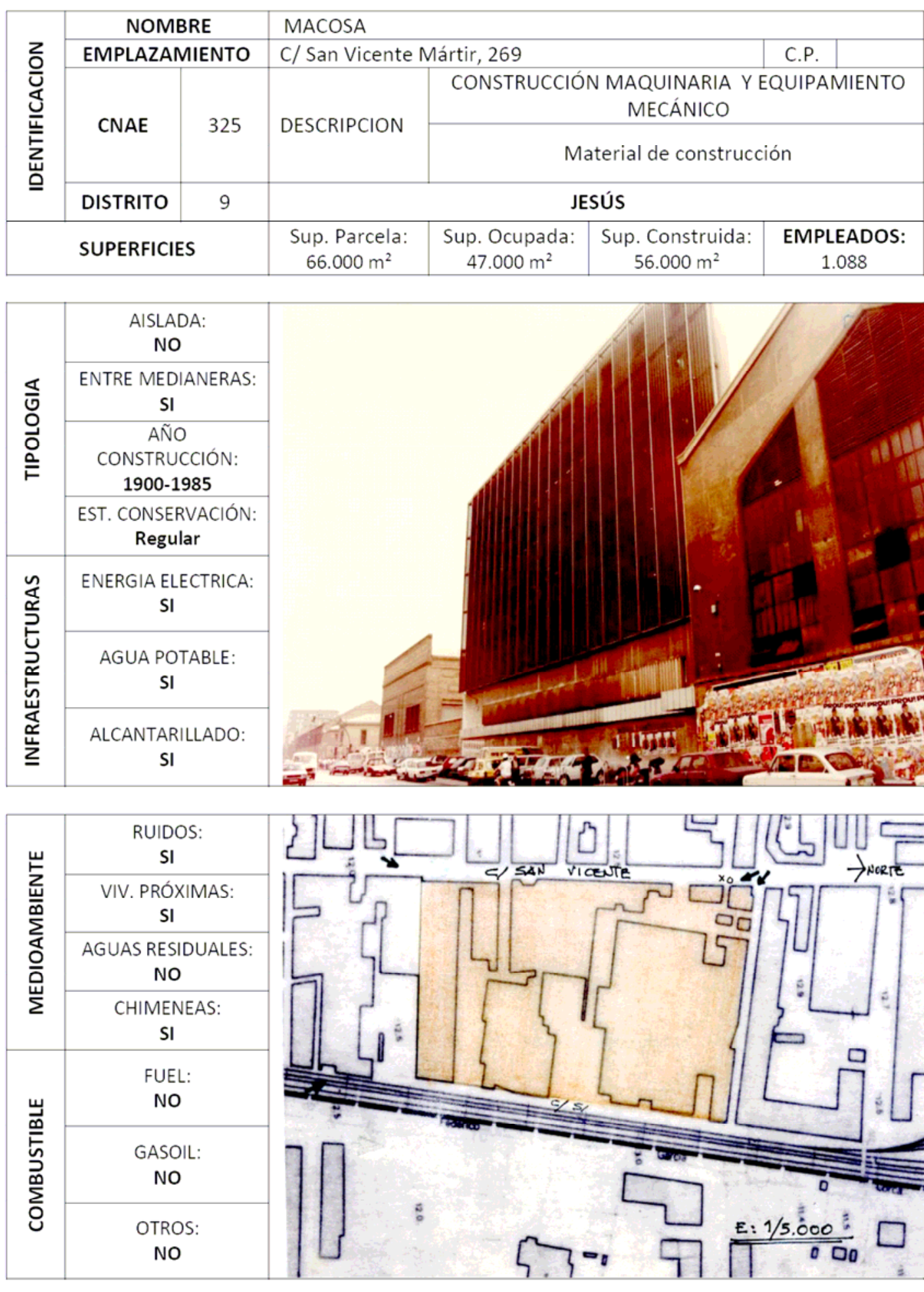

EN LA ACTUALIDAD: SIN ACTIVIDAD 


\section{FICHA DATOS DE LA INDUSTRIA}

LOCALIZACION ACTUALIZADA DE ACTIVIDADES INDUSTRIALES EN EL

MEDIO URBANO DE VALENCIA

\begin{tabular}{|c|c|c|c|c|c|c|c|}
\hline \multirow{5}{*}{ 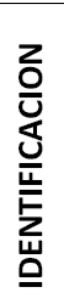 } & \multirow{2}{*}{\multicolumn{2}{|c|}{$\begin{array}{c}\text { NOMBRE } \\
\text { EMPLAZAMIENTO }\end{array}$}} & \multicolumn{5}{|c|}{ MIGUEL SANCHIS PASTOR S.A. } \\
\hline & & & \multicolumn{3}{|c|}{ C/ Mosen Febrer, 23} & C.P. & \\
\hline & \multirow{2}{*}{ CNAE } & \multirow{2}{*}{462} & \multirow{2}{*}{ DESCRIPCION } & \multicolumn{4}{|c|}{ INDUSTRIA DE LA MADERA } \\
\hline & & & & \multicolumn{4}{|c|}{ Elaboración chapas de madera } \\
\hline & DISTRITO & 9 & \multicolumn{5}{|c|}{ JESÚS } \\
\hline \multicolumn{3}{|c|}{ SUPERFICIES } & $\begin{array}{l}\text { Sup. Parcela: } \\
2000 \mathrm{~m}^{2}\end{array}$ & $\begin{array}{l}\text { Sup. Ocupada: } \\
2000 \mathrm{~m}^{2}\end{array}$ & $\begin{array}{l}\text { Sup. Construida: } \\
2000 \mathrm{~m}^{2}\end{array}$ & EMP & $\begin{array}{l}\text { LEADOS: } \\
74\end{array}$ \\
\hline
\end{tabular}
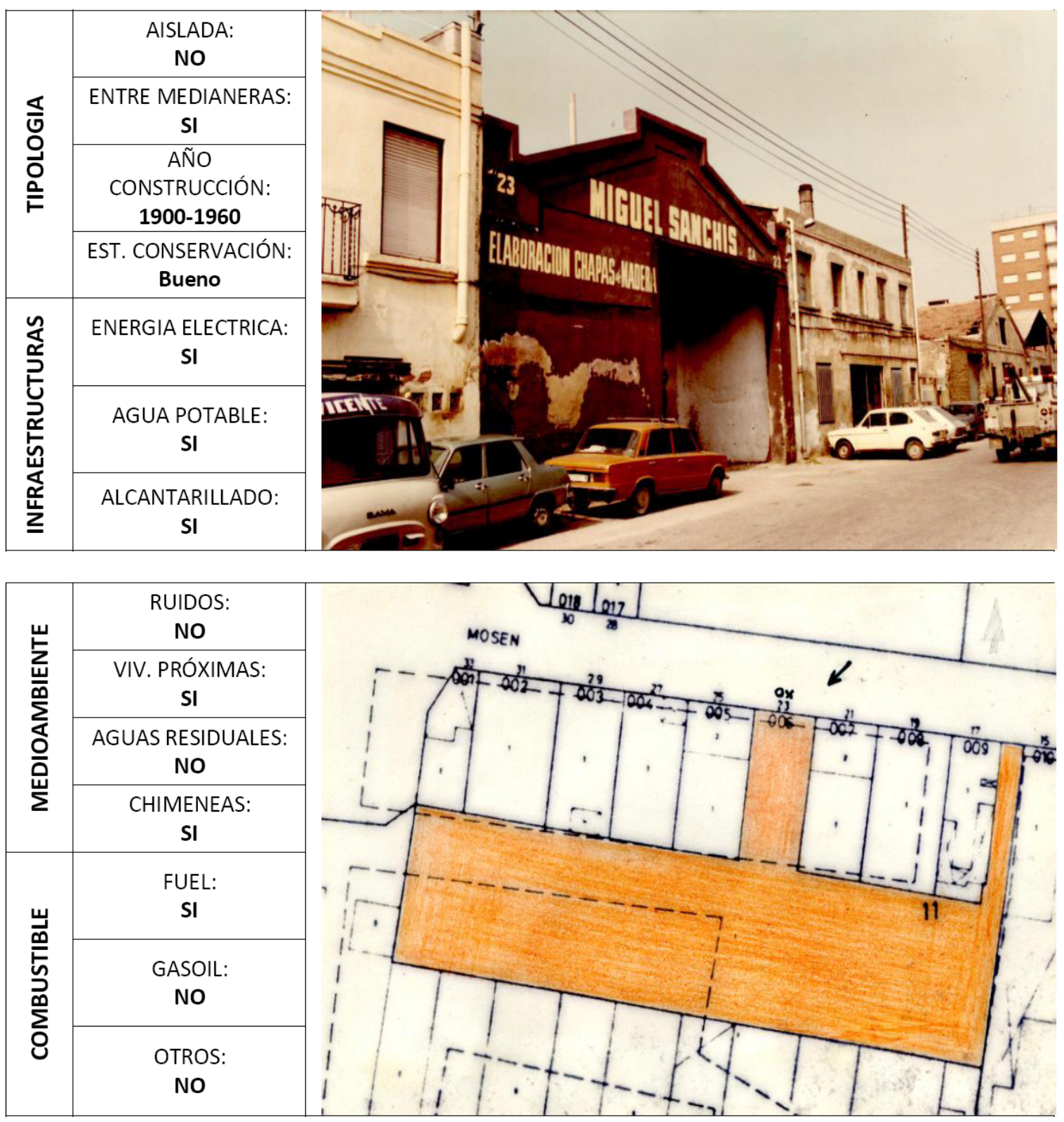


\section{FICHA DATOS DE LA INDUSTRIA}

LOCALIZACION ACTUALIZADA DE ACTIVIDADES INDUSTRIALES EN EL

\section{MEDIO URBANO DE VALENCIA}

\begin{tabular}{|c|c|c|c|c|c|c|}
\hline \multirow{5}{*}{ 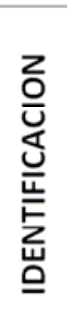 } & \multirow{2}{*}{\multicolumn{2}{|c|}{$\begin{array}{c}\text { NOMBRE } \\
\text { EMPLAZAMIENTO }\end{array}$}} & \multicolumn{4}{|c|}{ BELENGUER S.A. } \\
\hline & & & \multicolumn{3}{|c|}{ C/ San Vicente Mártir, 271} & C.P. \\
\hline & \multirow{2}{*}{ CNAE } & \multirow{2}{*}{417} & \multirow{2}{*}{ DESCRIPCION } & \multicolumn{3}{|c|}{$\begin{array}{c}\text { INDUSTRIA DE PRODUCTOS ALIMENTICIOS, } \\
\text { BEBIDAS, ETC. }\end{array}$} \\
\hline & & & & \multicolumn{3}{|c|}{ Harinas } \\
\hline & DISTRITO & 9 & \multicolumn{4}{|c|}{ JESÚS } \\
\hline \multicolumn{3}{|c|}{ SUPERFICIES } & $\begin{array}{l}\text { Sup. Parcela: } \\
6000 \mathrm{~m}^{2}\end{array}$ & $\begin{array}{l}\text { Sup. Ocupada: } \\
4000 \mathrm{~m}^{2}\end{array}$ & $\begin{array}{l}\text { Sup. Construida: } \\
9000 \mathrm{~m}^{2}\end{array}$ & $\begin{array}{c}\text { EMPLEADOS: } \\
38\end{array}$ \\
\hline
\end{tabular}
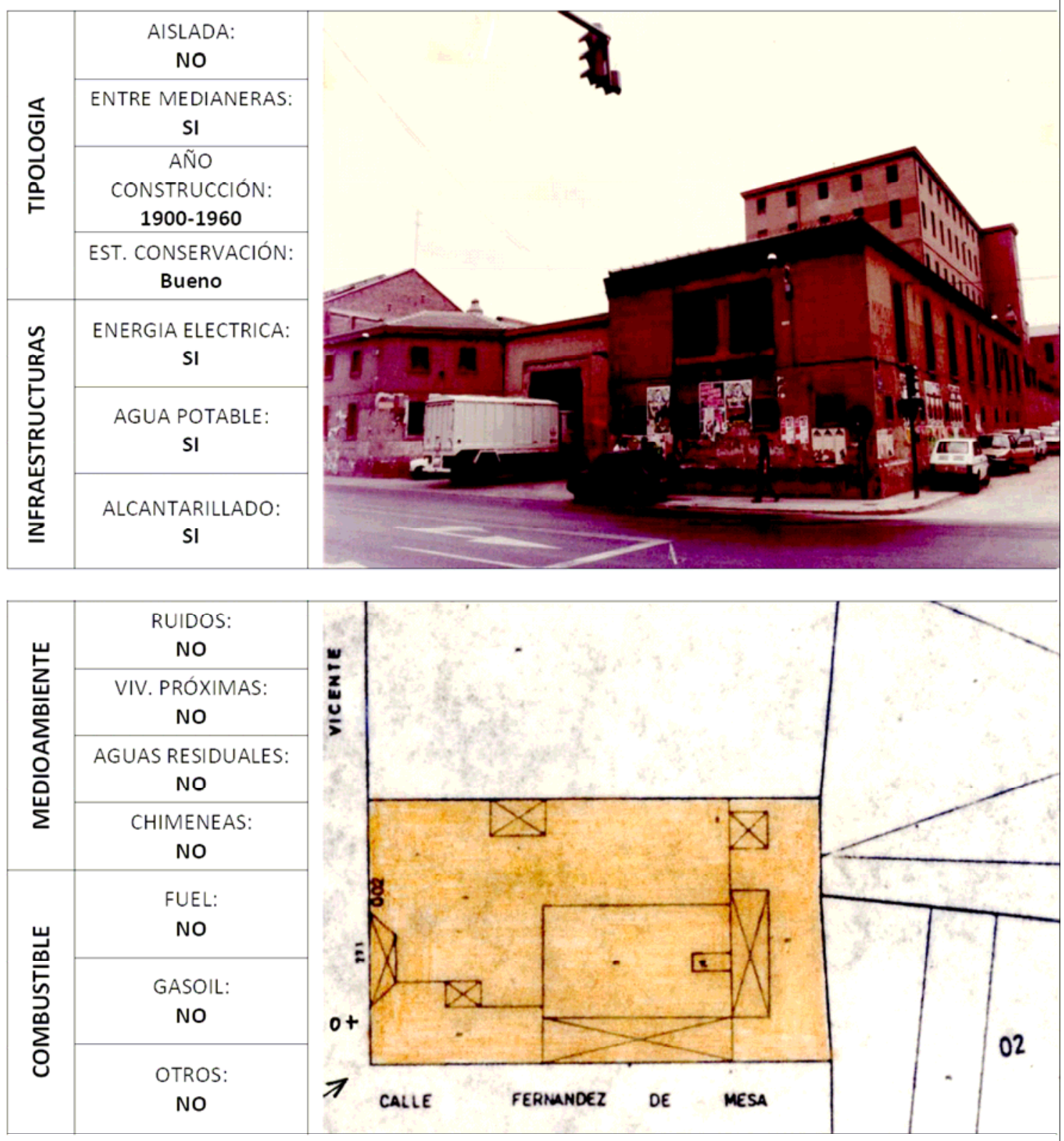


\section{FICHA DATOS DE LA INDUSTRIA}

LOCALIZACION ACTUALIZADA DE ACTIVIDADES INDUSTRIALES EN EL

MEDIO URBANO DE VALENCIA

\begin{tabular}{|c|c|c|c|c|c|c|c|}
\hline \multirow{5}{*}{ 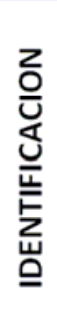 } & \multirow{2}{*}{\multicolumn{2}{|c|}{$\begin{array}{c}\text { NOMBRE } \\
\text { EMPLAZAMIENTO }\end{array}$}} & \multicolumn{5}{|c|}{ CRISTALMET S.L. } \\
\hline & & & \multicolumn{3}{|c|}{ Pza. de Segovia, 2} & C.P. & \\
\hline & \multirow{2}{*}{ CNAE } & \multirow{2}{*}{346} & \multirow{2}{*}{ DESCRIPCION } & \multicolumn{4}{|c|}{$\begin{array}{c}\text { CONSTRUCCIÓN MAQUINARIA Y MATERIAL } \\
\text { ELÉCTRICO }\end{array}$} \\
\hline & & & & \multicolumn{4}{|c|}{ Iluminación } \\
\hline & DISTRITO & 9 & \multicolumn{5}{|c|}{ JESÚS } \\
\hline \multicolumn{3}{|c|}{ SUPERFICIES } & $\begin{array}{l}\text { Sup. Parcela: } \\
1.330 \mathrm{~m}^{2}\end{array}$ & $\begin{array}{c}\text { Sup. Ocupada: } \\
1.330 \mathrm{~m}^{2}\end{array}$ & $\begin{array}{l}\text { Sup. Construida: } \\
1.330 \mathrm{~m}^{2}\end{array}$ & EMP & $\begin{array}{l}\text { LEADOS: } \\
42\end{array}$ \\
\hline
\end{tabular}
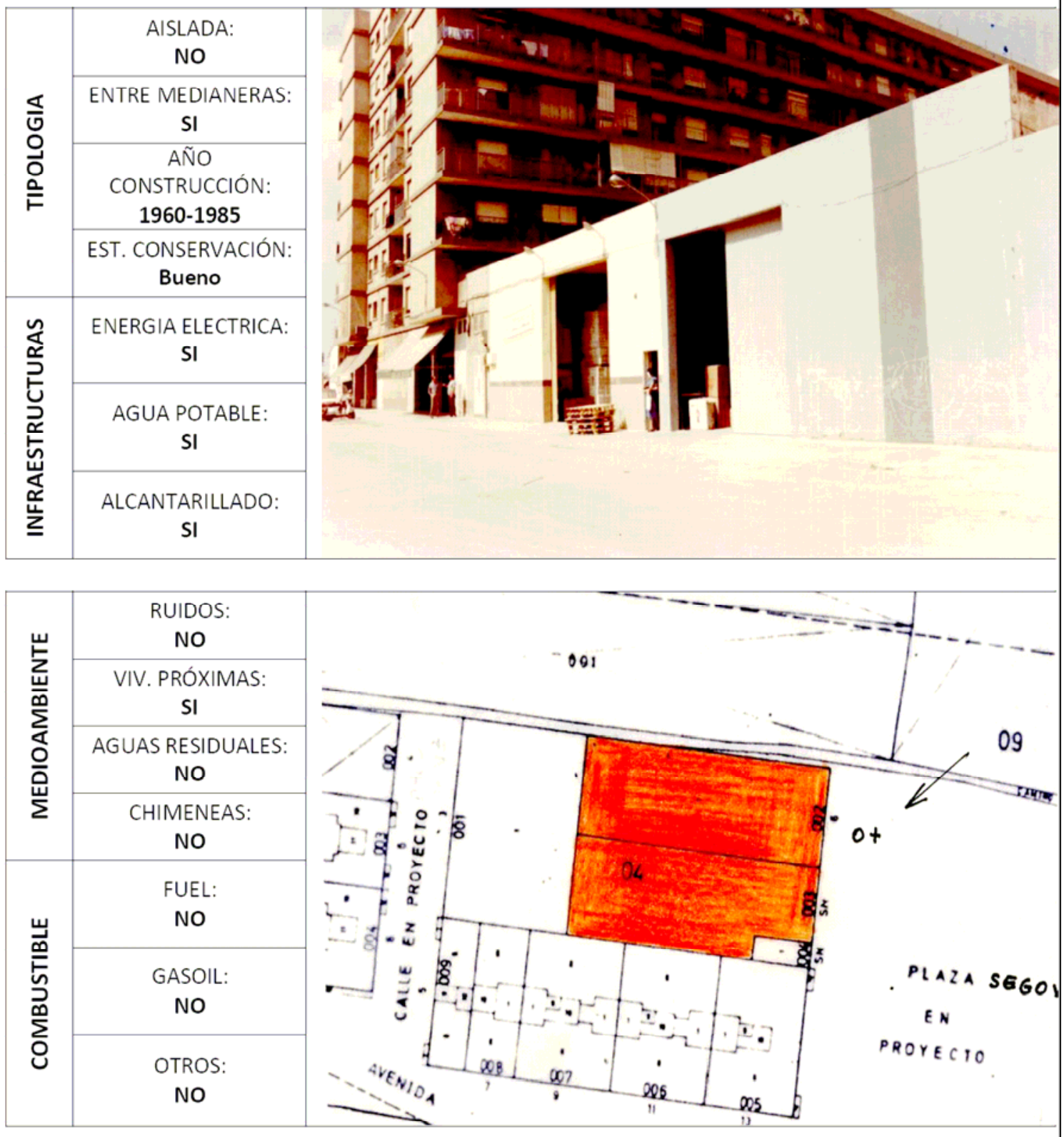


\section{FICHA DATOS DE LA INDUSTRIA}

LOCALIZACION ACTUALIZADA DE ACTIVIDADES INDUSTRIALES EN EL MEDIO URBANO DE VALENCIA

\begin{tabular}{|c|c|c|c|c|c|c|c|}
\hline \multirow{5}{*}{ 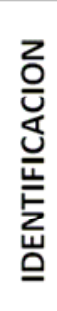 } & \multirow{2}{*}{\multicolumn{2}{|c|}{$\begin{array}{c}\text { NOMBRE } \\
\text { EMPLAZAMIENTO }\end{array}$}} & \multicolumn{5}{|c|}{ INDUSTRIAS M.A.G. } \\
\hline & & & \multicolumn{3}{|c|}{ C/ San Vicente Mártir, 204} & C.P. & \\
\hline & \multirow[b]{2}{*}{ CNAE } & \multirow[b]{2}{*}{504} & \multirow[b]{2}{*}{ DESCRIPCION } & \multicolumn{4}{|c|}{ CONSTRUCCIÓN } \\
\hline & & & & \multicolumn{4}{|c|}{ Refrigeración } \\
\hline & DISTRITO & 9 & \multicolumn{5}{|c|}{ JESÚS } \\
\hline \multicolumn{3}{|c|}{ SUPERFICIES } & $\begin{array}{l}\text { Sup. Parcela: } \\
600 \mathrm{~m}^{2}\end{array}$ & $\begin{array}{l}\text { Sup. Ocupada: } \\
600 \mathrm{~m}^{2}\end{array}$ & $\begin{array}{l}\text { Sup. Construida: } \\
600 \mathrm{~m}^{2}\end{array}$ & EMPL & $\begin{array}{l}\text { ADOS: } \\
7\end{array}$ \\
\hline
\end{tabular}
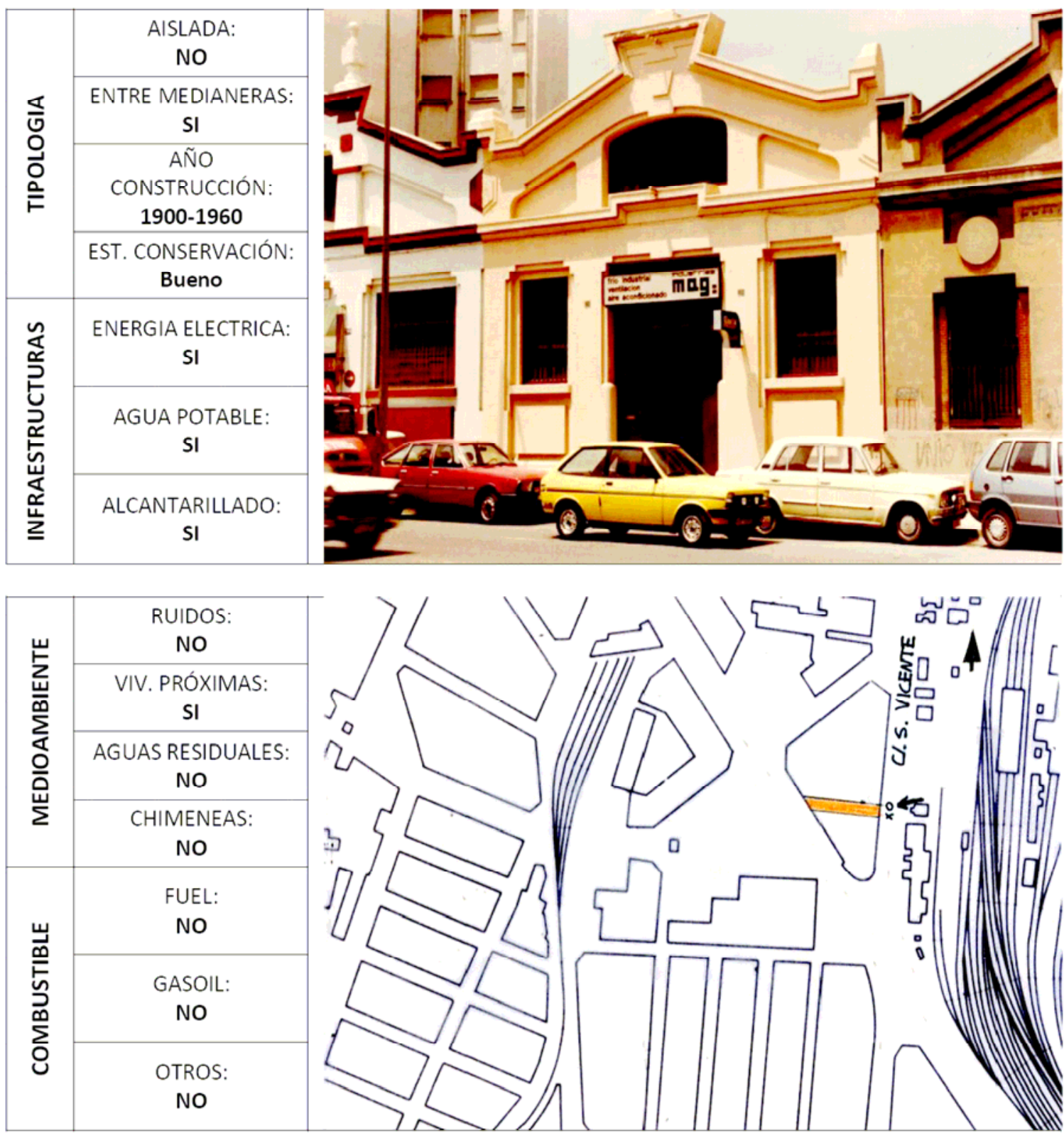


\section{EVOLUCIÓN}

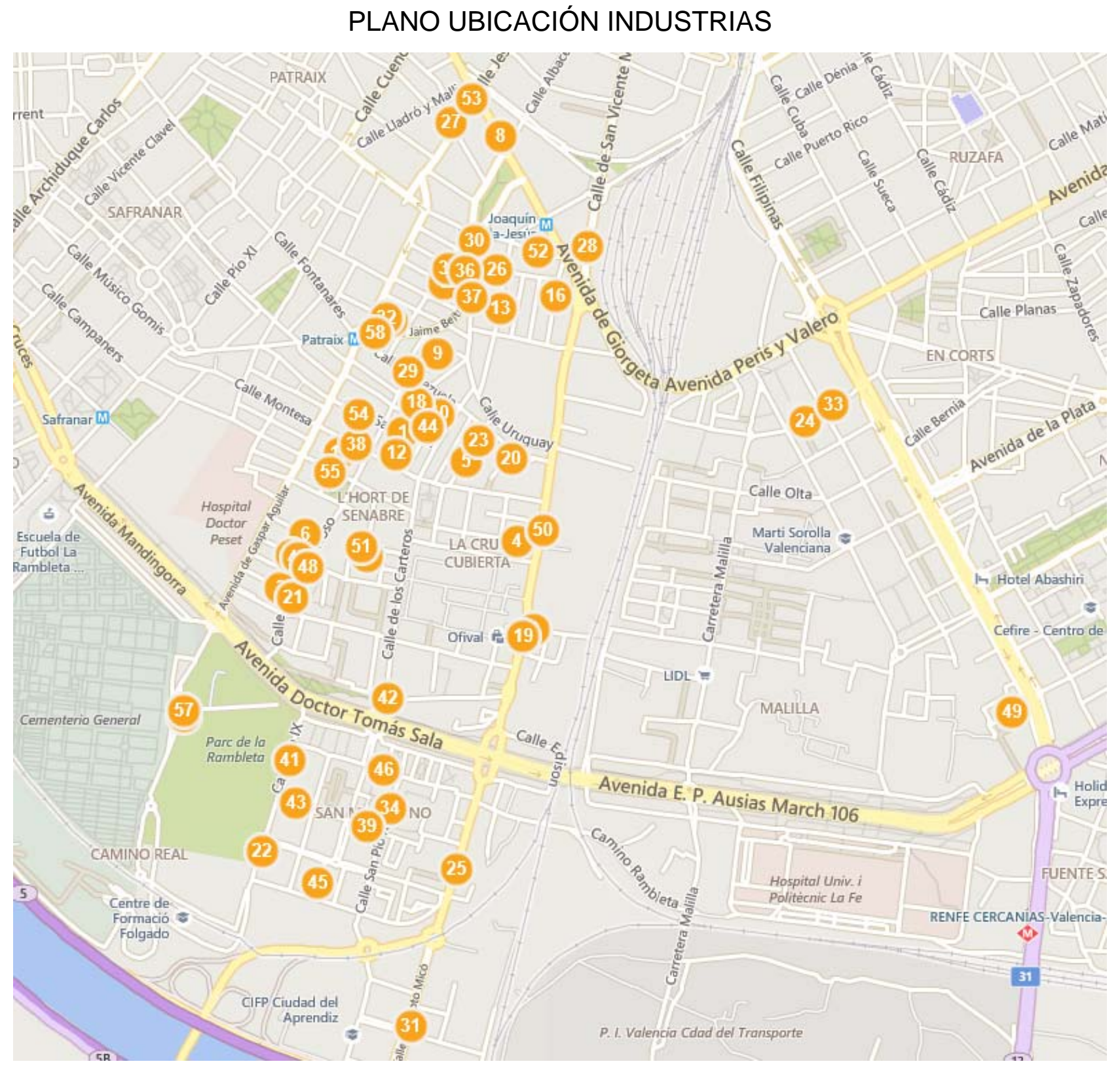

LISTADO DE INDUSTRIAS Y ACTIVIDAD.-

1. Manuel Minguillón

Fabricación de otros muebles

\section{Francisco Cervera Palomares}

Fabricación de otros muebles 
3. Alfredo Pastor García

Fabricación de otros muebles

4. NIVEL DÍEZ C.B.

Fabricación de otros muebles

5. GARPE CARPINTERÍA S.C.P.

Fabricación de otros muebles

6. Isabel M. Sánchez González

Fabricación de otros muebles

7. LOHAN DISEÑO EN JOYERÍA S.L.

Fabricación de artículos de joyería y artículos similares

8. Miguel López Pau

Fabricación de artículos de joyería y artículos similares

9. Vicente Pedro Venegas

Fabricación de artículos de joyería y artículos similares

10. Salvador Carbo Romero

Fabricación de instrumentos musicales

11. STRINGSFIELD C.B.

Fabricación de instrumentos musicales

12. Ángeles Ruiz Flores

Fabricación de artículos confeccionados textiles, excepto prendas de vestir

13. Arturo Torremocha García

Acabado textiles

14. PROMIXDENT S.L.

Fabricación instrumentos y suministros médicos y odontológicos.

15. Diego Giménez Martí

Fabricación instrumentos y suministros médicos y odontológicos.

16. LIMAK S.L.

Fabricación de carpintería metálica

17. BURNAN ALZAREY S.L.

Fabricación de carpintería metálica

18. Salvador Alonso Alegre

Fabricación de cerraduras y herrajes

19. Benito Clemente Simó

Fundición de otros metales no férreos

20. Vicente Roig Vicente

Mantenimiento y reparación de vehículos a motor

21. FARMALEXPA AUTO MOTOR S.L.

Mantenimiento y reparación de vehículos a motor

22. Antonio Gutiérrez Parra

Mantenimiento y reparación de vehículos a motor 
23. Raúl Escamilla Abellán

Mantenimiento y reparación de vehículos a motor

24. JOSÉ GÓMEZ MONTES RACING S.L.

Mantenimiento y reparación de vehículos a motor

25. José Vicente Bartual Alonso

Mantenimiento y reparación de vehículos a motor

\section{Antonio Sancha López}

Mantenimiento y reparación de vehículos a motor

27. Marcos Sanz García

Mantenimiento y reparación de vehículos a motor

28. AUTOWASH SILA C.B.

Mantenimiento y reparación de vehículos a motor

29. TALLERES GRACIA C.B.

Mantenimiento y reparación de vehículos a motor

30. PROFESIONAL REPAIR CAR S.L.

Mantenimiento y reparación de vehículos a motor

31. Francisco Expósito Ortiz

Mantenimiento y reparación de vehículos a motor

32. Manuel Molero Martínez

Mantenimiento y reparación de vehículos a motor

33. Arsenio Julián Chavarría

Mantenimiento y reparación de vehículos a motor

34. Félix Serrano Blasco

Mantenimiento y reparación de vehículos a motor

35. TALLERES MALVI, SDAD CIVIL

Mantenimiento y reparación de vehículos a motor

36. Emilio Lara Palencia

Mantenimiento y reparación de vehículos a motor

37. Rodolfo Valentino García Mariscal

Mantenimiento y reparación de vehículos a motor

38. Antonio José Sánchez Posadas

Mantenimiento y reparación de vehículos a motor

39. Antonio Gavilán Villodre

Mantenimiento y reparación de vehículos a motor

40. Miguel Sanchis Company

Mantenimiento y reparación de vehículos a motor

41. Antonio Díaz Aguilar

Mantenimiento y reparación de vehículos a motor

42. Manuel Castander Portillo

Fabricación de otros muebles 
43. SAEZ MORALES C.B.

Fabricación de otros muebles

44. Cristóbal Martínez Roa

Fabricación de otros muebles

45. Francisco Javier Navarrete Ordo

Fabricación de carpintería metálica

46. Eduardo Molina López

Fabricación de pan y productos frescos de panadería y pastelería.

47. Francisco José Pons Boix

Fabricación de pan y productos frescos de panadería y pastelería

48. Juan Carlos Hernández Cebrián

Fabricación de pan y productos frescos de panadería y pastelería

49. Mario Hernández Cebrián

Fabricación de galletas y productos de panadería y pastelería de larga duración

50. SILOS LA PUNTA S.L.

Fabricación de productos de molinería

51. Ibañez Victoria, Salvador

Otras actividades de impresión y artes gráficas

52. COPIX S.C.

Otras actividades de impresión y artes gráficas

53. COPIA 2

Otras actividades de impresión y artes gráficas

54. FRONT GRAFIC S.L.

Otras actividades de impresión y artes gráficas

55. GRÁFICAS ARROLUS S.L.

Otras actividades de impresión y artes gráficas

56. MÁRMOLES ARTISTICOS CHOVER, S.A.

Mantiene la actividad

57. Rafael Flores Raya

Mantiene la actividad

58. COOP. OBRERA PRODUCCIÓN ARTES GRÁFICAS

Mantiene la actividad 
ESTADO ACTUAL DE LOS ANTIGUOS EDIFICIOS INDUSTRIALES DE INTERES.-

- macosa

C/ San Vicente Mártir no 269 (FA-2)

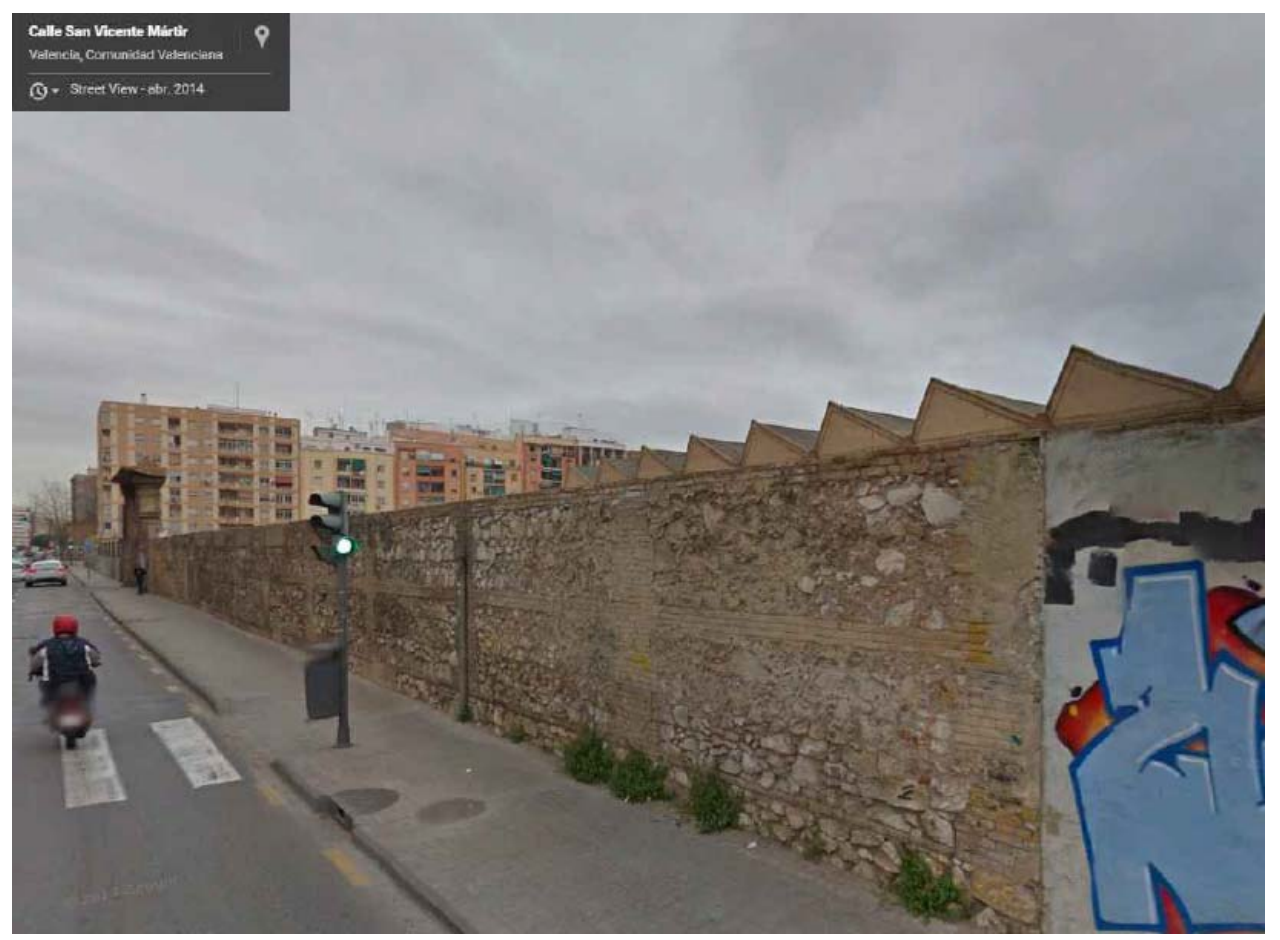

Foto 52: Solar. Antigua ubicación MACOSA. C/ San Vicente Mártir, 269. Valencia. 2014 Fuente: WEB. http://www.google.es/maps (Street View).

- EL TURIA

C/ San Vicente Mártir no 271 (FC-1)

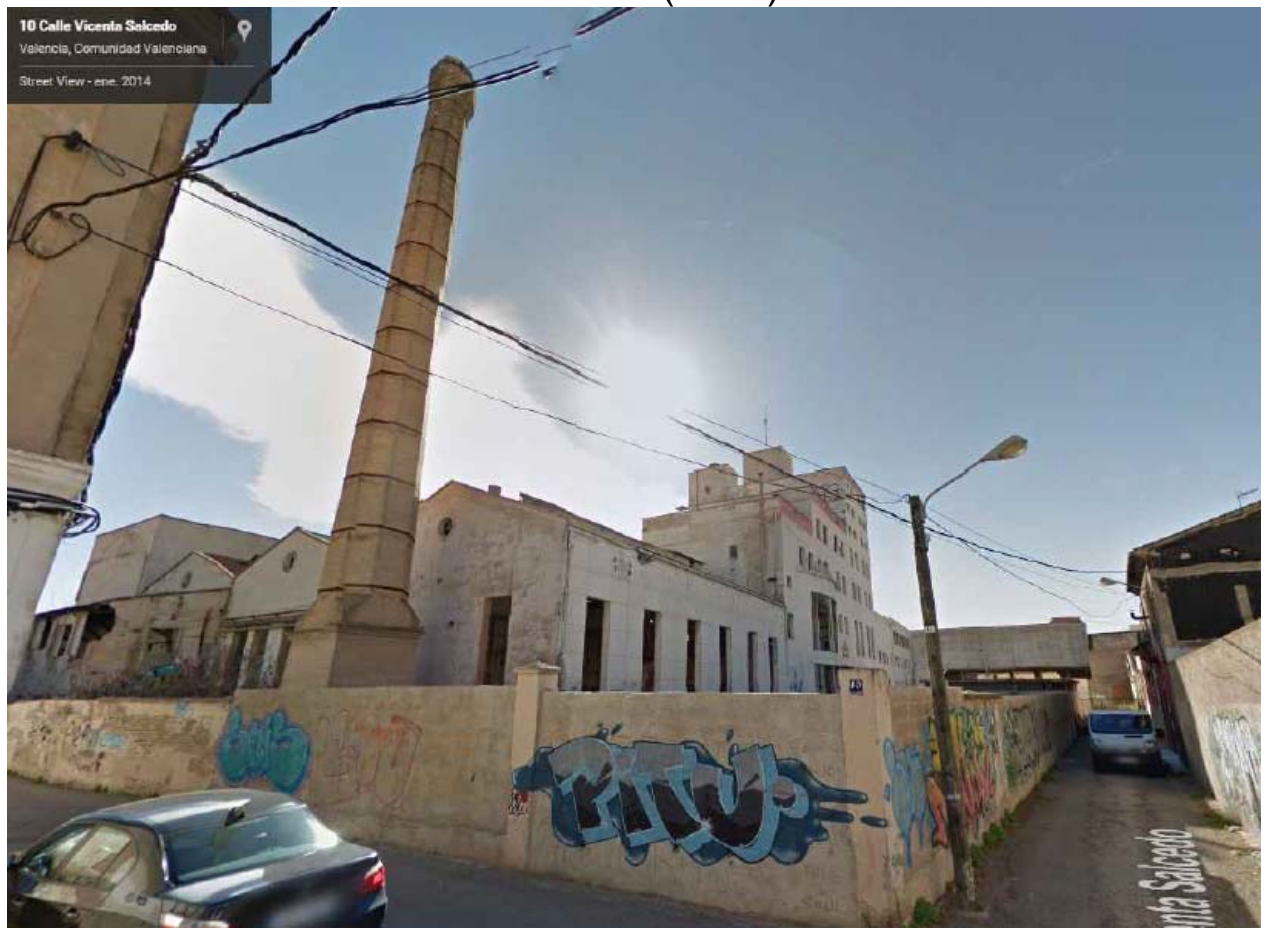

Foto 53: Antigua ubicación EL TURIA. C/ San Vicente Mártir, 271. Valencia. 2014

Fuente: WEB. http://Www.google.es/maps (Street View). 
- BELENGUER

C/ San Vicente Mártir № 299 (6F/5000-1)

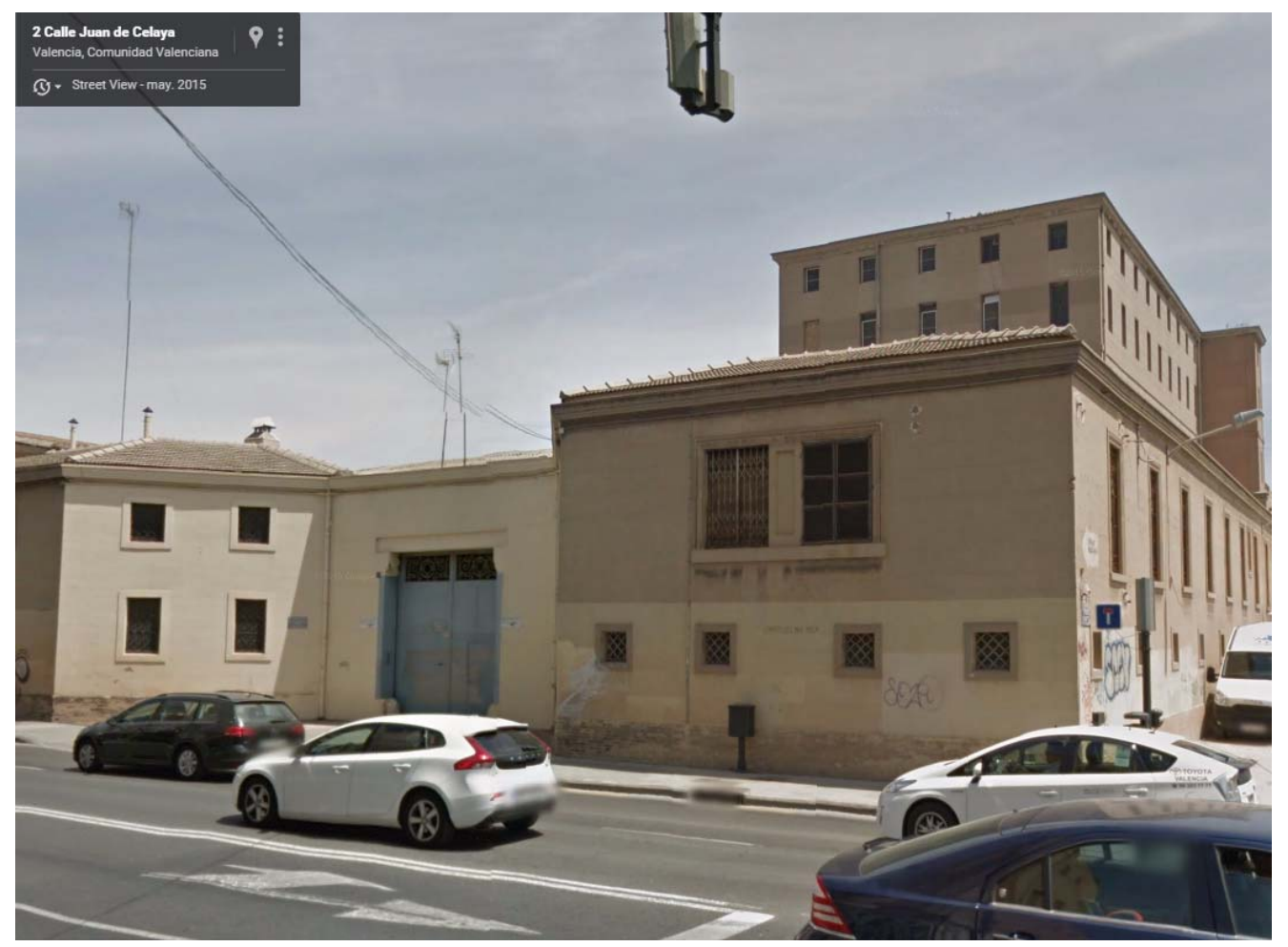

Foto 54: Antigua fábrica de harina. BELENGUER. C/ San Vicente Mártir, 299. Valencia. 2015 Fuente: WEB. http://www.google.es/maps (Street View). 


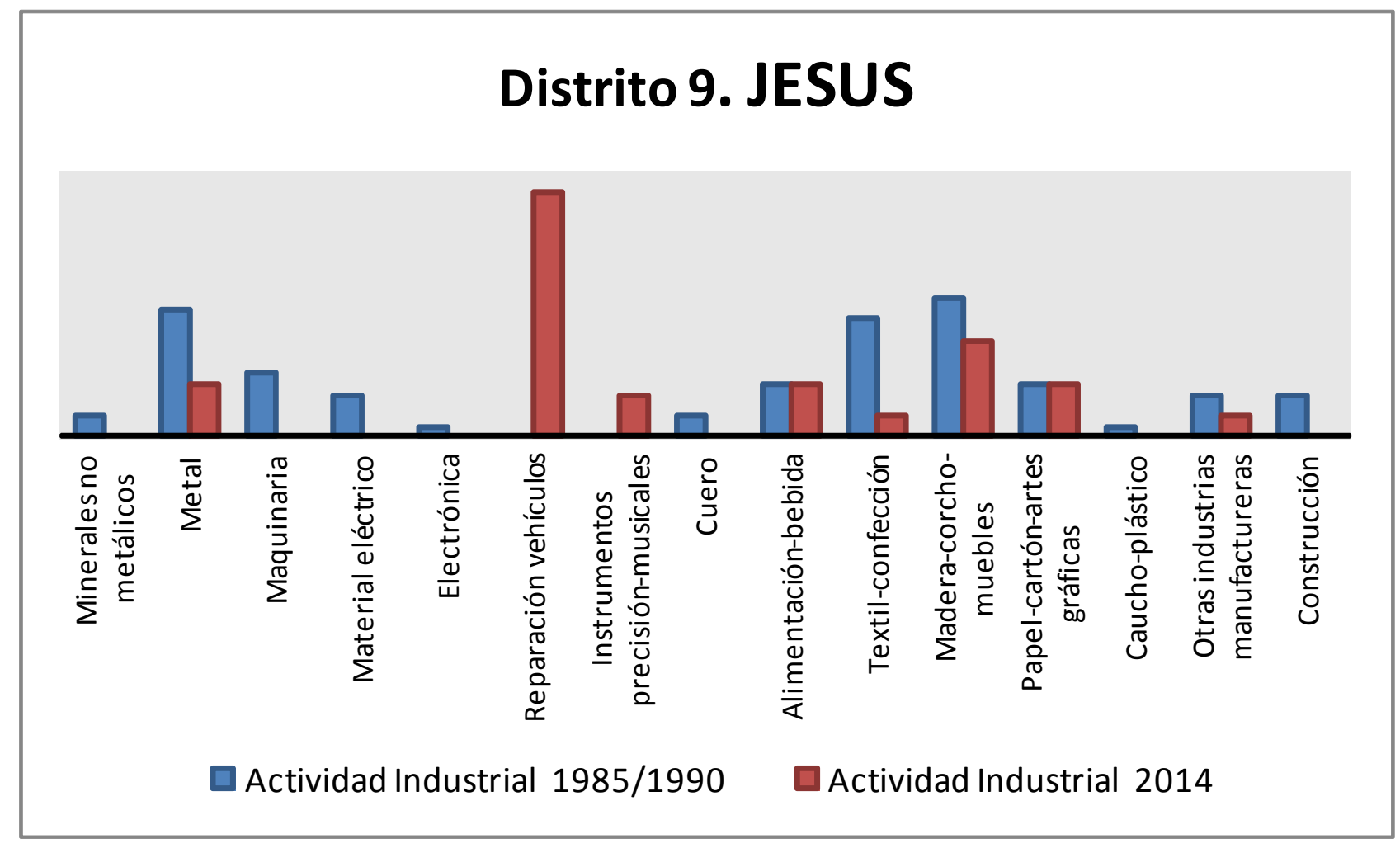

EVOLUCIÓN DEL IMPACTO AMBIENTAL

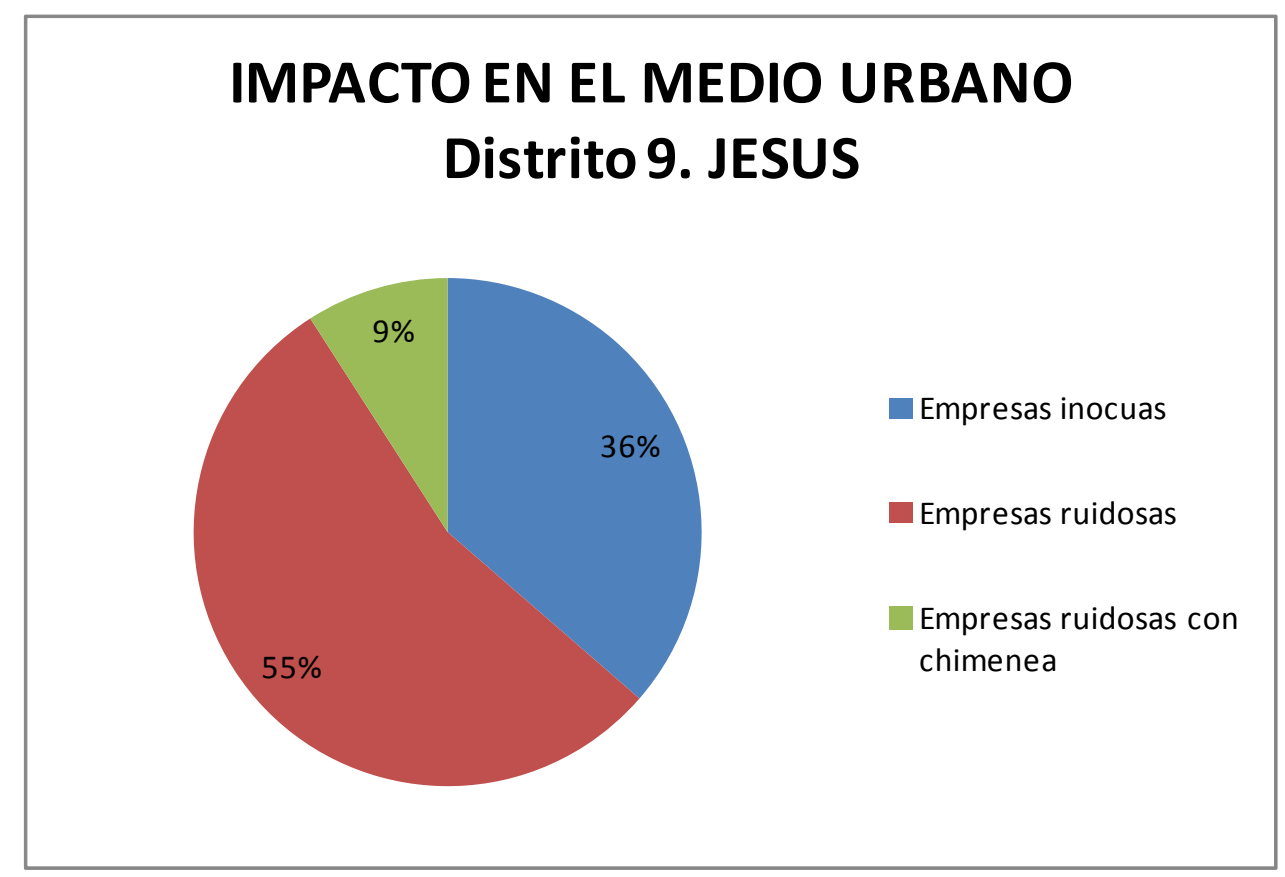




\section{FICHAS TIPO \\ FICHA DATOS DE LA INDUSTRIA}

LOCALIZACION ACTUALIZADA DE ACTIVIDADES INDUSTRIALES EN EL MEDIO URBANO DE VALENCIA
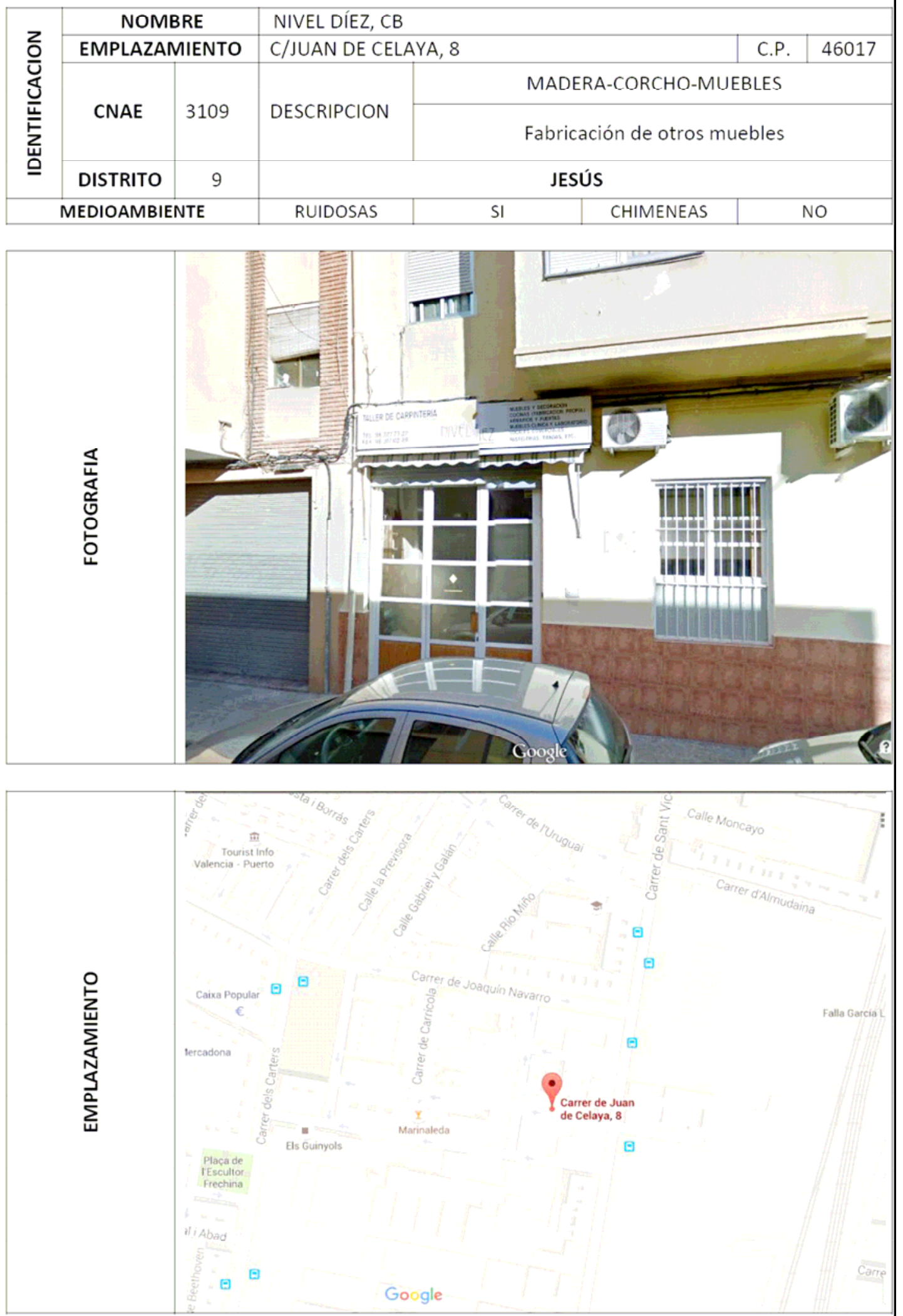


\section{FICHA DATOS DE LA INDUSTRIA}

LOCALIZACION ACTUALIZADA DE ACTIVIDADES INDUSTRIALES EN EL MEDIO URBANO DE VALENCIA

\begin{tabular}{|c|c|c|c|c|c|c|c|}
\hline \multirow{5}{*}{ 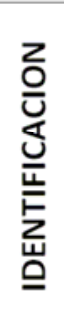 } & \multirow{2}{*}{\multicolumn{2}{|c|}{$\begin{array}{c}\text { NOMBRE } \\
\text { EMPLAZAMIENTO }\end{array}$}} & \multicolumn{5}{|c|}{ MANUEL CASTANDER PORTILLO } \\
\hline & & & \multicolumn{3}{|c|}{ C/TOMÁS DE VILLAROYA, 28} & C.P. & 46017 \\
\hline & \multirow{2}{*}{ CNAE } & \multirow{2}{*}{3109} & \multirow{2}{*}{ DESCRIPCION } & \multicolumn{4}{|c|}{ MADERA-CORCHO-MUEBLES } \\
\hline & & & & \multicolumn{4}{|c|}{ Fabricación de otros muebles } \\
\hline & DISTRITO & 9 & \multicolumn{5}{|c|}{ JESÚS } \\
\hline \multicolumn{3}{|c|}{ MEDIOAMBIENTE } & RUIDOSAS & SI & CHIMENEAS & & 0 \\
\hline
\end{tabular}
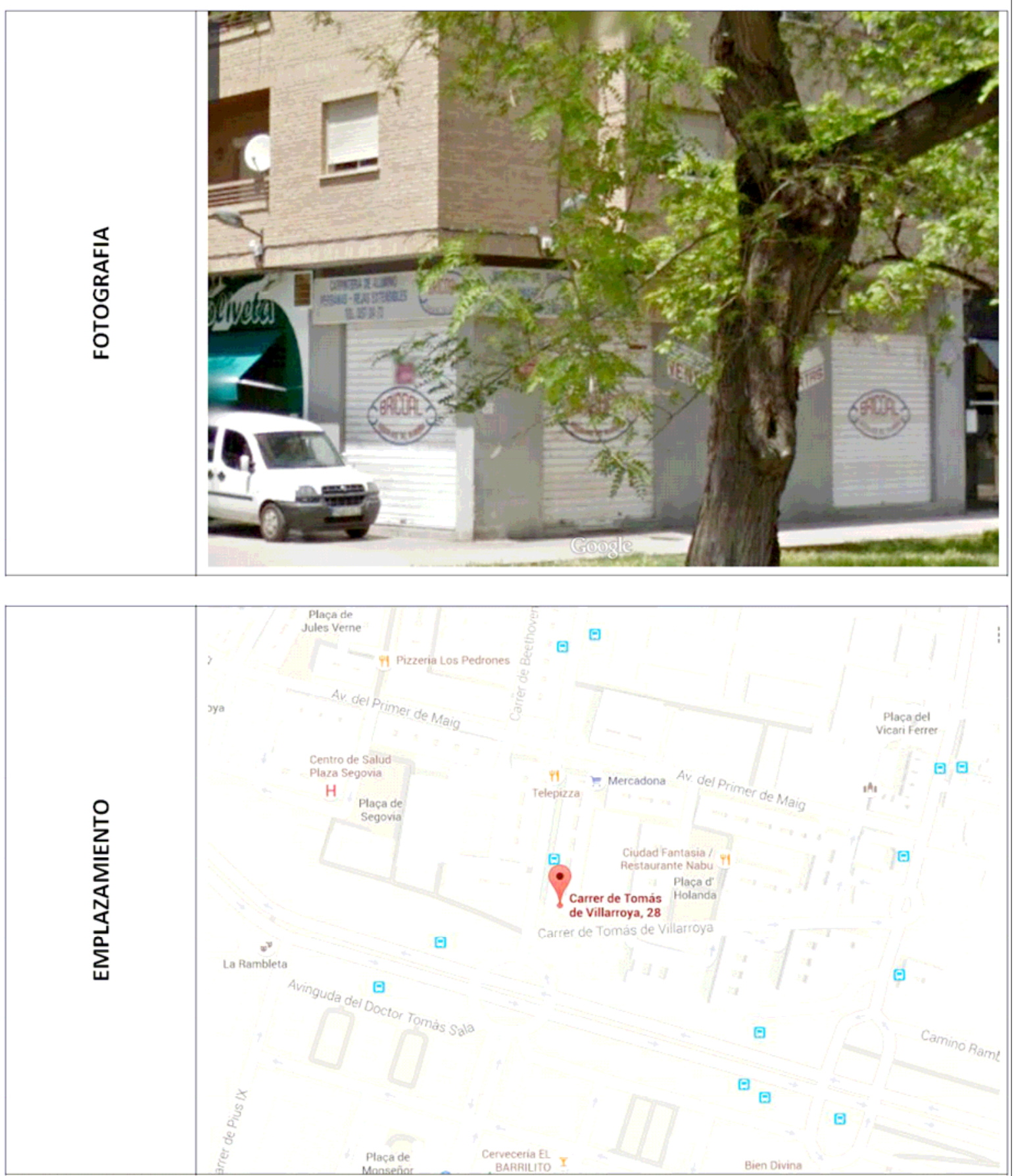


\section{FICHA DATOS DE LA INDUSTRIA}

LOCALIZACION ACTUALIZADA DE ACTIVIDADES INDUSTRIALES EN EL MEDIO URBANO DE VALENCIA
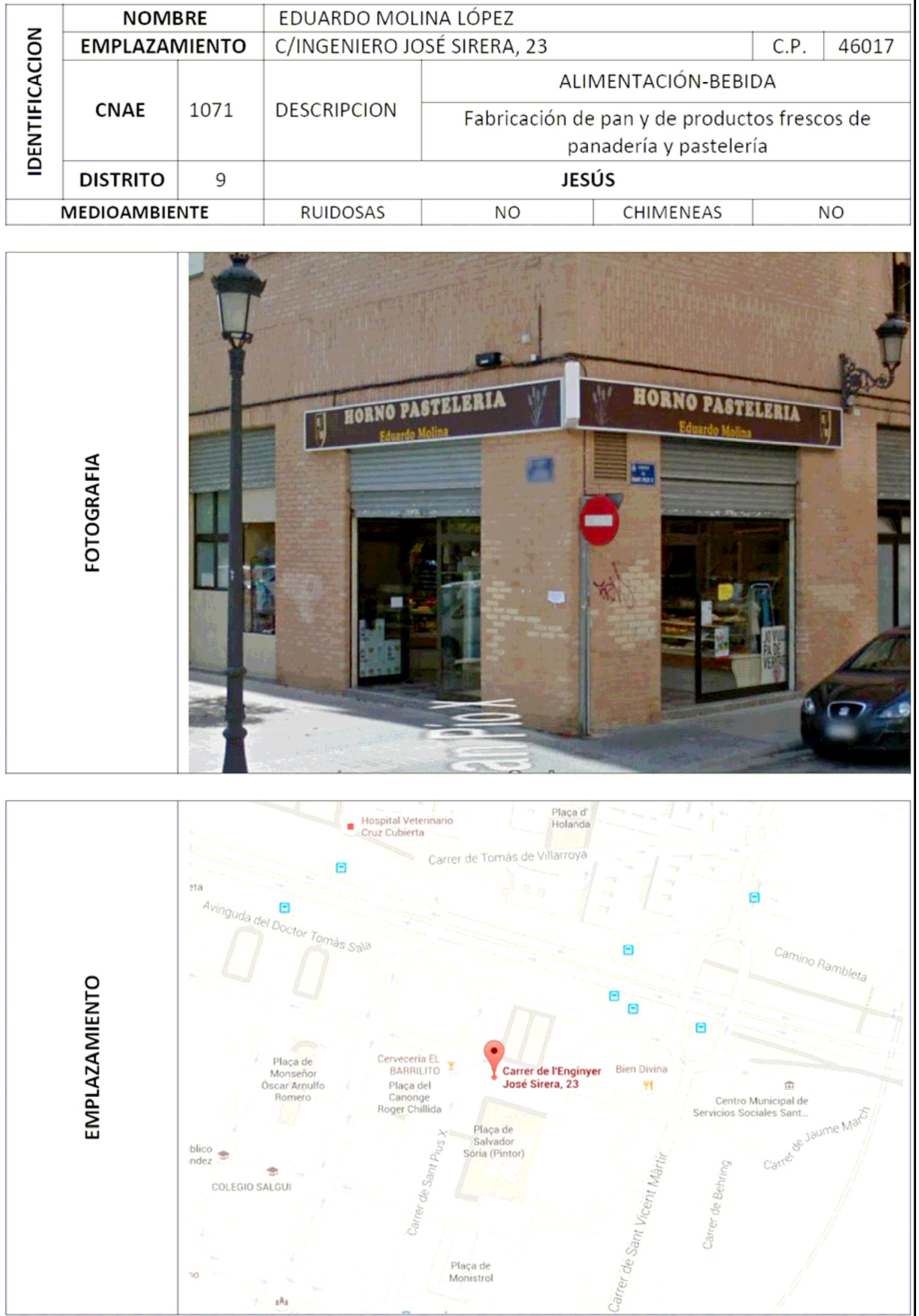


\section{FICHA DATOS DE LA INDUSTRIA}

LOCALIZACION ACTUALIZADA DE ACTIVIDADES INDUSTRIALES EN EL MEDIO URBANO DE VALENCIA

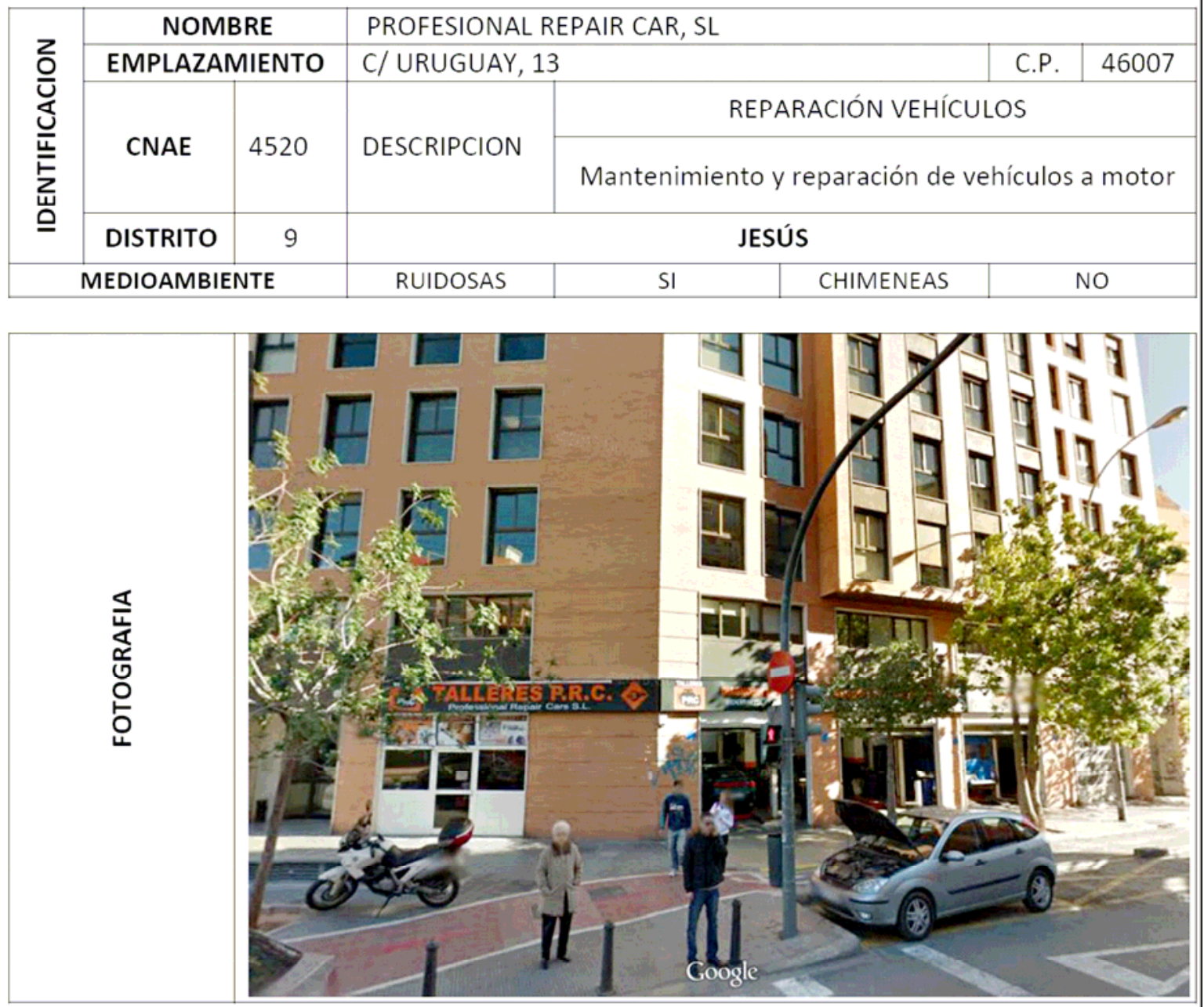

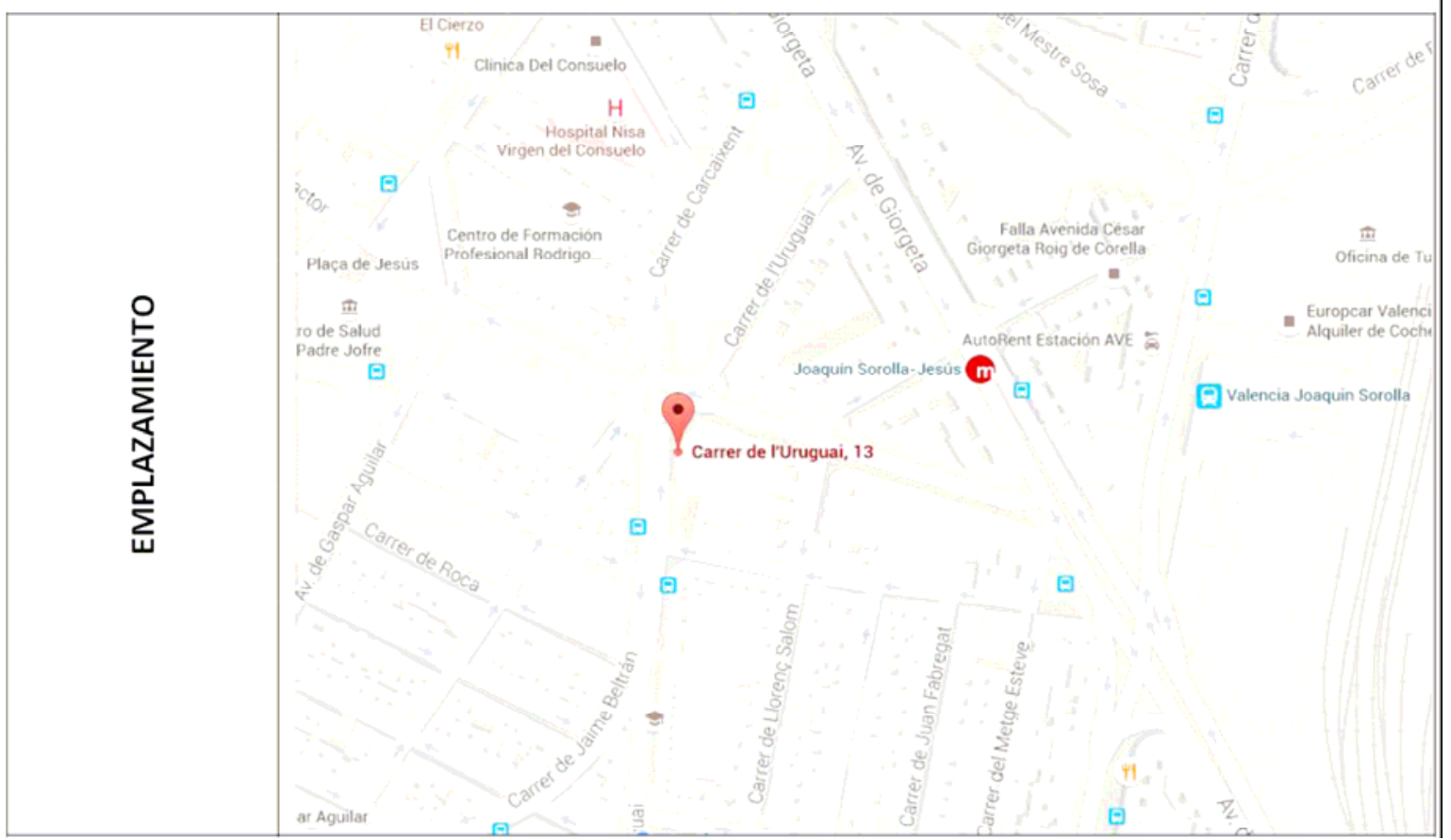




\section{FICHA DATOS DE LA INDUSTRIA}

LOCALIZACION ACTUALIZADA DE ACTIVIDADES INDUSTRIALES EN EL MEDIO URBANO DE VALENCIA

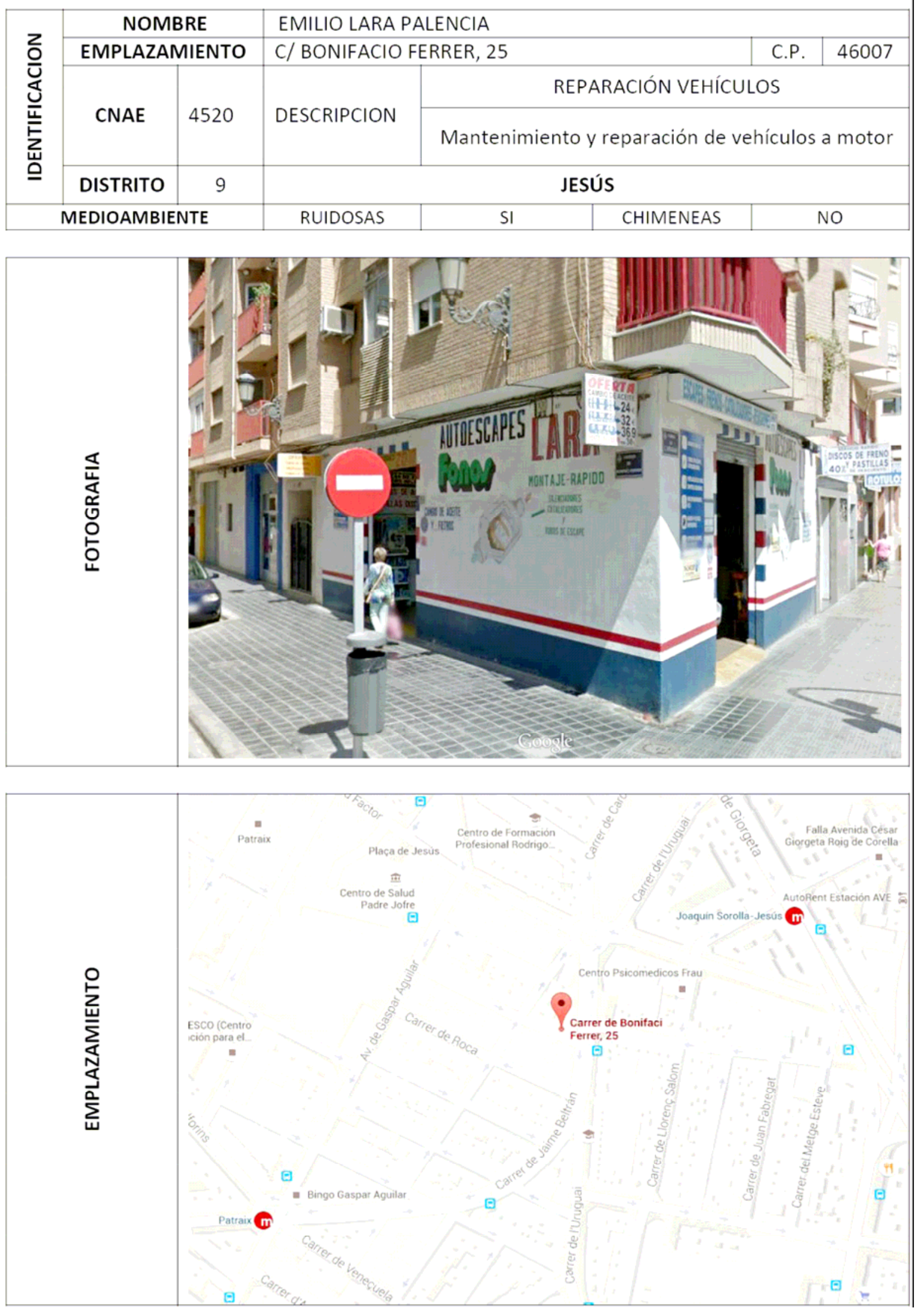




\section{DISTRIT0 10.- QUATRE CARRERES}

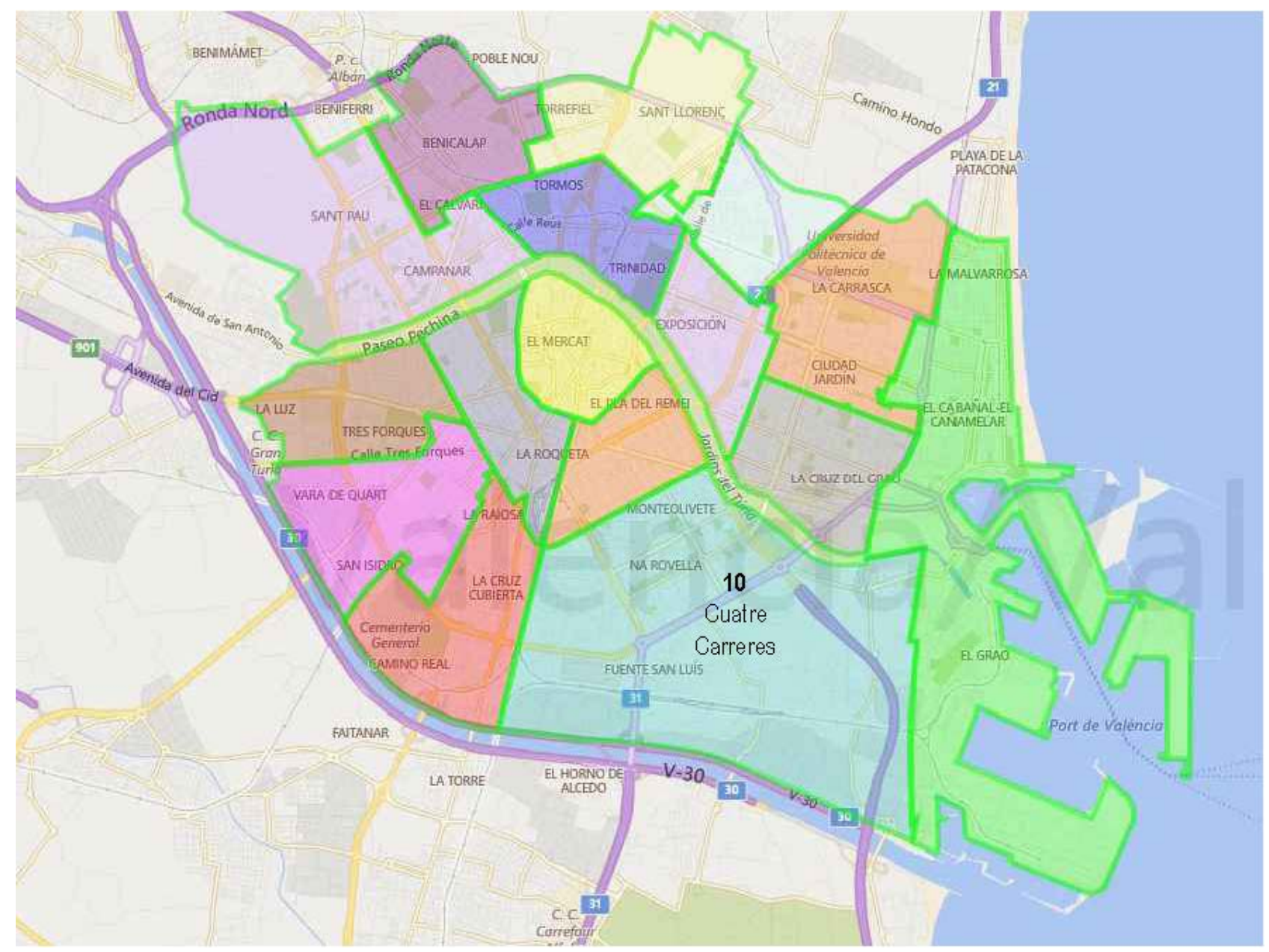

\section{LÍMITES GEOGRÁFICOS.}

Avd. Peris y Valero, Cauce Viejo del Turia, Autopista del Saler, Camino de Nazaret, Mar Mediterráneo, Nuevo Cauce del Turia y línea de Ferrocarril Valencia-Madrid. 


\section{EVOLUCIÓN DEL 1985-2014}

\section{PLANO UBICACIÓN INDUSTRIAS}

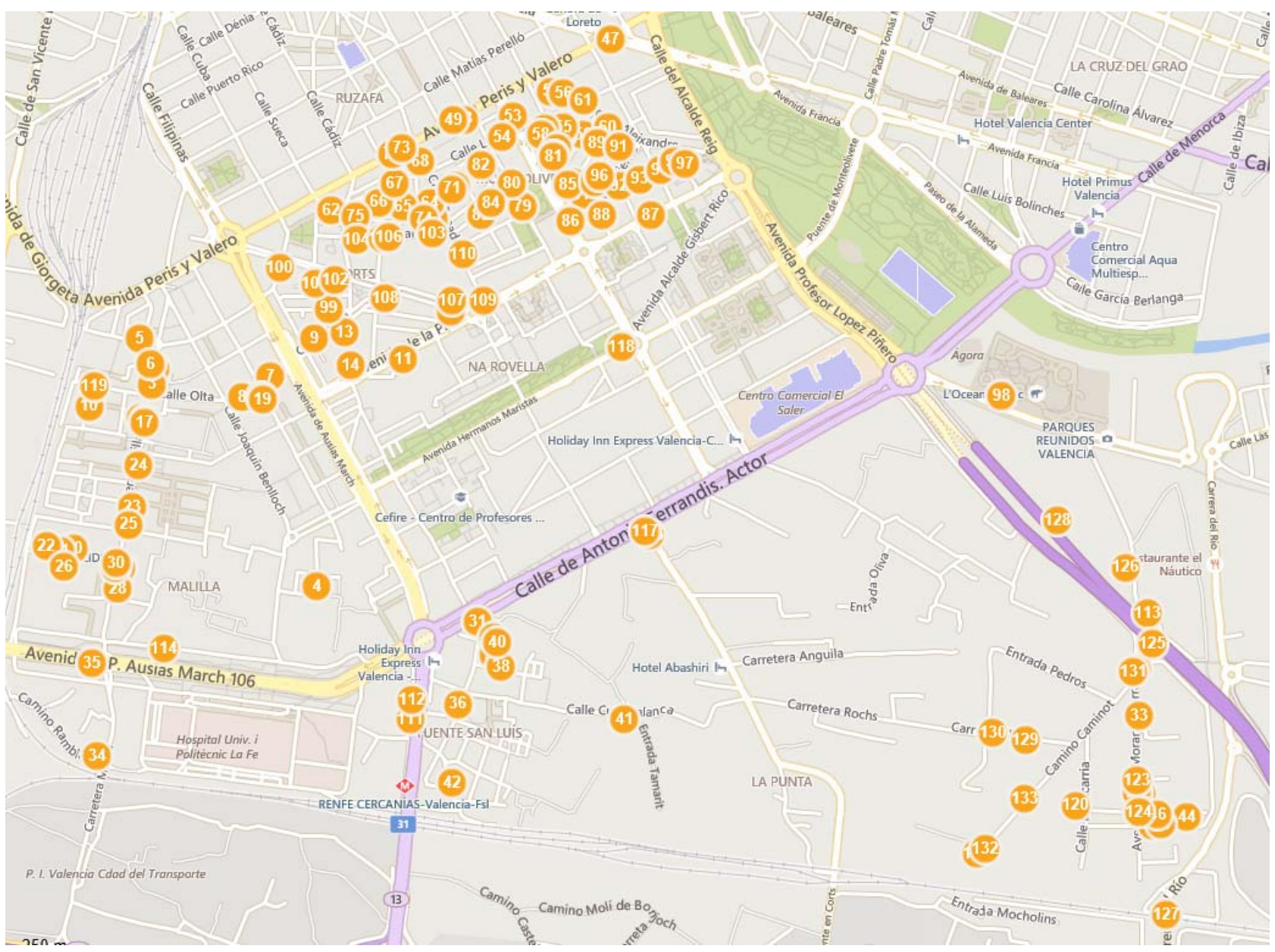

LISTADO DE INDUSTRIAS Y ESTADO ACTUAL :-

1. Pastor F.

Nueva ordenación - Calle

2. Manuel Roca Mesa

Reparación de ordenadores

3. ALIMENTOS LEVANTE, S.A.

Solar sin edificar

4. VAPREL, S.A.

Maquinaria- Herramientas 
5. V. Viguer

Mantiene la actividad

6. Villanova Company, $\mathbf{R}$.

Sin actividad

7. COMERCIAL LEVANTINA DE NEUMATICOS, S.A.

Mantiene la actividad

8. BERNAT RODRIGO, S.L.

Supermercado

9. INDUCLIMA, S.A.

Componentes eléctricos

10. EL DUVAL, S.A.

Colegio

11. Avallone Belda, Juan José

Nueva ordenación- Zona verde

12. MAFOR, S.L.

FERMAX

13. Calabuig Sanz, J.B.

Mantiene la actividad

14. Vicente Montaner Agusti

Obra nueva

15. METALGRA

Nueva ordenación

16. ARTIERRO, S.L.

Solar

17. INECROM, S.L.

Sin actividad

18. CURTIDOS PARERA, S.A.

Mantiene la actividad

19. CURTIDOS LITORAL, S.L.

Club deportivo

20. M. CERRILLO, S.A.

Recambios del automóvil

21. MECANO-UTIL, S.L.

Sin actividad

22. VULCANIZACIONES PASCUAL, J.

Sin actividad

23. FRANCISCO RUEDA, S.L.

Solar sin edificar

24. CROMADOS PASTOR, S.L.

Solar sin edificar 
25. TAPIZADOS MARTÍNEZ MEDINA, S.A.

Solar sin edificar

26. INDERE, S.A.

Mantiene la actividad

27. GIL GÓMEZ, S.L.

Obra nueva

28. S.A. ECHEVARRÍA

Obra nueva

29. VICENTE TATAY TOMÁS, S.A.

Obra nueva

30. Soto Lluesa, A.

Obra nueva

31. MUEBLES MOCHOLI, S.A.

Nueva ordenación- Calle

32. García Hompanera, María Luisa

Sin datos

33. Mas Martínez, J.V.

Sin datos

34. VOLQUETES IBÁÑEZ, S.L.

Artes gráficas

35. COHEFER SOCIEDAD COOPERATIVA LIMITADA

Nueva ordenación- Boulevard

36. Salcedo Jabaloyas, J.

Sin actividad

37. Juan Salcedo Jabaloyas

Sin actividad

38. VIDAL CRESPO, S.A.

Sin actividad

39. V. ASENSI Y CIA, S.L.

Solar

40. TABLEROS ROSELL, S.A.

Sin actividad

41. HIGON QUILIS, S.L.

Sin actividad

42. HIERROS HERGA, S.L.

Sin actividad

43. TALLERES MOYA, S.L.

Mantiene la actividad

44. COALSA

Mantiene la actividad 
45. Badía Alegre, Francisco

Industria plásticos

46. HIERROS SAN MARCELINO S.A.

Mantiene la actividad

47. S.K.F. ESPAÑOLA S.A.

Sin actividad

48. Llop Mocholí, V.

Envío de dinero

49. TOLDOS ABAN S.L.

Taller automóvil

50. INDUSTRIAS PLÁSTICAS TORMAR S.A.

Sin actividad

51. ALBIÑANA S.A.

Peluquería

52. VEMA IBÉRICA S.A.

Mantenimiento de electrodomésticos

53. Eliseo Aranda

Mantiene la actividad

54. PETER'S TORTEN SHOP S.A.

Sin actividad

55. Galdón Lluch, V.

Mantiene la actividad

56. Vasas Kovack, $P$.

Reparación de ordenadores

57. Martínez Maya, J.

Sin actividad

58. FOTOMECÁNICA CARRERES S.L.

Mantiene la actividad

59. Gimeno Martínez, J.

Sin datos

60. Aznar Climent, Vicente

Obra nueva

61. ELECTRICIDAD ROLUX

Mantiene la actividad

62. LÓPEZ Y MUNT S.L.

Sin actividad

63. Ramón Chuliá Bueso

Limpiezas

64. Pérez Luciano, S.

Sin datos 
65. Juan Fayos

Sin actividad

66. HIJOS DE MANUEL RAMOS S.L.

Mantiene la actividad

67. Tárrega Pérez, R.

Obra nueva

68. CONSTRUCCIONES METÁLICAS VIENRI S.L.

Obra nueva

69. Dutor Moreno, B.

Obra nueva

70. Segrelles Orch, M.

Sin actividad

71. GRÁFICAS ANDUJAR S.A.

Obra nueva

72. S.A. DE LUZ

Placas de matrícula

73. P. Amorós

Sin actividad

74. HROGU S.L.

Sin datos

75. Olmos Pascual, A.

Sin actividad

76. CIERRES METÁLICOS F. DÍAZ S.A.

Sin actividad

77. INDUSTRIAS H.V.M. S.A.

Sin actividad

78. R. Doménech

Sin actividad

79. S. Moret Fenollosa

Mantiene la actividad

80. ASCENSORES SORIANO S.A.

Ofimática

81. MECANO DENTAL

Sin actividad

82. Martínez Armengol, Ramón

Sin actividad

83. Safont Oliver M.

Obra nueva

84. GRAFICAS VILLANUEVA PEREZ

Sin actividad 
85. IMPASAL S.L.

Sin actividad

86. W. NAVARRO MERCURI S.A.

Supermercado

87. Sornosa Domingo J.

Entidad bancaria

88. ELECTRO CAYNO S.L.

Cristalería

89. BOLSOS QUILES S.A.

Sin actividad

90. Rogelio Pont

Sin actividad

91. TEDISA S.L.

Sin actividad

92. Navarro Rodrigo

Mantiene la actividad

93. Busquet Gruat

Sin actividad

94. SERTECO S.L.

Sin datos

95. Aragonés $\mathrm{F}$.

Pub- Karaoke

96. Martínez Molins V.

Carpintería de aluminio

97. MANUFACTURAS VEGA S.A.

Sin actividad

98. Vicente López Clemente

Oceanogràfic

99. INCALGAS S.L.

Oficinas CB

100. PAYDOS S.L.

Sin actividad

101. Enrique Borreda "BOMAR"

Sin datos

102. Monzón A.

Sin datos

103. JOSEV S.L.

Sin actividad

104. López Borrás R.

Sin actividad 
105. Crespo Ballester, José

Sin actividad

106. Vda. de Navarro

Sin actividad

107. CHARACTER

Mantiene la actividad

108. Gimeno Miro J.

Venta on-line

109. TABLEROS ORTEGA MINGUET

Reprografía

110. A. Subirats Casanovas

Restaurante

111. MECANIZADOS S.A.

Automoción

112. MINGUEZ S.A.

Concesionario

113. VDA. DE RODRÍGUEZ ERRANDO S.A.

Mantiene la actividad

114. ARDEVA S.L.

Nueva ordenación- Calle

115. FRIGORIFICOS MONTOLIU

Nueva ordenación- Boulevard sur

116. KOSY

Sin actividad

117. ALBERTO MORA GALIANA S.A.

Nueva ordenación

118. Pérez Sánchez, Amado

Nueva ordenación- Solar

119. GRAFICAS RIVER

Sin actividad

120. MADERAS JOSÉ M ${ }^{a}$ FERRERO VIDAL S.A.

Mantiene la actividad

121. Fábrica de muebles SOON

Sin actividad

122. BULLYCAN

Sin actividad

123. METÁLICA VALENCIANA S.A.

Sin actividad

124. Navarro Beneyto R.

Mantiene la actividad 
125. Peidro Coscollá, Manuel

Talleres

126. María Lliso Dionisio

Mantiene la actividad

127. Yerbes Sanz V.

Nueva ordenación- Vías de tren

128. CAYBASA

Solar sin edificar

129. PUERTAS CUBELLS

Mantiene la actividad

130. Vicente Mengod

Mantiene la actividad

131. Manuel Dobón

Solar

132. TRANS-CON

Solar

133. CONTENEDORES

Nueva ordenación- Naves y huerta

134. DEPURADORAS AGUAS DE PINEDO

Mantiene la actividad

CARACTERÍSTICAS DEL ASENTAMIENTO INDUSTRIAL.

- Asentamiento industrial heterogéneo, cono el distrito en que se emplaza, donde gran parte de su superficie es zona de huerta. Se distinguen por tanto dos zonas industriales:

- Zona Urbana Consolidada:

Es la franja comprendida entre la Avd. Peris y Valero, Cauce Viejo del Turia, Avd. de la Plata y Avd. Ausias March (Pista de Silla).

Sus características son las siguientes:

- Uso residencial dominante.

- Industria de pequeña superficie situada en el núcleo urbano tradicional (Monteolivete, Ruzafa) en plantas baja de edificios de viviendas entre medianeras.

- Zona Urbana no consolidada:

Comprende los desarrollos urbanos recientes que tienen lugar a lo largo de un eje viario tradicional ocupando superficie de huerto y quedando envuelto 
por esta, produciendo un notable deterioro del paisaje. Es este el caso de los asentamientos industriales de Carrera Malilla, Carrera de la Font de Sant LLuis, Carrera en Corts y del Camino del Caminot.

Sus características son las siguientes:

- Industria de pequeña y mediana superficie situada en las márgenes del eje viario que las genera y en locales de tipo industrial generalmente entre medianeras.

- Buena parte de las industrias carecen de alcantarillado, vertiendo directamente a acequias. El resto de los servicios urbanísticos suelen ser deficientes.

- Surgen en áreas de huerta sin tener en cuenta su entorno con el consiguiente deterioro del paisaje.

\section{CARACTERÍSTICAS DE LOS LOCALES COMERCIALES.}

Ya han sido descritos en el punto anterior. Cabe mencionar sin embargo las superficies ocupadas por almacenes de contenedores a lo largo del Co del Caminot y las grandes infraestructuras situadas junto a la margen izquierda del río Turia: Estación Depuradora de Aguas, Mercavalencia y Estación de clasificación de mercancías de la Fuente de San Luis.

\section{CARACTERÍSTICAS DE LAS ACTIVIDADES.}

Se censaron inicialmente 134 industrias y en el período de vigencia del Plan General han quedado solamente 23 creándose 65 nuevas industrias.

Las actividades dominantes son madera y muebles, productos metálicos, construcción de maquinaria, calzado y confección y contenedores.

\section{IMPACTO EN EL MEDIO AMBIENTE.}

La contaminación ambiental es escasa en la zona urbana consolidada, por tratarse de pequeñas industrias poco contaminantes y por la existencia de alcantarillado, reduciéndose casi exclusivamente a las molestias de tipo acústico como consecuencia de la proximidad entre industrias y viviendas.

Tiene sin embargo mayor importancia en las zonas urbanas no consolidadas, por tratarse de áreas de huerta, con notables deficiencias en infraestructura y servicios 
urbanísticos y por la degradación paisajística que producen las actividades de tipo industrial en las zonas de huerta.

El transporte generado por la industria en el interior del distrito no es importante salvo en casos puntuales (Estación de clasificación de la Fuente de San Luis, Mercavalencia) y en menor grado las concentraciones industriales a lo largo de los caminos tradicionales (Malilla, Fuente de San Luis, Co del Caminot, etc.). Por otra parte es de gran Importancia el tráfico que discurre por la Avd. Ausias March (Ctra. Nacional 340) y por la Avd. Peris y Valero que, si bien no tiene su origen en el distrito, le afecta negativamente, en especial a su paso por la citada Avd. de Peris y Valero donde los humos y ruidos producidos por los vehículos son muy considerables.

\section{EDIFICIOS INDUSTRIALES DE INTERES.}

- Martínez Medina.

Avd. Ausias March ํㅜ16 / 6F/5000)

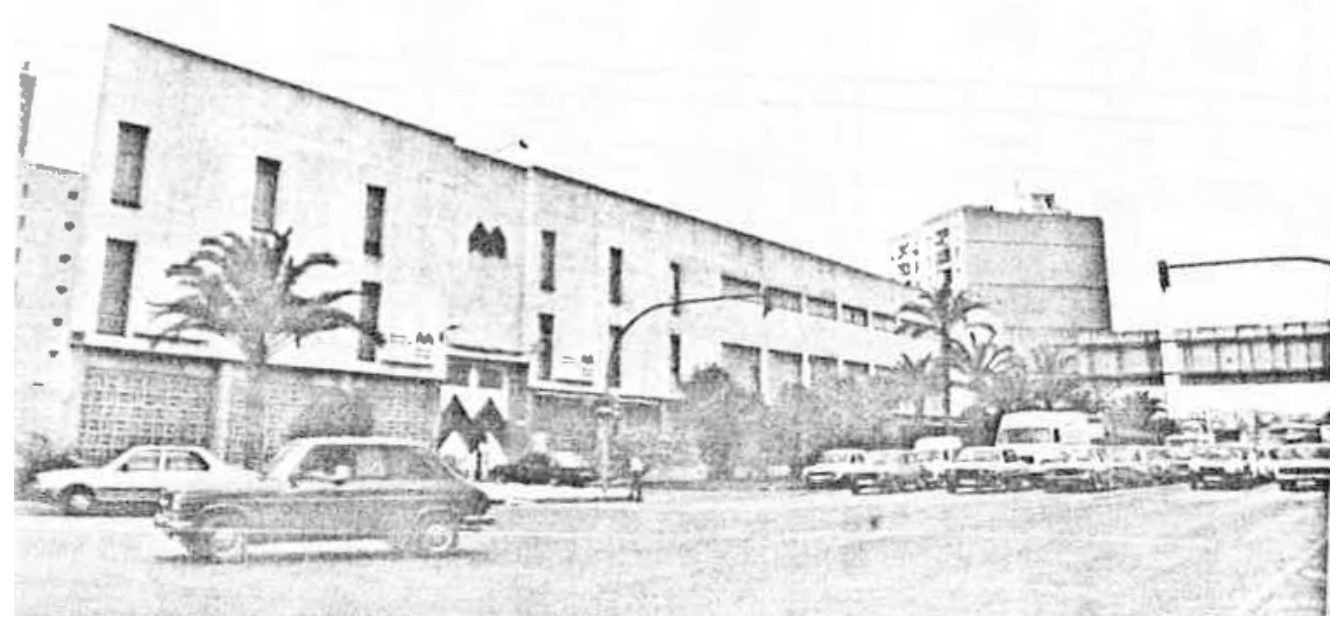

Foto 55: Fábrica de muebles. Martínez Medina, S.A. Avda. Ausias March, 16. Valencia.1985. Fuente: Elaboración propia 
TIPOLOGÍA EDIFICACIÓN

\section{TIPOLOGÍA DE EDIFICACIÓN Distrito 10. QUATRE CARRERES}

AISLADO ENTRE MEDIANERAS

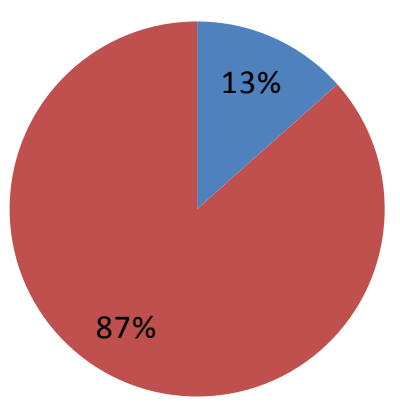




\section{ACTIVIDAD INDUSTRIAL, SUPERFICIE Y EMPLEO}

\begin{tabular}{|c|c|c|c|c|c|}
\hline \multicolumn{6}{|c|}{ DISTRITO 10 - QUATRE CARRERES (ATIVIDAD INDUSTRIAL Y EMPLEO) } \\
\hline ACTIVIDAD & $\begin{array}{c}\text { № } \\
\text { EMPRESAS }\end{array}$ & $\begin{array}{c}\text { SUP. ACTIVIDAD } \\
\text { IND }\left(\mathrm{m}^{2}\right)\end{array}$ & $\begin{array}{c}\text { \% SUP. } \\
\text { INDUSTRIAL }\end{array}$ & $\begin{array}{c}\text { № } \\
\text { EMPLEADOS }\end{array}$ & $\begin{array}{c}\text { DENSIDAD } \\
\text { EMPLEO } \\
\text { (empleados } / \mathrm{m}^{2} \\
\text { actividad) }\end{array}$ \\
\hline PRODUCCIÓN Y PRIMERA TRANSFORMACIÓN DE METALES & 1 & 2496 & 1,21 & 6 & 0,0024 \\
\hline INDUSTRIAS DE PRODUCTOS MINERALES NO METÁLICOS & 2 & 1030 & 0,50 & 32 & 0,0311 \\
\hline INDUSTRIA QUÍMICA & 3 & 14500 & 7,01 & 62 & 0,0043 \\
\hline FABRICACIÓN DE PRODUCTOS METÁLICOS & 28 & 21710 & 10,49 & 254 & 0,0117 \\
\hline CONSTRUCCIÓN DE MAQUINARIA Y EQUIPO MECÁNICO & 14 & 14673 & 7,09 & 239 & 0,0163 \\
\hline CONSTRUCCIÓN DE MAQUINARIA Y MATERIAL ELÉCTRICO & 4 & 1197 & 0,58 & 28 & 0,0234 \\
\hline CONSTRUCCIÓN DE VEHÍCULOS AUTOMÓVILES Y SUS PIEZAS DE REPUESTO & 2 & 2650 & 1,28 & 20 & 0,0075 \\
\hline CONSTRUCCIÓN DE OTRO MATERIAL DE TRANSPORTE & 1 & 600 & 0,29 & 8 & 0,0133 \\
\hline FABRICACIÓN DE INSTRUMENTOS DE PRECISIÓN, ÓPTICA Y SIMILARES & 2 & 328 & 0,16 & 25 & 0,0762 \\
\hline INDUSTRIAS DE PRODUCTOS ALIMENTICIOS, BEBIDAS Y TABACO & 12 & 4250 & 2,05 & 63 & 0,0148 \\
\hline INDUSTRIAS DE PRODUCTOS ALIMENTICIOS, BEBIDAS Y TABACO & 1 & 160 & 0,08 & 4 & 0,0250 \\
\hline INDUSTRIA DEL CUERO & 5 & 1530 & 0,74 & 67 & 0,0438 \\
\hline INDUSTRIA DEL CALZADO Y DEL VESTIDO Y OTRAS CONFECCIONES TEXTILES & 2 & 1800 & 0,87 & 51 & 0,0283 \\
\hline INDUSTRIAS DE MADERA, CORCHO Y MUEBLES DE MADERA & 18 & 50853 & 24,58 & 454 & 0,0089 \\
\hline INDUSTRIA DEL PAPEL Y FABRICACIÓN DE ARTÍCULOS DE PAPEL, ARTES GRÁFICAS & 9 & 3285 & 1,59 & 105 & 0,0320 \\
\hline INDUSTIAS DE TRANSFORMACIÓN DEL CAUCHO Y MATERIAS PLÁSTICAS & 13 & 8256 & 3,99 & 95 & 0,0115 \\
\hline OTRAS INDUSTRIAS MANUFACTURERAS & 2 & 1720 & 0,83 & 24 & 0,0140 \\
\hline CONSTRUCCIÓN & 5 & 840 & 0,41 & 48 & 0,0571 \\
\hline ACTIVIDADES ANEXAS A LOS TRANSPORTES & 2 & 44000 & 21,27 & & 0,0000 \\
\hline CONTENEDORES & 1 & 28000 & 13,53 & & 0,0000 \\
\hline SIN IDENTIFICAR & 7 & 3003 & 1,45 & 52 & 0,0173 \\
\hline TOTAL & 134 & 206881 & 100 & 1637 & 0,0079 \\
\hline
\end{tabular}

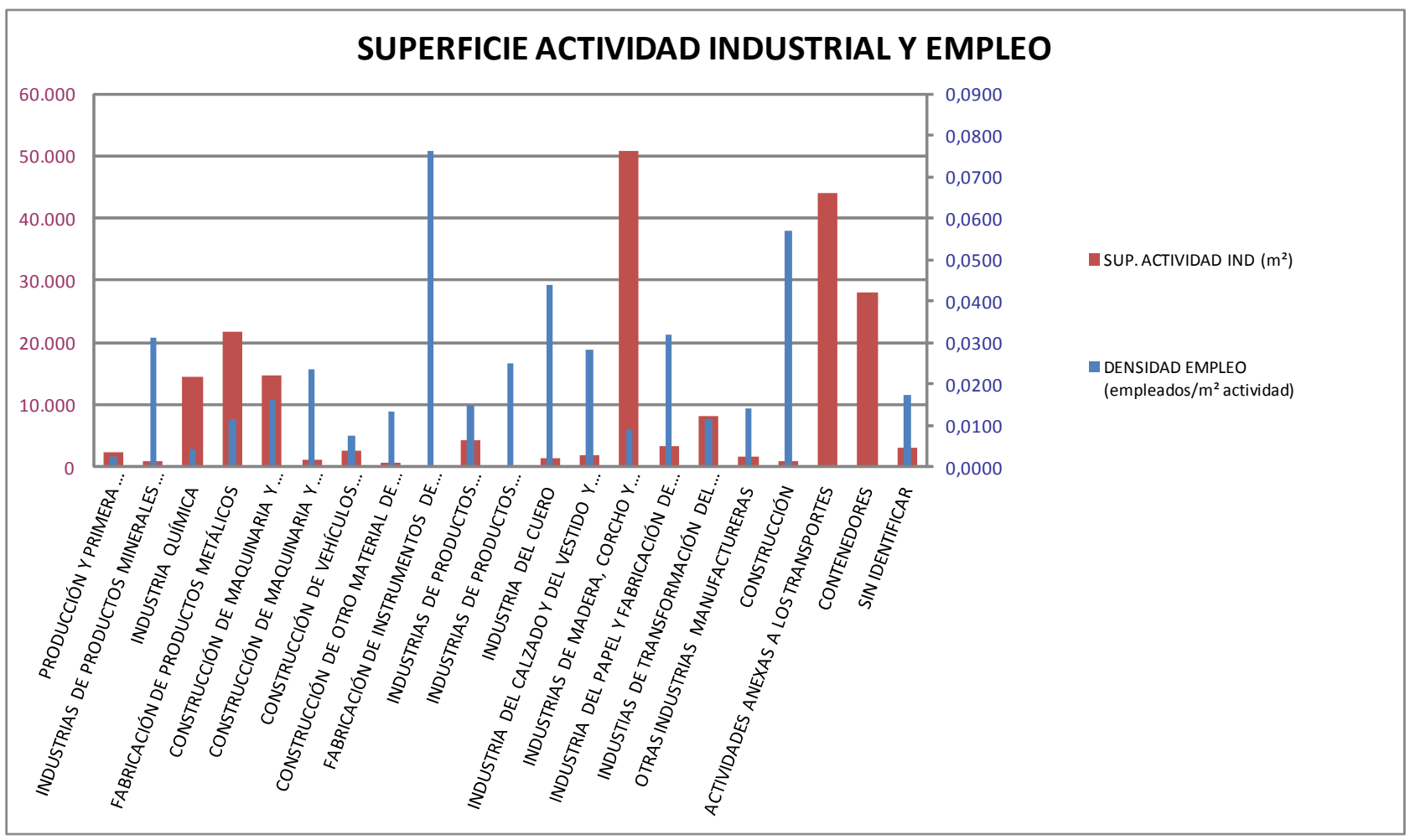




\section{IMPACTO AMBIENTAL}

\begin{tabular}{|c|c|c|c|c|c|}
\hline \multicolumn{6}{|c|}{ DISTRITO 10 - QUATRE CARRERES (INFORMACIÓN URBANÍSTICA) } \\
\hline ACTIVIDAD & $\begin{array}{l}\text { № } \\
\text { EMPRESAS }\end{array}$ & $\begin{array}{c}\text { ENTRE } \\
\text { MEDIANERAS }\end{array}$ & RUIDOSAS & $\begin{array}{c}\text { EMPRESAS } \\
\text { CON } \\
\text { CHIMENEA }\end{array}$ & $\begin{array}{l}\text { RUIDOSAS Y } \\
\text { CHIMENEA }\end{array}$ \\
\hline PRODUCCIÓN Y PRIMERA TRANSFORMACIÓN DE METALES & 1 & 0 & 0 & 0 & 0 \\
\hline INDUSTRIAS DE PRODUCTOS MINERALES NO METÁLICOS & 2 & 2 & 2 & 0 & 0 \\
\hline INDUSTRIA QUÍMICA & 3 & 3 & 1 & 0 & 0 \\
\hline FABRICACIÓN DE PRODUCTOS METÁLICOS & 28 & 24 & 18 & 0 & 0 \\
\hline CONSTRUCCIÓN DE MAQUINARIA Y EQUIPO MECÁNICO & 14 & 13 & 7 & 0 & 0 \\
\hline CONSTRUCCIÓN DE MAQUINARIA Y MATERIAL ELÉCTRICO & 4 & 4 & 1 & 0 & 0 \\
\hline CONSTRUCCIÓN DE VEHÍCULOS AUTOMÓVILES Y SUS PIEZAS DE REPUESTO & 2 & 2 & 2 & 0 & 0 \\
\hline CONSTRUCCIÓN DE OTRO MATERIAL DE TRANSPORTE & 1 & 1 & 1 & 0 & 0 \\
\hline FABRICACIÓN DE INSTRUMENTOS DE PRECISIÓN, ÓPTICA Y SIMILARES & 2 & 2 & 0 & 0 & 0 \\
\hline INDUSTRIAS DE PRODUCTOS ALIMENTICIOS, BEBIDAS Y TABACO & 12 & 12 & 2 & 3 & 0 \\
\hline INDUSTRIAS DE PRODUCTOS ALIMENTICIOS, BEBIDAS Y TABACO & 1 & 1 & 0 & 0 & 0 \\
\hline INDUSTRIA DEL CUERO & 5 & 5 & 3 & 0 & 0 \\
\hline INDUSTRIA DEL CALZADO Y DEL VESTIDO Y OTRAS CONFECCIONES TEXTILES & 2 & 2 & 1 & 0 & 0 \\
\hline INDUSTRIAS DE MADERA, CORCHO Y MUEBLES DE MADERA & 18 & 15 & 13 & 1 & 0 \\
\hline $\begin{array}{l}\text { INDUSTRIA DEL PAPEL Y FABRICACIÓN DE ARTÍCULOS DE PAPEL, ARTES GRÁFICAS } \\
\text { Y EDICIÓN }\end{array}$ & 9 & 9 & 5 & 0 & 0 \\
\hline INDUSTIAS DE TRANSFORMACIÓN DEL CAUCHO Y MATERIAS PLÁSTICAS & 13 & 9 & 8 & 0 & 0 \\
\hline OTRAS INDUSTRIAS MANUFACTURERAS & 2 & 2 & 1 & 0 & 0 \\
\hline CONSTRUCCIÓN & 5 & 5 & 0 & 1 & 0 \\
\hline ACTIVIDADES ANEXAS A LOS TRANSPORTES & 2 & SIN DATOS & SIN DATOS & SIN DATOS & SIN DATOS \\
\hline CONTENEDORES & 1 & SIN DATOS & SIN DATOS & SIN DATOS & SIN DATOS \\
\hline SIN IDENTIFICAR & 7 & 6 & 2 & 0 & 0 \\
\hline TOTAL & 134 & 117 & 67 & 5 & 0 \\
\hline
\end{tabular}

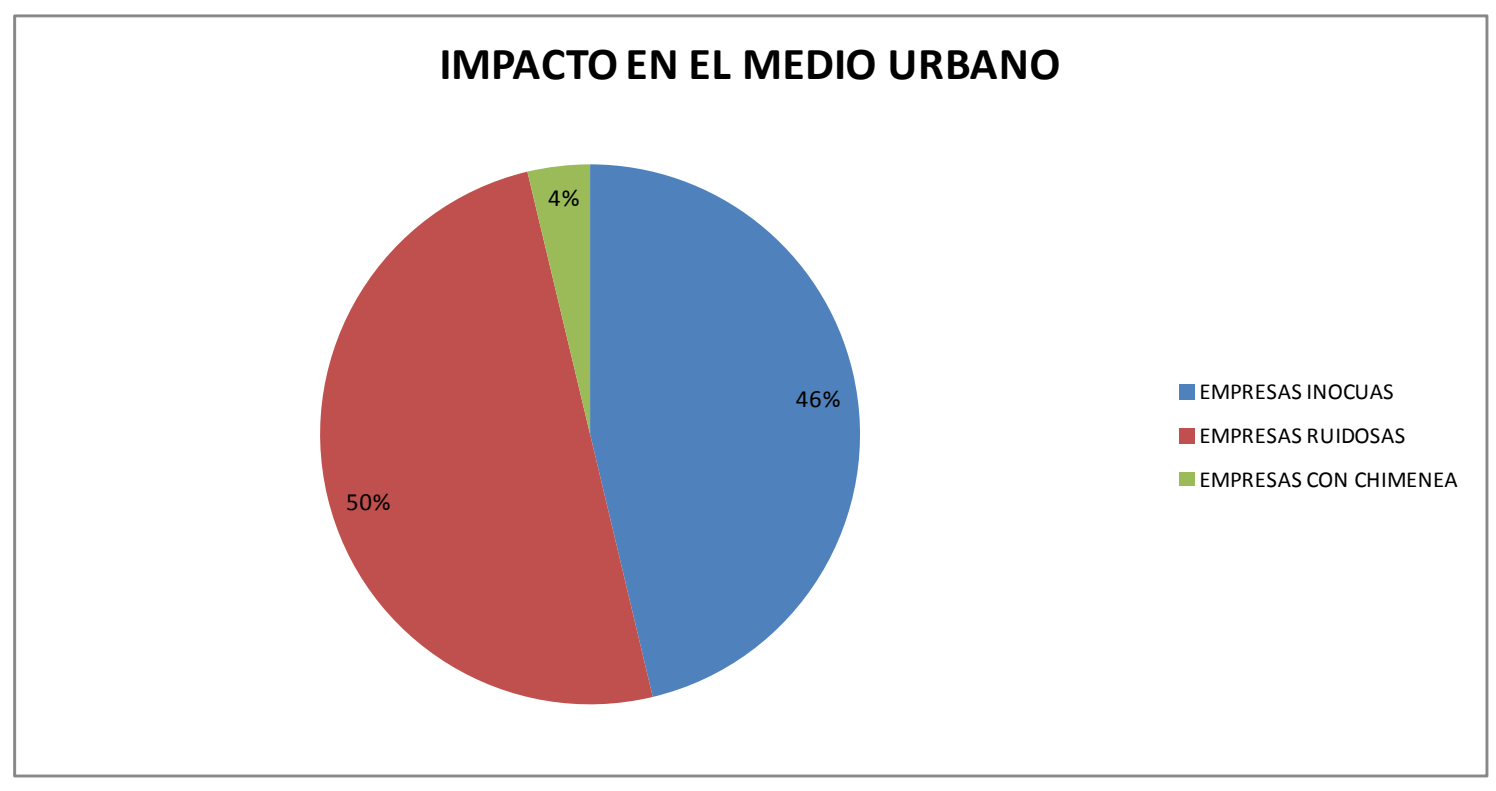




\section{FICHAS TIPO \\ FICHA DATOS DE LA INDUSTRIA}

LOCALIZACION ACTUALIZADA DE ACTIVIDADES INDUSTRIALES EN EL MEDIO URBANO DE VALENCIA

\begin{tabular}{|c|c|c|c|c|c|c|c|}
\hline \multirow{5}{*}{ 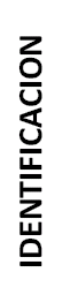 } & \multirow{2}{*}{\multicolumn{2}{|c|}{$\begin{array}{c}\text { NOMBRE } \\
\text { EMPLAZAMIENTO }\end{array}$}} & \multicolumn{5}{|c|}{ VICENTE MENGOD } \\
\hline & & & \multicolumn{3}{|c|}{ C/ Camino Rochs } & C.P. & \\
\hline & \multirow[b]{2}{*}{ CNAE } & \multirow[b]{2}{*}{316} & \multirow[b]{2}{*}{ DESCRIPCION } & \multicolumn{4}{|c|}{ FABRICACIÓN PRODUCTOS METALICOS } \\
\hline & & & & \multicolumn{4}{|c|}{ Cerrajeria } \\
\hline & DISTRITO & 10 & \multicolumn{5}{|c|}{ CUATRE CARRERES } \\
\hline \multicolumn{3}{|c|}{ SUPERFICIES } & $\begin{array}{c}\text { Sup. Parcela: } \\
1.900 \mathrm{~m}^{2}\end{array}$ & $\begin{array}{l}\text { Sup. Ocupada: } \\
750 \mathrm{~m}^{2}\end{array}$ & $\begin{array}{l}\text { Sup. Construida: } \\
750 \mathrm{~m}^{2}\end{array}$ & EMP & $\begin{array}{l}\text { LEADOS: } \\
11\end{array}$ \\
\hline
\end{tabular}
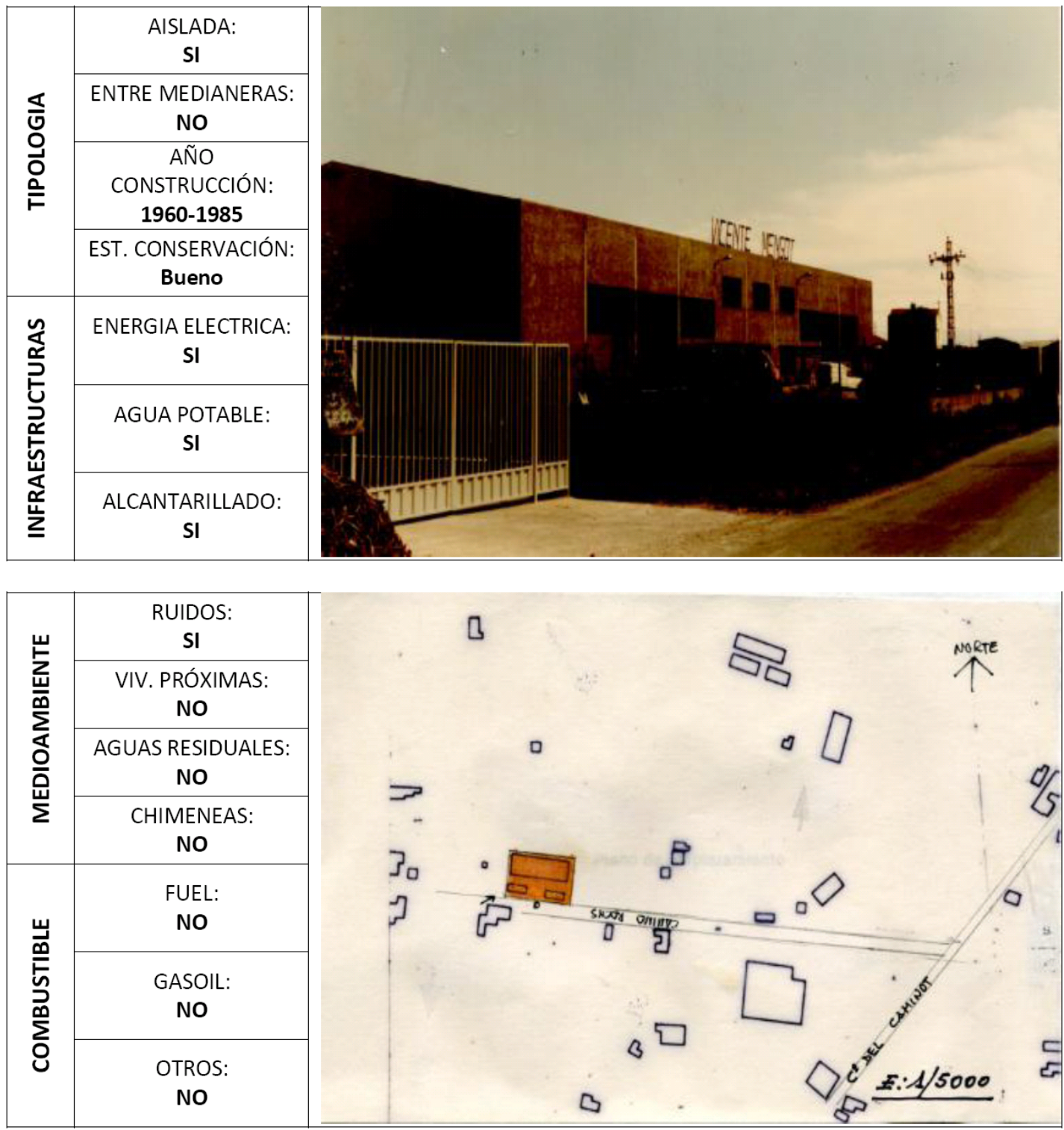


\section{FICHA DATOS DE LA INDUSTRIA}

LOCALIZACION ACTUALIZADA DE ACTIVIDADES INDUSTRIALES EN EL MEDIO URBANO DE VALENCIA

\begin{tabular}{|c|c|c|c|c|c|c|c|}
\hline \multirow{5}{*}{$\begin{array}{l}z \\
\text { 은 } \\
\text { 넌 } \\
\text { 言 } \\
\text { 븜 }\end{array}$} & \multirow{2}{*}{\multicolumn{2}{|c|}{$\begin{array}{c}\text { NOMBRE } \\
\text { EMPLAZAMIENTO }\end{array}$}} & \multicolumn{5}{|c|}{ CURTIDOS LITORAL, S.A. } \\
\hline & & & \multicolumn{3}{|c|}{ C/Juan Ramon Jimenez, $\mathrm{n}-40-42$} & C.P. & \\
\hline & \multirow{2}{*}{ CNAE } & \multirow{2}{*}{441} & \multirow{2}{*}{ DESCRIPCION } & \multicolumn{4}{|c|}{ INDUSTRIA DEL CUERO } \\
\hline & & & & \multicolumn{4}{|c|}{ Curtidos } \\
\hline & DISTRITO & 10 & \multicolumn{5}{|c|}{ CUATRE CARRERES } \\
\hline \multicolumn{3}{|c|}{ SUPERFICIES } & $\begin{array}{c}\text { Sup. Parcela: } \\
575 \mathrm{~m}^{2}\end{array}$ & $\begin{array}{l}\text { Sup. Ocupada: } \\
575 \mathrm{~m}^{2}\end{array}$ & $\begin{array}{l}\text { Sup. Construida: } \\
575 \mathrm{~m}^{2}\end{array}$ & EMP & $\begin{array}{l}\text { LEADOS: } \\
18\end{array}$ \\
\hline
\end{tabular}
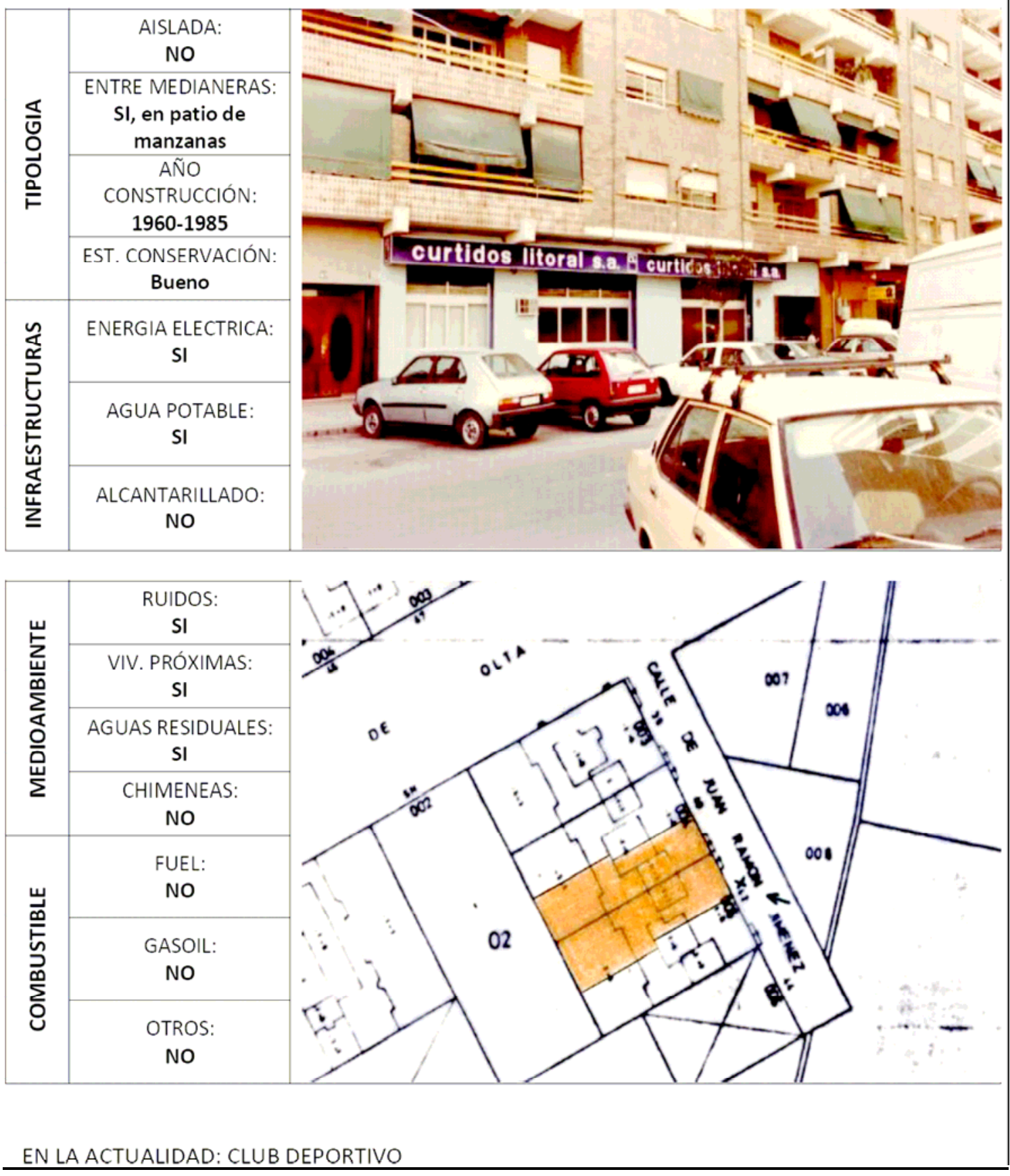


\section{FICHA DATOS DE LA INDUSTRIA}

LOCALIZACION ACTUALIZADA DE ACTIVIDADES INDUSTRIALES EN EL

MEDIO URBANO DE VALENCIA

\begin{tabular}{|c|c|c|c|c|c|c|c|}
\hline \multirow{5}{*}{ 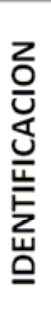 } & \multirow{2}{*}{\multicolumn{2}{|c|}{$\begin{array}{c}\text { NOMBRE } \\
\text { EMPLAZAMIENTO }\end{array}$}} & \multicolumn{5}{|l|}{ COALSA, S.A. } \\
\hline & & & \multicolumn{3}{|c|}{ C/Jesus Morante Borras, $n \cong 211$} & C.P. & \\
\hline & \multirow{2}{*}{ CNAE } & \multirow{2}{*}{319} & \multirow{2}{*}{ DESCRIPCION } & \multicolumn{4}{|c|}{ FABR. PRODUCTOS METALICOS } \\
\hline & & & & \multicolumn{4}{|c|}{ Mecanica en general } \\
\hline & DISTRITO & 10 & \multicolumn{5}{|c|}{ CUATRE CARRERES } \\
\hline & \multicolumn{2}{|c|}{ SUPERFICIES } & $\begin{array}{l}\text { Sup. Parcela: } \\
900 \mathrm{~m}^{2}\end{array}$ & $\begin{array}{l}\text { Sup. Ocupada: } \\
798 \mathrm{~m}^{2}\end{array}$ & $\begin{array}{l}\text { Sup. Construida: } \\
798 \mathrm{~m}^{2}\end{array}$ & EMP & EADOS: \\
\hline
\end{tabular}

\begin{tabular}{|c|c|}
\hline \multirow{4}{*}{$\begin{array}{l}\nwarrow \\
\text { ত্ } \\
\text { 음 } \\
\text { 을 }\end{array}$} & $\begin{array}{l}\text { AISLADA: } \\
\text { NO }\end{array}$ \\
\hline & $\begin{array}{c}\text { ENTRE MEDIANERAS: } \\
\text { SI }\end{array}$ \\
\hline & $\begin{array}{c}\text { AÑO } \\
\text { CONSTRUCCIÓN: } \\
\text { 1960-1985 }\end{array}$ \\
\hline & $\begin{array}{c}\text { EST. CONSERVACIÓN: } \\
\text { Bueno }\end{array}$ \\
\hline \multirow{3}{*}{ 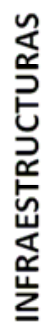 } & $\begin{array}{c}\text { ENERGIA ELECTRICA: } \\
\text { SI }\end{array}$ \\
\hline & $\begin{array}{c}\text { AGUA POTABLE: } \\
\text { SI }\end{array}$ \\
\hline & $\begin{array}{c}\text { ALCANTARILLADO: } \\
\text { SI }\end{array}$ \\
\hline
\end{tabular}
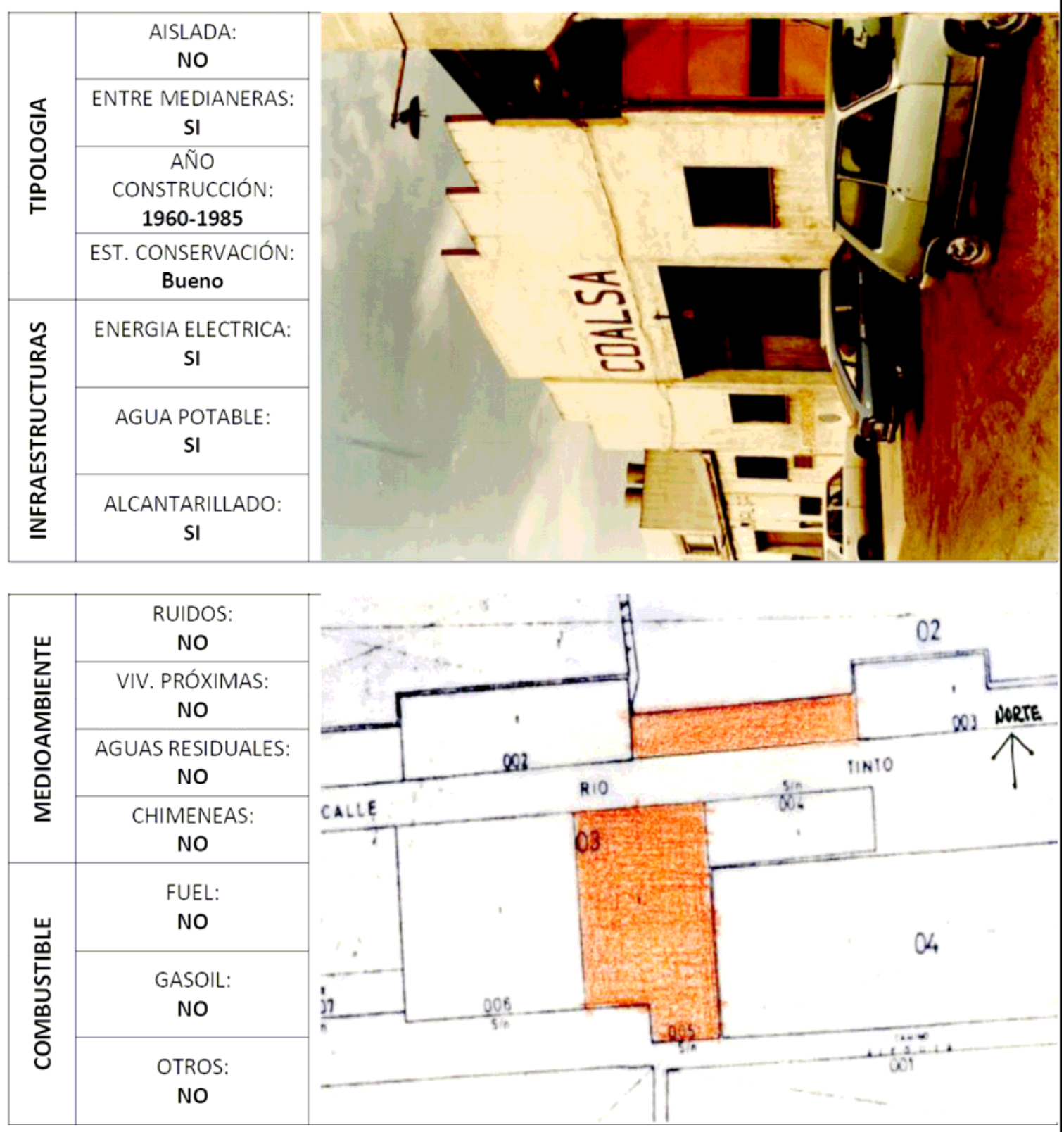


\section{FICHA DATOS DE LA INDUSTRIA}

LOCALIZACION ACTUALIZADA DE ACTIVIDADES INDUSTRIALES EN EL MEDIO URBANO DE VALENCIA

\begin{tabular}{|c|c|c|c|c|c|c|c|}
\hline \multirow{5}{*}{ 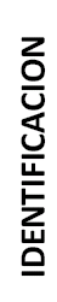 } & \multirow{2}{*}{\multicolumn{2}{|c|}{$\begin{array}{c}\text { NOMBRE } \\
\text { EMPLAZAMIENTO }\end{array}$}} & \multicolumn{5}{|l|}{ R. DOMENECH } \\
\hline & & & \multicolumn{3}{|c|}{ C/Granada, no 18} & C.P. & \\
\hline & \multirow{2}{*}{ CNAE } & \multirow{2}{*}{474} & \multirow{2}{*}{ DESCRIPCION } & \multicolumn{4}{|c|}{ IND. PEPEL, ARTES GRAFICAS, ETC. } \\
\hline & & & & \multicolumn{4}{|c|}{ Encuadernaciones Gráficas } \\
\hline & DISTRITO & 10 & \multicolumn{5}{|c|}{ CUATRE CARRERES } \\
\hline & \multicolumn{2}{|c|}{ SUPERFICIES } & $\begin{array}{c}\text { Sup. Parcela: } \\
380 \mathrm{~m}^{2}\end{array}$ & $\begin{array}{l}\text { Sup. Ocupada: } \\
380 \mathrm{~m}^{2}\end{array}$ & $\begin{array}{l}\text { Sup. Construida: } \\
380 \mathrm{~m}^{2}\end{array}$ & EMF & $\begin{array}{l}\text { EADOS: } \\
14\end{array}$ \\
\hline
\end{tabular}
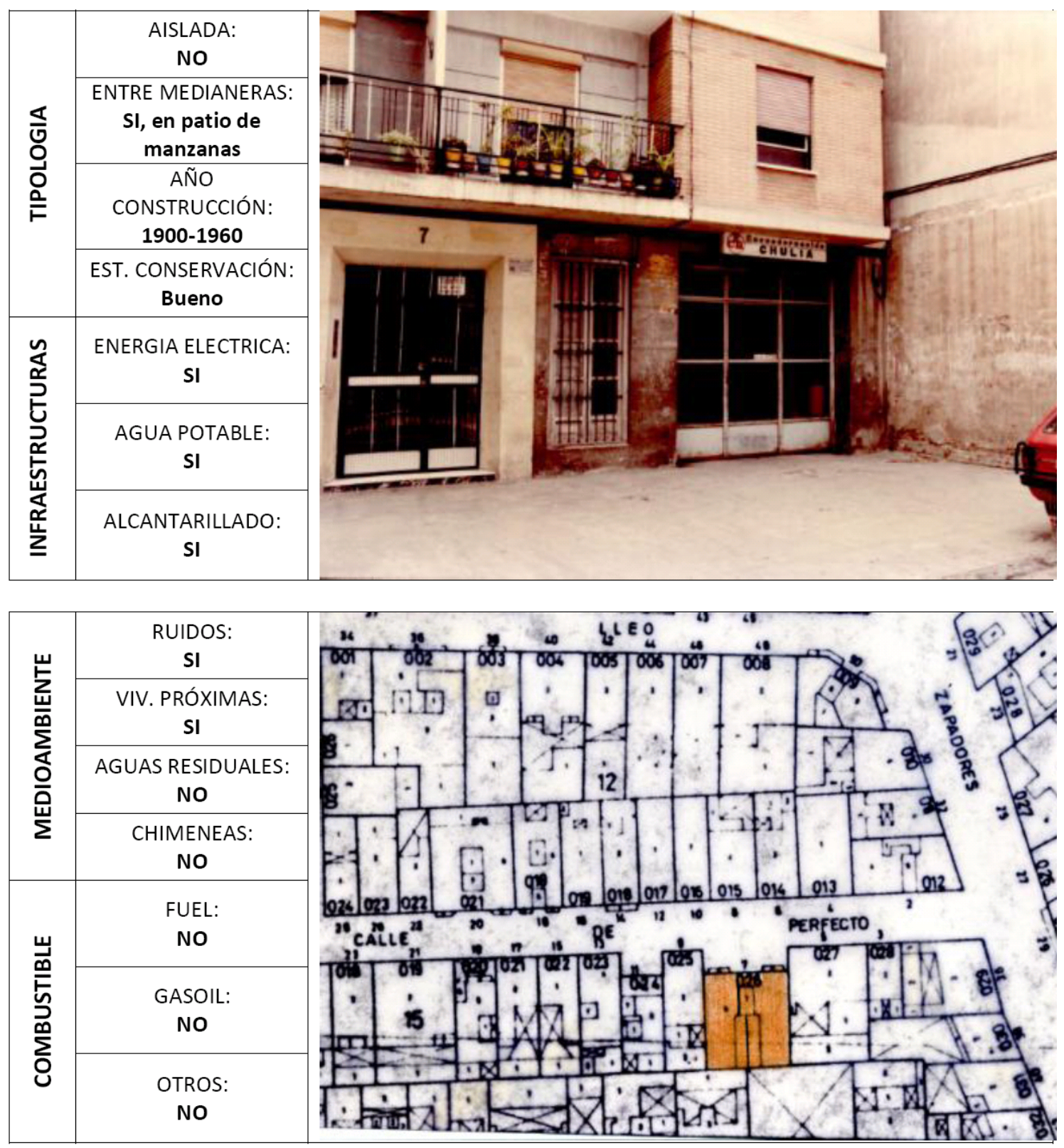


\section{EVOLUCIÓN}

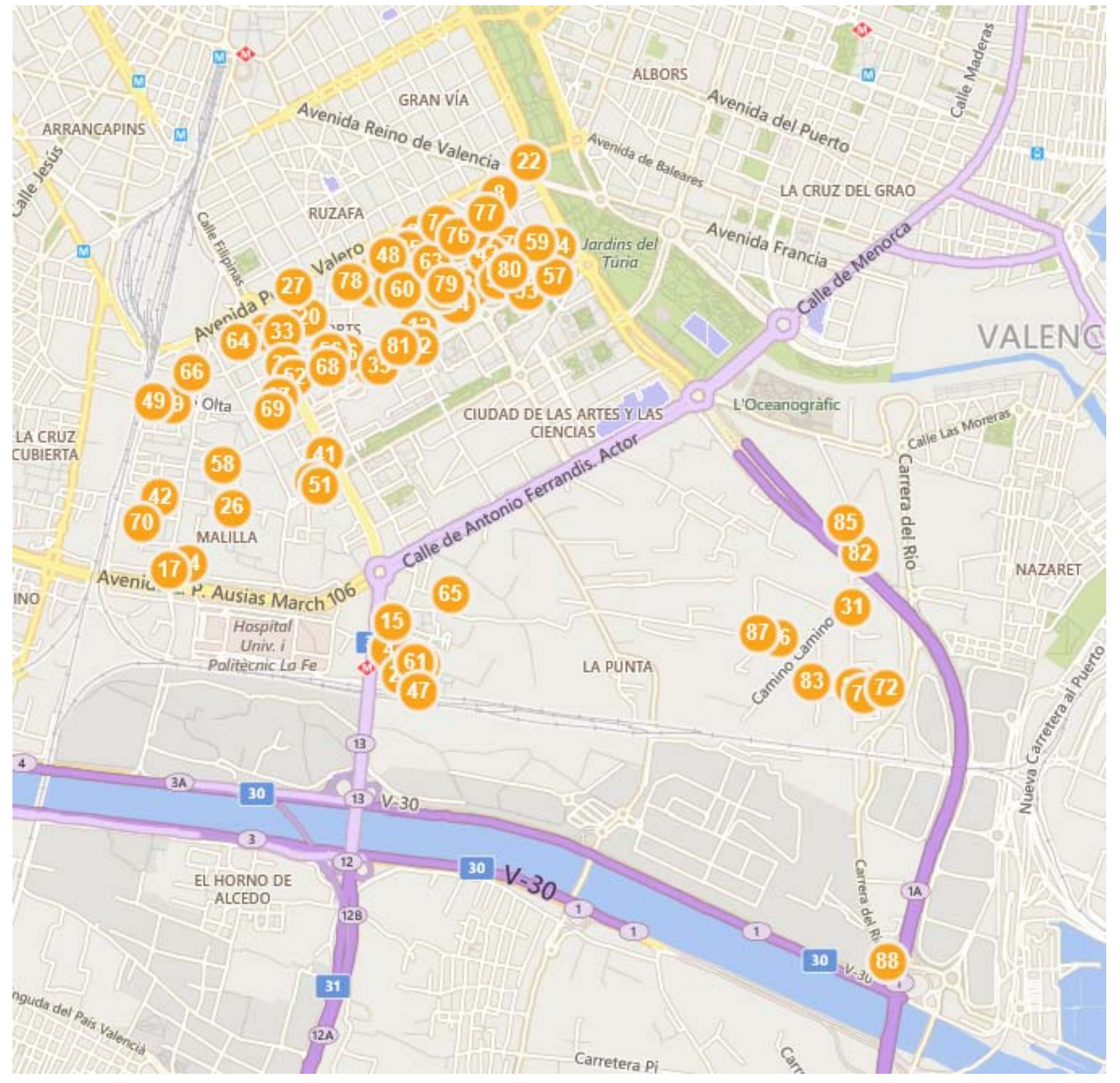

\section{LISTADO DE INDUSTRIAS Y ACTIVIDAD.-}

\section{Ismael Guillem Bonilla}

Fabricación de otros muebles

2. Rafael S. Vidal Guillem

Fabricación de otros muebles

\section{Francisco Navarro Ortega}

Fabricación de carpintería metálica 
4. MOCHOLI MUEBLES A MEDIDA C.B.

Fabricación de otros muebles

5. FAVORIT JOYEROS S.L.

Fabricación de artículos de joyería y artículos similares

6. Manuel Valera Peyró

Fabricación de artículos de joyería y artículos similares

\section{Pablo Estrer Martínez}

Fabricación de artículos confeccionados textiles, excepto prendas de vestir

8. KASSUMAY FUSION S.L.

Fabricación de artículos confeccionados textiles, excepto prendas de vestir

9. Germán Soler Gómez

Fabricación de artículos confeccionados textiles, excepto prendas de vestir

10. José Manuel Hernández Zorio

Fabricación instrumentos y suministros médicos y odontológicos

11. Juan Vicente Gómez Oltra

Fabricación instrumentos y suministros médicos y odontológicos

12. Isabel Aranda Bolufer

Fabricación de componentes electrónicos

13. Francisco Javier Valle Galiano

Fabricación instrumentos y suministros médicos y odontológicos

14. Antonio Marcos Camarena

Fabricación de envases y embalajes de plástico

15. José Vicente Sebastiá Sanjuán

Fabricación de cerraduras y herrajes

16. TALLERES APARICIO Y CAMACHO S.L.

Mantenimiento y reparación de vehículos a motor

17. PIT BOXES S.L.

Mantenimiento y reparación de vehículos a motor

18. Rafael Tudela González

Mantenimiento y reparación de vehículos a motor

19. TALLERES PLAZA SCP

Mantenimiento y reparación de vehículos a motor

20. Ramón Hortelano Campillo

Mantenimiento y reparación de vehículos a motor

21. Heliodoro Lope Sanguesa

Mantenimiento y reparación de vehículos a motor

22. José Miguel García Albert

Mantenimiento y reparación de vehículos a motor

23. Tomás Manuel Raga

Mantenimiento y reparación de vehículos a motor 
24. Vicente Bertolín Barón

Mantenimiento y reparación de vehículos a motor

25. TALLERES OSVAL S.L.

Mantenimiento y reparación de vehículos a motor

26. APPELATOR S.L.

Mantenimiento y reparación de vehículos a motor

27. Antonio Arcos Rebollo

Mantenimiento y reparación de vehículos a motor

28. Francisco García Capilla

Mantenimiento y reparación de vehículos a motor

29. Agustín Delicado Ponce

Mantenimiento y reparación de vehículos a motor

30. SPORT AUTO REPARACIÓN DE VEHÍCULOS S.L.

Mantenimiento y reparación de vehículos a motor

31. TALLERES ROMÁN GARCíA S.L.

Mantenimiento y reparación de vehículos a motor

32. Lorenzo Navarro Mocholí

Mantenimiento y reparación de vehículos a motor

33. César Gramaje Soler

Mantenimiento y reparación de vehículos a motor

34. AUTOVIFER S.L.

Mantenimiento y reparación de vehículos a motor

35. TALLERES MADUEÑO S.L.

Mantenimiento y reparación de vehículos a motor

36. Ramón Germán Torres

Mantenimiento y reparación de vehículos a motor

37. TALLERES LA UNIÓN C.B.

Mantenimiento y reparación de vehículos a motor

38. Salvador Cuevas Torrent

Mantenimiento y reparación de vehículos a motor

39. Francisco Casa Álvarez

Mantenimiento y reparación de vehículos a motor

40. Antoni Esteve Roig

Mantenimiento y reparación de vehículos a motor

41. Gregorio Pardo Ferrer

Mantenimiento y reparación de vehículos a motor

42. Antonio Carrasco Chamón

Mantenimiento y reparación de vehículos a motor

43. Carlos Viguer Castelló

Mantenimiento y reparación de vehículos a motor 
44. OSVAL C.B.

Mantenimiento y reparación de vehículos a motor

45. Juan Andreu Solaz

Fabricación de otros muebles

46. Enrique García Gómez

Fabricación de otros muebles

47. Antonio Pardo Quílis

Fabricación de otros muebles

48. Álvaro Pareja Gimeno

Fabricación de otros productos de madera; artículos de corcho, cestería y espartería.

49. Antonia Fernández Torres

Confección de otras prendas de vestir y accesorios.

50. COMPOSTURAS ORIENTE C.B.

Confección de otras prendas de vestir exteriores.

51. Rosario Aver Herrera

Confección de otras prendas de vestir exteriores.

52. Joaquín Quílez Martínez

Fabricación de pan y productos frescos de panadería y pastelería.

53. PASTELERÍAS NIBS S.L.

Fabricación de pan y productos frescos de panadería y pastelería

54. LLEPOLPAN S.L.

Fabricación de pan y productos frescos de panadería y pastelería

55. PETER FRUEH ECKERT C.B.

Fabricación de galletas y productos de panadería y pastelería de larga duración

56. Esteban Romero Torralbo

Fabricación de cacao, chocolate y productos de confitería.

57. DI MASSIMO ELITE S.L.

Fabricación de perfumes y cosméticos.

58. Canuto López, $\mathrm{M}^{\mathrm{a}}$ del Mar

Otras actividades de impresión y artes gráficas

59. GRAFICAS JGA. IMAGEN Y PUBLICIDAD

Otras actividades de impresión y artes gráficas

60. GRÁFICAS CEBRIÀ C.B.

Otras actividades de impresión y artes gráficas

61. ENGAGEMENT DARA MARCAS S.L.

Otras actividades de impresión y artes gráficas

62. Carbonell Peña, Carolina

Otras actividades de impresión y artes gráficas

63. IMPRESIONES GRÁFICAS MARLE S.L.

Otras actividades de impresión y artes gráficas 
64. Banaclocha Rausell, Amparo

Otras actividades de impresión y artes gráficas

65. Kurta Valentina

Otras actividades de impresión y artes

66. V. Viguer

Mantiene la actividad

67. COMERCIAL LEVANTINA DE NEUMATICOS, S.A.

Mantiene la actividad

68. Calabuig Sanz, J.B.

Mantiene la actividad

69. CURTIDOS PARERA, S.A.

Mantiene la actividad

70. INDERE, S.A.

Mantiene la actividad

71. TALLERES MOYA, S.L.

Mantiene la actividad

72. COALSA

Mantiene la actividad

73. HIERROS SAN MARCELINO S.A.

Mantiene la actividad

74. Eliseo Aranda

Mantiene la actividad

75. Galdon Lluch, v.

Mantiene la actividad

76. FOTOMECÁNICA CARRERES S.L.

Mantiene la actividad

77. Electricidad Rolux

Mantiene la actividad

78. HIJOS DE MANUEL RAMOS S.L.

Mantiene la actividad

79. S. Moret Fenollosa

Mantiene la actividad

80. Navarro Rodrigo

Mantiene la actividad

81. Character

Mantiene la actividad

82. VDA. DE RODRÍGUEZ ERRANDO S.A.

Mantiene la actividad

83. MADERAS JOSÉ M $M^{\mathrm{a}}$ FERRERO VIDAL S.A.

Mantiene la actividad 
84. Navarro Beneyto R.

Mantiene la actividad

85. María Lliso Dionisio

Mantiene la actividad

86. Puertas Cubells

Mantiene la actividad

87. Vicente Mengod

Mantiene la actividad

88. Depuradora Aguas de Pinedo

Mantiene la actividad

ESTADO ACTUAL DE LOS ANTIGUOS EDIFICIOS INDUSTRIALES DE INTERES.-

- Martínez Medina.

Avd. Ausias March №16 / 6F/5000)

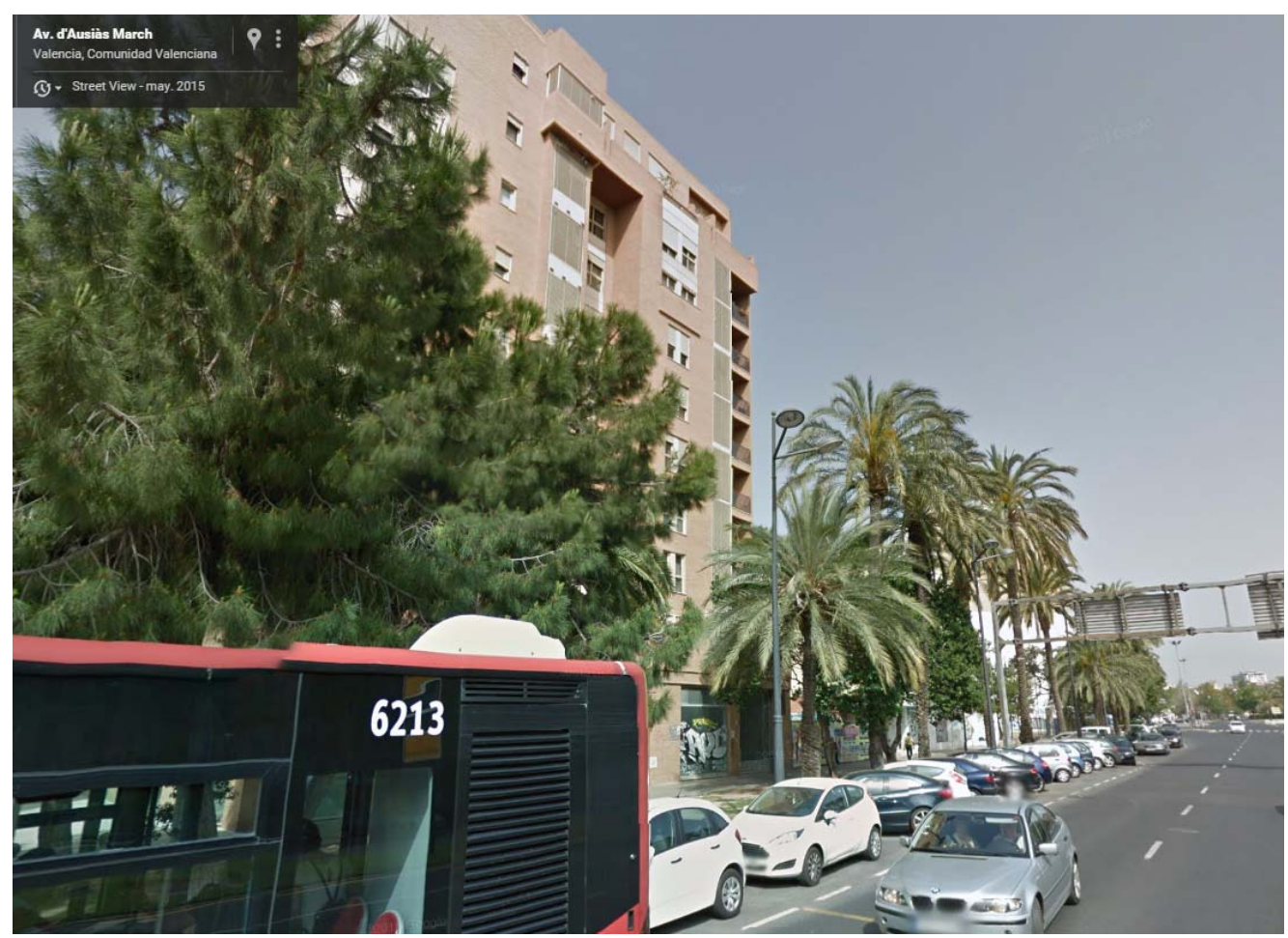

Foto 56: Edificios residenciales. Avda. Ausias March, 16. Valencia. 2015

Fuente: WEB. http://www.google.es/maps (Street View). 


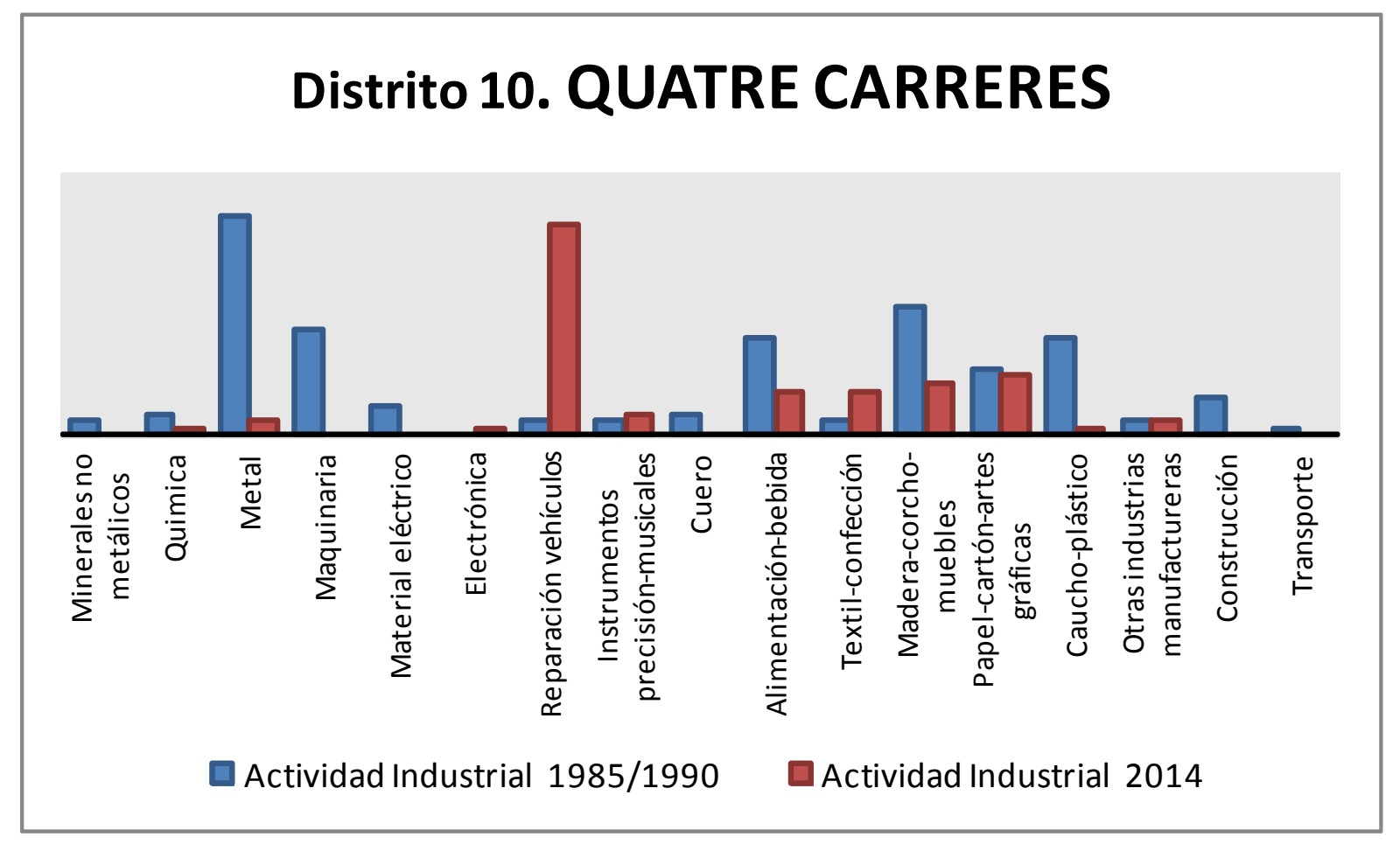

EVOLUCIÓN DEL IMPACTO AMBIENTAL

\section{IMPACTO EN EL MEDIO URBANO Distrito 10. QUATRE CARRERES}

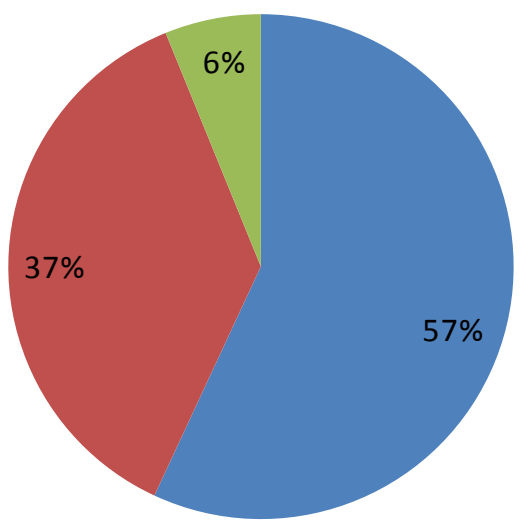

\section{Empresas inocuas}

Empresas ruidosas

Empresas ruidosas con chimenea 


\section{FICHAS TIPO \\ FICHA DATOS DE LA INDUSTRIA}

LOCALIZACION ACTUALIZADA DE ACTIVIDADES INDUSTRIALES EN EL

MEDIO URBANO DE VALENCIA

\begin{tabular}{|c|c|c|c|c|c|c|c|}
\hline \multirow{5}{*}{ 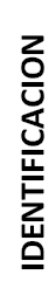 } & \multirow{2}{*}{\multicolumn{2}{|c|}{$\begin{array}{c}\text { NOMBRE } \\
\text { EMPLAZAMIENTO }\end{array}$}} & \multicolumn{5}{|c|}{ GERMÁN SOLER GÓMEZ } \\
\hline & & & \multicolumn{3}{|c|}{ C/ISLA CABRERA, 16} & C.P. & 46026 \\
\hline & \multirow[b]{2}{*}{ CNAE } & \multirow[b]{2}{*}{1392} & \multirow[b]{2}{*}{ DESCRIPCION } & \multicolumn{4}{|c|}{ TEXTIL-CALZADO-CONFECCIÓN } \\
\hline & & & & \multicolumn{4}{|c|}{$\begin{array}{l}\text { Fabricación de artículos confeccionados con } \\
\text { textiles, excepto prendas de vestir }\end{array}$} \\
\hline & DISTRITO & 10 & \multicolumn{5}{|c|}{ QUATRE CARRERES } \\
\hline & \multicolumn{2}{|c|}{ MEDIOAMBIENTE } & RUIDOSAS & NO & CHIMENEAS & & 0 \\
\hline
\end{tabular}
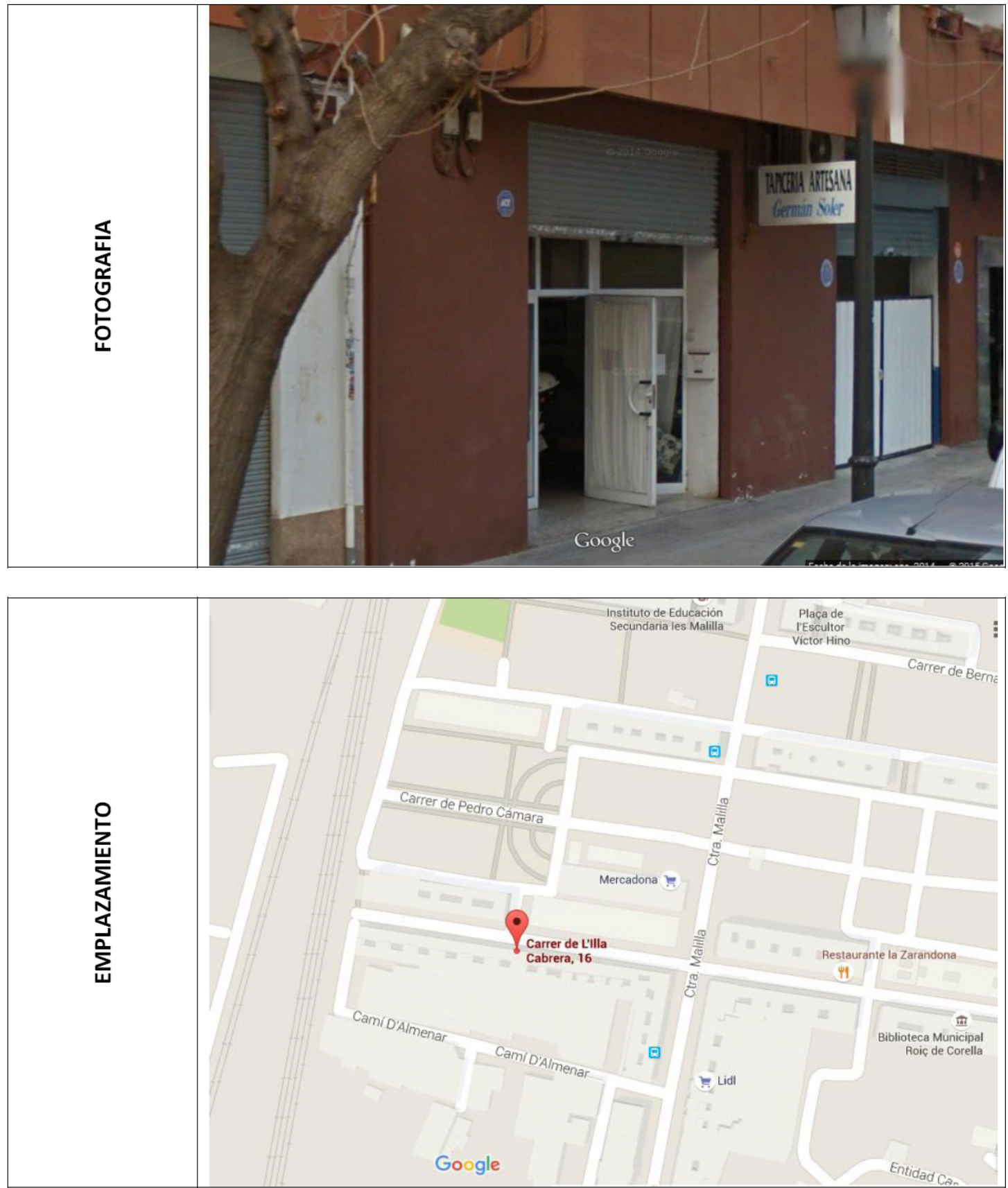


\section{FICHA DATOS DE LA INDUSTRIA}

LOCALIZACION ACTUALIZADA DE ACTIVIDADES INDUSTRIALES EN EL MEDIO URBANO DE VALENCIA

\begin{tabular}{|c|c|c|c|c|c|c|c|}
\hline \multirow{5}{*}{ 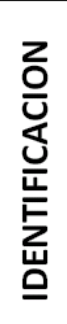 } & \multirow{2}{*}{\multicolumn{2}{|c|}{$\begin{array}{c}\text { NOMBRE } \\
\text { EMPLAZAMIENTO }\end{array}$}} & \multicolumn{5}{|c|}{ ENGAGEMENT DARA MARCAS, S.L. } \\
\hline & & & \multicolumn{3}{|c|}{ C/ PINTOR JOVER, 17} & C.P. & 46013 \\
\hline & \multirow{2}{*}{ CNAE } & \multirow{2}{*}{1812} & \multirow{2}{*}{ DESCRIPCION } & \multicolumn{4}{|c|}{ PAPEL-CARTÓN-ARTES GRÁFICAS } \\
\hline & & & & \multicolumn{4}{|c|}{ Otras actividades de impresión y artes gráficas } \\
\hline & DISTRITO & 10 & \multicolumn{5}{|c|}{ QUATRE CARRERES } \\
\hline \multicolumn{3}{|c|}{ MEDIOAMBIENTE } & RUIDOSAS & NO & CHIMENEAS & & IO \\
\hline
\end{tabular}
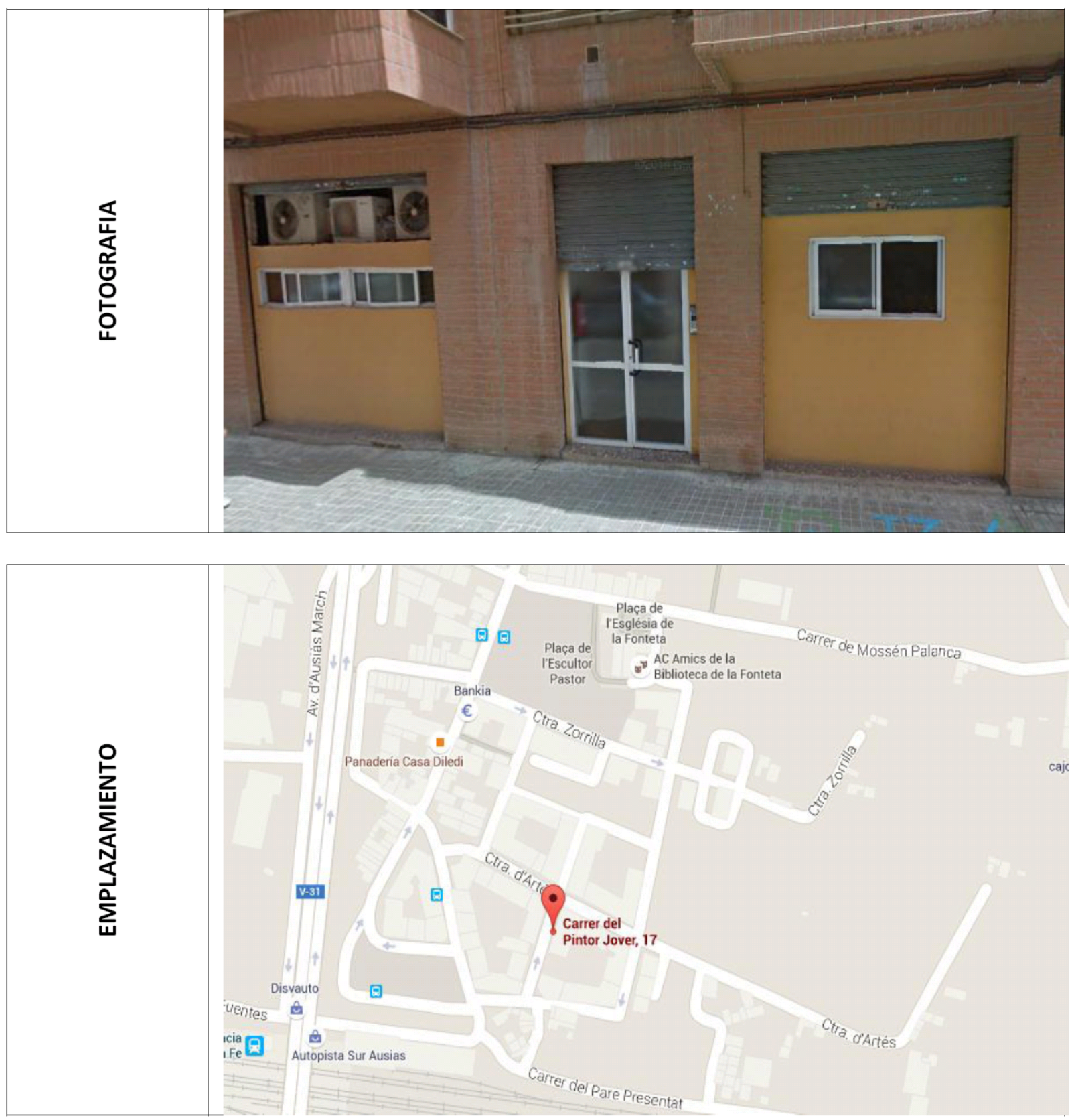


\section{FICHA DATOS DE LA INDUSTRIA}

LOCALIZACION ACTUALIZADA DE ACTIVIDADES INDUSTRIALES EN EL MEDIO URBANO DE VALENCIA

\begin{tabular}{|c|c|c|c|c|c|c|c|}
\hline \multirow{5}{*}{ 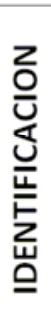 } & \multirow{2}{*}{\multicolumn{2}{|c|}{$\begin{array}{c}\text { NOMBRE } \\
\text { EMPLAZAMIENTO }\end{array}$}} & \multicolumn{5}{|c|}{ TALLERES APARICIO Y CAMACHO, SL } \\
\hline & & & \multicolumn{3}{|c|}{ C/TIRANT LO BLANCH, 4} & C.P. & 46013 \\
\hline & \multirow{2}{*}{ CNAE } & \multirow{2}{*}{4520} & \multirow{2}{*}{ DESCRIPCION } & \multicolumn{4}{|c|}{ REPARACIÓN VEHÍCULOS } \\
\hline & & & & \multicolumn{4}{|c|}{ Mantenimiento y reparación de vehículos a motor } \\
\hline & DISTRITO & 10 & \multicolumn{5}{|c|}{ QUATRE CARRERES } \\
\hline \multicolumn{3}{|c|}{ MEDIOAMBIENTE } & RUIDOSAS & SI & CHIMENEAS & & 10 \\
\hline
\end{tabular}
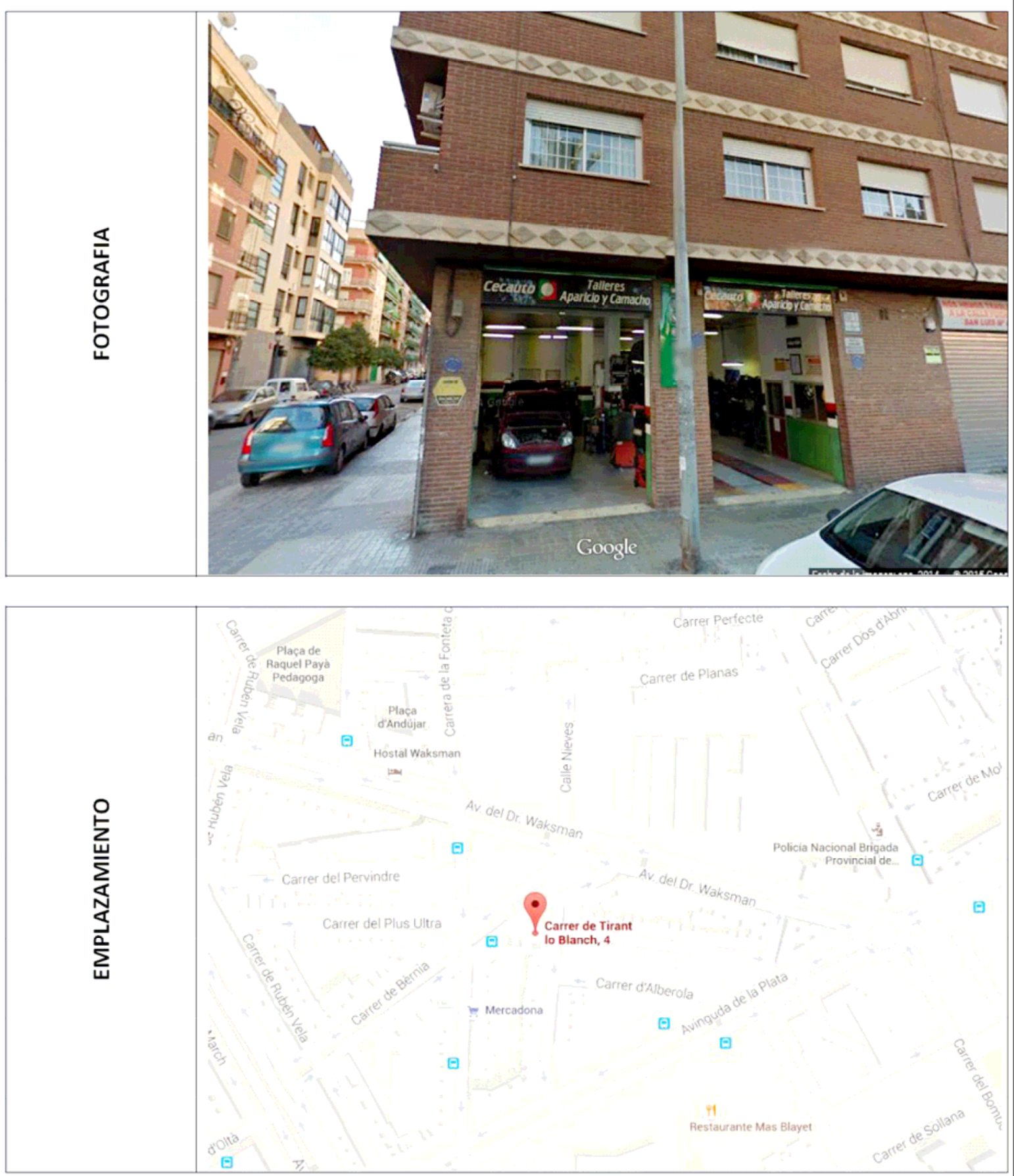


\section{FICHA DATOS DE LA INDUSTRIA}

LOCALIZACION ACTUALIZADA DE ACTIVIDADES INDUSTRIALES EN EL MEDIO URBANO DE VALENCIA

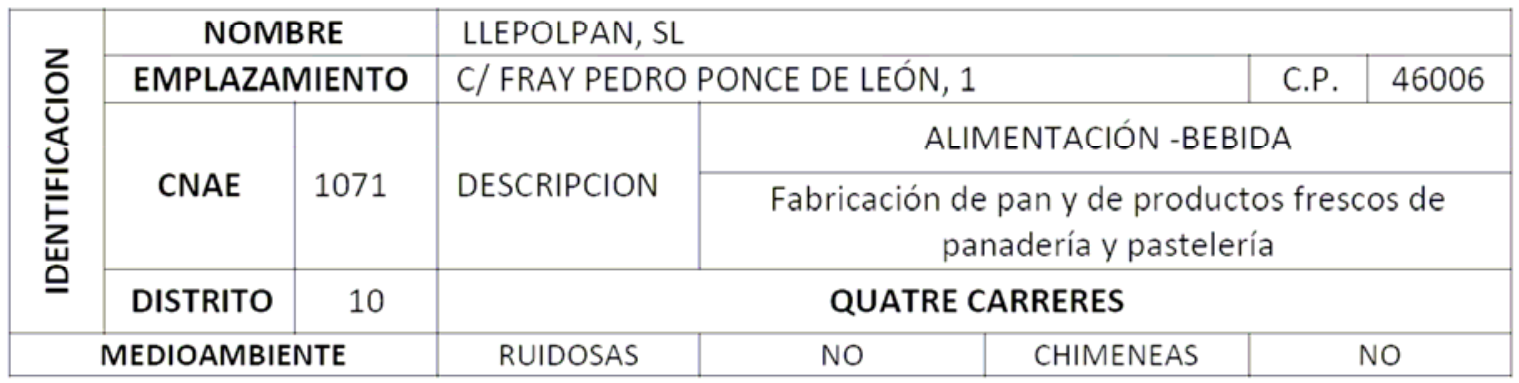
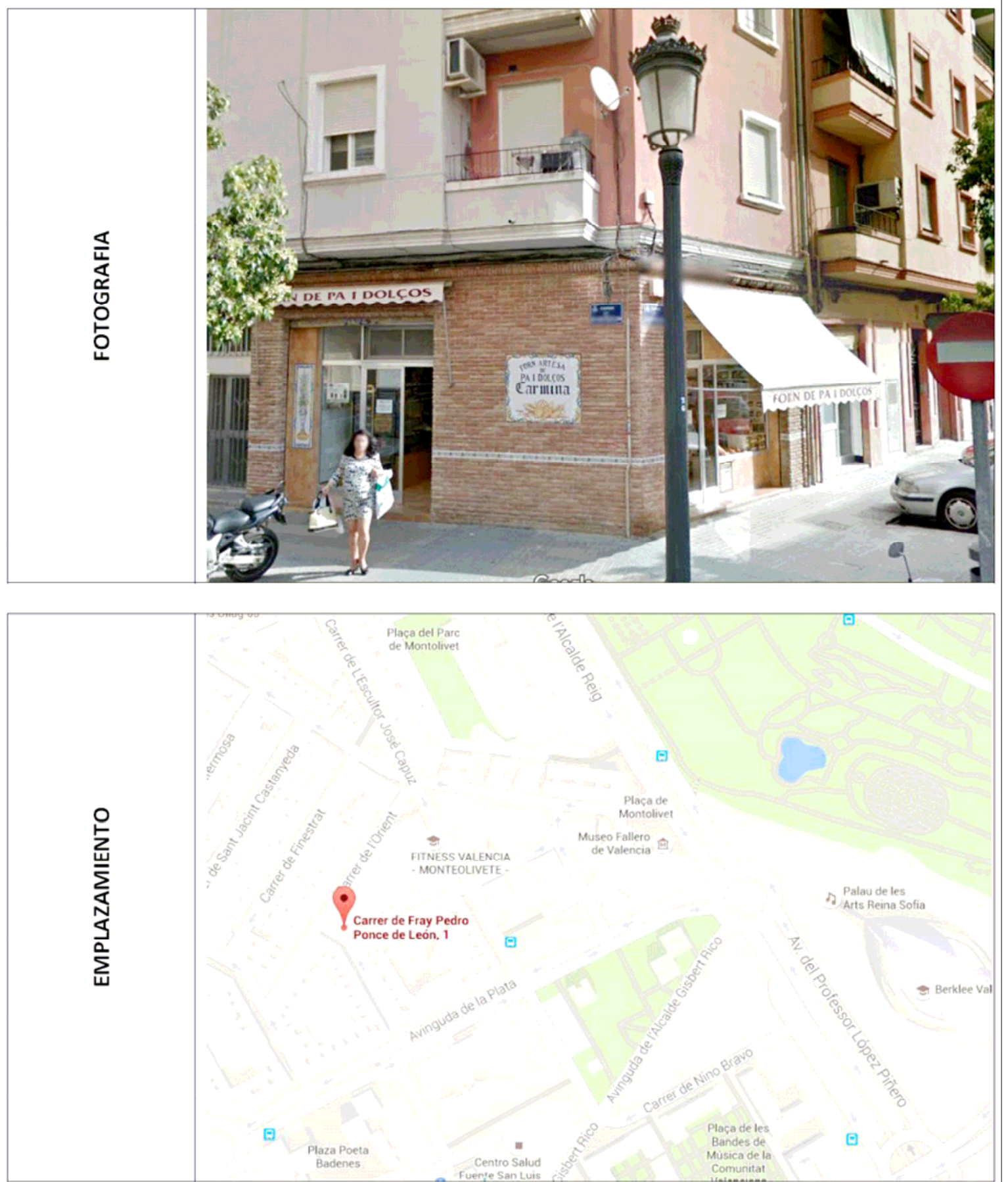


\section{FICHA DATOS DE LA INDUSTRIA}

LOCALIZACION ACTUALIZADA DE ACTIVIDADES INDUSTRIALES EN EL MEDIO URBANO DE VALENCIA

\begin{tabular}{|c|c|c|c|c|c|c|c|}
\hline \multirow{5}{*}{ 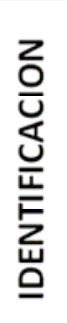 } & \multirow{2}{*}{\multicolumn{2}{|c|}{$\begin{array}{c}\text { NOMBRE } \\
\text { EMPLAZAMIENTO }\end{array}$}} & \multicolumn{5}{|c|}{ CANUTO LÓPEZ Ma DEL MAR } \\
\hline & & & \multicolumn{3}{|c|}{ C/ BERNAT DESCOLL, 37} & C.P. & 46026 \\
\hline & \multirow{2}{*}{ CNAE } & \multirow{2}{*}{1812} & \multirow{2}{*}{ DESCRIPCION } & \multicolumn{4}{|c|}{ PAPEL-CARTÓN-ARTES GRÁFICAS } \\
\hline & & & & \multicolumn{4}{|c|}{ Otras actividades de impresión y artes gráficas } \\
\hline & DISTRITO & 10 & \multicolumn{5}{|c|}{ QUATRE CARRERES } \\
\hline \multicolumn{3}{|c|}{ MEDIOAMBIENTE } & RUIDOSAS & NC & CHIMENEAS & & $\mathrm{O}$ \\
\hline
\end{tabular}

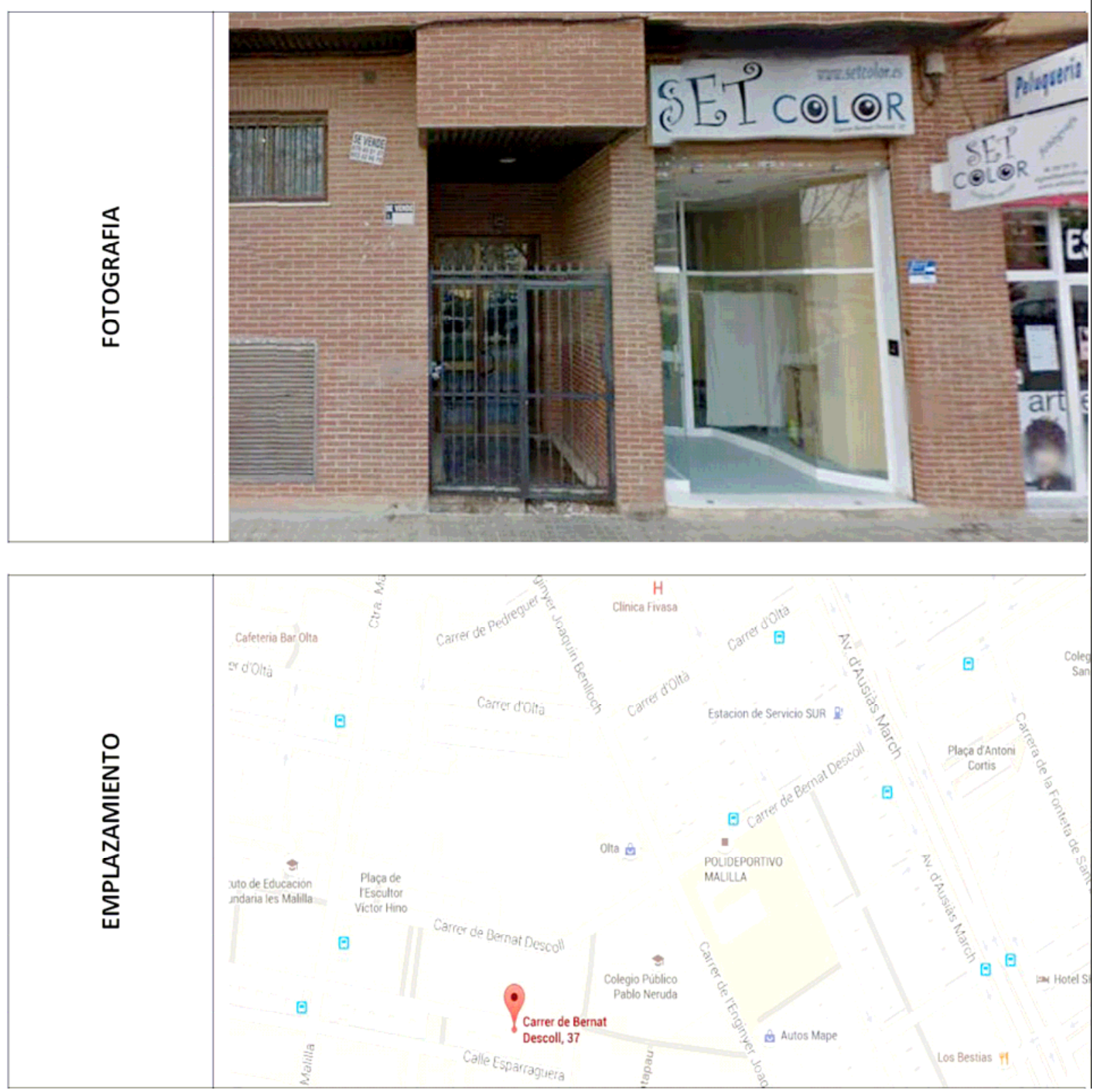


DISTRITO 11.- POBLATS MARITIMS

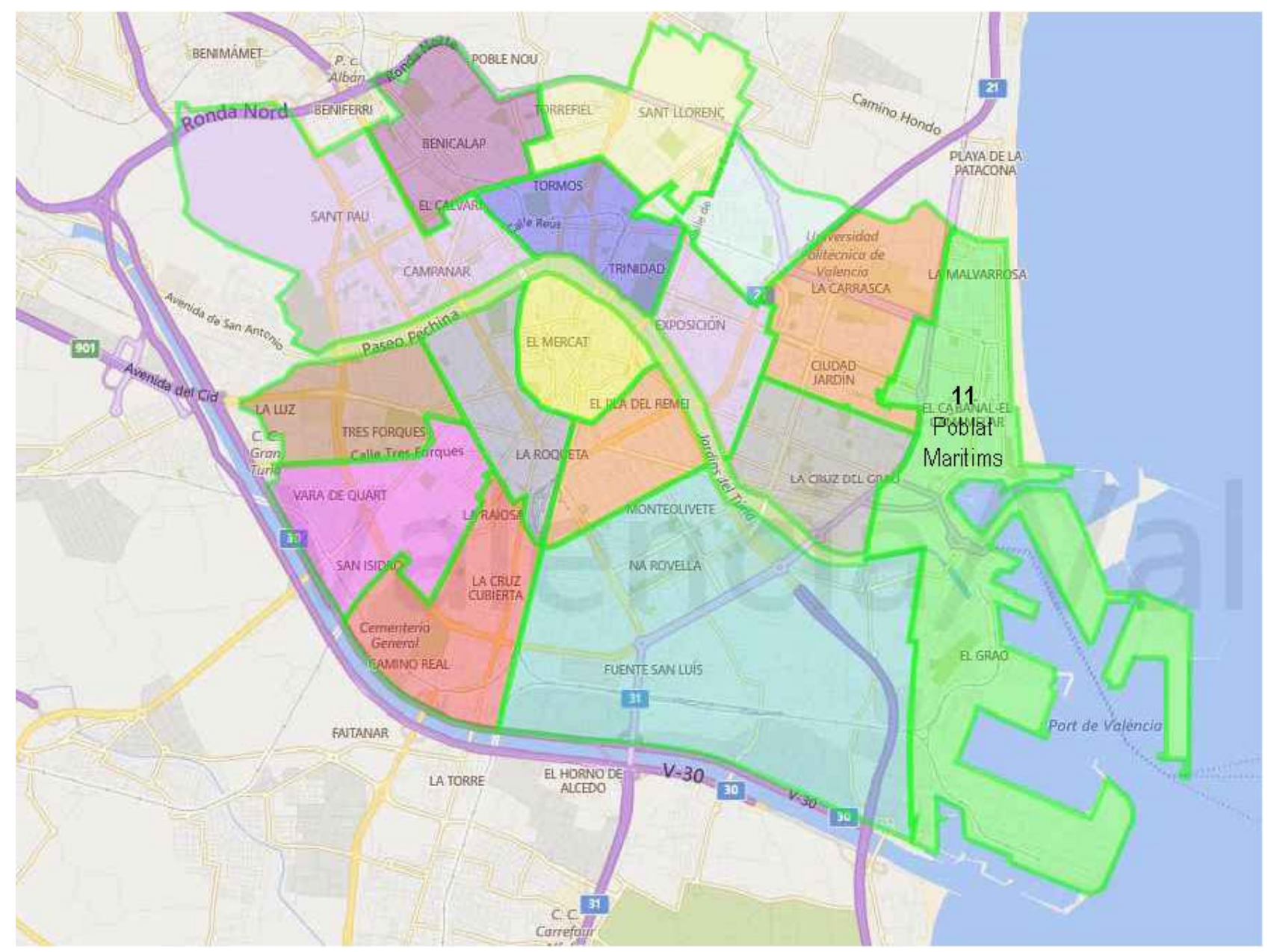

\section{LÍMITES GEOGRÁFICOS.}

- Mar Mediterráneo, Acequia de Vera, ferrocarril de Barcelona y Camino de Roca. 


\section{EVOLUCIÓN DEL 1985-2014}

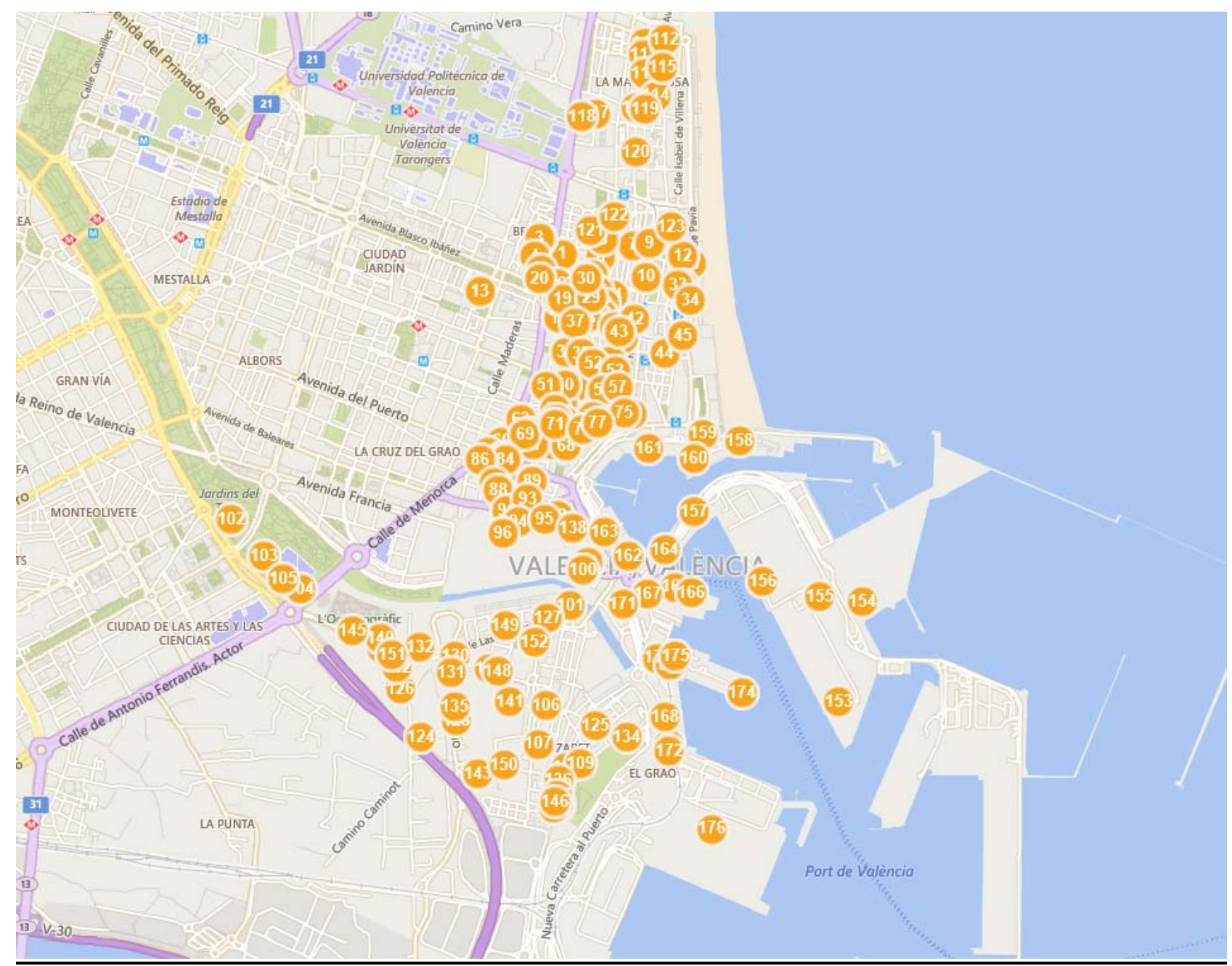

LISTADO DE INDUSTRIAS Y ACTIVIDAD.-

\section{Dolores Viller España}

Aire acondicionado

\section{Juan Ruiz}

Club de atletismo

3. Castellón Esteban. C

Troquelado

4. Francisco Campos Casanova

Obra nueva 
5. Chiva Sanpedro, Manuel

Obra nueva

6. Miguel González Molla

Óptica Ferrandis

7. Benlloch Soler, M.

Sin datos

8. Lerma Camacho Manuel

Sin actividad

9. ECOMER, S.A.

Sin actividad

10. TELESERVICIO, S.L.

Sin actividad

11. Adolfo Alonso Rodríguez

Sin actividad

12. Ortiz Andrés, José Luis

Sin actividad

13. BRITEL

Tienda MILAR

14. Rafael Ripoll Jordán

Herbolario

15. Pérez Sánchez, Indalecio

Nueva ordenación ESTACION CABAÑAL

16. VALLEJO Y MARCOS, S.L.

Carpintería metálica

17. Terencio Martínez, D.

Solar

18. Bernad López, J. Antonio

Sin actividad

19. Ribes Golfe, Luis

Sin actividad

20. Montoliu Escrich, M.

Solar

21. TALLERES MUÑOZ CROM

Sin actividad

22. Villorra Maestro, Faustino

Sin actividad

23. Salvador Pastor Savall

Cafés Pastor

24. Verdeguer Barbera, Manuel

Sin actividad 
25. Moreno Muñoz, Manuel

Sin actividad

26. Maria Navarro Alabau

Solar

27. Manuel Mir Blat

Obra nueva

28. Vilchez Ruiz, Rosendo

Sin actividad

29. Roig Genoves, L.

Sin actividad

30. Marzo Cuartero, Roberto

Sin actividad

31. TALLERES SANDOL, S.L.

Cerrado

32. ASTILLEROS PALAU

Cerrado

33. Coloma Belenguer, J.

Solar

34. Biosca Montes, José

Sin actividad

35. Marín Ruiz, Juan

Escuela infantil

36. DISYMOL, S.A.

Sin actividad

37. Ferrer Fornás, J.

Nueva ordenación, parque.

38. Granero Martínet, J.

Parking

39. Lluna, V.

Horno

40. Cruañes Terencio, $F$.

Obra nueva, centro óptico.

41. CONSTRUCCIONES CASAÑ HNOS., S.L.

Sin actividad

42. Silva Boo, José

Tere estilista

43. Roberto Nacher Planelles

Sin actividad

44. Bueso Estellés, Vicente

Sin actividad 
45. COOPERATIVA DE CALAFATES DE VALENCIA

Solar

46. REGISTROS NORMALIZADOS, S.A.

Otra industria, SEGOVIA

47. ANJUCA, S.L.

Sin actividad

48. Pardo Rabadán, Francisco

Iglesia evangélica

49. FRIGHER

Sin actividad

50. DVP, S.A.

Solar

51. VALENMAR

Recambios del automóvil, SUVIMA

52. Vicente P. Marques Barbera

Sin actividad

53. Vicenta Ramos Valls

Parking

54. Guinart Pechuan, Antonio

Cerrado

55. PRUCA

Sin actividad

56. Pedro López

Sin actividad

57. ELECA, S.A.

Cerrado

58. MAERTO DE LA VERA, S.L.

Nueva ordenación

59. TALLERES MURO, S.L.

Taller

60. TALLERES TOMAS PASCUAL, S.L.

Talleres Tomas Pascual

61. Joaquín Pérez

Sin actividad

62. RANER, S.A.

Cerrado

63. CALDERERIA VALENCIANA MARITIMA, S.L.

Obra nueva

64. VDA. DE J. RUIZ PROHENS, S.L.

Taller mecánico 
65. González Gómez, Luis Maria

Sin actividad

66. PLASPEL, S.L.

Gimnasio

67. TALLERES VDA. EDUARDO MONFORT

Obra nueva

68. CHERUVINO VALSANGIACOMO, S.A.

Solar

69. REDUCTORES R.E.F., S.L.

KEW Servicio técnico

70. Juan Pineda Carbonell

Sin actividad

71. Antonio Rodrigo García

Sin actividad

72. Pérez, F.

Horno

73. CONSTRUCCIONES MACANICAS VIANA, S.L.

Obra nueva

74. Cambralla Lujan, Antonio

Cerrado

75. Pérez Roig, Amadeo

Sin actividad

76. IMPRENTA ESPEJO

Imprenta

77. Alarcón Arguello, M.

Pastelería

78. Iglesies Feaces, Andres

Obra nueva

79. DURAGLIA

Sin actividad

80. IMPRENTA LITOGRAFIA ORTEGA

Imprenta-litografía

81. TALLERES SANCHEZ ROSELLO, S.L.

Obra nueva

82. Graullera Sanz, Abelardo

Obra nueva

83. INDUSTRIAS PROSPER, S.L.

Urban-Youth Hostal

84. Jaime Valera Ribera

Corti-Hogar 
85. TALLERES NOGUERA, S.L.

Obra nueva

86. COROMINA INDUSTRIAL, S.A.

Nueva ordenación

87. Ramón Alberola, M.

Sin actividad

88. JOSE HERNANDEZ IRANZO, S.A.

Cerrado

89. Mas Piza, Juan José

Talleres Mas

90. BURBEN, S.A.

Edificio en rehabilitación

91. BURBEN, S.A. I ALMACENES

Edificio rehabilitado (Espai d' innovació i creació)

92. MADERAS Y CHAPAS BOIX, S.A.

Nueva ordenación

93. RAFISA, S.L.

Solar

94. COMAVE, S.A.

Solar

95. Francisco Ferrandis Sanz

Obra nueva

96. CAMPSA

Nueva ordenación (Circuito)

97. HISPANO BANDANG, S.A.

Nueva ordenación

98. MENASA

Sin actividad

99. MECANICA Y ELECTRIDAD NAVAL, S.A.

Sin actividad

100. HIERROS Y METALES V. SOTO

Sin actividad

101. Sabal Sanz, G.

Sin actividad

102. SDAD. COOP. LTA. T. MORERAS

Ciudad de las ciencias

103. SOCIEDAD ESPAÑOLA DEL OXIGENO, S.A.

Ciudad de las ciencias

104. COOPERATIVA CARROCEROS REUNIDOS

Ciudad de las ciencias 
105. TALLERES NAVALES VALENCIA, S.A.

Ciudad de las ciencias

106. Jaime Martínez Quiles

Solar

107. Juan de Cabo Furió

Sin actividad

108. EXTINTORES GALERA, S.A.

Sin actividad

109. INDUSTRIAS CONCARD, S.A.

Sin actividad

110. MADERAS MARTINEZ, S.A.

Ceres floristes

111. Hernández Zahonero, $A$.

Nueva ordenación, parque.

112. Alonso Fernández

Herboristería MalvaDiet

113. Gimeno Lliso, A.

Horno

114. Semper Miralles, José Enrique

Sin actividad

115. Máñez Villora, Ventura

Cerrado

116. Medel Díaz, Francisco

Sin actividad

117. Tarazona Estrela, Félix

Horno

118. ZEPOL'S, S.A.

Sin actividad

119. LEDEM'S, S.L.

Café heladería

120. Jurat Pérez, José Luis

Taller Moto Mas

121. Navalón Valcarcer, Valeriano

Construcciones López y Bernat, S.I.

122. Romero Cervero, Fernando

Sin actividad

123. Ávila Julia, Francisco

Solar

124. JORGAR, S.L.

Cerrado 
125. ARLESA (Aceiteras Reunidas de Levante, S.A.)

Solar

126. ALFREDO GINER Y SOBRINOS, SRC

Sin actividad

127. AUTOCARES LUZ, S.A.

Nueva ordenación, solar.

128. CAMPSA (Cochera)

COTRANSA, S.A.

129. COVALMA, S.A.

Solar

130. NAUTICA VICMAN, S.A.

Nueva ordenación, viviendas.

131. SILOS TURIA

Sin actividad

132. PAPELERA DEL PILAR, S.A.

Nueva ordenación

133. FOMESA

Sin actividad

134. ASTILLEROS CARABAL, S.L.

Solar

135. MADERAS VALENCIA

Sin actividad

136. TALLERES MONTALVI, S.L.

Solar

137. José Jareño Segovia

Sin actividad

138. TAFISA

Parking circuito

139. COVALMA, S.A.

Solar (Repetida 129)

140. Ferrer Andreu, Manuel

Nueva ordenación, Oceanográfic

141. CENTRAMARES

Solar

142. GRUAS Fco. ALAPONT

Grúas Alapont

143. MADERAS RAIMUNDO DIAZ, S.A.

Solar

144. TRASVASE SOLER

Sin Actividad 
145. INTERCONTAINERS

Nueva ordenación, Oceanográfic

146. COTRANSA / CONVAL

Sin actividad

147. BENLLOCH

Zona verde nueva ordenación

148. CESA REPAIR

Nueva ordenación, viviendas.

149. ROCA MOZO

Nueva ordenación, zona verde.

150. CONTENEMAR

Sin actividad

151. VALCOMARES

Sin actividad

152. HIJOS DE FRCO. ARGUIMBAU

Nueva ordenación, (zona verde)

153. MARITIMA VALENCIANA

Puerto

154. 1SEA-LAND

Puerto

155. CONTENEMAR

Zona puerto

156. VAPORES SUARDIAZ VALENCIA, S.A.

Zona puerto

157. FORD ESPAÑA (DEPT. DE TRAFICO)

Nueva ordenación.

158. ALDEASA

Nueva ordenación (Marina Juan Carlos I)

159. DOCKS

Nueva ordenación (Zona verde)

160. FLETRANS

Nueva ordenación (Edificio Veles e vents)

161. TRANSVALEAR

Edificio nuevo

162. TRAFRUME, S.A.

Sin datos

163. TRANSMEDITERRANEA

Tinglado 4

164. ROCA Y MONZO

Nueva ordenación 
165. VALPORT, S.A.

Terminal pasajeros Acciona

166. F.E.I.S.A.

Nueva actividad

167. UNION NAVAL DE LEVANTE, S.A.

Boluda

168. ENDECASA

Mantiene la actividad

169. TERMINALES PORTUARIAS, S.A.

Mantiene la actividad

170. CENTRAMARES

Nueva ordenación

171. CASASUS

Parking

172. INDUSTRIAS QUIMICAS DE CARBUROS, S.A.

Mantiene la actividad

173. PRODUCTOS ASFALTICOS, S.A.

Mantiene la actividad

174. VALENCIANA DE CEMENTOS

Mantiene la actividad

175. DEMADRISA

Mantiene la actividad

176. AGUILAR Y PERIS, S.A.

Ampliación puerto

CARACTERÍSTICAS DEL ASENTAMIENTO INDUSTRIAL.-

Asentamiento heterogéneo en el que se distinguen cuatro zonas:

\section{Zona Norte:}

Que corresponde a las áreas urbanas de Cabañal y Malvarrosa, en la que se alternan las industrias de carácter histórico (artesanal) y de nueva implantación.

Se distinguen dos sub-zonas:

a) Polígono industrial delimitado por, la C/ Vicente Brull, Avda. del Puerto,

Ferrocarril de Barcelona y Estación del Cabañal.

Reúne las siguientes características:

. Industria agrupada

. Asentamiento homogéneo respecto al tamaño y tipología industrial 
- Industria localizada en edificios de mediana superficie y tipología industrial (naves), entre medianeras.

. Perfil urbano uniforme

. Bajo nivel de actividad y alto grado de abandono.

b) Es la resultante de excluir de la zona Norte la subzona a) anteriormente descrita.

Reúne las siguientes características:

. Industria dispersa.

. Asentamiento homogéneo por tamaño y tipología.

. Industrias de pequeña superficie.

. Situadas en plantas bajas de edificios de viviendas entre medianeras.

En ambas subzonas la contaminación ambiental es escasa y la industria está integrada en el paisaje urbano.

\section{Zona Centro:}

Comprendida entre la Avda. del Puerto y el Cauce Viejo del Turia.

Características:

. Asentamiento industrial correspondiente a la primera mitad del Siglo XX.

. Coexiste con el uso residencial pero predominando sobre este.

- Industria agrupada y homogénea tipológicamente.

- Locales específicamente industriales, entre medianeras, de mediana superficie, excepto en el cas0 de CAMPSA (gran superficie) y naves aisladas.

. Contaminación ambiental moderada.

. Características formales semejantes a las de la subzona a) del apartado anterior.

. Imagen urbana deteriorada.

Zona Sur (Nazaret):

La comprendida entre el Cauce del Turia y el limite Sur del distrito.

Características:

. Asentamiento Industrial de reciente implantación excepto a lo largo del 
Camino de Las Moreras.

. Existen dos tipos de localización claramente diferenciados:

a) Industria de pequeña superficie ubicada en bajes de viviendas entre medianeras en el área residencial consolidada.

b) Grandes superficies de almacenamiento, especialmente contenedores, situada en área de huerta y concentrada mayoritariamente en las inmediaciones del Camino de Las Moreras y carretera vieja del Saler.

- Notable índice de contaminación en los vertidos de la Industria papelera y minino en el resto por tratarse de superficie de almacenamiento.

. Deficiente Infraestructura y servicios urbanísticos.

\section{Puerto Autónomo:}

Características:

. Es un centro de distribución de mercancías y de enlace de transporte marítimo y terrestre a escala nacional.

- Incluye en su recinto empresas tan importantes como la Unión Naval do Levante que ocupa a 1.500 trabajadores.

. La superficie que ocupa equivale al $20-25 \%$ aproximadamente del total municipal destinado a usos industriales y a grandes infraestructuras y centros de almacenamiento.

- Genera un elevado flujo de transporte pesado de mercancía, con cierta frecuencia de elevada peligrosidad.

\section{CARACTERÍSTICAS DE LOS LOCALES.}

Ya han sido descritas en el punto anterior.

\section{CARACTERÍSTICAS DE LAS ACTIVIDADES.}

Se censaron inicialmente 176 industrias y en el período de vigencia del Plan General han quedado solamente 17 creándose 49 nuevas industrias.

Las actividades dominantes son construcción naval y reparación de buques, madera, corcho y muebles, productos alimenticios, productos metálicos y actividades anexas al transporte. 
Debe destacarse el bajo nivel de empleo que, pese a la gran superficie ocupada, suponen las bases de contenedores en el conjunto del distrito.

IMPACTO EN EL MEDIO AMBIENTE.

Ya han sido descritas.

EDIFICIOS INDUSTRIALES DE INTERES.-

- DURAGLIA.

C/ Lirio, no $11 \quad$ (Clave CL-21

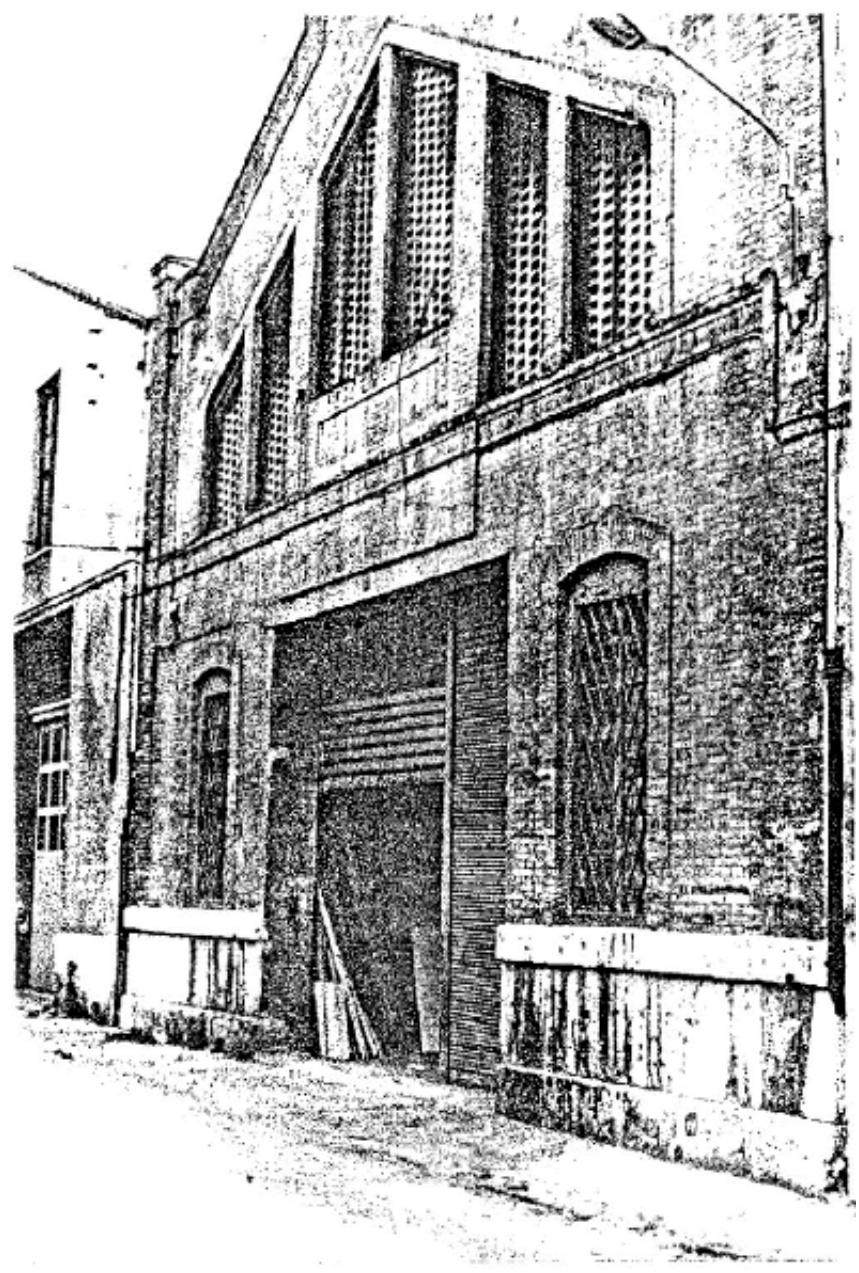

Foto 57: Industria de madera. Duraglia. C/ Lirio,11.Valencia.1985.

Fuente: Elaboración propia 
- MAS PIZA, J.J.

C/ Padre Porta, № 8 (Clave CM-1)

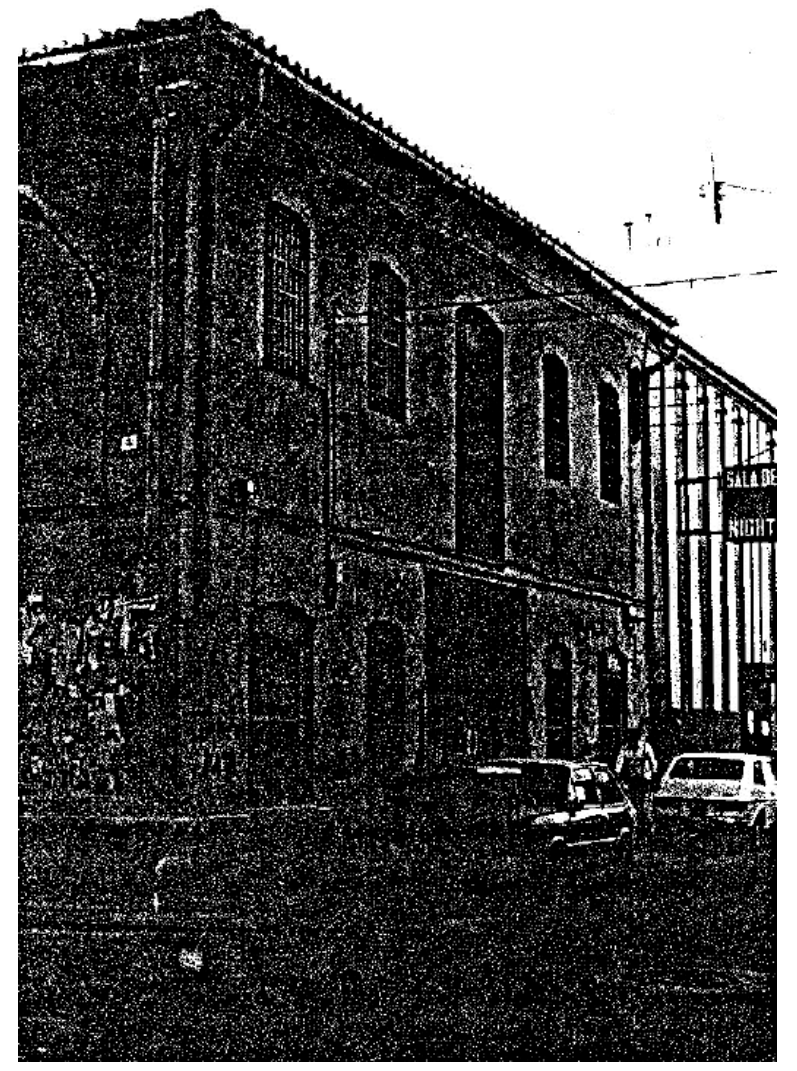

Foto 58: Empresa de reparación y mantenimiento de buques. Mas Piza, J.J. C/ Padre Porta, 8. Valencia.1985. Fuente: Elaboración propia

- BURBEN.

C/ Poeta San Martín Aguirre, oㅡ 2 (Clave CZ- 1. CZ-2)

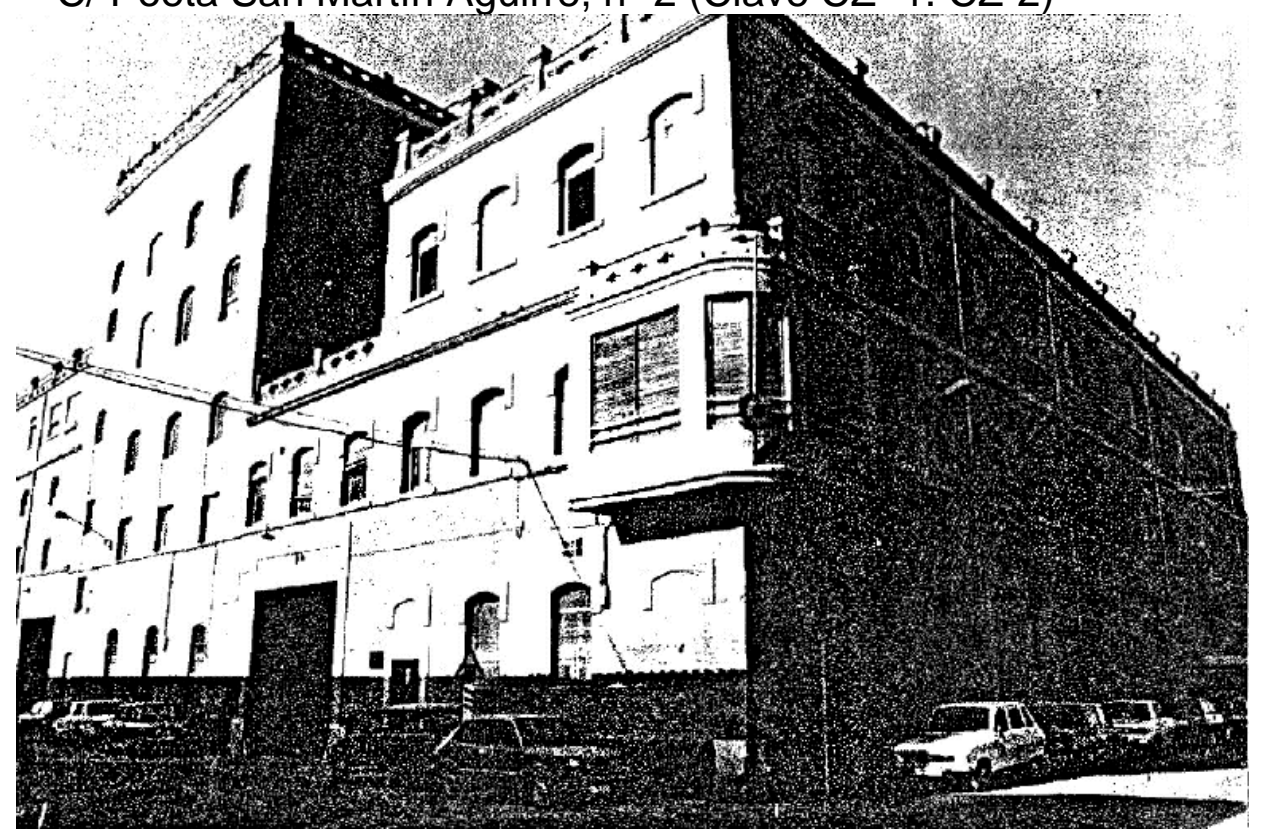

Foto 59: Industria de piensos. (harinera) Burben, S.A. C/ Poeta San Martín Aguirre, 2.Valencia.1985.

Fuente: Elaboración propia 
- ARLESA.

C/ Castell de Pop, no 31. (Clave 63-5000-2)

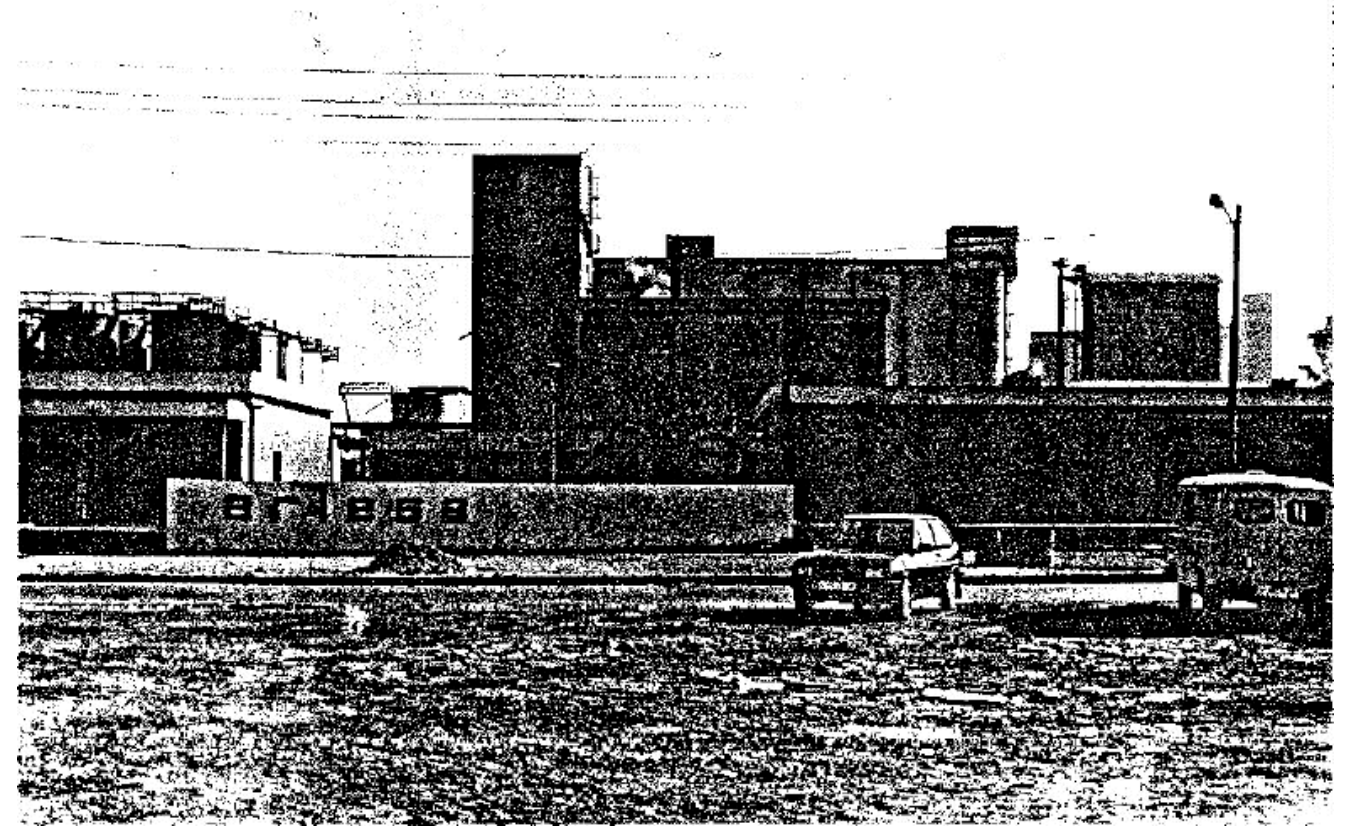

Foto 60: Fábrica de extracción de aceites de semillas oleaginosas y orujo de aceituna. Arlesa Aceiteras Reunidas de Levante, S.A. C/ Castell de Pop, 31.Valencia.1985.

Fuente: Elaboración propia

- ATARAZANAS

Pza. Juan Antonio Benlllure, s/n. (Clave CN-2)

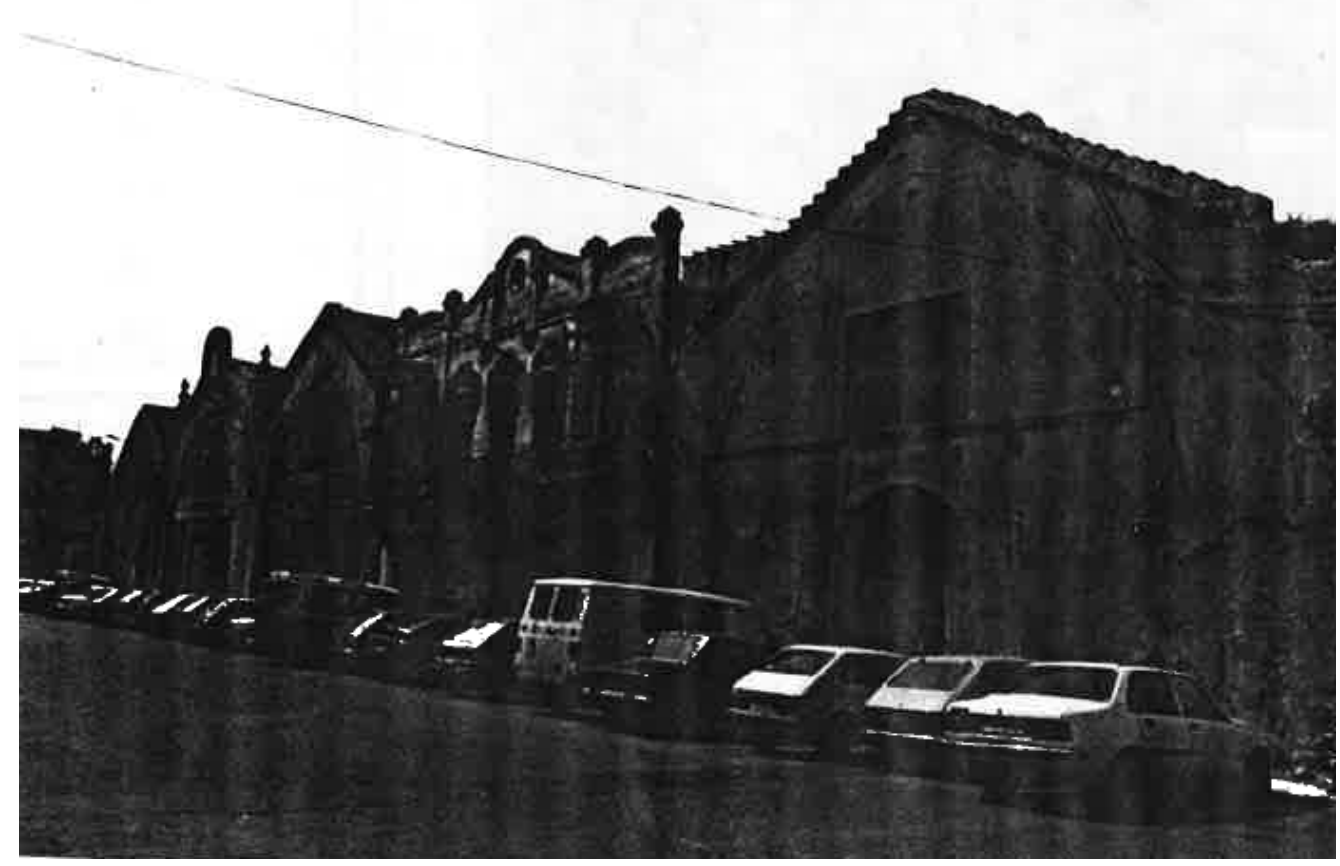

Foto 61: Naves almacén. Atarazanas. Pza. Juan Antonio Benlliure, s.n..Valencia.1985.

Fuente: Elaboración propia 
TIPOLOGÍA EDIFICACIÓN

\section{TIPOLOGÍA DE EDIFICACIÓN \\ Distrito 11. POBLATS MARÍTIMS}

AISLADO ENTRE MEDIANERAS

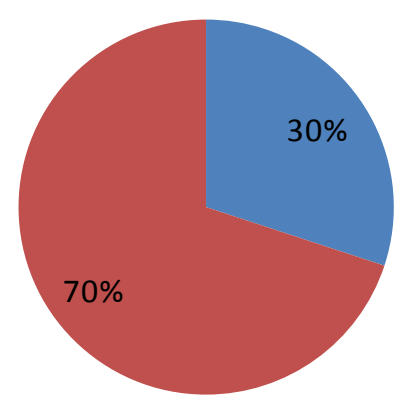




\section{ACTIVIDAD INDUSTRIAL, SUPERFICIE Y EMPLEO}

\begin{tabular}{|c|c|c|c|c|c|}
\hline ACTIVIDAD & $\begin{array}{c}\stackrel{N}{N}= \\
\text { EMPRESAS }\end{array}$ & $\begin{array}{l}\text { SUP. ACTIVIDAD } \\
\text { IND }\left(\mathrm{m}^{2}\right)\end{array}$ & $\begin{array}{c}\text { \% SUP. } \\
\text { INDUSTRIAL }\end{array}$ & $\begin{array}{c}\mathrm{N} \cong \\
\text { EMPLEADOS }\end{array}$ & $\begin{array}{c}\text { DENSIDAD } \\
\text { EMPLEO } \\
\text { (empleados/m² } \\
\text { actividad) }\end{array}$ \\
\hline \begin{tabular}{|l} 
INDUSTRIAS DE PRODUCTOS MINERALES NO METÁLICOS \\
\end{tabular} & 1 & 700 & 0,07 & 4 & 0,0057 \\
\hline INDUSTRIA QUÍMICA & 3 & 8550 & 0,88 & 66 & 0,0077 \\
\hline FABRICACIÓN DE PRODUCTOS METÁLICOS & 36 & 12613 & 1,29 & 289 & 0,0229 \\
\hline CONSTRUCCIÓN DE MAQUINARIA Y EQUIPO MECÁNICO & 6 & 25285 & 2,59 & 133 & 0,0053 \\
\hline CONSTRUCCIÓN DE MAQUINARIA Y MATERIAL ELÉCTRICO & 4 & 2013 & 0,21 & 47 & 0,0233 \\
\hline FABRICACIÓN DE MATERIAL ELECTRÓNICO & 2 & 324 & 0,03 & 9 & 0,0278 \\
\hline CONSTRUCCIÓN DE VEHÍCULOS AUTOMÓVILES Y SUS PIEZAS DE REPUESTO & 5 & 4120 & 0,42 & 65 & 0,0158 \\
\hline CONSTRUCCIÓN NAVAL, REPARACIÓN Y MANTENIMIENTO DE BUQUES & 9 & 114849 & 11,77 & 1519 & 0,0132 \\
\hline INDUSTRIAS DE PRODUCTOS ALIMENTICIOS, BEBIDAS Y TABACO & 16 & 53007 & 5,43 & 183 & 0,0035 \\
\hline INDUSTRIAS DE PRODUCTOS ALIMENTICIOS, BEBIDAS Y TABACO & 6 & 9416 & 0,96 & 112 & 0,0119 \\
\hline \begin{tabular}{|l|l|l|l} 
INDUSTRIA TEXTIL \\
\end{tabular} & 4 & 733 & 0,08 & 40 & 0,0546 \\
\hline \begin{tabular}{|l} 
INDUSTRIA DEL CALZADO Y DEL VESTIDO Y OTRAS CONFECCIONES TEXTILES \\
\end{tabular} & 6 & 1619 & 0,17 & 147 & 0,0908 \\
\hline INDUSTRIAS DE MADERA, CORCHO Y MUEBLES DE MADERA & 19 & 102085 & 10,46 & 178 & 0,0017 \\
\hline $\begin{array}{l}\text { INDUSTRIA DEL PAPEL Y FABRICACIÓN DE ARTÍCULOS DE PAPEL, ARTES GRÁFICAS Y } \\
\text { EDICIÓN }\end{array}$ & 4 & 16851 & 1,73 & 116 & 0,0069 \\
\hline \begin{tabular}{|l} 
INDUSTIAS DE TRANSFORMACIÓN DEL CAUCHO Y MATERIAS PLÁSTICAS \\
\end{tabular} & 4 & 984 & 0,10 & 9 & 0,0091 \\
\hline OTRAS INDUSTRIAS MANUFACTURERAS & 3 & 542 & 0,06 & 11 & 0,0203 \\
\hline CONSTRUCCIÓN & 4 & 3630 & 0,37 & 16 & 0,0044 \\
\hline TRANSPORTES TERRESTRES & 3 & 27295 & 2,80 & 292 & 0,0107 \\
\hline ACTIVIDADES ANEXAS A LOS TRANSPORTES & 1 & 98500 & 10,09 & 180 & 0,0018 \\
\hline SERVICIOS Y ACTIVIDADES RECREATIVAS & 1 & 120 & 0,01 & 6 & 0,0500 \\
\hline CONTENEDORES & 34 & 491488 & 50,35 & 245 & 0,0005 \\
\hline SIN IDENTIFICAR & 4 & 1373 & 0,14 & 14 & 0,0102 \\
\hline TOTAL & 175 & 976097 & 100 & 3681 & 0,0038 \\
\hline
\end{tabular}

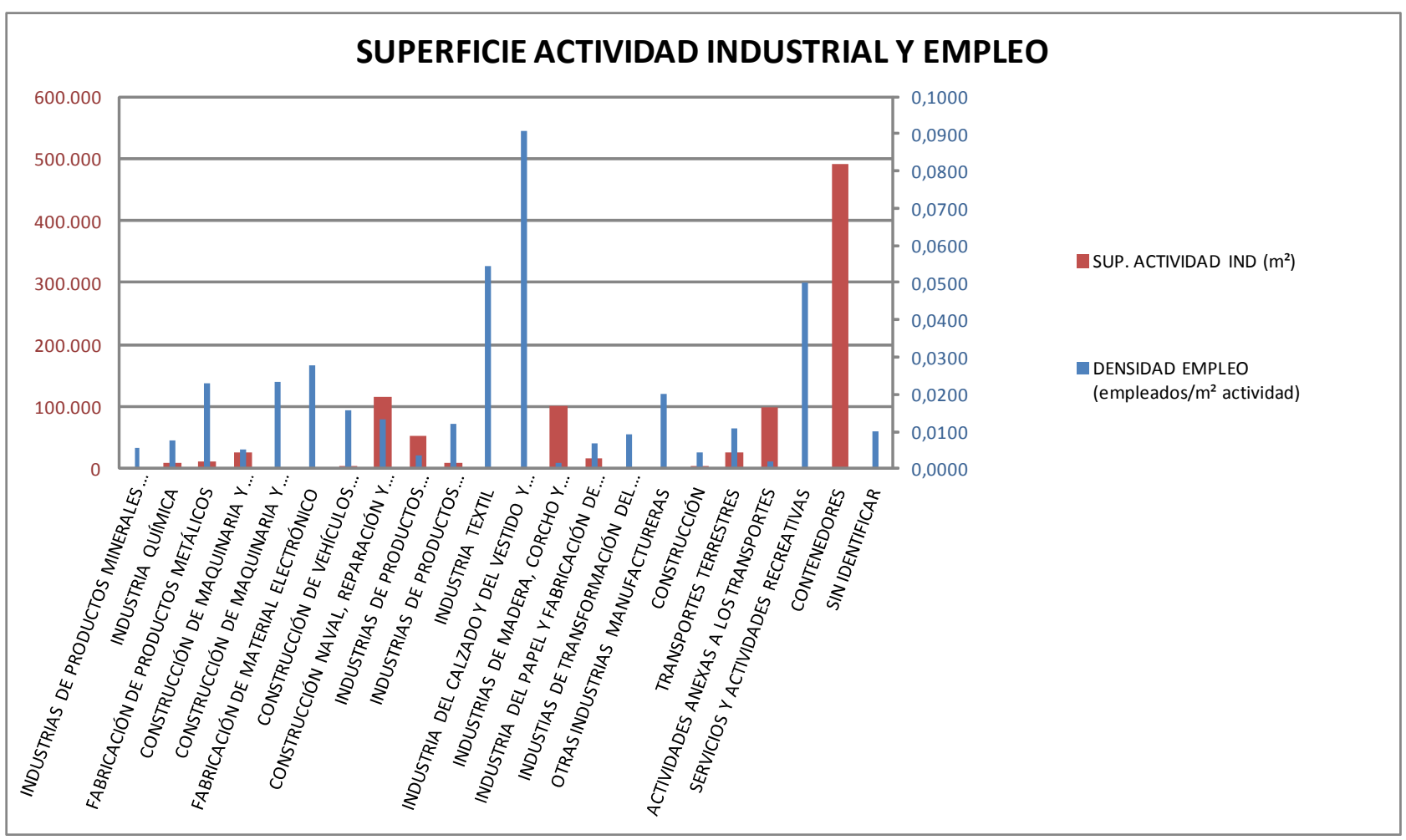


IMPACTO AMBIENTAL

\begin{tabular}{|c|c|c|c|c|c|}
\hline \multicolumn{6}{|c|}{ DISTRITO 11 - POBLATS MARITIMS (INFORMACIÓN URBANÍSTICA) } \\
\hline ACTIVIDAD & $\begin{array}{c}\text { № } \\
\text { EMPRESAS }\end{array}$ & $\begin{array}{l}\text { ENTRE } \\
\text { MEDIANERAS }\end{array}$ & RUIDOSAS & $\begin{array}{l}\text { EMPRESAS } \\
\text { CON } \\
\text { CHIMENEA }\end{array}$ & $\begin{array}{l}\text { RUIDOSAS Y } \\
\text { CHIMENEA }\end{array}$ \\
\hline INDUSTRIAS DE PRODUCTOS MINERALES NO METÁLICOS & 1 & 1 & 0 & 0 & 0 \\
\hline INDUSTRIA QUÍMICA & 3 & 1 & 1 & 0 & 0 \\
\hline FABRICACIÓN DE PRODUCTOS METÁLICOS & 36 & 32 & 20 & 1 & 0 \\
\hline CONSTRUCCIÓN DE MAQUINARIA Y EQUIPO MECÁNICO & 6 & 5 & 0 & 0 & 6 \\
\hline CONSTRUCCIÓN DE MAQUINARIA Y MATERIAL ELÉCTRICO & 4 & 4 & 2 & 0 & 0 \\
\hline FABRICACIÓN DE MATERIAL ELECTRÓNICO & 2 & 2 & 0 & 0 & 0 \\
\hline CONSTRUCCIÓN DE VEHÍCULOS AUTOMÓVILES Y SUS PIEZAS DE REPUESTO & 5 & 4 & 3 & 1 & 1 \\
\hline CONSTRUCCIÓN NAVAL, REPARACIÓN Y MANTENIMIENTO DE BUQUES & 9 & 3 & 4 & 0 & 1 \\
\hline INDUSTRIAS DE PRODUCTOS ALIMENTICIOS, BEBIDAS Y TABACO & 16 & 15 & 1 & 13 & 0 \\
\hline INDUSTRIAS DE PRODUCTOS ALIMENTICIOS, BEBIDAS Y TABACO & 6 & 6 & 0 & 2 & 1 \\
\hline INDUSTRIA TEXTIL & 4 & 3 & 1 & 0 & 0 \\
\hline INDUSTRIA DEL CALZADO Y DEL VESTIDO Y OTRAS CONFECCIONES TEXTILES & 6 & 6 & 1 & 0 & 0 \\
\hline INDUSTRIAS DE MADERA, CORCHO Y MUEBLES DE MADERA & 19 & 15 & 9 & 2 & 0 \\
\hline $\begin{array}{l}\text { INDUSTRIA DEL PAPEL Y FABRICACIÓN DE ARTÍCULOS DE PAPEL, ARTES GRÁFICAS Y } \\
\text { EDICIÓN }\end{array}$ & 4 & 4 & 4 & 0 & 0 \\
\hline INDUSTIAS DE TRANSFORMACIÓN DEL CAUCHO Y MATERIAS PLÁSTICAS & 4 & 4 & 2 & 0 & 0 \\
\hline OTRAS INDUSTRIAS MANUFACTURERAS & 3 & 3 & 1 & 0 & 0 \\
\hline CONSTRUCCIÓN & 4 & 3 & 0 & 0 & 0 \\
\hline TRANSPORTES TERRESTRES & 3 & 1 & 1 & 0 & 0 \\
\hline ACTIVIDADES ANEXAS A LOS TRANSPORTES & 1 & 0 & 0 & 1 & 0 \\
\hline SERVICIOS Y ACTIVIDADES RECREATIVAS & 1 & 1 & 0 & 0 & 0 \\
\hline CONTENEDORES & 34 & 6 & 6 & 0 & 0 \\
\hline SIN IDENTIFICAR & 4 & 4 & 2 & 0 & 0 \\
\hline TOTAL & 175 & 123 & 58 & 20 & 9 \\
\hline
\end{tabular}

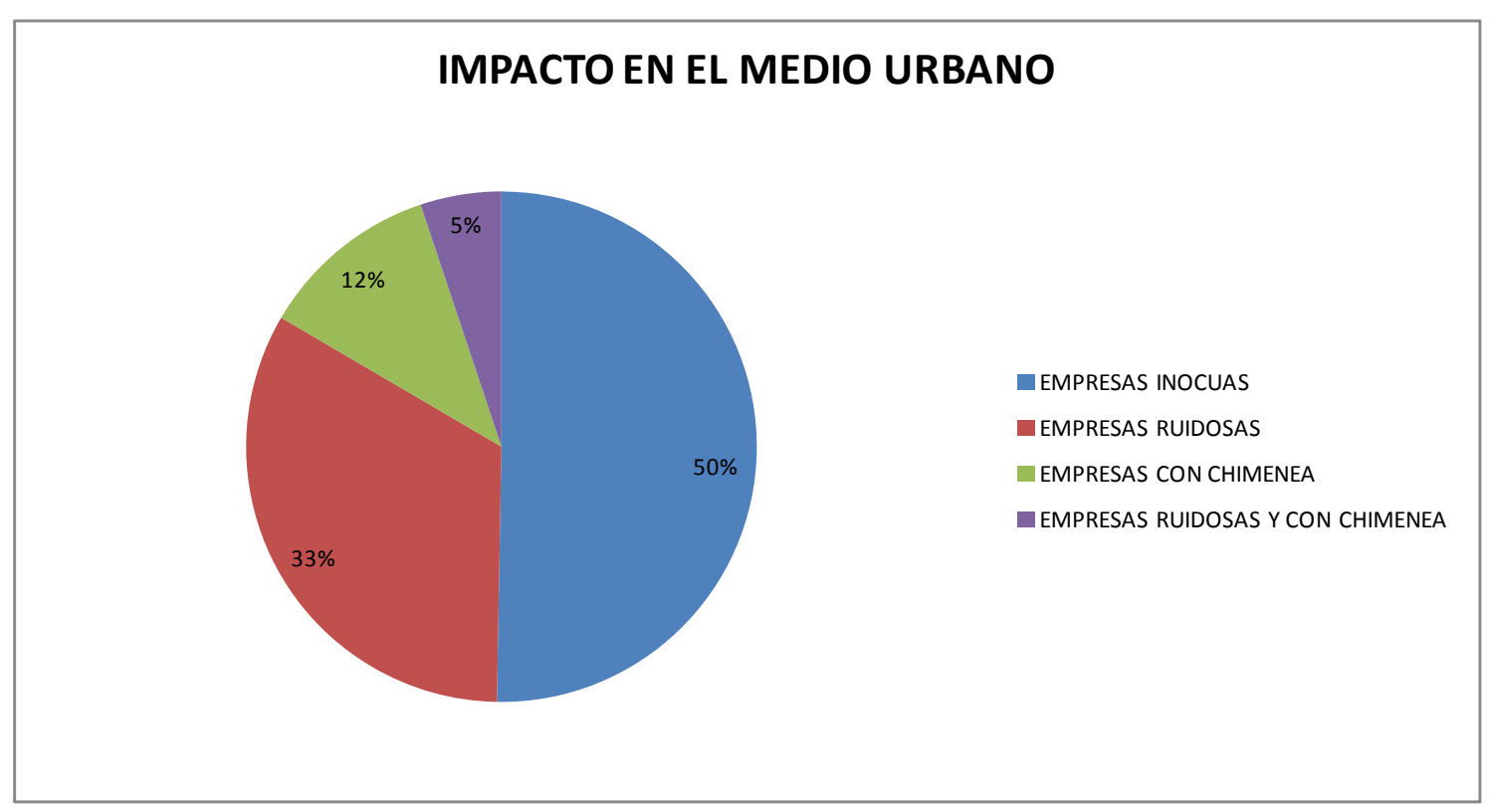




\section{FICHAS TIPO \\ FICHA DATOS DE LA INDUSTRIA}

LOCALIZACION ACTUALIZADA DE ACTIVIDADES INDUSTRIALES EN EL MEDIO URBANO DE VALENCIA

\begin{tabular}{|c|c|c|c|c|c|c|c|}
\hline \multirow{5}{*}{ 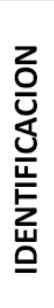 } & \multirow{2}{*}{\multicolumn{2}{|c|}{$\begin{array}{c}\text { NOMBRE } \\
\text { EMPLAZAMIENTO }\end{array}$}} & \multicolumn{5}{|c|}{ SALVADOR PASTOR SAVALL "CAFÉS PASTOR" } \\
\hline & & & \multicolumn{3}{|c|}{ C/ José Benlliure, 210} & C.P. & \\
\hline & \multirow{2}{*}{ CNAE } & \multirow{2}{*}{423.1} & \multirow{2}{*}{ DESCRIPCION } & \multicolumn{4}{|c|}{$\begin{array}{l}\text { INDUSTRIA DE PRODUCTOS ALIMENTICIOS, } \\
\text { BEBIDAS, ETC. }\end{array}$} \\
\hline & & & & \multicolumn{4}{|c|}{ Tostadero de café } \\
\hline & DISTRITO & 11 & \multicolumn{5}{|c|}{ POBLATS MARÍTIMS } \\
\hline \multicolumn{3}{|c|}{ SUPERFICIES } & $\begin{array}{l}\text { Sup. Parcela: } \\
\qquad 80 \mathrm{~m}^{2}\end{array}$ & $\begin{array}{l}\text { Sup. Ocupada: } \\
80 \mathrm{~m}^{2}\end{array}$ & $\begin{array}{l}\text { Sup. Construida: } \\
80 \mathrm{~m}^{2}\end{array}$ & EMP & $\begin{array}{l}\text { EADOS: } \\
4\end{array}$ \\
\hline
\end{tabular}
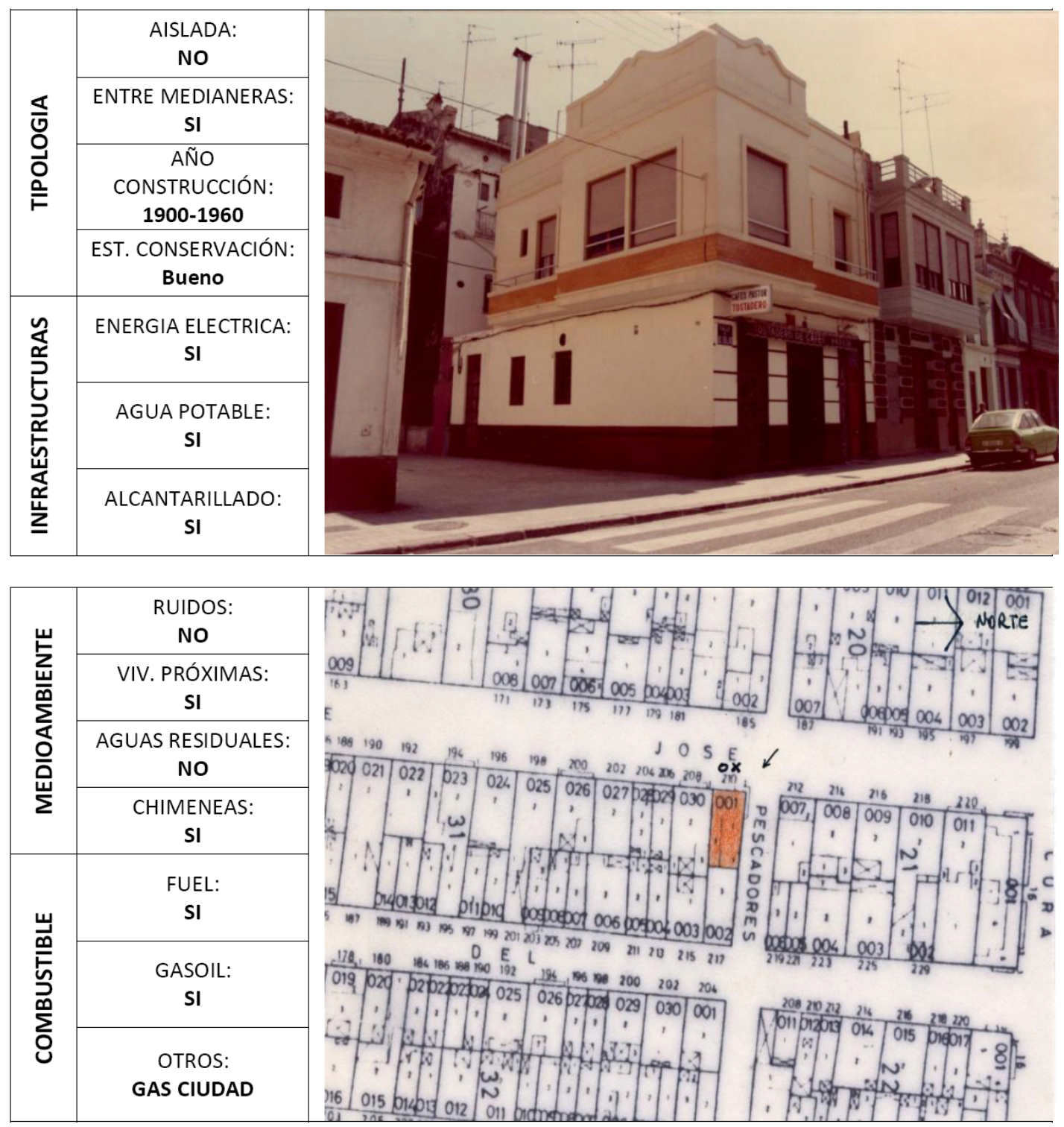

EN LA ACTUALIDAD: MANTIENE LA ACTIVIDAD 


\section{FICHA DATOS DE LA INDUSTRIA}

LOCALIZACION ACTUALIZADA DE ACTIVIDADES INDUSTRIALES EN EL MEDIO URBANO DE VALENCIA

\begin{tabular}{|c|c|c|c|c|c|c|c|}
\hline \multirow{5}{*}{ 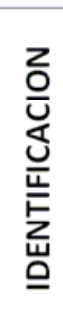 } & \multirow{2}{*}{\multicolumn{2}{|c|}{$\begin{array}{c}\text { NOMBRE } \\
\text { EMPLAZAMIENTO }\end{array}$}} & \multicolumn{5}{|c|}{ TALLERES SANDOL S.L. } \\
\hline & & & \multicolumn{3}{|c|}{ C/ Eugenia Viñes, 62} & C.P. & \\
\hline & \multirow{2}{*}{ CNAE } & \multirow{2}{*}{319} & \multirow{2}{*}{ DESCRIPCION } & \multicolumn{4}{|c|}{ FABRICACIÓN DE PRODUCTOS METÁLICOS } \\
\hline & & & & \multicolumn{4}{|c|}{ Mecánica general } \\
\hline & DISTRITO & 11 & \multicolumn{5}{|c|}{ POBLATS MARÍTIMS } \\
\hline & \multicolumn{2}{|c|}{ SUPERFICIES } & $\begin{array}{c}\text { Sup. Parcela: } \\
1.590 \mathrm{~m}^{2}\end{array}$ & $\begin{array}{c}\text { Sup. Ocupada: } \\
1.200 \mathrm{~m}^{2}\end{array}$ & $\begin{array}{c}\text { Sup. Construida: } \\
1.200 \mathrm{~m}^{2}\end{array}$ & EMP & $\begin{array}{l}\text { EADOS: } \\
22\end{array}$ \\
\hline
\end{tabular}

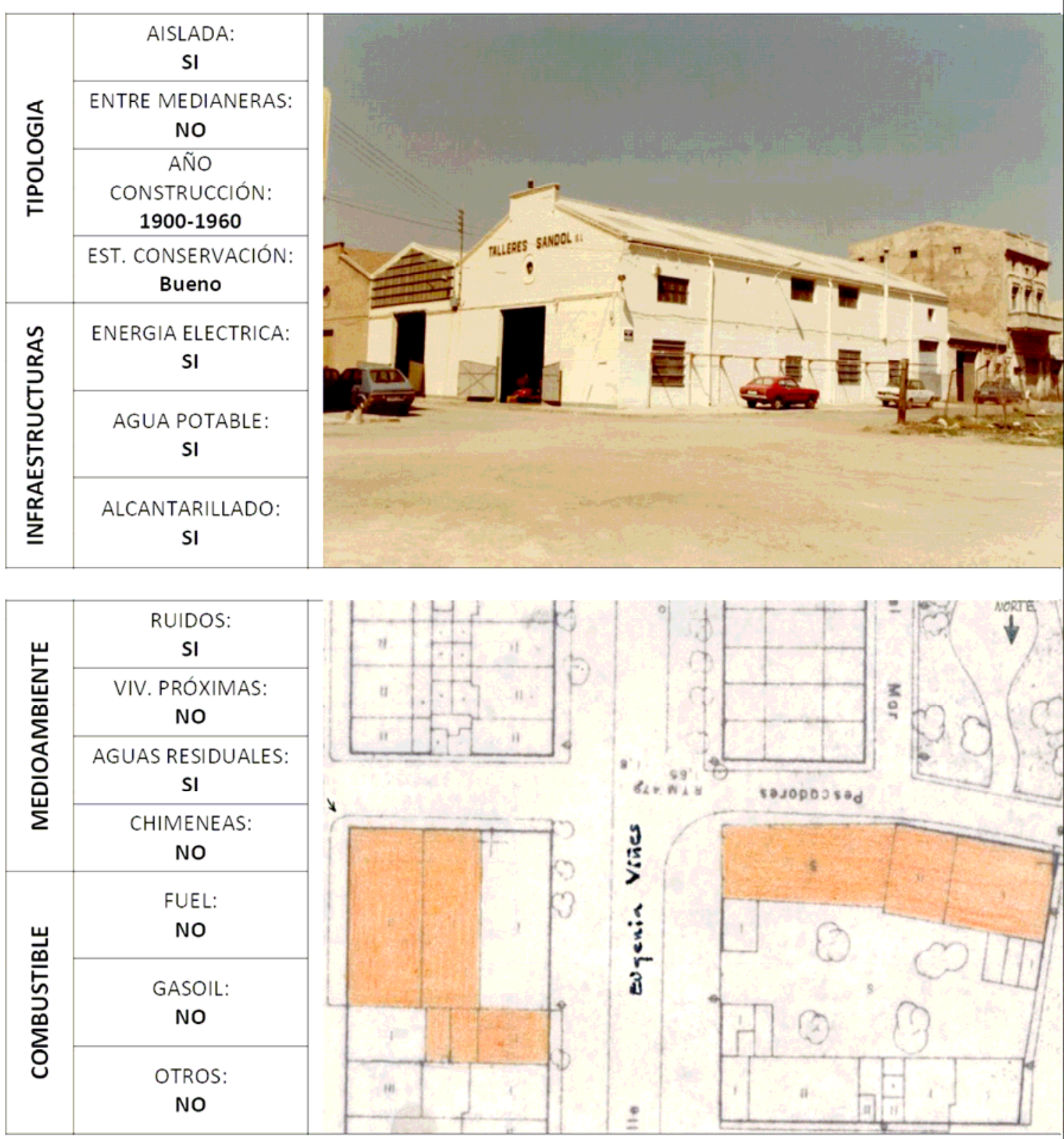




\section{FICHA DATOS DE LA INDUSTRIA}

LOCALIZACION ACTUALIZADA DE ACTIVIDADES INDUSTRIALES EN EL MEDIO URBANO DE VALENCIA

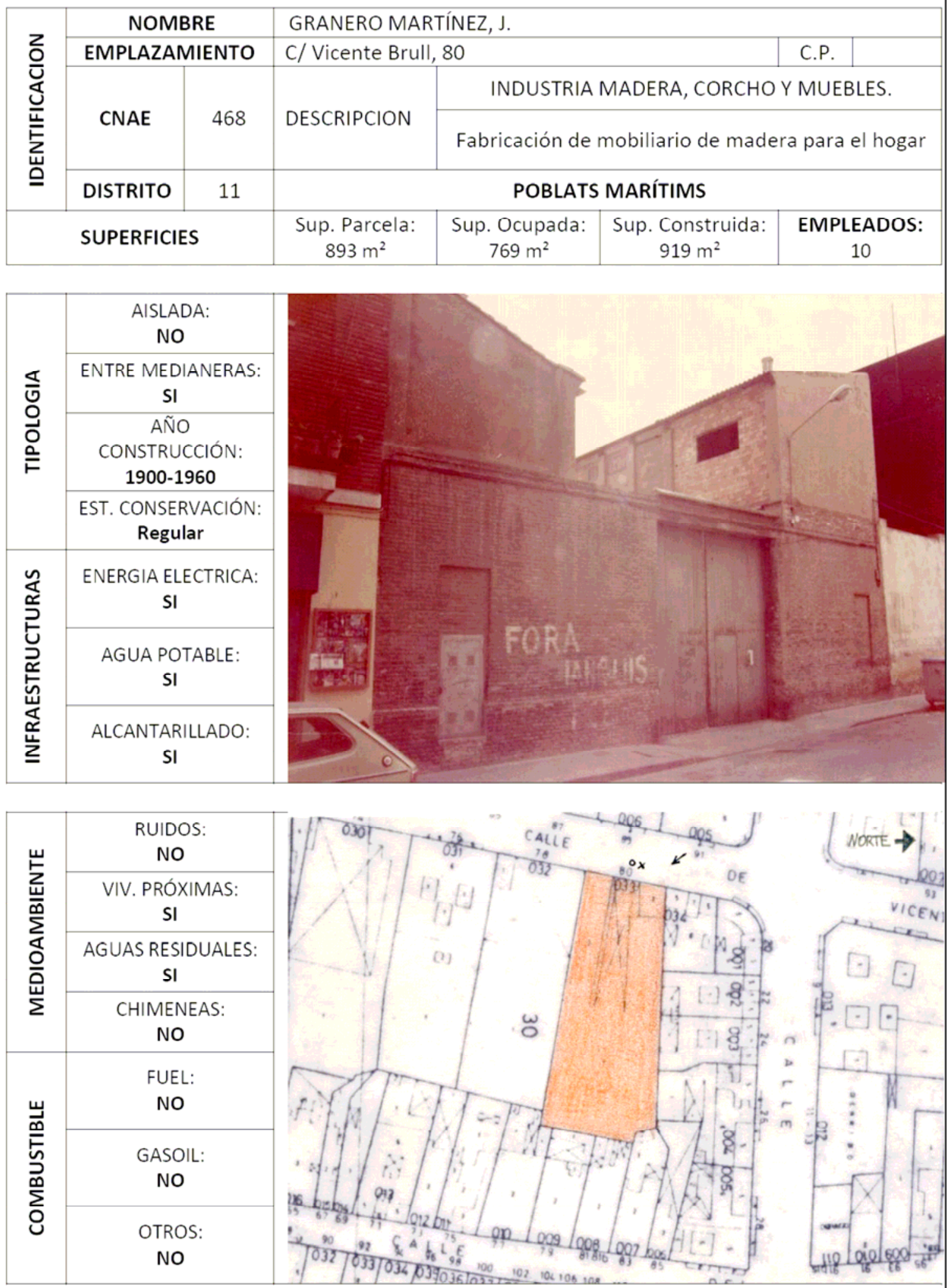




\section{FICHA DATOS DE LA INDUSTRIA}

LOCALIZACION ACTUALIZADA DE ACTIVIDADES INDUSTRIALES EN EL

MEDIO URBANO DE VALENCIA

\begin{tabular}{|c|c|c|c|c|c|c|}
\hline \multirow{5}{*}{ 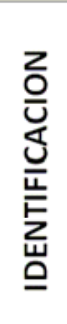 } & \multirow{2}{*}{\multicolumn{2}{|c|}{$\begin{array}{c}\text { NOMBRE } \\
\text { EMPLAZAMIENTO }\end{array}$}} & \multicolumn{4}{|c|}{ MAMERTO DE LA VARA S.L. } \\
\hline & & & \multicolumn{3}{|c|}{ C/ José Aguirre, 2} & C.P. \\
\hline & \multirow{2}{*}{ CNAE } & \multirow{2}{*}{425} & \multirow{2}{*}{ DESCRIPCION } & \multicolumn{3}{|c|}{$\begin{array}{c}\text { INDUSTRIA PRODUCTOS ALIMENTICIOS, BEBIDAS, } \\
\text { ETC }\end{array}$} \\
\hline & & & & \multicolumn{3}{|c|}{ Elaboración y crianza de vinos } \\
\hline & DISTRITO & 11 & \multicolumn{4}{|c|}{ POBLATS MARÍTIMS } \\
\hline \multicolumn{3}{|c|}{ SUPERFICIES } & $\begin{array}{l}\text { Sup. Parcela: } \\
2.000 \mathrm{~m}^{2}\end{array}$ & $\begin{array}{c}\text { Sup. Ocupada: } \\
2.000 \mathrm{~m}^{2}\end{array}$ & $\begin{array}{l}\text { Sup. Construida: } \\
2.000 \mathrm{~m}^{2}\end{array}$ & $\begin{array}{l}\text { EMPLEADOS: } \\
9\end{array}$ \\
\hline
\end{tabular}
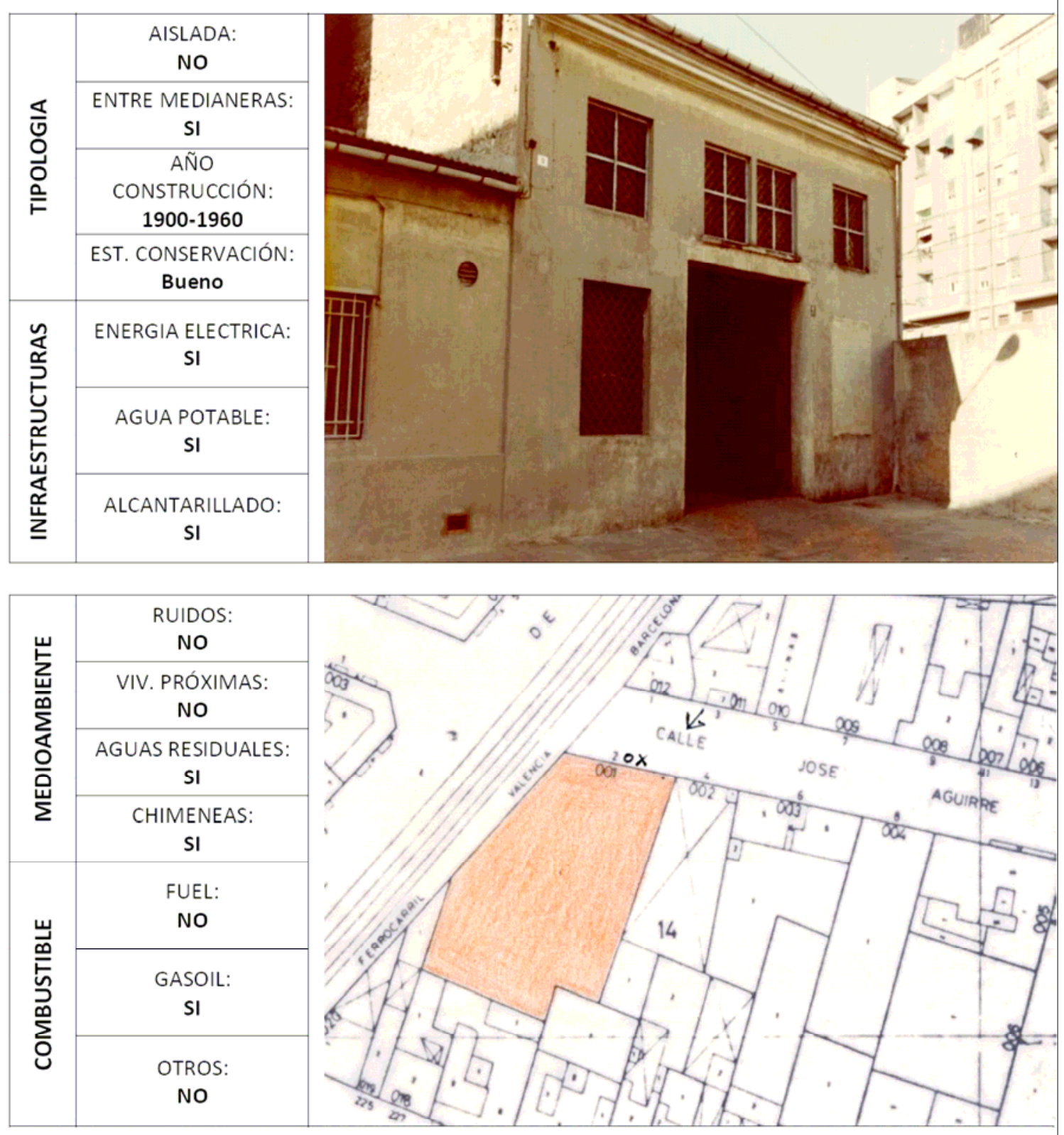

EN LA ACTUALIDAD: NUEVA ORDENACIÓN. 


\section{FICHA DATOS DE LA INDUSTRIA}

LOCALIZACION ACTUALIZADA DE ACTIVIDADES INDUSTRIALES EN EL MEDIO URBANO DE VALENCIA

\begin{tabular}{|c|c|c|c|c|c|c|c|}
\hline \multirow{5}{*}{ 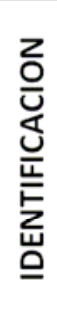 } & \multirow{2}{*}{\multicolumn{2}{|c|}{$\begin{array}{c}\text { NOMBRE } \\
\text { EMPLAZAMIENTO }\end{array}$}} & \multicolumn{5}{|c|}{ COROMINA INDUSTRIAL S.A. } \\
\hline & & & \multicolumn{3}{|c|}{ C/ Islas Canarias, 174} & C.P. & \\
\hline & \multirow{2}{*}{ CNAE } & \multirow{2}{*}{253.1} & \multirow{2}{*}{ DESCRIPCION } & \multicolumn{4}{|c|}{ INDUSTRIAS QUÍMICAS } \\
\hline & & & & \multicolumn{4}{|c|}{ Fabricación de gases comprimidos } \\
\hline & DISTRITO & 11 & \multicolumn{5}{|c|}{ POBLATS MARÍTIMS } \\
\hline \multicolumn{3}{|c|}{ SUPERFICIES } & $\begin{array}{l}\text { Sup. Parcela: } \\
\quad 3.800 \mathrm{~m}^{2}\end{array}$ & $\begin{array}{c}\text { Sup. Ocupada: } \\
3.000 \mathrm{~m}^{2}\end{array}$ & $\begin{array}{l}\text { Sup. Construida: } \\
3.000 \mathrm{~m}^{2}\end{array}$ & EMPL & $\begin{array}{l}\text { EADOS: } \\
25\end{array}$ \\
\hline
\end{tabular}

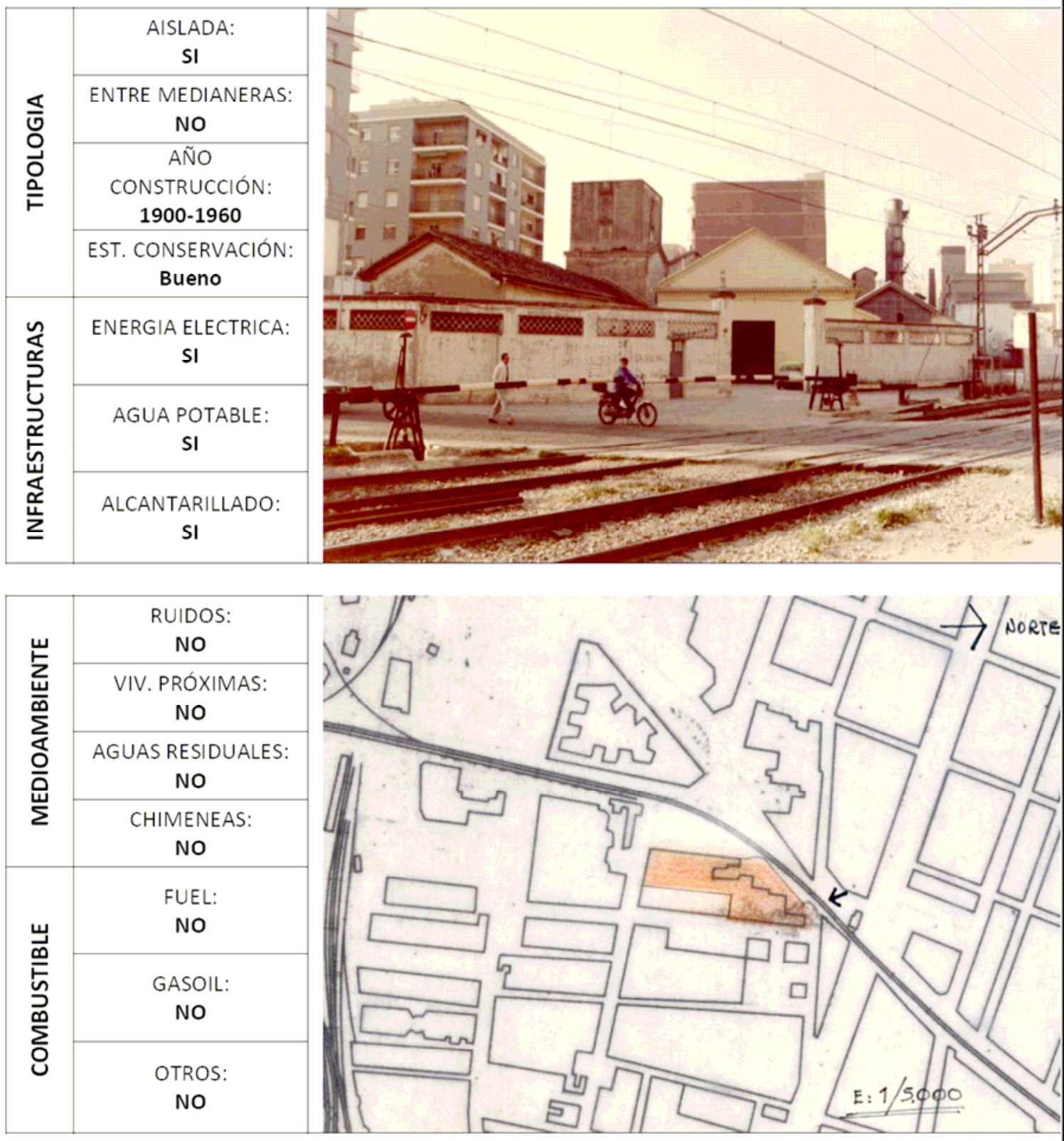

EN LA ACTUALIDAD: NUEVA ORDENACIÓN- EDIFICIO DE VIVIENDAS. 


\section{EVOLUCIÓN}

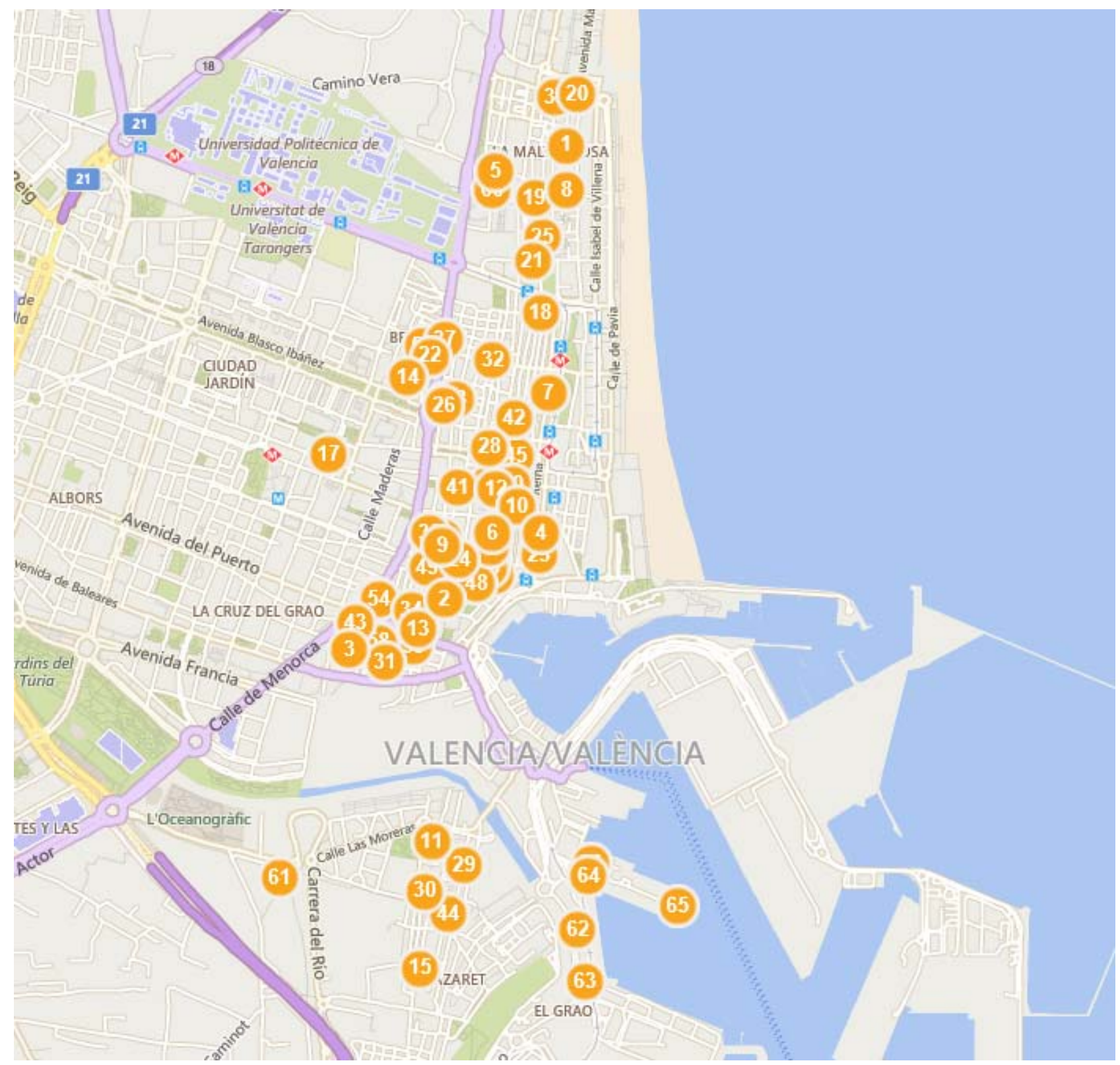

LISTADO DE INDUSTRIAS Y ACTIVIDAD.-

\section{Francisco Javier Fernández}

Fabricación de otros muebles.

02. Hector Brau Iglesias

Fabricación de otros muebles

\section{Francisco Mejía Campos}

Fabricación de otros muebles 
04. José Muñoz Ruiz

Fabricación de muebles de oficina y de establecimientos comerciales

05. Manuel Castro Contreras

Fabricación de otros muebles

06. José Vicente Ruiz Cubells

Fabricación de otros muebles

07. José Luis Silva Boo

Fabricación de artículos de joyería y artículos similares

08. Juan Guasque Jover

Fabricación de artículos de joyería y artículos similares

09. 2007 SEGO VELAS, S.L.

Fabricación de artículos confeccionados con textiles, excepto prendas de vestir

10. Carlos Manuel Navarro

Fabricación de artículos confeccionados con textiles, excepto prendas de vestir

11. ZIRLAB DENTAL, S.L.

Fabricación instrumentos y suministros médicos y odontológicos

12. $M^{\mathrm{a}}$ Dolores Cebrián Colomino

Fabricación instrumentos y suministros médicos y odontológicos

13. ORTOPASTE, S.L.

Fabricación instrumentos y suministros médicos y odontológicos

14. Ramón Fuster Latorre

Fabricación de envases y embalajes de plástico

15. PROY. EST. VALENCIA DE INTEG, SCV

Fabricación de artículos de papelería

16. SPRIN AUTO VALENCIA, S.L.

Mantenimiento y reparación de vehículos a motor

17. Enrique Tarín Sotomayor

Mantenimiento y reparación de vehículos a motor

18. Vicente Peña Martín

Mantenimiento y reparación de vehículos a motor

19. OCTANO MOTOS, S.L.

Mantenimiento y reparación de vehículos a motor

20. José Dolz Giner

Mantenimiento y reparación de vehículos a motor

21. Rafael Martínez Sierra

Mantenimiento y reparación de vehículos a motor

22. Oscar Bosca Mateu

Mantenimiento y reparación de vehículos a motor

23. Santiago Fernández Ayuso

Mantenimiento y reparación de vehículos a motor 
24. Martina Celeste Santamaría

Mantenimiento y reparación de vehículos a motor

25. MOTO MAS, C.B.

Mantenimiento y reparación de vehículos a motor

26. AUTOMOCIÓN BENAVENT, S.L.

Mantenimiento y reparación de vehículos a motor

27. $\mathbf{M}^{\mathrm{a}}$ Carmen Ruiz Collado

Mantenimiento y reparación de vehículos a motor

28. Agustín Jarque Ortiz

Mantenimiento y reparación de vehículos a motor

29. Carmen Haro Martínez

Mantenimiento y reparación de vehículos a motor

30. Fernando Pascual Garrido

Mantenimiento y reparación de vehículos a motor

31. Alfredo Gabaldón Bermúdez

Mantenimiento y reparación de vehículos a motor

32. José Luis Sánchez Cejudo

Mantenimiento y reparación de vehículos a motor

33. Juan Carlos Ipa Pérez

Mantenimiento y reparación de vehículos a motor

34. Francisco Javier Cavero Gómez

Mantenimiento y reparación de vehículos a motor

35. Gigi Ciurea Sorín

Mantenimiento y reparación de vehículos a motor

36. SANSIONEU, S.L.

Mantenimiento y reparación de vehículos a motor

37. Pedro Jiménez López

Fabricación de otros muebles

38. Ma Pilar Pérez Dolz

Fabricación de otros muebles

39. Eva María García Cervera

Confección de otras prendas de vestir exteriores

40. Ana María Ocón Montoro

Confección de otras prendas de vestir y accesorios

41. Joaquín Pérez Gil

Confección de otras prendas de vestir y accesorios

42. $M^{\mathrm{a}}$ Dolores González Caparrós

Confección de otras prendas de vestir y accesorios

43. Josefa García Denia

Elaboración de zumos de frutas y hortalizas 
44. José Manuel Clemente Navarro

Elaboración de pan y de productos frescos de panadería y pastelería

45. José Enrique Montañana Álvarez

Elaboración de pan y de productos frescos de panadería y pastelería

46. HONO CARDO, S.L.

Elaboración de pan y de productos frescos de panadería y pastelería

47. CANYAMELAR IMORESORES, S.L.

Actividades de impresión y artes gráficas

48. Espejo Pérez Fernando

Otras actividades de impresión y artes gráficas

49. Lacomba Gómez J. Cristobal

Otras actividades de impresión y artes gráficas

50. Castellon Estevan. C

Mantiene la actividad. Troquelado

51. VALLEJO Y MARCOS, S.L.

Mantiene la actividad. Carpintería metálica

52. Salvador Pastor Savall

Mantiene la actividad. Cafés Pastor

53. Lluna, $\mathrm{V}$.

Mantiene la actividad. Horno

54. TALLERES MURO, S.L.

Mantiene la actividad. Taller

55. TALLERES TOMAS PASCUAL, S.L.

Mantiene la actividad. Talleres Tomas Pascual

56. Perez, F.

Mantiene la actividad. Horno

57. Alarcón Arguello, M.

Mantiene la actividad. Pastelería

58. IMPRENTA LITOGRAFIA ORTEGA

Mantiene la actividad. Imprenta-litografía

59. Mas Piza, Juan José

Mantiene la actividad. Talleres Mas

60. Tarazona Estrela, Felix

Mantiene la actividad. Horno

61. GRUAS Fco. ALAPONT

Mantiene la actividad. Grúas Alapont

62. ENDECASA

Mantiene la actividad

63. INDUSTRIAS QUIMICAS DE CARBUROS, S.A.

Mantiene la actividad. 
64. PRODUCTOS ASFALTICOS, S.A.

Mantiene la actividad.

65. VALENCIANA DE CEMENTOS

Mantiene la actividad.

66. DEMADRISA

Mantiene la actividad.

ESTADO ACTUAL DE LOS ANTIGUOS EDIFICIOS INDUSTRIALES DE INTERES.-

- DURAGLIA.

C/ Lirio, no $11 \quad$ (Clave CL-21

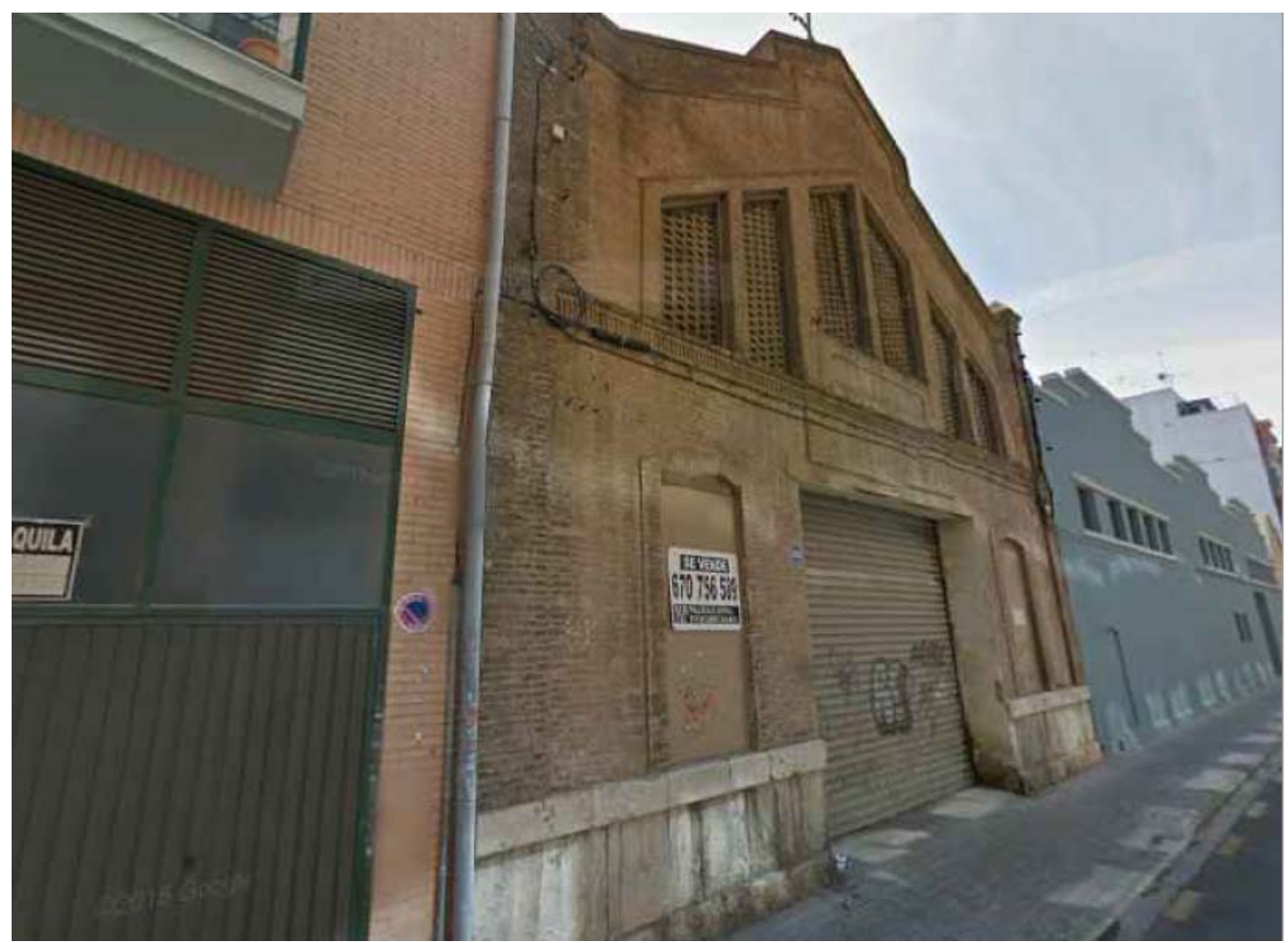

Foto 62: Antigua industria de madera. Duraglia. C/ Lirio,11.Valencia.2015

Fuente: WEB. http://www.google.es/maps (Street View). 
- MAS PIZA, J.J.

C/ Padre Porta, no 8 (Clave CM-1)

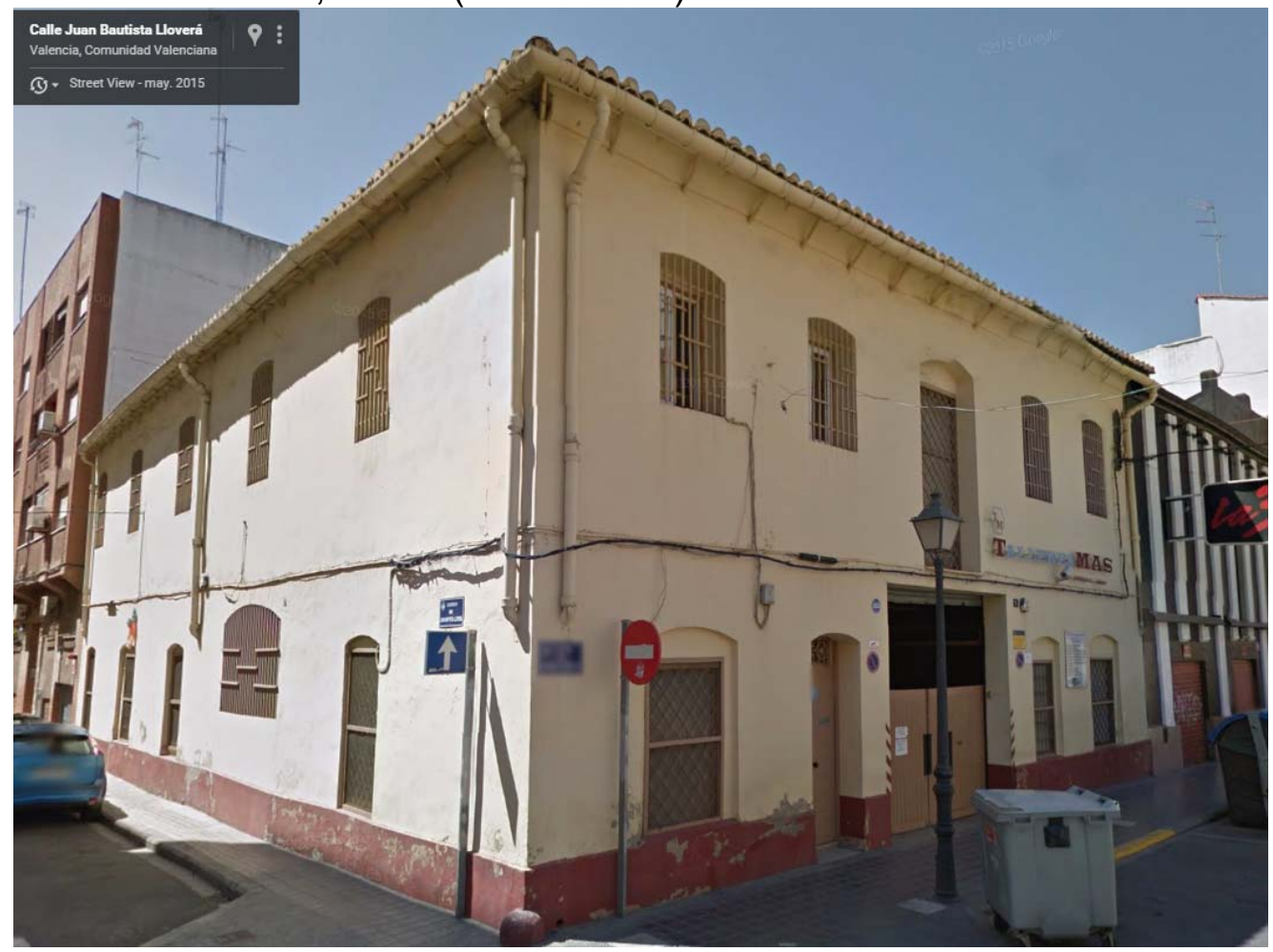

Foto 63: Taller mecánico. C/ Padre Porta, 8. Valencia.2015.

Fuente: WEB. http://www.google.es/maps (Street View).

\section{- BURBEN.}

C/ Poeta San Martín Aguirre, no 2 (Clave CZ- 1. CZ-2)

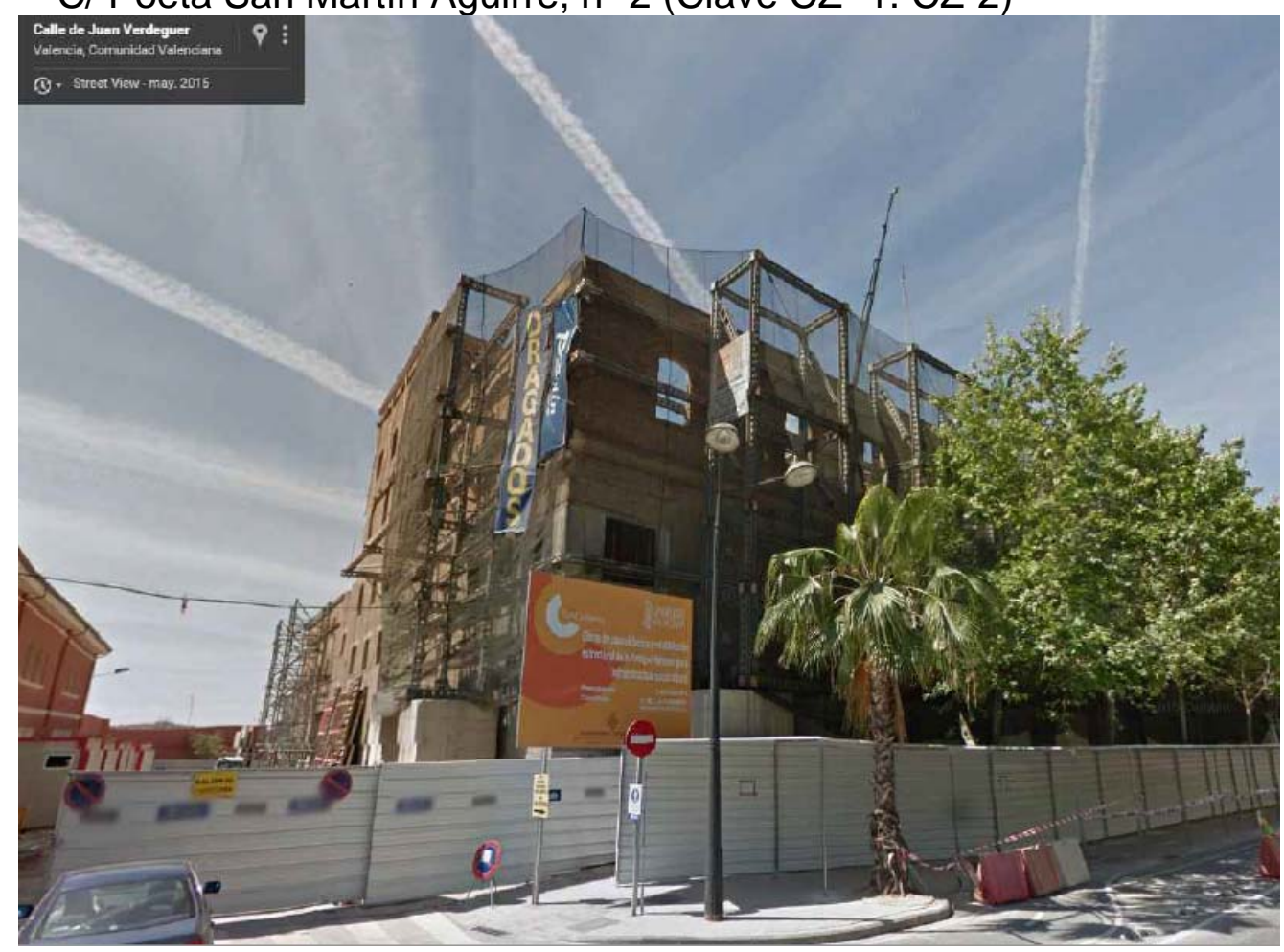

Foto 64: Rehabilitación de antigua harinera. Cl Poeta San Martín Aguirre, 2. Valencia.2015

Fuente: WEB. http://www.google.es/maps (Street View). 
- ARLESA.

C/ Castell de Pop, nº 31. (Clave 63-5000-2)

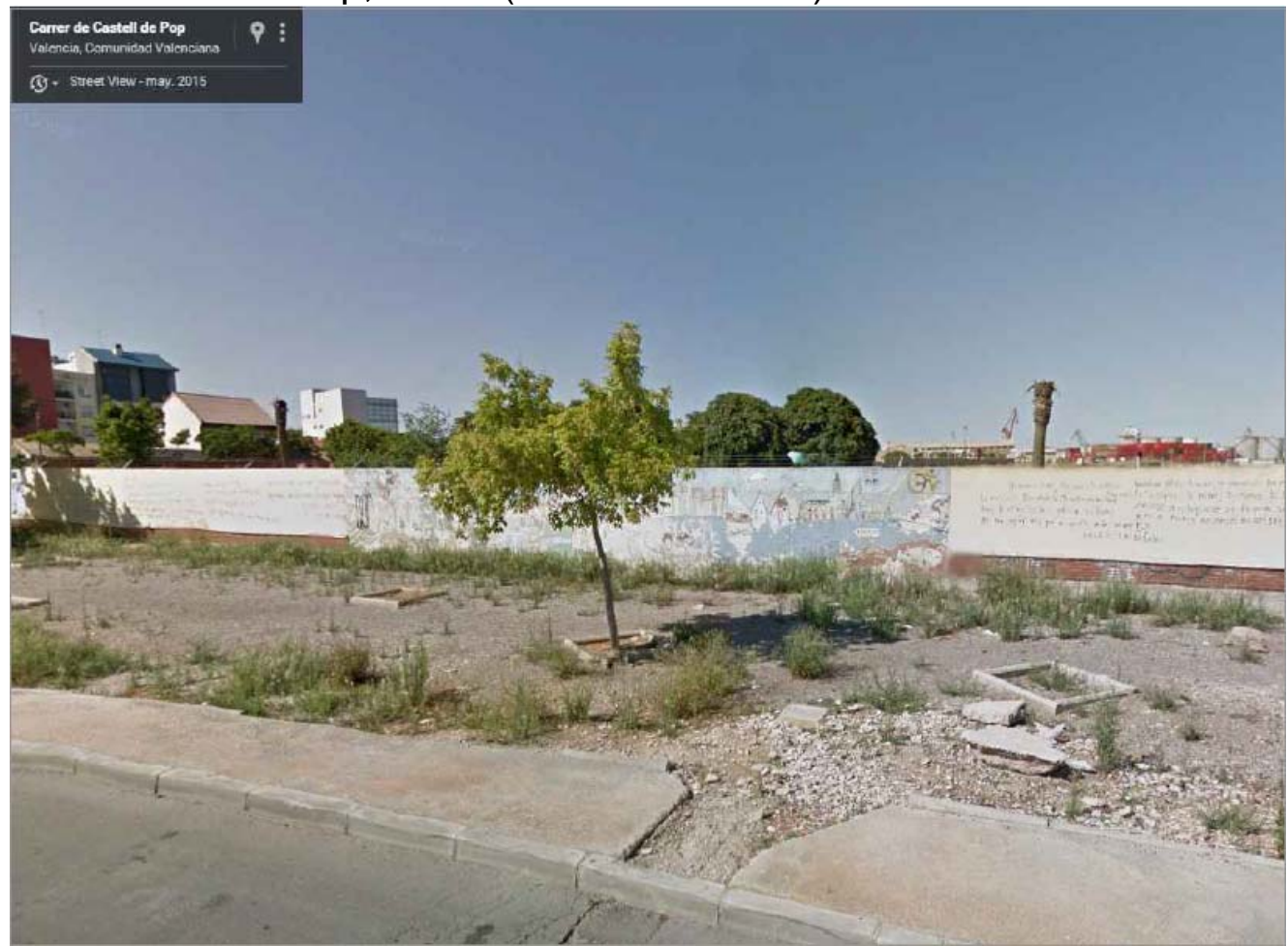

Foto 65: Solar. C/ Castell de Pop, 31. Valencia. 2015

Fuente: WEB. http://www.google.es/maps (Street View)

- ATARAZANAS

Pza. Juan Antonio Benlliure, s/n. (Clave CN-2)

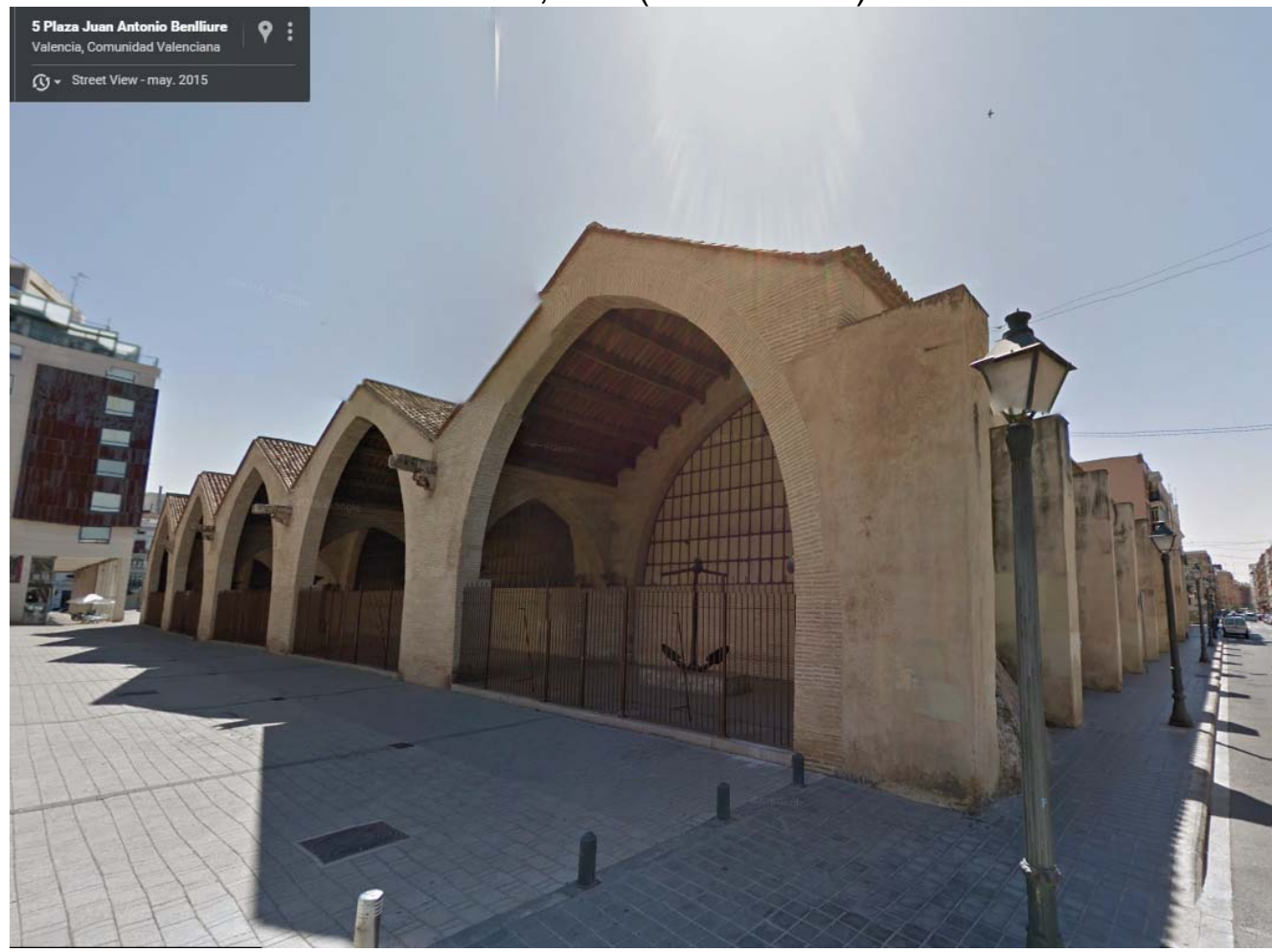

Foto 66: Atarazanas. Pza. Juan Antonio Benlliure, s.n.. Valencia. 2015

Fuente: WEB. http://www.google.es/maps (Street View). 


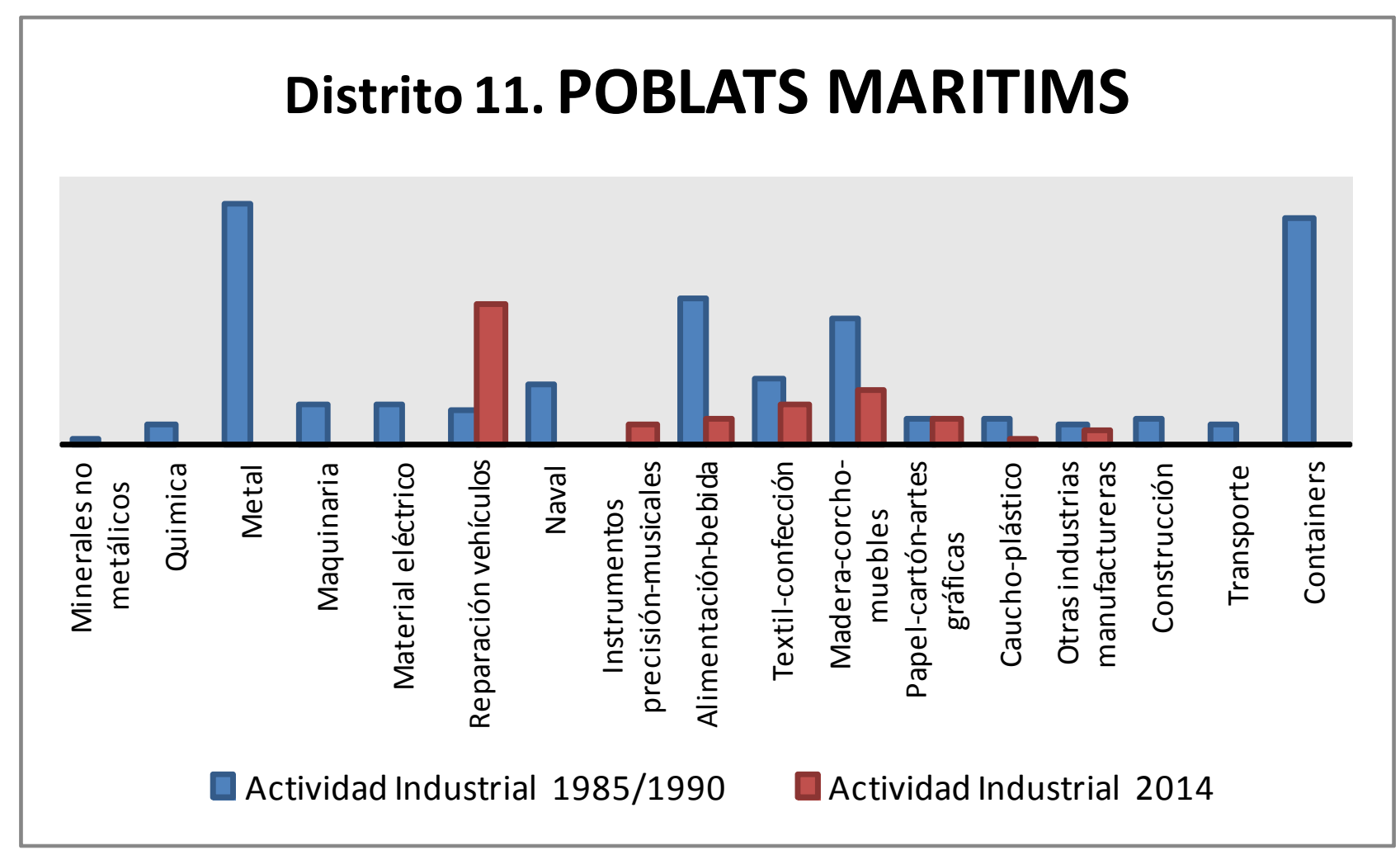

EVOLUCIÓN DEL IMPACTO AMBIENTAL

IMPACTO EN EL MEDIO URBANO Distrito 11. POBLATS MARITIMS

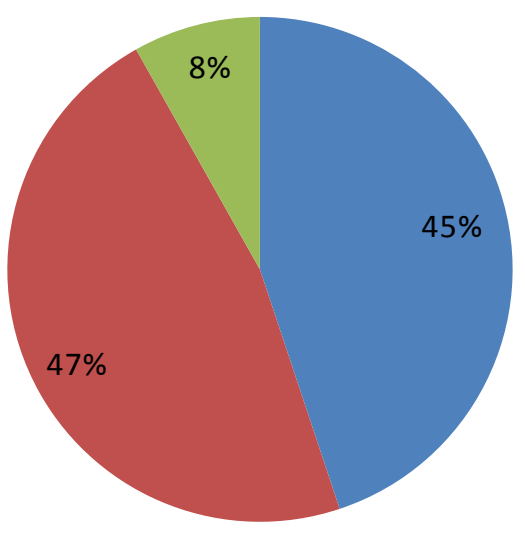

Empresas inocuas

Empresas ruidosas

Empresas ruidosas con chimenea 


\section{FICHAS TIPO \\ FICHA DATOS DE LA INDUSTRIA}

LOCALIZACION ACTUALIZADA DE ACTIVIDADES INDUSTRIALES EN EL

\begin{tabular}{|c|c|c|c|c|c|c|}
\hline \multicolumn{7}{|c|}{$\begin{array}{l}\text { MEDIO URBANO DE VALE } \\
\text { MANUEL CASTRO CONTRERAS }\end{array}$} \\
\hline \multirow{4}{*}{ 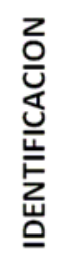 } & \multicolumn{2}{|c|}{ EMPLAZAMIENTO } & \multicolumn{2}{|c|}{ C/DR. ÁLVARO LÓPEZ, 45} & C.P. & 46011 \\
\hline & \multirow[b]{2}{*}{ CNAE } & \multirow[b]{2}{*}{3109} & \multirow[b]{2}{*}{ DESCRIPCION } & \multicolumn{3}{|c|}{ MADERA-CORCHO-MUEBLES } \\
\hline & & & & \multicolumn{3}{|c|}{ Fabricación de otros muebles } \\
\hline & DISTRITO & 11 & \multicolumn{4}{|c|}{ POBLATS MARÍTIMS } \\
\hline & IEDIOAMBI & VTE & RUIDOSAS & CHIMENEAS & & 0 \\
\hline
\end{tabular}

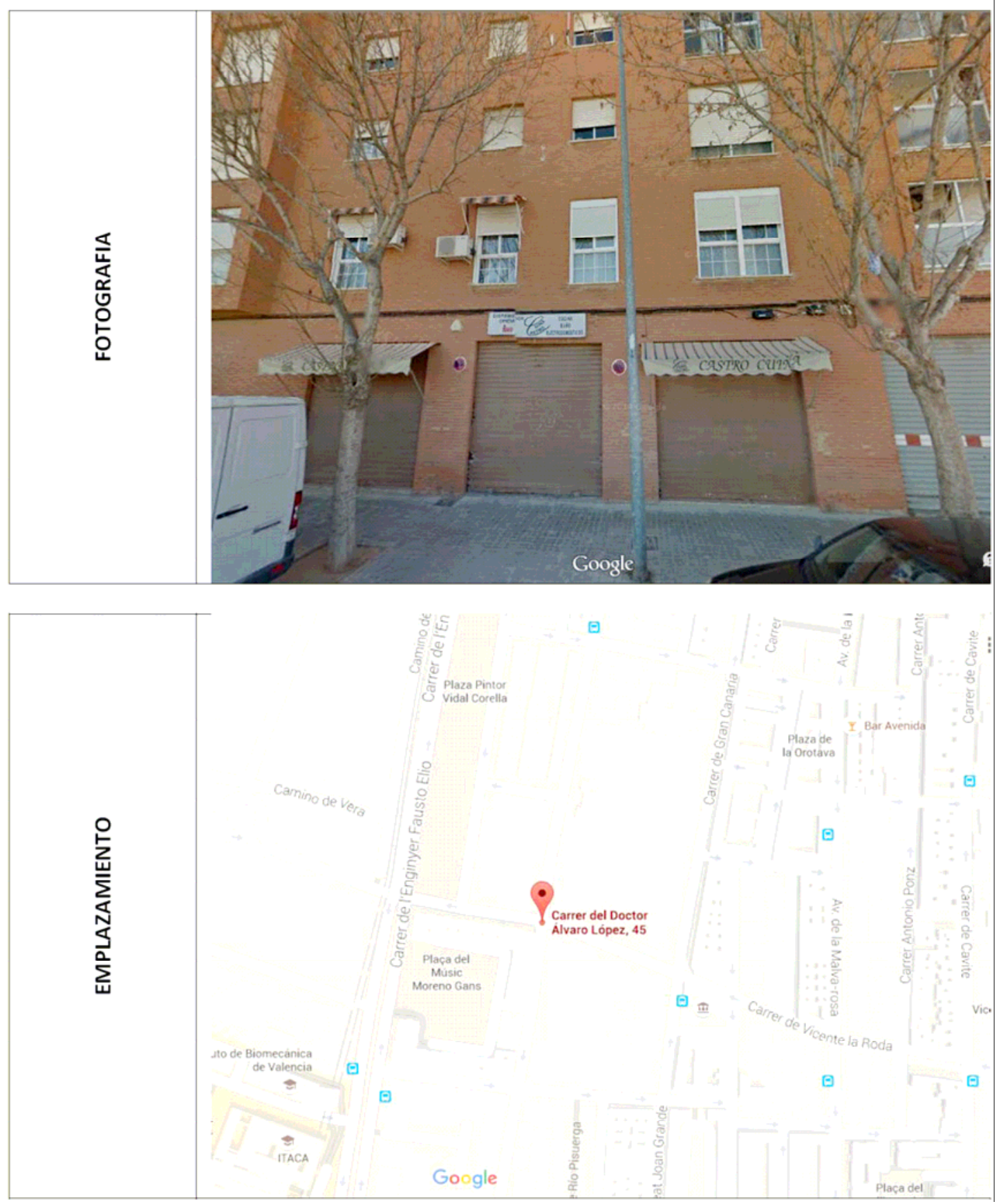




\section{FICHA DATOS DE LA INDUSTRIA}

LOCALIZACION ACTUALIZADA DE ACTIVIDADES INDUSTRIALES EN EL MEDIO URBANO DE VALENCIA

\begin{tabular}{|c|c|c|c|c|c|c|c|}
\hline \multirow{5}{*}{ 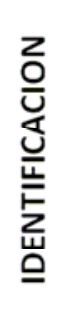 } & \multirow{2}{*}{\multicolumn{2}{|c|}{$\begin{array}{c}\text { NOMBRE } \\
\text { EMPLAZAMIENTO }\end{array}$}} & \multicolumn{5}{|c|}{ JOSE MANUEL CLEMENTE NAVARRO } \\
\hline & & & \multicolumn{3}{|c|}{ C/ ALTA DEL MAR, 61} & C.P. & 46024 \\
\hline & \multirow[b]{2}{*}{ CNAE } & \multirow[b]{2}{*}{1071} & \multirow[b]{2}{*}{ DESCRIPCION } & \multicolumn{4}{|c|}{ ALIMENTACIÓN-BEBIDA } \\
\hline & & & & \multicolumn{4}{|c|}{$\begin{array}{c}\text { Elaboración de pan y de productos frescos de } \\
\text { panadería y pastelería }\end{array}$} \\
\hline & DISTRITO & 11 & \multicolumn{5}{|c|}{ POBLATS MARÍTIMS } \\
\hline \multicolumn{3}{|c|}{ MEDIOAMBIENTE } & RUIDOSAS & NO & CHIMENEAS & & NO \\
\hline
\end{tabular}

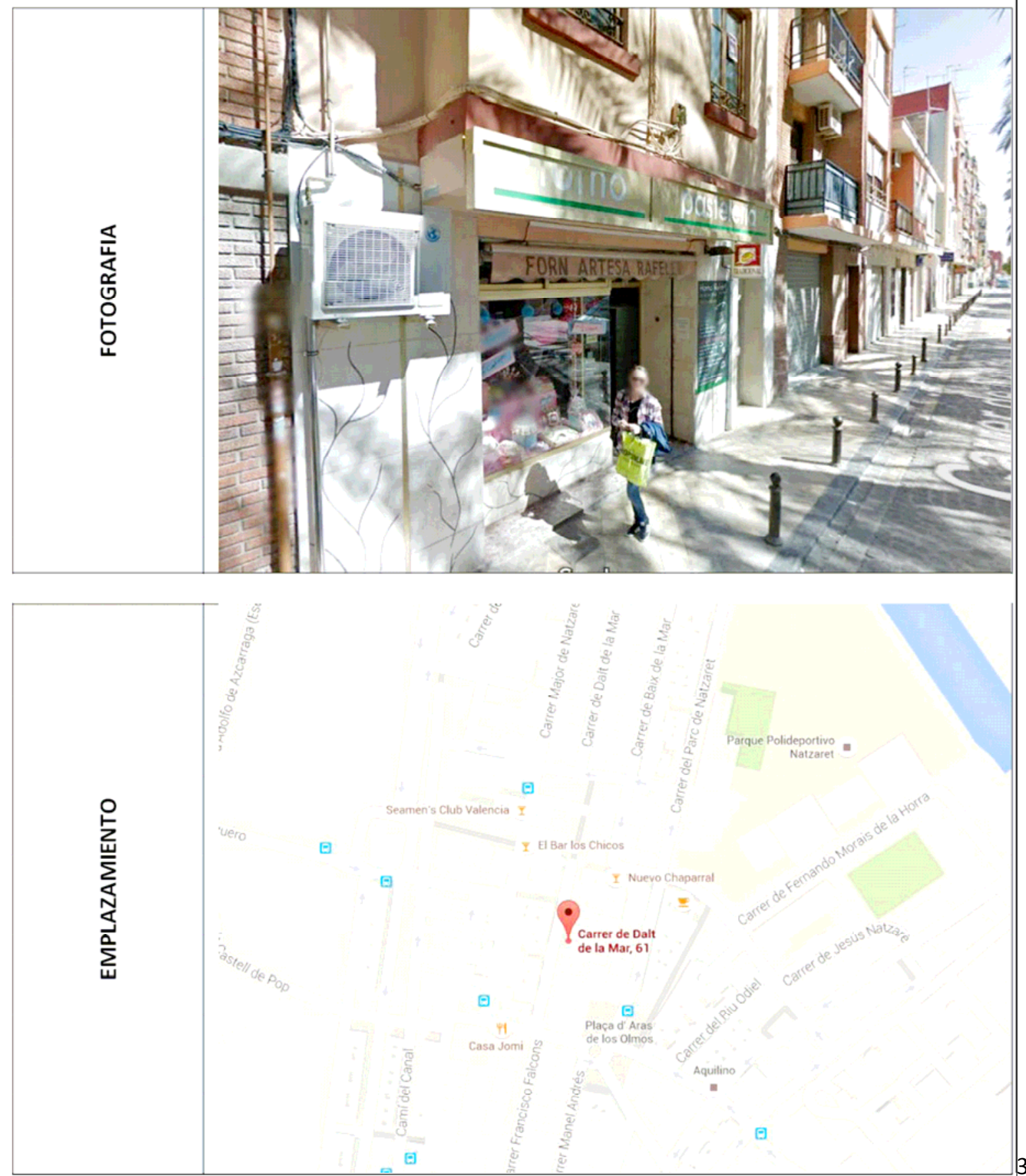




\section{FICHA DATOS DE LA INDUSTRIA}

LOCALIZACION ACTUALIZADA DE ACTIVIDADES INDUSTRIALES EN EL

MEDIO URBANO DE VALENCIA

\begin{tabular}{|c|c|c|c|c|c|c|c|}
\hline \multirow{5}{*}{ 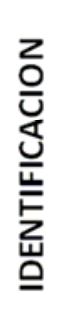 } & \multirow{2}{*}{\multicolumn{2}{|c|}{$\begin{array}{c}\text { NOMBRE } \\
\text { EMPLAZAMIENTO }\end{array}$}} & \multicolumn{5}{|c|}{ SANSIONEU, SL } \\
\hline & & & \multicolumn{3}{|c|}{ C/ ERNESTO ANASTASIO, 43} & C.P. & 46011 \\
\hline & \multirow{2}{*}{ CNAE } & \multirow{2}{*}{4520} & \multirow{2}{*}{ DESCRIPCION } & \multicolumn{4}{|c|}{ REPARACIÓN VEHÍCULOS } \\
\hline & & & & \multicolumn{4}{|c|}{ Mantenimiento y reparación de vehículos a motor } \\
\hline & DISTRITO & 11 & \multicolumn{5}{|c|}{ POBLATS MARÍTIMS } \\
\hline \multicolumn{3}{|c|}{ MEDIOAMBIENTE } & RUIDOSAS & $\mathrm{SI}$ & CHIMENEAS & & SI \\
\hline
\end{tabular}

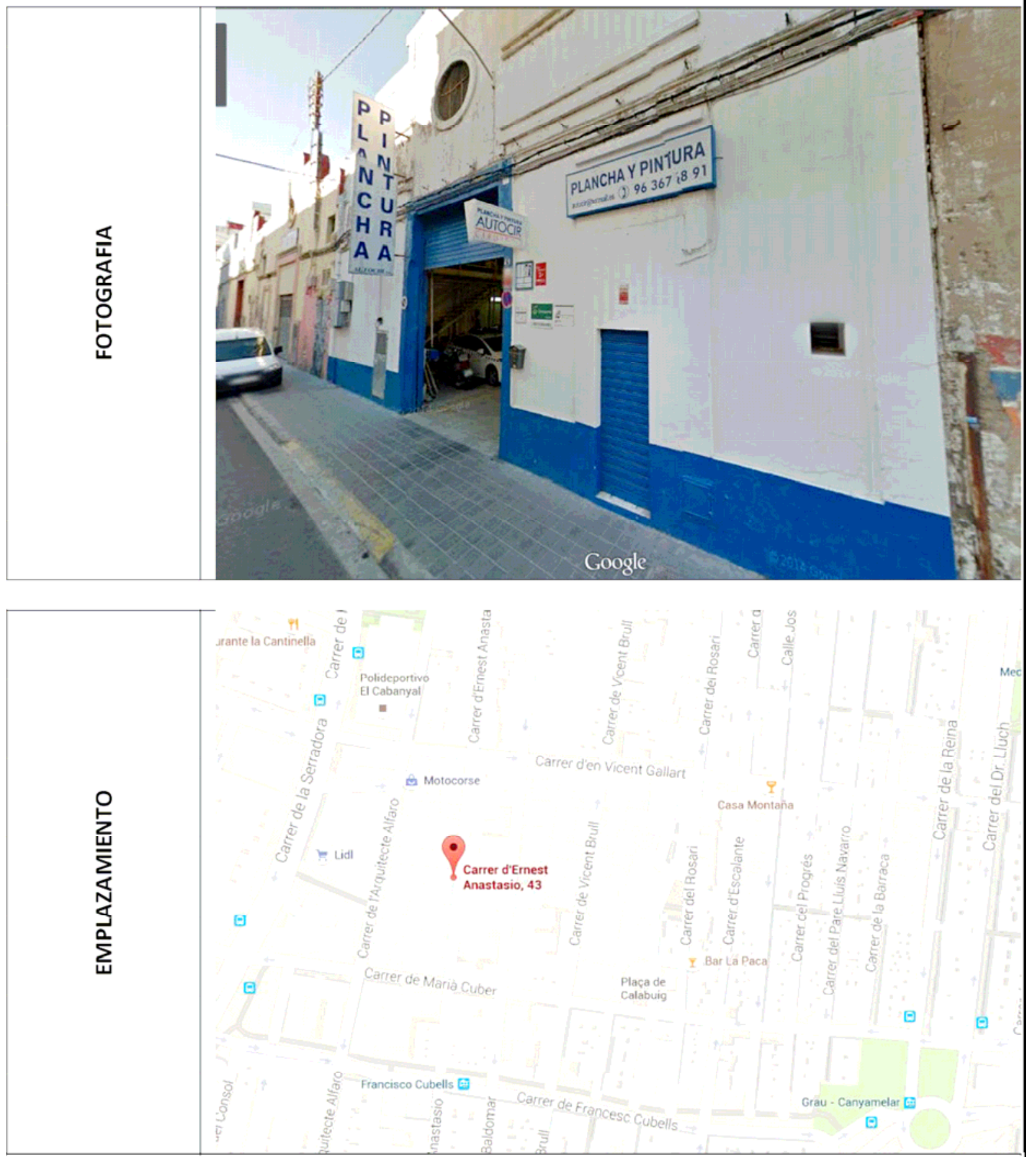




\section{FICHA DATOS DE LA INDUSTRIA}

LOCALIZACION ACTUALIZADA DE ACTIVIDADES INDUSTRIALES EN EL

MEDIO URBANO DE VALENCIA

\begin{tabular}{|c|c|c|c|c|c|c|c|}
\hline \multirow{5}{*}{ 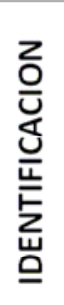 } & \multirow{2}{*}{\multicolumn{2}{|c|}{$\begin{array}{c}\text { NOMBRE } \\
\text { EMPLAZAMIENTO }\end{array}$}} & \multicolumn{5}{|c|}{2007 SEGO VELAS, SL } \\
\hline & & & \multicolumn{3}{|c|}{ C/ERNESTO ANASTASIO, 40} & C.P. & 46011 \\
\hline & \multirow[b]{2}{*}{ CNAE } & \multirow[b]{2}{*}{1392} & \multirow[b]{2}{*}{ DESCRIPCION } & \multicolumn{4}{|c|}{ TEXTIL-CALZADO-CONFECCIÓN } \\
\hline & & & & \multicolumn{4}{|c|}{$\begin{array}{l}\text { Fabricación de artículos confeccionados con } \\
\text { textiles, excepto prendas de vestir }\end{array}$} \\
\hline & DISTRITO & 11 & \multicolumn{5}{|c|}{ POBLATS MARÍTIMS } \\
\hline \multicolumn{3}{|c|}{ MEDIOAMBIENTE } & RUIDOSAS & NO & CHIMENEAS & & NO \\
\hline
\end{tabular}
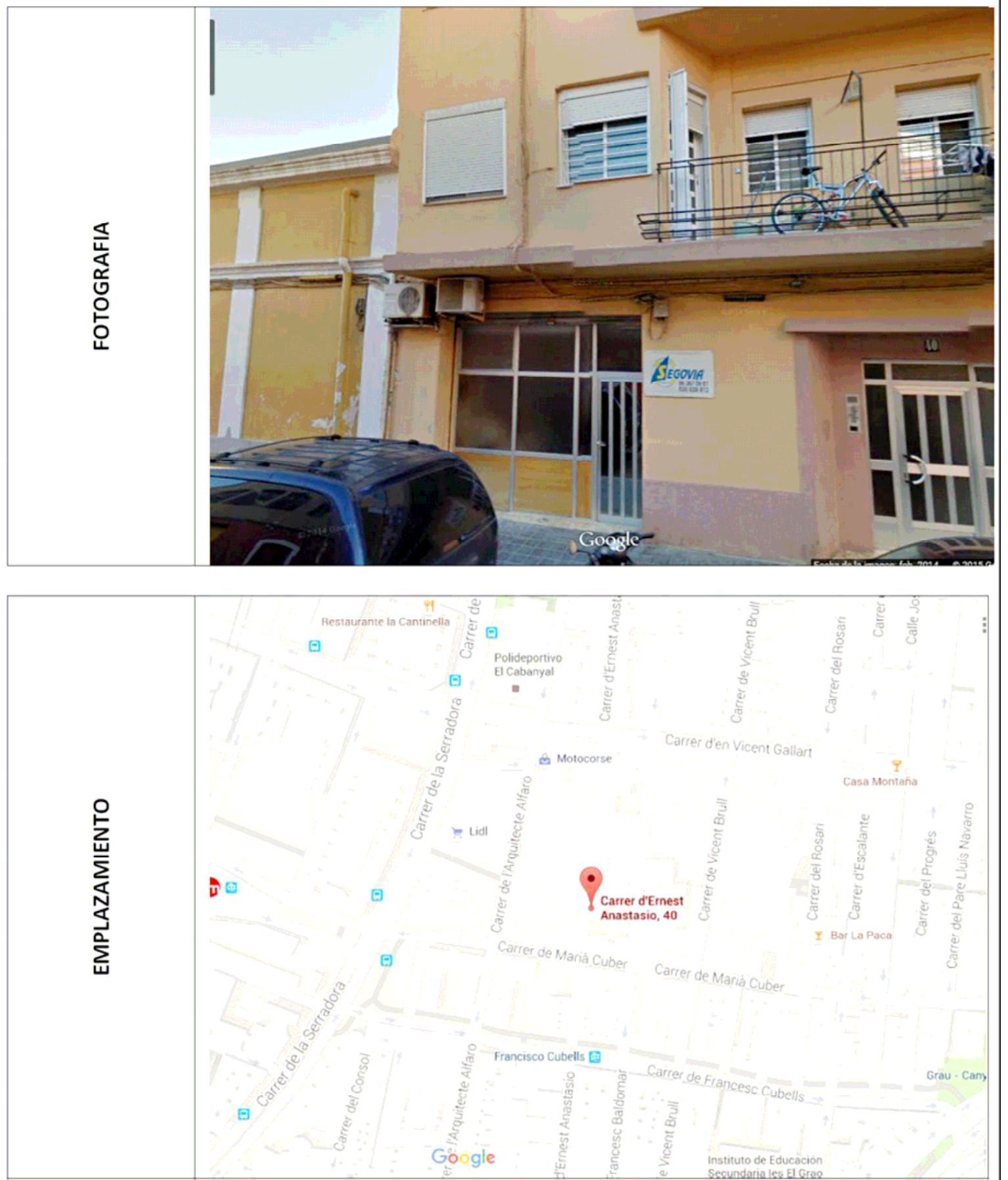


\section{FICHA DATOS DE LA INDUSTRIA}

LOCALIZACION ACTUALIZADA DE ACTIVIDADES INDUSTRIALES EN EL MEDIO URBANO DE VALENCIA

\begin{tabular}{|c|c|c|c|c|c|c|c|}
\hline \multirow{5}{*}{ 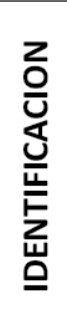 } & \multirow{2}{*}{\multicolumn{2}{|c|}{$\begin{array}{c}\text { NOMBRE } \\
\text { EMPLAZAMIENTO }\end{array}$}} & \multicolumn{5}{|c|}{ PEDRO JIMÉNEZ LÓPEZ } \\
\hline & & & \multicolumn{3}{|c|}{ C/ CONDE DE ALMENARA, 1} & C.P. & 46011 \\
\hline & \multirow{2}{*}{ CNAE } & \multirow{2}{*}{3109} & \multirow{2}{*}{ DESCRIPCION } & \multicolumn{4}{|c|}{ MADERA-CORCHO-MUEBLES } \\
\hline & & & & \multicolumn{4}{|c|}{ Fabricación de otros muebles } \\
\hline & DISTRITO & 11 & \multicolumn{5}{|c|}{ POBLATS MARÍTIMS } \\
\hline & \multicolumn{2}{|c|}{ MEDIOAMBIENTE } & RUIDOSAS & & CHIMENEAS & & NO \\
\hline
\end{tabular}
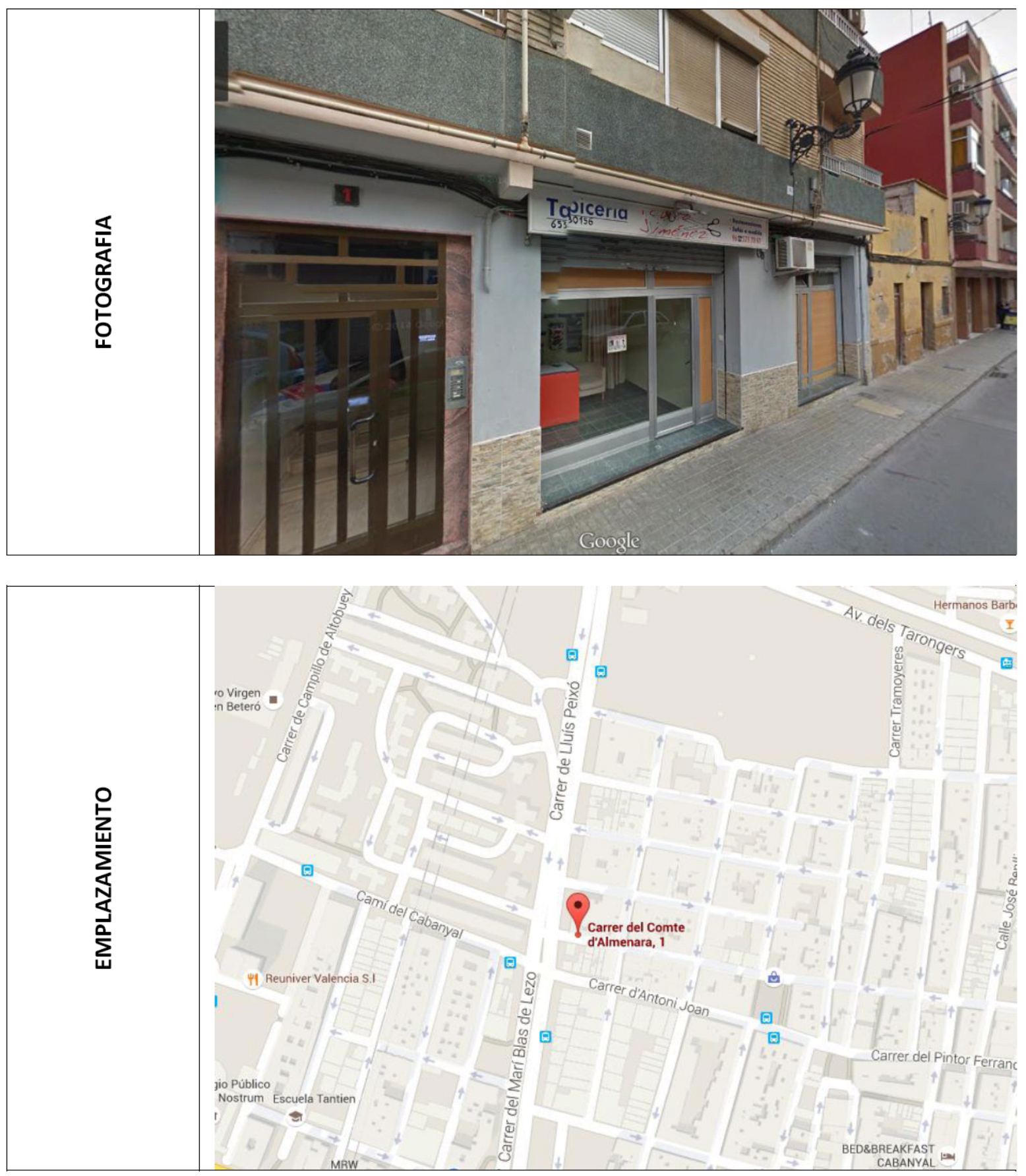


\section{DISTRITO 12 .- CAMINS AL GRAU}

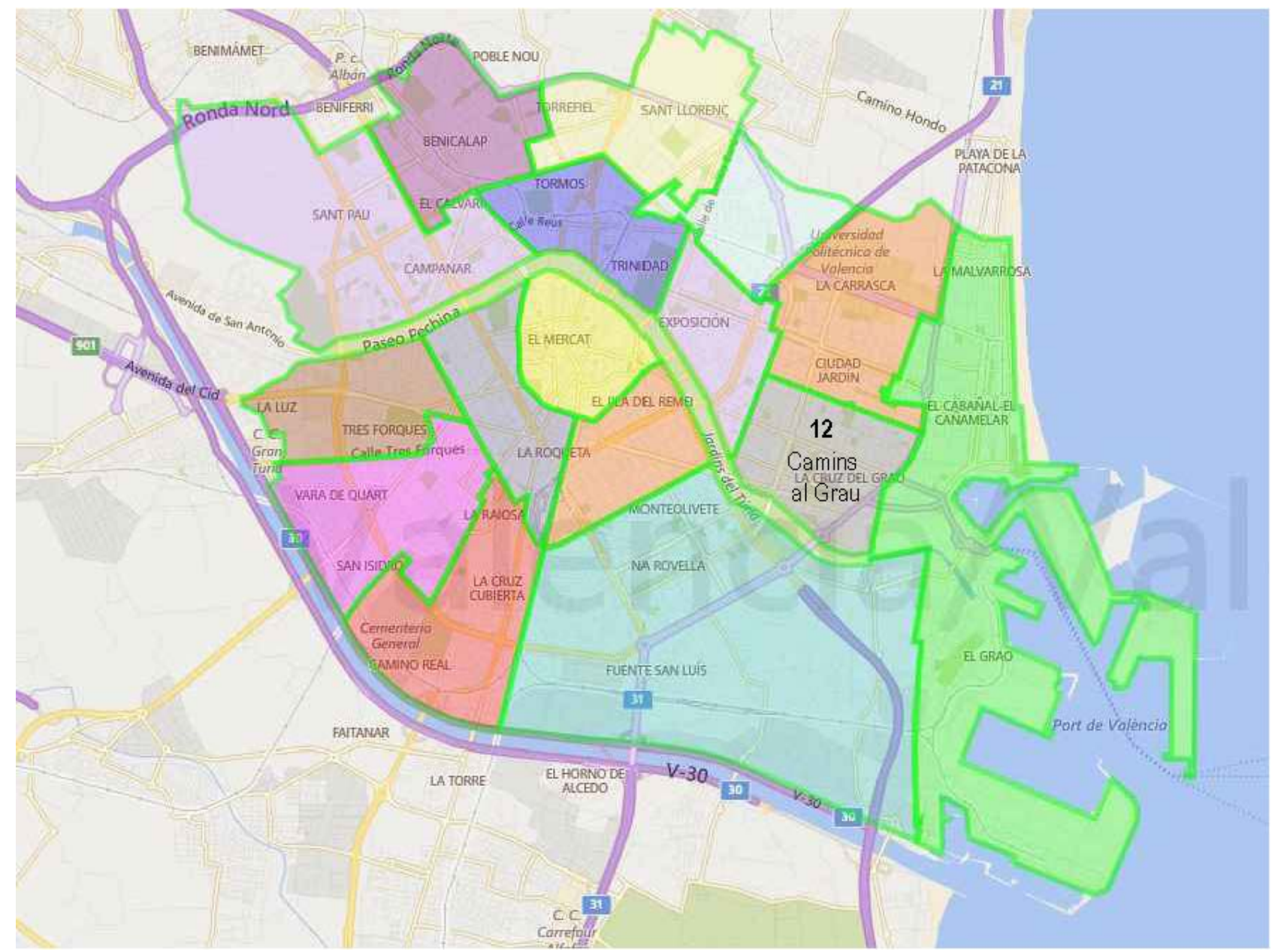

\section{LÍMITES GEOGRÁFICOS}

Cauce Viejo del Turia, FF.CC. Valencia-Barcelona, C/ Santos Justo y Pastor, C/ Eduardo Bosca y Avd. Cardenal Benlloch. 


\section{EVOLUCIÓN DEL 1985-2014}

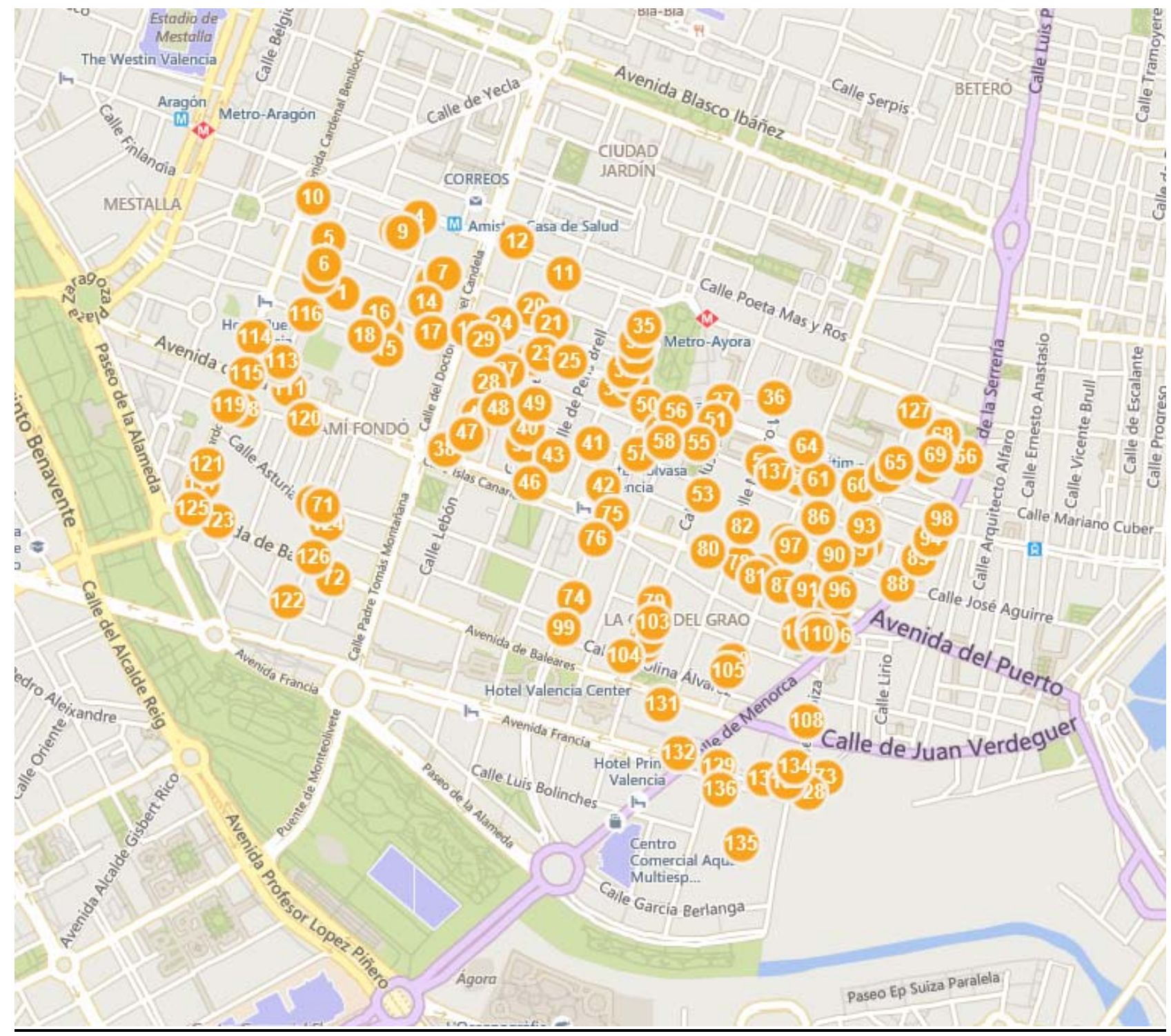

LISTADO DE INDUSTRIAS Y ACTIVIDAD.-

1. Felipe Peña, L.

Comercio

2. MATRIVAL, S.A.

Comercio

3. DIMUCA, S.L.

Sin actividad

4. Sanchis Canet, J.

Talleres Belenguer 
5. Rafael Calatayud Pertegaz

Sin actividad

6. Langa Estorell, J.M.

Obra nueva, lavadero.

7. CONSERVACIONES TELEFONICAS, S.A.

Mantiene la actividad

8. Fernando Marín Ferrando

Taller y otras

9. Fuster Simón, J.

Cerrado

10. Amparo Isabel Berga

Sin actividad

11. INEVAL, S.L.

Comercio

12. DONETA, S.A.

Bazar y alimentación

13. CAMILO MONZO, S.L.

Sin actividad

14. Martínez Jarque, E.

Sin actividad

15. MASPER, S.A.

Supermercado. Mercadona

16. CENTRAELECTRIC, S.A.

Taller

17. MERKOMAT ESTRUCTURA, S.A.

no 44 - 3 Sin actividad

18. PROYEX

Cerrado

19. García Vizcaino, A.

El Rincón del Asturiano. Bar

20. TRASVOX, S.A.

Sin actividad

21. Juan Cuesta Raya

Cerrado

22. Chacartegui España, V.

Mantiene la actividad. Joyería

23. Rafael Lasa Sáez

Mantiene la actividad. Pastelería

24. Otero García, F.

Cristalería 
25. CHOCOLATES SUCHARD, S.A.E.

CORTICOLORS

26. J. BAYO LAGUARDA, S.L.

Sin actividad

27. ACUARIO

Sin actividad

28. Toledo Sahuquillo, José

Cerrado

29. Vicente Gómez Tarazona

Nueva actividad

30. SANCHEZ PAMPLONA, S.L.

SUMINISTROS MAEZTU, S.L.

31. IND. METALURGICAS MONCUNILL, S.A.

Cerrado

32. TUCONSA

Varios comercios

33. COINVAL, S.A.

Casal fallero

34. J. Fuertes

Carpintería de aluminio

35. Pascual Martínez

Peluquería "QUIQUE"

36. Cancio Guitar, José

Administración de fincas

37. Salvador Monclus Aparisi

Nueva ordenación. Zona verde.

38. DERIVADOS LACTEOS, S.A.

Sin actividad

39. MUEBLINTER, S.A.

Obra nueva

40. MADERA ESPAÑOLA, S.A.

Cerrado

41. SERRA LUX

Obra nueva

42. TEOVY, S.A.

Scaetter radio. Cerrado

43. Juan Pérez, J.

EST Instalaciones. Cerrado

44. TEINSA, S.L.

Sin actividad 
45. MANUFACTURAS ROWELT, S.A.

Club de escalada "EL BUNKER"

46. TECNIDEX

Obra nueva

47. ELECTRO INDUSTRIAL MEDITERRANEO, S.A.

Mantiene la actividad

48. REAL - LUX

Cerrado

49. MANUFACTURAS GRALO

Mantiene la actividad. Joyería.

50. Maximiliano Soto

Solar

51. Campos Tomas, $\mathbf{R}$.

Cerrado

52. INDUSTRIAS PLASTICAS BELTRAN

Sin actividad

53. Llopis Minguez, M.

Lanas y toldos

54. TINTAS IMPRENTA CH. LORILLEUX

Obra nueva

55. MACANIZADOS REIG, S.A.

Cerrado

56. MANUFACTURAS GERSA, S.L.

Sin actividad

57. FRANCISCO GARCIA E HIJOS, S.L.

Sin actividad

58. Seguí Franch, F.

Cerrado

59. TRAGSA

Obra nueva

60. INDUSTRIAS FAL, S.A.

Sin actividad

61. HIJO PASCUAL MARTINEZ SALA, S.A.

Obra nueva

62. Bou Alpera, $M$.

Nueva ordenación. Zona verde

63. SOCIEDAD ESPAÑOLA DE CARBUROS METALICOS

Nueva ordenación

64. HNOS. CASTILLA

Mantiene la actividad. Horno 
65. Moreno Castro, F.

Nueva ordenación. Zona verde

66. ALUFRED, S.A.

Bar cervecería "J.M."

67. GONAIG, S.A.

Bar "SERRERIA"

68. ALUFRED

Sin actividad

69. Jaime Gil

DANZA ESPAI MC

70. HNOS. GONZALEZ E HIJOS, S.A.

Nueva ordenación. Viviendas

71. MANUFACTURAS ARACIL, S.L.

Cerrado

72. HIERROS AGUILAR HNOS., S.A.

Nueva ordenación. Viviendas

73. HIJOS DE MIGUEL HERNANDEZ, S.A.

Nueva ordenación. Solar

74. DE ALBA, S.A.

Nueva actividad

75. ESPACIO LEVANTE, S.A.

Nueva ordenación. Zona verde

76. V. ROCA RUIZ, S.A.

Frutería

77. INDUSTRIAS ACEITERAS CASANOVA

Edificio rehabilitado

78. VENTO, S.A.

Nueva actividad

79. Dolz Pérez, A.

Cerrado

80. FERTILIZANTES DEL TURIA, S.A.

Obra nueva. Viviendas

81. MADERAS JANNONE

Obra nueva

82. GRAFICAS RONDA, S.L.

Mantiene la actividad

83. V. Ballester

Mantiene la actividad

84. Vicente Gandia Pla

Obra nueva 
85. FRIO INDUSTRIAL, S.A.

Obra nueva "BALLESOL"

86. MARTINEZ GABARDA, S.L.

Cerrado

87. Bellver Pallas, José

Solar

88. Tomas Buch, J.

Nueva actividad "EXPAMEX"

89. Oltra Alberola, E.

Obra nueva

90. Sanjaime Vidal, Miguel

Cerrado

91. Palomero Sanahuja, P.

Cerrado

92. BERBEGAL, S.L.

Mantiene la actividad

93. AUGUSTO EGLI, S.A.

Obra nueva

94. NICOLAS STABILE Y CIA, S.R.C.

Obra nueva

95. HORNO LEVANTE

Obra nueva

96. JUAN MARKESSINIS, S.A.

Obra nueva

97. IMPRENTA ANDRES

Cerrado

98. VERULOSA

Obra Nueva

99. INDO, S.A.

Mantiene la actividad

100. Sanz Gómez, J.A.

Lavadero, sin actividad

101. Gea Femenia, F.

Restauración de muebles

102. Luis Trilles Planells

Nueva actividad

103. García Latorre, G.

Solar

104. Núñez Ferrer, T.

Cerrado 
105. José $M^{\mathrm{a}}$ Lucena Layunta

Cerrado

106. TALLERES GENOVOIS, S.A.

Nueva ordenación. Zona verde

107. PROD. Y CATALIZADORES QUIMICOS

Obra nueva

108. Roig Aullana, F.

Mantiene la actividad

109. San Esteban Latorre, $M$.

Nueva industria

110. HIERROS SOPENA, S.L.

Nueva ordenación

111. Miguel Señalada, J.M.

Edificio rehabilitado

112. Gimeno García, Ana

Edificio en construcción

113. Roig Inaches, A.

Cerrado

114. DAYPIN SEÑALIZACIONES, S.A.

Sin actividad

115. LONAS Y TOLDOS VALERO

Tintorería lavandería

116. Vicenta García Saturnino

Oficinas "GRUPO RIBA"

117. HARRY WALKER

Nueva industria

118. GIACOBINO Y MOMPO

Cerrado

119. Fernando Gómez Sánchez

Mantiene la actividad

120. TALLERES HERDACO, S.L.

Cerrado

121. TUBOS Y HIERROS INDUSTRIALES, S.A.

Obra nueva. Viviendas

122. MANIS LEVANTE, S.A.

Nueva actividad

123. NUTREXPA, S.A.

Cerrado

124. CALDERERÍA LOPEZ HNOS., S.A.

Nueva ordenación. Solar 
125. UNION ALCOHOLERA ESPAÑOLA, S.A.

Nueva ordenación

126. Llanas Vila, $\mathbf{R}$.

Nueva ordenación

127. PERMAR ELECTRICA, S.L.

Cerrado

128. KOMEC

Nueva ordenación. Solar

129. Rodríguez Sanz, Ricardo

Nueva ordenación. Solar

130. INDUSTRIAS QUIMICAS CANARIAS

Nueva ordenación. Viviendas

131. COMPAÑIA ESPAÑOLA DE GAS, S.A.

Nueva ordenación. Zona verde

132. CLIMA PUNTO ROJO, S.A.

Nueva ordenación

133. TALLERES VICENT, S.L.

Nueva ordenación. Solar

134. GEMAR, S.A.

Nueva ordenación

135. CROS, S.A.

Edificio rehabilitado

136. INDUSTRIAS EL PUERTO, S.L.

Obra nueva

137. BODEGAS SCHENK, S.A.

Nueva ordenación. Viviendas.

138. SISSI, S.A.

Solar

CARACTERÍSTICAS DEL ASENTAMIENTO INDUSTRIAL

Asentamiento industrial heterogéneo, en el que se diferencias tres zonas según sus características:

\section{Zona Sur}

Situada entre el Camino Hondo del Grao y el Cauce Viejo del Turia, con la inclusión de la Compañía Española de Gas.

Reúne las siguientes características: 
. Asentamiento Industrial Histórico (final Siglo XIX).

- Industrias de gran superficie, (Cross, Industrias Químicas Canarias) importantes en el contexto económico local por su notable volumen de producción.

. Homogéneo en cuanto a tipología (edificaciones aisladas sobre parcelas de gran superficie) y características de la actividad (industrias químicas de elevado grado de contaminación).

. Concentración, especialmente a lo largo de la margen izquierda del río, que le confiere una imagen fuertemente industrial.

. El uso industrial dominante históricamente, está siendo sustituido por el residencial, llegando ya a ser preponderante este ultimo en el área comprendida entre la Avd. del Puerto y el Camino Hondo del Grao.

. Deficiente infraestructura y servicios urbanísticos: La red viaria tradicional está siendo transformada por el crecimiento urbano, y la ausencia de alcantarillado supone el vertido directo al río Turia y su consiguiente contaminación

\section{Zona B (Nor-Este)}

Delimitada por la C/ de la Industria, C/ Pintor Maella, Co Hondo, Ferrocarril de Barcelona y C/ Santos Justo y Pastor.

Las características de este asentamiento son las siguientes:

. Histórico (Finales del siglo XIX).

. Uso industrial dominante, aunque sujeto actualmente a un fuerte proceso de sustitución residencial.

. Agrupado.

. Homogéneo en cuanto a tamaño y emplazamiento, con características similares al área industrial situada entre el Puerto y el Ferrocarril, es decir, naves de mediano tamaño entre medianeras.

\section{Zona C (Nor-Oeste)}

Delimitada por Co Hondo del Grao, Avd. Cardenal Benlloch, C/ Santos Justo y Pastor y $\mathrm{C} /$ de la Industria.

Sus características son las siguientes: 


\section{. Uso residencial dominante}

- Asentamiento industrial de nueva implantación, excepto a lo largo de la Avd. del Puerto, donde se sitúan edificios industriales de principios de siglo. . Industria dispersa

- Homogénea en cuanto a tamaño (pequeña superficie) y tipo de implantación (en plantas bajas de edificios de viviendas).

\section{CARACTERÍSTICAS DE LOS LOCALES INDUSTRIALES}

Existen tres tipos de locales industriales que diferencias las tres zonas definidas en el punto anterior.

- De gran superficie de parcela, edificación aislada, asentadas históricamente, en áreas urbanas no consolidadas (Zona 1).

- De mediana superficie, edificación Industrial (nave) entre medianeras, asentados históricamente y relativamente integrados en la trama urbana (Zona 2)

- De pequeña superficie, situados en planta baja de edificios de viviendas, de reciente implantación, totalmente integrados en la trama urbana (Zona 3)

\section{CARACTERÍSTICAS DE LAS ACTIVIDADES.}

Se censaron inicialmente 138 industrias y en el período de vigencia del Plan General han quedado solamente 12 creándose 48 nuevas industrias.

Las actividades dominantes industria química, alimentación y bebidas, productos metálicos, energía y agua y calzado y confección.

Pese a la gran importancia de las Industrias químicas en cuanto a ocupación de superficie y a impacto medioambiental no son estas las de mayor nivel de empleo. Por contra la fabricación de productos metálicos y industria de la confección y calzado ocupan un mayor numero de trabajadores, empleando una superficie muy inferior.

\section{IMPACTO EN EL MEDIO AMBIENTE.}

La contaminación ambiental a lo largo de la margen izquierda del río es la de mayor índice en el término municipal de Valencia, tanto en vertidos como en 
humos, mientras que la ausencia de viviendas en sus proximidades evita que se produzcan molestias por ruidos.

La importancia de la producción de estas empresas genera un transporte pesado importante, que carece de una red viaria adecuada.

Caso distinto es el de las zonas restantes, de moderada o nula contaminación, lo que las hace compatible con el uso residencial.

\section{INTEGRACIÓN EN EL ENTORNO.}

La integración en el entorno es distinta en las tres zonas diferenciadas:

\section{ZONA A}

Es netamente industrial, situada en un área degradada sin Infraestructura ni servicios urbanísticos.

La gran superficie requerida por estas industrias y su elevado nivel de contaminación impiden su compatibilidad con el uso residencial.

\section{ZONA B}

Área de uso industrial que produce una contaminación moderada (básicamente ruidos) integrada en la trama urbana y compatible con el uso residencial.

Genera transporte de mercancías de cierta importancia en volumen y frecuencia aunque cuenta con una trama viaria diversificada y aceptable.

\section{ZONA C}

Área de uso residencial dominantemente, con industria pequeña, de escasa incidencia medioambiental perfectamente integrada en la trama urbana. 


\section{EDIFICIOS INDUSTRIALES DE INTERES.}

- Ind. Aceiteras Casanova.

Avd. del Puerto ํㅡ 253 (BY-1)

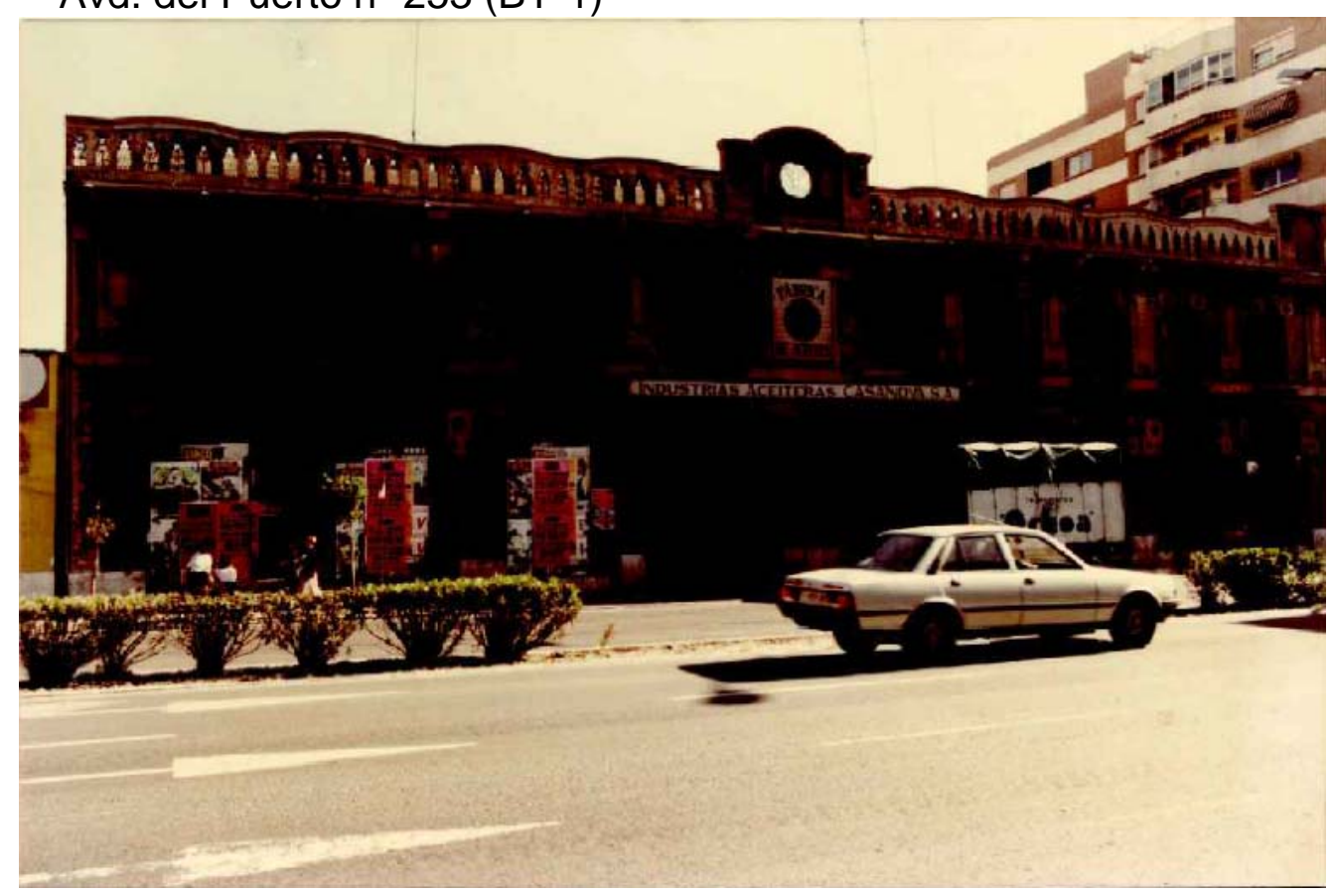

Foto 67: Naves de tratamiento de aceites y grasas para usos industriales. Industrias aceiteras Casanova. Avda. del Puerto, 253. Valencia.1985. Fuente: Elaboración propia

- U. Alcoholera Española.

Eduardo Bosca nำ 35 (69-4)

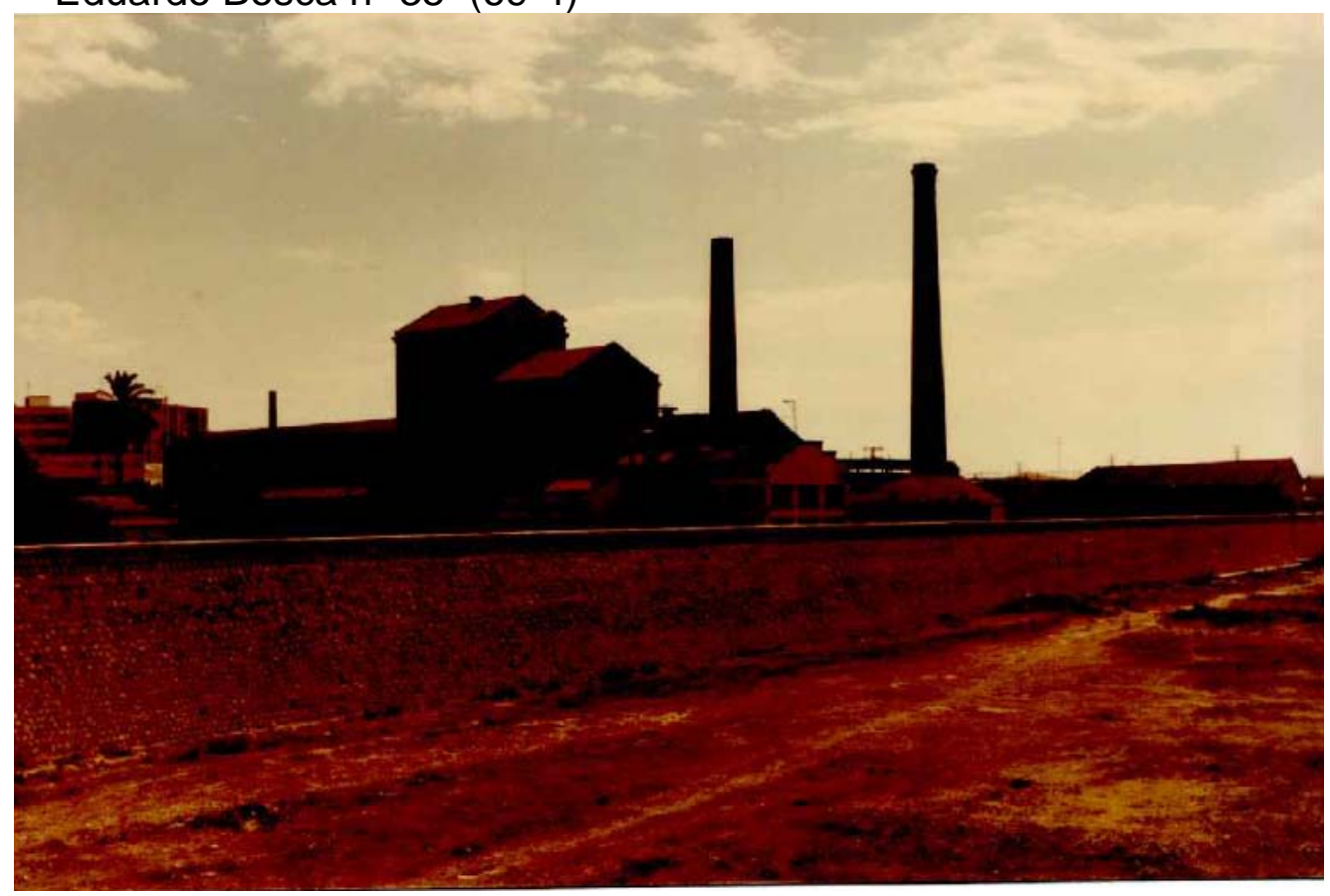

Foto 68: Destilación y rectificación de alcoholes. Unión Alcoholera Española, S.A.Valencia.1985. Fuente: Elaboración propia 
- I. Químicas Canarias.

Cํ Hondo Grao n 50 (6G/5000-5)

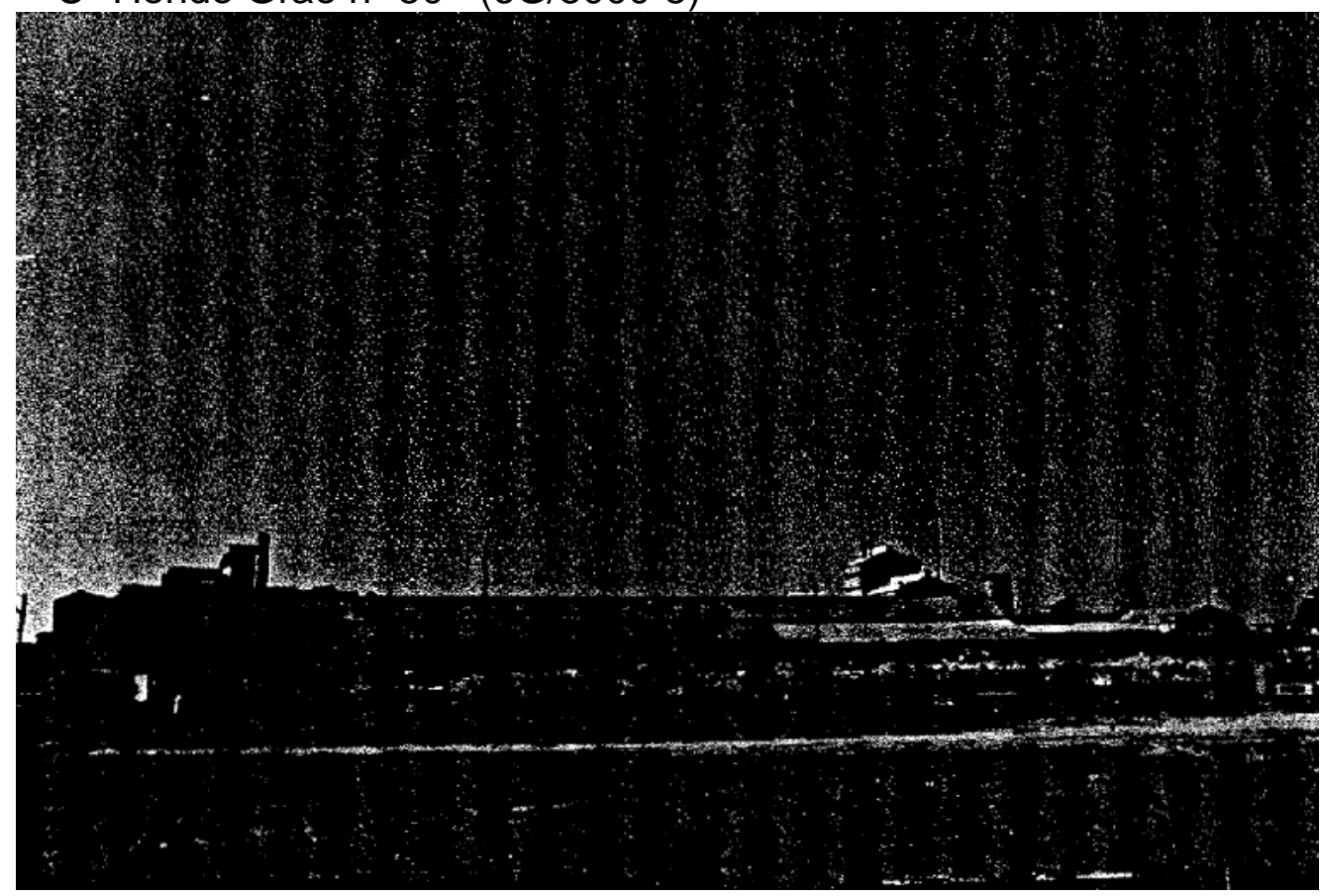

Foto 69: Industrias químicas Canarias. Camino Hondo del Grao, 50. Valencia.1985. Fuente: Elaboración propia.

- Clima Punto Rojo.

Senda de Carmona ํo 2 (6G/5000-7)

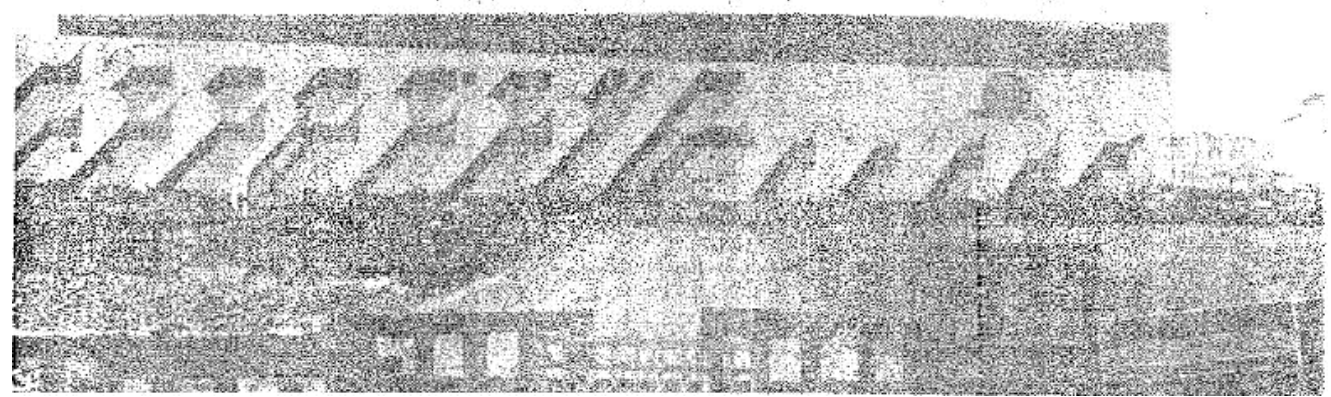

Foto 70: Fabricación de electrodomésticos. Clima Punto Rojo. Senda de Carmona, 2 Valencia.1985. Fuente: Elaboración propia. 
- Cross, S.A.

Co Hondo del Grao.s/n (6G/5000-8)

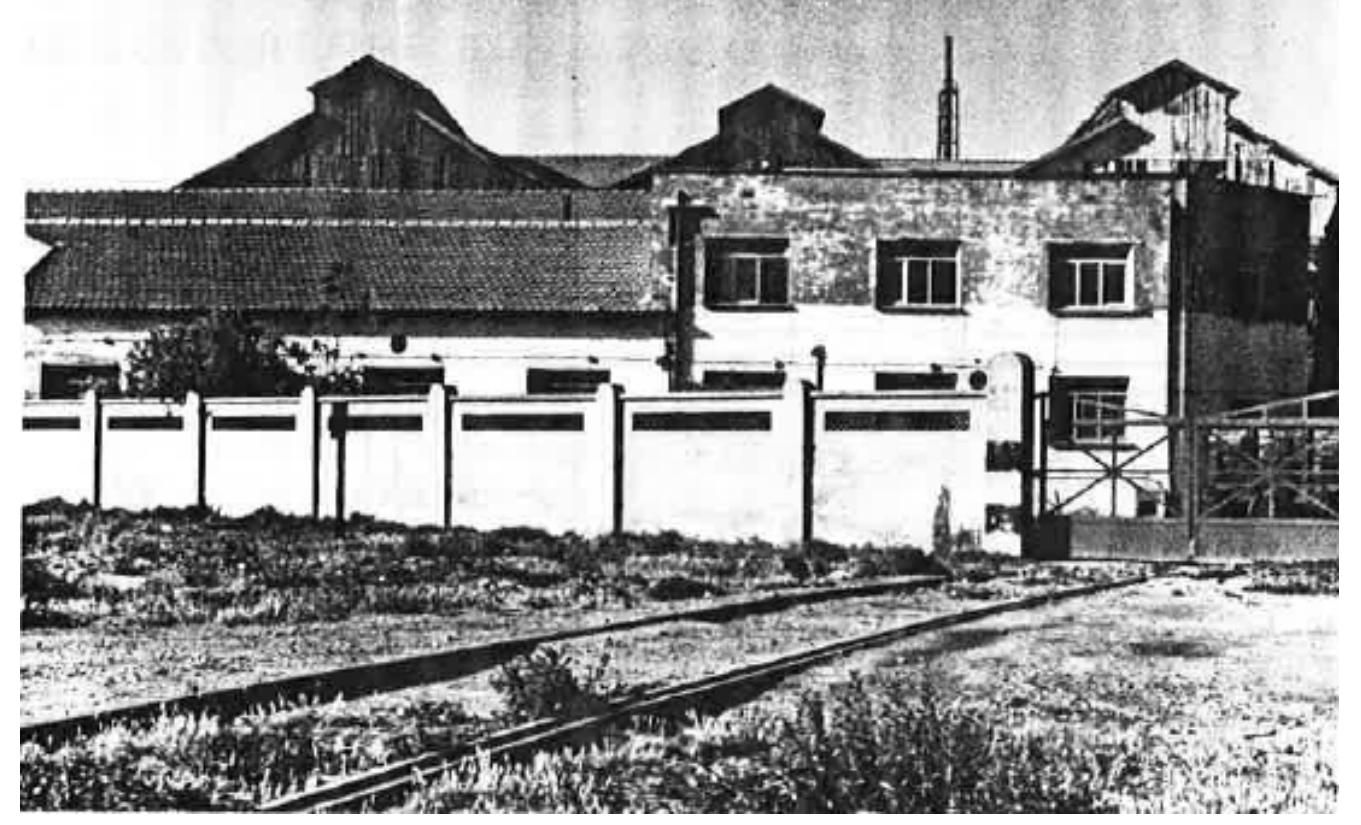

Foto 71: Industria de fabricación de abonos. Cros, S.A.. Camino Hondo del Grao, 2.Valencia.1985. Fuente: Elaboración propia

- Abonos J. Campos Crespo.

Islas Canarias, 247 (CL 1)

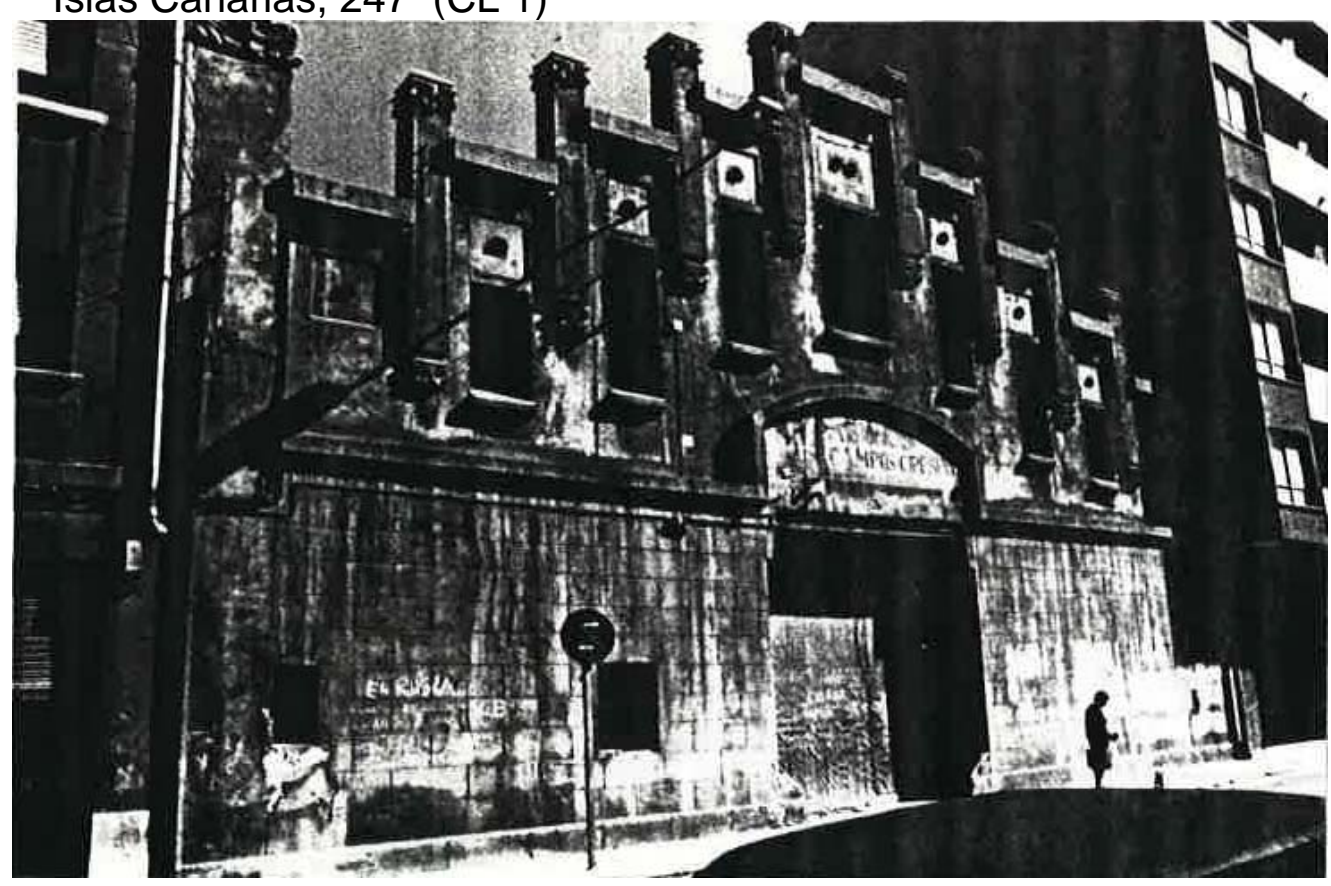

Foto 72: Industria de fabricación de abonos. Abonos José Campos Crespo.

C/ Islas Canarias, 247alencia.1985. Fuente: Elaboración propia 
TIPOLOGÍA DE EDIFICACIÓN

\section{TIPOLOGÍA DE EDIFICACIÓN \\ Distrito 12. CAMINS AL GRAU}

AISLADO ENTRE MEDIANERAS

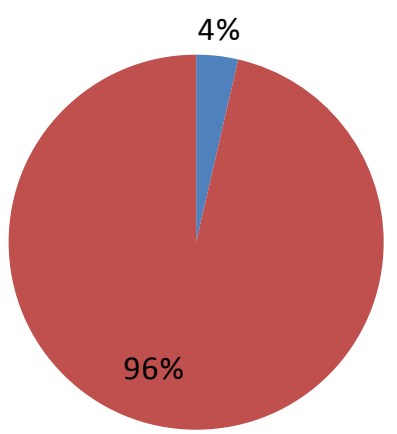




\section{ACTIVIDAD INDUSTRIAL, SUPERFICIE Y EMPLEO}

\begin{tabular}{|c|c|c|c|c|c|}
\hline \multicolumn{6}{|c|}{ DISTRITO 12 - CAMINS AL GRAU (ATIVIDAD INDUSTRIAL Y EMPLEO) } \\
\hline ACTIVIDAD & $\begin{array}{c}\text { № } \\
\text { EMPRESAS }\end{array}$ & $\begin{array}{c}\text { SUP. ACTIVIDAD } \\
\text { IND }\left(\mathrm{m}^{2}\right)\end{array}$ & $\begin{array}{c}\text { \% SUP. } \\
\text { INDUSTRIAL }\end{array}$ & $\begin{array}{c}\text { No } \\
\text { EMPLEADOS }\end{array}$ & $\begin{array}{c}\text { DENSIDAD } \\
\text { EMPLEO } \\
\text { (empleados } / \mathrm{m}^{2} \\
\text { actividad) }\end{array}$ \\
\hline $\begin{array}{l}\text { PRODUCCIÓN, TRANSPORTE Y DISTRIBUCIÓN DE ENERGÍA ELÉCTRICA, GAS VAPOR } \\
\text { Y AGUA CALIENTE }\end{array}$ & 1 & 29404 & 7,76 & 30 & 0,0010 \\
\hline PRODUCCIÓN Y PRIMERA TRANSFORMACIÓN DE METALES & 1 & 1100 & 0,29 & 24 & 0,0218 \\
\hline INDUSTRIA QUÍMICA & 10 & 222378 & 58,70 & 370 & 0,0017 \\
\hline FABRICACIÓN DE PRODUCTOS METÁLICOS & 35 & 23030 & 6,08 & 484 & 0,0210 \\
\hline CONSTRUCCIÓN DE MAQUINARIA Y EQUIPO MECÁNICO & 5 & 4470 & 1,18 & 60 & 0,0134 \\
\hline CONSTRUCCIÓN DE MAQUINARIA Y MATERIAL ELÉCTRICO & 11 & 7259 & 1,92 & 166 & 0,0229 \\
\hline FABRICACIÓN DE MATERIAL ELECTRÓNICO & 4 & 3210 & 0,85 & 65 & 0,0202 \\
\hline CONSTRUCCIÓN DE VEHÍCULOS AUTOMÓVILES Y SUS PIEZAS DE REPUESTO & 4 & 2455 & 0,65 & 23 & 0,0094 \\
\hline CONSTRUCCIÓN DE OTRO MATERIAL DE TRANSPORTE & 1 & 1200 & 0,32 & 10 & 0,0083 \\
\hline FABRICACIÓN DE INSTRUMENTOS DE PRECISIÓN, ÓPTICA Y SIMILARES & 1 & 1000 & 0,26 & 54 & 0,0540 \\
\hline INDUSTRIAS DE PRODUCTOS ALIMENTICIOS, BEBIDAS Y TABACO & 9 & 1398 & 0,37 & 38 & 0,0272 \\
\hline INDUSTRIAS DE PRODUCTOS ALIMENTICIOS, BEBIDAS Y TABACO & 8 & 59275 & 15,65 & 261 & 0,0044 \\
\hline INDUSTRIA TEXTIL & 2 & 1800 & 0,48 & 22 & 0,0122 \\
\hline INDUSTRIA DEL CUERO & 3 & 1340 & 0,35 & 62 & 0,0463 \\
\hline INDUSTRIA DEL CALZADO Y DEL VESTIDO Y OTRAS CONFECCIONES TEXTILES & 7 & 6649 & 1,76 & 465 & 0,0699 \\
\hline INDUSTRIAS DE MADERA, CORCHO Y MUEBLES DE MADERA & 11 & 4928 & 1,30 & 67 & 0,0136 \\
\hline INDUSTRIA DEL PAPEL Y FABRICACIÓN DE ARTÍCULOS DE PAPEL, ARTES GRÁFICAS & 6 & 1193 & 0,31 & 32 & 0,0268 \\
\hline INDUSTRIAS DE TRANSFORMACIÓN DEL CAUCHO Y MATERIAS PLÁSTICAS & 6 & 1600 & 0,42 & 47 & 0,0294 \\
\hline OTRAS INDUSTRIAS MANUFACTURERAS & 5 & 1040 & 0,27 & 37 & 0,0356 \\
\hline CONSTRUCCIÓN & 7 & 1990 & 0,53 & 73 & 0,0367 \\
\hline TRANSPORTES TERRESTRES & 1 & 2100 & 0,55 & 17 & 0,0081 \\
\hline TOTAL & 138 & 378819 & 100 & 2407 & 0,0064 \\
\hline
\end{tabular}

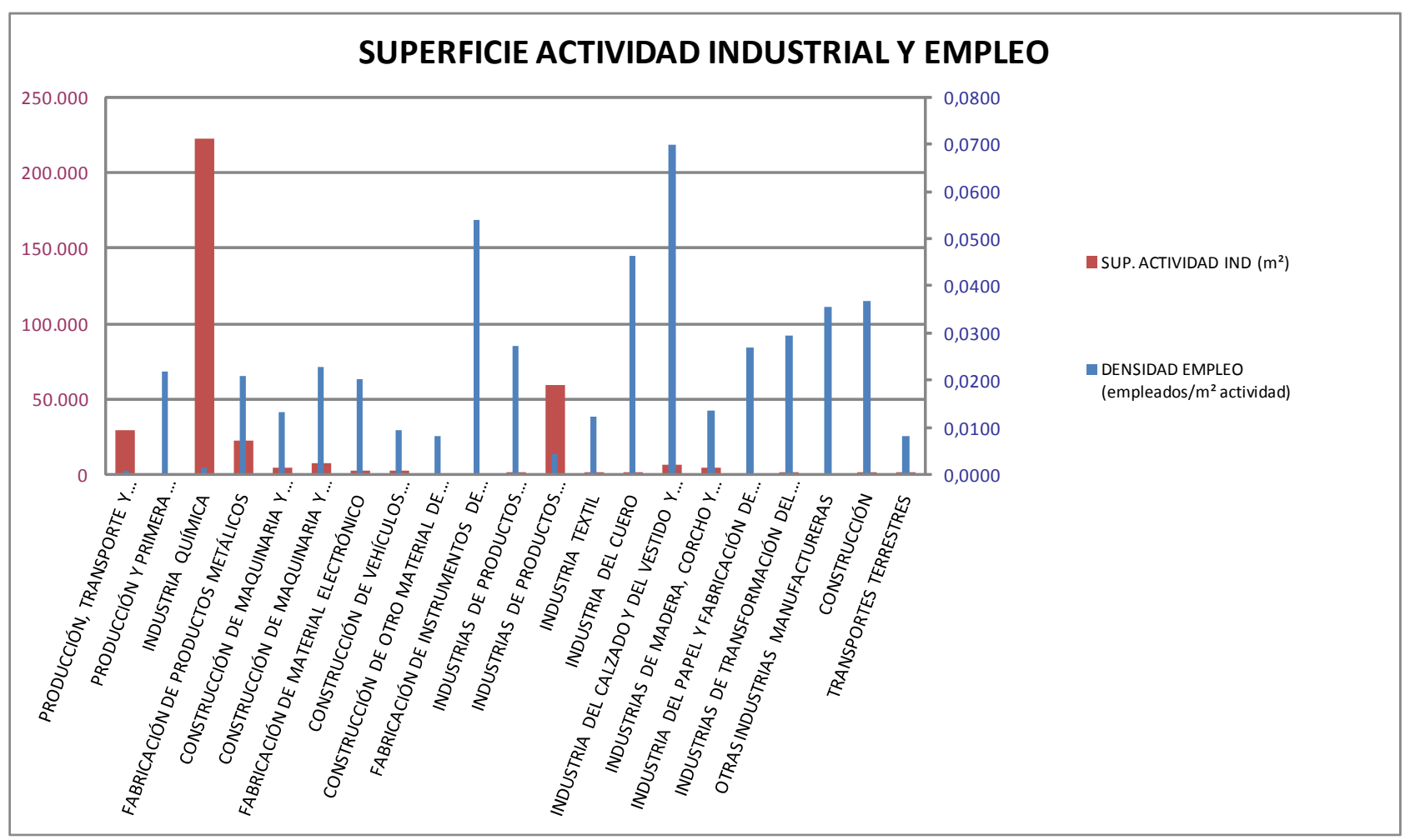


IMPACTO AMBIENTAL

\begin{tabular}{|c|c|c|c|c|c|}
\hline \multicolumn{6}{|c|}{ DISTRITO 12 - CAMINS AL GRAU (INFORMACIÓN URBANÍSTICA) } \\
\hline ACTIVIDAD & $\begin{array}{l}\text { NNo } \\
\text { EMPRESAS }\end{array}$ & $\begin{array}{c}\text { ENTRE } \\
\text { MEDIANERAS }\end{array}$ & RUIDOSAS & $\begin{array}{c}\text { EMPRESAS } \\
\text { CON } \\
\text { CHIMENEA }\end{array}$ & $\begin{array}{l}\text { RUIDOSAS Y } \\
\text { CHIMENEA }\end{array}$ \\
\hline $\begin{array}{l}\text { PRODUCCIÓN, TRANSPORTE Y DISTRIBUCIÓN DE ENERGÍA ELÉCTRICA, GAS VAPOR } \\
\text { Y AGUA CALIENTE }\end{array}$ & 1 & 1 & 0 & 0 & 1 \\
\hline PRODUCCIÓN Y PRIMERA TRANSFORMACIÓN DE METALES & 1 & 1 & 1 & 0 & 0 \\
\hline INDUSTRIA QUÍMICA & 10 & 8 & 0 & 2 & 2 \\
\hline FABRICACIÓN DE PRODUCTOS METÁLICOS & 35 & 34 & 14 & 0 & 4 \\
\hline CONSTRUCCIÓN DE MAQUINARIA Y EQUIPO MECÁNICO & 5 & 5 & 0 & 1 & 1 \\
\hline CONSTRUCCIÓN DE MAQUINARIA Y MATERIAL ELÉCTRICO & 11 & 10 & 2 & 1 & 1 \\
\hline FABRICACIÓN DE MATERIAL ELECTRÓNICO & 4 & 4 & 0 & 0 & 0 \\
\hline CONSTRUCCIÓN DE VEHÍCULOS AUTOMÓVILES Y SUS PIEZAS DE REPUESTO & 4 & 4 & 2 & 0 & 0 \\
\hline CONSTRUCCIÓN DE OTRO MATERIAL DE TRANSPORTE & 1 & 1 & 1 & 0 & 0 \\
\hline FABRICACIÓN DE INSTRUMENTOS DE PRECISIÓN, ÓPTICA Y SIMILARES & 1 & 1 & 1 & 0 & 0 \\
\hline INDUSTRIAS DE PRODUCTOS ALIMENTICIOS, BEBIDAS Y TABACO & 9 & 9 & 0 & 7 & 0 \\
\hline INDUSTRIAS DE PRODUCTOS ALIMENTICIOS, BEBIDAS Y TABACO & 8 & 7 & 0 & 3 & 2 \\
\hline INDUSTRIA TEXTIL & 2 & 2 & 1 & 0 & 0 \\
\hline INDUSTRIA DEL CUERO & 3 & 3 & 1 & 0 & 0 \\
\hline INDUSTRIA DEL CALZADO Y DEL VESTIDO Y OTRAS CONFECCIONES TEXTILES & 7 & 7 & 0 & 0 & 1 \\
\hline INDUSTRIAS DE MADERA, CORCHO Y MUEBLES DE MADERA & 11 & 11 & 4 & 0 & 3 \\
\hline $\begin{array}{l}\text { INDUSTRIA DEL PAPEL Y FABRICACIÓN DE ARTÍCULOS DE PAPEL, ARTES GRÁFICAS } \\
\text { Y EDICIÓN }\end{array}$ & 6 & 6 & 3 & 0 & 0 \\
\hline INDUSTRIAS DE TRANSFORMACIÓN DEL CAUCHO Y MATERIAS PLÁSTICAS & 6 & 6 & 3 & 0 & 0 \\
\hline OTRAS INDUSTRIAS MANUFACTURERAS & 5 & 5 & 0 & 0 & 0 \\
\hline CONSTRUCCIÓN & 7 & 7 & 0 & 0 & 0 \\
\hline TRANSPORTES TERRESTRES & 1 & 1 & 0 & 0 & 0 \\
\hline TOTAL & 138 & 133 & 33 & 14 & 15 \\
\hline
\end{tabular}

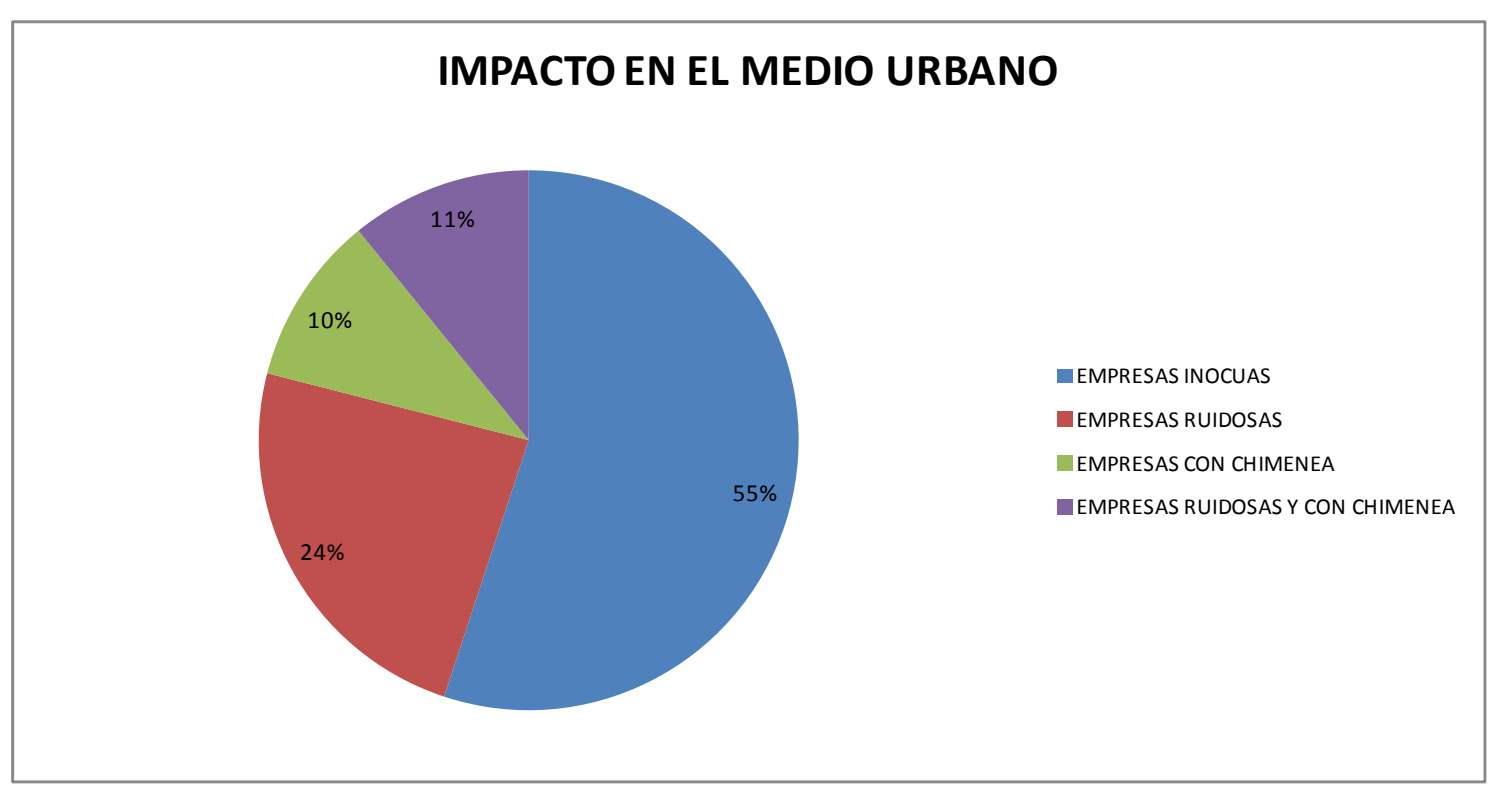




\section{FICHAS TIPO \\ FICHA DATOS DE LA INDUSTRIA}

LOCALIZACION ACTUALIZADA DE ACTIVIDADES INDUSTRIALES EN EL MEDIO URBANO DE VALENCIA

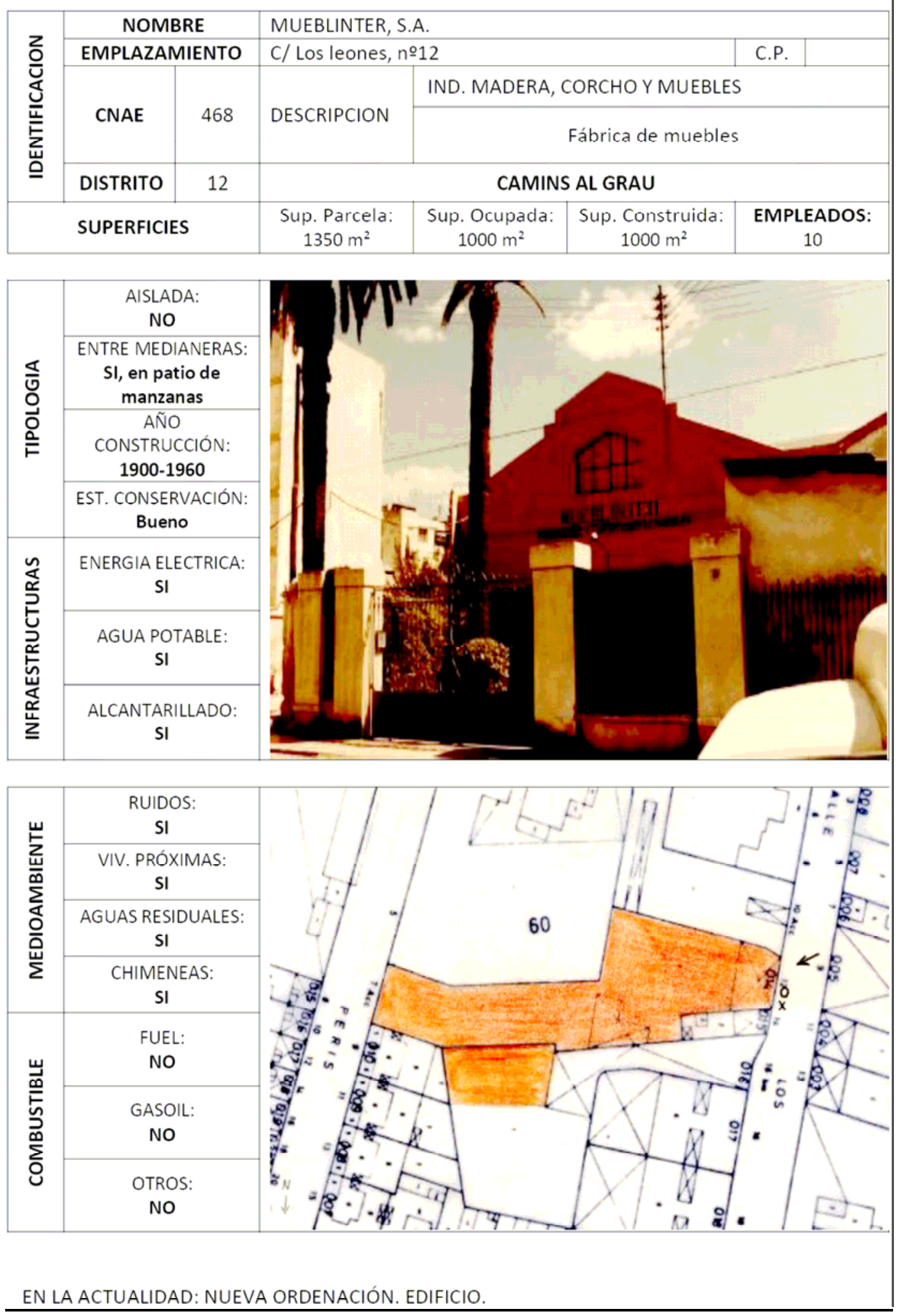




\section{FICHA DATOS DE LA INDUSTRIA}

LOCALIZACION ACTUALIZADA DE ACTIVIDADES INDUSTRIALES EN EL MEDIO URBANO DE VALENCIA

\begin{tabular}{|c|c|c|c|c|c|c|c|}
\hline \multirow{5}{*}{ 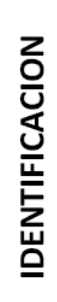 } & \multirow{2}{*}{\multicolumn{2}{|c|}{$\begin{array}{c}\text { NOMBRE } \\
\text { EMPLAZAMIENTO }\end{array}$}} & \multicolumn{5}{|c|}{ ELECTRO INDUSTRIAL MEDITTERANEO, S.A. } \\
\hline & & & \multicolumn{3}{|c|}{ C/Duque de Gaeta, no 7 y 9} & C.P. & \\
\hline & \multirow{2}{*}{ CNAE } & \multirow[b]{2}{*}{341} & \multirow{2}{*}{ DESCRIPCION } & \multicolumn{4}{|c|}{ COST.MAQ. YMATERIAL ELECTRICO } \\
\hline & & & & \multicolumn{4}{|c|}{ Material electrico } \\
\hline & DISTRITO & 12 & \multicolumn{5}{|c|}{ CAMINS AL GRAU } \\
\hline & \multicolumn{2}{|c|}{ SUPERFICIES } & $\begin{array}{c}\text { Sup. Parcela: } \\
2158 \mathrm{~m}^{2}\end{array}$ & $\begin{array}{c}\text { Sup. Ocupada: } \\
1269 \mathrm{~m}^{2}\end{array}$ & $\begin{array}{l}\text { Sup. Construida: } \\
2158 \mathrm{~m}^{2}\end{array}$ & EMPI & $\begin{array}{l}\text { EADOS: } \\
10\end{array}$ \\
\hline
\end{tabular}
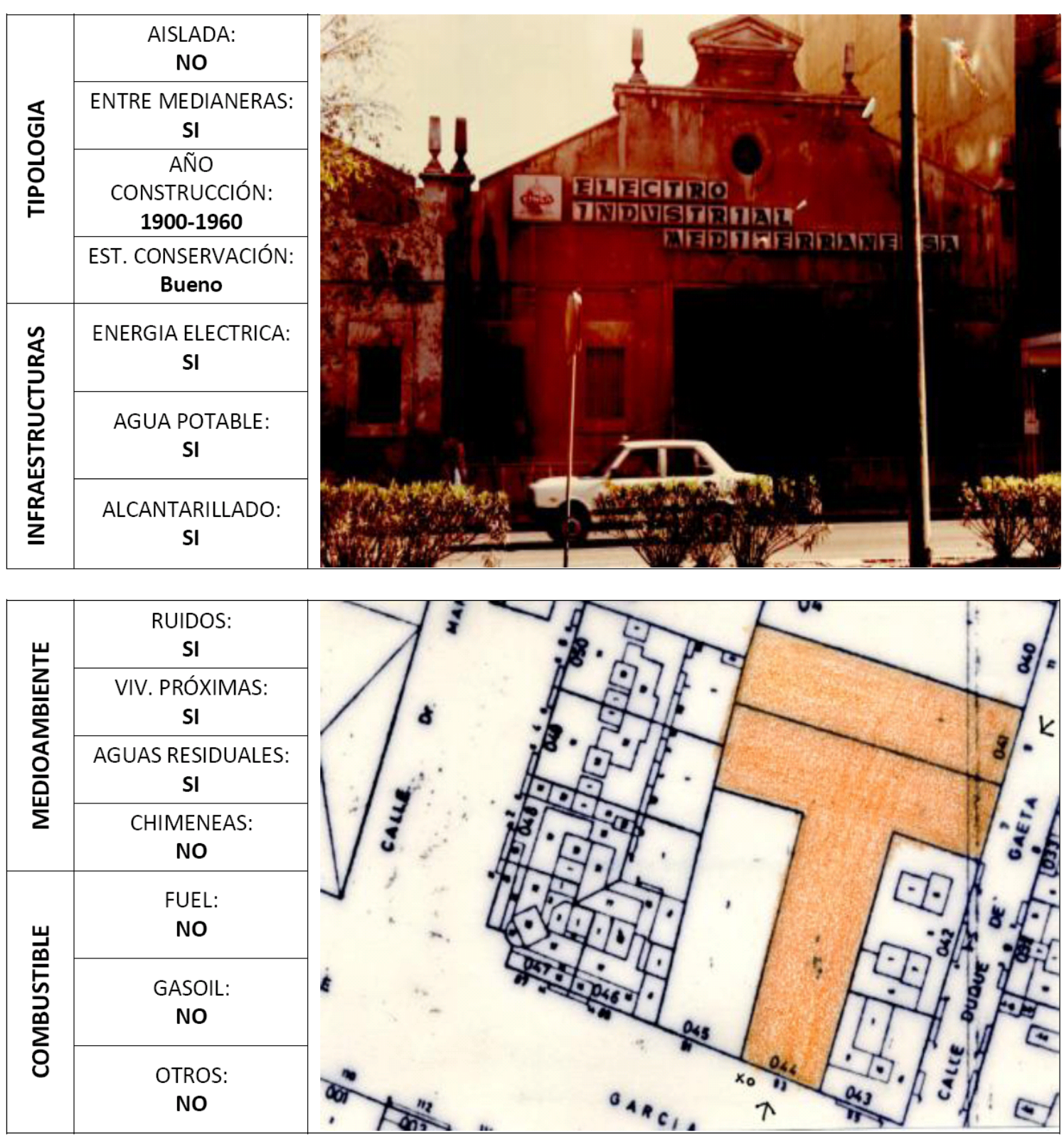


\section{FICHA DATOS DE LA INDUSTRIA}

LOCALIZACION ACTUALIZADA DE ACTIVIDADES INDUSTRIALES EN EL MEDIO URBANO DE VALENCIA

\begin{tabular}{|c|c|c|c|c|c|c|c|}
\hline \multirow{5}{*}{ 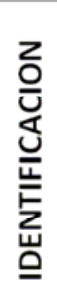 } & \multirow{2}{*}{\multicolumn{2}{|c|}{$\begin{array}{c}\text { NOMBRE } \\
\text { EMPLAZAMIENTO }\end{array}$}} & \multicolumn{5}{|c|}{ INDUSTRIAS ACEITERAS CASANOVA } \\
\hline & & & \multicolumn{3}{|c|}{ AVD. Del Puerto, $\mathrm{n} \cong 193$} & C.P. & \\
\hline & \multirow[b]{2}{*}{ CNAE } & \multirow[b]{2}{*}{253} & \multirow[b]{2}{*}{ DESCRIPCION } & \multicolumn{4}{|c|}{ INDUSTRIA QUIMICA } \\
\hline & & & & \multicolumn{4}{|c|}{$\begin{array}{c}\text { Tratamiento de aceites y grasas para udos } \\
\text { industriales. }\end{array}$} \\
\hline & DISTRITO & 12 & \multicolumn{5}{|c|}{ CAMINS AL GRAU } \\
\hline & \multicolumn{2}{|c|}{ SUPERFICIES } & $\begin{array}{l}\text { Sup. Parcela: } \\
\quad 7000 \mathrm{~m}^{2}\end{array}$ & $\begin{array}{l}\text { Sup. Ocupada: } \\
\qquad 3000 \mathrm{~m}^{2}\end{array}$ & $\begin{array}{l}\text { Sup. Construida: } \\
3000 \mathrm{~m}^{2}\end{array}$ & EMPI & ADOS: \\
\hline
\end{tabular}

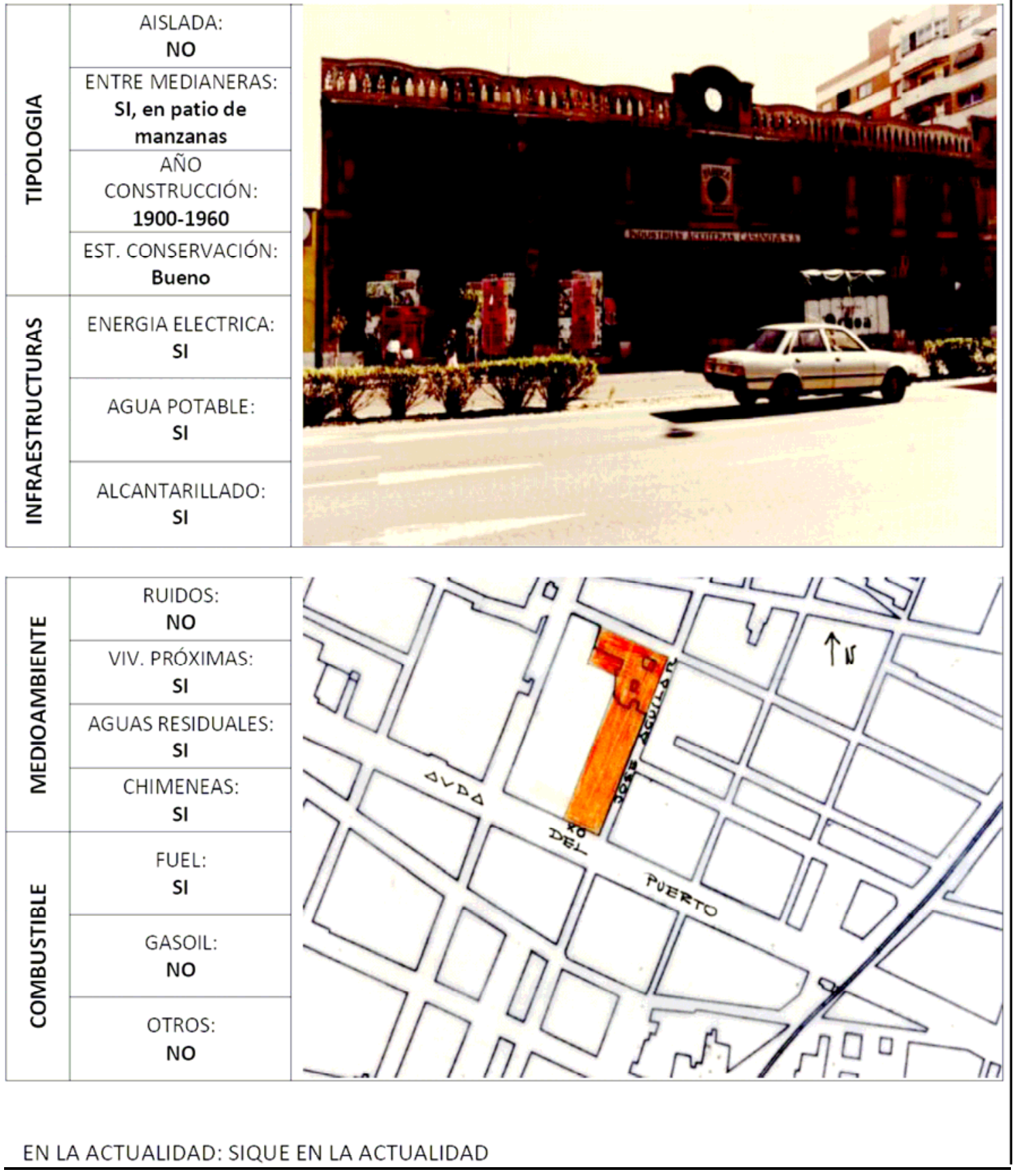




\section{EVOLUCIÓN}

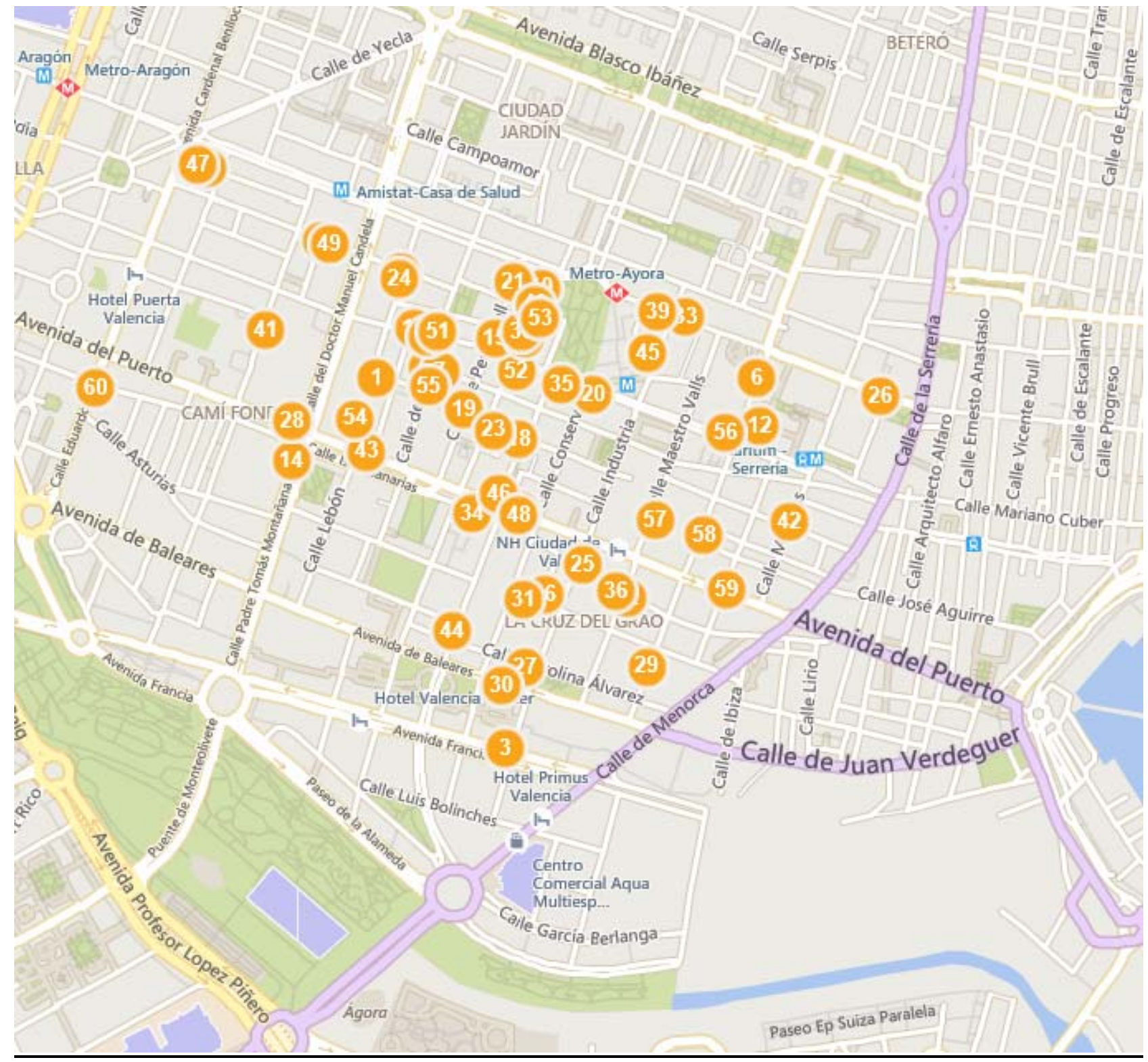

LISTADO DE INDUSTRIAS Y ACTIVIDAD.-

\section{Tomas Exojo Luengo}

Fabricación de otros muebles

\section{José Luis Antúnez Bravo}

Fabricación de otros muebles

03. PLAN B KITCHEN, S.L.

Fabricación de muebles de oficina y de establecimientos comerciales 


\section{Francisco Javier Fortea Bellido}

Fabricación de artículos de joyería y artículos similares

05. José Sonora Navarro

Fabricación de artículos de joyería y artículos similares

06. Trinidad Taroncher Bosch

Fabricación de artículos confeccionados con textiles, excepto prendas de vestir

\section{Florentina López Pérez}

Fabricación de artículos confeccionados con textiles, excepto prendas de vestir

\section{Ana $M^{\mathrm{a}}$ Aroca Lucas}

Fabricación de artículos confeccionados con textiles, excepto prendas de vestir

09. CERAMOTECNIC

Fabricación de instrumentos musicales y suministros médicos y odontológicos

\section{Luis Caballero Arias}

Fabricación de instrumentos musicales y suministros médicos y odontológicos

\section{Miguel García Domingo}

Fabricación de instrumentos musicales y suministros médicos y odontológicos

12. José Añon Estelles

Fabricación de instrumentos musicales y suministros médicos y odontológicos

\section{Manuel Martínez Gil}

Fabricación de otros productos de caucho

14. Francisco Javier Teresa Pozo

Mantenimiento y reparación de vehículos de motor

\section{Manuel S. Martínez Costal}

Mantenimiento y reparación de vehículos de motor

16. Pascual M. Castellar Rodrigo

Mantenimiento y reparación de vehículos de motor

\section{Jesús Real Gil}

Mantenimiento y reparación de vehículos de motor

\section{Manuel Vivo Company}

Mantenimiento y reparación de vehículos de motor

\section{Héctor Gimeno Herrero}

Mantenimiento y reparación de vehículos de motor

20. Juan Domingo Sayago Ponce

Mantenimiento y reparación de vehículos de motor

21. Francisco Gómez Clemente

Mantenimiento y reparación de vehículos de motor

21. Antonio Marques Leiva

Mantenimiento y reparación de vehículos de motor

\section{José Luis Gómez González}

Mantenimiento y reparación de vehículos de motor 
24. KASHMIR MOTOR, S.L.

Mantenimiento y reparación de vehículos de motor

25. TALLERES GARRIGA, C.B.

Mantenimiento y reparación de vehículos de motor

26. TALLERES RODRÍGUEZ, C.B.

Mantenimiento y reparación de vehículos de motor

\section{Juan Manuel Huelamo Fernández}

Mantenimiento y reparación de vehículos de motor

28. JA CORDELLAT PÉREZ, C.B.

Mantenimiento y reparación de vehículos de motor

29. Luisa Johana Bejarano

Mantenimiento y reparación de vehículos de motor

30. CHAPA Y PINTURA BAÑEARES, S.L.

Mantenimiento y reparación de vehículos de motor

31. Pablo Serrano Segura

Mantenimiento y reparación de vehículos de motor

32. Diego Javier Caldeira

Mantenimiento y reparación de vehículos de motor

33. Jorge García Martí

Mantenimiento y reparación de vehículos de motor

34. SERVICIO INTEGRAL DEL AUTOMOVIL MARTÍNEZ, S.L.

Mantenimiento y reparación de vehículos de motor

\section{TALLERES MONSORIU}

Mantenimiento y reparación de vehículos de motor

36. José Vicente Sánchez Camacho

Mantenimiento y reparación de vehículos de motor

37. Ignacio Hidalgo Ledesma

Fabricación de otros muebles

38. Sebastián Olmos Duque

Fabricación de otros muebles

39. Juan Díaz García

Fabricación de otros productos de madera, artículos de corcho, cestería y espartería

40. HERMANOS COSTA

Fabricación de otros productos de madera, artículos de corcho, cestería y espartería

41. Julio Vicente Almiñana Reig

Confección de otras prendas de vestir y accesorios

42. Miguel Ángel Ruiz Román

Fabricación de pan y de productos frescos de panadería y pastelería

43. Auli León Salazar Javier

Fabricación de pan y de productos frescos de panadería y pastelería 
44. MEETINGCOOK, S.L.

Fabricación de pan y de productos frescos de panadería y pastelería

45. Torres Muñoz

Otras actividades de impresión y artes gráficas

46. Arnedo Mínguez, Pedro

Otras actividades de impresión y artes gráficas

47. AMPARO ISABEL BERGA, S.L.

Otras actividades de impresión y artes gráficas

48. Torres Villarroya, José

Otras actividades de impresión y artes gráficas

49. CONSERVACIONES TELEFONICAS, S.A.

Mantiene la actividad

50. Chacartegui España, V.

Mantiene la actividad. Joyería

51. Rafael Lasa Saez

Mantiene la actividad. Pastelería

52. SANCHEZ PAMPLONA, S.L.

SUMINISTROS MAEZTU, S.L.

53. J. Fuertes

Carpintería de aluminio

54. ELECTRO INUSTRIAL MEDITERRANEO, S.A.

Mantiene la actividad

55. MANUFACTURAS GRALO

Mantiene la actividad. Joyería

56. HNOS. CASTILLA

Mantiene la actividad. Horno

57. GRAFICAS RONDA, S.L.

Mantiene la actividad

58. V. Ballester

Mantiene la actividad

59. BERBEGAL, S.L.

Mantiene la actividad

60. Fernando Gómez Sánchez

Mantiene la actividad 
ESTADO ACTUAL DE LOS ANTIGUOS EDIFICIOS INDUSTRIALES DE INTERES.-

- Ind. Aceiteras Casanova.

Avd. del Puerto ํㅡ 253 (BY-1)

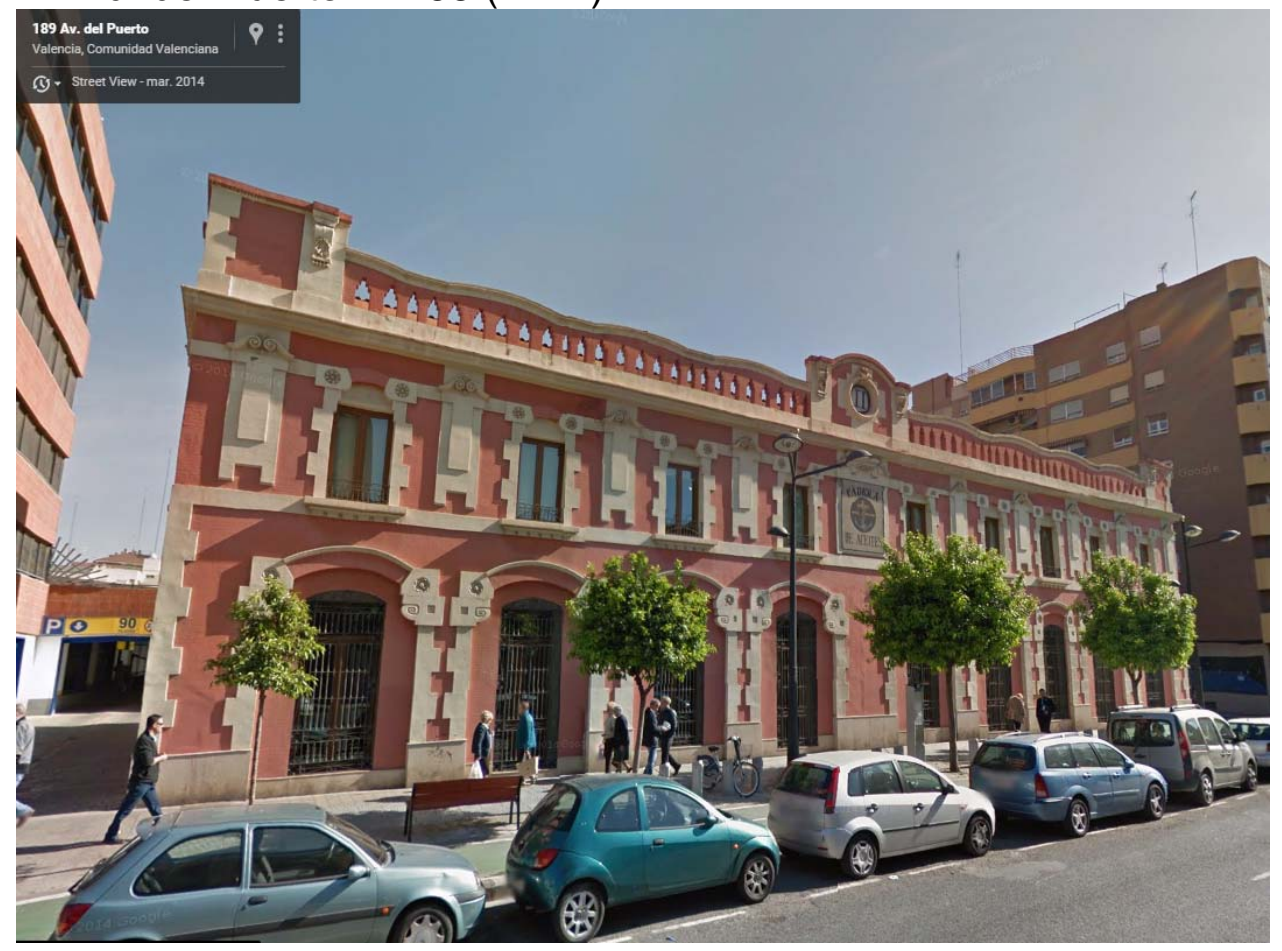

Foto 73. Edificio administrativo. Avda. del Puerto, 253. Valencia.2014.

Fuente: WEB. http://www.google.es/maps (Street View).

- U. Alcoholera Española.

Eduardo Boscá 5 (69-4)

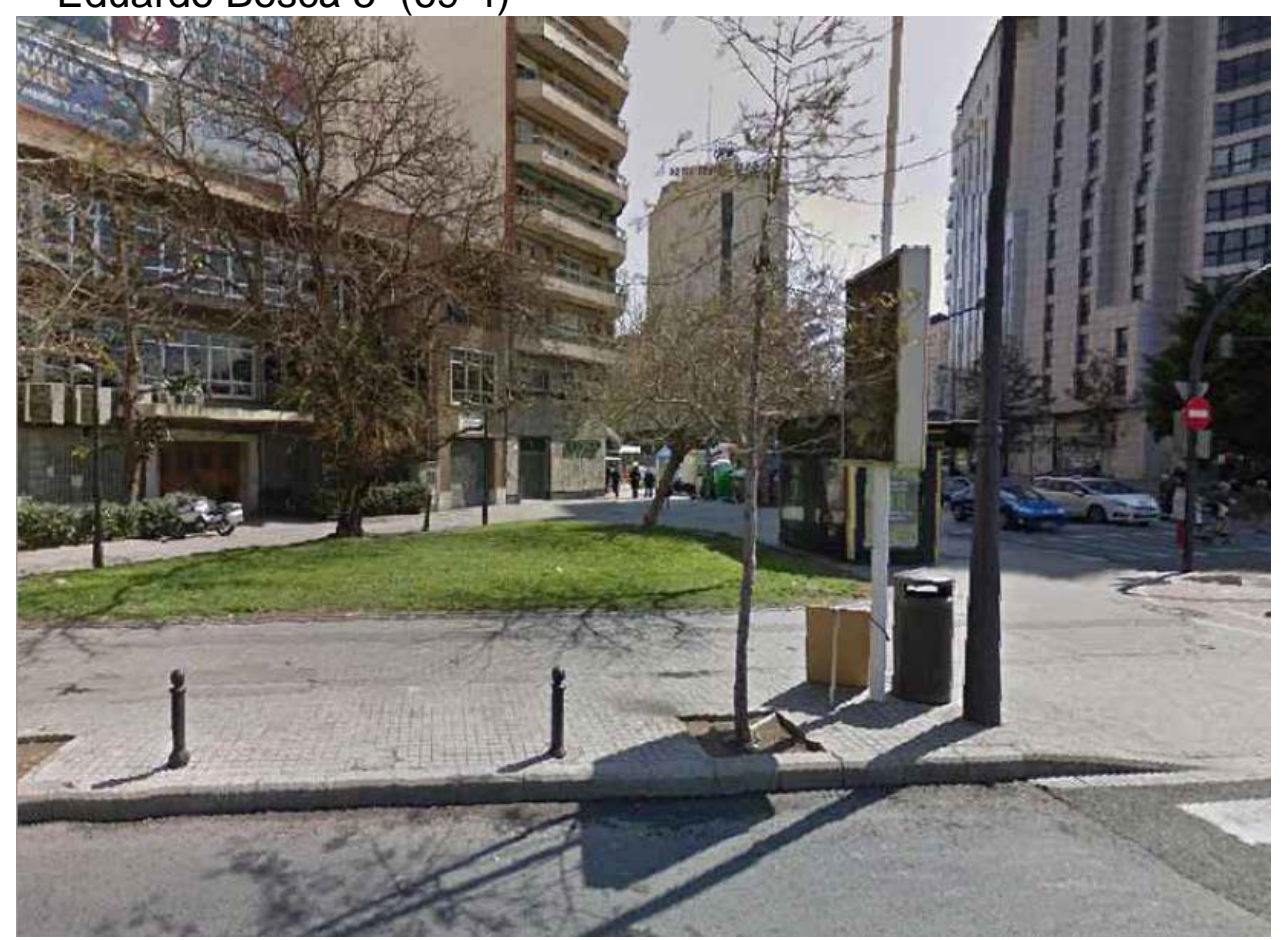

Foto 74. Edificios residenciales. C/ Eduardo Boscá, 5. Valencia.2014.

Fuente: WEB. http://Www.google.es/maps (Street View). 
- I. Químicas Canarias.

Co Hondo Grao n 50 (6G/5000-5)

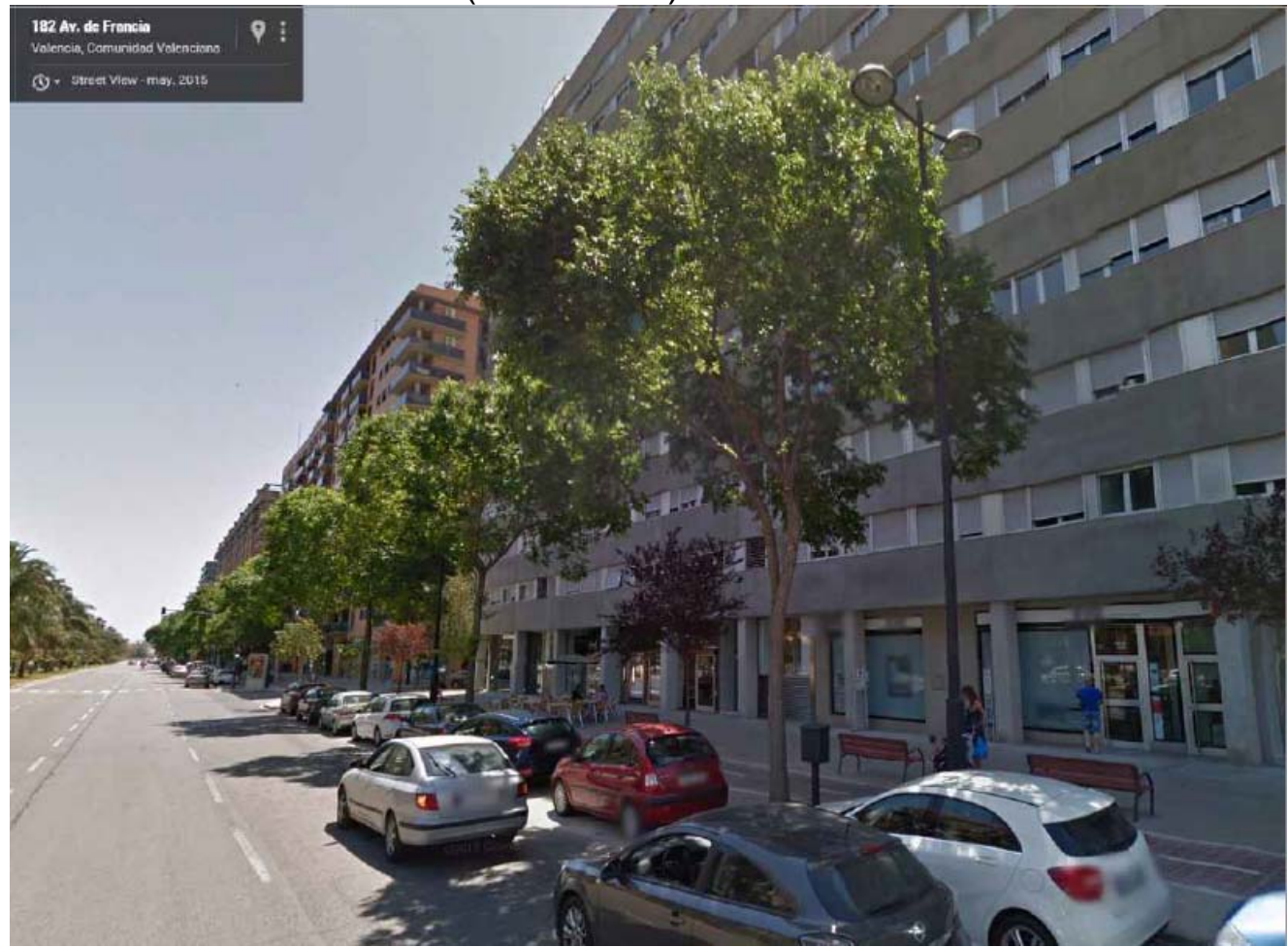

Foto 75. Edificios residenciales. Avda. de Francia. Valencia.2015.

Fuente: WEB. http://Www.google.es/maps (Street View).

- Clima Punto Rojo.

Senda de Carmona nำ 2 (6G/5000-7)

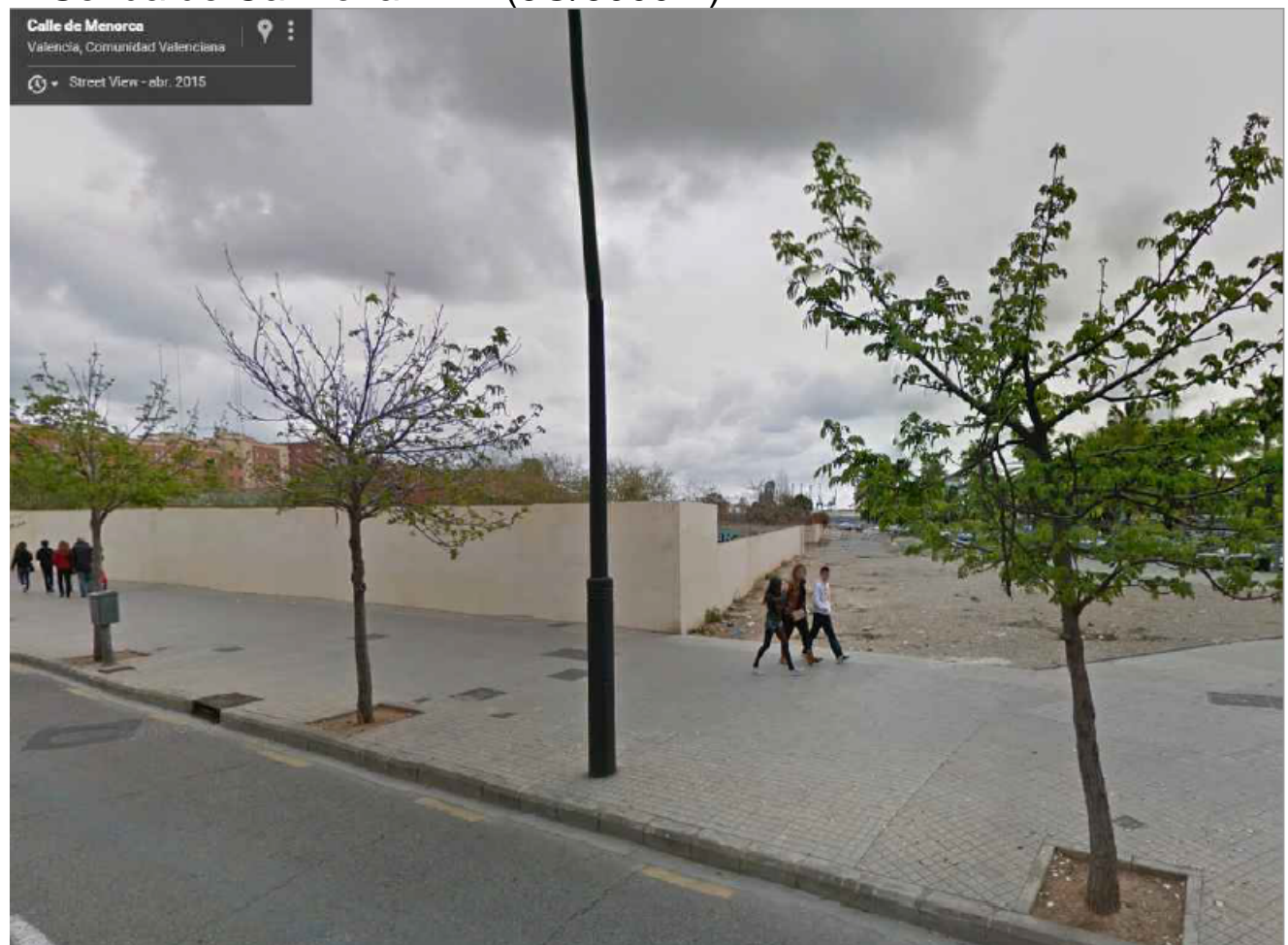

Foto 76. Solar. C/ Menorca. Valencia.2015.

Fuente: WEB. http://Www.google.es/maps (Street View). 
- Cross, S.A.

Co Hondo del Grao.s/n (6G/5000-8)

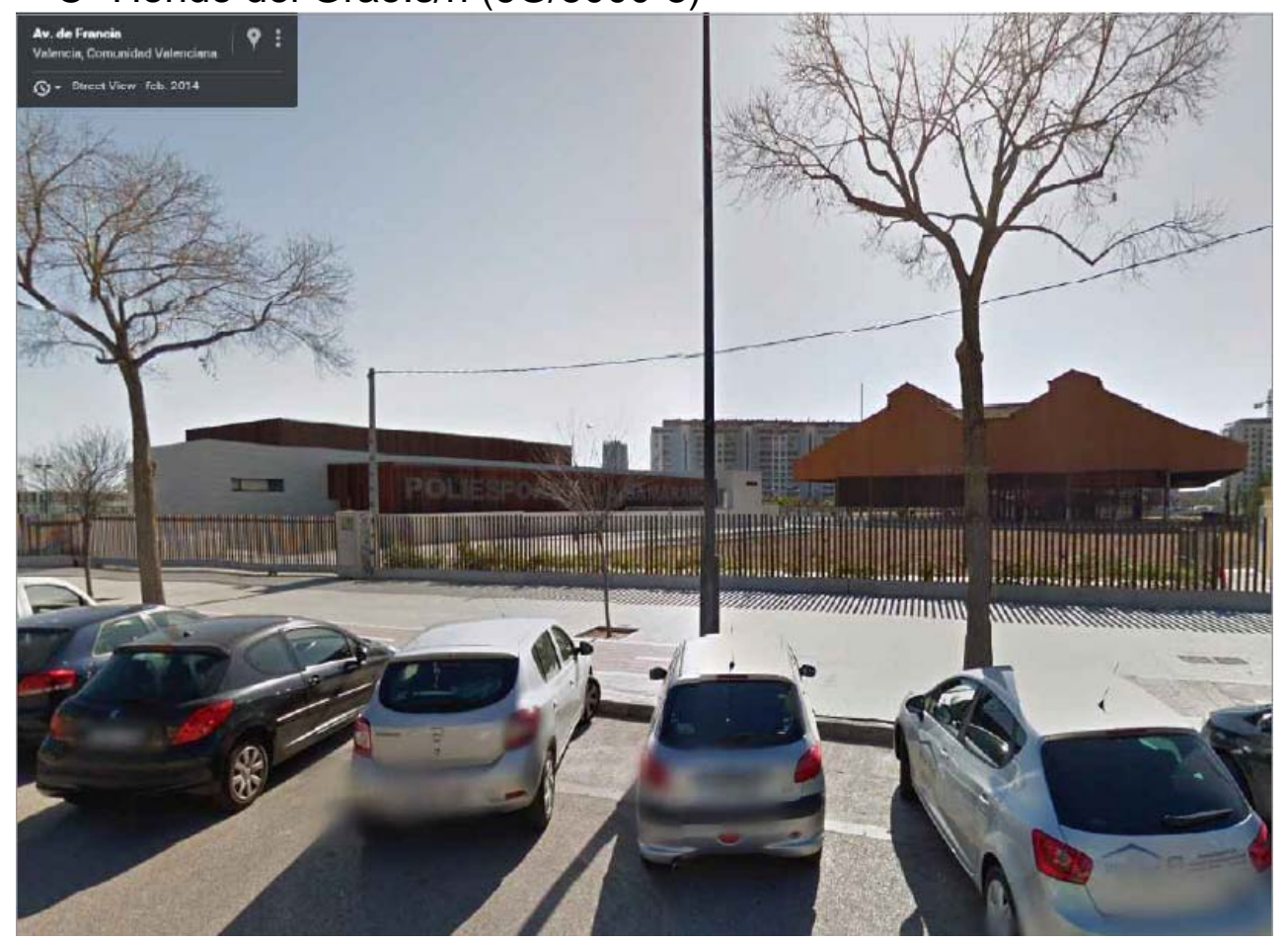

Foto 77. Centro deportivo y cultural. Avda. de Francia. Valencia.2014.

Fuente: WEB. http://www.google.es/maps (Street View).

- Abonos J. Campos Crespo.

Islas Canarias, 247 (CL 1)

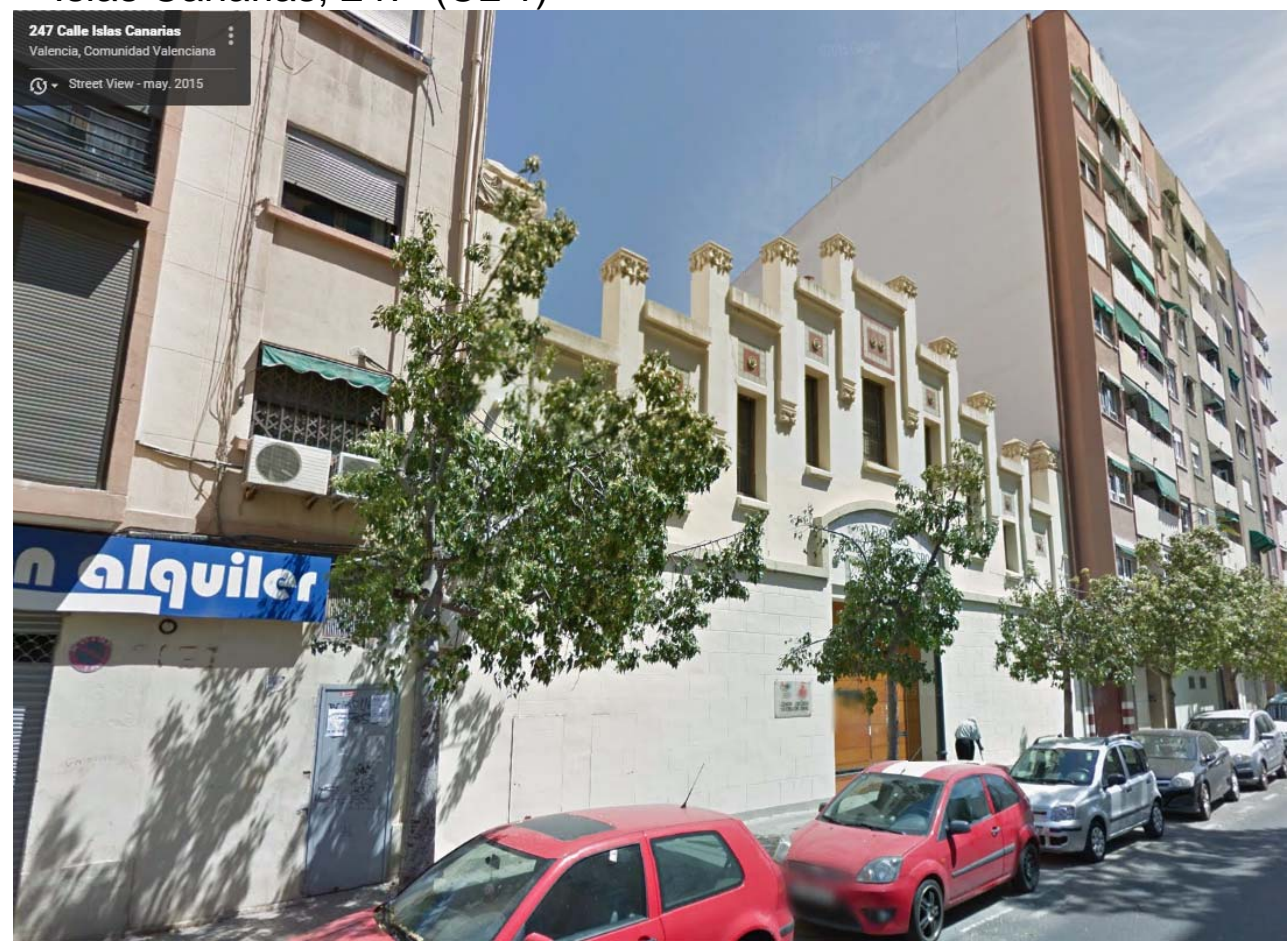

Foto 77.Centro Municipal.C/ Islas Canarias, 247. Valencia.2015.

Fuente: WEB. http://www.google.es/maps (Street View). 


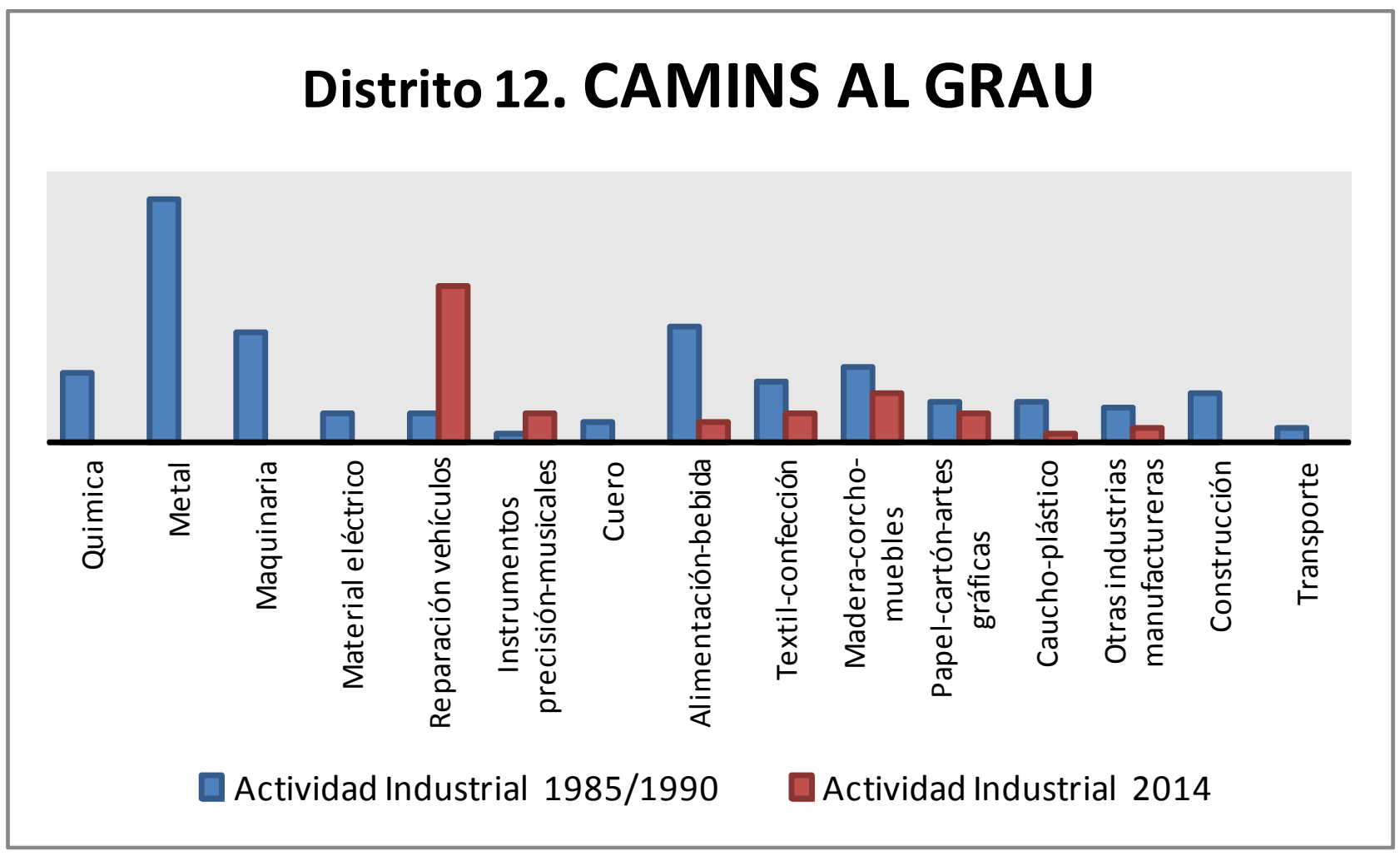

EVOLUCIÓN DEL IMPACTO AMBIENTAL

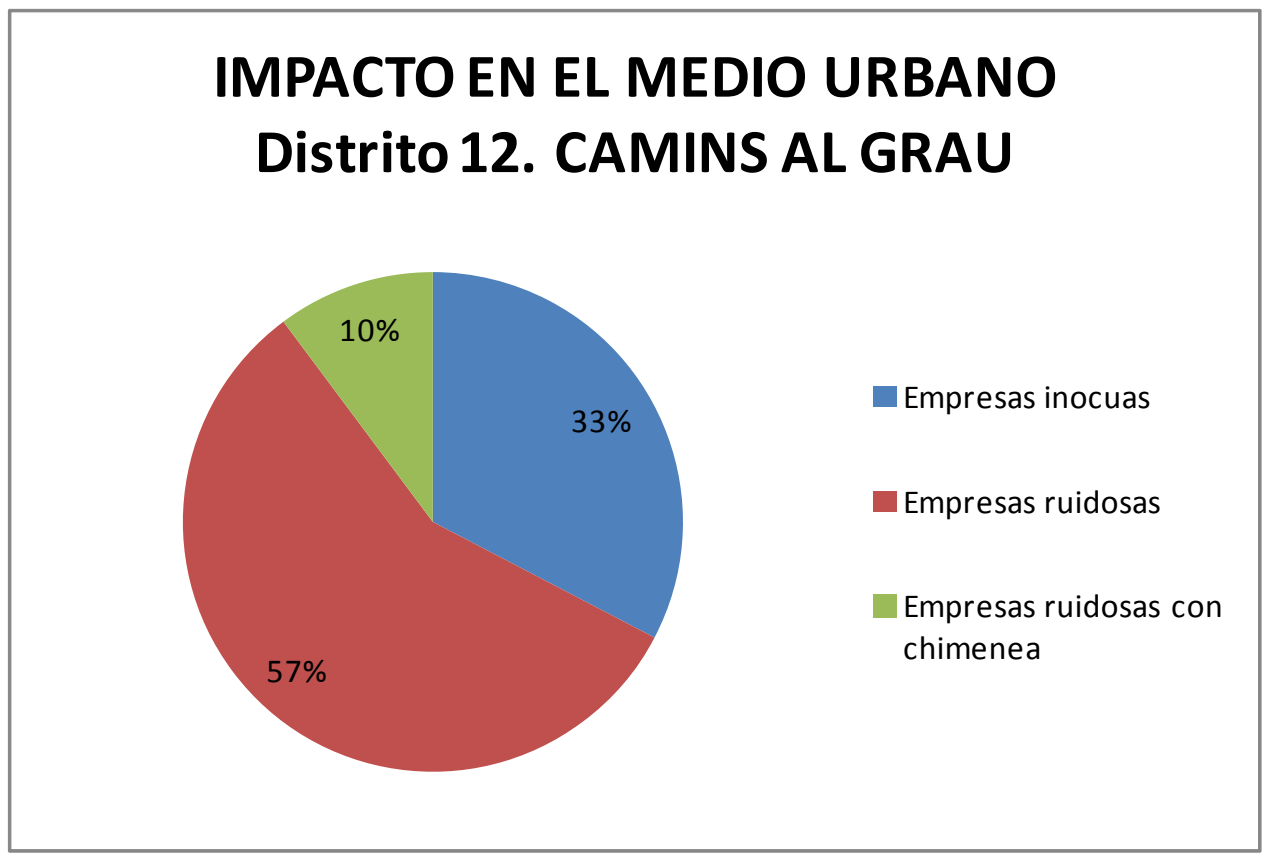




\section{FICHAS TIPO \\ FICHA DATOS DE LA INDUSTRIA}

LOCALIZACION ACTUALIZADA DE ACTIVIDADES INDUSTRIALES EN EL MEDIO URBANO DE VALENCIA

\begin{tabular}{|c|c|c|c|c|c|c|c|}
\hline \multirow{5}{*}{ 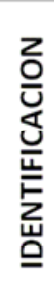 } & \multirow{2}{*}{\multicolumn{2}{|c|}{$\begin{array}{c}\text { NOMBRE } \\
\text { EMPLAZAMIENTO }\end{array}$}} & \multicolumn{5}{|c|}{ JOSE LUIS ANTUNEZ BRAVO } \\
\hline & & & \multicolumn{3}{|c|}{ C/SALVADOR PAU, 28} & C.P. & 46021 \\
\hline & \multirow{2}{*}{ CNAE } & \multirow{2}{*}{3109} & \multirow{2}{*}{ DESCRIPCION } & \multicolumn{4}{|c|}{ MADERA-CORCHO-MUEBLES } \\
\hline & & & & \multicolumn{4}{|c|}{ Fabricación de otros muebles } \\
\hline & DISTRITO & 12 & \multicolumn{5}{|c|}{ CAMINS AL GRAU } \\
\hline \multicolumn{3}{|c|}{ MEDIOAMBIENTE } & RUIDOSAS & SI & CHIMENEAS & \multicolumn{2}{|c|}{ NO } \\
\hline
\end{tabular}
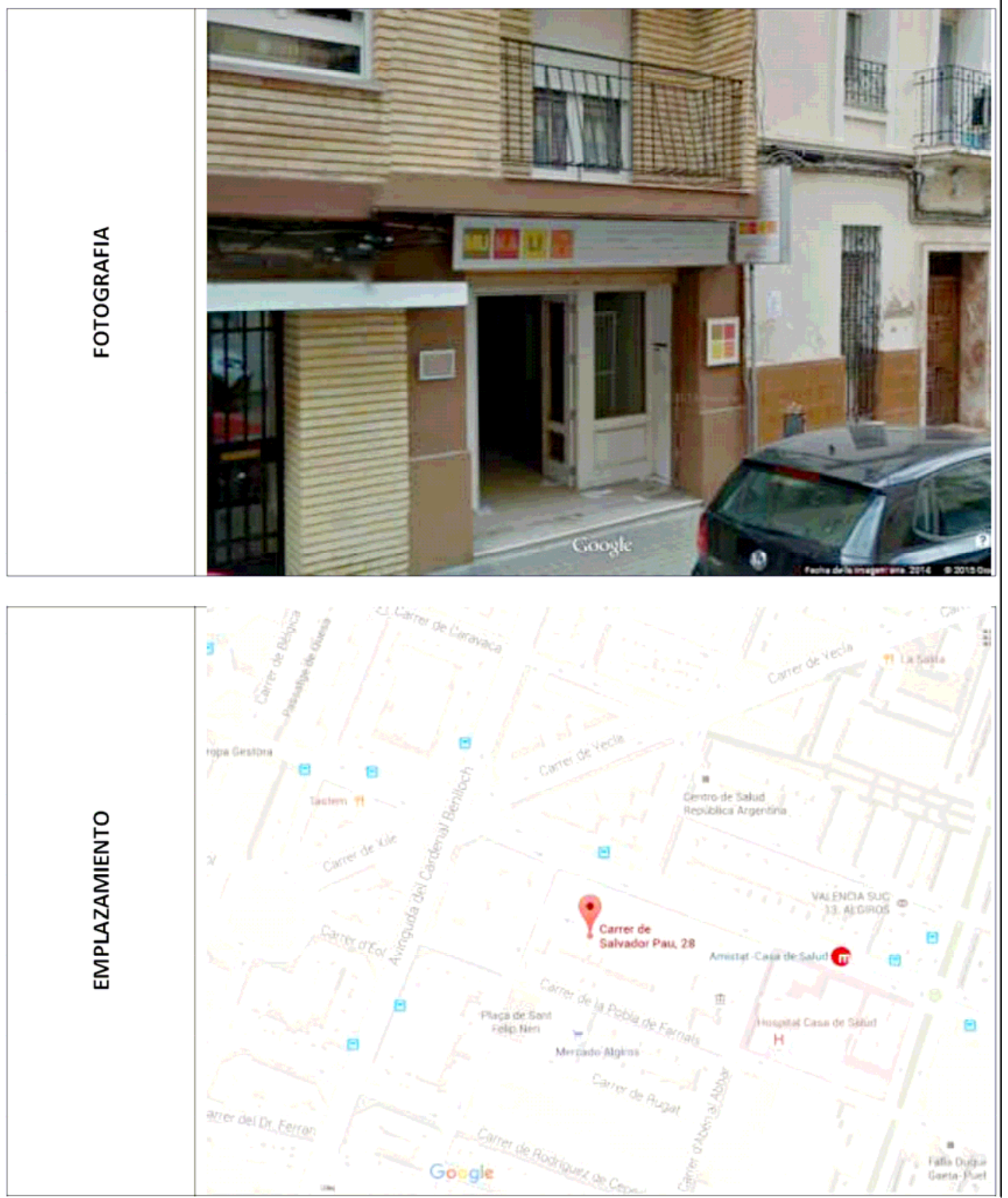


\section{FICHA DATOS DE LA INDUSTRIA}

LOCALIZACION ACTUALIZADA DE ACTIVIDADES INDUSTRIALES EN EL MEDIO URBANO DE VALENCIA

\begin{tabular}{|c|c|c|c|c|c|c|c|}
\hline \multirow{5}{*}{ 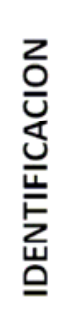 } & \multirow{2}{*}{\multicolumn{2}{|c|}{$\begin{array}{c}\text { NOMBRE } \\
\text { EMPLAZAMIENTO }\end{array}$}} & \multicolumn{5}{|c|}{ TORRES VILLAROYA JOSE } \\
\hline & & & \multicolumn{3}{|c|}{ AVENIDA DEL PUERTO, 176} & C.P. & 46023 \\
\hline & \multirow{2}{*}{ CNAE } & \multirow[b]{2}{*}{1812} & \multirow{2}{*}{ DESCRIPCION } & \multicolumn{4}{|c|}{ PAPEL-CARTON- ARTES GRÁFICAS } \\
\hline & & & & \multicolumn{4}{|c|}{ Otras actividades de impresión y artes gráficas } \\
\hline & DISTRITO & 12 & \multicolumn{5}{|c|}{ CAMINS AL GRAU } \\
\hline \multicolumn{3}{|c|}{ MEDIOAMBIENTE } & RUIDOSAS & $\mathrm{SI}$ & CHIMENEAS & & 0 \\
\hline
\end{tabular}
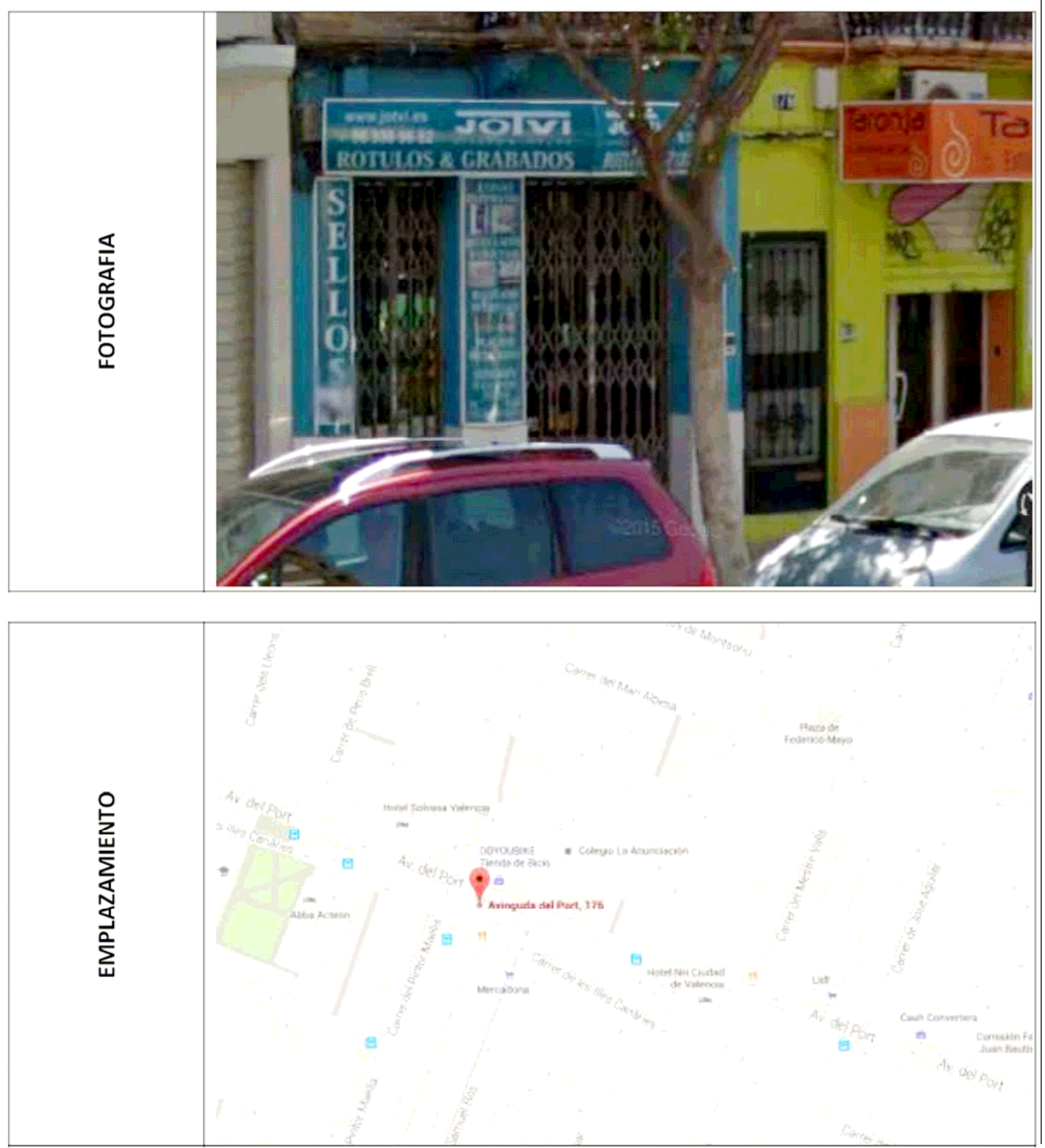


\section{FICHA DATOS DE LA INDUSTRIA}

LOCALIZACION ACTUALIZADA DE ACTIVIDADES INDUSTRIALES EN EL MEDIO URBANO DE VALENCIA

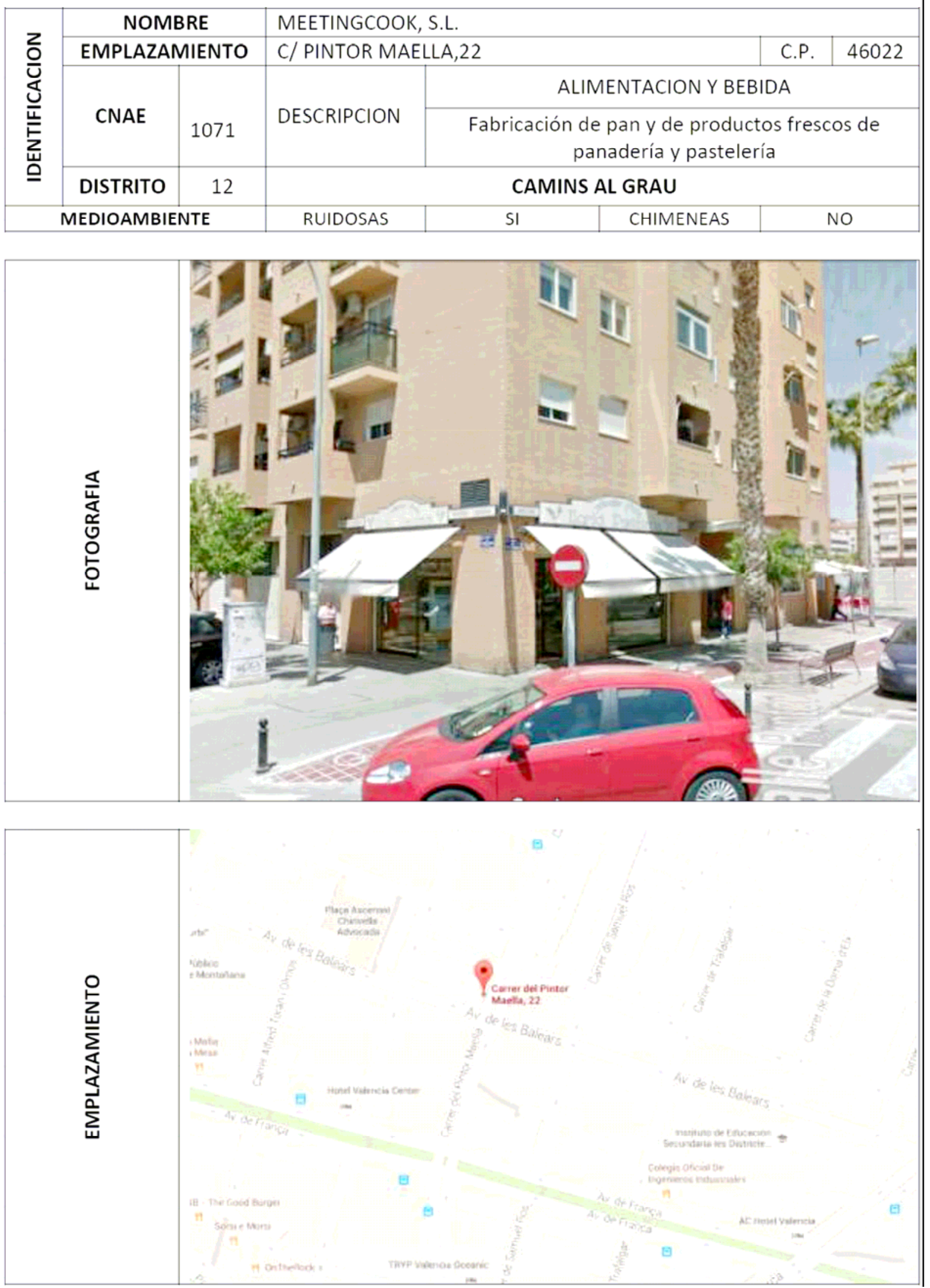




\section{FICHA DATOS DE LA INDUSTRIA}

LOCALIZACION ACTUALIZADA DE ACTIVIDADES INDUSTRIALES EN EL

\begin{tabular}{|c|c|c|c|c|c|c|c|}
\hline \multicolumn{8}{|c|}{ MEDIO URBANO DE VALENCIA } \\
\hline \multirow{5}{*}{ 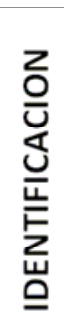 } & \multirow{2}{*}{\multicolumn{2}{|c|}{$\begin{array}{c}\text { NOMBRE } \\
\text { EMPLAZAMIENTO }\end{array}$}} & \multicolumn{5}{|c|}{ PASCUAL M. CASTELLAR RODRIGO } \\
\hline & & & \multicolumn{3}{|c|}{ C/ JUAN BAUTISTA MARCO, 11} & C.P. & 46023 \\
\hline & \multirow[b]{2}{*}{ CNAE } & \multirow[b]{2}{*}{4520} & \multirow{2}{*}{ DESCRIPCION } & \multicolumn{4}{|c|}{ REPARACION DE VEHICULOS } \\
\hline & & & & \multicolumn{4}{|c|}{$\begin{array}{c}\text { Mantenimiento y reparación de vehículos de } \\
\text { motor }\end{array}$} \\
\hline & DISTRITO & 12 & \multicolumn{5}{|c|}{ CAMINS AL GRAU } \\
\hline \multicolumn{3}{|c|}{ MEDIOAMBIENTE } & RUIDOSAS & SI & CHIMENEAS & & 0 \\
\hline
\end{tabular}

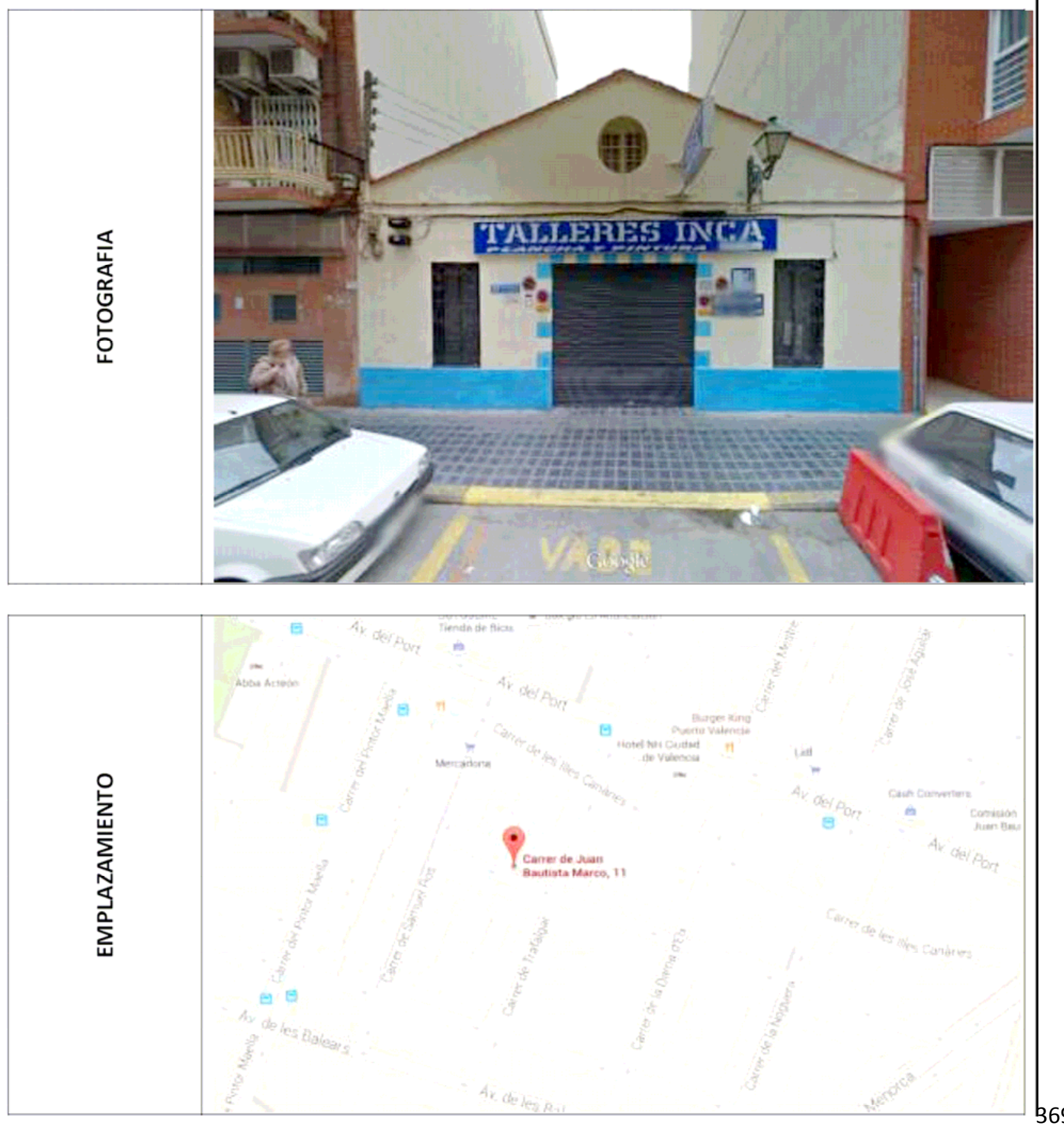




\section{FICHA DATOS DE LA INDUSTRIA}

LOCALIZACION ACTUALIZADA DE ACTIVIDADES INDUSTRIALES EN EL

MEDIO URBANO DE VALENCIA

\begin{tabular}{|c|c|c|c|c|c|c|c|}
\hline \multirow{5}{*}{ 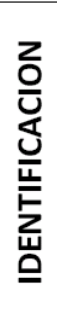 } & \multirow{2}{*}{\multicolumn{2}{|c|}{$\begin{array}{c}\text { NOMBRE } \\
\text { EMPLAZAMIENTO }\end{array}$}} & \multicolumn{5}{|c|}{ ANA Ma AROCA LUCAS } \\
\hline & & & \multicolumn{3}{|c|}{ C/ DUQUE DE GAETA,47 } & C.P. & 46022 \\
\hline & \multirow{2}{*}{ CNAE } & \multirow[b]{2}{*}{1392} & \multirow{2}{*}{ DESCRIPCION } & \multicolumn{4}{|c|}{ TEXTIL-CALZADO-CONFECCION } \\
\hline & & & & \multicolumn{4}{|c|}{$\begin{array}{c}\text { Fabricación de articulos confeccionados con } \\
\text { textiles,excepto prendas de vestir }\end{array}$} \\
\hline & DISTRITO & 12 & \multicolumn{5}{|c|}{ CAMINS AL GRAU } \\
\hline \multicolumn{3}{|c|}{ MEDIOAMBIENTE } & RUIDOSAS & SI & CHIMENEAS & \multicolumn{2}{|c|}{ NO } \\
\hline
\end{tabular}
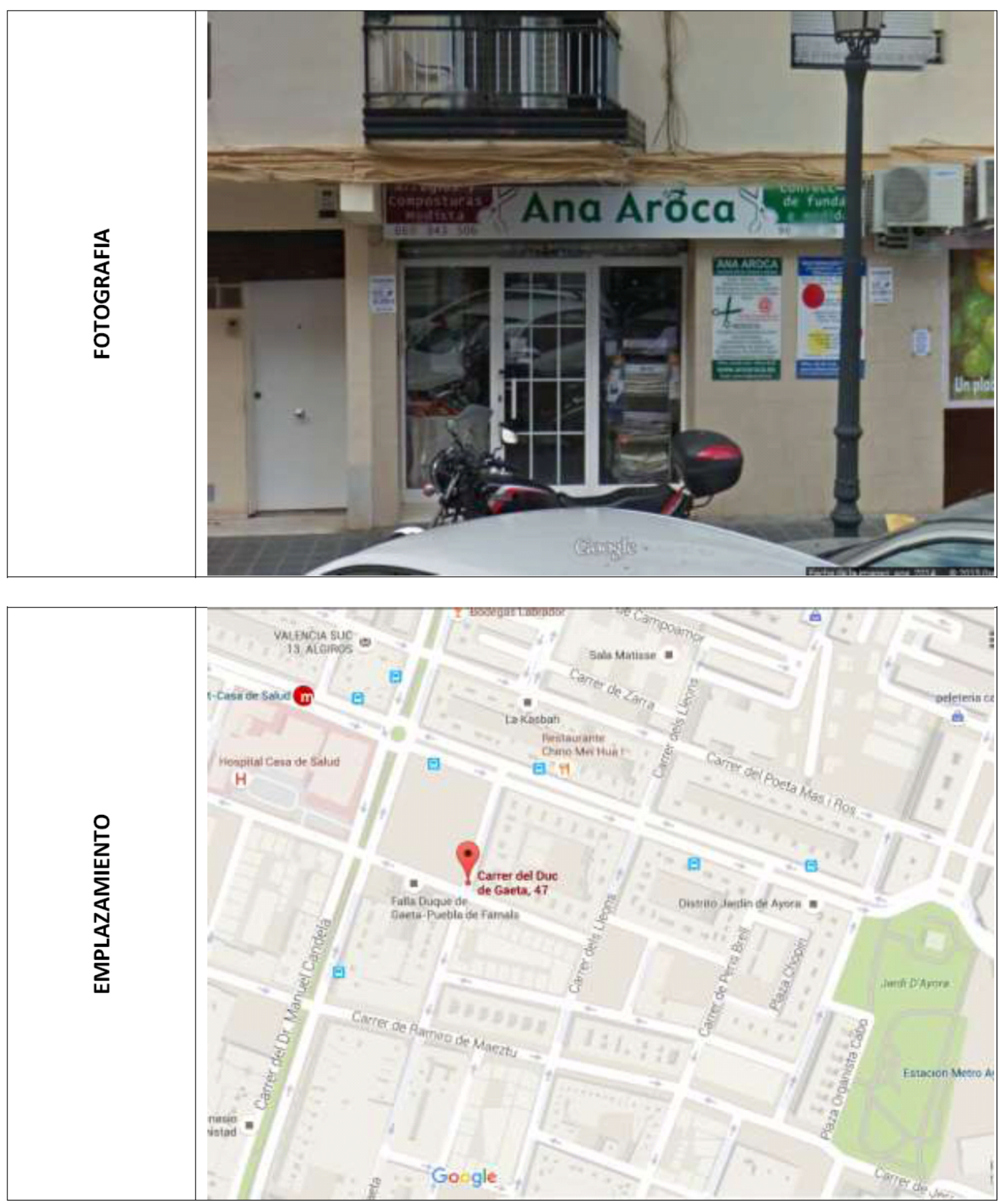


\section{CONCLUSIONES}

\section{CONCLUSIONES GENERALES}

La presencia y desarrollo de la actividad industrial en las áreas urbanas responde a razones económicas. Por un lado las economías de aglomeración es decir, las ventajas económicas derivadas de la concentración de actividades complementarias que junto a la existencia de mercados de trabajos amplios y especializados, mayores niveles de desarrollo de las comunicaciones y servicios y la proximidad a los puntos de consumo favorecen la creación y el mantenimiento de industrias en el seno de las áreas urbanas.

Por otro lado las economías externas, es decir, el hecho de que parte de los costos de las empresas sean factores no inherentes a ellas, como es el caso de las infraestructuras y servicios urbanísticos básicos, accesos rodados, abastecimiento de agua, energía eléctrica, alcantarillado, teléfonos, etc. hacen que sea más rentable para una empresa producir en las áreas urbanas que en las áreas rurales.

Son éstas razones de localización que afectan especialmente a las grandes y medianas empresas puesto que en las empresas pequeñas suelen tener mayor importancia al arraigo a determinadas zonas, la proximidad a la residencia del propietario, así como otros factores de tipo personal.

\section{CONCLUSIONES PARTICULARES PARA LA CIUDAD DE VALENCIA}

La realidad de la actividad industrial en la Ciudad de Valencia es que se renueva constantemente, aunque depende mucho de tipo de actividad industrial.

Como prueba de ello podemos citar al Distrito Uno que en el año 85 tenia 40 empresas y en la actualidad 2014 tiene 39, pero únicamente subsisten 4 de las antiguas. Son empresas inocuas no molestas y adaptadas a los tiempos actuales.

Las industrias molestas y ruidosas han desaparecido, casi siempre por la presión de los vecinos y de acuerdo con las ordenanzas actuales tanto de Actividades como del $P G$, dando paso al comercio. 
Lo cierto es que la industria esta en constante movimiento, lo cual se contrapone a épocas pasadas, que era mas artesanal y se asentaba en lugares y calles concretas, la actividad industrial perduraba muchos años,

En la actualidad, se ven influenciadas por Cambios Estructurales a nivel Nacional y Europeo y sujetas a Ciclos Económicos que determinan su futuro próximo o bien Urbanísticos que delimitan las actividades y su emplazamiento Tal ha sido el caso del Naval, Químico, el Metal o la Madera sobre todo el sector del Tablero, tan importantes durante muchos años pero en la actualidad en franca decadencia.

Solo tendríamos que retroceder 55 años para ver imágenes como la fotografía siguiente en la que se ve mano de obra poco especializada ( niños) y barata, que es el comienzo del despegue económico ligado a los sistemas de producción, con productos de calidad a bajo precio.

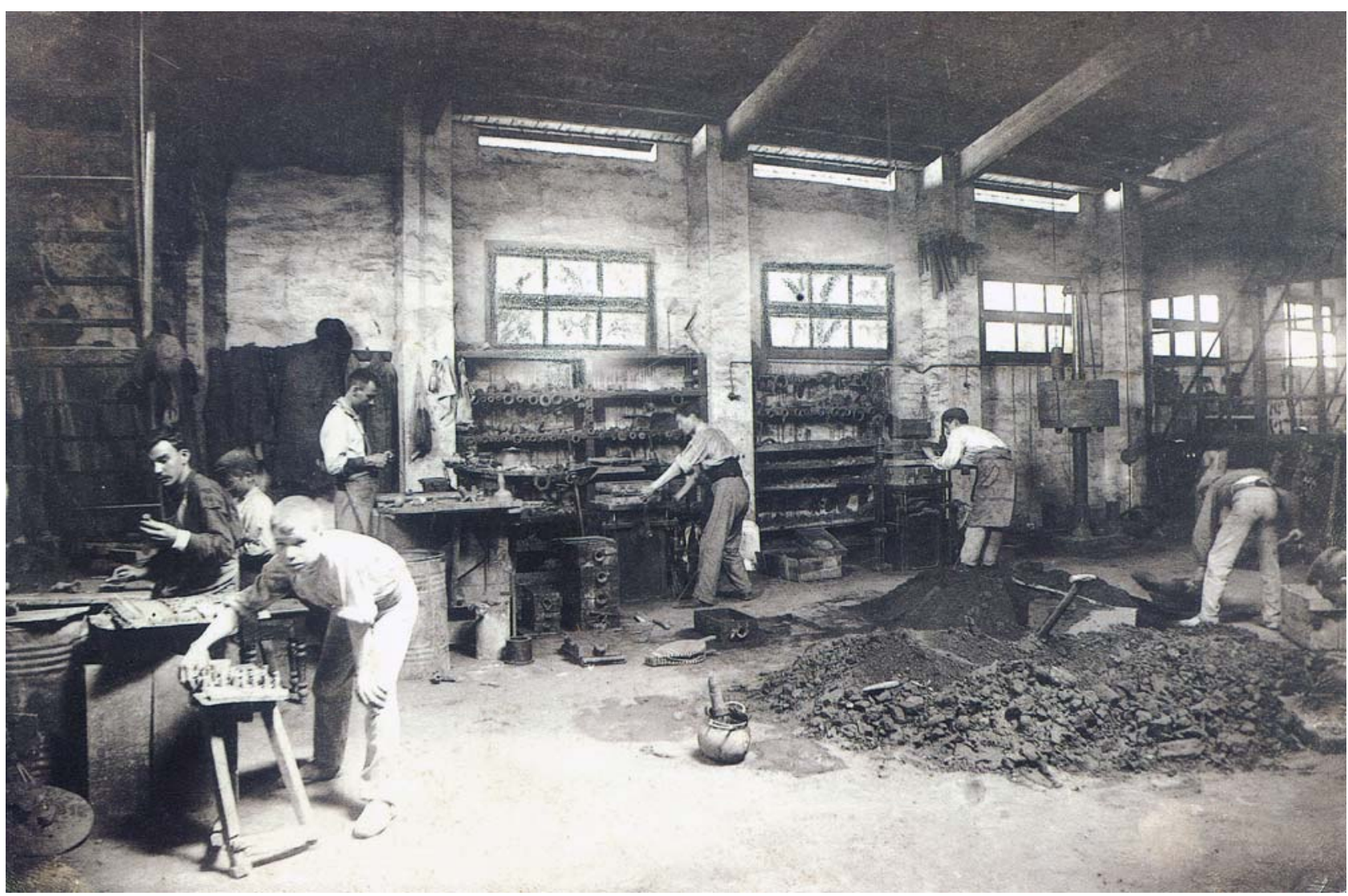

Foto 78: Nave de fundido y colado de la fundición Moreno en Valencia. Anónimo.

Fuente: Álvarez, A. y Ballester, B. Ayuntamiento de Valencia. VALENCIA INDUSTRIAL: LaS fundiciones. Valencia. 2001 (p.161)

Eso lo podemos trasladar en la actualidad a muchos países Africanos o Asiáticos y la pregunta es ¿Cómo se puede subsistir en los países industrializados frente al libre comercio?. Respuesta: Con mucha dificultad. 
Todos vestimos y calzamos con prendas no hechas en el país donde vivimos, sin embargo no hace mucho no era así.

Lo que nos indica que el Textil (Feycu en Chirivella) y el Calzado (Segarra) Madera (Mariner) por citar algunas entre otras se han visto abocados prácticamente a su desaparición, solamente subsiste la calidad junto al marketing

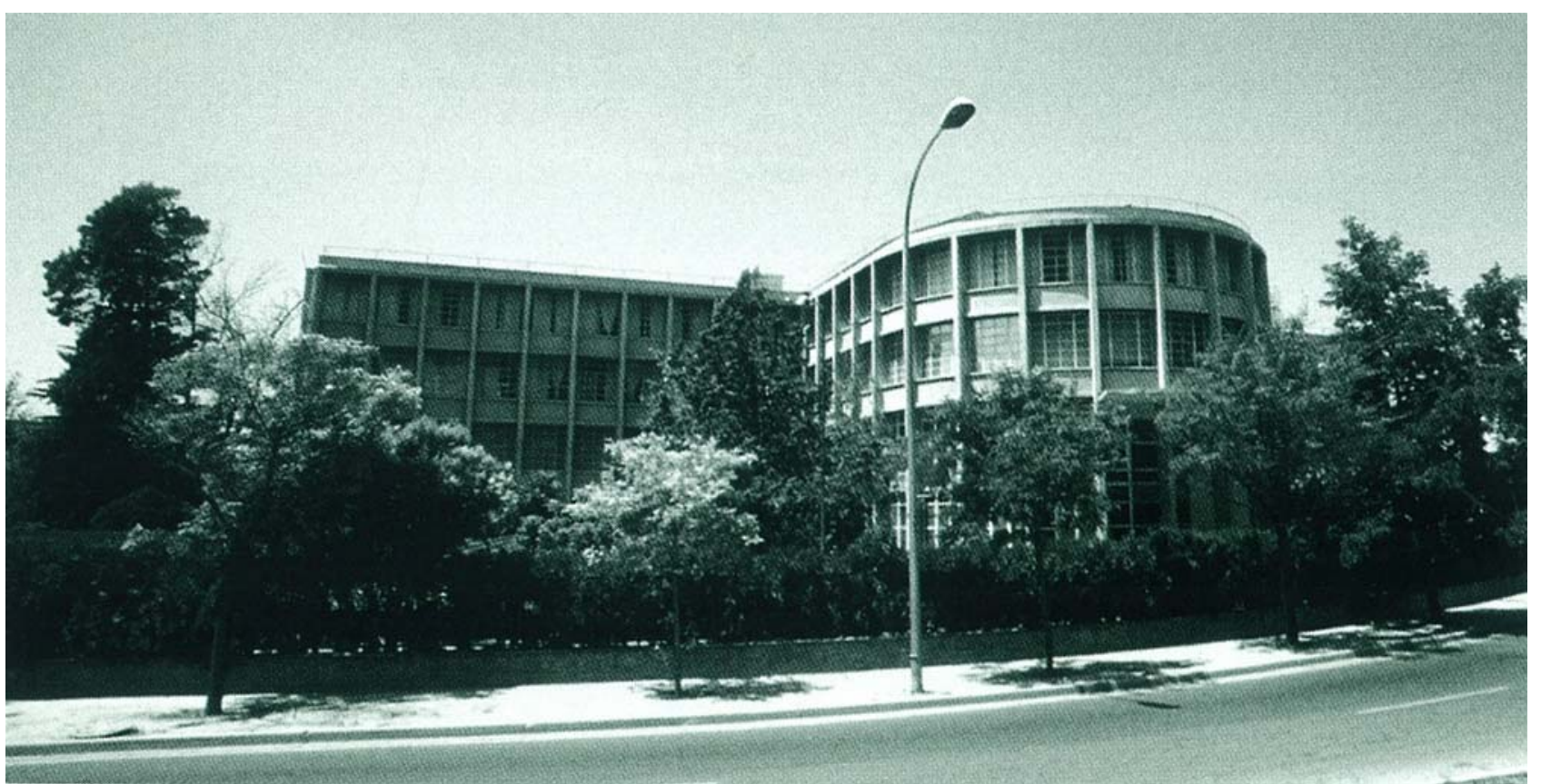

Foto 79: Nave textil. Feycu. Pza. de España. s.n. Xirivella, Valencia.1965

Fuente: Patronato de la Fundación DOCOMOMO Ibérico. La arquitectura de la industria, 1925-1965. Barcelona. 2005. (p.175).

Hay una serie de factores que le condicionan, a nivel internacional, nacional y local a las actividades industriales, no solamente le condicionan los aspectos urbanísticos sino también los políticos y económicos.

Podemos decir que:

1.- Con los Acuerdos Europeos de Libre Comercio, se eliminan básicamente el Proteccionismo económico, pilar importante en el sector Agrícola, Ganadero y Alimentación, ello trae consigo el empobrecimiento sistemático del sector poco competitivo por las explotaciones tan pequeñas que tenemos y además poco industrializadas. Es mas barato importar que producir.

El sector artesanal tan arraigado en nuestra ciudad desde tiempos inmemoriales prácticamente desaparece frente al mercado Asiático para pasar a la importación y 
el comercio.

Aldaia, un pueblo industrial dedicado al abanico, el tablero y el mueble, prácticamente no tiene fábricas de abanicos, alguno queda que lo hace de forma artesanal, todos los fabricantes importan y comercian productos ya elaborados. La mayor parte de ellos vendían en el Centro Histórico.

Alacuas tenía la fábrica de tableros más importante de Europa, Tableros Ferrer con una superficie aproximada de $20.000 \mathrm{~m} 2$ y un número de trabajadores similar al del Centro Histórico o Campanar, pues ha sucumbido a la presión Asiática, es más barato comprar que fabricar.

Al sector Textil y Madera le sucede exactamente lo mismo, en un periodo de 20 años prácticamente desaparecen todas las empresas

En el año 85, el Metal representa el 18,6\%, la Alimentación el 12\%, la Madera el $10,30 \%$, el textil el $7 \%$, prácticamente estos sectores representan el $48 \%$ de la industria y todos ellos afectados con posterioridad por el libre comercio entre áreas de libre competencia e inversión.

Ante tal situación la industria se tiene que reconvertir en una situación muy desfavorable, a ello se añadirán otros factores que le provocaran un desenlace poco deseado por todos, tanto social como económico, que será la especulación del suelo que ocupa. Esa es una de las máximas preocupaciones entre otras que tiene la Ley Sobre el Régimen del Suelo y Ordenación Urbana de 1990

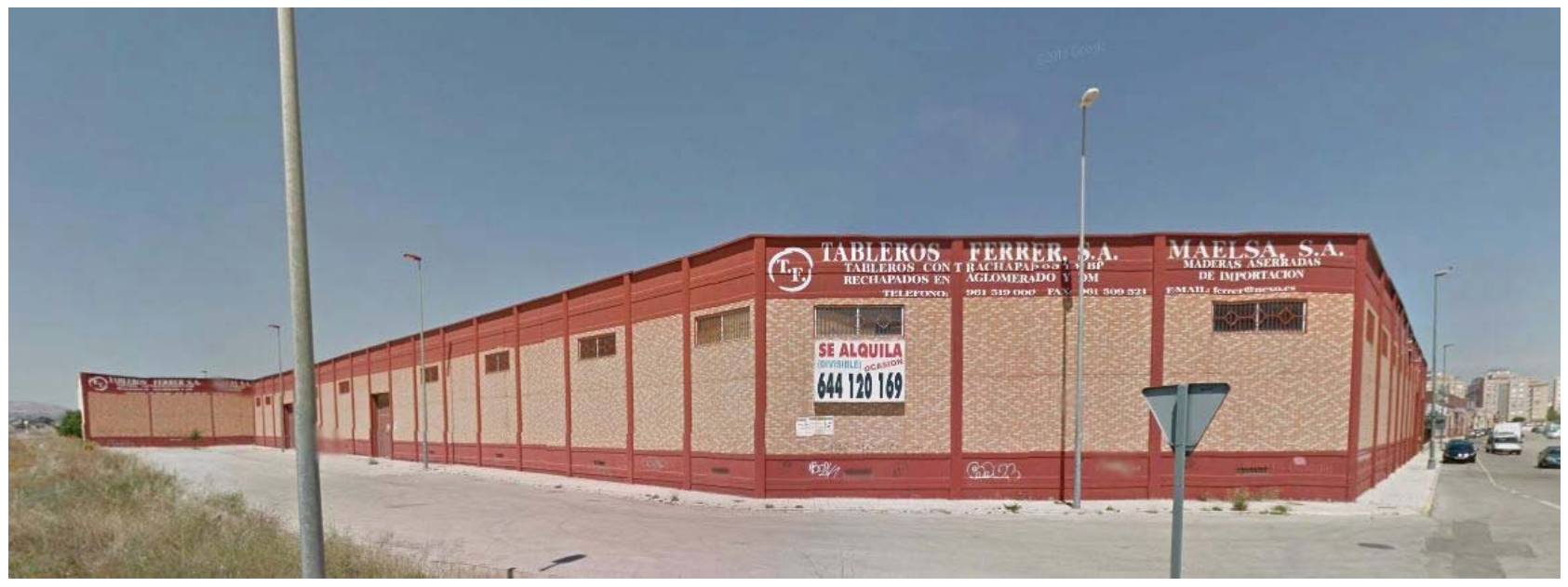

Foto 80. Nave de tableros. Tableros Ferrer, S.A. Cami Vell de Torrent, 60. Alacuas, Valencia. 2015 Fuente: Elaboración propia. 


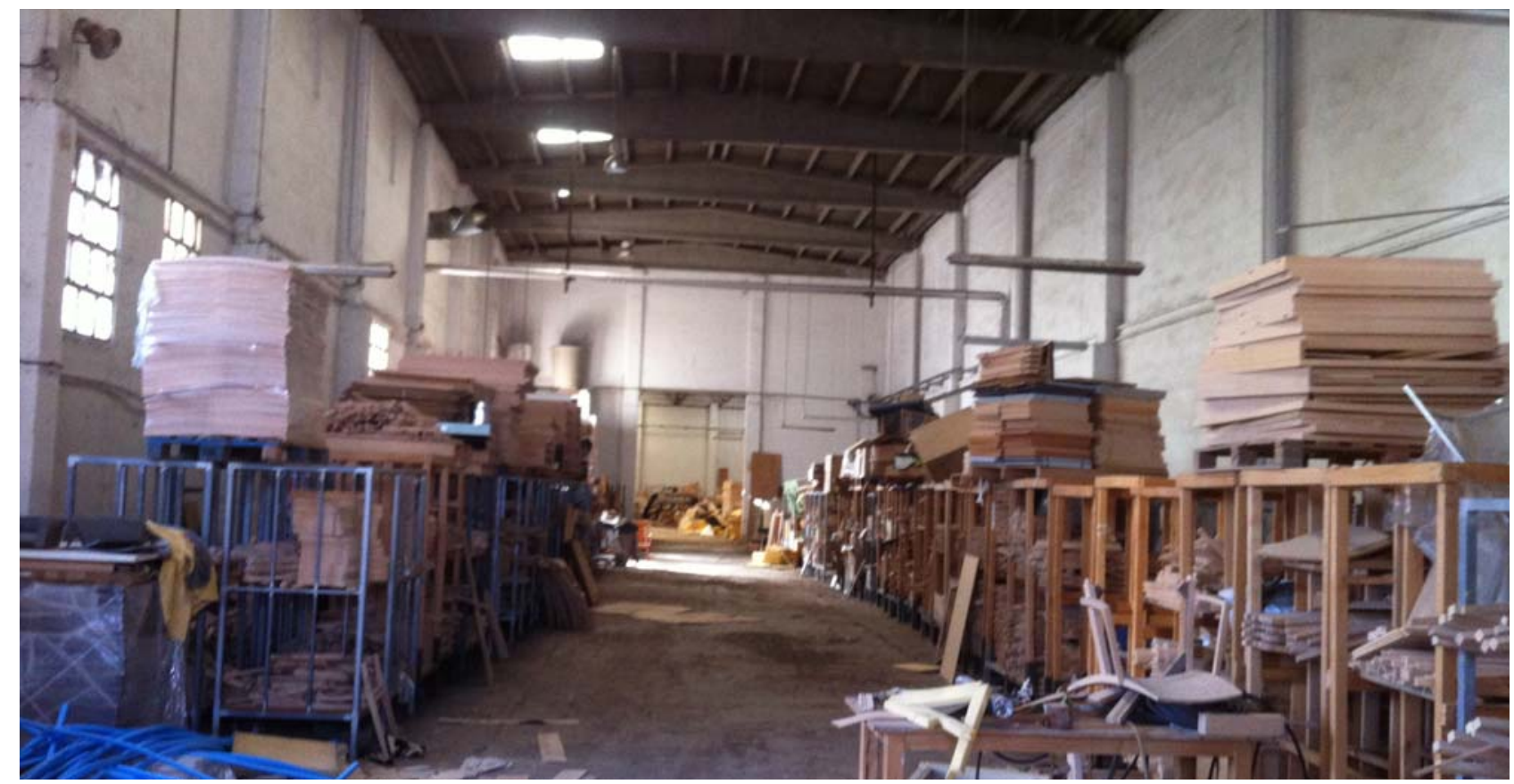

Foto 81. Vista interior de nave de tableros. Tableros Ferrer, S.A. Cami Vell de Torrent, 60. Alacuas, Valencia. 2015 Fuente: Elaboración propia.

2.- La parte Política se corresponde con la Reconversión Industrial que se empieza a elaborar después de la crisis económica de 1973, pero en realidad se hace de los 80 a los 90, en la que se toman medidas económica con la finalidad de ajustar la oferta a la demanda. Hoy mismo se esta repitiendo esta situación, no hace falta entender de economía para comprenderlo.

Tiene dos vertientes que nos afectaran muy directamente y que se entienden desde lo que se nos avecinaba en cuanto al libre comercio:

1. La primera es la limitación industrial de las empresas en crisis con exigencias de reducción de producción y la aplicación de nuevos sistemas de Organización y Gestión que lleva a la reducción de plantillas y en algunos casos a la práctica desaparición de las empresas.

Esta medida afecta directamente al sector naval, metal, textil, madera y alimentación que en nuestro rango de actividades ocupan los cinco primeros lugares. 
El sector del metal en nuestro caso las fundiciones ubicadas en la Avenida del Puerto prácticamente desaparecen. La madera, con la prohibición de importar cierta cantidad por el Puerto de Valencia y en condiciones que supone un encarecimiento de la materia prima, lentamente va desapareciendo.

El textil pierde competitividad por el encarecimiento de la mano de obra, cuando se le estaba pidiendo lo contrario.

El sector alimentario pierde las ayudas, y ello unido a los minifundios y su escasa competitividad, lleva al lugar donde nos encontramos hoy, donde el agricultor cobra escasamente 9 céntimos de euro por un kilogramo de naranjas y el comercio lo vende a un euro. La relación es de $0,09 €$ frente a $1 €$ y seguimos ahí por el carácter familiar de las explotaciones acumulando perdidas
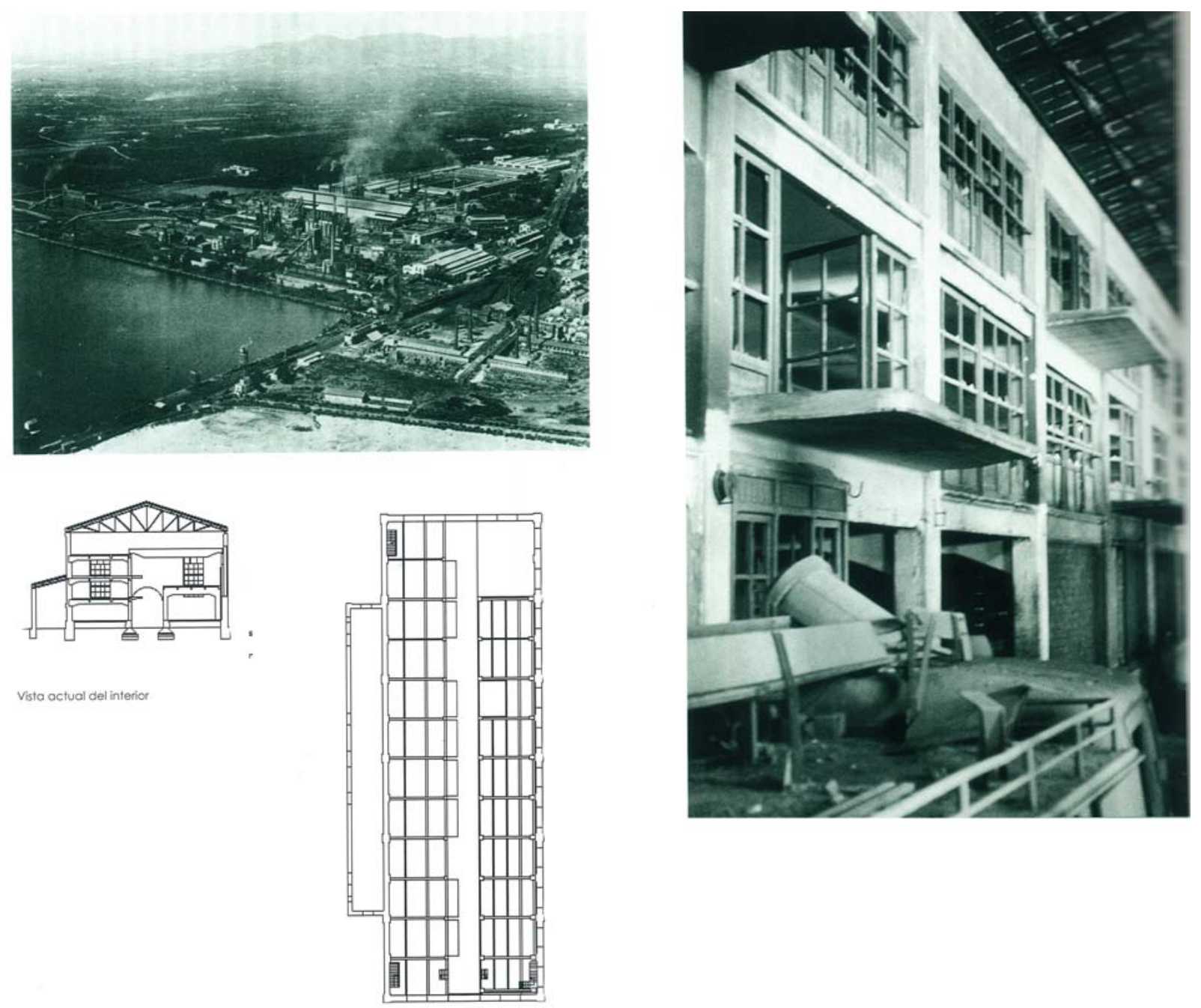

Foto 82: Vista aérea de Altos Hornos de Sagunto. Planta y sección transversal. Interior de almacén de efectos y de repuestos. Sagunto. Valencia. 1965. Fuente: Patronato de la Fundación DOCOMOMO Ibérico. La arquitectura de la industria, 1925-1965. Barcelona. 2005. (p.170). 
2. La segunda vertiente es la Reindustrialización, basada en la modernización tecnológica con ayudas estatales, financieras, fiscales y laborales. Aquí estamos en la misma situación que hoy. Muy poco eficaces.

Pregunta: ¿Quien le presta dinero a una empresa en crisis? ¿Que ha quedado del Puerto de Sagunto, cuantas parcelas tiene desocupadas y cuanto de eficaz ha sido la Reindustrialización?

De todo esto y con lo vivido nos queda claro que, los sectores industriales tienen que adaptarse al nuevo ciclo económico, buscando productos de mayor demanda (los tecnológicos) y sin quedarse estancados en los poco productivos (alimentación, textil...)

Con la incorporación a la Comunidad Económica Europea en 1986, se entra en el momento culminante de la reconversión industrial, y se produce en la ciudad de Valencia una reorganización constante industrial

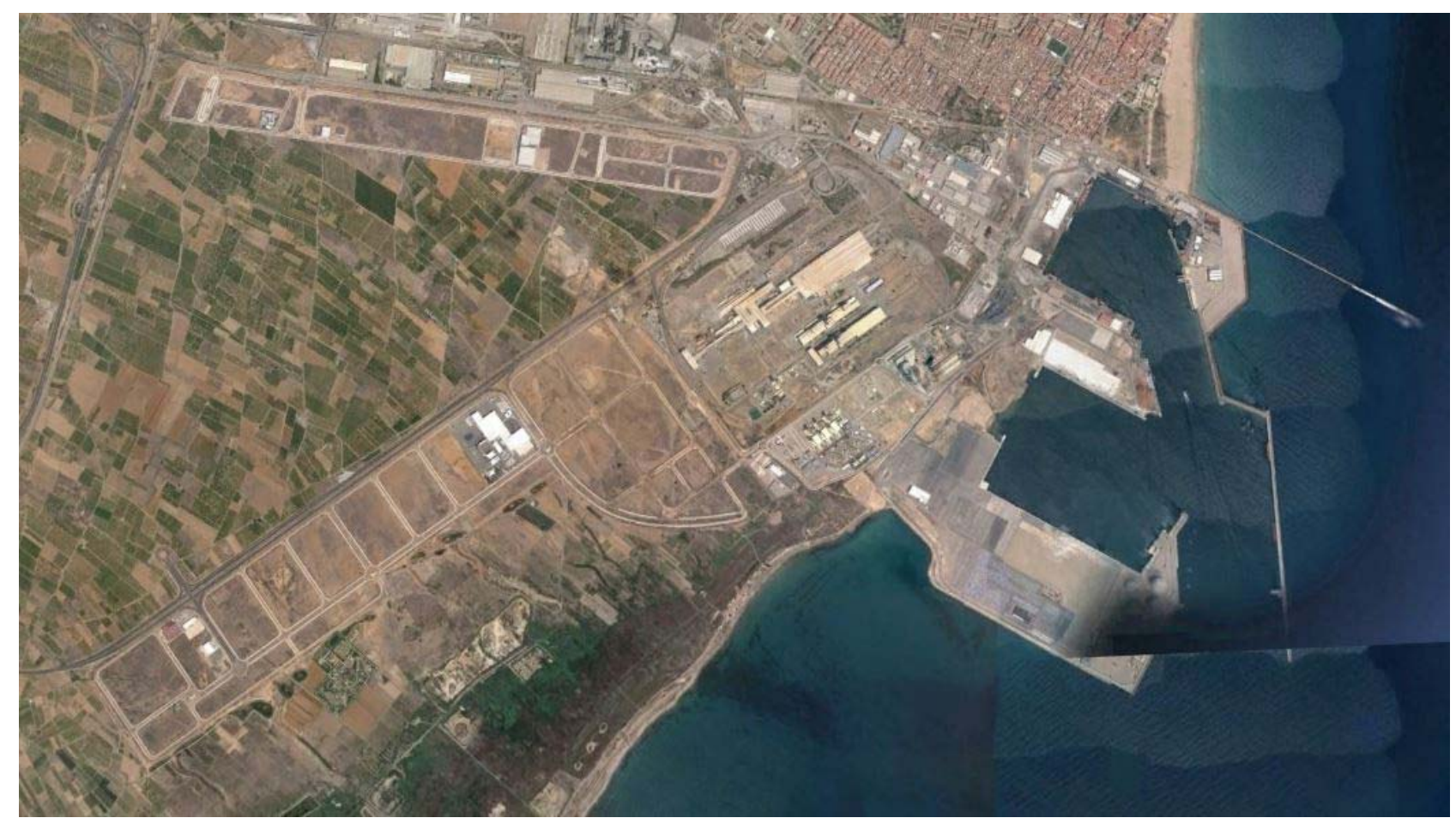

Foto 83: Vista aérea del Polígono "Puerto de Sagunto" Sagunto. Valencia. 2015

Fuente: WEB. http://www.google.es/maps 
Estos aspectos nos ayudaran a poder comprender el aspecto urbanístico de las industrias, sobre todo su comportamiento y el abandono de actividades tradicionales que se ven acorraladas económica, social y urbanísticamente.

3.- El aspecto Urbanístico está ligado íntimamente al político y económico, las empresas asentadas en Valencia no desaparecen o abandonan su emplazamiento por un solo motivo, que indudablemente puede ser, sino por un cúmulo de circunstancias por las que se ven obligadas a salir de la ciudad.

Seguidamente se muestran unos gráficos numéricos totales y de barras por distritos en los que se aprecia la Actividad Industrial en Valencia. Anteriormente los hemos visto distrito a distrito. 
GRAFICOS

INDUSTRIAS

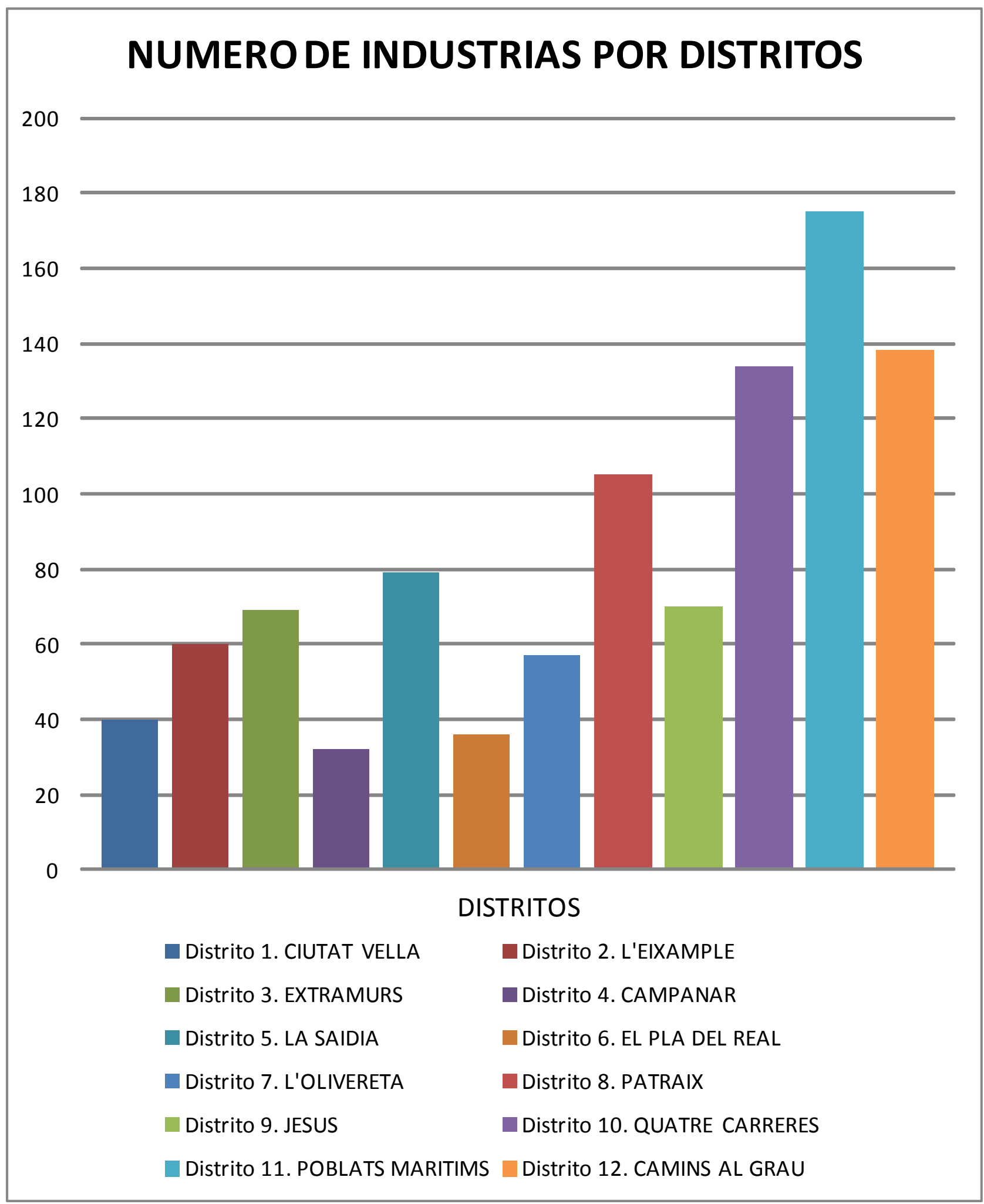




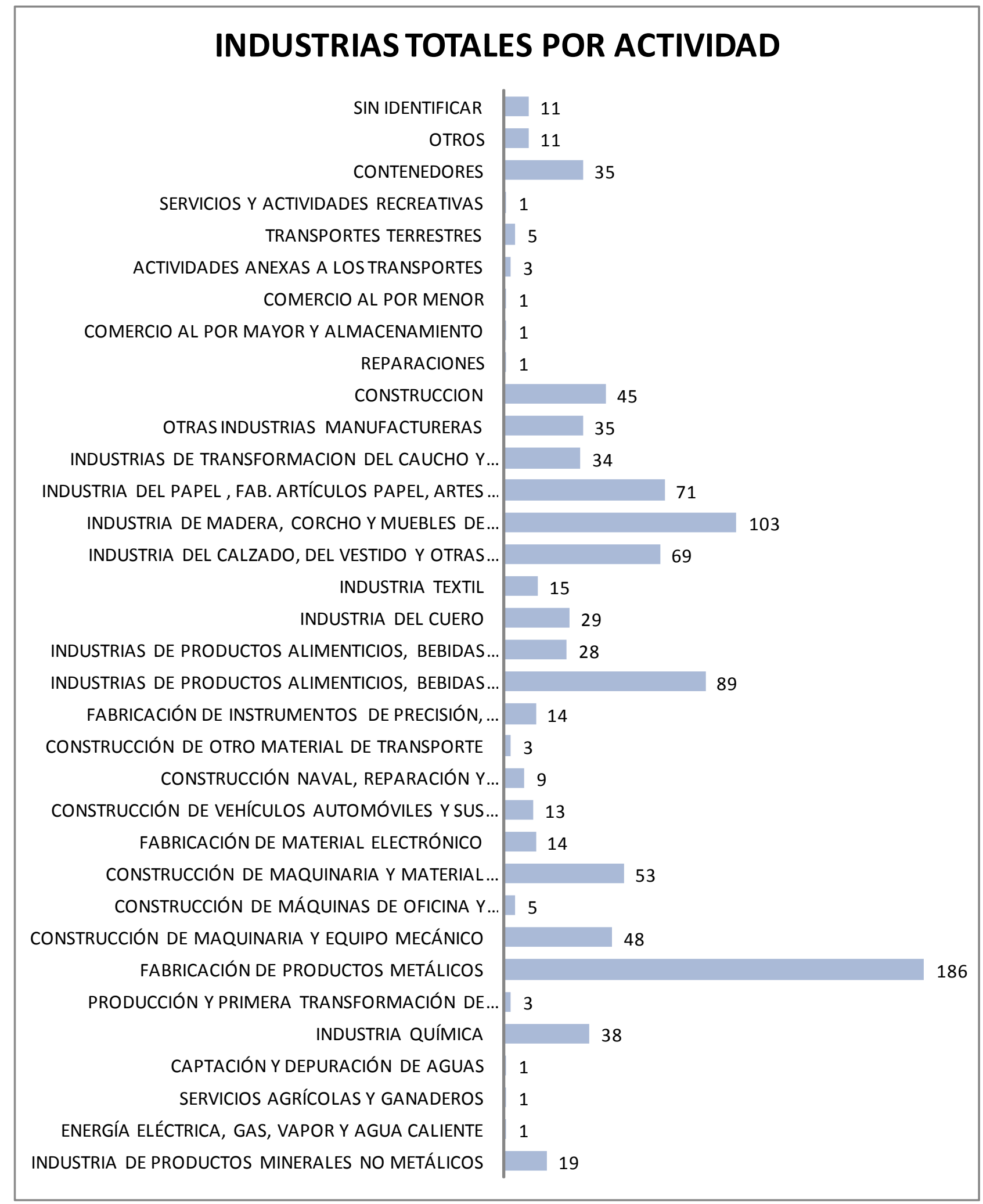




\begin{tabular}{|c|c|c|c|c|c|c|c|c|c|c|c|c|c|}
\hline & \begin{tabular}{|c|} 
Distrito 1 \\
Ciutat Vella \\
\end{tabular} & $\begin{array}{r}\text { Distrito } 2 \\
\text { L'Eixample } \\
\end{array}$ & $\begin{array}{l}\text { Distrito } 3 \\
\text { Extramurs } \\
\end{array}$ & $\begin{array}{c}\begin{array}{c}\text { Distrito } 4 \\
\text { Campanar }\end{array} \\
\end{array}$ & $\begin{array}{l}\text { Distrito } 5 \\
\text { La Saidia } \\
\end{array}$ & \begin{tabular}{|c|} 
Distrito 6 \\
El Pla del Real \\
\end{tabular} & $\begin{array}{c}\text { Distrito } 7 \\
\text { L'Olivereta } \\
\end{array}$ & $\begin{array}{l}\text { Distrito } 8 \\
\text { Patraix }\end{array}$ & $\begin{array}{c}\text { Distrito } 9 \\
\text { Jesús }\end{array}$ & \begin{tabular}{|c|}
$\begin{array}{c}\text { Distrito } 10 \\
\text { uatre Carrer }\end{array}$ \\
\end{tabular} & \begin{tabular}{|c|} 
Distrito 11 \\
blats Mariti \\
\end{tabular} & $\begin{array}{c}\text { Distrito } 12 \\
\text { Camins al Grau }\end{array}$ & \\
\hline & $\begin{array}{l}\text { E } \\
\text { M } \\
\text { P } \\
\text { R } \\
\text { E } \\
\text { S } \\
\text { A } \\
\text { S }\end{array}$ & $\begin{array}{l}\text { E } \\
\text { M } \\
\text { P } \\
\text { R } \\
\text { E } \\
\text { S } \\
\text { A } \\
\text { S }\end{array}$ & $\begin{array}{l}\text { E } \\
\text { M } \\
\text { P } \\
\text { R } \\
\text { E } \\
\text { S } \\
\text { A } \\
\text { S }\end{array}$ & $\begin{array}{l}\text { E } \\
\text { M } \\
\text { P } \\
\text { R } \\
\text { E } \\
\text { S } \\
\text { A } \\
\text { S }\end{array}$ & $\begin{array}{l}\text { E } \\
\text { M } \\
\text { P } \\
\text { R } \\
\text { E } \\
\text { S } \\
\text { A } \\
\text { S }\end{array}$ & $\begin{array}{l}\text { E } \\
\text { M } \\
\text { P } \\
\text { R } \\
\text { E } \\
\text { S } \\
\text { A } \\
\text { S }\end{array}$ & $\begin{array}{l}E \\
M \\
P \\
R \\
E \\
S \\
A \\
S\end{array}$ & $\begin{array}{l}\text { E } \\
\text { M } \\
\text { P } \\
\text { R } \\
\text { E } \\
\text { S } \\
\text { A } \\
\text { S }\end{array}$ & $\begin{array}{l}E \\
\text { M } \\
\text { P } \\
\text { R } \\
\text { E } \\
\text { S } \\
\text { A } \\
\text { S }\end{array}$ & $\begin{array}{l}\text { E } \\
\text { M } \\
\text { P } \\
\text { R } \\
\text { E } \\
\text { S } \\
\text { A } \\
\text { S }\end{array}$ & $\begin{array}{l}\text { E } \\
\text { M } \\
\text { P } \\
\text { R } \\
\text { E } \\
\text { S } \\
\text { A } \\
\text { S }\end{array}$ & \begin{tabular}{|l}
$E$ \\
$M$ \\
$P$ \\
$R$ \\
$E$ \\
$S$ \\
$A$ \\
$S$
\end{tabular} & \\
\hline INDUSTRIA DE PRODUCTOS MINERALES NO METÁLICOS & 1 & & 4 & 1 & 3 & 1 & & 4 & 2 & 2 & 1 & & 19 \\
\hline ENERGÍA ELÉCTRICA, GAS, VAPOR Y AGUA CALIENTE & & & & & & & & & & & & 1 & 1 \\
\hline SERVICIOS AGRÍCOLAS Y GANADEROS & & 1 & & & & & & & & & & & 1 \\
\hline CAPTACIÓN Y DEPURACIÓN DE AGUAS & & & & & & & & 1 & & & & & 1 \\
\hline INDUSTRIA QUÍMICA & 2 & 3 & 4 & & & 4 & 1 & 8 & & 3 & 3 & 10 & 38 \\
\hline PRODUCCIÓN Y PRIMERA TRANSFORMACIÓN DE METALES & & & & & & & & 1 & & 1 & & 1 & 3 \\
\hline FABRICACIÓN DE PRODUCTOS METÁLICOS & 3 & 8 & 14 & 5 & 14 & 5 & 8 & 18 & 12 & 28 & 36 & 35 & 186 \\
\hline CONSTRUCCIÓN DE MAQUINARIA Y EQUIPO MECÁNICO & & 1 & 2 & & 7 & 1 & 1 & 5 & 6 & 14 & 6 & 5 & 48 \\
\hline CONSTRUCCIÓN DE MÁQUINAS DE OFICINA Y ORDENADORES & 1 & 1 & & & & 2 & 1 & & & & & & 5 \\
\hline CONSTRUCCIÓN DE MAQUINARIA Y MATERIAL ELÉCTRICO & 2 & 6 & 6 & & 7 & 3 & 2 & 4 & 4 & 4 & 4 & 11 & 53 \\
\hline FABRICACIÓN DE MATERIAL ELECTRÓNICO & 1 & & & 2 & 1 & & 1 & 2 & 1 & & 2 & 4 & 14 \\
\hline CONSTRUCCIÓN DE VEHÍ́CULOS AUTOMÓVILES Y SUS PIEZAS DE REPUESTO & & & & & & 1 & & 1 & & 2 & 5 & 4 & 13 \\
\hline CONSTRUCCIÓN NAVAL, REPARACIÓN Y MANTENIMIENTO DE BUQUES & & & & & & & & & & & 9 & & 9 \\
\hline CONSTRUCCIÓN DE OTRO MATERIAL DE TRANSPORTE & & & & & 1 & & & & & 1 & & 1 & 3 \\
\hline FABRICACIÓN DE INSTRUMENTOS DE PRECISIÓN, ÓPTICA Y SIMILARES & 4 & 2 & 2 & 1 & & & 2 & & & 2 & & 1 & 14 \\
\hline INDUSTRIAS DE PRODUCTOS ALIMENTICIOS, BEBIDAS Y TABACOS & 3 & 12 & 3 & 5 & 8 & 4 & 10 & 4 & 3 & 12 & 16 & 9 & 89 \\
\hline INDUSTRIAS DE PRODUCTOS ALIMENTICIOS, BEBIDAS Y TABACOS & 1 & 1 & & & 2 & 1 & 1 & 5 & 2 & 1 & 6 & 8 & 28 \\
\hline INDUSTRIA DEL CUERO & & 2 & 2 & 6 & 5 & 1 & 1 & 2 & 2 & 5 & & 3 & 29 \\
\hline INDUSTRIA TEXTIL & 1 & & & & 3 & & 1 & 1 & 3 & & 4 & 2 & 15 \\
\hline INDUSTRIA DEL CALZADO, DEL VESTIDO Y OTRAS CONFECCIONES TEXTILES & 7 & 3 & 6 & 2 & 3 & 3 & 11 & 11 & 8 & 2 & 6 & 7 & 69 \\
\hline INDUSTRIA DE MADERA, CORCHO Y MUEBLES DE MADERA & 2 & 2 & 5 & 5 & 9 & 4 & 1 & 14 & 13 & 18 & 19 & 11 & 103 \\
\hline INDUSTRIA DEL PAPEL, FAB. ARTÍCULOS PAPELL, ARTES GRAFICAS Y EDICION & 6 & 12 & 13 & & 1 & & 7 & 8 & 5 & 9 & 4 & 6 & 71 \\
\hline INDUSTRIAS DE TRANSFORMACION DEL CAUCHO Y MATERIAS PLÁSTICAS & & 1 & 1 & 1 & 1 & & 2 & 4 & 1 & 13 & 4 & 6 & 34 \\
\hline OTRAS INDUSTRIAS MANUFACTURERAS & 3 & 1 & 5 & 3 & 1 & & 4 & 4 & 4 & 2 & 3 & 5 & 35 \\
\hline CONSTRUCCION & 3 & 3 & 2 & 1 & 6 & 1 & 3 & 6 & 4 & 5 & 4 & 7 & 45 \\
\hline REPARACIONES & & & & & & 1 & & & & & & & 1 \\
\hline COMERCIO AL POR MAYOR Y ALMACENAMIENTO & & 1 & & & & & & & & & & & 1 \\
\hline COMERCIO AL POR MENOR & & & & & & & & 1 & & & & & 1 \\
\hline \begin{tabular}{|l|} 
ACTIVIDADES ANEXAS A LOS TRANSPORTES \\
\end{tabular} & & & & & & & & & & 2 & 1 & & 3 \\
\hline TRANSPORTES TERRESTRES & & & & & & & & 1 & & & 3 & 1 & 5 \\
\hline SERVICIOS Y ACTIVIDADES RECREATIVAS & & & & & & & & & & & 1 & & 1 \\
\hline CONTENEDORES & & & & & & & & & & 1 & 34 & & 35 \\
\hline OTROS & & & & & 7 & 4 & & & & & & & 11 \\
\hline SIN IDENTIFICAR & & & & & & & & & & 7 & 4 & & 11 \\
\hline & 40 & 60 & 69 & 32 & 79 & 36 & 57 & 105 & 70 & 134 & 175 & 138 & 995 \\
\hline
\end{tabular}




\section{EMPLEADOS}

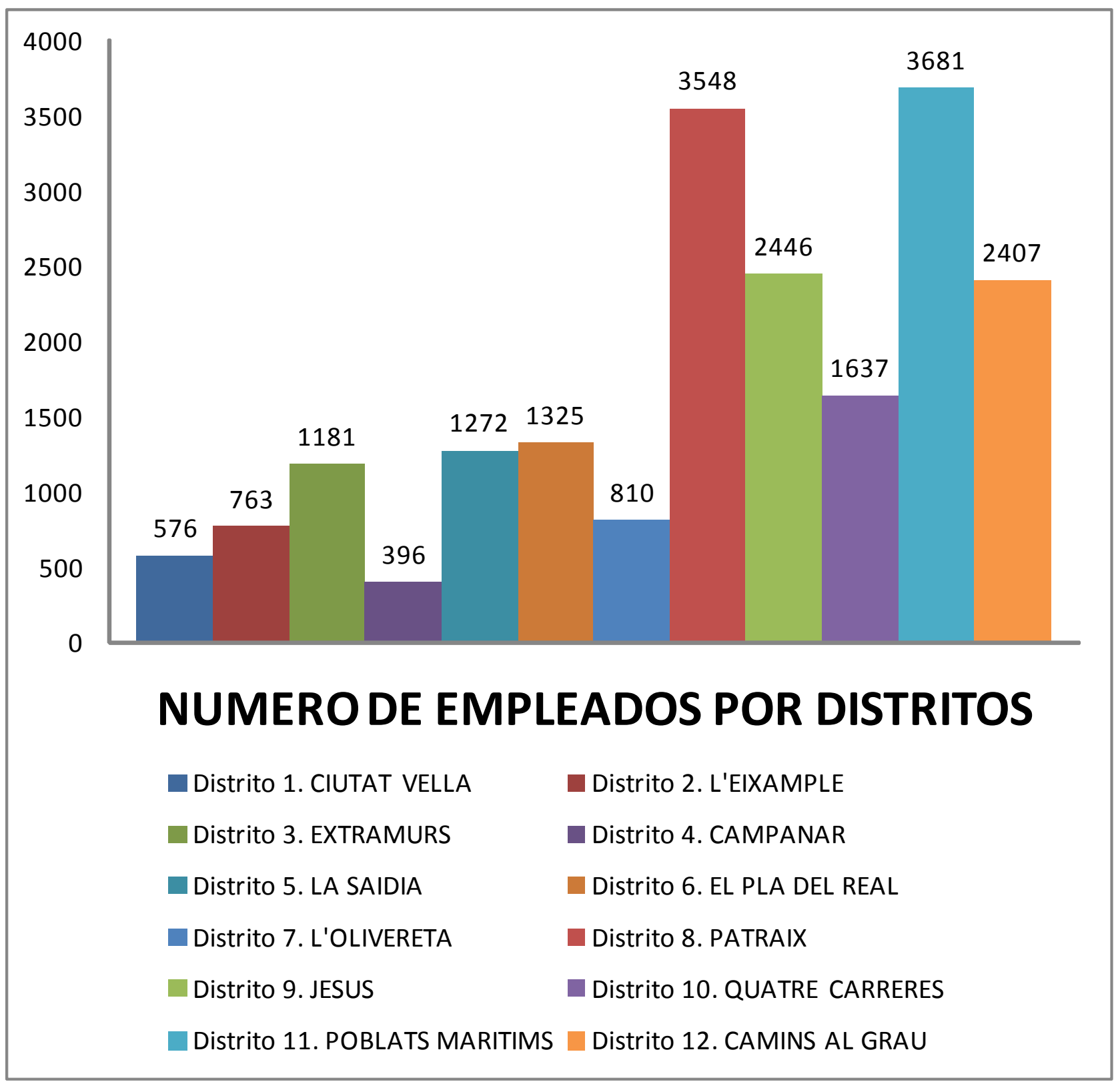




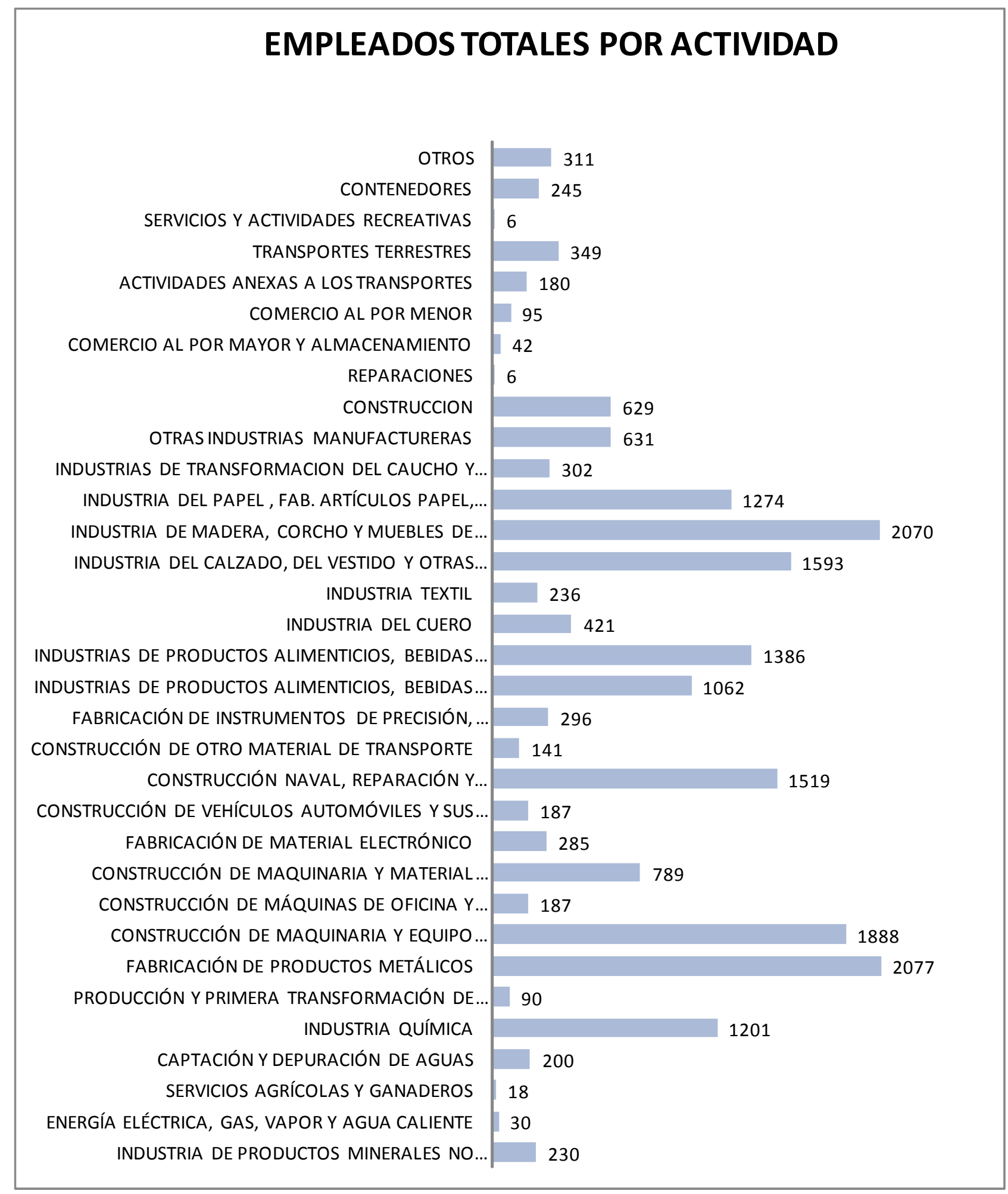




\begin{tabular}{|c|c|c|c|c|c|c|c|c|c|c|c|c|c|}
\hline & \begin{tabular}{|c|} 
Distrito 1 \\
Ciutat Vella
\end{tabular} & \begin{tabular}{|c|} 
Distrito 2 \\
L'Eixample
\end{tabular} & $\begin{array}{c}\text { Distrito } 3 \\
\text { Extramurs }\end{array}$ & \begin{tabular}{|c|} 
Distrito 4 \\
Campanar
\end{tabular} & $\begin{array}{l}\text { Distrito } 5 \\
\text { La Saidia }\end{array}$ & \begin{tabular}{|c|} 
Distrito 6 \\
Pla del Real
\end{tabular} & $\begin{array}{c}\text { Distrito } 7 \\
\text { L'Olivereta }\end{array}$ & $\begin{array}{l}\text { Distrito } 8 \\
\text { Parraix }\end{array}$ & $\begin{array}{l}\text { Distrito } 9 \\
\text { Jesús }\end{array}$ & \begin{tabular}{|c|}
$\begin{array}{c}\text { Distrito } 10 \\
\text { uatre Carrer }\end{array}$ \\
\end{tabular} & \begin{tabular}{|c|} 
Distrito 11 \\
blats Maritin
\end{tabular} & \begin{tabular}{|c|}
$\begin{array}{c}\text { Distrito } 12 \\
\text { Camins Grau }\end{array}$ \\
\end{tabular} & \\
\hline & $\begin{array}{l}E \\
M \\
P \\
L \\
E \\
A \\
A \\
D \\
O \\
S\end{array}$ & $\begin{array}{l}E \\
M \\
P \\
L \\
E \\
A \\
A \\
D \\
O \\
S\end{array}$ & $\begin{array}{l}E \\
M \\
P \\
\text { L } \\
\text { E } \\
A \\
D \\
O \\
\text { S } \\
\end{array}$ & $\begin{array}{l}\text { E } \\
M \\
P \\
\text { L } \\
\text { E } \\
A \\
D \\
O \\
\text { S } \\
\end{array}$ & $\begin{array}{l}E \\
M \\
P \\
L \\
E \\
A \\
A \\
D \\
D \\
S\end{array}$ & $\begin{array}{l}E \\
M \\
P \\
\text { L } \\
\text { E } \\
A \\
D \\
D \\
\text { O } \\
\end{array}$ & $\begin{array}{l}E \\
M \\
P \\
L \\
E \\
A \\
D \\
D \\
D \\
S\end{array}$ & $\begin{array}{l}E \\
M \\
P \\
L \\
E \\
A \\
D \\
O \\
S\end{array}$ & $\begin{array}{l}E \\
M \\
P \\
L \\
E \\
A \\
D \\
D \\
S\end{array}$ & $\begin{array}{l}E \\
M \\
P \\
\text { L } \\
\text { E } \\
A \\
D \\
D \\
\text { O } \\
\text { S }\end{array}$ & $\begin{array}{l}E \\
M \\
P \\
\text { L } \\
\text { E } \\
A \\
D \\
O \\
\text { O } \\
\text { S }\end{array}$ & $\begin{array}{l}E \\
M \\
P \\
\text { L } \\
\text { E } \\
A \\
D \\
O \\
\text { S } \\
\end{array}$ & \\
\hline INDUSTRIA DE PRODUCTOS MINERALES NO METÁLICOS & 8 & & 79 & 23 & 19 & 2 & & 25 & 38 & 32 & 4 & & 230 \\
\hline ENERGÍA ELÉCTRICA, GAS, VAPOR Y AGUA CALIENTE & & & & & & & & & & & & 30 & 30 \\
\hline SERVICIOS AGRÍCOLAS Y GANADEROS & & 18 & & & & & & & & & & & 18 \\
\hline CAPTACIÓN Y DEPURACIÓN DE AGUAS & & & & & & & & 200 & & & & & 200 \\
\hline INDUSTRIA QUÍMICA & 16 & 74 & 42 & & & 101 & 8 & 462 & & 62 & 66 & 370 & 1201 \\
\hline PRODUCCIÓN Y PRIMERA TRANSFORMACIÓN DE METALES & & & & & & & & 60 & & 6 & & 24 & 90 \\
\hline FABRICACIÓN DE PRODUCTOS METÁLICOS & 60 & 51 & 184 & 65 & 99 & 19 & 50 & 432 & 90 & 254 & 289 & 484 & 2077 \\
\hline CONSTRUCCIÓN DE MAQUINARIA Y EQUIPO MECÁNICO & & 4 & 18 & & 229 & 6 & 1 & 84 & 1114 & 239 & 133 & 60 & 1888 \\
\hline CONSTRUCCIÓN DE MÁQUINAS DE OFICINA Y ORDENADORES & 6 & 32 & & & & 109 & 40 & & & & & & 187 \\
\hline CONSTRUCCIÓN DE MAQUINARIA Y MATERIAL ELÉCTRICO & 17 & 67 & 59 & & 157 & 78 & 65 & 49 & 56 & 28 & 47 & 166 & 789 \\
\hline FABRICACIÓN DE MATERIAL ELECTRÓNICO & 42 & & & 24 & 12 & & 6 & 74 & 53 & & 9 & 65 & 285 \\
\hline CONSTRUCCIÓN DE VEHÍCULOS AUTOMÓVILES Y SUS PIEZAS DE REPUESTO & & & & & & 9 & & 70 & & 20 & 65 & 23 & 187 \\
\hline CONSTRUCCIÓN NAVAL, REPARACIÓN Y MANTENIMIENTO DE BUQUES & & & & & & & & & & & 1519 & & 1519 \\
\hline CONSTRUCCIÓN DE OTRO MATERIAL DE TRANSPORTE & & & & & 123 & & & & & 8 & & 10 & 141 \\
\hline FABRICACIÓN DE INSTRUMENTOS DE PRECISIÓN, ÓPTICA Y SIMILARES & 60 & 33 & 60 & 19 & & & 45 & & & 25 & & 54 & 296 \\
\hline INDUSTRIAS DE PRODUCTOS ALIMENTICIOS, BEBIDAS Y TABACOS & 21 & 105 & 42 & 22 & 101 & 28 & 54 & 347 & 58 & 63 & 183 & 38 & 1062 \\
\hline INDUSTRIAS DE PRODUCTOS ALIMENTICIOS, BEBIDAS Y TABACOS & 3 & 6 & & & 5 & 555 & 12 & 110 & 318 & 4 & 112 & 261 & 1386 \\
\hline INDUSTRIA DEL CUERO & & 21 & 42 & 104 & 72 & 5 & 6 & 16 & 26 & 67 & & 62 & 421 \\
\hline INDUSTRIA TEXTIL & 12 & & & & 40 & & 34 & 7 & 81 & & 40 & 22 & 236 \\
\hline INDUSTRIA DEL CALZADO, DEL VESTIDO Y OTRAS CONFECCIONES TEXTILES & 149 & 44 & 102 & 35 & 38 & 42 & 153 & 185 & 182 & 51 & 147 & 465 & 1593 \\
\hline INDUSTRIA DE MADERA, CORCHO Y MUEBLES DE MADERA & 30 & 28 & 160 & 25 & 87 & 123 & 23 & 720 & 175 & 454 & 178 & 67 & 2070 \\
\hline INDUSTRIA DEL PAPEL, FAB. ARTÍCULOS PAPEL, ARTES GRAFICAS Y EDICION & 73 & 135 & 177 & & 90 & & 179 & 252 & 115 & 105 & 116 & 32 & 1274 \\
\hline INDUSTRIAS DE TRANSFORMACION DEL CAUCHO Y MATERIAS PLÁSTICAS & & 10 & 10 & 3 & 8 & & 39 & 68 & 13 & 95 & 9 & 47 & 302 \\
\hline OTRAS INDUSTRIAS MANUFACTURERAS & 41 & 58 & 182 & 68 & 16 & & 46 & 103 & 45 & 24 & 11 & 37 & 631 \\
\hline CONSTRUCCION & 38 & 35 & 24 & 8 & 101 & 6 & 49 & 149 & 82 & 48 & 16 & 73 & 629 \\
\hline REPARACIONES & & & & & & 6 & & & & & & & 6 \\
\hline COMERCIO AL POR MAYOR Y ALMACENAMIENTO & & 42 & & & & & & & & & & & 42 \\
\hline COMERCIO AL POR MENOR & & & & & & & & 95 & & & & & 95 \\
\hline ACTIVIDADES ANEXAS A LOS TRANSPORTES & & & & & & & & & & & 180 & & 180 \\
\hline TRANSPORTES TERRESTRES & & & & & & & & 40 & & & 292 & 17 & 349 \\
\hline SERVICIOS Y ACTIVIDADES RECREATIVAS & & & & & & & & & & & 6 & & 6 \\
\hline CONTENEDORES & & & & & & & & & & & 245 & & 245 \\
\hline OTROS & & & & & 75 & 236 & & & & & & & 311 \\
\hline \multirow[t]{2}{*}{ SIN IDENTIFICAR } & & & & & & & & & & 52 & 14 & & 66 \\
\hline & 576 & 763 & 1181 & 396 & 1272 & 1325 & 810 & 3548 & 2446 & 1637 & 3681 & 2407 & 20042 \\
\hline
\end{tabular}




\section{SUPERFICIE}

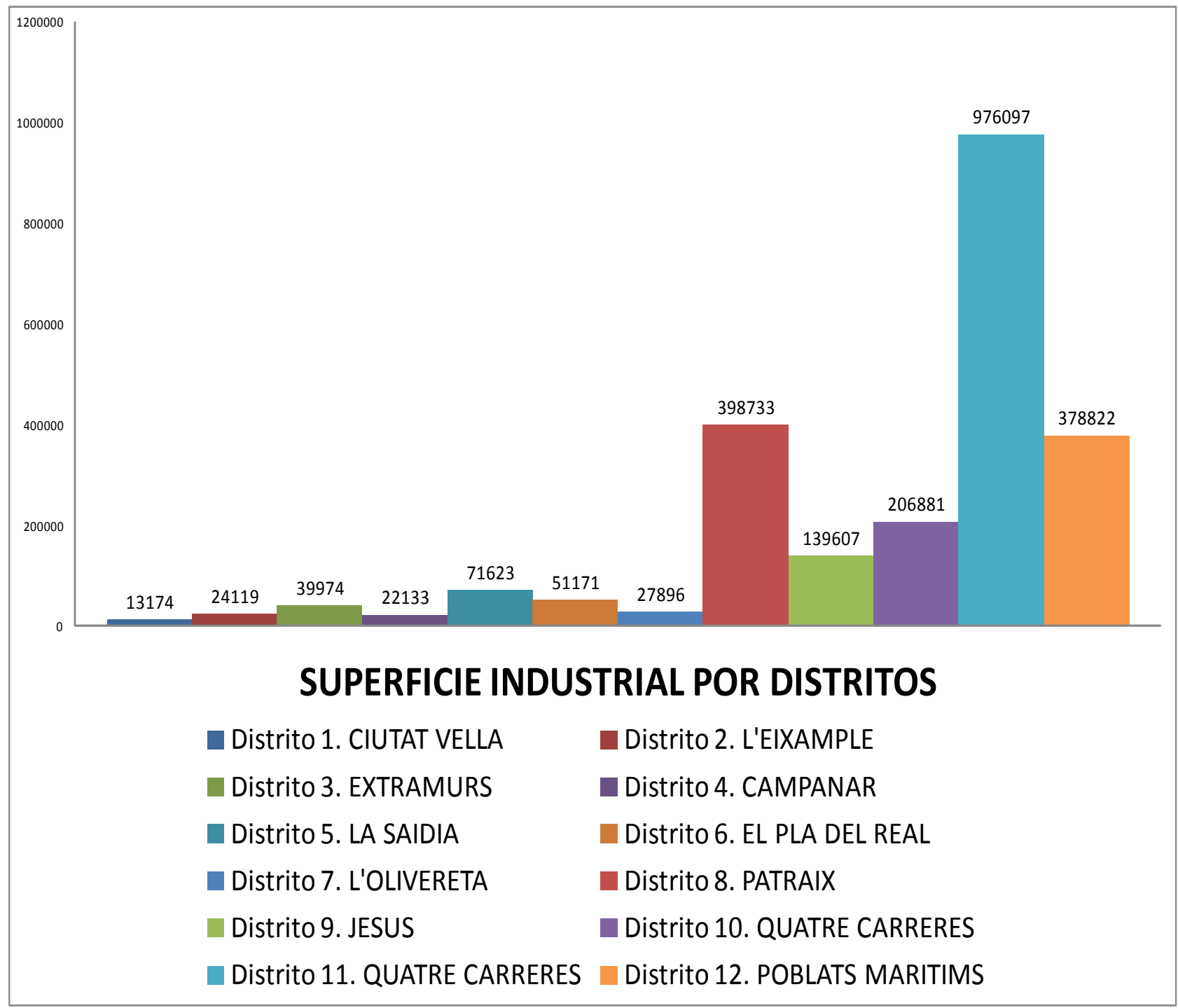




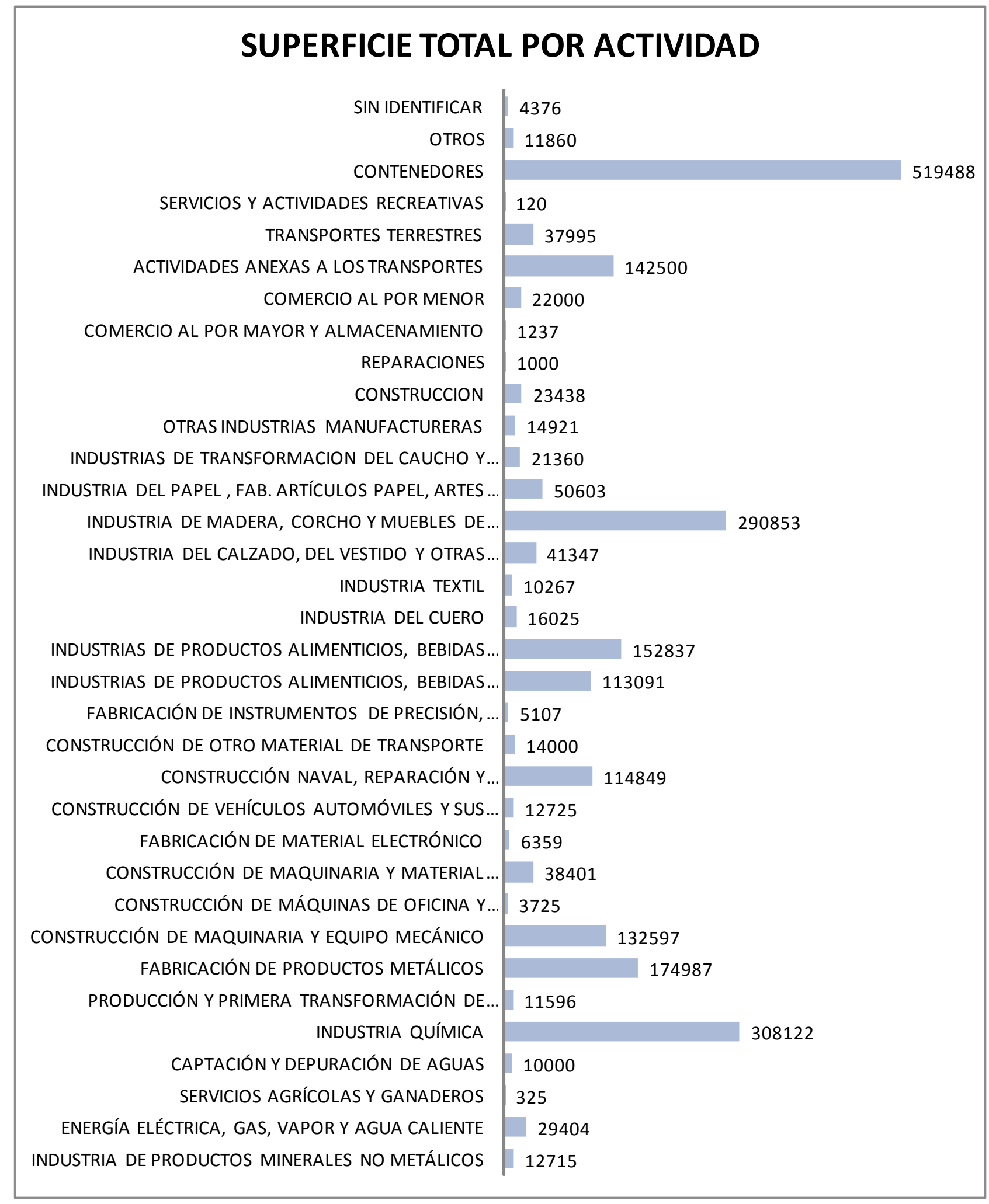




\begin{tabular}{|c|c|c|c|c|c|c|c|c|c|c|c|c|c|}
\hline & \begin{tabular}{|c|} 
Distrito 1 \\
Ciutat Vella \\
\end{tabular} & \begin{tabular}{|c|} 
Distrito 2 \\
L'Eixample \\
\end{tabular} & $\begin{array}{c}\text { Distrito } 3 \\
\text { Extramurs } \\
\end{array}$ & \begin{tabular}{|c|} 
Distrito 4 \\
Campanar \\
\end{tabular} & $\begin{array}{l}\text { Distrito } 5 \\
\text { La Saidia } \\
\end{array}$ & \begin{tabular}{|c|} 
Distrito 6 \\
Pla del Real \\
\end{tabular} & \begin{tabular}{|c|} 
Distrito 7 \\
L'Olivereta \\
\end{tabular} & $\begin{array}{l}\text { Distrito } 8 \\
\text { Patraix }\end{array}$ & $\begin{array}{c}\text { Distrito } 9 \\
\text { Jesús }\end{array}$ & \begin{tabular}{|l|} 
Distrito 10 \\
Q.Carreres \\
\end{tabular} & \begin{tabular}{|l|} 
Distrito 11 \\
P.Maritims \\
\end{tabular} & \begin{tabular}{|c|}
$\begin{array}{c}\text { Distrito } 12 \\
\text { Camins Grau }\end{array}$ \\
\end{tabular} & \\
\hline & $\begin{array}{l}\mathrm{S} \\
\mathrm{U} \\
\mathrm{P} \\
\mathrm{E} \\
\mathrm{R} \\
\mathrm{F} \\
\mathrm{I} \\
\mathrm{C} \\
\mathrm{I} \\
\mathrm{E}\end{array}$ & $\begin{array}{c}\mathrm{S} \\
\mathrm{U} \\
\mathrm{P} \\
\mathrm{E} \\
\mathrm{R} \\
\mathrm{F} \\
\mathrm{I} \\
\mathrm{C} \\
\mathrm{I} \\
\mathrm{E}\end{array}$ & $\begin{array}{l}\mathrm{S} \\
\mathrm{U} \\
\mathrm{P} \\
\mathrm{E} \\
\mathrm{R} \\
\mathrm{F} \\
\mathrm{I} \\
\mathrm{C} \\
\mathrm{I} \\
\mathrm{E}\end{array}$ & $\begin{array}{l}\mathrm{S} \\
\mathrm{U} \\
\mathrm{P} \\
\mathrm{E} \\
\mathrm{R} \\
\mathrm{F} \\
\mathrm{I} \\
\mathrm{C} \\
\mathrm{I} \\
\mathrm{E}\end{array}$ & $\begin{array}{l}S \\
U \\
P \\
E \\
R \\
F \\
I \\
C \\
I \\
E\end{array}$ & $\begin{array}{l}S \\
U \\
P \\
E \\
R \\
F \\
\text { I } \\
C \\
\text { I } \\
\text { E }\end{array}$ & $\begin{array}{l}S \\
U \\
P \\
E \\
R \\
F \\
I \\
C \\
I \\
E\end{array}$ & $\begin{array}{l}S \\
U \\
P \\
E \\
R \\
F \\
\text { I } \\
C \\
\text { I } \\
E\end{array}$ & $\begin{array}{l}S \\
U \\
P \\
E \\
R \\
F \\
I \\
C \\
I \\
E\end{array}$ & $\begin{array}{l}S \\
U \\
P \\
E \\
R \\
F \\
I \\
C \\
1 \\
E\end{array}$ & $\begin{array}{l}S \\
U \\
P \\
E \\
R \\
F \\
I \\
C \\
I \\
E\end{array}$ & $\begin{array}{l}S \\
U \\
\text { P } \\
E \\
R \\
F \\
\text { I } \\
C \\
\text { I } \\
\text { E }\end{array}$ & \\
\hline INDUSTRIA DE PRODUCTOS MINERALES NO METÁLICOS & 80 & & 2620 & 1295 & 620 & 1200 & & 2520 & 2650 & 1030 & 700 & & 12715 \\
\hline ENERGÍA ELÉCTRICA, GAS, VAPOR Y AGUA CALIENTE & & & & & & & & & & & & 29404 & 29404 \\
\hline SERVICIOS AGRÍCOLAS Y GANADEROS & & 325 & & & & & & & & & & & 325 \\
\hline CAPTACIÓN Y DEPURACIÓN DE AGUAS & & & & & & & & 10000 & & & & & 10000 \\
\hline INDUSTRIA QUÍMICA & 280 & 3325 & 4070 & & & 546 & 474 & 53999 & & 14500 & 8550 & 222378 & 308122 \\
\hline PRODUCCIÓN Y PRIMERA TRANSFORMACIÓN DE METALES & & & & & & & & 8000 & & 2496 & & 1100 & 11596 \\
\hline FABRICACIÓN DE PRODUCTOS METÁLICOS & 1960 & 2770 & 5294 & 5100 & 6032 & 1510 & 2055 & 89480 & 3433 & 21710 & 12613 & 23030 & 174987 \\
\hline CONSTRUCCIÓN DE MAQUINARIA Y EQUIPO MECÁNICO & & 400 & 859 & & 11895 & 70 & 200 & 6845 & 67900 & 14673 & 25285 & 4470 & 132597 \\
\hline CONSTRUCCIÓN DE MÁQUINAS DE OFICINA Y ORDENADORES & 208 & 250 & & & & 2240 & 1027 & & & & & & 3725 \\
\hline CONSTRUCCIÓN DE MAQUINARIA Y MATERIAL ELÉCTRICO & 800 & 1326 & 2690 & & 2280 & 430 & 686 & 17410 & 2310 & 1197 & 2013 & 7259 & 38401 \\
\hline FABRICACIÓN DE MATERIAL ELECTRÓNICO & 545 & & & 530 & 200 & & 150 & 1160 & 240 & & 324 & 3210 & 6359 \\
\hline CONSTRUCCIÓN DE VEHÍCULOS AUTOMÓVILES Y SUS PIEZAS DE REPUESTO & & & & & & 300 & & 3200 & & 2650 & 4120 & 2455 & 12725 \\
\hline CONSTRUCCIÓN NAVAL, REPARACIÓN Y MANTENIMIENTO DE BUQUES & & & & & & & & & & & 114849 & & 114849 \\
\hline CONSTRUCCIÓN DE OTRO MATERIAL DE TRANSPORTE & & & & & 12200 & & & & & 600 & & 1200 & 14000 \\
\hline FABRICACIÓN DE INSTRUMENTOS DE PRECISIÓN, ÓPTICA Y SIMILARES & 398 & 600 & 790 & 1500 & & & 491 & & & 328 & & 1000 & 5107 \\
\hline INDUSTRIAS DE PRODUCTOS ALIMENTICIOS, BEBIDAS Y TABACOS & 480 & 2891 & 770 & 1067 & 4642 & 545 & 6590 & 30901 & 6550 & 4250 & 53007 & 1398 & 113091 \\
\hline INDUSTRIAS DE PRODUCTOS ALIMENTICIOS, BEBIDAS Y TABACOS & 425 & 349 & & & 1150 & 23520 & 839 & 24100 & 33600 & 160 & 9416 & 59278 & 152837 \\
\hline INDUSTRIA DEL CUERO & & 560 & 435 & 6176 & 4252 & 200 & 240 & 724 & 568 & 1530 & & 1340 & 16025 \\
\hline INDUSTRIA TEXTIL & 300 & & & & 1250 & & 860 & 3950 & 1374 & & 733 & 1800 & 10267 \\
\hline INDUSTRIA DEL CALZADO, DEL VESTIDO Y OTRAS CONFECCIONES TEXTILES & 3708 & 950 & 2568 & 1445 & 730 & 1140 & 6448 & 11143 & 3147 & 1800 & 1619 & 6649 & 41347 \\
\hline INDUSTRIA DE MADERA, CORCHO Y MUEBLES DE MADERA & 1060 & 2190 & 6414 & 3570 & 13192 & 12300 & 800 & 79831 & 13630 & 50853 & 102085 & 4928 & 290853 \\
\hline INDUSTRIA DEL PAPEL, FAB. ARTÍCULOS PAPEL, ARTES GRAFICAS Y EDICION & 1830 & 4616 & 10087 & & 1400 & & 2251 & 7810 & 1280 & 3285 & 16851 & 1193 & 50603 \\
\hline INDUSTRIAS DE TRANSFORMACION DEL CAUCHO Y MATERIAS PLÁSTICAS & & 230 & 180 & 70 & 120 & & 1200 & 8190 & 530 & 8256 & 984 & 1600 & 21360 \\
\hline OTRAS INDUSTRIAS MANUFACTURERAS & 780 & 550 & 2910 & 1180 & 200 & & 1865 & 3124 & 1010 & 1720 & 542 & 1040 & 14921 \\
\hline CONSTRUCCION & 320 & 1550 & 287 & 200 & 4770 & 1000 & 1720 & 5746 & 1385 & 840 & 3630 & 1990 & 23438 \\
\hline REPARACIONES & & & & & & 1000 & & & & & & & 1000 \\
\hline COMERCIO AL POR MAYOR Y ALMACENAMIENTO & & 1237 & & & & & & & & & & & 1237 \\
\hline COMERCIO AL POR MENOR & & & & & & & & 22000 & & & & & 22000 \\
\hline ACTIVIDADES ANEXAS A LOS TRANSPORTES & & & & & & & & & & 44000 & 98500 & & 142500 \\
\hline TRANSPORTES TERRESTRES & & & & & & & & 8600 & & & 27295 & 2100 & 37995 \\
\hline SERVICIOS Y ACTIVIDADES RECREATIVAS & & & & & & & & & & & 120 & & 120 \\
\hline CONTENEDORES & & & & & & & & & & 28000 & 491488 & & 519488 \\
\hline OTROS & & & & & 6690 & 5170 & & & & & & & 11860 \\
\hline \multirow[t]{2}{*}{ SIN IDENTIFICAR } & & & & & & & & & & 3003 & 1373 & & 4376 \\
\hline & 13174 & 24119 & 39974 & 22133 & 71623 & 51171 & 27896 & 398733 & 139607 & 206881 & 976097 & 378822 & 2350230 \\
\hline
\end{tabular}

ESTUDIO DE LA ACTIVIDAD INDUSTRIAL Y SU IMPACTO EN EL MEDIO URBANO EN LA CIUDAD DE VALENCIA DESDE 1985

$$
\text { Amadeo Pascual Galán }
$$


Del análisis de los gráficos podemos sacar unas conclusiones claras en lo que respecta a superficies, empleo y número de industrias

\section{SUPERFICIE}

Podemos ver como:

- Los Contenedores, consumen con mucha diferencia, la mayor parte de la superficie industrial $519.488 \mathrm{~m} 2$.

Esta actividad tiene un bajo número de empleados 245 y muy pocas empresas (35) lo que supone 7 empleados por empresa. En realidad es una empresa de logística que genera un tráfico muy grande de camiones, es molesta y generalmente no tienen alcantarillado. Es lo contrario de lo que necesita una ciudad, por lo tanto se ha pensado en ello y lógicamente han tenido que salir de la ciudad la mayor parte de ellos.

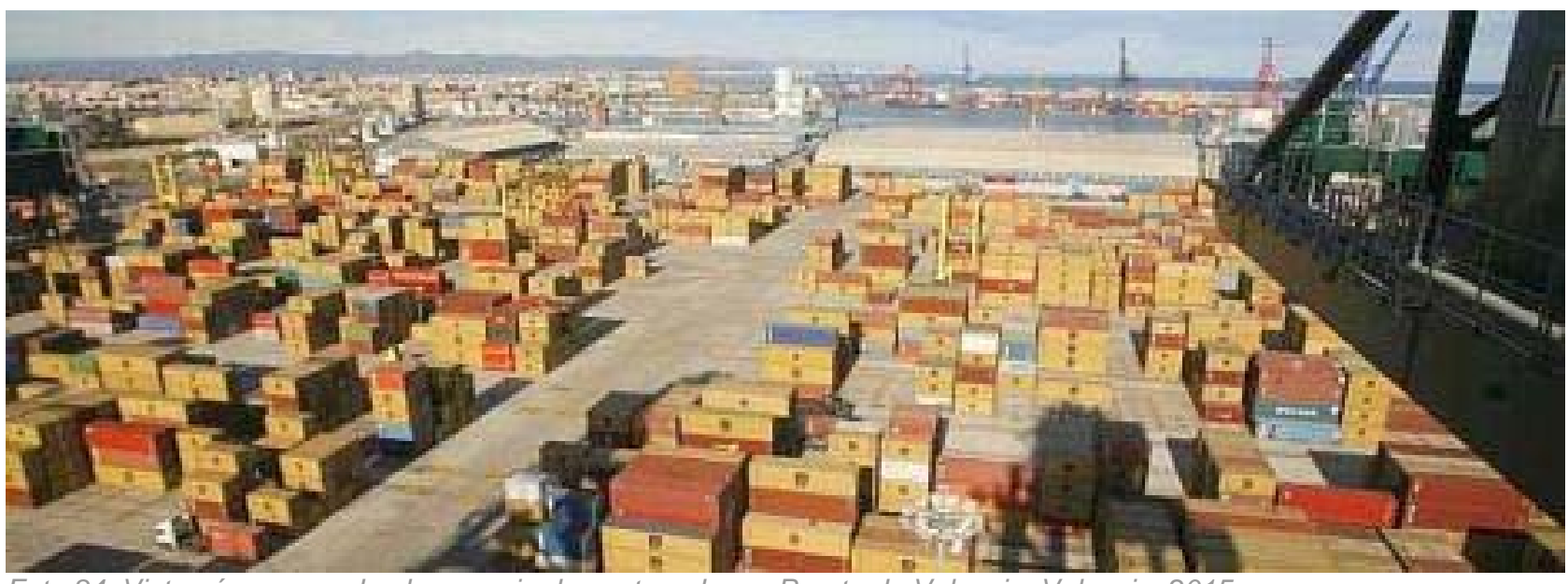

Foto 84: Vista aérea zona de almacenaje de contenedores. Puerto de Valencia. Valencia. 2015

Fuente: WEB. http://Www.google.es/maps

- La industria Química, consume $308.122 \mathrm{~m} 2$ emplea 1.201 personas y tiene 38 empresas. Son altamente contaminantes y la gestión de residuos se ha hecho de forma desordenada, tal es el caso de la Cross. Se le conocen vertidos de tierra contaminada en Valterna extendido en tongadas. Tales industrias han salido progresivamente de la ciudad. 


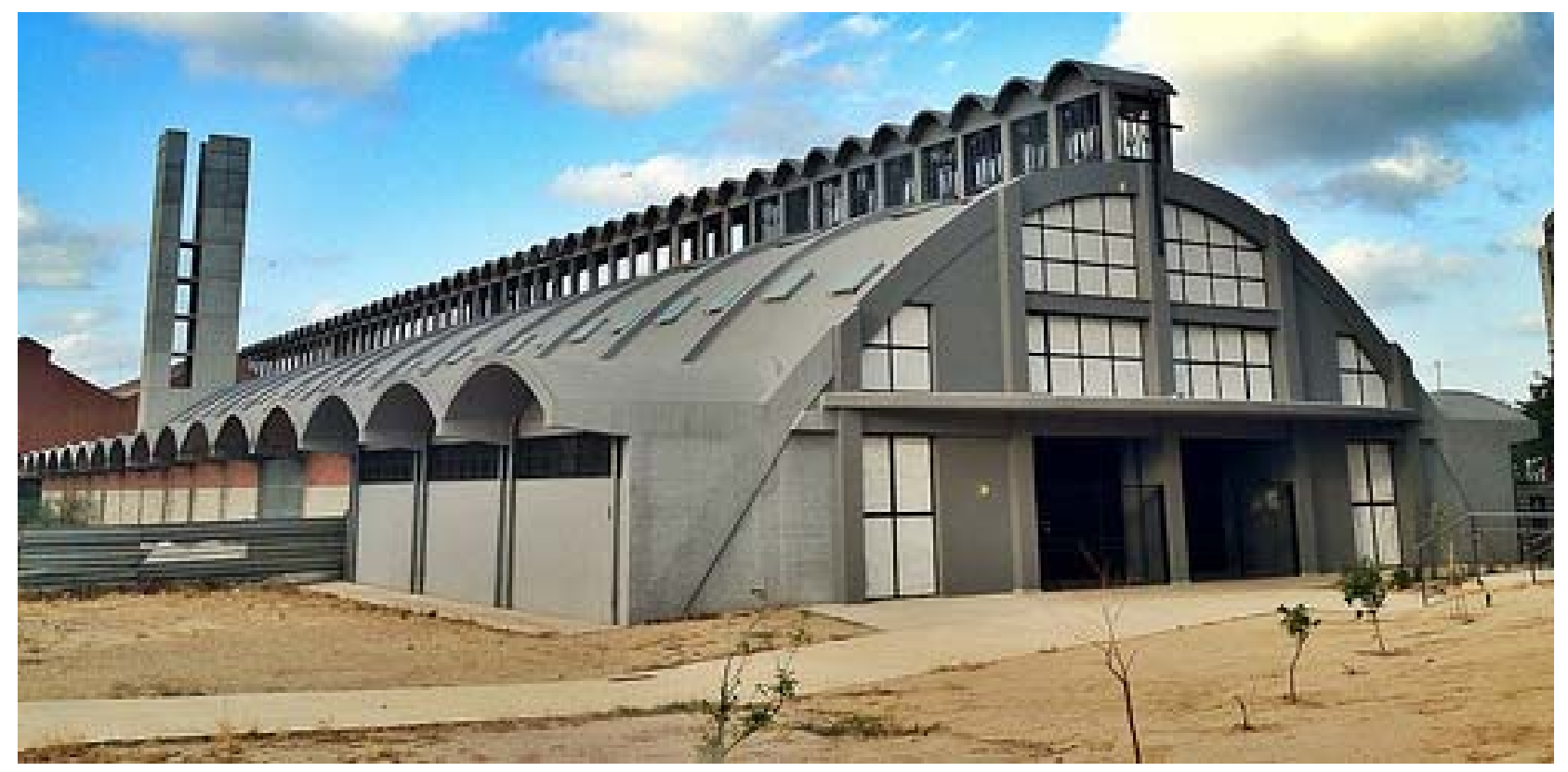

Foto 85: Nave Cros. Avda. de Francia.Valencia.2014.

Fuente: WEB. http://www.google.es/maps (Street View).

- La industria del Metal, si agrupamos maquinaria, equipos y productos metálicos, consumen $307.574 \mathrm{~m} 2$ con 3.965 empleados y tiene 234 empresas. Es una industria dispersa y fundamentalmente emplazada en los distritos marítimos. Son ruidosas y contaminación media a baja.

- La industria de la madera consume $290.853 \mathrm{~m} 2$, emplea 2.070 personas y tiene 103 empresas. Es una industria dispersa por la ciudad, podemos encontrar fábricas de muebles y almacenes en cualquier distrito. Son poco contaminantes en general excepto las fábricas de tableros por las chimeneas, pero son ruidosas.

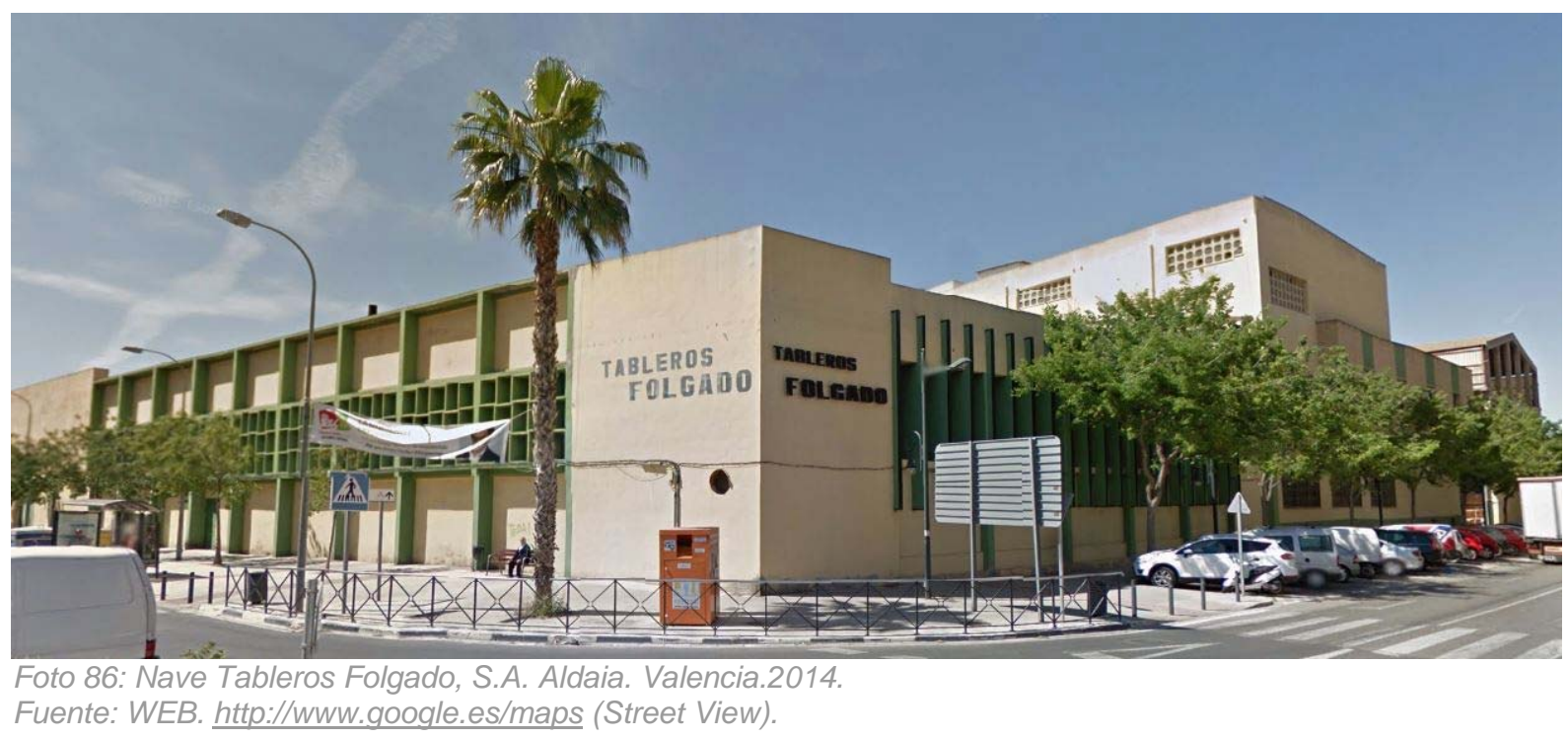


- La industria alimentaria, consume $265.928 \mathrm{~m} 2$., emplea 2.448 personas y tiene 117 empresas. Es una industria dispersa poco ruidosa pero contrariamente a lo que parece contaminante por los productos que emplea, entre ellos la sal y un alto consumo de agua

En los cuadros anexos las podemos ver en su totalidad. Se han seleccionado estas cinco por el alto consumo de suelo y su nivel de ocupación. Estos sectores han sufrido suertes diversas, pero prácticamente en su totalidad han salido de la ciudad y ocupaban el $71 \%$ del área industrial en Valencia.

Hay que destacar los contenedores, por la gran superficie que ocupan, el bajo de empleo y el transporte que necesitan. Pueden cambiar de lugar con facilidad, ya que no necesitan servicios especiales, ocupan zonas agrícolas y próximas al Puerto. Se necesita de un tratamiento específico para ellos.

El resto de actividades no plantea problemas excepto las cárnicas, que son altamente contaminantes, necesitan un alto consumo de agua y una depuradora especifica al igual que las químicas, aunque varía mucho de unas a otras, por lo general no son un ejemplo de convivencia ciudadana por los olores, chimeneas y contaminación.

\section{EL EMPLEO EN LA INDUSTRIA.}

Si consideramos la población de Valencia entorno a los 800.000 habitantes el empleo en la industria es muy bajo, entorno al 2,50 \%. Lo que nos indica que aunque la industria es dinámica en cuanto a los cambios, en realidad no tiene un peso especifico tan importante la ciudad, como puede ser el comercio, sin embargo ocupa un alto índice de suelo y por lo general es molesta.

Contrariamente a lo que podemos pensar, no es una ciudad típicamente industrial, Tenemos una idea romántica del Centro Histórico como artesanal, pero tiene muy pocas industrias, muy poco empleo y nada que ver con la artesanía.

Lo mismo podemos decir de los distritos 2 Eixample, 4 Campanar y 7 la Olivereta tiene un muy bajo índice industrial. 
Los que más empleo generan son los próximos al Puerto como son Camins al Grao y Poblats Maritims junto a los situados entorno a Jesús y Patraix.

\section{RELACIÓN INDUSTRIA-EMPLEO.}

Las Empresas van en paralelo a los empleos, tenemos una media de 21 empleados por empresa, pero ello no es totalmente cierto porque hay muchas empresas con un número de empleados inferior a 10 y otras con más de 100 empleados, pero lo que si podemos indicar que a la vista de los resultados obtenidos el tejido industrial se ha renovado por completo, adaptándose al momento actual únicamente perduran aproximadamente alrededor de 105 empresas en el 2014 frente a un total inventariado de 995 empresas desde 85 al 88 , lo que supone un $10 \%$ del total, habiéndose renovado casi por completo el tejido industrial.

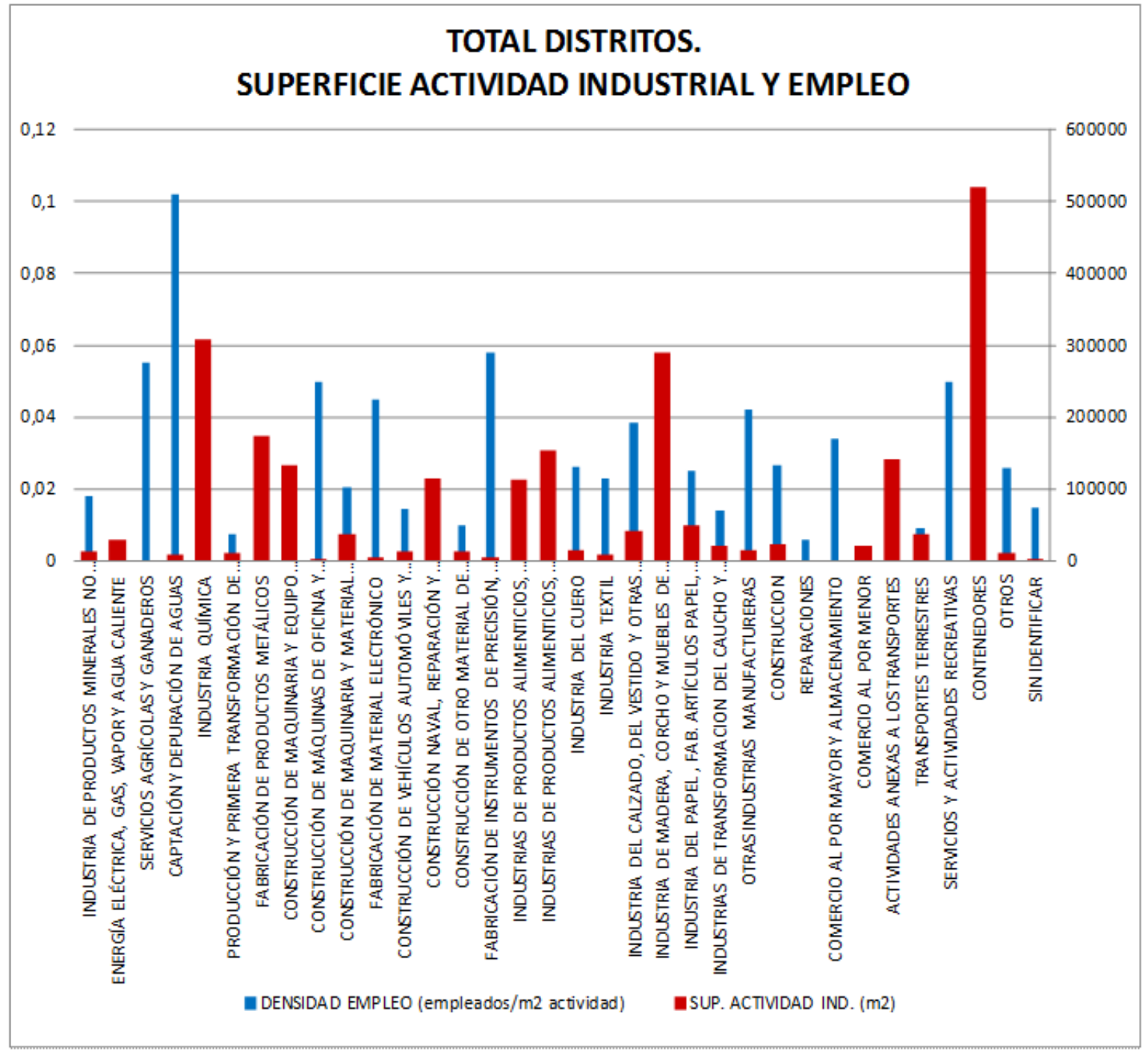


INDUSTRIA DE PRODUCTOS MINERALES NO METÁLICOS ENERGíA ELLÉCTRICA, GAS, VAPOR Y AGUA CALIENTE SERVICIOS AGRÍCOLAS Y GANADEROS

CAPTACIÓN Y DEPURACIÓN DE AGUAS

INDUSTRIA QUÍ́MICA

FABRICACIÓN DE PRODUCTOS METÁLCOS

CONSTRUCCIÓN DE MAQUINARIA Y EQUIPO MECÁNICO

CONSTRUCCÓN DE MÉQUINASDE OFICINAYORDNAD

CONSTRUCCIÓN DE MAQUINARIA Y MATERIAL ELÉCTRICO

FABRICACIÓN DE MATERIAL ELECTRÓNICO

CONSTRUCCÓN DE VEHÍCULS AUTOMÓVI SS Y SUS PIZZAS DE RUPUSTO CONSTRUCCIÓN NAVAL, REPARACIÓN Y MANTENIMIENTO DE BUQUES CONSTRUCCIÓN DE OTRO MATERIAL DE TRANSPORTE

FABRICACIÓN DE INSTRUMENTOS DE PRECISIÓN, ÓPTICA Y SIMILARES INDUSTRIAS DE PRODUCTOS AUIMENTICIOS BE, OASY TABACOS \begin{tabular}{l} 
INDUSTRIAS DE PRODUCTOS ALIMENTICIOS, BEBIDASY TABACOS \\
\hline INDUSTRIAS DE PRODUCTOS ALIMENTICIOS, BEBIDAS Y TABACOS \\
\hline
\end{tabular} NDUSTRIA DEL CUERO \begin{tabular}{|l}
\hline INDUSTRIA TEXTIL \\
\hline INDUSTRIA DEL CALZADO, DEL VESTIDO Y OTRAS CONFECCIONES TEXTILES \\
\hline
\end{tabular} INDUSTRIA DE MADERA, CORCHO Y MUEBLES DE MADERA

INDUSTRIA DEL PAPEL, FAB. ARTÍCULOS PAPEL, ARTES GRAFICAS Y EDICION INDUSTRIAS DE TRANSFORMACION DEL CAUCHO Y MATERIAS PLÁSTICAS OTRAS INDUSTRIAS MANUFACTURERAS \begin{tabular}{l} 
OTRASINDUCCION \\
\hline CONARACIONES \\
\hline
\end{tabular} COMERCIO AL POR MAYOR Y ALMACENAMIENTO

COMERCIO AL POR MENOR

ACTIVIDADES ANEXAS A LOS TRANSPORTES

SERVICIOS Y ACTIVIDADES RECREATIVAS

CONTENEDORES

OTROS

SIN IDENTIFICAR

\begin{tabular}{|c|c|c|c|c|c|c|c|c|c|c|c|c|c|c|c|c|c|c|c|c|c|c|c|c|c|c|c|c|c|c|c|c|c|c|c|}
\hline \multirow{3}{*}{\multicolumn{3}{|c|}{ 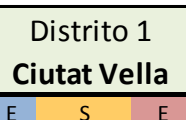 }} & \multirow{2}{*}{\multicolumn{3}{|c|}{$\begin{array}{c}\text { Distrito 2 } \\
\text { L'Eixample } \\
\end{array}$}} & \multirow{2}{*}{\multicolumn{3}{|c|}{$\begin{array}{l}\text { Distrito } 3 \\
\text { Extramurs }\end{array}$}} & \multirow{2}{*}{\multicolumn{3}{|c|}{$\begin{array}{l}\text { Distrito } 4 \\
\text { Campanar }\end{array}$}} & \multirow{2}{*}{\multicolumn{3}{|c|}{$\begin{array}{l}\text { Distrito } 5 \\
\text { La Saidia }\end{array}$}} & \multirow{2}{*}{\multicolumn{3}{|c|}{$\begin{array}{c}\text { Distrito } 6 \\
\text { El Pla del Real }\end{array}$}} & \multirow{2}{*}{\multicolumn{3}{|c|}{$\begin{array}{c}\text { Distrito } 7 \\
\text { L'Olivereta }\end{array}$}} & \multirow{2}{*}{\multicolumn{3}{|c|}{$\begin{array}{l}\text { Distrito } 8 \\
\text { Patraix }\end{array}$}} & \multirow{2}{*}{\multicolumn{3}{|c|}{$\begin{array}{l}\text { Distrito } 9 \\
\text { Jesús }\end{array}$}} & & $\begin{array}{l}\text { istrito } 1 \\
\text { trre Carr }\end{array}$ & & & $\begin{array}{l}\text { Distrito } 1 \\
\text { lats Mar }\end{array}$ & itims & & $\begin{array}{l}\text { strito } 1 \\
\text { ins al } \mathrm{C}\end{array}$ & \\
\hline & & & & & & & & & & & & & & & & & & & & & & & & & & & & & & & & & & & \\
\hline & ${ }_{s}^{s}$ & E & E & s & E & E & 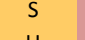 & E & 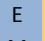 & 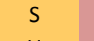 & 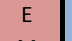 & $\mathrm{E}$ & s & 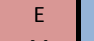 & 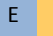 & $s$ & $\mathrm{E}$ & $\mathrm{E}$ & s & 2 & $\mathrm{E}$ & $s$ & $\mathrm{E}$ & $\mathrm{E}$ & s & $\mathrm{E}$ & 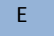 & 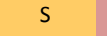 & $\mathrm{E}$ & L & s & $\mathrm{E}$ & $L^{2}$ & s & $\mathrm{E}$ \\
\hline & P & $\begin{array}{l}M \\
P\end{array}$ & $\begin{array}{l}M \\
\mathrm{M}\end{array}$ & $\begin{array}{l}u \\
p\end{array}$ & $\begin{array}{l}M \\
P\end{array}$ & $\begin{array}{l}M \\
P \\
P\end{array}$ & $\begin{array}{l}b \\
u^{b}\end{array}$ & $\begin{array}{l}M \\
p\end{array}$ & M & u & $\mathrm{M}$ & $\mathrm{M}$ & U & $\mathrm{M}$ & M & u & ${ }^{M}$ & M & U & $\mathrm{M}$ & M & U & $\mathrm{M}$ & M & U & $M$ & & U & M & M & 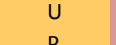 & M & 0 & U & M \\
\hline & $\mathrm{E}$ & $\mathrm{L}$ & R & $\mathrm{E}$ & $\mathrm{L}$ & R & $\mathrm{E}$ & $\mathrm{L}$ & R & $\mathrm{E}$ & $\mathrm{L}$ & & $\mathrm{E}$ & 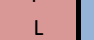 & $\mathrm{R}$ & $\mathrm{E}$ & L & $\mathrm{R}$ & $\mathrm{E}$ & L & R & $\mathrm{E}$ & L & $\mathrm{R}$ & $\mathrm{E}$ & L & $\mathrm{R}$ & $\mathrm{E}$ & L & $\mathrm{R}$ & E & L & $\mathrm{R}$ & $\mathrm{E}$ & \\
\hline & R & & & & & & R & $\mathrm{E}$ & $\mathrm{E}$ & & & & & & E & & & $\mathrm{E}$ & R & & & R & & E & R & & & R & & $\mathrm{E}$ & R & $\mathrm{E}$ & $\mathrm{E}$ & R & \\
\hline & $\mathrm{F}$ & A & s & $\mathrm{F}$ & A & s & $\mathrm{F}$ & A & s & $\mathrm{F}$ & A & s & $\mathrm{F}$ & A & s & $\mathrm{F}$ & A & $\mathrm{s}$ & $\mathrm{F}$ & A & s & $\mathrm{F}$ & $\mathrm{A}$ & s & $\mathrm{F}$ & A & $\mathrm{s}$ & $\mathrm{F}$ & $\mathrm{A}$ & $\mathrm{s}$ & $\mathrm{F}$ & A & $\mathrm{s}$ & $\mathrm{F}$ & A \\
\hline & & D & A & 1 & D & A & 1 & D & A & 1 & D & A & 1 & D & A & I & & A & I & $\mathrm{D}$ & A & 1 & $D$ & A & 1 & D & A & 1 & D & A & 1 & D & A & 1 & \\
\hline & c & 0 & & c & 0 & & c & & & c & 0 & & c & $\circ$ & & c & & & c & & & c & o & & c & 0 & $\mathrm{~s}$ & c & $\circ$ & $\mathrm{s}$ & c & 0 & $\mathrm{~s}$ & c & \\
\hline & $\mathrm{E}$ & & & & & & $\mathrm{E}$ & & & & & & & & & & & & & & & & & & & & & & & & & & & & \\
\hline & 80 & \begin{tabular}{|l|}
8 \\
\end{tabular} & & & & \begin{tabular}{l|l|}
4 \\
\end{tabular} & 2620 & 79 & 1 & 1295 & 23 & 3 & 620 & 19 & 1 & 1200 & 2 & & & & 4 & 2520 & 25 & 2 & 2650 & 38 & 2 & 1030 & 32 & 1 & 700 & 4 & & & \\
\hline & & & & & & & & & & & & & & & & & & & & & & & & & & & & & & & & & 1 & 29404 & 30 \\
\hline & & & 1 & 325 & \begin{tabular}{|l|l|}
18 \\
\end{tabular} & & & & & & & & & & & & & & & & & & & & & & & & & & & & & & \\
\hline & & & & & & & & & & & & & & & & & & & & & 1 & 10000 & 200 & & & & & & & & & & & & \\
\hline & 280 & 16 & 3 & 3325 & \begin{tabular}{|l|l|}
74 \\
\end{tabular} & \begin{tabular}{l|l}
4 \\
\end{tabular} & \begin{tabular}{|l|l|}
4070 \\
\end{tabular} & 42 & & & & & & & 4 & 546 & 101 & 1 & 474 & 8 & 8 & 53999 & 462 & & & & 3 & 14500 & 62 & 3 & 8550 & 66 & 10 & 222378 & 370 \\
\hline & & & & & & & & & & & & & & & & & & & & & $\begin{array}{l}1 \\
\end{array}$ & 8000 & 60 & & & & $\begin{array}{ll}1 \\
\end{array}$ & 2496 & 6 & & & & \begin{tabular}{l|l}
1 \\
\end{tabular} & 1100 & 24 \\
\hline & 1960 & 60 & 8 & 2770 & 51 & 14 & 5294 & $184 \mid$ & 5 & 5100 & 65 & 14 & 6032 & 99 & 5 & 1510 & 19 & 8 & 2055 & 50 & 18 & 89480 & 432 & \begin{tabular}{|l|}
12 \\
\end{tabular} & 3433 & 90 & 28 & 21710 & 254 & \begin{tabular}{l|l|}
36 \\
\end{tabular} & \begin{tabular}{|l|}
12613 \\
\end{tabular} & 289 & 35 & 23030 & 484 \\
\hline & & & 1 & 400 & 4 & 2 & 859 & 18 & & & & 7 & 11895 & 229 & 1 & 70 & 6 & 1 & 200 & 1 & 5 & \begin{tabular}{l|l|}
6845 \\
\end{tabular} & 84 & 6 & 67900 & 1114 & 14 & 14673 & 239 & 6 & 25285 & 133 & \begin{tabular}{|l|}
5 \\
\end{tabular} & 4470 & 60 \\
\hline 1 & 208 & 6 & 1 & 250 & \begin{tabular}{|l|l|}
32 & \\
\end{tabular} & & & & & & & & & & 2 & 2240 & 109 & 1 & 1027 & 40 & & & & & & & & & & & & & & & \\
\hline 2 & 800 & \begin{tabular}{|l|}
17 \\
\end{tabular} & 6 & 1326 & $67 \mid$ & 6 & 2690 & 59 & & & & 7 & 2280 & 157 & 3 & 430 & 78 & 2 & 686 & 65 & 4 & 17410 & 49 & 4 & 2310 & 56 & 4 & \begin{tabular}{|l|}
1197 \\
\end{tabular} & 28 & 4 & 2013 & 47 & 11 & 7259 & 166 \\
\hline & 545 & \begin{tabular}{|l|}
42 \\
\end{tabular} & & & & & & & 2 & 530 & 24 & 1 & 200 & 12 & & & & 1 & 150 & 6 & 2 & 1160 & 74 & 1 & 240 & 53 & & & & & 324 & 9 & & 3210 & 65 \\
\hline & & & & & & & & & & & & & & & 1 & 300 & 9 & & & & 1 & 3200 & 70 & & & & 2 & 2650 & 20 & 5 & 4120 & 65 & 4 & 2455 & 23 \\
\hline & & & & & & & & & & & & & & & & & & & & & & & & & & & & & & 9 & 4849 & 1519 & & & \\
\hline & & & & & & & & & & & & 1 & 12200 & 123 & & & & & & & & & & & & & 1 & 600 & 8 & & & & 1 & 1200 & 10 \\
\hline 4 & 398 & \begin{tabular}{|l|}
60 \\
\end{tabular} & 2 & 600 & \begin{tabular}{|l|l|}
33 \\
\end{tabular} & 2 & 790 & 60 & 1 & 1 & 19 & & & & & & & 2 & 491 & 4 & & & & & & & 2 & 328 & 25 & & & & & 1000 & 54 \\
\hline 3 & 480 & 21 & 12 & 2891 & 105 & 3 & 770 & 42 & 5 & 1067 & 22 & 8 & 4642 & 101 & 4 & 545 & 28 & 10 & 6590 & 54 & 4 & 30901 & 347 & 3 & 6550 & 58 & 12 & 4250 & 63 & 16 & 53007 & 183 & 9 & 1398 & 38 \\
\hline & 425 & 3 & 1 & 349 & 6 & & & & & & & 2 & & 5 & 12 & 23520 & |555 & 1 & 839 & 12 & 5 & 24100 & 110 & 2 & 33600 & 318 & - & 160 & 4 & 6 & 9416 & 112 & 8 & 59278 & 261 \\
\hline & & & 2 & 560 & \begin{tabular}{|l|}
21 \\
\end{tabular} & 2 & 435 & 42 & 6 & \begin{tabular}{l|l}
6176 \\
\end{tabular} & 104 & 5 & 4252 & 72 & 1 & 200 & 5 & 1 & 240 & 6 & 2 & 724 & 16 & 2 & 568 & 26 & 5 & 1530 & 67 & & & & 3 & 1340 & \begin{tabular}{|l|}
62 \\
\end{tabular} \\
\hline & 300 & \begin{tabular}{|l|}
12 \\
\end{tabular} & & & & & & & & & & 3 & 1250 & 40 & & & & 1 & 860 & 34 & 1 & 3950 & 7 & 3 & 1374 & 81 & & & & 4 & 733 & 40 & 2 & 800 & 22 \\
\hline & \begin{tabular}{|l|}
3708 \\
\end{tabular} & \begin{tabular}{|l|}
149 \\
\end{tabular} & 3 & \begin{tabular}{|l|}
950 \\
\end{tabular} & \begin{tabular}{|l|l|}
44 & \\
\end{tabular} & 6 & 2568 & 102 & 2 & \begin{tabular}{|l|l|}
1445 &
\end{tabular} & \begin{tabular}{|l|}
35 \\
\end{tabular} & 3 & 730 & 38 & 3 & \begin{tabular}{|l|l|}
1140 &
\end{tabular} & 42 & 11 & \begin{tabular}{|l|}
6448 \\
\end{tabular} & \begin{tabular}{|l|}
153 \\
\end{tabular} & 11 & 11143 & 185 & 8 & 3147 & 182 & 2 & 1800 & 51 & 6 & 1619 & 147 & 7 & 649 & 465 \\
\hline & 1060 & \begin{tabular}{|l|}
30 \\
\end{tabular} & 2 & 2190 & \begin{tabular}{|l|}
28 \\
\end{tabular} & 5 & \begin{tabular}{|l|}
6414 \\
\end{tabular} & 160 & 5 & \begin{tabular}{|l|l|}
3570 \\
\end{tabular} & 25 & 9 & 13192 & 87 & $4:$ & 12300 & 123 & 1 & 800 & \begin{tabular}{l|l}
23 \\
\end{tabular} & 14 & 79831 & 720 & 13 & 13630 & 175 & 18 & 50853 & 454 & \begin{tabular}{l|l|}
19 \\
\end{tabular} & 102085 & 178 & 11 & 4928 & 67 \\
\hline 6 & \begin{tabular}{|l|}
1830 \\
\end{tabular} & \begin{tabular}{|l|}
73 \\
\end{tabular} & \begin{tabular}{|l|}
12 \\
\end{tabular} & 4616 & \begin{tabular}{|l|}
135 \\
\end{tabular} & 13 & 10087 & 177 & & & & 1 & 1400 & 90 & & & & 7 & 2251 & 179 & 8 & 7810 & 252 & 5 & 1280 & 115 & 9 & 3285 & 105 & 4 & 16851 & 116 & 6 & 1193 & 32 \\
\hline & & & 1 & 230 & \begin{tabular}{|l|l|}
10 & \\
\end{tabular} & 1 & 18 & 10 & 1 & 70 & 3 & 1 & 1 & 8 & & & & 2 & 1200 & \begin{tabular}{l|l}
39 & \\
\end{tabular} & 4 & 8190 & 68 & 1 & 530 & 13 & 13 & \begin{tabular}{|l|}
8256 \\
\end{tabular} & 95 & 4 & 984 & 9 & 6 & 600 & 47 \\
\hline & 780 & \begin{tabular}{|l|l}
41 \\
\end{tabular} & 1 & 550 & \begin{tabular}{|l|l|}
58 \\
\end{tabular} & 5 & 2910 & 182 & 3 & \begin{tabular}{|l|l|}
1180 & \\
\end{tabular} & 68 & 1 & 200 & 16 & & & & 4 & 1865 & 46 & 4 & 3124 & 103 & 4 & 1010 & 45 & 2 & 1720 & 24 & 3 & 542 & 11 & 5 & 1040 & 37 \\
\hline & 320 & \begin{tabular}{|l|}
38 \\
\end{tabular} & 3 & 1550 & \begin{tabular}{|l|}
35 \\
\end{tabular} & 2 & 287 & \begin{tabular}{|l|}
24 \\
\end{tabular} & 1 & 200 & 8 & 6 & 4770 & 101 & 1 & 1000 & 6 & 3 & 1720 & 49 & 6 & 5746 & 149 & 4 & 1385 & 82 & 5 & 840 & 48 & 4 & 3630 & 16 & 7 & 1990 & 73 \\
\hline & & & & & & & & & & & & & & & 1 & 1000 & & & & & & & & & & & & & & & & & & & \\
\hline & & & 1 & \begin{tabular}{|l|}
1237 \\
\end{tabular} & \begin{tabular}{|l|l|}
42 & \\
\end{tabular} & & & & & & & & & & & & & & & & & & & & & & & & & & & & & & \\
\hline & & & & & & & & & & & & & & & & & & & & & 1 & 22000 & 95 & & & & & & & & & & & & \\
\hline & & & & & & & & & & & & & & & & & & & & & & & & & & & 2 & 44000 & & 1 & 3500 & 80 & & & \\
\hline & & & & & & & & & & & & & & & & & & & & & 1 & 8600 & 40 & & & & & & & 3 & 27295 & 292 & 1 & 2100 & 17 \\
\hline & & & & & & & & & & & & & & & & & & & & & & & & & & & & & & 1 & 120 & 6 & & & \\
\hline & & & & & & & & & & & & & & & & & & & & & & & & & & & 1 & 28000 & & 34 & 491488 & 245 & & & \\
\hline & & & & & & & & & & & & 7 & 6690 & 75 & 4 & 5170 & 23 & & & & & & & & & & & & & & & & & & \\
\hline & & & & & & & & & & & & & & & & & & & & & & & & & & & 7 & 3003 & 52 & 4 & \begin{tabular}{|l|}
1373 \\
\end{tabular} & 14 & & & \\
\hline & 74 & & 60 & 24119 & 76 & 69 & 39974 & 1181 & & \begin{tabular}{l|l}
22133 &
\end{tabular} & 396 & & 71623 & 1272 & 50. & 51171 & 1325 & 57 & 27896 & 810 & 105 & 398733 & 3548 & & 139607 & 2446 & 134 & 20688 & 1637 & 175 | & 976097 & 3681 & 138 & $378 \varepsilon$ & 24 \\
\hline
\end{tabular}




\section{SINTESIS}

El sentir ciudadano, junto al político del que hemos dado cuenta ya, con las normas del S. XIX y las normas urbanísticas dictadas por el PG 88 y el Reglamento sobre Actividades Molestas Nocivas Insalubres y Peligrosas del 99. Han dado lugar a que la industria haya emigrado a los Polígonos Industriales de la periferia.

Como síntesis se puede afirmar que la Ciudad de Valencia no es un área fuertemente Industrializada , tan solo cuenta con un 2,5\% de su población empleada en la Industria, pero se muestra muy dinámica adaptándose a los continuos Ciclos Económicos, ello se contrapone a siglos anteriores donde fue una ciudad industrial de primer orden.

Igualmente podemos indicar que se ha diseminado por la periferia, todo ello en beneficio de la Ciudad.

En los últimos cuarenta años:

- Los núcleos de población al Sur como son Alfafar, Benetuser, Sedavi, Catarroja, Albal y Beniparrell se especializaron en la madera y derivados dando lugar a una Industria totalmente consolidada a lo largo del Cami Reial.

- Los núcleos situados al Oeste como son Aldaia, Alacuas, Xirivella y Torrent tienen una industria más diversa pero también domina la madera, cerámica, maquinaria y alimentación, concentrado en diversos polígonos industriales.

- Los núcleos situados al Noroeste como son Mislata, Quart de Poblet, Paterna y Ribarroja tienen una industria más extensa y diversa, en los que conviven multitud de actividades, quizás es la mejor comunicada y la mas potente situada a lo largo de la A3 CV 30 A 7 CV 35.

El continuo trasiego de industrias deslocalizadas ha dado lugar a multitud de espacios nuevos tanto viales (Prolongación de la Alameda con las Chimeneas de la antigua Alcoholera) como edificios que en la actualidad tienen otro uso (Tabacalera, Cross, Naves Portuarias, Antiguos almacenes en la Avenida del Puerto). 
Esto ha sido repetitivo a lo largo de la historia, sirva como ejemplo los edificios de Tabacalera.

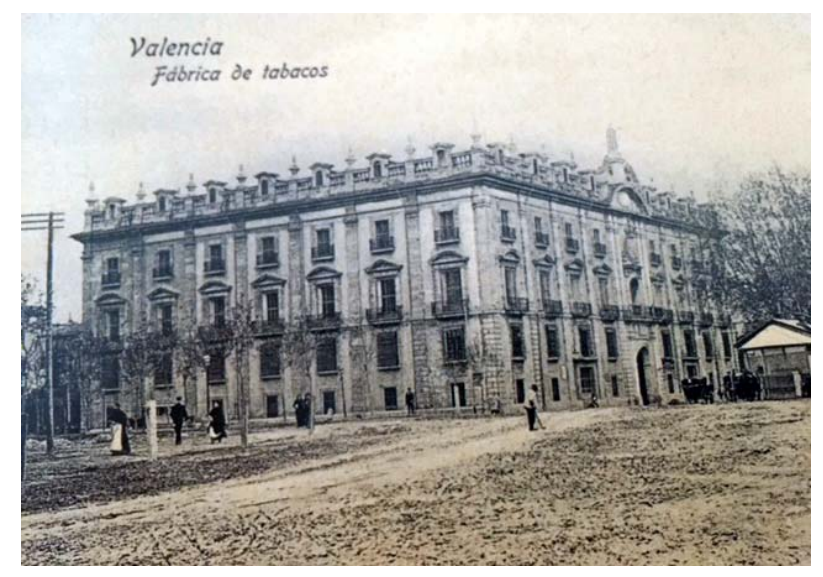

Foto 87: Fábrica de Tabacos. C/ Palacio de Justicia, s.n. Valencia. Principio S XX. Fuente: Álvarez, A. y Ballester, B. Ayuntamiento de Valencia. VALENCIA INDUSTRIAL: Las fundiciones. Valencia. 2001 (p.65).

Foto 89: Palacio de Justicia. Valencia.2015

Fuente: WEB. http://www.google.es/maps (Street View).

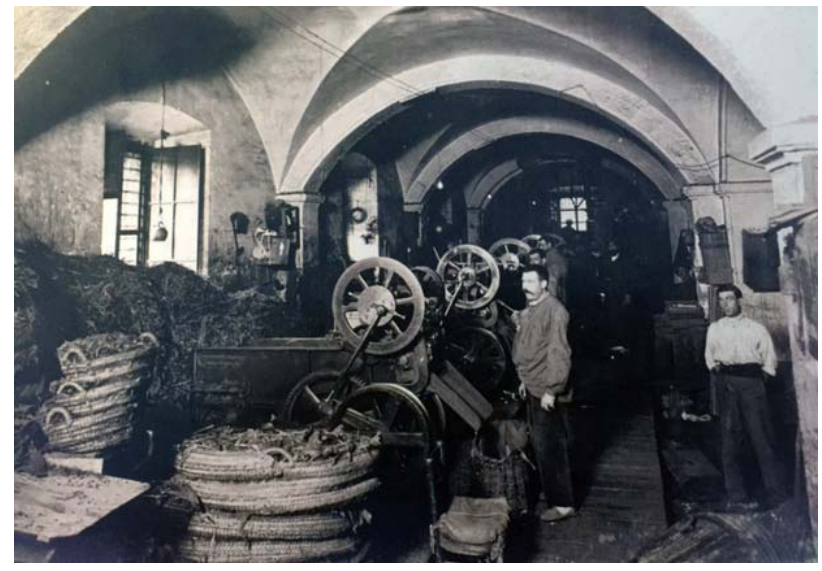

Foto 88: Interior antigua Fábrica de Tabacos. Valencia. Principio S XX. Fuente: Álvarez, A. y Ballester, B. Ayuntamiento de Valencia. VALENCIA INDUSTRIAL: Las fundiciones. Valencia. 2001 (p.212).

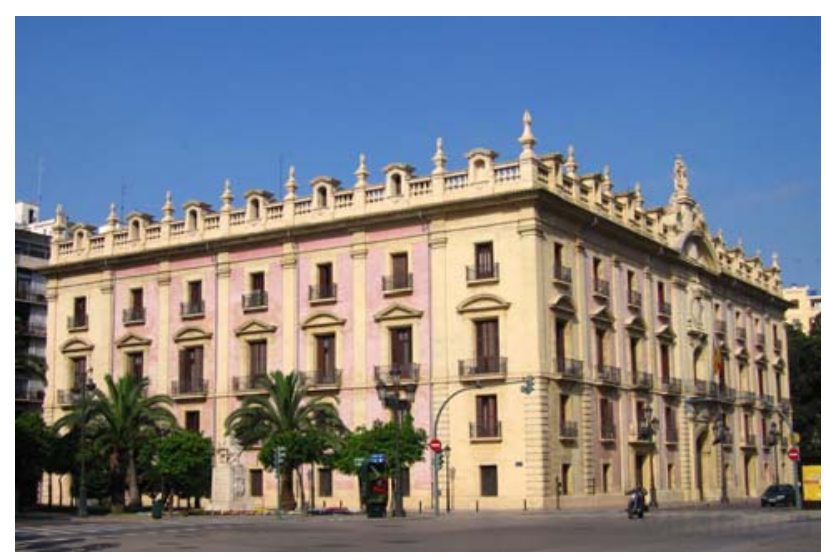

El Plan General del 88 en sus previsiones y ordenanzas industriales, ya contemplaba el aprovechamiento de determinados edificios industriales.

Un caso singular e histórico por su evolución es el de Tabacalera en la actualidad Palacio de Justicia, luego ocupó el Palacio de la Industria de la Exposición y pasó a ser Tabacalera y recientemente se ha transformado para acoger la nueva sede del Ayuntamiento. 


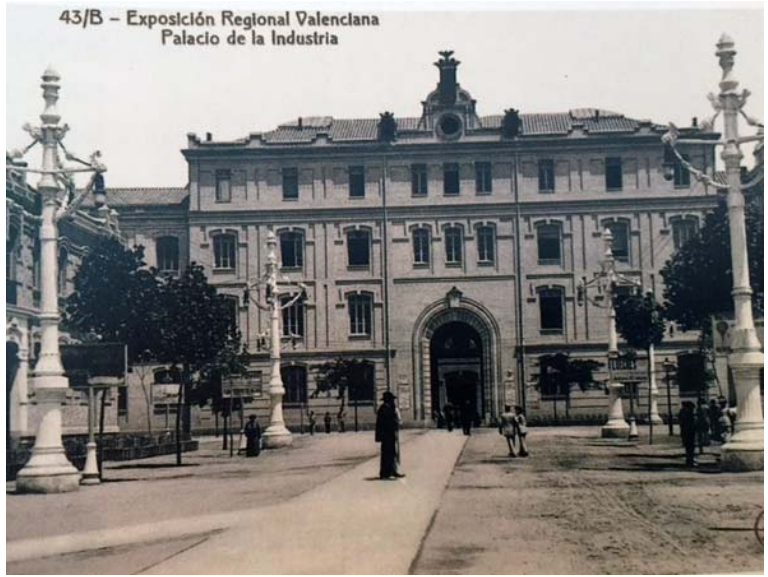

Foto 90: Palacio de la Industria.. C/ Amadeo de Saboya. Valencia. Principio S XX. Fuente: Álvarez, A. y Ballester B. Ayuntamiento de Valencia. VALENCIA INDUSTRIAL. Las fundiciones. Valencia. 2001 (p.69).

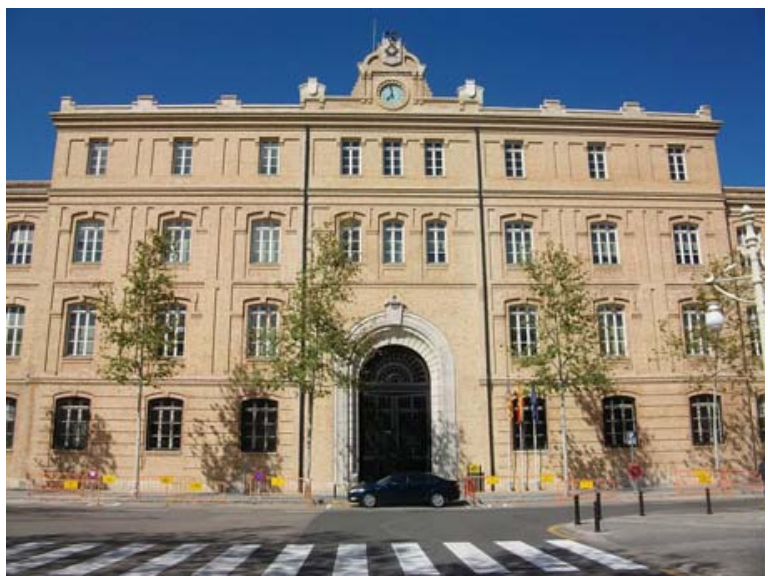

Foto 92: Ayuntamiento Valencia. Antiguo Palacio de la Industria. C/ Amadeo de Saboya. Valencia. 2015.

Fuente: WEB. http://www.google.es/maps (Street View).

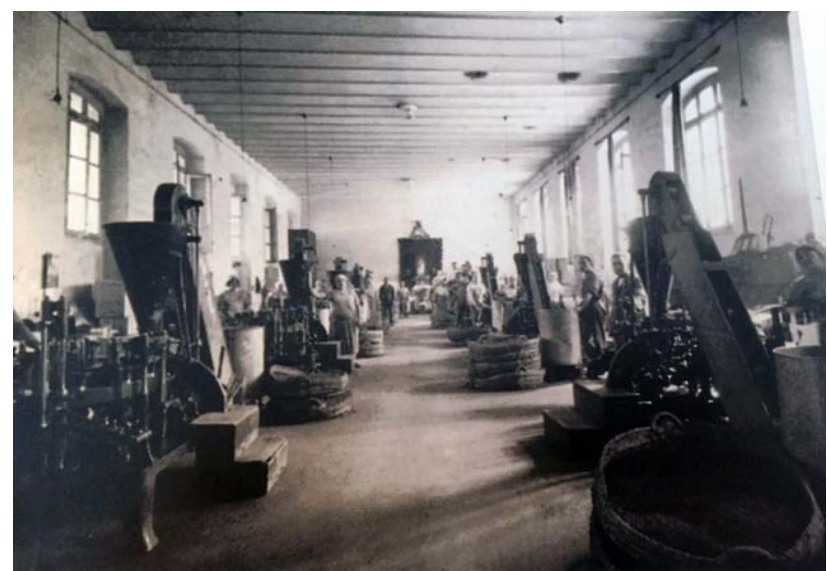

Foto 91: Interior antigua Fábrica de Tabacos. Valencia. Principio S XX. Fuente: Álvarez, A. y Ballester, B. Ayuntamiento de Valencia. VALENCIA INDUSTRIAL: Las fundiciones. Valencia. 2001 (p.213).

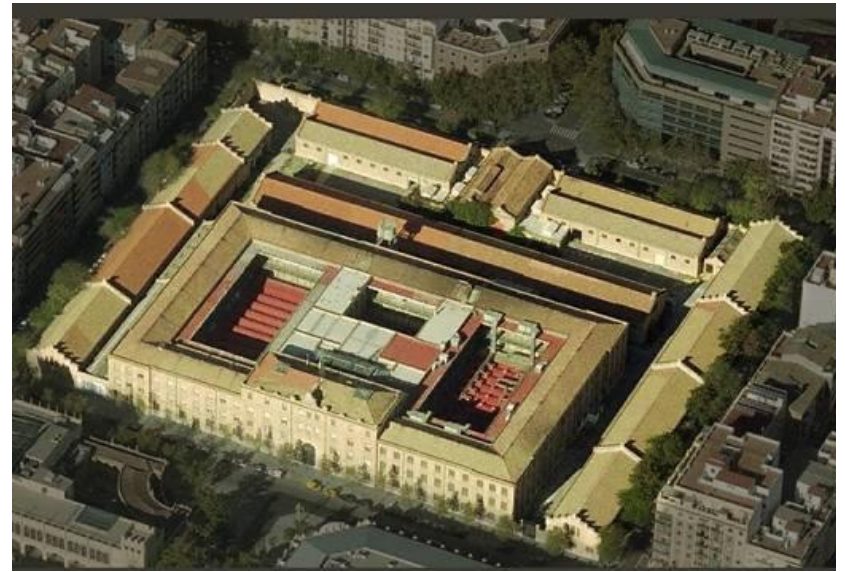

Foto 93: Simulación vista aérea antiguo Palacio Industria Valencia. 2013 Fuente: WEB. http://www.levante-emt.com/ Valencia/2013/07/30

El impacto ambiental ha ido disminuyendo con el paso del tiempo, por la continua descentralización industrial. Únicamente podríamos resaltar la permisividad que se tiene con el ruido en los pequeños talleres, pero esto es una cuestión generalizada que afecta igualmente al tráfico y locales de ocio.

Quizás lo que más se echa en falta, es una política coherente de apoyo industrial, que al final nos proporcione empleo y nos identifique. Esto sería una Reindustrialización ordenada y coherente, con apoyos a los sectores industriales en los que siempre hemos sido punteros e innovadores y que en muchos de ellos, hemos perdido los oficios y a los no sujetos a los ciclos económicos como son la alimentación que subsiste a duras penas y aquellos innovadores con una fuerte carga de investigación, con ayudas estatales, fiscales, laborales y financieras que tanto necesita la industria, para sobrevivir a los ciclos económicos. 


\section{NOTA ACLARATORIA AL TRABAJO REALIZADO}

En el presente estudio de localización Industrial, incluye unas fichas informativas, que se han elaborado diferenciando dos bloques de contenidos, descritos en los apartados 1 y 2 , en los que aparece la siguiente información.

Apartado 1.

- La identificación de las empresas.

- La superficie ocupada.

- Número de empresas.

- $\quad$ Número de empleados

- $\quad$ Impacto en el medio ambiente.

Apartado 2.

- Infraestructuras. (alumbrado, agua y energía)

- Servicios urbanísticos.

- Transporte.

- Tipología. (Tipología estructural y edad de la edificación)

Nuestro estudio se basa único y exclusivamente en el apartado 1, dejando la información obtenida en el apartado 2 para futuros estudios de investigación. 


\section{BIBLIOGRAFIA.}

\section{BIBLIOGRAFIA MÁS RELEVANTE}

Aguilar I. "Arquitectura industrial. Concepto, método y fuentes", Ed. Museo de Etnología de la Diputación de Valencia. Valencia, 1998. I.S.B.N.: 84-7795-174-8.

Aguilar I. "El orden industrial en la ciudad", Ed. Diputación de Valencia. Valencia, 1990. I.S.B.N.: 84-7795-030-X.

Alonso J. "La ingeniería industrial española en el siglo XX", Ed. Asociación de ingenieros industriales de Andalucía. Madrid, 1993. I.S.B.N.: 84-7952-122-8.

Álvarez A., Ballester B. "Valencia industrial: Las fundiciones". Ayuntamiento de Valencia. Valencia, 2005. I.S.B.N.: 84-8484-0009-3.

Castells M. "Sociología del espacio industrial", Ed. Ayuso. Madrid, 1977. I.S.B.N.: 84-3360193-3.

Cerdà M. "Patrimonio industrial". Universidad de Valencia. Valencia. 2011.

C.O.A.C.V.. "Guía de urbanización para diseño y formulación de Programas de Actuaciones Integradas. Fichas de vías tipo", Ed. C.O.A.C.V. Valencia, 1995. I.S.B.N. (vol. 2): 84-86828-13-9.

Dalmau J. De Miguel, E. Miquel, S. "Análisis estratégico de los sectores industriales y del turismo en la Comunidad Valenciana". Universidad Politécnica de Valencia. Valencia, 1993. I.S.B.N.: 84-7721-214-7.

"El ensanche de la ciudad de Valencia de 1884". C.O.A.C.V. Valencia, 1984.

Generalitat Valenciana. "Catálogo de suelo industrial de la Comunidad Valenciana", Ed. Seguridad y Promoción Industrial Valenciana (SEPIVA). Conselleria d'Ocupació, Indústria i Comerç. Valencia, 1997. I.S.B.N.: 84-482-1623-7.

Generalitat Valenciana. "Afecciones que inciden en la planificación urbanística y territorial en la Comunidad Valenciana". Conselleria d'Obres Públiques, Urbanisme i Transports. Valencia, 1998. I.S.B.N.: 84-482-1875-2.

Gómez Mendoza, J. "La estrategia oficial de promoción de suelo industrial en España". Ciudad e Industria. IV Congreso de Geografía. Oviedo 1975.

Hamilton F.E. "Modelos de localización industrial". Instituto de estudios de Administración Local. Madrid, 1971. 
Rosa $\mathrm{M}^{\mathrm{a}}$ Jordá Borrell. "La industria en el desarrollo del área metropolitana de Valencia". Universidad, Servicio de publicaciones. Valencia, 1986. I.S.B.N.: 84-370-0270-2

"La Gran Valencia. Trayectoria de un Plan General". Conselleria de Obras Públicas, Urbanismo y Transportes. Dirección General de Urbanismo. Valencia, 1986.

Larrosa, J. "Dispersión espacial de los talleres de la industria del calzado y afines en Elche". VI Jornadas de Geografía Industrial, Industria y Medio Ambiente.

Márquez Pérez, M. "Historia de la industria, comercio, navegación y agricultura del Reino de Valencia”. Imprenta Doménech. Valencia, 1910.

Martínez F. "La industrialización Valenciana 1834-1914". Generalitat Valenciana. Conselleria d'Industria, Comerç i Turisme. Valencia, 1995. I.S.B.N.: 84-482-0986-9.

"Ley sobre el régimen del suelo y ordenación urbana", Ed. Civitas, S.A., 1990. I.S.B.N.: 84-470-0399-X.

Nadal J. Carreras A., "Pautas regionales de la industrialización española", Ed. Ariel. Barcelona, 1990. I.S.B.N.: 84-344-6563-9.

Peñín, A. "La ordenación del territorio en la Comunidad Valenciana: La planificación urbanística". IEAL. Valencia, 1983. I.S.B.N.: 84-600-1202-6.

Pevsner N. "Historia de las tipologías arquitectónicas", Ed. Gustavo Gili S.A. Barcelona, 1979. I.S.B.N.: 84-252-0915-3.

Rodriguez Sánchez de Alva, A. "El suelo como factor de localización industrial". Centro de estudios de ordenación territorial y medio ambiente. Madrid, 1980. I.S.B.N.: 978-84-7433090-8

Serra J. "Elementos urbanos", Ed. Gustavo Gili S.A. Barcelona, 1996. I.S.B.N.: 84-2521679-6.

Teixidor de Otto, M.J. "Funciones y desarrollo urbano de Valencia". Instituto de geografía, Institución Alfonso el Magnánimo. Valencia, 1976. I.S.B.N.: 84-00-04263-8.

Tostoes A., García C., Landrove S. "La arquitectura de la industria, 1925-1965". Fundación DOCOMOMO Ibérico. Barcelona, 2005. I.S.B.N.: 84-609-1196-9

Vidal V. "Arquitectura e industria". Generalitat Valenciana. Valencia, 1988. I.S.B.N.: 847579-494-7. 


\section{ORGANISMOS CONSULTADOS}

- Consellería de Industria, Comercio y Turismo.

- Ministerio de trabajo (Altas en S. Social).

- Delegación Provincial del Ministerio de Hacienda.

- Excmo. Ayuntamiento de Valencia (Servicio de Radicación).

- Sociedad de Aguas Potables.

- Iberdrola.

- Cámara Oficial del Comercio, Industria y Navegación.

- Google.

\section{COLABORADORES}

DIRECTORES DE TESIS

Francisco Taberner Pastor

Jorge Luis Garcia Valldecabres

COLABORADORES

Manuel Adalid Gómez

Juan Catalá Peris

Marta Lozano Mateu

Blanca Mateu Camañes

Amadeo Pascual Agulló

Carlos Pascual Agulló

Covadonga Pascual Agulló

Carlos Paya Tenorio

Natalia Vanaclocha Mateu 


\section{RESUMEN TESIS DOCTORAL}

\section{1.- NOTA INFORMATIVA}

En el presente estudio de localización Industrial, incluye unas fichas informativas, que se han elaborado diferenciando dos bloques de contenidos, descritos en los apartados 1 y 2 , en los que aparece la siguiente información.

Apartado 1.

- $\quad$ La identificación de las empresas.

- $\quad$ La superficie ocupada.

- $\quad$ Número de empresas.

- $\quad$ Número de empleados

- $\quad$ Impacto en el medio ambiente.

Apartado 2.

- Infraestructuras. (alumbrado, agua y energía).

- Servicios urbanísticos.

- $\quad$ Transporte.

Tipología. (Tipología estructural y edad de la edificación).

Nuestro estudio se basa única y exclusivamente en el apartado 1, dejando la información obtenida en el apartado 2 para futuros estudios de investigación. 


\section{2.- RESUMEN}

Los factores que condicionan, a nivel Internacional, Nacional y Local las actividades industriales, no son solamente los aspectos urbanísticos sino también los políticos y económicos.

Podemos decir que:

1.- Con los Acuerdos Europeos de Libre Comercio, se eliminan básicamente el Proteccionismo económico, pilar importante en el sector Agrícola, Ganadero y Alimentación, ello trae consigo el empobrecimiento sistemático del sector poco competitivo por las explotaciones tan pequeñas que tenemos y además poco industrializadas. Es mas barato importar que producir.

El sector artesanal tan arraigado en nuestra ciudad desde tiempos inmemoriales prácticamente desaparece frente al mercado Asiático para pasar a la importación y el comercio.

Aldaia, un pueblo industrial dedicado al abanico, el tablero y el mueble, prácticamente no tiene fábricas de abanicos, alguno queda que lo hace de forma artesanal, todos los fabricantes importan y comercian productos ya elaborados. La mayor parte de ellos vendían en el Centro Histórico.

Alacuas tenía la fábrica de tableros más importante de Europa, Tableros Ferrer con una superficie aproximada de $20.000 \mathrm{~m} 2$ y un número de trabajadores similar al del Centro Histórico o Campanar, pues ha sucumbido a la presión Asiática, es más barato comprar que fabricar.

Al sector Textil y Madera le sucede exactamente lo mismo, en un periodo de 20 años prácticamente desaparecen todas las empresas.

En el año 85 , el Metal representa el 18,6\%, la Alimentación el 12\%, la Madera el $10,30 \%$, el textil el $7 \%$, prácticamente estos sectores representan el $48 \%$ de la industria y todos ellos afectados con posterioridad por el libre comercio entre áreas de libre competencia e inversión. 
Ante tal situación la industria se tiene que reconvertir en una situación muy desfavorable, a ello se añadirán otros factores que le provocaran un desenlace poco deseado por todos, tanto social como económico, que será la especulación del suelo que ocupa. Esa es una de las máximas preocupaciones entre otras que tiene la Ley Sobre el Régimen del Suelo y Ordenación Urbana de 1990.

2.- La parte Política se corresponde con la Reconversión Industrial que se empieza a elaborar después de la crisis económica de 1973, pero en realidad se hace de los 80 a los 90 , en la que se toman medidas económica con la finalidad de ajustar la oferta a la demanda. Hoy mismo se esta repitiendo esta situación, no hace falta entender de economía para comprenderlo.

Tiene dos vertientes que nos afectaran muy directamente y que se entienden desde lo que se nos avecinaba en cuanto al libre comercio:

1. La primera es la limitación industrial de las empresas en crisis con exigencias de reducción de producción y la aplicación de nuevos sistemas de Organización y Gestión que lleva a la reducción de plantillas y en algunos casos a la práctica desaparición de las empresas.

Esta medida afecta directamente al sector naval, metal, textil, madera y alimentación que en nuestro rango de actividades ocupan los cinco primeros lugares

El sector del metal en nuestro caso las fundiciones ubicadas en la Avenida del Puerto prácticamente desaparecen. La madera, con la prohibición de importar cierta cantidad por el Puerto de Valencia y en condiciones que supone un encarecimiento de la materia prima, lentamente va desapareciendo.

El textil pierde competitividad por el encarecimiento de la mano de obra, cuando se le estaba pidiendo lo contrario. 
El sector alimentario pierde las ayudas, y ello unido a los minifundios y su escasa competitividad, lleva al lugar donde nos encontramos hoy, donde el agricultor cobra escasamente 9 céntimos de euro por un kilogramo de naranjas y el comercio lo vende a un euro. La relación es de $0,09 €$ frente a $1 €$ y seguimos ahí por el carácter familiar de las explotaciones acumulando pérdidas.

2. La segunda vertiente es la Reindustrialización, basada en la modernización tecnológica con ayudas estatales, financieras, fiscales y laborales. Aquí estamos en la misma situación que hoy. Muy poco eficaces.

Pregunta: ¿Quien le presta dinero a una empresa en crisis? ¿Que ha quedado del Puerto de Sagunto, cuantas parcelas tiene desocupadas y cuanto de eficaz ha sido la Reindustrialización?

De todo esto y con lo vivido nos queda claro que, los sectores industriales tienen que adaptarse al nuevo ciclo económico, buscando productos de mayor demanda (los tecnológicos) y sin quedarse estancados en los poco productivos (alimentación, textil...)

Con la incorporación a la Comunidad Económica Europea en 1986, se entra en el momento culminante de la reconversión industrial, y se produce en la ciudad de Valencia una reorganización constante industrial.

Estos aspectos nos ayudaran a poder comprender el aspecto urbanístico de las industrias, sobre todo su comportamiento y el abandono de actividades tradicionales que se ven acorraladas económica, social y urbanísticamente.

3.- El aspecto Urbanístico está ligado íntimamente al político y económico, las empresas asentadas en Valencia no desaparecen o abandonan su emplazamiento por un solo motivo, que indudablemente puede ser, sino por un cúmulo de circunstancias por las que se ven obligadas a salir de la ciudad.

Seguidamente se muestran unos gráficos numéricos totales y de barras por distritos en los que se aprecia la Actividad Industrial en Valencia. Anteriormente los hemos visto distrito a distrito. 


\section{GRAFICOS}

\section{1 - INDUSTRIAS}

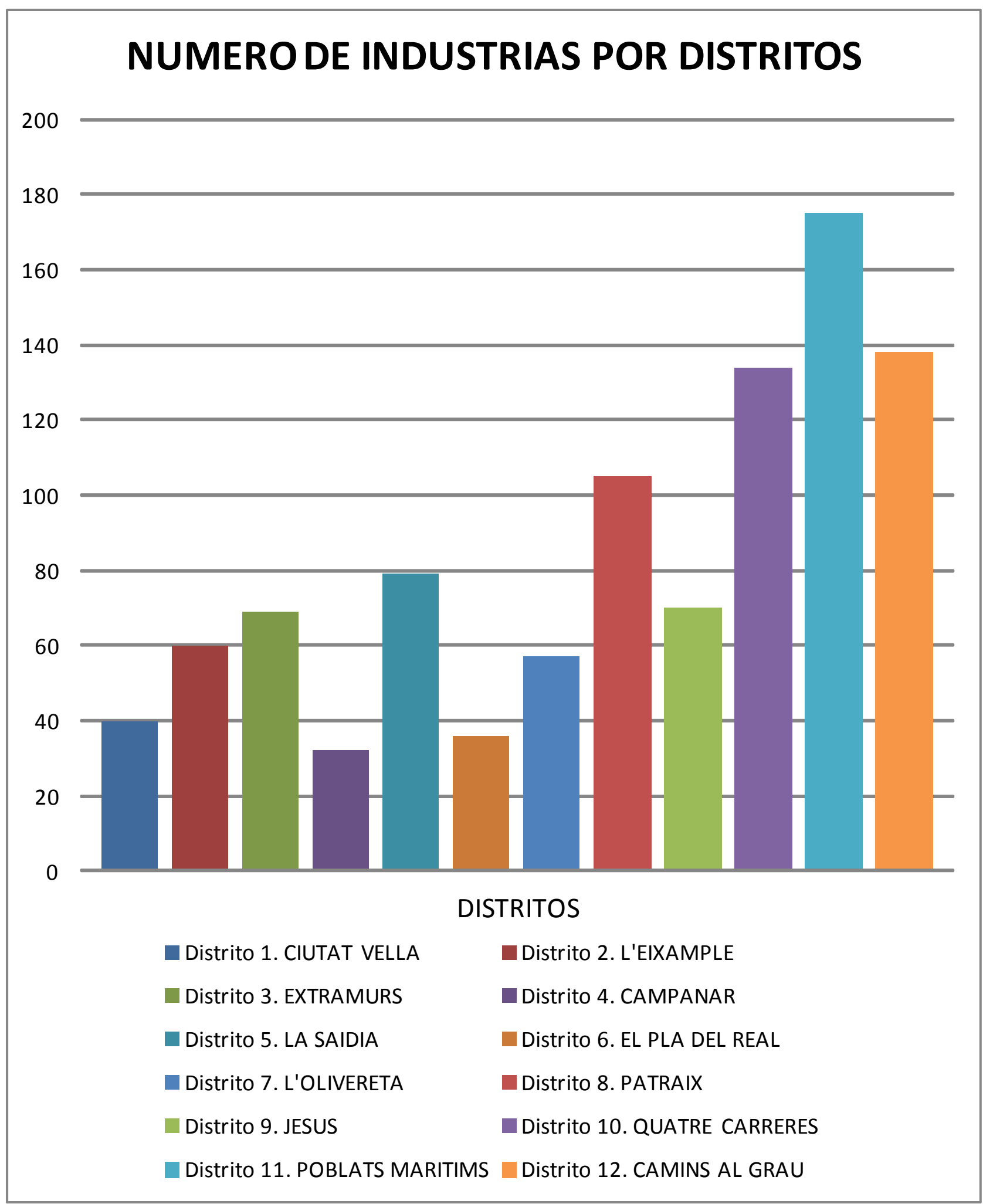




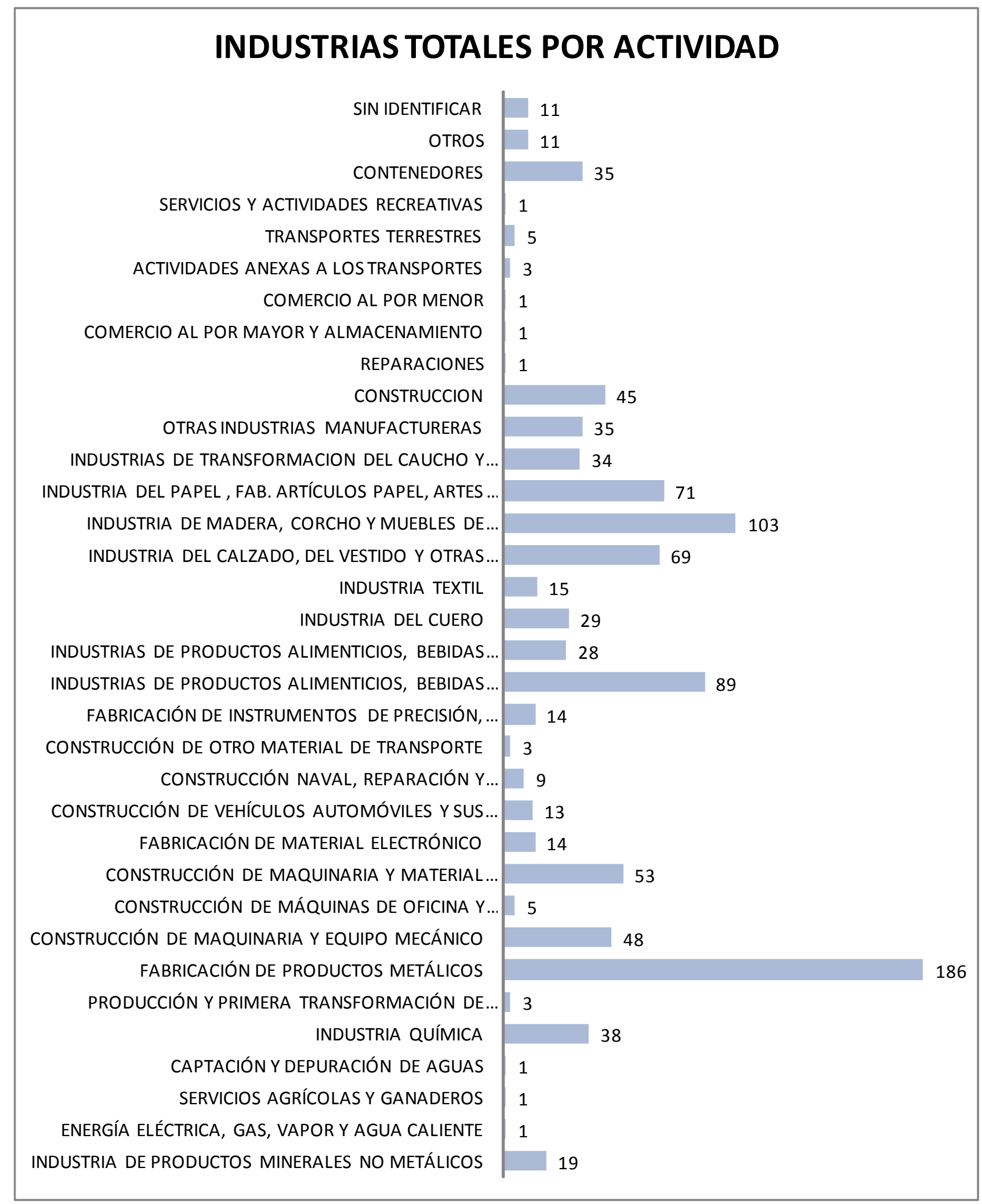




\section{2 - EMPLEADOS}

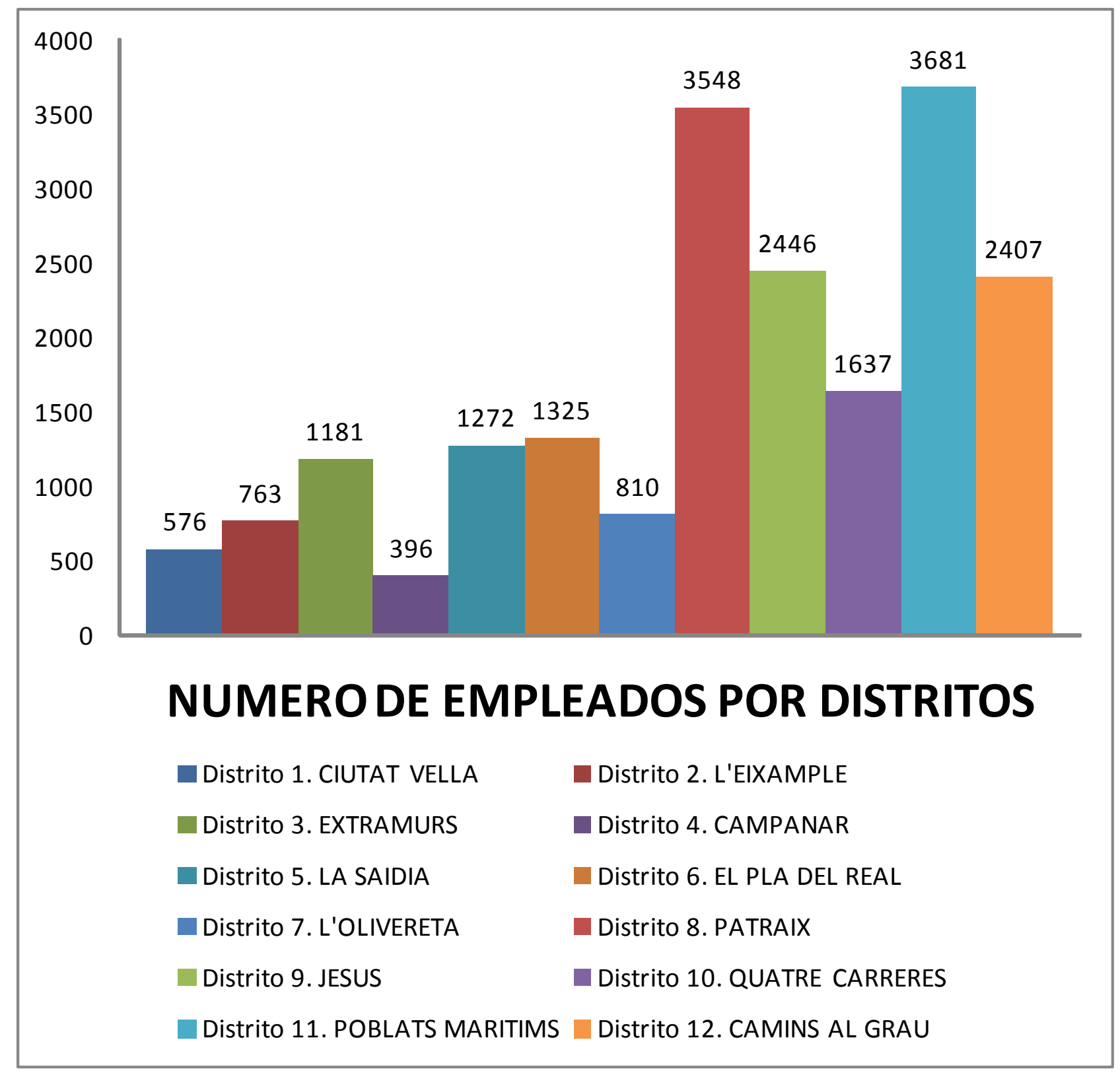




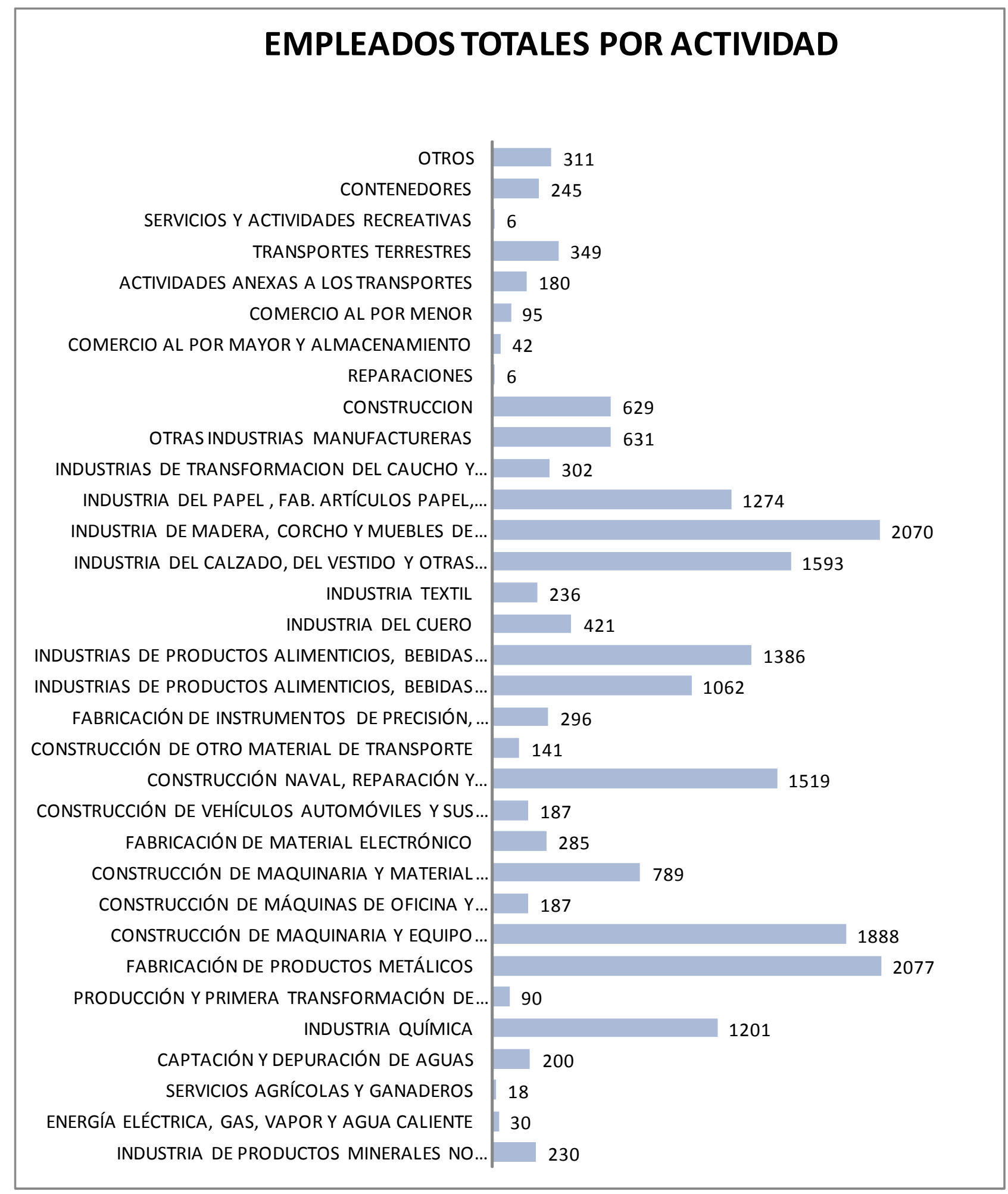




\section{3 - SUPERFICIE}

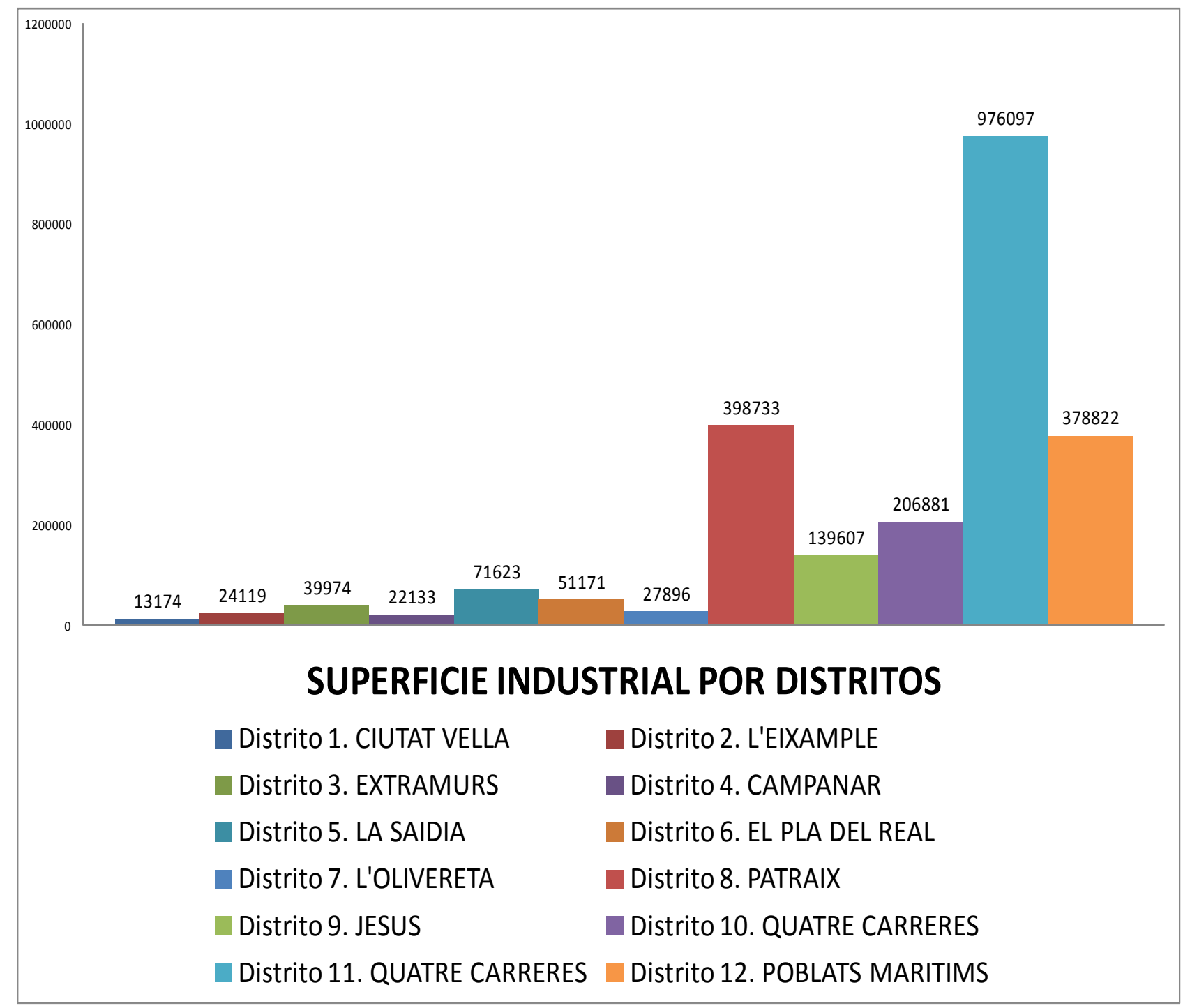




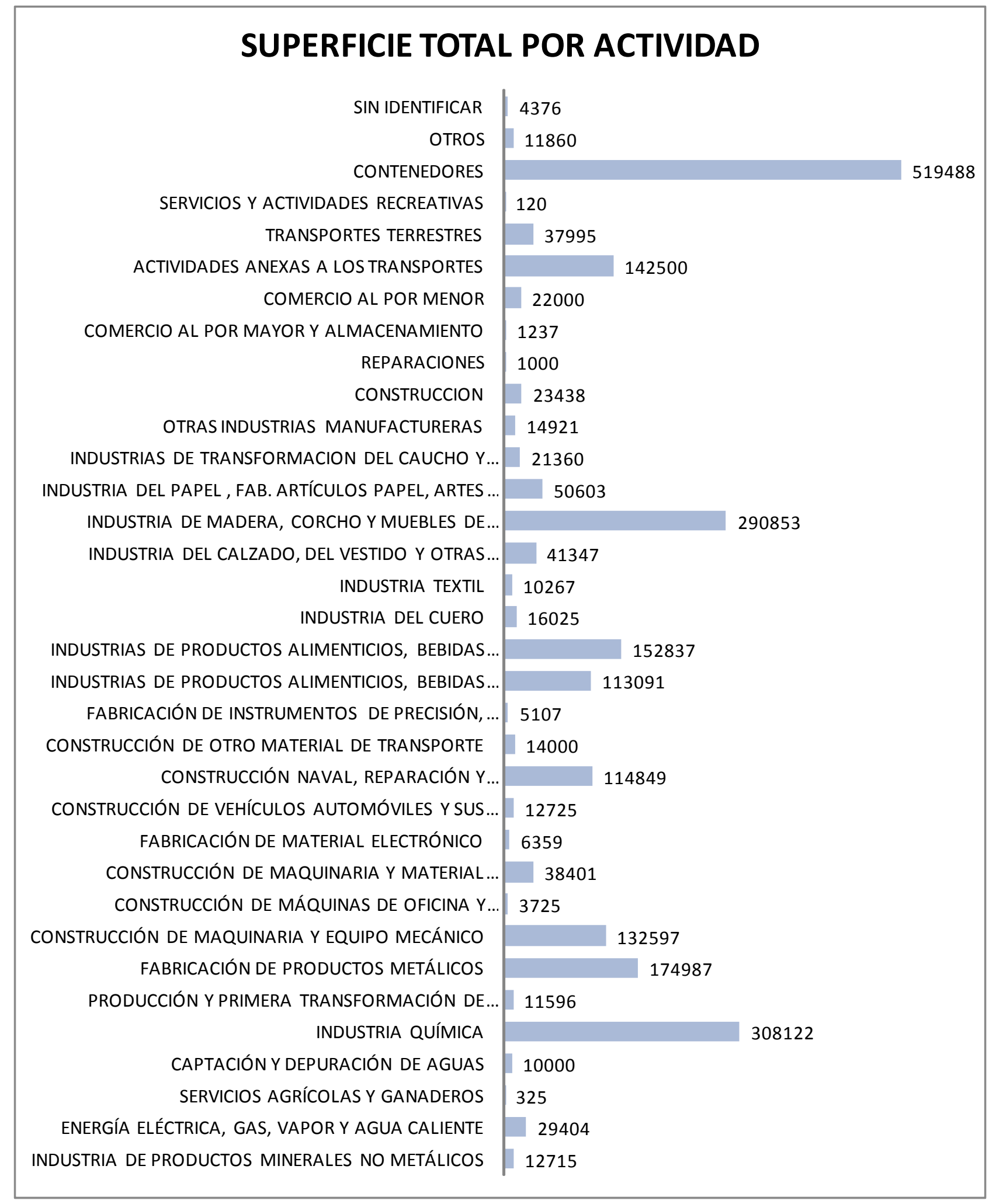


Como resumen podemos afirmar que la Ciudad de Valencia no es un área fuertemente Industrializada, tan solo cuenta con un 2,5\% de su población empleada en la Industria, pero se muestra muy dinámica adaptándose a los continuos Ciclos Económicos, ello se contrapone a siglos anteriores donde fue una ciudad industrial de primer orden.

Igualmente podemos indicar que se ha diseminado por la periferia, todo ello en beneficio de la Ciudad.

En los últimos cuarenta años:

- Los núcleos de población al Sur como son Alfafar, Benetuser, Sedavi, Catarroja, Albal y Beniparrell se especializaron en la madera y derivados dando lugar a una Industria totalmente consolidada a lo largo del Cami Reial.

- Los núcleos situados al Oeste como son Aldaia, Alacuas, Xirivella y Torrent tienen una industria más diversa pero también domina la madera, cerámica, maquinaria y alimentación, concentrado en diversos polígonos industriales.

- Los núcleos situados al Noroeste como son Mislata, Quart de Poblet, Paterna y Ribarroja tienen una industria más extensa y diversa, en los que conviven multitud de actividades, quizás es la mejor comunicada y la mas potente situada a lo largo de la A3 CV 30 A 7 CV 35.

El continuo trasiego de industrias deslocalizadas ha dado lugar a multitud de espacios nuevos tanto viales (Prolongación de la Alameda con las Chimeneas de la antigua Alcoholera) como edificios que en la actualidad tienen otro uso (Tabacalera, Cross, Naves Portuarias, Antiguos almacenes en la Avenida del Puerto).

Esto ha sido repetitivo a lo largo de la historia, sirva como ejemplo los edificios de Tabacalera.

El Plan General del 88 en sus previsiones y ordenanzas industriales, ya contemplaba el aprovechamiento de determinados edificios industriales. 
Un caso singular e histórico por su evolución es el de Tabacalera en la actualidad Palacio de Justicia, luego ocupó el Palacio de la Industria de la Exposición y pasó a ser Tabacalera y recientemente se ha transformado para acoger la nueva sede del Ayuntamiento.

El impacto ambiental ha ido disminuyendo con el paso del tiempo, por la continua descentralización industrial. Únicamente podríamos resaltar la permisividad que se tiene con el ruido en los pequeños talleres, pero esto es una cuestión generalizada que afecta igualmente al tráfico y locales de ocio.

Quizás lo que más se echa en falta, es una política coherente de apoyo industrial, que al final nos proporcione empleo y nos identifique. Esto sería una Reindustrialización ordenada y coherente, con apoyos a los sectores industriales en los que siempre hemos sido punteros e innovadores y que en muchos de ellos, hemos perdido los oficios y a los no sujetos a los ciclos económicos como son la alimentación que subsiste a duras penas y aquellos innovadores con una fuerte carga de investigación, con ayudas estatales, fiscales, laborales y financieras que tanto necesita la industria, para sobrevivir a los ciclos económicos. 